\title{
Yellow-billed Cuckoo Distribution, Abundance, and Habitat Use Along the Lower Colorado River and its Tributaries, 2007 Annual Report
}

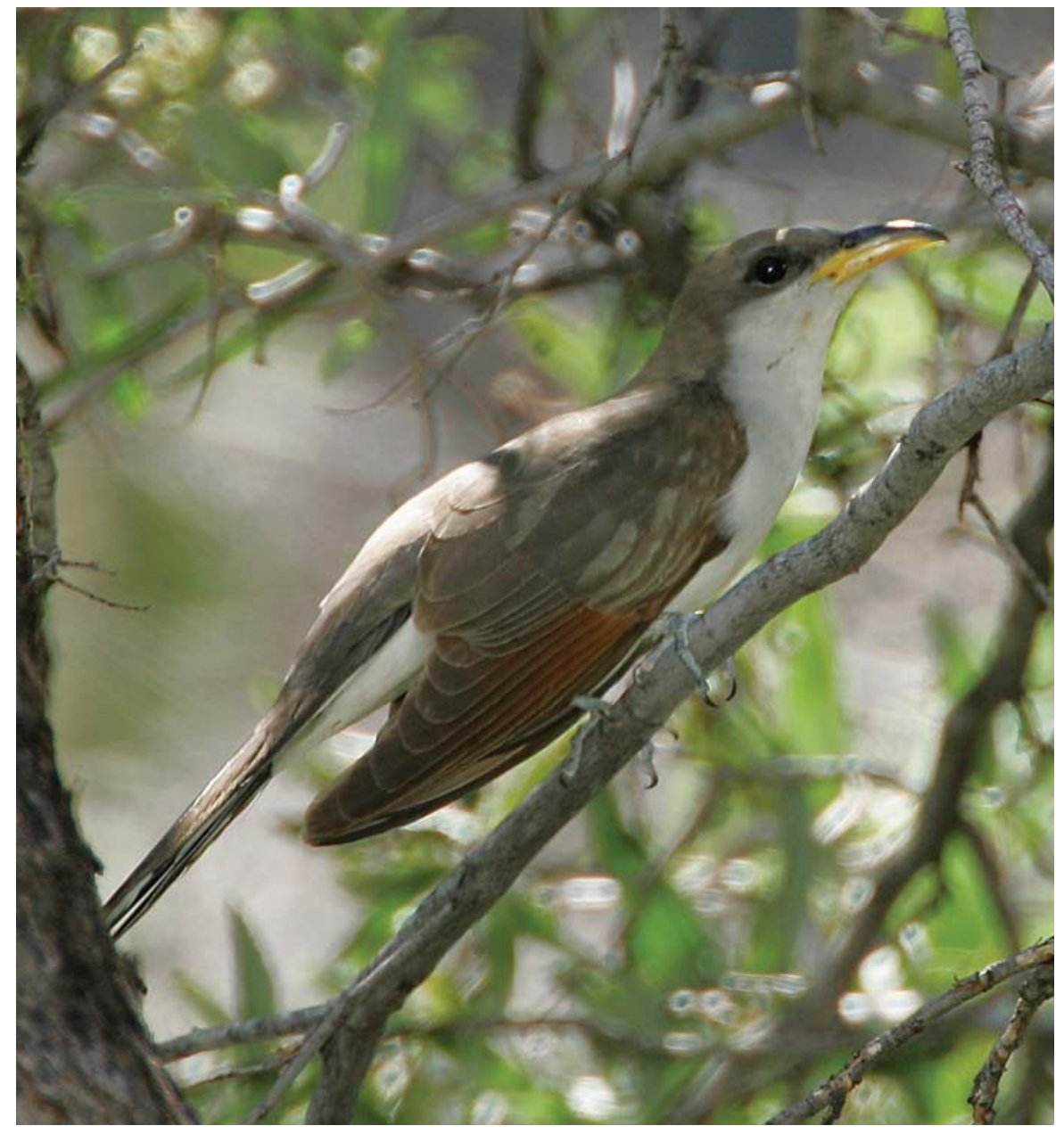

Open-File Report 2008-1177 
This page intentionally left blank 


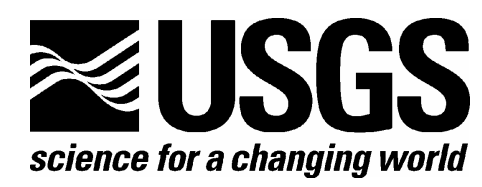

Funded by the Bureau of Reclamation

\section{Yellow-billed Cuckoo Distribution, Abundance, and Habitat Use Along the Lower Colorado River and Its Tributaries, 2007 Annual Report}

By Matthew J. Johnson, Scott L. Durst, Christopher M. Calvo, Laura Stewart, Mark K. Sogge, Geoffrey Bland, and Terry Arundel

Open-File Report 2008-1177

U.S. Department of the Interior

U.S. Geological Survey 


\section{U.S. Department of the Interior DIRK KEMPTHORNE, Secretary}

\section{U.S. Geological Survey \\ Mark D. Myers, Director}

U.S. Geological Survey, Reston, Virginia 2008

For product and ordering information:

World Wide Web: http://www.usgs.gov/pubprod

Telephone: 1-888-ASK-USGS

For more information on the USGS - the Federal source for science about the Earth, its natural and living resources, natural hazards, and the environment:

World Wide Web: http://www.usgs.gov

Telephone: 1-888-ASK-USGS

Any use of trade, product, or firm names is for descriptive purposes only and does not imply endorsement by the U.S. Government.

Although this report is in the public domain, permission must be secured from the individual copyright owners to reproduce any copyrighted material contained within this report.

Cover: Picture of Yellow-billed Cuckoo (ㄷ Bob Steele/VIREO).

Suggested citation:

Johnson, Matthew J., Durst, Scott L., Calvo, Christopher M., Stewart, Laura, Sogge, Mark K., Bland, Geoffrey, and Arundel, Terry, 2008, Yellow-billed Cuckoo distribution, abundance, and habitat use along the lower Colorado River and its tributaries, 2007 Annual Report: U.S. Geological Survey Open-File Report 2008-1177, 274 p.

[http://pubs.usgs.gov/of/2008/1177/]. 


\section{Contents}

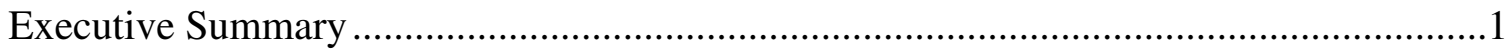

Chapter 1. Introduction ...........................................................................................

The Lower Colorado River Multi-Species Conservation Program...................................3

Yellow-billed Cuckoo Breeding Biology, Habitat, Distribution, and Status ...................4

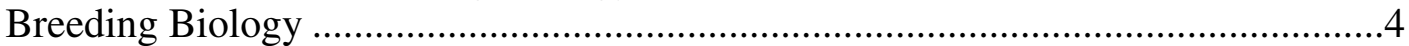

Habitat Requirements ....................................................................................

Historic Abundance, General Breeding Distribution, and Current Conservation

Status in the Western United States................................................................

Historic Population Status Along the Lower Colorado River.....................................

2006 USGS LCR MSCP Yellow-billed Cuckoo Research ..........................................

LCR MSCP Yellow-billed Cuckoo Project Objectives ……….....................................

Document Organization ....................................................................................10

Chapter 2: Yellow-Billed Cuckoo Breeding Surveys ......................................................11

Survey Location and Selection of Study Sites ………..........................................11

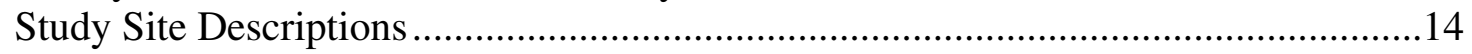

Pahranagat National Wildlife Refuge, NV (White River Drainage).........................14

Overton Wildlife Management Area, NV (Muddy River) ......................................15

Grand Canyon National Park/Lake Mead National Recreation Area, AZ

(Colorado River and Lake Mead) ..............................................................16

Havasu National Wildlife Refuge, AZ (Colorado River) ......................................17

Bill Williams River National Wildlife Refuge, AZ (Bill Williams River) ...............19

Ahakhav Tribal Preserve (Colorado River) (Elevation 94m; 308ft) .......................22

Cibola National Wildlife Refuge, AZ (Colorado River) ..........................................22

Picacho State Recreation Area, CA (Colorado River)

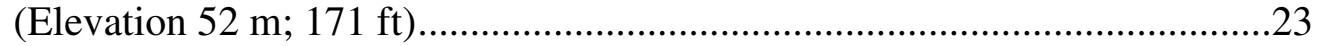

Imperial National Wildlife Refuge, AZ and CA (Colorado River)..........................24

Mittry Lake State Wildlife Management Area/Pratt Restoration Area, AZ

(Colorado River) (Elevation $52 \mathrm{~m}$; $171 \mathrm{ft}$ ) ...................................................24

Gila-Colorado River Confluence Area, AZ (Gila and Colorado Rivers) .................24

Yuma West Wetlands, AZ (Colorado River) (Elevation 36 m; $118 \mathrm{ft}$ ) ...................25

Limitrophe Division, AZ (Colorado River) ……………......................................25

Quigley Pond Wildlife Management Area, AZ (Gila River) (Elevation 67 m; 220

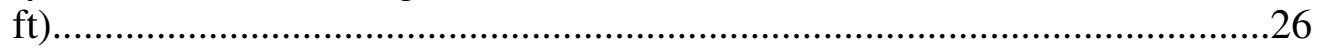

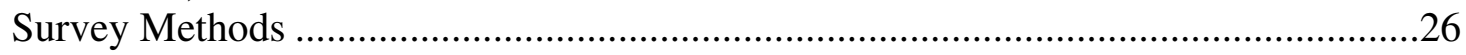

Survey Site Classifications ............................................................................28

Supplemental Follow-up Surveys ....................................................................28

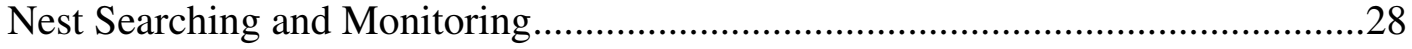

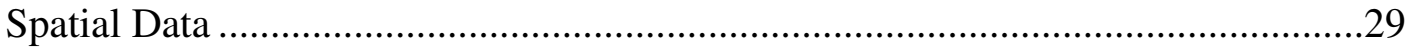

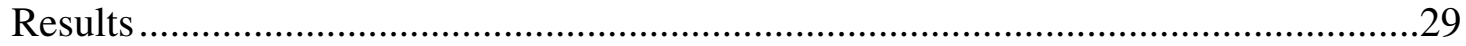

Yellow-billed Cuckoo Formal and Follow-up Detections, 2007 .............................29

Grand Canyon National Park/Lake Mead National Recreation Area, AZ

(Colorado River and Lake Mead) ..................................................................33

Yellow-billed Cuckoo Breeding Activity ..................................................................42

Nest Monitoring ……………………………………....................................43

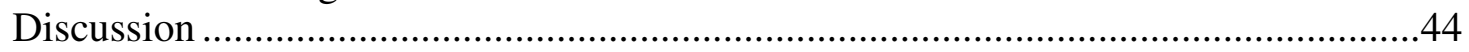

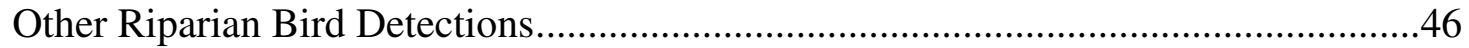




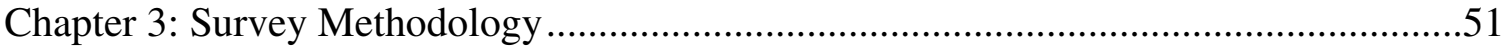

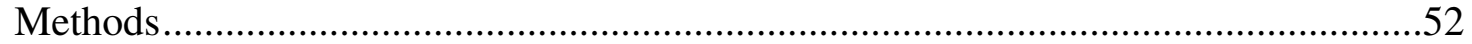

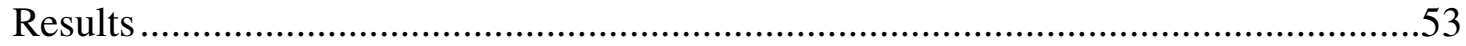

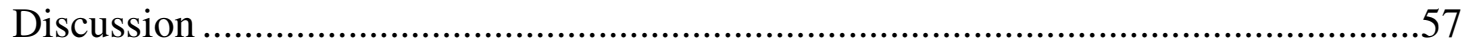

Chapter 4. Habitat Vegetation Characteristics...............................................................59

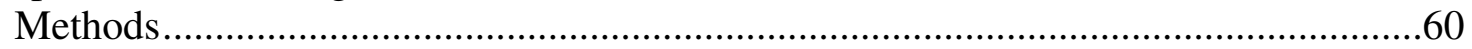

Vegetation Sampling Design................................................................................60

Vegetation Measures and Measurement Techniques ...............................................62

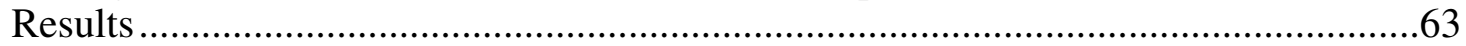

Yellow-billed Cuckoo Vegetation by Occupancy Status ...........................................63

Yellow-billed Cuckoo Vegetation by Geographic Area ..........................................69

Yellow-billed Cuckoo Vegetation at Bill Williams River NWR Sites ......................76

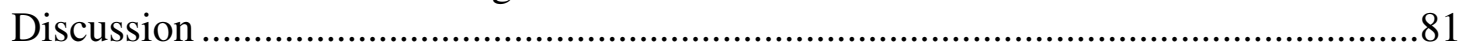

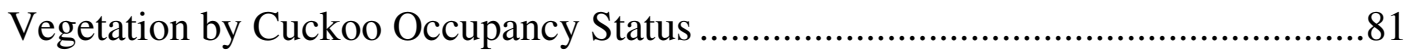

Vegetation by Geographic Area ............................................................................82

Vegetation among Occupied Sites at Bill Williams River NWR..............................83

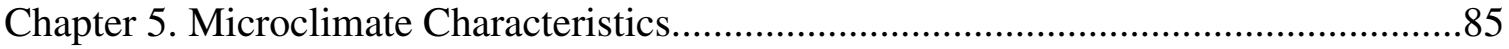

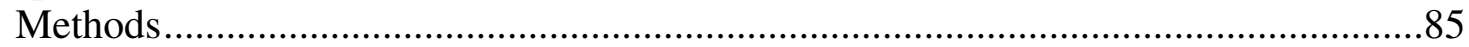

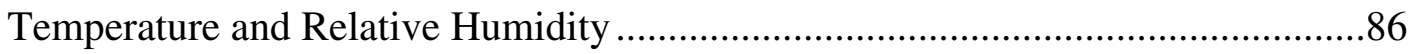

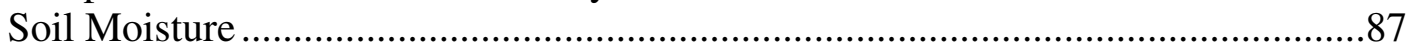

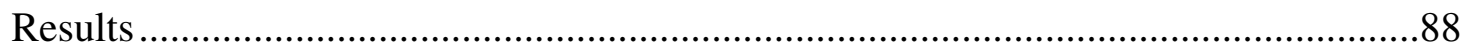

Temperature and Relative Humidity by Yellow-billed Cuckoo

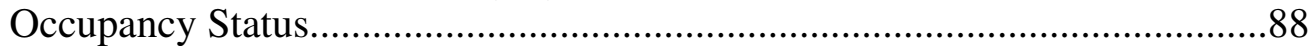

Temperature and Relative Humidity by Geographic Area........................................89

Temperature and Relative Humidity at Bill Williams River

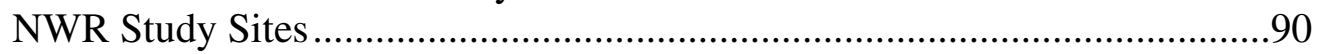

Microclimate and Canopy Cover .......................................................................91

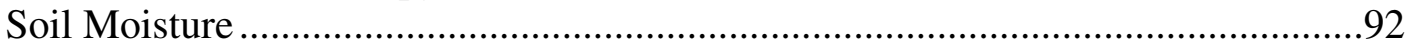

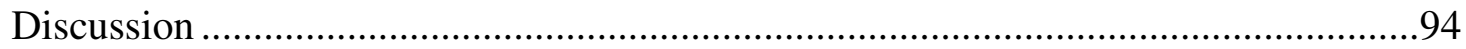

Chapter 6. Management and Research Considerations.......................................................97

Yellow-billed Cuckoo Presence/Absence Surveys .....................................................97

Evaluation of Survey Protocol for Yellow-Billed Cuckoos.........................................97

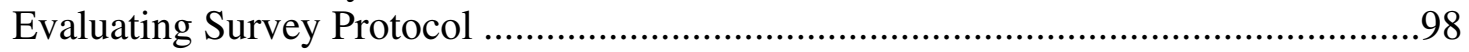

Estimating Detection Probability …………………...........................................98

Habitat Vegetation Characteristics.............................................................................99

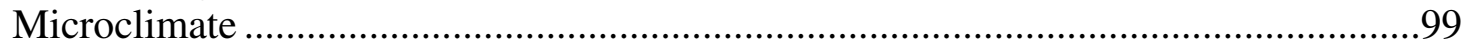

Identifying Core Yellow-billed Cuckoo Breeding Habitat ..........................................100

Using Occupancy Patterns to Identify Core Yellow-billed Cuckoo

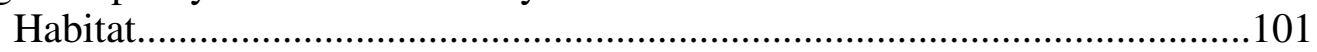

Methods for Yellow-billed Cuckoo Follow-up Visits............................................101

Identifying Yellow-billed Cuckoo Habitat Model Variables..........................................102

Chapter 7. 2006-2007 LCR MSCP Yellow-billed Cuckoo Research Summary ..............105

Yellow-Billed Cuckoo Presence/Absence Surveys ………………………….............105

Variation in Yellow-billed Cuckoo Detections, Occupied Sites and Habitat ..............108

Yellow-billed Cuckoo Breeding Verification ...........................................................110

Survey Methodology Evaluation ........................................................................111

Habitat Vegetation Characteristics..............................................................................111

Microclimate Characteristics ................................................................................112 


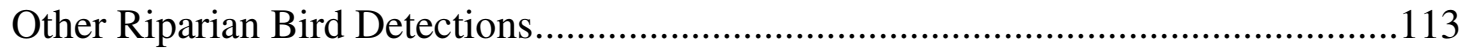

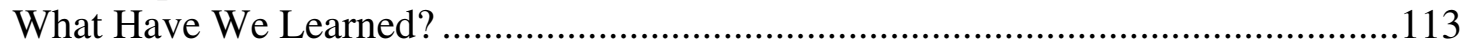

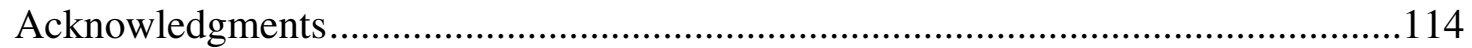

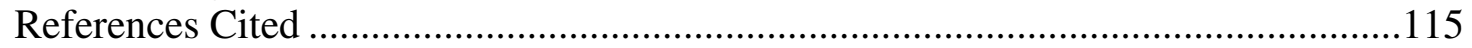

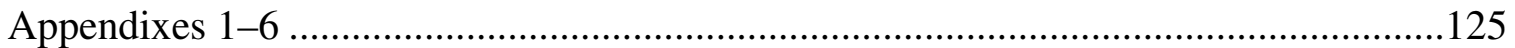

Appendix 1. Summary of Yellow-billed Cuckoo Detections by Survey

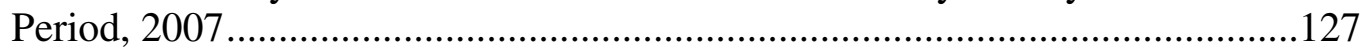

Appendix 2. Narrative Descriptions of Each Yellow-billed Cuckoo

Detection in the Lower Colorado River Watershed, 2007 ...............................129

Appendix 3. Incidental Yellow-billed Cuckoo Observations in the Lower Colorado River Watershed, 2007 .........................................................165

Appendix 4. Aerial Photographs of Yellow-billed Cuckoo Survey

Points and Detections According to Survey Period, 2007

Appendix 5. Habitat photos of yellow-billed cuckoo survey areas

and sites in the lower Colorado River Watershed, 2007 ................................235

Appendix 6. List of Other Bird Species Observed During

Yellow-billed Cuckoo Surveys in the Lower Colorado River Watershed ........253 
This page intentionally left blank 


\title{
Yellow-billed Cuckoo Distribution, Abundance, and Habitat Use Along the Lower Colorado River and Its Tributaries, 2007 Annual Report
}

\author{
By Matthew J. Johnson, Scott L. Durst, Christopher M. Calvo, Laura Stewart, \\ Mark K. Sogge, Geoffrey Bland, and Terry Arundel'
}

\section{Executive Summary}

This 2007 annual report details the second season of a 2-year study documenting western yellow-billed cuckoo (Coccyzus americanus occidentalis) distribution, abundance, and habitat use throughout the Lower Colorado River Multi-Species Conservation Program boundary area. We conducted cuckoo surveys at 40 sites within 14 areas, between 11 June and 9 September 2007. The 169 surveys across all sites yielded 163 yellow-billed cuckoo detections. Cuckoos were detected at 25 of the 40 sites, primarily at the Bill Williams River National Wildlife Refuge (NWR) study area $(n=139$ detections; 85 percent of all detections). Detections declined slightly through the cuckoo breeding season, with most detections occurring in the first and second survey periods (n $=92 ; 54$ percent). We detected breeding activity only at the Bill Williams River NWR, where we confirmed 27 breeding events, including two nesting observations. However, the breeding status of most detected birds was unknown.

We used playback broadcast recordings to survey for yellow-billed cuckoos. Compared to simple point counts or surveys, this method increases the number of detections of this secretive, elusive species. It has long been suspected that cuckoos have a fairly low response rate, and that the standard survey method of using broadcast recordings might fail to detect all birds present in an area. In 2007, we found that the majority (84 percent) of cuckoo detections were solicited through broadcast at all study sites. The number of solicited detections was highest during the first survey period and declined as the breeding season progressed, while the number of unsolicited detections (cuckoos heard calling before broadcast was initiated) remained fairly constant through the first, second, and third survey periods. The majority ( 66 percent) of cuckoo detections, solicited or unsolicited, were aural, 23 percent were both heard and seen, and 11 percent were visual detections only. We also found that 50 percent of all responses by cuckoos were evenly split between the first and second broadcasts at sites with $>10$ detections, while 45 percent of responses occurred after a single broadcast at the sites with $<10$ detections.

We refined our collection of vegetation data in 2007 and found that across the entire study area the dominant tree species were tamarisk (Tamarix spp.), willow (Salix

\footnotetext{
${ }^{1}$ Department of the Interior, U.S. Geological Survey, Southwest Biological Science Center, Flagstaff, Ariz.
} 
spp.), and cottonwood (Populus spp.). The smallest size class ( $<8 \mathrm{~cm}$ diameter at breast height) trees were the most common and were dominated by tamarisk, but cottonwood and willows were well represented in the larger size classes. Sites that were occupied by yellow-billed cuckoos generally had higher canopies, denser cover in the upper layers of the canopy, and sparse shrub layers compared to unoccupied sites that consistently had higher densities of woody species. As most occupied sites were within the Bill Williams River NWR and most unoccupied sites were at Grand Canyon National Park/Lake Mead National Recreation Area, vegetation characteristics at these study areas drove the cuckoo distribution patterns we observed in 2007. However, there was a range of habitat conditions in locations that were used by yellow-billed cuckoos across the entire lower Colorado River Multi-Species Conservation Program study area.

We measured microclimate variables (temperature, relative humidity, soil moisture) at occupied and unoccupied sites, and found that, across the entire study area, occupied sites were consistently cooler during the day and more humid during the day and night compared to unoccupied sites, but that soil moisture did not differ between occupied and unoccupied sites. While most cuckoo detections occurred at Bill Williams River NWR, with generally cooler and more humid conditions, cuckoos were also detected at study areas that had hotter and dryer microclimate conditions. We did not find any relationship of canopy cover characteristics to temperature or soil moisture, suggesting that more complicated factors are involved in determining microclimate regime, possibly including canopy height, dominant tree species, proximity to water, the nature of surrounding habitat, or other variables. Although microclimate conditions might play a significant role in cuckoo habitat selection or breeding ecology, the factors underlying microclimate conditions in riparian patches are not currently fully understood. 


\section{Chapter 1. Introduction}

\section{The Lower Colorado River Multi-Species Conservation Program}

The Lower Colorado River Multi-Species Conservation Program (LCR MSCP 2004) is a coordinated, comprehensive, long-term, multi-agency effort to conserve native species, work towards the recovery of endangered species, and protect and maintain wildlife habitat on the lower Colorado River. The LCR MSCP's purposes are to (1) protect the lower Colorado River environment while ensuring the certainty of existing river water and power operations, (2) address the needs of threatened and endangered wildlife under the Endangered Species Act (ESA), and (3) circumvent federal and state listing of additional species from the lower Colorado River. The MSCP covers areas up to and including the full-pool elevations of Lakes Mead, Mohave, and Havasu, and the historical floodplain of the Colorado River from Lake Mead to the United States-Mexico Southerly International Boundary, a distance of about 400 river miles. Conservation measures currently focus on the area from Hoover Dam to the border, but might include the Grand Canyon in the future.

The LCR MSCP Habitat Conservation Plan (HCP) measures are designed to meet the biological goals for 26 covered species, including the western yellow-billed cuckoo (Coccyzus americanus occidentalis). On 25 July 2001, the U.S. Fish and Wildlife Service (USFWS) found that the western yellow-billed cuckoo (i.e., populations west of the crest of the Rocky Mountains) represents a distinct population segment and warrants protection under the Endangered Species Act as "threatened," but that listing of the cuckoo was precluded by other higher priority listing actions. Thus, it became a Candidate Species under the Endangered Species Act (USFWS 2002). The HCP requires the Bureau of Reclamation ('Reclamation') to restore 5,940 acres of cottonwood (Populus spp.) - willow (Salix spp.) riparian forest, including 4,050 acres specifically for the yellow-billed cuckoo. The Science Strategy is designed to provide Reclamation with a science-based process for ensuring that relevant new information generated over the 50year term of the LCR MSCP (2004) is used to guide implementation of HCP conservation measures. The restoration goals are to create native cottonwood-willow riparian forest that promotes yellow-billed cuckoo conservation and recovery. Additionally, Reclamation plans to establish a standardized survey protocol, and to monitor yellow-billed cuckoos at each restoration site and along the entire lower Colorado River to evaluate long-term trends and the effects of HCP conservation measures.

Specifically, the LCR MSCP conservation measures relative to breeding yellowbilled cuckoos include the following:

1. Conduct surveys and research, as appropriate, to collect information necessary to better define the yellow-billed cuckoo's breeding habitat requirements, and to design and manage fully functioning habitats.

2. Monitor and adaptively manage created habitat and evaluate the habitat needs of yellow-billed cuckoos. Reconstructed habitats covered under the MSCP will be 
managed to maintain their functions as habitat over the term of the LCR MSCP (2004). Created habitat will be monitored and adaptively managed over time to determine which types and frequency of management activities that might be required to maintain created cottonwood-willow and honey mesquite (Prosopis spp.) as habitat for yellow-billed cuckoos.

3. Create 1,639 ha (4,050 acres) of yellow-billed cuckoo habitat. Of the 2,404 ha (5,940 acres) of created cottonwood-willow, at least 1,639 ha (4,050 acres) will be designed to provide breeding and migration habitat for cuckoos along the lower Colorado River. A total of 1,093 ha (2,700 acres) will be designed and managed to provide habitat for both yellow-billed cuckoos and southwestern willow flycatchers (Empidonax traillii extimus); 546 ha (1,350 acres) will be restored specifically for the cuckoo.

\section{Yellow-billed Cuckoo Breeding Biology, Habitat, Distribution, and Status}

\section{Breeding Biology}

The yellow-billed cuckoo (Coccyzus americanus) is a Neotropical migrant that summers in northern Mexico, the United States, and southern Canada from early June through early September, and winters primarily in South America (Hughes 1999). Cuckoos begin arriving in Arizona in late May and in California in late May-early June (Bent 1940, Hughes 1999). Nesting activities usually take place between late June and late July, but can begin as early as late May, and continue through late September (Hughes 1999, Laymon et al. 1997, Halterman 2003). Nesting peaks in mid-June through August, later than most co-occurring bird species. The timing of nesting can be influenced by an abundance of cicadas, katydids, caterpillars, and other large prey items, which are the bulk of the species' diet (Hamilton and Hamilton 1965, Rosenberg et al. 1982, Hughes 1999).

Nest building takes 1-2 days. Incubation begins as soon as the first egg is laid, and lasts for 11 days (Hughes 1999). Clutch size in western populations averages just over two eggs, but ranges up to four (Laymon et al. 1997). Both adults incubate the eggs and brood the young, and approximately one-third of nests have a third adult assisting with care of the young. Eggs hatch asynchronously, and nestlings are fed large food items, such as katydids (Tettigoniidae), tree frogs (Hylidae), large caterpillars (Lepidoptera), and cicadas (Cicadidae) (Laymon et al. 1997). After fledging at 5-7 days, young are dependent on the adults for approximately 3 weeks (Laymon and Halterman 1985). The number of broods reared per breeding season is unclear. Western populations were thought to raise a single-brood (Hamilton and Hamilton 1965, Hughes 1999), but recent observations indicate that at least some individuals double-brood (M. Halterman, pers. comm.). Although it is not possible to differentiate between the sexes of cuckoos in the field, it is possible to identify second-year birds (one-year-olds) from older birds by their yellow orbital skin (Pyle et al. 1997).

Cuckoos do not exhibit classic territorial behavior, and the behaviors and vocalizations of unpaired birds are unknown (Hughes 1999, Laymon et al. 1997, Halterman 2002). Cuckoos can move broadly throughout riparian and adjacent vegetation, especially early in the season and post-breeding. Such cuckoos might be 
foraging or evaluating potential breeding sites for the current or subsequent breeding seasons. Similarly, migrating cuckoos can be found in habitats that might not have the same vegetation types or characteristics as those in which they breed. As a result, cuckoos are sometimes detected in non-riparian vegetation or within riparian vegetation that is not suitable for breeding. Thus, not every location at which a cuckoo is detected during the summer months can be considered as breeding habitat. The level of adult yearto-year breeding site fidelity is not well known, but is likely relatively low, based on large yearly fluctuations in cuckoo detections at some sites. These natural history traits complicate survey efforts and our ability to determine and characterize breeding habitat.

\section{Habitat Requirements}

Western yellow-billed cuckoos are thought to require structurally complex riparian vegetation with tall trees and a dense woody vegetative understory (Halterman 1991, Hughes 1999). They breed in large blocks of riparian vegetation, particularly woodlands with cottonwoods and willows (Ehrlich et al. 1988, USFWS 2002). Nesting cuckoos along the Sacramento River in California were estimated to need riparian habitat patches ranging from 10 to 40 ha (Gaines 1974, Laymon et al. 1997, Halterman 1991). In California, dense riparian understory foliage appears to be an important factor in nest site selection, while cottonwood trees are an important component of foraging habitat (Laymon et al. 1997, USFWS 2002). In the West, cuckoos nest almost exclusively close to water and many researchers have hypothesized that the species might be restricted to moist river bottoms because of humidity requirements for successful breeding (Hamilton and Hamilton 1965, Rosenberg et al. 1991). Much of what is known about yellow-billed cuckoo habitat use in Arizona is the result of surveys conducted in 1998 and 1999 by both the Arizona Game and Fish Department (AGFD) and the U.S. Geological Survey (Corman and Magill 2000). The AGFD-USGS surveys show that cuckoo detection rates were highest in cottonwood-willow-ash (Fraxinus spp.) and mesquite bosque-hackberry (Celtis spp.) habitats. Yellow-billed cuckoos were much less common in Arizona sycamore (Platanus wrightii) — cottonwood habitat, sycamore-alder (Alnus spp.) habitat, and areas with more than 75 percent tamarisk cover.

\section{Historic Abundance, General Breeding Distribution, and Current Conservation Status in the Western United States}

Western yellow-billed cuckoos have historically bred in riparian areas from western Washington to northern Mexico, including Oregon, southwestern Idaho, California, Nevada, Utah, western Colorado, Arizona, New Mexico, and western Texas (American Ornithologists' Union 1983, 1998). Although analysis of population trends is difficult because quantitative data, including historic population estimates, are generally lacking, rough extrapolations of historic and current information suggest that the yellowbilled cuckoo's habitat distribution, range, and population numbers have declined substantially across much of the western United States over the past 50 years (USFWS 1985, USFWS 2002). Cuckoo populations have suffered severe range contractions during the last 80 years, and the species has been extirpated from British Columbia, Washington, Oregon, and possibly Nevada (Hughes 1999). Currently, western populations of the yellow-billed cuckoo breed in localized areas of California, Arizona, New Mexico, extreme western Texas, Sonora, Chihuahua, and south irregularly to Zacatecas, Mexico (Howell and Webb 1995, Russell and Monson 1998, Hughes 1999). Local breeding is 
irregular in Utah (J. Parrish pers. comm., Johnson and O'Brien 1998) and western Colorado (Kingery 1998). The yellow-billed cuckoos found in California, southern Nevada, Arizona, and New Mexico west of the Pecos River are western yellow-billed cuckoos; we use the two names interchangeably when discussing any yellow-billed cuckoo west of the crest of the Rocky Mountains.

Yellow-billed cuckoo populations have declined throughout the species' range (Hughes 1999); western populations, in particular, have decreased and suffered range reductions during the last 80 years (Laymon and Halterman 1987a, Hughes 1999). In 1986, a petition was filed to establish the western yellow-billed cuckoo as endangered in the states of California, Washington, Oregon, Idaho, and Nevada (Manolis et al. 1986). The published 12-month finding determined that the petitioned action was not warranted, because the petitioned area did not encompass either a distinct subspecies or a distinct population segment. Another petition was filed, resulting in a 25 July 2001 finding by the USFWS that the western yellow-billed cuckoo (i.e., populations west of the continental divide) represents a distinct population segment and warrants protection under the Endangered Species Act as "threatened," but that listing of the cuckoo was precluded by other higher priority listing actions. Thus, it became a Candidate Species under the Endangered Species Act; it is a species for which the Fish and Wildlife Service "has sufficient information on their biological status and threats to propose them as endangered or threatened under the ESA, but for which development of the proposed listing regulation is precluded by other higher priority listing activities" (USFWS 2002). Candidate species receive no statutory protection under the ESA. However, the Fish and Wildlife Service "encourages the formation of partnerships to conserve these species because they are by definition species that may warrant future protection under the ESA" (USFWS 2002).

Probable factors believed to have contributed to population declines in the West are the loss, fragmentation, and alteration of native riparian breeding habitat, the possible loss of wintering habitat, and pesticide use on breeding and wintering grounds (Gaines and Laymon 1984, Franzreb 1987, Laymon and Halterman 1987a, Hughes 1999). Local extinctions and low colonization rates also might have contributed to the declines (Laymon and Halterman 1989). Populations might also be further limited by food availability for the young, therefore cuckoos might not nest if the food supply at the breeding grounds, which is likely affected by drought conditions (Newton 1980, Durst 2004, Scott et al. 2004), is inadequate (Veit and Petersen 1993).

The early literature documents dozens of locations in California where the species was reported and/or collected historically, sometimes in apparent abundance, but has not been found subsequently (Gaines 1974, Gaines and Laymon 1984, Hughes 1999). During the late 19th century, the California breeding population was estimated to be at least 15,000 pairs (Hughes 1999). However, Gaines (1974) believed that predevelopment cuckoo populations in California were even greater than implied by the early literature, due to the species' inconspicuous behavior and the fact that large tracts of floodplain riparian habitat had already been lost to development before the first records and before accounts of the species began appearing in the literature. Grinnell (1915) described yellow-billed cuckoos as a common breeder, widely distributed in suitable river bottom habitats, but by 1940 the cuckoo populations were reduced due to declines in the amount and suitability of habitat (Grinnell and Miller 1944, Small 1994). Many modern investigators have concluded that there was a catastrophic decline of the cuckoo in California following the start of the major era of development, beginning about the mid- 
1800s (Gaines and Laymon 1984, Laymon and Halterman 1987b, Launer et al. 1990). The species was listed as threatened in California in 1971, and was listed as endangered in 1987. Statewide surveys in 1986-87 found that only three areas in California supported more than about five breeding pairs on a regular basis: the Sacramento River between Colusa and Red Bluff, the South Fork of the Kern River, and the lower Colorado River (Laymon and Halterman 1987a).

In Arizona, the yellow-billed cuckoo was once considered a fairly common breeding species within riparian forests dominated by cottonwood, willow, and/or mesquite throughout the state (Stephens 1903, Swarth 1905, 1914, Visher 1910, Phillips et al. 1964, Corman and Magill 2000). A 1977 statewide Arizona survey of habitat thought to be suitable for cuckoos found an estimated total of 205-214 pairs, with more than half of these along the lower Colorado River (Gaines and Laymon 1984). Past estimates suggested that fewer than 200 pairs remained in 1986 (Layman and Halterman 1987a), and that fewer than 50 pairs were present five years later (Ehrlich et al. 1992). Prompted by continued concern regarding severe population declines, habitat loss, and the lack of statewide data, the USFWS initiated yellow-billed cuckoo surveys in 1998 and 1999. Cuckoos were documented along 25 drainages; an estimated 73 pairs were detected in 1998 and 172 pairs in 1999. The primary concentrations in Arizona were along the major drainages of the Agua Fria, San Pedro, and Verde Rivers, Cienega and Sonoita Creeks, and the Bill Williams River tributary within the lower Colorado River region (Corman and Magill 2000, Johnson et al. 2006a). The Arizona Game and Fish Department has designated the yellow-billed cuckoo as a Wildlife of Special Concern in Arizona, and the U.S. Forest Service Regional Forester designated it a Sensitive Species on National Forests within Arizona and New Mexico (Region 3) (AGFD 2002). In addition, it is considered likely to become an endangered species throughout all or a significant portion of its range on the Navajo Nation if action is not taken (Navajo Nation 2005).

Until recently, there were few details about cuckoo distribution and abundance in Nevada. From 2000 to 2004, the Nevada Division of Wildlife (NDOW) coordinated surveys at selected riparian areas in southern Nevada, with results varying greatly by year and site. For example, detections at Warm Springs Ranch and Moapa NWR varied from 19 individuals (4 pairs and 11 single cuckoos) in 2001 (Furtek et al 2002) to just a single bird in 2003 (Braden et al. 2005a) and in 2004 (Braden et al. 2005b). The number of detections at Mormon Mesa Littlefield North and Mesquite Bridge also varied: there were 8 in 2000, 6-10 in 2001, 0 in 2002, and 1 in 2003 (Braden et al. 2005a). From 2000 through 2002, the Southern Sierra Research Station (SSRS) also surveyed four sites in southern Nevada: Clover Creek at Caliente, Upper Pahranagat Lake, the Virgin River at Littlefield, and Meadow Valley Wash from river miles 39 to 57. SSRS detected one cuckoo pair at Pahranagat and one individual at Littlefield in 2000 (Halterman 2001), and four pairs and five single cuckoos in 2001 (Halterman 2002); SSRS and NDOW detected one or two pairs in 2002 (Halterman 2003). The Nevada Natural Heritage Program ranks the western yellow-billed cuckoo as critically imperiled (Nevada Natural Heritage Program 2004)

\section{Historic Population Status Along the Lower Colorado River}

Yellow-billed cuckoos were once considered abundant throughout the riparian floodplain along the lower Colorado River. Grinnell and Miller (1944) cited only 
Stephen's (1903) observations of several cuckoos near Needles in 1902. Surveys in midJune 1964 along the lower Colorado River near Laguna Dam indicated that the density of yellow-billed cuckoos was similar to, and possibly higher than, that on the San Pedro River in southeastern Arizona (Hamilton and Hamilton 1965).

A substantial population of cuckoos was detected north of Laguna Dam during the 1960s and 1970s, suggesting that the Colorado River above Laguna Dam might have been the last stronghold for the yellow-billed cuckoo in California (Gaines and Laymon 1984). Four to twelve cuckoos per season were reported from 1964 to 1975 near Laguna Dam in June and July (Gaines and Laymon 1984). Then, using species-specific protocols, Gaines (1977) detected 65 cuckoos along the lower Colorado River on the California side of the river. During surveys in the 1970s and 1980s a dramatic decline of the species was noted along the lower Colorado River. In both Arizona and California, the lower Colorado River and its tributaries supported an estimated 180-240 pairs in 1976-77, a number that had declined by an estimated 80-90 percent by 1986 (Laymon and Halterman 1987a). Rosenberg et al. (1991) estimated a decline of 93 percent along the lower Colorado River between 1976 and 1986, coinciding with habitat loss from high water levels of long duration in 1983-84 and 1986 (Laymon and Halterman 1987b, Ohmart et al. 1988, Rosenberg et al. 1991). In 1998, no pairs were found in the parts of California west of the Colorado River that had been occupied in 1976-77 (Halterman 1998). Losses have been greatest at lower elevations, below $900 \mathrm{~m}$ (3000 ft) along the lower Colorado River and its major tributaries, which have been strongly affected by upstream dams, flow alterations, channel modifications, and clearing of land for agriculture (Groschupf 1987).

The Bill Williams River National Wildlife Refuge (NWR), a tributary of the lower Colorado River, has had the largest known population of yellow-billed cuckoos since the 1960s. The refuge consists primarily of riparian habitat along the Bill Williams River from Lake Havasu upstream to Planet Ranch, approximately $16 \mathrm{~km}$ (10 miles). The riparian habitat is dominated by a cottonwood-willow overstory with a dense understory of cottonwood, willow, and tamarisk. The Bill Williams River NWR riparian habitat is the most continuous, unfragmented habitat of its kind in the lower Colorado River Basin.

The Bill Williams River NWR cuckoo population was surveyed in 1993, 1994, and 1997-2004 (Halterman and Laymon 1994, 1995; Halterman 1998, 2001, 2002, 2003, 2004). Despite repeated surveys, trends in abundance were difficult to detect from these survey results because the amount of survey effort varied annually and, prior to 2001, survey results were given in terms of estimated numbers of pairs rather than numbers of detections. Estimated pairs ranged from 28 to 30 in 1993, 26 in 1994, 12 in 1997, and 6 to 9 in 1999. A total of 11 nests were found when combining nests from 1993, 1994, and 1997. Then starting in 2001, results were reported as numbers of detections, which varied annually: 78 in 2001, 34 in 2002, and 42 in 2003.

\section{USGS LCR MSCP Yellow-billed Cuckoo Research}

In 2006, under the Lower Colorado River Multi-Species Conservation Program (LCR MSCP), the USGS initiated a 2-year study documenting western yellow-billed cuckoo (C.a. occidentalis) distribution, abundance, and habitat use throughout the LCR MSCP boundary area (Johnson et al. 2007). Yellow-billed cuckoos were surveyed at 55 sites within 17 areas. The 243 visits across all sites yielded 180 yellow-billed cuckoo detections. Cuckoos were detected at 27 of the 55 sites, primarily at the Bill Williams 
River National Wildlife Refuge sites ( $\mathrm{n}=117$ detections) and the Grand Canyon National Park-Lake Mead National Recreation Area delta sites ( $n=29$ detections). In 2006, the majority (72 percent) of cuckoo detections were solicited through a broadcast at all study sites. The number of solicited detections peaked during the first half of July and then declined as the breeding season progressed, while the number of unsolicited detections (cuckoos heard calling before broadcast was initiated) remained fairly constant. Cuckoos in areas with the largest populations had the highest rate of vocalizations before a broadcast or after the first broadcast (first of five broadcasts). In contrast, more than half the responses at sites with fewer cuckoos ( $<10$ detections per site) first occurred after three or more broadcast recordings.

During the first year of this research, preliminary analysis of vegetation data (Johnson et al. 2007) from yellow-billed cuckoo occupied and unoccupied sites focused on general patterns in the distribution and abundance of woody species. Tamarisk was the most common tree, due to the abundance of small $(<8 \mathrm{~cm} \mathrm{dbh})$ plants. Occupied sites tended to have higher average canopy cover, attributable to higher average cover of the mid and low canopy. The dominant canopy at occupied sites most often consisted of cottonwood or willow trees. When densities of trees in different size classes were compared between occupied and unoccupied sites, cuckoos did not use areas with the highest density of small trees $(<8 \mathrm{~cm} \mathrm{dbh})$, but used areas with lower densities of small trees and larger native trees. This study also measured microclimate variables (temperature, relative humidity, soil moisture) at occupied and unoccupied sites. Microclimate measurements at Grand Canyon NP-Lake Mead NRA and Bill Williams River NWR showed that locations occupied by yellow-billed cuckoos were slightly cooler and more humid than unoccupied sites. On average, soil moisture was slightly higher at occupied cuckoo locations.

\section{LCR MSCP Yellow-billed Cuckoo Project Objectives}

The objectives of this project, initiated in 2006 as part of the LCR MSCP, were to document the distribution, abundance, and habitat use of yellow-billed cuckoos in riparian areas of the lower Colorado River, and to provide information relevant to the Habitat Conservation Plan measures. Yellow-billed cuckoo surveys provide information on their status and distribution, and establish baseline data that can be used for continued monitoring of cuckoo populations and riparian vegetation under the MSCP. There are four specific project objectives.

1. Conduct comprehensive, repeatable surveys in all potentially suitable habitat types within the LCR MSCP project boundary. This work contributes to baseline information on yellow-billed cuckoo populations within these areas. All other avian species encountered within riparian habitats are also recorded.

2. Evaluate the effectiveness of the current yellow-billed cuckoo breeding season survey protocol (Halterman et al. 2006) and refine it to use over the term of the MSCP.

3. Determine breeding habitat selection and preferences in the areas of concern. This includes comparing habitat characteristics between occupied and unoccupied sites to identify factors that might influence habitat selection by breeding cuckoos.

4. Identify core yellow-billed cuckoo breeding habitat to use as a basis for future habitat expansion through restoration efforts. 


\section{Document Organization}

This document is organized into six chapters. Chapter 2 (Yellow-billed Cuckoo Breeding Surveys) describes the effort and results of the yellow-billed cuckoo surveys and breeding activity during the 2007 breeding season. Chapter 3 (Survey Methods) provides descriptive information about how cuckoos responded to our survey methods. It also poses hypotheses and questions that might prove useful in further optimizing the cuckoo survey protocol. Chapter 4 (Yellow-billed Cuckoo Habitat Vegetation) describes the riparian vegetation sampling design, provides results on vegetation characteristics in the study areas, and compares characteristics of occupied and unoccupied sites. Chapter 5 (Microclimate Analysis) describes the design and results of microclimate sampling in occupied and unoccupied patches of riparian habitat. Chapter 6 (Management and Research Considerations) describes the options for moving forward with cuckoo presence/absence surveys, yellow-billed cuckoo survey methods, and vegetation and microclimate measurements in order to provide information needed to guide conservation efforts such as (1) restoring cuckoo habitat along the lower Colorado River, (2) identifying core cuckoo breeding habitat, and (3) identifying potential breeding habitat. 


\section{Chapter 2: Yellow-Billed Cuckoo Breeding Surveys}

The Lower Colorado River Multi-Species Conservation Plan of 2004 calls for the identification of areas used by yellow-billed cuckoos via survey and the collection of information necessary to better define the species' habitat requirements. This information will then be used to design and maintain riparian habitat suitable for yellow-billed cuckoos in the LCR MSCP planning area, which should help reduce the likelihood of future federal listing of this species. This project was initiated in the spring of 2006, and standardized cuckoo surveys were conducted throughout the breeding seasons in 2006 and 2007. The purpose of this chapter is to document the results of the 2007 surveys.

\section{Survey Location and Selection of Study Sites}

The MSCP boundary covers areas up to and including the full-pool elevations of Lake Mead, Lake Mohave, Lake Havasu, and the historical floodplain of the Colorado River from Lake Mead to the United States-Mexico Southerly International Boundary, a distance of about 644 river $\mathrm{km}$ (400 river miles). In order to determine the current yellow-billed cuckoo breeding range within the lower Colorado River Basin, we examined historic detection sites (Gaines 1977, Gaines and Laymon 1984, Halterman and Laymon 1994, 1995; Halterman 1998, 2001, 2002, 2003, 2004) and our previous survey efforts in 2005 and 2006 (Johnson et al. 2006b, and Johnson et al. 2007), which included sites along the Gila River near Yuma, Arizona, the Muddy River in Southern Nevada, and Pahranagat National Wildlife Refuge in the White Water River drainage, Nevada (Figure 2.1).

Specific yellow-billed cuckoo survey sites were initially selected using the 'look see' method. This approach, which was employed during previous AGFD-UAGA surveys, calls for identification of suitable habitats before conducting surveys (see Bibby et al. 1992). It relies on prior knowledge of possible habitat preferences, expert opinion, and knowledge of the basic biology of the species in question (Halterman et al. 2006). We also selected sites based on historical detections collected in 2005 (Johnson et al. 2006b), which is a preferred method for surveying rare birds (Dawson 1981) when the goal is detection of all occurrences of a species within constraints such as time. Most of our survey sites were identified using these methods prior to the 2006 field season. In 2007, we added three survey sites. Big Horn Draw at Lake Mead NWR was surveyed due to its habitat growth from 2006 to 2007, and Teepee Trail as well as North Burn at the Bill Williams River NWR was added to better encompass some of the wider portions of the riparian habitat that exists there.

In 2007 we discontinued conducting some portions of surveys previously done in 2006 at Pahranagat NWR, Littlefield Bridge, Mesquite Bridge, Lake Mohave, and Imperial NWR Paradise sites, and many areas along the Gila River (Gila River sites at Hwy. 95, Gila River Welton site and the Gila River Ligurta Site). The decision to discontinue surveying these areas was based on our evaluation of the current habitat conditions, lack of cuckoo detections in 2005 and 2006, and consultation with the Bureau of Reclamation. Finally, some sites at the Bill Williams River NWR were split from one survey site into two or more sites for logistical purposes, mainly their immense length. For example, Cave Wash was split into portions of Cottonwood Patch and Honeycomb Bend. Many of our yellow-billed cuckoo survey areas overlap with southwestern willow 


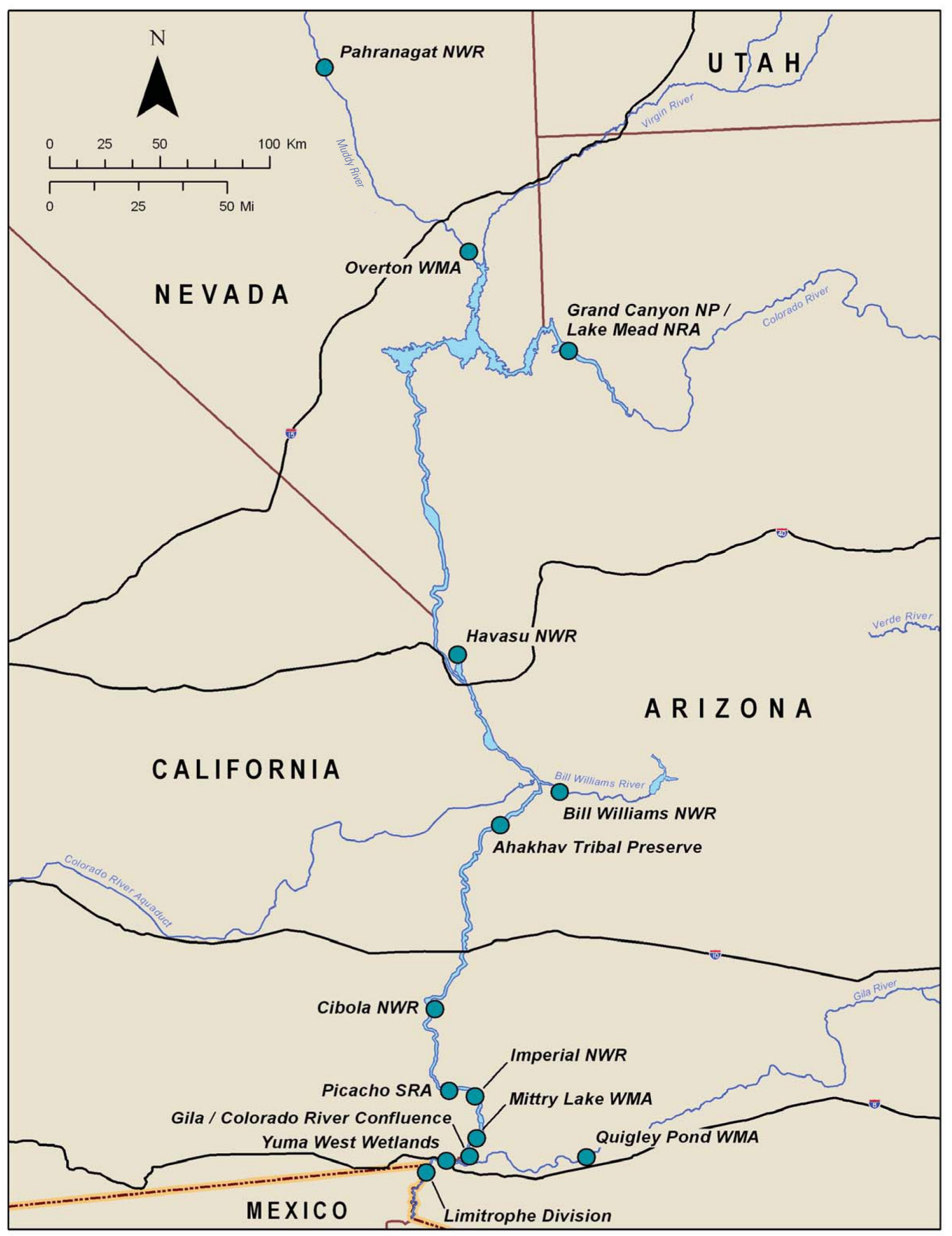

Figure 2.1. Yellow-billed cuckoo survey areas along the Muddy River, Nevada, and lower Colorado, Bill Williams, and Gila Rivers in Arizona and California, 2007. 
flycatcher surveys areas, which have their own established site names (Table 2.1). Some of cuckoo surveys encompass a much larger area than do the flycatcher areas they are named after; in a few cases they do not overlap at all.

Table 2.1. Yellow-billed cuckoo (YBCU) and southwestern willow flycatcher (SWIFL) 2007 sites names in the lower Colorado River watershed along the Muddy, Virgin, and White Rivers in Nevada, and the Colorado, Bill Williams, and Gila Rivers in Arizona and California.

\begin{tabular}{|c|c|}
\hline YBCU 2007 Site Name & SWIFL 2007 Site Name \\
\hline Pahranagat NWR-Pahranagat North & Pahranagat North \\
\hline Pahranagat NWR-Pahranagat South & Pahranagat South \\
\hline Overton WMA-Honeybee Pond & Overton WMA to the south \\
\hline Overton WMA-Overton Wildlife & Overton WMA \\
\hline Grand Canyon NP/Lake Mead NRA-RM 274.5 & RM $274.5 \mathrm{~N}$ \\
\hline Grand Canyon NP/Lake Mead NRA-Cuckoo Beach & Kowlp Corner, RM 286N, Twin Coves \\
\hline Grand Canyon NP/Lake Mead NRA-Iceberg Ridge & Bradley Bay \\
\hline Grand Canyon NP/Lake Mead NRA-Chuckwalla Cove & Chuckwalla Cove \\
\hline Grand Canyon NP/Lake Mead NRA-Big Horn Draw & NA \\
\hline Havasu NWR-Pintail Slough & NA \\
\hline Havasu NWR-North Dike & NA \\
\hline Havasu NWR-Topock Marsh Restoration & NA \\
\hline Havasu NWR-Topock Tamarisk & NA \\
\hline Bill Williams River NWR-Teepee Trail & NA \\
\hline Bill Williams River NWR-Cottonwood Patch & Site 8 \\
\hline Bill Williams River NWR-Cave Wash & Site 8 \\
\hline Bill Williams River NWR-Honeycomb Bend & Site 8 \\
\hline Bill Williams River NWR-Mineral Wash & Beaver Pond, Site 8 \\
\hline Bill Williams River NWR-Big Bend & Mineral Wash \& Beaver Pond \\
\hline Bill Williams River NWR-Gibraltar Rock & None, but near Site 5 \\
\hline Bill Williams River NRA-Sandy Wash & Site 5 \\
\hline Bill Williams River NWR-Fox Wash & Site 5 \\
\hline Bill Williams River NWR-Mosquito Flats & Site $3 \&$ Site 5 \\
\hline Bill Williams River NWR-Saguaro Slot & Site 1, Site 2, Site 3, Site 4, Site 11 \\
\hline Bill Williams River NWR-North Burn & NA \\
\hline Bill Williams River NWR-Bill Williams River Marsh & Site 1 , Site 2 , Site 4 , Site 11 \\
\hline Ahakhav Tribal Preserve-CRIT Restoration & NA \\
\hline Cibola NWR-Cibola North Restoration & NA \\
\hline
\end{tabular}


Table 2.1. Yellow-billed cuckoo (YBCU) and southwestern willow flycatcher (SWIFL) 2007 sites names in the lower Colorado River watershed along the Muddy, Virgin, and White Rivers in Nevada, and the Colorado, Bill Williams, and Gila Rivers in Arizona and California.-Continued

\begin{tabular}{ll}
\hline \multicolumn{1}{c}{ YBCU 2007 Site Name } & \multicolumn{1}{c}{ SWIFL 2007 Site Name } \\
\hline Cibola NWR-Cibola Nature Trail Restoration & Cibola Nature Trail \\
Cibola NWR-Cibola Eucalyptus Restoration & NA \\
Cibola NWR-Cibola South Restoration & NA \\
Picacho SRA & Picacho NW \\
Imperial NWR-Imperial South Restoration & Imperial Nursery, Nursery NW \\
Mittry Lake WMA/Pratt Restoration & Mittry South \\
Gila/Colorado River Confluence-Colorado Confluence & Gila Confluence North, Gila Confluence \\
Gila/Colorado River Confluence-Gila Confluence & Gila Confluence North, Gila Confluence \\
Yuma West Wetlands & NA \\
Limitrophe Division-Limitrophe Division North & Morelos Dam \\
Limitrophe Division-Limitrophe Division South & Gadsden, Hunters Hole \\
Gila River/Quigley Pond WMA & NA \\
\hline
\end{tabular}

\section{Study Site Descriptions}

A site is a discrete location-typically one or more distinct habitat patches - that is surveyed for yellow-billed cuckoos. We use survey area to mean the entire area that encompasses one or more sites. Therefore, a survey area such as the Bill Williams River NWR may contain multiple sites, such as Sandy Wash. The survey area and descriptions are listed below beginning with the most upstream locations and progressing downstream; this is true both within the entire study area and for each side drainage. Additional details on each site and the associated surveys and detections are presented in Appendix 2, Appendix 4 and Appendix 5.

\section{Pahranagat National Wildlife Refuge, NV (White River Drainage)}

The entire Pahranagat National Wildlife Refuge encompasses 2,177 ha (5,380 acres) in southern Nevada, approximately $132 \mathrm{~km}$ (82 miles) northwest of Las Vegas (Figure 2.1; Appendix 4). All surveys were conducted at the upper Pahranagat Lake, the only site in the refuge with appropriate cuckoo habitat. The habitat consists of patches of native willow and cottonwood at the inflow and outflow of upper Pahranagat Lake, which is fed by Pahranagat Springs just north of the lake. The upland habitat adjacent to the lake is Mohave Desert consisting of creosote (Larrea tridentate) and desert scrub. We divided this area into two survey sites covering: (1) the northern lake shore, and (2) southern lake shore which also included potential cuckoo habitat that follows U.S. Highway 93 to the south. In 2006, we surveyed the entire lake perimeter. In 2007, we excluded the Pahranagat East and West sites because of they lacked suitable cuckoo habitat. 


\section{Pahranagat North (Elevation 1,026 m; 3,366 ft)}

The north end of upper Pahranagat Lake supports the best quality cuckoo habitat (Appendixes 4 and 5). It consists of large Fremont cottonwood (Populus fremontii) and Goodding's willow (Salix gooddingii) trees. The height of the relatively closed canopy is 15-18 $\mathrm{m}$ (49-59 ft). The understory consists of forbs and grasses, with little apparent tree recruitment. In 2007, standing water was not present within this site, and in September, the lake receded considerably from the site. This site is surrounded by marsh along the lake's edge, which consists mainly of lizard tail (Yerba manza).

\section{Pahranagat South (Elevation 1,020 m; 3,346 ft)}

Pahranagat South consists of a relatively small stringer of Goodding's willow, coyote willow (Salix exigua), and Fremont cottonwood lining a developed channel that carries the outflow from upper Pahranagat Lake (Appendixes 4 and 5). Canopy height is 16-18 $\mathrm{m}(52-59 \mathrm{ft})$. The site is bordered by open marsh on the lake side. Tamarisk and Russian-olive (Elaeagnus angustifolia) form a sparse understory. Standing water was not present within this site in 2007 . The upland habitat adjacent to this site is creosote and desert scrub. There are extensive trails and campsites in and around this site that impact the riparian vegetation. The riparian habitat follows both sides of U.S. Highway 93 and becomes sparser away from the lake.

\section{Overton Wildlife Management Area, NV (Muddy River)}

The Overton Wildlife Management Area (WMA) consists of 7,146 ha (17,657 acres) located at the inflow of the Muddy River into the Overton Arm of Lake Mead (Figure 2.1; Appendix 4). The study area consists of seasonally flooded marshes, dense tamarisk, willow patches, scattered mesquite thickets, and isolated stringers of Fremont cottonwood. There are agricultural fields and ponds throughout the wildlife management area that are managed for waterfowl. Numerous roads cross the refuge, allowing for easy access to all sites. We surveyed two survey sites within Overton WMA in 2007 but excluded the 2006 sites of Overton North and Overton Tamarisk because of unsuitable cuckoo habitat.

\section{Honey Bee Pond (Elevation $375 \mathrm{~m} ; 1,230 \mathrm{ft}$ )}

This is the largest pond in the Wildlife Management Area (Appendixes 4 and 5). The site consists of tamarisk, Fremont cottonwood, coyote willow, and a few scattered California fan palms (Washingtonia filifera). Canopy height is 4-6 m (13-19 ft). The understory is comprised of baccharis (Baccharis spp.), tamarisk, and giant reed (Arundo donax). In 2007, standing water was present within this site, and the banks of the pond overflowed in July. A dense stand of tamarisk surrounds the pond area.

\section{Overton Wildlife (Elevation $371 \mathrm{~m} ; 1,217 \mathrm{ft}$ )}

This is a small isolated site with a multi-layered canopy that consists of coyote willow and tamarisk, as well as a re-vegetation site that consists of dense even-aged coyote willow

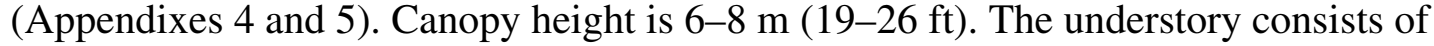
young willow, tamarisk, and arrowweed (Pluchea sericea). A canal divides the site, and, 
in July, the canal flooded resulting in standing water within the site. Most of the site is surrounded by dense monoculture tamarisk.

\section{Grand Canyon National Park/Lake Mead National Recreation Area, AZ (Colorado River and Lake Mead)}

Since 1997, deposited sediments had been exposed by declining water levels where the Colorado River emerges from the Grand Canyon and flows into the northern end of Lake Mead (Figure 2.1; Appendix 4). Where these deposited sediments occurred, adequate habitat for yellow-billed cuckoos had developed. In 2006, yellow-billed cuckoos occupied and bred in these sites. However, since 2000, a 31-m (102 ft) drop in lake levels has lowered the water table and stressed the vegetation at these sites. Over a

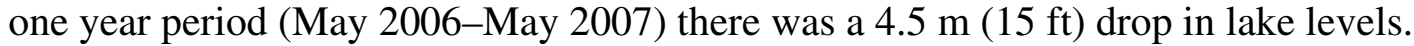
Riparian habitat consisting of willow, tamarisk, and baccharis that developed on those deposited sediments, is now almost all dead due to the lack of water and erosion, all caused from the declining lake level. In 2007, we observed tamarisk and some willow recruitment along the river's edge. This area is divided into five sites, one new site (Big Horn Draw) that developed into adequate cuckoo habitat in 2007, RM274.5, Cuckoo Beach, Iceberg Ridge and Chuckwalla Cove. In 2007, we excluded the Spencer Canyon site because of unsuitable cuckoo habitat.

\section{RM 274.5 (Elevation $360 \mathrm{~m} ; 1,181 \mathrm{ft}$ )}

RM 274.5 is approximately $19 \mathrm{~km}$ (11.8 miles) upstream from the Cuckoo Beach site, and consists mainly of dense Goodding's willow and tamarisk with sparse patches of cattail marsh (Typhus spp.; Appendixes 4 and 5). Canopy height is 8-10 m (26-32 ft). The understory is consists of young tamarisk, baccharis, and young Goodding's willow, with an average height of $2 \mathrm{~m}(6.5 \mathrm{ft})$. Standing water was present during all surveys in 2007 due to the large number of seeps and creeks. The site is bordered by dense tamarisk, desert upland, and steep canyon walls. In 2007, we extended this survey area upstream along the river's edge approximately 800 m compared to our 2006 surveys.

\section{Cuckoo Beach (Elevation $340 \mathrm{~m} ; 1,115 \mathrm{ft}$ )}

Cuckoo Beach is approximately $1.5 \mathrm{~km}(0.9$ miles $)$ upstream from the Iceberg Ridge site, and lies on both sides of the river (Appendixes 4 and 5). It consists of stringers of Gooding's willow 8-12 m (26-39 ft) in height, extending inland approximately $60 \mathrm{~m}(197 \mathrm{ft})$. Tamarisk (canopy height is 6-8 $\mathrm{m}(20-26 \mathrm{ft})$ is dominant toward the back of the site (away from the river), where there are also sand dunes and desert scrub. The understory consists of tamarisk and Goodding's willows, 1-1.5 m (3 ft) tall. In 2007, standing water was not present within this site. The adjacent habitat is desert upland. By July of 2007, approximately 50 percent of the Goodding's willow had died. By August, 100 percent had died downstream on the river left portion of the site. Though some young Goodding's willow still exists on the upstream right portion of the site, 90 percent of the overstory was dying by August. Also, 100 percent of the marsh vegetation was dry and dying by July. Soil band erosion was evident all along the river's edge. In 2007, we also documented cattle at this site. 


\section{Iceberg Ridge (Elevation 345 m; 1,132 ft)}

Iceberg Ridge is a crescent-shaped patch within a cove approximately $300 \mathrm{~m}$ (984 ft) upstream from Chuckwalla Cove on river left (Appendixes 4 and 5). This site consists of small stringers of Goodding's willow and tamarisk. The upstream portion is sparsely vegetated, with open spaces between the willow and tamarisk. The middle section consists of multi-aged Goodding's willow. The downstream section is dense Goodding's willow with a canopy of approximately 4-5 m (13-16 ft) tall, although a majority of the upper canopy ( $>5 \mathrm{~m} ; 16 \mathrm{ft}$ ) is dead or dying. In 2007 there was no standing water at this site. The marsh vegetation consisting of reeds (Phragmites spp.) and cattails that thrived in 2006 had died by July 2007. The site is bordered by desert upland habitat, and thick tamarisk. In July of 2007, 60 percent of the Goodding's willow was dead at this site. By August, 80 percent was dead. Tamarisk recruitment was documented all along the edge of the river at this site.

\section{Chuckwalla Cove (Elevation $340 \mathrm{~m} ; 1,115 \mathrm{ft}$ )}

Chuckwalla Cove is the first large delta site upstream from Lake Mead NRA proper, located on river right approximately $14.5 \mathrm{~km}$ (9 miles) from the South Cove boat ramp (Appendixes 4 and 5). Suitable yellow-billed cuckoo habitat consisting of large patches of Goodding's willow and tamarisk had developed in exposed sediment, low water areas over the past six years. The habitat is spread throughout the entire floodplain, for approximately $250 \mathrm{~m}(820 \mathrm{ft})$ perpendicular to the river's edge. The Goodding's willow at this site are found in stringers that extend perpendicular to the river. Canopy

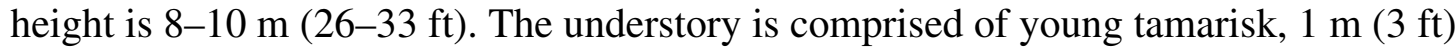
tall. In 2007, standing water was not present within this site. The adjacent habitat is desert upland. In 2007, we found high mortality rates (60 percent in August) of Goodding's willow due to the drop in lake levels. Willow recruitment was non-existent, yet tamarisk recruitment was high.

\section{Big Horn Draw (Elevation 340m, 1,115 ft)}

Big Horn Draw is a small site, located $500 \mathrm{~m}(1640 \mathrm{ft})$ downstream from Chuckwalla Cove, approximately $14 \mathrm{~km}$ (8.7 miles) from the South Cove boat ramp (Appendixes 4 and 5). In 2006, we noted that this site could potentially develop into suitable cuckoo habitat. In 2007, we surveyed this site three times, but did not conduct a fourth survey because the majority of the Goodding's Willow had died by August due to the drop in lake levels. The habitat consisted of a stringer of mixed Goodding's willow and tamarisk along the river's edge, approximately $500 \mathrm{~m}(1640 \mathrm{ft})$ long, and $30 \mathrm{~m}(98 \mathrm{ft})$ wide. Canopy height is 4-5 $\mathrm{m}(13-16 \mathrm{ft})$. The understory is dominated by young tamarisk,

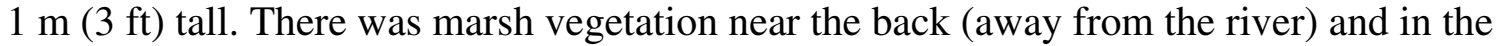
middle of the site that consisted of reeds (Phragmites spp.) and cattails, but this dried up by July. In 2007, there was no standing water at this site. This patch backs up to the steep Iceberg Ridge wall consisting of desert upland habitat.

\section{Havasu National Wildlife Refuge, AZ (Colorado River)}

The Havasu National Wildlife Refuge is 15,181 ha (37,515 acres), including approximately 45 river $\mathrm{km}$ (28 river miles) of the Colorado River (Figure 2.1; Appendix 4). Topock Marsh is an old marsh within the existing river meander, covering 
approximately 1619 ha (4000 acres) of the refuge, and is where most of the riparian habitat in the refuge exists. It is maintained through a dike system established with the creation of the refuge. Topock Marsh presently consists of 40 percent of all backwater habitat on the entire Colorado River system. In 2007, we divided the Havasu National Wildlife Refuge area into four yellow-billed cuckoo survey sites, excluding two sites (Sacramento Wash and Havasu Tamarisk) from our 2006 survey because of lack of suitable cuckoo habitat.

\section{Pintail Slough (Elevation $135 \mathrm{~m}$; $443 \mathrm{ft}$ )}

Pintail Slough is a restoration site that consists of young Fremont cottonwood with a small area of large Fremont cottonwoods (Appendixes 4 and 5). The younger portion of the site is only four years old and lacks an understory or multi-layered canopy. Canopy height is 4-6 m (13-20 ft) in the young portion of the site and 12-15 m (39-9 ft) in the older section. The site is surrounded by tamarisk, arrowweed, four-wing saltbush (Atriplex canescens), and some mesquite. The site is bordered by old agricultural fields, dikes, and a grid of roads. In 2007, standing water was occasionally present within this site.

\section{North Dike (Elevation $137 \mathrm{~m} ; 449 \mathrm{ft}$ )}

The North Dike site is comprised of two restoration plots located about $300 \mathrm{~m}$ (984 ft) south of Pintail Slough. It consists of large Fremont cottonwoods with sparse mesquite along the edges of the plot (Appendixes 4 and 5). Canopy height is 8-10 $\mathrm{m}$ (26$33 \mathrm{ft}$ ). The understory consists of forbs and grasses. The smaller younger plot is mainly Fremont cottonwood and sparse mesquite, 1-2 m (3-6 ft) tall, with an understory of tall grasses. There was intermittent standing water within this site in 2007 and occasional water in the surrounding canals. There is also a large patch of tamarisk and arrowweed surrounding the site, and old agricultural fields and roads bordering each plot.

\section{Topock Marsh Restoration (Elevation 136 m; $446 \mathrm{ft}$ )}

The Topock Marsh restoration site is adjacent to the Colorado River, consisting of five-year-old Fremont cottonwoods intermixed with two-year-old Fremont cottonwoods and Goodding's willow planted in rows, with a small dense mesquite restoration plot adjacent to the site (Appendixes 4 and 5). Canopy height is 5-7 $\mathrm{m}(16-23 \mathrm{ft})$. There was no standing water within this site in 2007. A large patch of tamarisk and arrowweed, agriculture fields, and roads surround the site. In late July, a large part of the northern side of the plot that borders the agriculture field was thinned extensively.

\section{Topock Tamarisk (Elevation $143 \mathrm{~m} ; 469 \mathrm{ft}$ )}

Topock Tamarisk is along the western end of Sacramento Wash, which is near I40 (Appendixes 4 and 5). This site consists of Athel tamarisk (Tamarix aphylla) with a dense overstory. There is no understory within this site, although there is a thick duff layer and many downed trees and branches. A small stringer of tall cottonwoods runs along a dirt road that borders the site. Canopy height is 10-13 m (33-43) ft). In 2007, standing water was present at this site during late July and August due to the flooding of Sacramento Wash. The site is surrounded by a large patch of young monotypic tamarisk, arrowweed, and creosote. 


\section{Bill Williams River National Wildlife Refuge, AZ (Bill Williams River)}

The Bill Williams River, a tributary of the Colorado River, runs 64 km (40 miles) from Alamo Dam to the confluence of the Colorado River. Alamo Lake, which is behind Alamo Dam, is fed by the Big Sandy and Santa Maria Rivers. Bill Williams River National Wildlife Refuge is a 2,489 ha (6,150 acres) area that stretches from Cave Wash downstream to the Colorado River-Bill Williams River confluence, a distance of approximately $16 \mathrm{~km}$ (10 miles) (Figure 2.1; Appendix 4). Bill Williams River NWR is a unique riparian system that consists of sandy washes, marsh, and riparian areas that offer some of the last naturally occurring large cottonwood-willow stands along the lower Colorado River. The entire riparian area and the floodplain are flanked by Sonoran desert upland habitat.

We divided the Bill Williams River NWR into thirteen cuckoo survey sites. We chose most of the sites (see below) in 2006 based on historic survey routes where cuckoos had been detected from 1994, 1995, 1998, and 2001-03 (Halterman and Laymon 1994, Halterman and Laymon 1995, Halterman 1998, 2001, 2002, 2003). We also added survey routes that connected each site within the refuge riparian system. In 2007, we added two sites that we did not cover in 2006; North Burn and Teepee Trail. For logistical purposes, we split one of our longer survey routes (Cave Wash) into three shorter survey routes; Cottonwood Patch, Cave Wash, and Honeycomb Bend.

Survey site descriptions are listed below beginning with the most upstream locations and progressing downstream.

\section{Teepee Trail (Elevation $180 \mathrm{~m} ; 590 \mathrm{ft}$ )}

Teepee Trail is located on the northeastern edge of the refuge (Appendixes 4 and 5). The site consists of a small strip of suitable habitat $600 \mathrm{~m}$ (1969 ft) long. Teepee Trail is approximately 1.5 kilometers $(0.93 \mathrm{mi})$ from the nearest surface water and is not contiguous with other cuckoo habitat within the refuge. The understory of this site is dominated by dense tamarisk while the overstory is made up of Fremont cottonwood and, to a lesser extent, Goodding's willow. Canopy height is 6 to $8 \mathrm{~m}$ (19 to $26 \mathrm{ft}$ ). There is no standing water within this site. The site is surrounded by a combination of sparse tamarisk and fallow fields to the south and by Sonoran Desert upland to the north.

\section{Cave Wash (Elevation $175 \mathrm{~m} ; 574 \mathrm{ft}$ )}

Cave Wash is located in the eastern portion of the refuge (Appendixes 4 and 5). The site is a wide floodplain, with the western portion consisting of young Goodding's willows and Fremont cottonwoods along the river's edge. The eastern portion of the site is made up of large Fremont cottonwoods farther from the water. The riparian patches within the floodplain are well developed with very little understory. The vegetation at this site is extremely thick in some places. Canopy height is 8-10 m $(26-33 \mathrm{ft})$ in the western part of the site and up to $18 \mathrm{~m}(59 \mathrm{ft})$ in the eastern part. The river is braided at this site allowing thick riparian patches and standing water to alternate with dry, sandy washes away from the main river channel. This site is surrounded by Sonoran Desert upland. In 2006, this site also covered Honeycomb Bend and Cottonwood Patch sites, but was split in 2007 for logistical purposes. 


\section{Cottonwood Patch (Elevation 181m; $593 \mathrm{ft}$ )}

Cottonwood Patch is the eastern portion of the 2006 Cave Wash survey (Appendixes 4 and 5). The site consists of a lush but thin stringer of Fremont cottonwoods. The canopy is 8-10 m (26-33 ft) and consists of Fremont cottonwood. The understory is sparse, consisting of tamarisk and some small Fremont cottonwoods. Cottonwood Patch is located within $30 \mathrm{~m}(98 \mathrm{ft})$ of the Bill Williams River, but the river runs underground in this part of the refuge. A small puddle is the only surface water near Cottonwood Patch. The site is surrounded by Sonoran Desert upland.

\section{Honeycomb Bend (Elevation $171 \mathrm{~m}$; 561ft)}

This site is the western arm of the 2006 Cave Wash survey. It consists of multilayered, uneven aged Goodding's willow and Fremont cottonwoods that line both banks of the river (Appendixes 4 and 5). The Bill Williams River flows at the surface in this site and has a wide floodplain, which allows some patches of riparian vegetation to grow away from the main channel. The understory consists mainly of tamarisk of variable density. Canopy height is $8-15 \mathrm{~m}(26-49 \mathrm{ft})$, depending on the individual stand. It is surrounding by Sonoran Desert upland to the north and south.

\section{Mineral Wash (Elevation $160 \mathrm{~m} ; 525 \mathrm{ft}$ )}

Mineral Wash has dense, mature riparian vegetation lining both banks (Appendixes 4 and 5). The vegetation is dominated by native species, but also contains an exotic component. There are many patches with multi-layered, uneven-aged Fremont cottonwood and Goodding's willow stands with a dense understory of Goodding's willow, tamarisk, mesquite, and other shrubs. Historical flooding is evident in this section

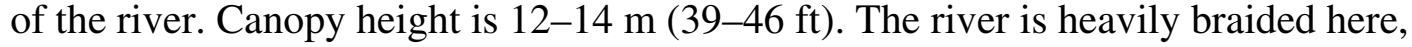
causing riparian patches to be thicker, with standing water away from the main river channel. This site is surrounded by Sonoran Desert upland.

\section{Big Bend (Elevation $165 \mathrm{~m}$; 541ft)}

Big Bend is a large bend in the Bill Williams River that winds through Bill Williams River Canyon (Appendixes 4 and 5). The canyon varies in width throughout the site and patchy dense riparian vegetation lines the riverbanks throughout. The vegetation is dominated by native species, but also has braided tamarisk throughout. There are many patches with multi-layered uneven-aged Fremont cottonwood and Goodding's willow stands with a dense understory of tamarisk. Bulrush (Scirpus spp.) lines the riverbank

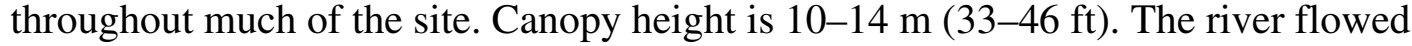
through Big Bend during all surveys in 2007. This site is surrounded by sandy deltas and contains extensive patches of mesquite that extend into the canyon floodplain. There are strips of young willow and cottonwood in areas where the sandy uplands have flooded. This site is surrounded by Sonoran Desert upland.

\section{Gibraltar Rock (Elevation $145 \mathrm{~m} ; 476 \mathrm{ft}$ )}

Gibraltar Rock consists of a large sandy floodplain with large areas of cobble. This washed-out section of the river is straddled at either end by two lush riparian patches consisting of mature and young Fremont cottonwoods, and young Goodding's willow 
(Appendixes 4 and 5). There are tamarisk stringers throughout the site and thicker tamarisk extending into the upland desert habitat. Canopy height is 10-12 m (33-39 ft). The river flowed through the eastern third of the site during 2007. The site is surrounded by Sonoran Desert upland.

\section{Sandy Wash (Elevation $146 \mathrm{~m} ; 473 \mathrm{ft}$ )}

The Sandy Wash site has lush riparian habitat on either side of dry, sandy braids of several river washes. Within this site, the river runs against a cliff face on the northern side of the patch, away from the main part of the riparian habitat (Appendixes 4 and 5). The patches consist of large Fremont cottonwoods and Goodding's willows, with a thick understory dominated by tamarisk, younger Fremont cottonwood and Goodding's willow. Canopy height is 12-14 m (39-46 ft). The river washes did not flow during any surveys in 2007, but a stagnant pool in the river bed stayed wet throughout. The site is surrounded by mesquite and palo verde (Parkinsonia microphylla) to the south and by Sonoran Desert upland to the north.

\section{Fox Wash (Elevation $145 \mathrm{~m} ; 476 \mathrm{ft}$ )}

Fox Wash is located on the northern edge of the western portion of the refuge (Appendixes 4 and 5). It is extremely diverse, consisting of a dry river bed and desert washes lined with tamarisk stringers, burnt tamarisk, and downed wood. There is a unique section of large Fremont cottonwood and Goodding's willow with very little understory, leaving it very open except for widely dispersed young tamarisk. Canopy

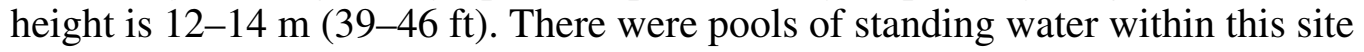
intermittently during 2007. The site is surrounded by patches of mesquite and blue palo verde to the south and by Sonoran Desert upland to the north.

\section{Mosquito Flats (Elevation $140 \mathrm{~m} ; 459 \mathrm{ft}$ )}

Mosquito Flats borders the refuge's broadest riparian area, which is approximately $600 \mathrm{~m}$ (1968 ft) wide (Appendixes 4 and 5). We focused our surveys on the southern edge of the site. The patch consists of native and exotic vegetation in multiple stages of growth. Large Fremont cottonwood and Goodding's willow are present throughout the site. Canopy height is $12-14 \mathrm{~m}$ (39-46 ft). Some areas of the site have a relatively open understory while other areas contain very dense tamarisk or Goodding's willow. There was intermittent standing water within this site during 2007. Mosquito Flats is bordered by large patches of mesquite, blue palo verde, and arrowweed.

\section{Saguaro Slot (Elevation $135 \mathrm{~m} ; 443 \mathrm{ft}$ )}

Saguaro Slot is an extremely dense site with both native and exotic vegetation,

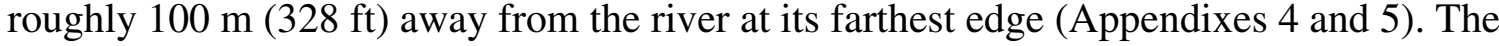
overstory includes many large Goodding's willows and limited Fremont cottonwoods. The understory is made up of many thick clumps of small-diameter tamarisk and dense stands of small Goodding's willow. There are numerous downed logs and a thick

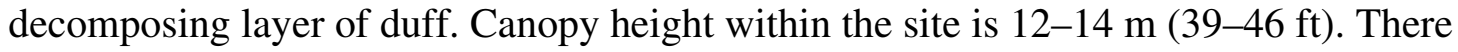
were pools of standing water during all 2007 surveys. The site is surrounded by a dense mesquite thicket. 


\section{North Burn (Elevation $151 \mathrm{~m} ; 495 \mathrm{ft}$ )}

The North Burn site is located on the northern edge of the wide riparian patch, its southern border is the Mosquito Flats site (Appendixes 4 and 5). North Burn was not surveyed in 2006 due to inaccessibility, but became accessible due to vegetation clearing from a fire in late July 2006. There are numerous large Fremont cottonwoods and Goodding's willow throughout the site. Canopy height is 12-14 m (39-46 ft).

Goodding's willow and tamarisk create a thick understory. A side channel of the river flows through the western portion of the site while the eastern portion is dry. The middle section of the site borders the area burned in 2006. The burn itself consists of large native trees that are mostly dead now with regenerating tamarisk. North Burn is surrounded by very dense mesquite and blue palo verde, to the north the site is bordered by Sonoran Desert upland.

\section{Bill Williams River Marsh (Elevation 133 m; $436 \mathrm{ft}$ )}

Bill Williams River Marsh was accessed by boat by paddling from Lake Havasu to the confluence of the Bill Williams River, then continuing upriver approximately 1.6 $\mathrm{km}$ (0.9 miles), to the beginning of the site (Appendixes 4 and 5). Habitat consists mainly of Fremont cottonwood and Goodding's willow along the river's edge and throughout the floodplain, with tamarisk and Goodding's willow making up most of the understory. The understory is extremely dense in some areas due to the thick tamarisk. Canopy height is 12-14 m (39-46 ft). Marsh vegetation is abundant along the banks, and stagnant pools of water are present just beyond the river's edge within the riparian area. The site is bordered to the south by Sonoran Desert.

\section{Ahakhav Tribal Preserve (Colorado River) (Elevation 94m; 308ft)}

The Ahakhav Tribal Preserve is located on the Colorado River Indian Tribes land, $2 \mathrm{~km}$ (5 miles) south of Parker, AZ (Figure 2.1; Appendix 4). The preserve was established in 1995 and now encompasses 507 ha (1,253 acres) dedicated to the restoration of backwater and riparian habitat.

The preserve is a revegetation site that consists of Fremont cottonwood, Goodding's willow, and mesquite adjacent to the Colorado River (Appendixes 4 and 5). Trees were planted at different times to create a multi-layered structure. Additionally, stands of varying age and species composition, including some composed solely of mesquite, have been planted creating a mosaic of patches throughout the site. Canopy

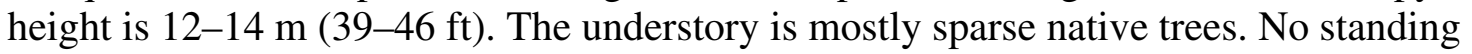
water was present within the site in 2007, but it is regularly irrigated. The Preserve is surrounded by agricultural fields.

\section{Cibola National Wildlife Refuge, AZ (Colorado River)}

The Cibola National Wildlife Refuge (NWR) encompasses 6,729 ha (16,627 acres) in the floodplain of the lower Colorado River (Figure 2.1; Appendix 4). The primary flow of the river through the refuge is via a canalized section constructed in the late 1960s, while the original river channel forms the western boundary of the refuge at the California border. Approximately 809 ha (2000 acres) of the refuge is farmed for migratory waterfowl and 318 ha (785 acres) consists of Sonoran Desert. Most of the alluvial river bottom is dominated by tamarisk, mesquite, and arrowweed. Survey sites 
were located at riparian restoration plots planted within the past $10-15$ years. Two fires occurred on the refuge during the 2006 field season, the first on 17 July and the second on 10 August. In 2007, we noted recruitment of arrowweed and tamarisk in these burned areas. No fires occurred in 2007. We surveyed four sites at Cibola National Wildlife Refuge in 2007. Two sites (Cibola Cross River, Cibola East Side) surveyed in 2006 were not surveyed in 2007 due to lack of suitable cuckoo habitat.

\section{Cibola North Restoration (Elevation $68 \mathrm{~m} ; 223 \mathrm{ft}$ )}

The Cibola North Restoration site consists of young (2-3 years old) Freemont cottonwoods and is approximately $500 \mathrm{~m}(1640 \mathrm{ft})$ north of the Cibola Nature Trail site (Appendixes 4 and 5). The site was planted in an abandoned agricultural field. Canopy height is 4-6 m (13-20 ft). In 2007, standing water was not present within the site. It is bordered by agriculture lands, with a paved road on the north side.

\section{Cibola Nature Trail Restoration (Elevation $74 \mathrm{~m} ; 243 \mathrm{ft}$ )}

The Cibola Nature Trail Restoration site was planted in 1999. It is dominated by cottonwood planted in a horseshoe-shaped ring: The north section is dominated by a lower canopy of willow and the south section is dominated by mesquite with a tall grass understory (Appendixes 4 and 5). A public nature trail passes through the site. Canopy height is 10-12 m (33-39 ft). The Colorado River is approximately $2 \mathrm{~km}$ (1.2 miles) away. Refuge staff periodically irrigated the site in 2007 . Therefore, standing water was present in the north part of the horseshoe-shaped ring. The site is surrounded by agriculture fields.

\section{Cibola Eucalyptus Restoration (Elevation $71 \mathrm{~m} ; 233 \mathrm{ft}$ )}

The Cibola Eucalyptus Restoration site consists of eucalyptus trees, but also contains numerous Freemont cottonwoods (Appendixes 4 and 5). Other tree species present include tamarisk, mesquite, and palo verde. A refuge levee road bisects the site, which extends for $1 \mathrm{~km}$ (3.3 ft) north-south. Canopy height is 10-12 m (33-39 ft). The Colorado River lies $100 \mathrm{~m}$ (328 ft) to the east and in 2007 there was no standing water within this site. It is bordered by dense stands of tamarisk, mesquite, and arrowweed.

\section{Cibola South Restoration (Elevation 62 m; $203 \mathrm{ft}$ )}

The Cibola South Restoration site has an open understory and is dominated by rows of planted cottonwoods interspersed with willow (Appendixes 4 and 5). This site lies about $300 \mathrm{~m}(984 \mathrm{ft})$ west of the Colorado River and is irrigated by refuge staff. Canopy height is $10-15 \mathrm{~m}$ (33-49 ft). In 2007, standing water was not present within this site. The site is bordered by tamarisk and dense stands of mesquite.

\section{Picacho State Recreation Area, CA (Colorado River) (Elevation 52 m; 171 ft)}

The Picacho State Recreation Area is 46 ha (120 acre) located on the California side of the Colorado River, within the Imperial National Wildlife Refuge (Figure 2.1; Appendixes 4 and 5). Most of the recreation area is dominated by desert scrub and washes, and includes restored riparian vegetation adjacent to the headquarters and the river. The canopy is dominated by large Fremont cottonwoods, with scattered 
Goodding's willow. The understory is composed of Goodding's willow, mesquite, palo verde, and arrowweed. The riparian area surrounding the study area consists almost entirely of tamarisk. Canopy height is 12-14 m (39-46 ft). In 2006, there was no evidence of standing water within this study area. This entire area is surrounded by desert upland habitat.

\section{Imperial National Wildlife Refuge, AZ and CA (Colorado River)}

The Imperial National Wildlife Refuge encompasses 10,428 ha (25,768 acres), including an unchannelized 50-km (31-mile) stretch of the Colorado River (Figure 2.1; Appendix 4). The refuge borders Cibola NWR to the south. It is dominated by desert ridges and riparian vegetation along the Colorado River. Native riparian vegetation is rare, and most of the habitat is dominated by tamarisk and reeds (Phragmites spp.). In 2007, we surveyed for yellow-billed cuckoos at the Imperial South Restoration site; the Imperial Paradise site was surveyed in 2006, but not in 2007 due to lack of adequate cuckoo habitat.

\section{Imperial South Restoration (Elevation $56 \mathrm{~m} ; 184 \mathrm{ft}$ )}

The Imperial South Restoration site was planted in 1993 (Appendixes 4 and 5). The canopy is dominated by Fremont cottonwoods, with Goodding's willow, mesquite,

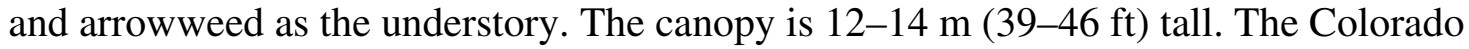
River lies $200 \mathrm{~m}(656 \mathrm{ft})$ to the west, and the refuge staff periodically flooded this site. However, in 2007 there was no evidence of standing water within this site. Marsh habitat occurs to the north and east of the site. To the south and west, additional habitat restoration is currently being constructed to benefit riparian vegetation and native fish. The entire site is a matrix of marsh vegetation, roads, and stringers of cottonwoods, ponds, and waterways. Upland desert with mesquite borders the site.

\section{Mittry Lake State Wildlife Management Area/Pratt Restoration Area, AZ (Colorado River) (Elevation $52 \mathrm{~m} ; 171 \mathrm{ft}$ )}

The Mittry Lake State Wildlife Management Area consists of the Pratt Restoration Area and the adjacent Betty's Kitchen, a small recreation site managed by the Bureau of Land Management (Figure 2.1; Appendixes 4 and 5). The Pratt Restoration Site is dominated by a tall canopy of Freemont cottonwood (12-14 m; 39-46 ft) and Goodding's willow. Most of the site has an open understory covered by leaf litter. The southern part of the site is dominated by a dense baccharis and scattered young Freemont cottonwoods. Betty's Kitchen is dominated by 8-10 m (26-33 ft) tall Athel tamarisk and large mesquite trees $8 \mathrm{~m}(26 \mathrm{ft})$ tall. The rest of the survey area is open water or marsh. In 2007, there was evidence of standing water within the Pratt Restoration site during the month of July. This entire site is surrounded by agriculture fields and Sonoran Desert upland habitat.

\section{Gila-Colorado River Confluence Area, AZ (Gila and Colorado Rivers)}

This study area is located $10 \mathrm{~km}$ (6.2 miles) east of Yuma and is managed by the

Bureau of Land Management (Figure 2.1; Appendix 4). The riparian habitat in this area is dominated by tamarisk and is mainly bordered by agriculture. The habitat at the 
confluence and upriver from the confluence was surveyed for cuckoos. This area was divided into two survey sites, the Colorado River Confluence site and the Gila River site.

\section{Colorado River (Elevation $39 \mathrm{~m} ; 128 \mathrm{ft}$ )}

Within this site, we surveyed suitable riparian habitat along the north side of the river from kayaks (Appendixes 4 and 5). Thin stringers of Fremont cottonwood and Goodding's willow occur close to the river; habitat north of the river's edge is not suitable for cuckoos. Canopy height is $8-10 \mathrm{~m}(26-33 \mathrm{ft})$. Near the Gila-Colorado confluence, the riparian habitat transitions into a citrus orchard. On the south side of the river a thin belt of riparian vegetation exists between the river and the agricultural fields, which is almost entirely tamarisk. In 2007, there was no evidence of standing water within this site.

\section{Gila River (Elevation $39 \mathrm{~m} ; 128 \mathrm{ft}$ )}

The Gila River site is dominated by tamarisk (Appendixes 4 and 5), but also includes small patches of Fremont cottonwood and coyote willow. The site is largely unsuitable habitat. Canopy height within the site is 8-10 $\mathrm{m}(26-33 \mathrm{ft})$. There is riparian vegetation close to the river, but much of what remains is marginal with broad expanses of tamarisk and arrowweed in between native habitat. Canopy height is 8-10 m (26-33 $\mathrm{ft}$ ). In 2007, there was no evidence of standing water within this site. Agricultural fields border the Gila River on the north and south sides of the river. In late August of 2006, one of the best remaining patches within this site consisted of native Fremont cottonwoods, but was altered by a local farmer using heavy machinery. In 2007, the majority of those trees have now died.

\section{Yuma West Wetlands, AZ (Colorado River) (Elevation 36 m; 118 ft)}

This site is surrounded by urban development on the southeast edge of Yuma, AZ (Figure 2.1; Appendixes 4 and 5). It is managed by the city of Yuma, Bureau of Reclamation, and Cocopah (Kwapa) Indian Tribe. Most of the wetland is a riparian restoration plot that borders the Colorado River on one side and a levee on the other. The vegetation is composed of Fremont cottonwood, Goodding's willow, and mesquite that are approximately 8-10 years old. Canopy height is 8-10 $\mathrm{m}(26-33 \mathrm{ft})$. Management activities at the study area include regular irrigation and exotic species removal. There was evidence of standing water within this study area in 2007. The southern edge of the park is bordered by a railroad right-of-way; the northern edge is bordered by a housing park, Interstate 10, and a large expanse of low desert scrub. This is the second year we have completed full yellow-billed cuckoo surveys at this study area.

\section{Limitrophe Division, AZ (Colorado River)}

The Limitrophe Division survey area starts at the International Border near Morales Dam and extend to San Luis, Arizona, at the International Border with Mexico (Figure 2.1; Appendix 4). We only surveyed the riparian habitat on the east side of the river (United States side). The habitat is enclosed by a series of tightly controlled gates and is actively patrolled by border security personnel. We requested permission to enter the study area from the Border Patrol prior to each survey. Agricultural fields border the 
riparian habitat on both sides the Colorado River. The Limitrophe Division area was divided into two sites, Limitrophe North Site and Limitrophe South.

\section{Limitrophe Division North (Elevation $36 \mathrm{~m} ; 118 \mathrm{ft}$ )}

This site starts at the International Border below Morales Dam and extends to the northern border of the Cocopah Indian Tribal lands (Appendixes 4 and 5). The riparian habitat transitions from Fremont cottonwood and Goodding's willow to tamarisk. In some places the site is dominated by arrowweed. Canopy height is $4-10 \mathrm{~m}(13-33 \mathrm{ft})$. In 2007, there was no evidence of standing water within this site. During June 2007, a fire burned 10 ha of the established survey route. There are agricultural fields adjacent to the site.

\section{Limitrophe Division South (Elevation $33 \mathrm{~m} ; 108 \mathrm{ft}$ )}

This site starts at the southern border of the Cocopah Indian Tribal lands and continues to San Luis, AZ, the Southerly International Border with Mexico (Appendixes 4 and 5). The habitat transitions frequently between dense exotic/native vegetation and sparse scrub. Limitrophe Division South has two main patches of suitable riparian habitat that are separated by more than $2 \mathrm{~km}$ (1.2 miles) of sparse scrub dominated by arrowweed. The southern patch is a mix of Freemont cottonwood, Goodding's Willow, and marsh, while the northern patch consists of Freemont cottonwood, tamarisk, and Goodding's Willow. No marsh exists within this section. Canopy height is 4-10 m (13$33 \mathrm{ft}$ ). In 2007, there was no evidence of standing water within this site. There are agricultural fields surrounding the site.

\section{Quigley Pond Wildlife Management Area, AZ (Gila River) (Elevation 67 m; 220 ft)}

The Quigley Pond Wildlife Management Area is located in the Gila River floodplain approximately $6 \mathrm{~km}$ (4 miles) south of the U.S. Highway 8 at the Tacna exit (Figure 2.1; Appendixes 4 and 5). It is managed by the Arizona Game \& Fish Department. The site includes a restoration plot dominated by Fremont cottonwood with a small number of Goodding's willow in the understory. Adjacent to the restoration plot is a larger section of mixed native-exotic habitat with a canopy of mostly young Fremont cottonwood and Goodding's willow, and a dense understory of arrowweed. Approximately $500 \mathrm{~m}$ (1640 ft) to the north is the Gila River and an area mostly dominated by tamarisk. Canopy height is 8-14 $\mathrm{m}(26-46 \mathrm{ft})$. The Arizona Game \& Fish Department irrigates the restoration site and in 2007 there was standing water within this site. The surrounding landscape consists of agricultural fields.

\section{Survey Methods}

Surveys for presence/absence of cuckoos were conducted following established methods (Laymon 1998a, 1998b; Halterman et al. 2006; Johnson et al. 2006b) that involve a minimum of four surveys distributed among four defined survey periods between 10 June and 15 September (Table 2.2). Surveys at each site were staggered at least 10 days apart to assure visits throughout the potential breeding season and to increase the likelihood of detecting nesting cuckoos. If cuckoos were detected during the fourth survey period, which might indicate that cuckoos were still breeding at that site, a fifth survey was conducted. 
Table 2.2. Number of official surveys and yellow-billed cuckoo survey detections per survey period in 2007 at sites in the lower Colorado River watershed along the Muddy, Virgin, and White Rivers in Nevada, and the Colorado, Bill Williams, and Gila Rivers in Arizona and California.

\begin{tabular}{lllll}
\hline \multicolumn{1}{c}{ Survey Period } & \multicolumn{1}{c}{ Survey Dates } & \multicolumn{1}{c}{$\begin{array}{c}\text { No. of Surveys } \\
(\mathbf{n = 1 6 9 )}\end{array}$} & $\begin{array}{c}\text { Detections } \\
(\mathbf{n}=163)\end{array}$ \\
\hline 1 & $6 / 11-6 / 28$ & 40 & 48 & \\
2 & $7 / 1-7 / 18$ & 41 & 44 & \\
3 & $7 / 25-8 / 11$ & 40 & 39 & 27 \\
4 & $8 / 13-9 / 5^{*}$ & 38 & 5 & \\
5 & $9 / 5-9 / 9$ & 10 & & 5 \\
\hline
\end{tabular}

*There was a 15 point survey at Topock Tamarisk during the $4^{\text {th }}$ survey period that couldn't be conducted until $9 / 5$.

We used a taped recording of the yellow-billed cuckoo's kowlp call (Hughes 1999) during surveys. Broadcast equipment was capable of projecting this call at least

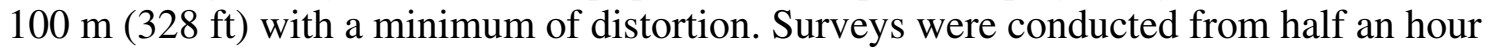
before sunrise until 11:00 a.m., and were terminated if shade temperatures exceeded $41^{\circ} \mathrm{C}$ $\left(110^{\circ} \mathrm{F}\right)$ or during steady rainfall. One transect (i.e., a series of points from which the tape was broadcast) was established through the habitat for every $200 \mathrm{~m}(656 \mathrm{ft})$ of habitat width. No cuckoos have been detected nesting in patches 2 ha (5 acres) or smaller in Arizona or California (Corman and Magill 2000, Halterman et al. 2006), thus we did not survey patches smaller than this size. We did not always conduct surveys from within the habitat because the playback vocalizations are broadcast loudly enough to cover a large area (i.e. $100 \mathrm{~m}$ ). We selected survey points that were no more than $15 \mathrm{~m}(49 \mathrm{ft})$ from the habitat edge and not surrounded by dense vegetation in order to more easily detect cuckoos that responded by flying closer, but did not vocalize. In some cases, we surveyed small narrow stringers of habitat, steep banks, and backwater sloughs playing the tape from a boat. We bypassed areas of unsuitable habitat (e.g., a monoculture of young tamarisk or an extensive cobble bar) between patches if the unsuitable habitat was at least $300 \mathrm{~m}(984 \mathrm{ft})$ in extent.

At each survey point, we started by remaining quiet for one minute to acclimate to the ambient noise and to listen for spontaneously calling cuckoos. If no cuckoos were heard in this one-minute period, the surveyor then played the kowlp call once, followed by one minute of silence to listen for a response. If no detections occurred, this broadcastlisten sequence was repeated up to an additional four times. If there was no detection at a

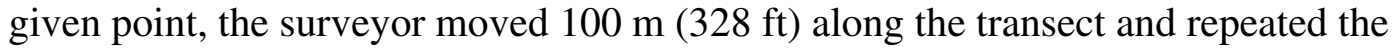
broadcast-listen protocol. If a cuckoo was detected at the survey point, the surveyor moved $300 \mathrm{~m}(984 \mathrm{ft})$ before resuming survey broadcasts to reduce the probability of redetecting or attracting the same individual.

We recorded Universal Transverse Mercator (UTM) coordinates (using Global Positioning System [GPS] units), GPS accuracy, estimated number of individual cuckoos detected, and estimated distance and direction (i.e., the compass bearing) from the surveyor to the detected cuckoo at all survey points. At each survey site, we also recorded the UTM coordinates of the survey site boundaries (including start and stop points), and provided a description of the habitat and surrounding area. 
When a yellow-billed cuckoo was detected, the surveyor briefly attempted to determine the number and breeding status of the individuals present by making direct behavioral observations and by nest searching. All behaviors were recorded including the cuckoo's use of the habitat patch, interactions between individuals, types of vocalizations, and any breeding behavior. After the survey was completed, the surveyor went back to where birds were detected and tried to determine the number cuckoo detected and their breeding status.

\section{Survey Site Classifications}

Based on survey results across all four visits, sites were classified as either occupied (a yellow-billed cuckoo had been detected at a site during at least two survey periods) or unoccupied. The presence of a cuckoo at a site does not necessarily equate to pairing and breeding at that location. Breeding was considered "confirmed" only if an active cuckoo nest was found, copulation was observed, and/or recently fledged young were seen. The detection of multiple cuckoos during one or more surveys or of cuckoos carrying food or nesting material was suggestive of pairing and breeding, but was not considered confirmation.

\section{Supplemental Follow-up Surveys}

Varying numbers of supplemental visits were made to areas with yellow-billed cuckoo survey detections. The purpose of these supplemental visits was to more fully ascertain yellow-billed cuckoo use of site. Supplemental visits also provided additional opportunities to observe breeding behavior and search for nests. When making a supplemental visit, observers did not follow survey protocol and used vocalization broadcasts sparingly (when birds were not being detected). The observers mainly focused on the areas within a site where cuckoos were previously detected or at the sites with the highest likelihood for cuckoo presence and breeding activity. Supplemental follow-up visits differed from surveys in that observers filled out detection information for every location a cuckoo was observed at, even if that meant recording the same individual multiple times. For example, if a cuckoo was seen on river right then flew to river left, then it was counted as one detection if the observer could positively determine it was the same bird. This allowed us to determine exactly which areas cuckoos were detected in within a given site. The same data were taken for supplemental survey detections as were taken for formal survey detections. For each supplemental visit, we also recorded start and stop UTMs for the portion of the site we visited that day.

\section{Nest Searching and Monitoring}

Nest searching was conducted by one of three methods: (1) keying in on the densest area of cuckoo activity: (2) using several observers to triangulate on cuckoo vocalizations; (3) or by searching every tree within a 100-m (328-ft) radius of a detection (Martin and Geupel 1993). When a nest was located, observers took a GPS reading from approximately $10 \mathrm{~m}(33 \mathrm{ft})$ away to minimize disturbance; a reading was later taken directly beneath the nest once it became inactive. Nests were checked every 2-7 days, depending on the stage of the nest when first found. When checking a nest, the nest was first observed from a distance of $20 \mathrm{~m}(66 \mathrm{ft})$ to ascertain its stage. Contents were checked only if an adult was not on the nest and only if the nest was in the incubation or 
early nestling stage, at which time we documented the number of eggs and nestlings along with their estimated age. If the nest was found to be empty, the area was searched for fledglings or signs of predation (Rourke et al. 1999). Inactive nests continued to be checked in order to search for fledglings. Vegetation measurements were taken at each nest after it became inactive.

\section{Spatial Data}

From orthorectified color aerial photography provided by the Bureau of Reclamation, we produced digital orthophoto quarter quads (DOQQs) to create aerial maps of study sites (Appendix 4). These maps were overlain with survey points (the coordinate point from which a broadcast survey was conducted), survey detections (the coordinate point at which the surveyor estimated the cuckoo to be located), supplemental visit detections, and locations of breeding activity. The GIS themes are projected in UTM Zone 11 north; the datums are NAD 1983 (horizontal) and NGVD 1929 (vertical), and the spheroid is GRS 1980. The software used to compile the maps, in meters, was ArcView GIS Version 3.3 (ESRI Corp.).

\section{Results}

\section{Yellow-billed Cuckoo Formal and Follow-up Detections, 2007}

During the 2007 field season, we surveyed 40 sites between 11 June and 9 September for a total of 312 official survey hours. The 169 individual surveys resulted in a total of 163 yellow-billed cuckoo detections at 25 of our 40 sites ( 62.5 percent). The vast majority of detections were at Bill Williams River NWR ( $\mathrm{n}=139$; 85 percent; Figure 2.2; Appendix 2). Fifteen sites (37.5 percent) were classified as occupied, including twelve of the thirteen sites at the Bill Williams River NWR (Table 2.3). Official survey detections declined with each survey period, with 48 detections during the first period and 44,39,27, and 5 detections in the second through fifth survey periods, respectively (Figure 2.3). We also had 93 supplemental surveys (follow-up surveys) over the same time period, mainly in the Bill Williams River NWR. The 204 hours spent on these visits resulted in 253 additional cuckoo detections. 


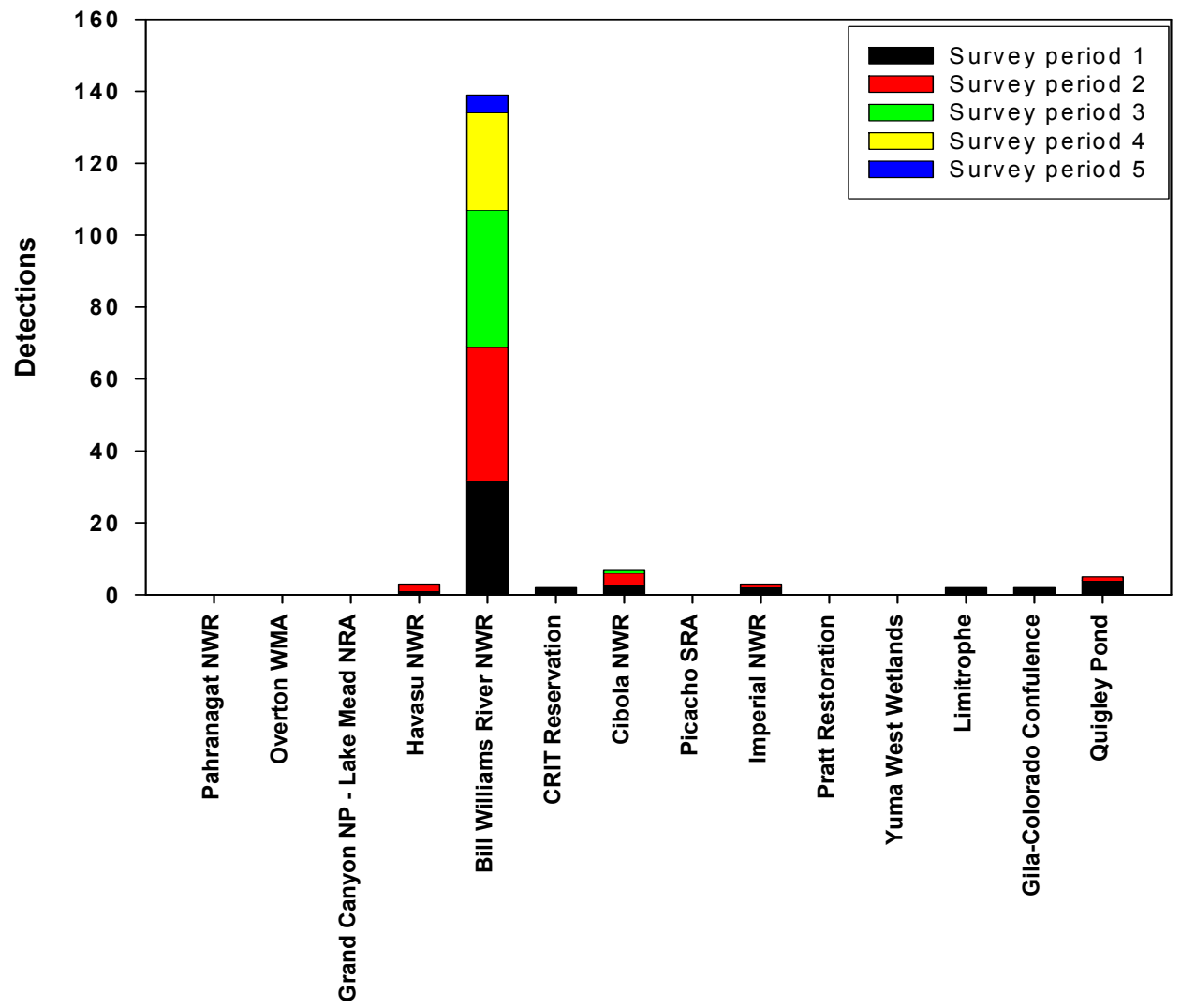

Geographic Area

Figure 2.2. Summary of yellow-billed cuckoo detections by survey period and geographic area within the LCR MSCP boundary area, 2007. Results are only from formal surveys.

Table 2.3. Number of yellow-billed cuckoos detected at each survey site during each survey period within the LCR MSCP boundary area, 2007. ${ }^{*}=$ occupied site, NS $=$ no survey.

\begin{tabular}{llllll}
\hline \multicolumn{1}{c}{ Survey Site Name } & Survey 1 & Survey 2 & Survey 3 & Survey 4 & Survey 5 \\
\hline & NS & 0 & 0 & 0 & NS \\
\hline Pahranagat South & 0 & 0 & 0 & 0 & NS \\
Pahranagat North & \multicolumn{6}{c}{ Overton WMA } \\
\hline \multicolumn{7}{c}{0} & 0 & 0 & 0 & NS \\
\hline Honeybee Pond & 0 & 0 & 0 & 0 & NS \\
Overton Wildlife & 0 & Grand Canyon NP/Lake Mead NRA & \\
\hline River Mile 274 & 0 & 0 & 0 & 0 & NS \\
Cuckoo Beach & 0 & 0 & 0 & 0 & NS \\
Iceberg Ridge & 0 & 0 & 0 & 0 & NS \\
Chuckwalla Cove & 0 & 0 & 0 & 0 & NS \\
Big Horn Draw & 0 & 0 & 0 & NS & NS
\end{tabular}


Table 2.3. Number of yellow-billed cuckoos detected at each survey site during each survey period within the LCR MSCP boundary area, 2007. ${ }^{*}=$ occupied site, NS = no survey.-Continued

\begin{tabular}{|c|c|c|c|c|c|}
\hline Survey Site Name & Survey 1 & Survey 2 & Survey 3 & Survey 4 & Survey 5 \\
\hline \multicolumn{6}{|c|}{ Havasu NWR } \\
\hline Pintail Slough & 0 & 1 & 0 & 0 & NS \\
\hline North Dike & 0 & 1 & 0 & NS & NS \\
\hline Topock Marsh Rest. & 1 & 0 & 0 & 0 & NS \\
\hline Topock Tamarisk & 0 & 0 & 0 & 0 & NS \\
\hline \multicolumn{6}{|c|}{ Bill Williams River NWR } \\
\hline Teepee Trail & 0 & 0 & 1 & 0 & NS \\
\hline Cottonwood Patch* & 3 & 3 & 2 & 0 & NS \\
\hline Cave Wash* & 2 & 3 & 3 & 3 & 0 \\
\hline Honeycomb Bend* & 5 & 3 & 2 & 1 & 0 \\
\hline Mineral Wash* & 13 & 7 & 5 & 2 & 0 \\
\hline Big Bend* & 4 & 7 & 2 & 6 & 1 \\
\hline Gibraltar Rock* & 4 & 4 & 0 & 1 & 0 \\
\hline Sandy Wash* & 0 & 3 & 6 & 3 & 2 \\
\hline Fox Wash* & 0 & 1 & 1 & 0 & NS \\
\hline Mosquito Flats* & 0 & 3 & 6 & 4 & 2 \\
\hline Saguaro Slot* & 0 & 2 & 4 & 2 & 0 \\
\hline North Burn* & 0 & 1 & 2 & 2 & 0 \\
\hline Bill Williams Marsh* & 1 & 0 & 4 & 3 & 0 \\
\hline \multicolumn{6}{|c|}{ Ahakhav Tribal Preserve } \\
\hline $\begin{array}{l}\text { Ahakhav Tribal Preserve } \\
\text { Cibola NWR }\end{array}$ & 2 & 0 & 0 & 0 & NS \\
\hline North Restoration & 0 & 0 & 1 & 0 & NS \\
\hline Nature Trail Restoration & 2 & 0 & 0 & 0 & NS \\
\hline Eucalyptus Restoration & 0 & 2 & 0 & 0 & NS \\
\hline South Restoration* & 1 & 1 & 0 & 0 & NS \\
\hline \multicolumn{6}{|c|}{ Picacho SRA } \\
\hline Picacho SRA & 0 & 0 & 0 & 0 & NS \\
\hline \multicolumn{6}{|c|}{ Imperial NWR } \\
\hline $\begin{array}{l}\text { Imperial South } \\
\text { Restoration* }\end{array}$ & 2 & 1 & 0 & 0 & NS \\
\hline \multicolumn{6}{|c|}{ Mittry Lake WMA } \\
\hline Pratt Restoration & 0 & 0 & 0 & 0 & $\mathrm{NS}$ \\
\hline \multicolumn{6}{|c|}{ Gila/Colorado Confluence } \\
\hline Colorado Confluence & 2 & 0 & 0 & 0 & NS \\
\hline Gila Confluence & 0 & 0 & 0 & 0 & NS \\
\hline \multicolumn{6}{|c|}{ Yuma West Wetlands } \\
\hline Yuma West Wetlands & 0 & 0 & 0 & 0 & NS \\
\hline \multicolumn{6}{|c|}{ Limitrophe Division } \\
\hline Limitrophe Div. North & 0 & 0 & 0 & 0 & NS \\
\hline $\begin{array}{l}\text { Limitrophe Div. South } \\
\text { Quigley Pond WMA* }\end{array}$ & 2 & 0 & 0 & 0 & NS \\
\hline Quigley Pond WMA* & 4 & 1 & 0 & 0 & NS \\
\hline
\end{tabular}




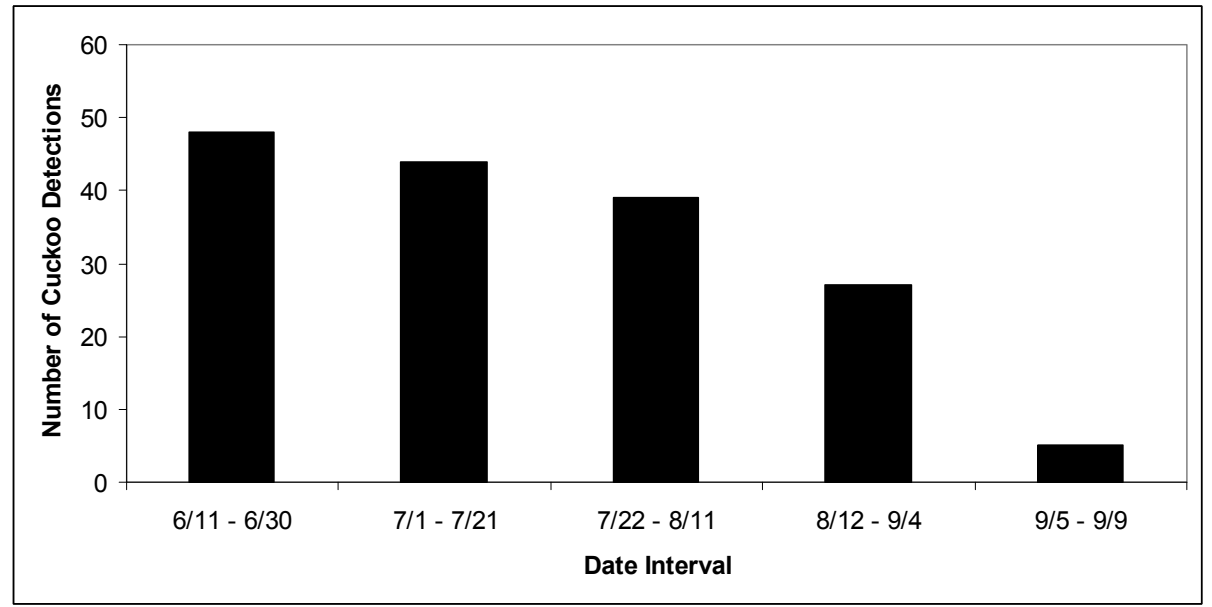

Figure 2.3. Summary of yellow-billed cuckoo detections by survey period within the LCR MSCP boundary area, 2007. Results are only from formal surveys.

Survey area and site results are listed below starting with the most upstream locations and proceeding downstream; for both the entire study area and within each side drainage. Additional details on each survey area and site and supplemental follow-up survey detections are presented in Appendixes 2 and Appendixes 4.

\section{Pahranagat National Wildlife Refuge, NV (White River Drainage)}

We conducted seven surveys at Pahranagat NWR in 2007 (Table 2.4). We had no yellow-billed cuckoo detections and, therefore no follow-up surveys were performed. Yellow-billed cuckoos were detected in 2000 at Pahranagat NWR (Halterman 2001) and in 2006 we had one yellow-billed cuckoo detection at Pahranagat North. This bird was unpaired and no further detections occurred at the refuge (Johnson et al 2007).

Table 2.4. Dates (2007) for yellow-billed cuckoo surveys conducted at Pahranagat National Wildlife Refuge, NV.

\begin{tabular}{|c|c|c|c|c|c|}
\hline Site Name & Survey Period & $\begin{array}{c}\text { Survey Period } \\
2\end{array}$ & $\begin{array}{c}\text { Survey Period } \\
3\end{array}$ & $\begin{array}{c}\text { Survey Period } \\
4\end{array}$ & $\begin{array}{c}\text { Survey Period } \\
5\end{array}$ \\
\hline Pahranagat North & $6 / 27$ & $7 / 17$ & $7 / 30$ & $8 / 26$ & no survey \\
\hline Pahranagat South & no survey & $7 / 17$ & $7 / 30$ & $8 / 26$ & no survey \\
\hline
\end{tabular}

\section{Overton Wildlife Management Area, NV (Muddy River)}

We conducted eight cuckoo surveys at Overton WMA in 2007 (Table 2.5). In 2007, no yellow-billed cuckoos were detected and, therefore no follow-up surveys were performed. Cuckoos were detected at Overton WMA at the Honey Bee Pond site in 2000 and 2002 (McKernan and Braden 2001, Rathbun and Braden 2003). In 2006, there were seven yellow-billed cuckoo detections; four at Honeybee Pond and three at the Overton Wildlife site. Both sites were confirmed occupied in 2006, but breeding was not confirmed at either site (Johnson et al. 2007). 
Table 2.5. Dates (2007) for yellow-billed cuckoo surveys conducted at Overton Wildlife Management Area, NV.

\begin{tabular}{lcccccc}
\hline \multicolumn{1}{c}{ Site Name } & Survey Period & \multicolumn{1}{c}{ Survey Period } & Survey Period & Survey Period & Survey Period \\
& & $\mathbf{1}$ & $\mathbf{2}$ & $\mathbf{3}$ & $\mathbf{5}$ \\
\hline Honeybee Pond & $6 / 26$ & $7 / 18$ & $7 / 29$ & $8 / 27$ & no survey \\
Overton Wildlife & $6 / 16$ & $7 / 12$ & $8 / 10$ & $8 / 22$ & no survey \\
\hline
\end{tabular}

\section{Grand Canyon National Park/Lake Mead National Recreation Area, AZ (Colorado River and Lake Mead)}

In 2007, we completed 19 yellow-billed cuckoo surveys (Table 2.6) and six supplemental follow-up surveys (Table 2.7) at five Grand Canyon/Lake Mead sites. No yellow-billed cuckoos were detected in 2007. We completed follow-up surveys at this survey area because we had 29 yellow-billed cuckoo detections in 2006 (RM $274.5=1$ cuckoo; Cuckoo Beach = 10 cuckoos; Iceberg Ridge = 3 cuckoos; and Chuckwalla Cove $=15$ cuckoos; Johnson et al. 2007). We also confirmed breeding at Chuckwalla Cove in 2006.

Table 2.6. Dates (2007) for yellow-billed cuckoo surveys in Grand Canyon National Park and Lake Mead National Recreation Area, AZ.

\begin{tabular}{|c|c|c|c|c|c|}
\hline Site Name & $\begin{array}{c}\text { Survey Period } \\
1 \\
\end{array}$ & $\begin{array}{c}\text { Survey Period } \\
2 \\
\end{array}$ & $\begin{array}{c}\text { Survey Period } \\
3 \\
\end{array}$ & $\begin{array}{c}\text { Survey Period } \\
4 \\
\end{array}$ & $\begin{array}{l}\text { Survey } \\
\text { Period } 5 \\
\end{array}$ \\
\hline RM 274.5 & $6 / 17$ & $7 / 13$ & $8 / 9$ & $8 / 23$ & no survey \\
\hline Cuckoo Beach & $6 / 16$ & $7 / 12$ & $8 / 10$ & $8 / 22$ & no survey \\
\hline Iceberg Ridge & $6 / 15$ & $7 / 11$ & $8 / 8$ & $8 / 22$ & no survey \\
\hline Chuckwalla Cove & $6 / 15$ & $7 / 12$ & $8 / 8$ & $8 / 22$ & no survey \\
\hline Big Horn Draw & $6 / 15$ & $7 / 12$ & $8 / 8$ & no survey & no survey \\
\hline
\end{tabular}

Table 2.7. Dates (2007) for yellow-billed cuckoo follow-up surveys at Grand Canyon National Park and Lake Mead National Recreation Area, AZ.

\begin{tabular}{llllll}
\hline \multicolumn{1}{c}{ Site Name } & Survey Period & Survey Period & Survey Period & Survey Period & Survey Period \\
\hline RM 274.5 & no survey & no survey & no survey & no survey & no survey \\
Cuckoo Beach & $6 / 28,6 / 29$ & no survey & no survey & no survey & no survey \\
Iceberg Ridge & $6 / 28,6 / 29$ & no survey & no survey & no survey & no survey \\
Chuckwalla Cove & $6 / 28,6 / 29$ & no survey & no survey & no survey & no survey \\
Big Horn Draw & no survey & no survey & no survey & no survey & no survey \\
\hline
\end{tabular}

Havasu National Wildlife Refuge, AZ (Colorado River)

We conducted 16 yellow-billed cuckoo surveys in 2007 (Table 2.8) and four follow-up surveys (Table 2.9) at four sites within the Havasu National Wildlife Refuge, AZ. 
Table 2.8. Dates (2007) for yellow-billed cuckoo surveys at the Havasu National Wildlife Refuge, AZ.

\begin{tabular}{|c|c|c|c|c|c|}
\hline Site Name & $\begin{array}{c}\text { Survey Period } \\
1 \\
\end{array}$ & $\begin{array}{c}\text { Survey Period } \\
2\end{array}$ & $\begin{array}{c}\text { Survey Period } \\
3\end{array}$ & $\begin{array}{c}\text { Survey Period } \\
4\end{array}$ & $\begin{array}{c}\text { Survey } \\
\text { Period } 5 \\
\end{array}$ \\
\hline Pintail Slough & $6 / 19$ & $7 / 10$ & $7 / 28$ & no survey & no survey \\
\hline North Dike & $6 / 11$ & $7 / 3$ & $7 / 25$ & $8 / 15$ & no survey \\
\hline Topock Marsh Rest. & $6 / 12$ & $7 / 9$ & $7 / 26$ & $8 / 14$ & no survey \\
\hline Topock Tamarisk & $6 / 13,6 / 28$ & $7 / 12$ & $7 / 31$ & $9 / 5$ & no survey \\
\hline
\end{tabular}

Table 2.9. Dates (2007) for follow-up surveys at Havasu National Wildlife Refuge, AZ.

\begin{tabular}{lllllc}
\hline \multicolumn{1}{c}{ Site Name } & Survey Period & Survey Period & Survey Period & Survey Period & Survey Period \\
& \multicolumn{1}{c}{} & $\mathbf{2}$ & $\mathbf{3}$ & $\mathbf{4}$ & $\mathbf{5}$ \\
\hline Pintail Slough & no survey & $7 / 10$ & no survey & no survey & no survey \\
North Dike & no survey & $7 / 3$ & no survey & no survey & no survey \\
$\begin{array}{l}\text { Topock Marsh Rest. } \\
\text { no survey }\end{array}$ & no survey & $7 / 26,7 / 27$ & no survey & no survey & \\
Topock Tamarisk & no survey & no survey & no survey & no survey & no survey \\
\hline
\end{tabular}

Yellow-billed cuckoos were detected at Pintail Slough, North Dike, and Topock Marsh Restoration (Table 2.10). Pintail Slough and North Dike were classified as occupied sites with cuckoos being detected during two survey periods. The Topock Marsh Restoration site was classified unoccupied as we did not have detections during multiple surveys. The two cuckoos detected at North Dike during survey period two were seen concurrently and heard counter calling. Breeding was unconfirmed for all cuckoos detected at Havasu NWR. See Appendix 2 for a detailed description of each yellow-billed cuckoo detection.

In 2006, a single yellow-billed cuckoo was detected at the Pintail Slough site during the first survey period, the site was classified as unconfirmed and no cuckoos were detected during later surveys (Johnson et al. 2007).

Table 2.10. Yellow-billed cuckoo detections in 2007 at Havasu National Wildlife Refuge, AZ. Detections during cuckoo follow-up surveys are displayed in parenthesis.

\begin{tabular}{lllllll}
\hline \multicolumn{1}{c}{ Site Name } & \multicolumn{1}{c}{$\begin{array}{c}\text { Survey } \\
\text { Period 1 }\end{array}$} & $\begin{array}{c}\text { Survey } \\
\text { Period 2 }\end{array}$ & $\begin{array}{c}\text { Survey } \\
\text { Period 3 }\end{array}$ & $\begin{array}{c}\text { Survey } \\
\text { Period 4 }\end{array}$ & $\begin{array}{c}\text { Survey } \\
\text { Period 5 }\end{array}$ & $\begin{array}{c}\text { Total } \\
\text { Detections }\end{array}$ \\
\hline Pintail Slough & $0(0)$ & 1 & 0 & 0 & no survey & 1 \\
North Dike & 1 & $0(2)$ & 1 & 0 & no survey & $2(2)$ \\
Topock Marsh Rest. & 1 & 0 & $0(7)$ & 0 & no survey & $1(7)$ \\
Topock Tamarisk & 0 & 0 & 0 & 0 & no survey & 0 \\
Total & $2(0)$ & $0(2)$ & $0(7)$ & 0 & no survey & $4(9)$ \\
\hline
\end{tabular}




\section{Bill Williams River National Wildlife Refuge, AZ (Bill Williams River)}

In 2007, we completed 62 formal yellow-billed cuckoo surveys and 83 follow-up surveys at 13 sites in the Bill Williams River NWR (Table 2.11, Table 2.12).

Table 2.11. Dates (2007) for yellow-billed cuckoo surveys at the Bill Williams River National Wildlife Refuge, AZ.

\begin{tabular}{lccccc}
\hline \multicolumn{1}{c}{ Site Name } & \multicolumn{1}{c}{$\begin{array}{c}\text { Survey } \\
\text { Period 1 }\end{array}$} & $\begin{array}{c}\text { Survey } \\
\text { Period 2 }\end{array}$ & $\begin{array}{c}\text { Survey } \\
\text { Period 3 }\end{array}$ & $\begin{array}{c}\text { Survey } \\
\text { Period 4 }\end{array}$ & $\begin{array}{c}\text { Survey } \\
\text { Period 5 }\end{array}$ \\
\hline Teepee Trail & $6 / 26$ & $7 / 12$ & $7 / 28$ & $8 / 14$ & no survey \\
Cottonwood Patch & $6 / 26$ & $7 / 12$ & $7 / 28$ & $8 / 14$ & no survey \\
Cave Wash & $6 / 26$ & $7 / 12$ & $7 / 25$ & $8 / 14$ & $9 / 5$ \\
Honeycomb Bend & $6 / 19$ & $7 / 9$ & $8 / 7$ & $8 / 23$ & $9 / 5$ \\
Mineral Wash & $6 / 18$ & $7 / 2$ & $7 / 30$ & $8 / 13$ & $9 / 6$ \\
Big Bend & $6 / 12$ & $7 / 2$ & $7 / 25$ & $8 / 13$ & $9 / 6$ \\
Gibraltar Rock & $6 / 13$ & $7 / 3$ & $7 / 26$ & $8 / 15$ & $9 / 6$ \\
Sandy Wash & $6 / 17$ & $7 / 11$ & $7 / 26$ & $8 / 15$ & $9 / 7$ \\
Fox Wash & $6 / 11$ & $7 / 3$ & $8 / 11$ & $8 / 21$ & no survey \\
Mosquito Flats & $6 / 14$ & $7 / 11$ & $8 / 8$ & $8 / 21$ & $9 / 7$ \\
Saguaro Slot & $6 / 13$ & $7 / 11$ & $8 / 1$ & $8 / 21$ & $9 / 7$ \\
North Burn & $6 / 27$ & $7 / 17$ & $8 / 8$ & $8 / 26$ & $9 / 9$ \\
Bill Williams Marsh & $6 / 14$ & $7 / 15$ & $8 / 1$ & $8 / 24$ & $9 / 8$ \\
\hline
\end{tabular}

Table 2.12. Dates (2007) of follow-up surveys Bill Williams River National Wildlife Refuge, AZ.

\begin{tabular}{|c|c|c|c|c|c|}
\hline Site Name & $\begin{array}{c}\text { Survey Period } \\
1\end{array}$ & $\begin{array}{c}\text { Survey Period } \\
2\end{array}$ & $\begin{array}{c}\text { Survey Period } \\
3\end{array}$ & $\begin{array}{c}\text { Survey Period } \\
4\end{array}$ & $\begin{array}{c}\text { Survey Period } \\
5\end{array}$ \\
\hline Teepee Trail & no survey & no survey & no survey & no survey & no survey \\
\hline Cottonwood Patch & $6 / 28$ & $\begin{array}{l}7 / 1,7 / 14,7 / 16, \\
7 / 18\end{array}$ & $7 / 25,7 / 28,8 / 7$ & $8 / 23$ & no survey \\
\hline Cave Wash & $6 / 26$ & $\begin{array}{l}7 / 1,7 / 12,7 / 14 \\
7 / 16,7 / 18\end{array}$ & $7 / 25,8 / 7$ & $8 / 23$ & no survey \\
\hline Honeycomb Bend & $6 / 20,6 / 29$ & $\begin{array}{l}7 / 3,7 / 9,7 / 10 \\
7 / 12,7 / 14 \\
7 / 18\end{array}$ & $8 / 7,8 / 10$ & $\begin{array}{l}8 / 14,8 / 23 \\
8 / 27\end{array}$ & no survey \\
\hline Mineral Wash & $6 / 19,6 / 29$ & $7 / 10,7 / 14$ & $7 / 24,7 / 30$ & $8 / 13$ & no survey \\
\hline Big Bend & $6 / 15,6 / 20$ & $7 / 14,7 / 17$ & $7 / 29,8 / 7,8 / 9$ & $8 / 25$ & $9 / 6$ \\
\hline Gibraltar Rock & $\begin{array}{l}6 / 15,6 / 25 \\
6 / 30\end{array}$ & $7 / 13,7 / 16$ & $7 / 29,8 / 9$ & $8 / 26$ & no survey \\
\hline Sandy Wash & $6 / 13,6 / 25$ & $\begin{array}{l}7 / 11,7 / 15 \\
7 / 17\end{array}$ & $7 / 26,7 / 29,8 / 8$ & $\begin{array}{l}8 / 24,8 / 26 \\
8 / 27,8 / 28 \\
8 / 29\end{array}$ & no survey \\
\hline
\end{tabular}


Table 2.12. Dates (2007) of follow-up surveys Bill Williams River National Wildlife Refuge, AZ.-Continued

\begin{tabular}{llllll}
\hline \multicolumn{1}{c}{ Site Name } & Survey Period & Survey Period & Survey Period & Survey Period & Survey Period \\
& \multicolumn{1}{c}{ S } & 2 & $\mathbf{3}$ & $\mathbf{4}$ & no survey \\
\hline Fox Wash & no survey & no survey & $8 / 11$ & no survey & no survey \\
Mosquito Flats & $6 / 17$ & no survey & $8 / 8,8 / 11$ & no survey & no survey \\
Saguaro Slot & $6 / 27$ & $7 / 15$ & no survey & $8 / 21,8 / 27$, & no survey \\
North Burn & no survey & no survey & no survey & no survey & no survey \\
Bill Williams Marsh & no survey & no survey & $8 / 24,8 / 29$ & no survey & \\
\hline
\end{tabular}

In 2007, formal yellow-billed cuckoo surveys resulted in 139 cuckoo detections; 244 additional cuckoo detections occurred during follow-up surveys (Table 2.13). The Big Bend and Mineral Wash sites had the greatest number of detections, with at least one cuckoo detection at all sites within the refuge. All sites at Bill Williams River NWR except for Teepee Trail were classified as occupied.

The Bill Williams River NWR was the only geographical area with confirmed breeding in 2007. Breeding activities were observed at seven sites (Cottonwood Patch, Cave Wash, Honeycomb Bend, Big Bend, Gibraltar Rock, Sandy Wash, and Bill Williams Marsh) and breeding was confirmed in each of these sites except Teepee Trail and in Bill Williams Marsh, where only a food carry was observed (Appendix 2).

Tale 2.13. Yellow-billed cuckoo detections in 2007 at the Bill Williams River NWR. Detections during cuckoo follow-up surveys are displayed in parenthesis.

\begin{tabular}{lllllll}
\hline \multicolumn{1}{c}{ Site Name } & \multicolumn{1}{c}{$\begin{array}{c}\text { Survey } \\
\text { Period 1 }\end{array}$} & \multicolumn{1}{c}{$\begin{array}{c}\text { Survey } \\
\text { Period 2 }\end{array}$} & $\begin{array}{c}\text { Survey } \\
\text { Period 3 }\end{array}$ & $\begin{array}{c}\text { Survey } \\
\text { Period 4 }\end{array}$ & $\begin{array}{c}\text { Survey } \\
\text { Period 5 }\end{array}$ & $\begin{array}{c}\text { Total } \\
\text { Detections }\end{array}$ \\
\hline Teepee Trail & 0 & 0 & 1 & 0 & no survey & 1 \\
Cottonwood Patch & $3(4)$ & $3(8)$ & $2(1)$ & $0(0)$ & no survey & $8(13)$ \\
Cave Wash & $2(3)$ & $3(33)$ & $3(8)$ & $3(0)$ & 0 & $11(44)$ \\
Honeycomb Bend & $5(9)$ & $3(6)$ & $2(5)$ & $1(4)$ & 0 & $11(24)$ \\
Mineral Wash & $13(11)$ & $7(0)$ & $5(11)$ & $2(1)$ & 0 & $27(23)$ \\
Big Bend & $4(7)$ & $7(14)$ & $2(5)$ & $6(16)$ & $1(1)$ & $20(43)$ \\
Gibraltar Rock & $4(11)$ & $4(19)$ & $0(2)$ & $1(0)$ & 0 & $9(32)$ \\
Sandy Wash & $0(1)$ & $3(11)$ & $6(18)$ & $3(6)$ & 2 & $14(36)$ \\
Fox Wash & 0 & 1 & $1(1)$ & 0 & no survey & $2(1)$ \\
Mosquito Flats & $0(0)$ & 3 & $6(12)$ & 4 & 2 & $15(12)$ \\
Saguaro Slot & $0(1)$ & $2(3)$ & 4 & $2(8)$ & 0 & $8(12)$ \\
North Burn & 0 & 1 & 2 & 2 & 0 & 5 \\
Bill Williams Marsh & 1 & 0 & 4 & $3(3)$ & 0 & $8(3)$ \\
Total & $32(47)$ & $37(94)$ & $38(63)$ & $27(38)$ & $5(1)$ & $139(243)$ \\
\hline
\end{tabular}


In 2006, there were 117 cuckoo detections within Bill Williams River NWR. The number of 2006 cuckoo detections at each site is as follows; Cave Wash $=21$ cuckoo detections Mineral Wash $=15$ cuckoos, Big Bend $=19$ cuckoos, Gibraltar Rock $=8$ cuckoos, Sandy Wash $=14$ cuckoos, Fox Wash $=1$ cuckoo, Mosquito Flats $=17$ cuckoo detections, Saguaro Slot = 10 cuckoos, and Bill Williams River Marsh = 12 cuckoo detections (Johnson et al. 2007). During the 2006 field season, we only had confirmed breeding at the Big Bend and Saguaro Slot sites, compared to confirmed breeding at seven sites within the refuge in 2007.

\section{Ahakhav Tribal Preserve-Colorado River Indian Tribes' Land}

We conducted four survey visits at four sites within the Ahakhav Tribal Preserve (Table 2.14): no follow-up surveys were performed because of logistical constraints.

Table 2.14. Dates (2007) for yellow-billed cuckoo surveys at the Ahakhav Tribal Preserve, AZ.

\begin{tabular}{|c|c|c|c|c|c|}
\hline Site Name & $\begin{array}{c}\text { Survey Period } \\
1\end{array}$ & $\begin{array}{c}\text { Survey Period } \\
2 \\
\end{array}$ & $\begin{array}{c}\text { Survey Period } \\
3 \\
\end{array}$ & $\begin{array}{c}\text { Survey Period } \\
4\end{array}$ & $\begin{array}{c}\text { Survey } \\
\text { Period } 5\end{array}$ \\
\hline Ahakhav Tribal Pres. & $6 / 16$ & $7 / 18$ & $7 / 31$ & $8 / 28$ & no survey \\
\hline
\end{tabular}

During the 2007 breeding season we had two yellow-billed cuckoo detections (Table 2.15). Cuckoos were detected only during the first survey period, so Ahakhav Tribal Preserve was classified as unoccupied. We had two cuckoo detections during the same survey, but these detections were separate (not counter-calling) and did not indicate that these were paired birds. Breeding was not confirmed at Ahakhav Tribal Preserve. This was the first year complete yellow-billed cuckoo surveys (i.e., four surveys) were completed

Table 2.15. Yellow-billed cuckoo detections in 2007 at Ahakhav Tribal Preserve, AZ.

\begin{tabular}{llccccc}
\hline \multicolumn{1}{c}{ Site Name } & $\begin{array}{c}\text { Survey } \\
\text { Period 1 }\end{array}$ & $\begin{array}{c}\text { Survey } \\
\text { Period 2 }\end{array}$ & $\begin{array}{c}\text { Survey } \\
\text { Period 3 }\end{array}$ & $\begin{array}{c}\text { Survey } \\
\text { Period 4 }\end{array}$ & $\begin{array}{c}\text { Survey } \\
\text { Period 5 }\end{array}$ & $\begin{array}{c}\text { Total } \\
\text { Detections }\end{array}$ \\
\hline $\begin{array}{l}\text { Ahakhav Tribal } \\
\text { Pres. }\end{array}$ & 2 & 0 & 0 & 0 & no survey & 2 \\
\hline
\end{tabular}

Cibola National Wildlife Refuge, AZ (Colorado River)

We conducted 16 survey visits at four sites within Cibola NWR (Table 2.16); no follow-up surveys were completed because of logistical constraints.

Table 2.16. Dates (2007) of yellow-billed cuckoo surveys at the Cibola National Wildlife Refuge, $A Z$.

\begin{tabular}{llllccc}
\hline \multicolumn{1}{c}{ Site Name } & Survey Period & Survey Period & Survey Period & Survey Period & Survey \\
$\mathbf{1}$ & $\mathbf{1}$ & $\mathbf{2}$ & $\mathbf{3}$ & $\mathbf{4}$ & Period 5 \\
\hline Cibola North Rest. & $6 / 16$ & $7 / 2$ & $7 / 27$ & $8 / 24$ & no survey \\
Cibola Nature Trail & $6 / 16$ & $7 / 2$ & $7 / 27$ & $8 / 24$ & no survey \\
Cibola South Rest. & $6 / 16$ & $7 / 2$ & $7 / 27$ & $8 / 24$ & no survey \\
$\begin{array}{l}\text { Cibola Eucalyptus } \\
\text { Rest. }\end{array}$ & $6 / 16$ & $7 / 2$ & $7 / 27$ & $8 / 24$ & no survey \\
\hline
\end{tabular}


During the 2007 breeding season, we had seven yellow-billed cuckoo detections (Table 2.17). Cuckoos were detected at all four sites, but only Cibola South Restoration was classified as occupied. We had two cuckoo detections during the same survey at the Cibola Nature Trail and at the Eucalyptus Restoration sites, but these detections were separate (not counter-calling) and did not indicate that these were paired birds. Breeding was not confirmed at any of the sites at Cibola NWR.

Table 2.17. Yellow-billed cuckoo detections in 2007 at Cibola National Wildlife Refuge, AZ.

\begin{tabular}{lllllll}
\hline \multicolumn{1}{c}{ Site Name } & $\begin{array}{c}\text { Survey } \\
\text { Period 1 }\end{array}$ & $\begin{array}{c}\text { Survey } \\
\text { Period 2 }\end{array}$ & $\begin{array}{c}\text { Survey } \\
\text { Period 3 }\end{array}$ & $\begin{array}{c}\text { Survey } \\
\text { Period 4 }\end{array}$ & $\begin{array}{c}\text { Survey } \\
\text { Period 5 }\end{array}$ & $\begin{array}{c}\text { Total } \\
\text { Detections }\end{array}$ \\
\hline Cibola North Rest. & 0 & 0 & 1 & 0 & no survey & 1 \\
Cibola Nature Trail & 2 & 0 & 0 & 0 & no survey & 2 \\
Cibola South Rest. & 1 & 1 & 0 & 0 & no survey & 2 \\
Cibola Eucalyptus & 0 & 2 & 0 & 0 & no survey & 2 \\
Rest. & 3 & 3 & 1 & 0 & no survey & 7 \\
Total & & & & & & \\
\hline
\end{tabular}

In 2005, two cuckoos were detected at the Cibola South Restoration site, and one was detected at the Cibola Cross River site (Johnson et al. 2006b). In 2006, we had yellow-billed cuckoo detections at two sites, Cibola Nature Trail Restoration and the Cibola South Restoration site (Johnson et al. 2007). The Cibola Nature Trail Restoration site was the only site classified as occupied, yet no breeding behavior was observed, and only one cuckoo was confirmed per detection.

\section{Picacho State Recreation Area, CA (Colorado River)}

We conducted four yellow-billed cuckoo surveys at Picacho State Recreation Area in 2007 with no yellow-billed cuckoo detections-thus, no follow-up surveys were performed (Table 2.18).

Table 2.18. Dates (2007) for yellow-billed cuckoo surveys at the Picacho State Recreation Area, CA.

\begin{tabular}{|c|c|c|c|c|c|}
\hline Site Name & $\begin{array}{c}\text { Survey Period } \\
1\end{array}$ & $\begin{array}{c}\text { Survey Period } \\
2\end{array}$ & $\begin{array}{c}\text { Survey Period } \\
3 \\
\end{array}$ & $\begin{array}{c}\text { Survey Period } \\
4\end{array}$ & $\begin{array}{l}\text { Survey } \\
\text { Period } 5\end{array}$ \\
\hline Picach & $6 / 27$ & $7 / 18$ & $8 / 1$ & $8 / 28$ & no survey \\
\hline
\end{tabular}

In 2006, a single yellow-billed cuckoo was detected during survey period three at Picacho State Recreation Area (Johnson et al. 2007). This cuckoo was only detected once, and responded eagerly to the broadcast. One cuckoo was also heard vocalizing in early July (second survey period) by a SWCA consulting firm Willow Flycatcher Project employee near where our individual cuckoo was detected. No breeding behavior was observed during either detection. 
Imperial National Wildlife Refuge, AZ (Colorado River)

In 2007, we conducted four yellow-billed cuckoo surveys at Imperial NWR, but we had no follow-up surveys due to logistical constraints (Table 2.19).

Table 2.19. Dates (2007) of yellow-billed cuckoo surveys at Imperial National Wildlife Refuge, AZ.

\begin{tabular}{|c|c|c|c|c|c|}
\hline Site Name & $\begin{array}{c}\text { Survey Period } \\
1\end{array}$ & $\begin{array}{c}\text { Survey Period } \\
2\end{array}$ & $\begin{array}{c}\text { Survey Period } \\
3\end{array}$ & $\begin{array}{c}\text { Survey Period } \\
4\end{array}$ & $\begin{array}{l}\text { Survey } \\
\text { Period } 5\end{array}$ \\
\hline Imperial South Rest. & $6 / 27$ & $7 / 18$ & $7 / 31$ & $8 / 28$ & no survey \\
\hline
\end{tabular}

This site was classified as occupied because cuckoos were detected during two different survey periods; two detections in the first survey period and one in the second. No detections were confirmed after 18 July (Table 2.20). All detections were of individual birds and breeding was not confirmed.

Table 2.20. Yellow-billed cuckoo detections in 2007 at Imperial National Wildlife Refuge, AZ.

\begin{tabular}{lcccccc}
\hline \multicolumn{1}{c}{ Site Name } & $\begin{array}{c}\text { Survey } \\
\text { Period 1 }\end{array}$ & $\begin{array}{c}\text { Survey } \\
\text { Period 2 }\end{array}$ & $\begin{array}{c}\text { Survey } \\
\text { Period 3 }\end{array}$ & $\begin{array}{c}\text { Survey } \\
\text { Period 4 }\end{array}$ & $\begin{array}{c}\text { Survey } \\
\text { Period 5 }\end{array}$ & $\begin{array}{c}\text { Total } \\
\text { Detections }\end{array}$ \\
\hline $\begin{array}{l}\text { Imperial South } \\
\text { Rest. }\end{array}$ & 2 & 1 & 0 & 0 & no survey & 3 \\
\hline
\end{tabular}

In 2005, a single cuckoo was detected during two visits at the Imperial South Restoration site (Johnson et al. 2006b). In 2006, three cuckoos were detected at the Imperial South Restoration site (Johnson et al. 2007). These detections were of cuckoos vocalizing simultaneously in two different areas of the refuge and ,during a later followup survey, we observed a cuckoo carrying food, but breeding was not confirmed.

\section{Mittry Lake State Wildlife Management Area/Pratt Restoration Area, AZ (Colorado River)}

In 2007, we conducted four surveys at the Mittry Lake SWM/Pratt Restoration site. As no cuckoos were detected at this site, no follow-up visits were performed (Table 2.21). During 2006, we had no cuckoo detections at this site, but in 2005 we detected one cuckoo during the second survey period (Johnson et al. 2006b, Johnson et al. 2007).

Table 2.21. Dates (2007) of yellow-billed cuckoo surveys at Mittry Lake State WMA/Pratt Restoration Area. AZ.

\begin{tabular}{|c|c|c|c|c|c|}
\hline Site Name & $\begin{array}{c}\text { Survey Period } \\
1\end{array}$ & $\begin{array}{c}\text { Survey Period } \\
2 \\
\end{array}$ & $\begin{array}{c}\text { Survey Period } \\
3 \\
\end{array}$ & $\begin{array}{c}\text { Survey Period } \\
4\end{array}$ & $\begin{array}{c}\text { Survey } \\
\text { Period } 5\end{array}$ \\
\hline Pratt Restoration & $6 / 11$ & $7 / 3$ & $7 / 26$ & $8 / 15$ & no survey \\
\hline
\end{tabular}

Gila-Colorado River Confluence, AZ (Gila and Colorado Rivers)

In 2007, we conducted eight surveys at the Gila/Colorado Confluence sites, but due to logistical constraints no follow-up surveys performed (Table 2.22). 
Table 2.22. Dates (2007) of yellow-billed cuckoo surveys at the area of the Gila RiverColorado River confluence, AZ.

\begin{tabular}{llllccc}
\hline \multicolumn{1}{c}{ Site Name } & Survey Period & Survey Period & Survey Period & Survey Period & Survey \\
& $\mathbf{1}$ & $\mathbf{2}$ & $\mathbf{3}$ & $\mathbf{4}$ & Period 5 \\
\hline Colorado Confluence & $6 / 26$ & $7 / 12$ & $8 / 11$ & $8 / 27$ & no survey \\
Gila Confluence & $6 / 26$ & $7 / 11$ & $8 / 11$ & $8 / 27$ & no survey \\
\hline
\end{tabular}

We had two separate yellow-billed cuckoo detections at the Colorado Confluence site on river right during the first survey period (Table 2.23). No detections occurred here after 26 June. No cuckoos were detected at the Gila Confluence site. In 2007, the Colorado Confluence was classified as unoccupied and both birds (observed during same survey period) we observed along the Colorado River were unpaired.

Table 2.23. Yellow-billed cuckoo detections in 2007at the Gila River-Colorado River confluence, AZ.

\begin{tabular}{lllllll}
\hline \multicolumn{1}{c}{ Site Name } & \multicolumn{1}{c}{ Survey } & Survey & Survey & Survey & Survey & Total \\
Period 1 & Period 2 & Period 3 & Period 4 & Period 5 & Detections \\
\hline $\begin{array}{l}\text { Colorado } \\
\text { Confluence }\end{array}$ & 2 & 0 & 0 & 0 & no survey & 2 \\
Gila Confluence & 0 & 0 & 0 & 0 & no survey & 0 \\
\hline
\end{tabular}

In 2006, we had two cuckoo detections at the Colorado Confluence site over two survey periods (Johnson et al. 2007). During the first visit, two counter-calling birds were confirmed in the same patch, but breeding was not confirmed. In 2005, cuckoos were also detected at this same site, but breeding also was not confirmed (Johnson et al. 2006b).

\section{Yuma West Wetlands, AZ (Colorado River)}

In 2007, we completed four surveys at the Yuma West Wetlands with no yellowbilled cuckoo detections (Table 2.24). In 2006, no cuckoos were detected at this site either (Johnson et al 2007). This restoration site is four years old and might not yet have the correct vegetation structure for cuckoo breeding needs.

Table 2.24. Dates (2007) of yellow-billed cuckoo surveys at the area of the Yuma West Wetlands, AZ.

\begin{tabular}{lccccc}
\hline \multicolumn{1}{c}{ Site Name } & Survey Period & Survey Period & Survey Period & Survey Period & Survey \\
& $\mathbf{1}$ & $\mathbf{2}$ & $\mathbf{3}$ & $\mathbf{4}$ & Period 5 \\
\hline $\begin{array}{l}\text { Yuma West } \\
\text { Wetlands }\end{array}$ & $6 / 25$ & $7 / 10$ & $7 / 30$ & $8 / 13$ & no survey \\
\hline
\end{tabular}

Limitrophe Division, AZ (Colorado River)

We completed eight yellow-billed cuckoo surveys at the Limitrophe Division sites in 2007 (Table 2.25). No follow-up surveys were completed due to logistical constraints. 
Table 2.25. Dates (2007) of yellow-billed cuckoo surveys at the Limitrophe Division, AZ.

\begin{tabular}{llllll}
\hline \multicolumn{1}{c}{ Site Name } & Survey Period & \multicolumn{1}{c}{ Survey Period } & Survey Period & Survey Period & Survey \\
$\mathbf{2}$ & & $\mathbf{2}$ & $\mathbf{3}$ & $\mathbf{4}$ & Period 5 \\
\hline Limitrophe Div. & $6 / 14$ & $7 / 11$ & $7 / 29$ & $8 / 26$ & no survey \\
$\begin{array}{l}\text { North } \\
\text { Limitrophe Div. }\end{array}$ & $6 / 13$ & $7 / 13$ & $7 / 28$ & $8 / 25$ & no survey \\
South & & & &
\end{tabular}

We had no cuckoo detections at the Limitrophe North site, but we had two cuckoo detections at the Limitrophe South site during the first survey period (Table 2.26). Breeding was not confirmed and this site was classified as unoccupied.

Table 2.26. Yellow-billed cuckoo detections in 2007 at the Limitrophe Division, AZ.

\begin{tabular}{lllllll}
\hline \multicolumn{1}{c}{ Site Name } & $\begin{array}{c}\text { Survey } \\
\text { Period 1 }\end{array}$ & $\begin{array}{c}\text { Survey } \\
\text { Period 2 }\end{array}$ & $\begin{array}{c}\text { Survey } \\
\text { Period 3 }\end{array}$ & $\begin{array}{c}\text { Survey } \\
\text { Period 4 }\end{array}$ & $\begin{array}{c}\text { Survey } \\
\text { Period 5 }\end{array}$ & $\begin{array}{c}\text { Total } \\
\text { Detections }\end{array}$ \\
\hline $\begin{array}{l}\text { Limitrophe Div. } \\
\begin{array}{l}\text { North } \\
\text { Limitrophe Div. }\end{array}\end{array}$ & 0 & 0 & 0 & 0 & no survey & 0 \\
South & 2 & 0 & 0 & 0 & no survey & 2 \\
\hline
\end{tabular}

In 2005, we had six cuckoo detections at Limitrophe Division North and one detection at Limitrophe Division South (Johnson et al. 2006b). In 2006, six cuckoos were detected in the area, all at Limitrophe Division North (Johnson et al. 2007). The cuckoos detected near the Morelos Dam were detected during three surveys periods.

\section{Quigley Pond Wildlife Management Area, AZ (Gila River)}

In 2007, four surveys were conducted at Quigley Pond WMA with two follow-up surveys (Table 2.27).

Table 2.27. Dates (2007) of yellow-billed cuckoo surveys at Quigley Pond WMA, AZ. Dates of cuckoo follow-up surveys are displayed in parenthesis.

\begin{tabular}{cccccc}
\hline Site Name & Survey Period & Survey Period & Survey Period & Survey Period & Survey \\
& $\mathbf{1}$ & $\mathbf{2}$ & $\mathbf{3}$ & $\mathbf{4}$ & Period 5 \\
\hline Quigley Pond & $6 / 12(6 / 13)$ & $7 / 9(7 / 10)$ & $7 / 28$ & $8 / 14$ & no survey \\
\hline
\end{tabular}

We had four cuckoo detections during the first survey period and one detected in the second survey period (Table 2.28). We classified this site as occupied. All cuckoo detections at this site were of unpaired birds.

Table 2.28. Yellow-billed cuckoo survey detections in 2007 at Quigley Pond WMA, AZ. Detections during cuckoo follow-up surveys are displayed in parenthesis.

\begin{tabular}{ccccccc}
\hline Site Name & $\begin{array}{c}\text { Survey } \\
\text { Period 1 }\end{array}$ & $\begin{array}{c}\text { Survey } \\
\text { Period 2 }\end{array}$ & $\begin{array}{c}\text { Survey } \\
\text { Period 3 }\end{array}$ & $\begin{array}{c}\text { Survey } \\
\text { Period 4 }\end{array}$ & $\begin{array}{c}\text { Survey } \\
\text { Period 5 }\end{array}$ & $\begin{array}{c}\text { Total } \\
\text { Detections }\end{array}$ \\
\hline Quigley Pond & $4(0)$ & $1(0)$ & 0 & 0 & no survey & 5 \\
\hline
\end{tabular}


In 2005, we had eight yellow-billed cuckoo detections at this site. A pair was detected during one survey, with one cuckoo carrying nest material, but breeding was not confirmed (Johnson et al. 2006b).

In 2006, we detected a single cuckoo during the first survey period (Johnson et al. 2007). This cuckoo was seen foraging in a cotton field on the edge of the restoration area. Subsequent surveys yielded no further detections.

\section{Yellow-billed Cuckoo Breeding Activity}

Over the course of the 2007 field season, 27 breeding events were documented in 7 of our 40 survey sites (17.5 percent). Detailed descriptions of these activities can be found in Appendix 2. All breeding activity in 2007 occurred in the Bill Williams River NWR (Figure 2.4). The majority (59 percent) of these events took place during the second survey period (1 July-21 July). We detected the lowest breeding activity in the first or fifth survey periods. The most common evidence of breeding activity was observations of food carrying, followed closely by detections of fledglings.

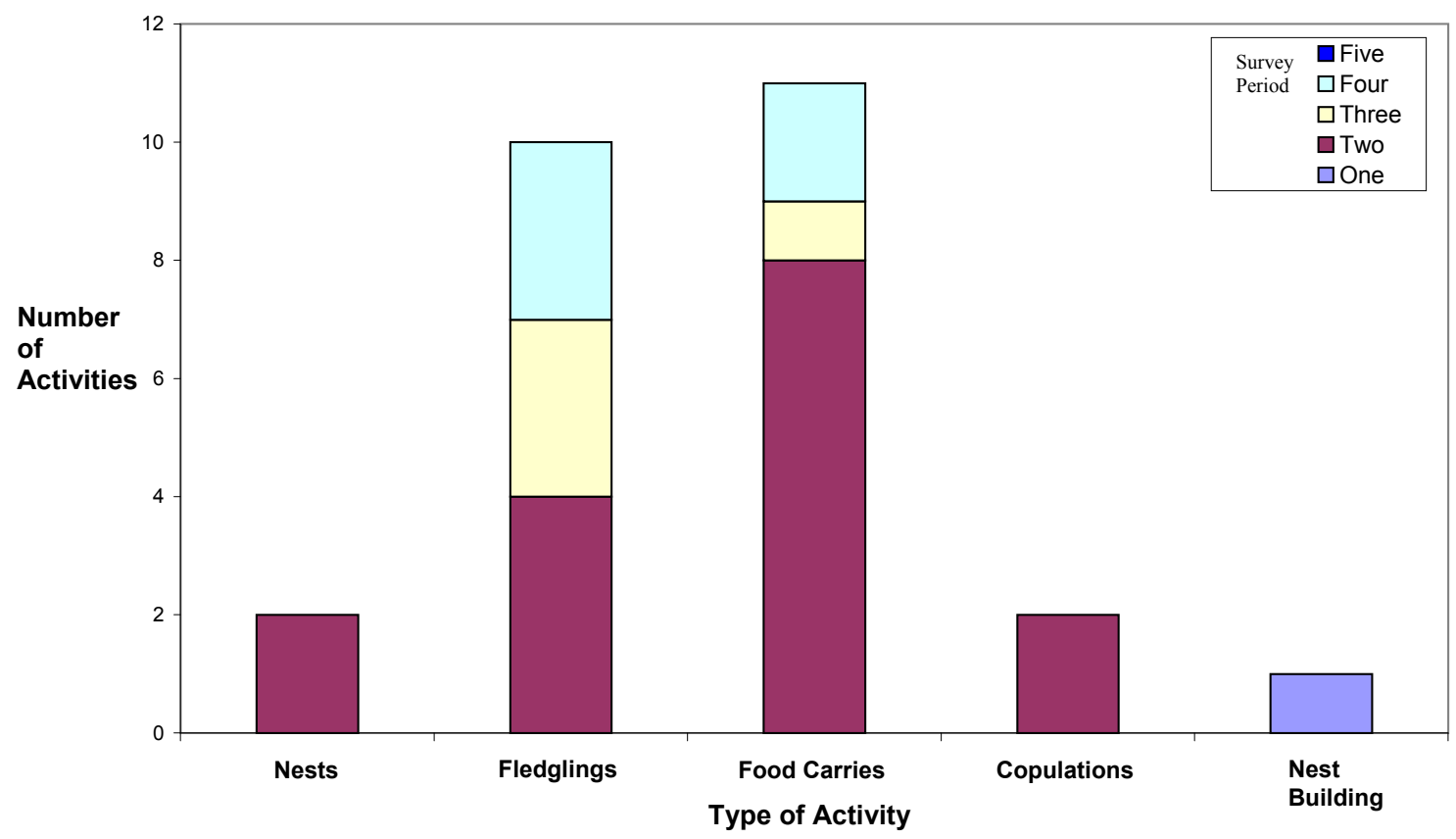

Figure 2.4. Number and survey period of each breeding activity at Bill Williams River NWR within the LCR MSCP boundary area, 2007.

The number of food carries varied considerably throughout the breeding season, and was most evident (73 percent of observations) during the second survey period (Figure 2.4). Fledglings were found consistently in survey periods 2, 3, and 4. Three of these fledges were found within $15 \mathrm{~m}$ of a documented nest, the others were found several hundred meters from the nearest known nest. Two copulations were observed in 2007 , both in the second survey period. One other breeding activity was recorded during 
the first survey period in Honeycomb Bend when two adult cuckoos were observed placing leaves on a tree branch.

The number of breeding activities varied between sites as well and Honeycomb Bend and Big Bend had by far the most observed activity (Figure 2.5). Food carries were documented at all our breeding sites and fledglings were found at five of the seven (72 percent). Nests and copulations were less widespread; they were observed at respectively two of the seven (43 percent) and two of the seven ( 29 percent) breeding sites.

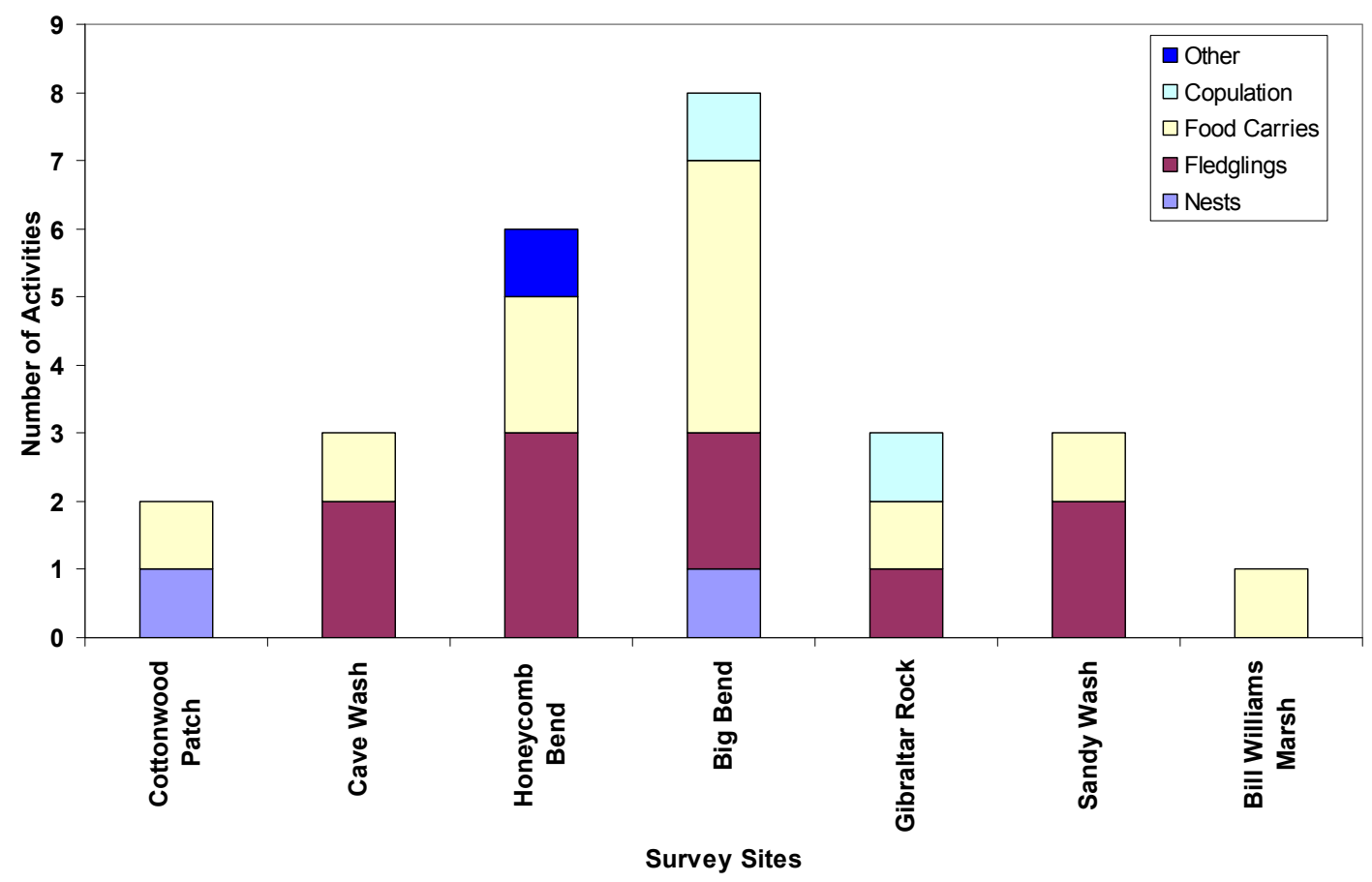

Figure 2.5. Number of type of breeding activities by survey site at Bill Williams River NWR within the LCR MSCP boundary area, 2007.

\section{Nest Monitoring}

We located two yellow-billed cuckoo nests in 2007. The success of each nest was unknown as fledging occurred between successive visits to the nest. Below, we will discuss in detail, the progression of each nest.

\section{Cottonwood Patch}

The Cottonwood Patch cuckoo nest was located along with an adult at the nest on 14 July. The nest was constructed in a Fremont cottonwood $(10 \mathrm{~m}$ tall; $32.8 \mathrm{ft})$ that was part of a stringer comprised of the same species. This stringer had little understory, but what was present consisted of Fremont cottonwood and tamarisk, with the canopy above the nest closed (Table 2.27). The nest was located within $20 \mathrm{~m}$ of a small puddle that was the only surface water in the area. On 16 July, a nestling was observed when an adult 
attempted to deliver a large, green prey item. We estimated the nestling's age to be one day based on its black and somewhat slick appearance. On 18 July, we again saw an adult cuckoo and one nestling. During nest checks on 25 July, 7 August, and 23 August, no activity was observed at the nest. The outcome of the nest (i.e., whether the nestling successfully fledged) was unknown.

\section{Big Bend}

The Big Bend cuckoo nest was located on 13 August in a tamarisk (6.4 m tall; $20.9 \mathrm{ft})$ close to the river $(15 \mathrm{~m} ; 49.2 \mathrm{ft})$. The overstory consisted of tamarisk and was heavily covered, while the understory was 50 percent covered (Table 2.29). A large Goodding's willow was located adjacent to the nest tree. During our first visit, an adult cuckoo was on the nest and movement was seen inside the nest. On 14 August, a nestling was observed sitting on the rim of the nest. Its feathers were sheathed and streaks of skin were still visible around the bill. At this time, we estimated the nestling's age to be 7-8 days. On 22 August, the nestling was not present in the nest and no fledglings were

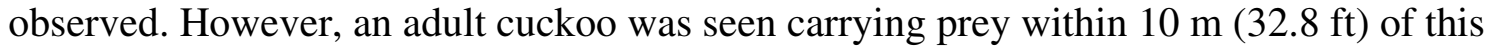
nest.

Vegetation measurements were taken at each nest after it became inactive. Percent cover measurements are shown in Table 2.29, and nest and substrate measurements for each nest are shown in Table 2.30.

Table 2.29. Percent cover measurements of yellow-billed cuckoo nests at Bill Williams River NWR within the LCR MSCP, 2007.

\begin{tabular}{ccccccc}
\hline Nest ID & $\begin{array}{c}\text { \% Overhead } \\
\text { cover }\end{array}$ & $\begin{array}{c}\text { \% Under- } \\
\text { nest cover }\end{array}$ & $\begin{array}{c}\text { \% Side } \\
\text { cover N }\end{array}$ & $\begin{array}{c}\text { \% Side } \\
\text { cover S }\end{array}$ & $\begin{array}{c}\text { \% Side } \\
\text { cover E }\end{array}$ & $\begin{array}{c}\text { \% Side } \\
\text { cover W }\end{array}$ \\
\hline CPNest1 & $45 \%$ & $15 \%$ & $5 \%$ & $20 \%$ & $18 \%$ & $10 \%$ \\
BBNest1 & $85 \%$ & $50 \%$ & $45 \%$ & $40 \%$ & $70 \%$ & $80 \%$ \\
\hline
\end{tabular}

Table 2.30. Yellow-billed cuckoo nest and substrate measurements at Bill Williams River NWR within the LCR MSCP, 2007.

\begin{tabular}{cllllll}
\hline Nest ID & \multicolumn{1}{c}{$\begin{array}{c}\text { UTM } \\
\text { coordinates }\end{array}$} & Substrate & $\begin{array}{c}\text { Substrate } \\
\text { DBH (cm) }\end{array}$ & $\begin{array}{c}\text { Substrate } \\
\text { height }(\mathbf{m})\end{array}$ & $\begin{array}{c}\text { Nest height } \\
(\mathbf{m})\end{array}$ & $\begin{array}{c}\text { Distance to } \\
\text { water (m) }\end{array}$ \\
\hline CPNest1 & $227747 \mathrm{E}$ & $\begin{array}{l}\text { Freemont } \\
\text { cottonwood }\end{array}$ & 15 & 10 & 1 & 16 \\
BBNest1 & $\begin{array}{l}3794239 \mathrm{~N} \\
774359 \mathrm{E}\end{array}$ & $\begin{array}{l}\text { Tamarisk } \\
3795439 \mathrm{~N}\end{array}$ & 11 & 6.4 & 3.7 & 3 \\
\hline
\end{tabular}

\section{Discussion}

Yellow-billed cuckoos have historically been considered a common breeding species within extensive riparian forests throughout the lower Colorado River Basin (Swarth 1905, Visher 1910, Phillips et al. 1964). In 1976, the estimated number of breeding cuckoo pairs along the lower Colorado River and its five tributaries was 846 (Groschupf 1987). Later studies found a 93 percent decline along the lower Colorado River between 1976 and 1986 and an estimated 71 to 75 percent decline on the Bill Williams River delta during the same period (Rosenburg et al. 1991). 
Our 2007 yellow-billed cuckoo surveys included most areas that were historically surveyed throughout the lower Colorado River Basin. We had163 cuckoo detections, the majority (85 percent) of which were in the Bill Williams River NWR. The exact number of cuckoos present in our survey sites is not known as there was no way to tell whether detections on separate surveys represented the same or different individuals. Thus, the detections summarized above should not be interpreted as a count of the number of cuckoos present or as the number of birds breeding at a site. The Bill Williams River NWR continues to have the highest number of yellow-billed cuckoos. This area represents the largest swath and highest habitat quality of appropriate yellow-billed cuckoo habitat on the lower Colorado River. Because of differences in survey methods, specific areas surveyed, and probable differences in the criteria used to estimate the number of individuals, it is difficult to make direct comparisons between our results and estimates of cuckoo number from previous studies.

However, we can compare the occupancy of yellow-billed cuckoos between our 2006 and 2007 surveys, the two years we have conducted surveys within the lower Colorado River Multi-Species Conservation Program boundary. At the Grand Canyon/Lake Mead area and sites, we had three occupied sites in 2006 with confirmed breeding at the Chuckwalla Cove (Johnson et al. 2007). In 2007, we had zero yellowbilled cuckoo detections and therefore no occupied sites in this area. At Havasu National Wildlife Refuge in 2006, we had no occupied sites and only one cuckoo detection. In 2007, we had one occupied site at the North Dike survey site within Havasu NWR and one cuckoo detection at Pintail Slough. Within the Bill Williams River NWR area, we had eight occupied sites in 2006 and confirmed breeding at two sites. In 2007, ten sites were designated as occupied within Bill Williams River NWR and we confirmed breeding at seven of those sites. At Cibola NWR, we had one designated occupied site in 2006 Cibola Nature Trail Restoration and 2007 Cibola South Restoration site, we did not confirm breeding during either year. At Imperial NWR, Imperial South restoration was the only site designated occupied for both 2006 and 2007, breeding was not confirmed for either year, however in 2006 a pair was observed performing courtship. Among the Yuma, AZ sites, two sites were occupied in 2006 (Colorado/Gila Confluence and Limitrophe North), and in 2007, one site were designated occupied (Quigley Pond WMA). In 2005, Quigley Pond was designated occupied, where a pair was observed performing courtship. Breeding was not confirmed within any of the Yuma, AZ sites in either 2006 or 2007. With the exception of Bill Williams River NWR, there was substantial variation between sites and years in occupancy and breeding confirmation.

There are a number of factors that might account for this variation. There were several patterns in our detections that reinforce the idea that cuckoos within the entire LCR MSCP study area can readily move between survey areas and sites. For example, the habitat at several sites where cuckoos were detected was far outside the range of normal within this region and was probably not suitable for nesting. We also had several sites with just single detection of a cuckoo. We believe the individuals found in such sites were likely non-breeding "wanderers," migrants, or birds breeding elsewhere, but foraging within the patch it was detected in.

Yearly variation is very obvious within the Grand Canyon NP/Lake Mead NRA area. In 2006 there were 29 yellow-billed cuckoo detections at the Grand Canyon NP/ Lake Mead NRA study area and three occupied sites (Cuckoo Beach, Iceberg Ridge, and Chuckwalla Cove); however, we did not detect any cuckoos at Grand Canyon NP/ Lake Mead NRA in 2007. During the cuckoo breeding season, the elevation of Lake Mead was 
approximately $4.5 \mathrm{~m}$ (15 ft) lower in 2007 compared to 2006

(http://www.usbr.gov/lc/region/g4000/hourly/mead-elv.html) because of long-term drought conditions in the Colorado River watershed. The greatest impact to the riparian habitat that might be due to these declining lake levels is the dramatic increase in the proportion of snags we detected in vegetation sampling plots between the two years. In 2006, snags made up 14 percent of the entire woody vegetation, but accounted for 46 percent in 2007. However this apparent drought induced stress on the vegetation at Grand Canyon NP/Lake Mead NRA was not evident in soil moisture. In 2006, soil moisture ranged between 8-11 percent at unoccupied and occupied sites, respectively, but, in 2007, soil moisture at Grand Canyon NP/Lake Mead NRA averaged 9 percent, identical to values at the Bill Williams River NWR that was densely occupied by yellow-billed cuckoos.

Historically, sites within Grand Canyon NP/Lake Mead NRA have likely been exposed to periodic drought and disturbance; therefore, these sites may not be the most suitable locations for habitat restoration efforts. For this reason, continued long-term studies of yellow-billed cuckoo occupancy patterns should be conducted throughout the lower Colorado River. Information about occupancy patterns would be useful for identifying sites suitable for habitat restoration and capable of promoting eventual cuckoo occupancy.

It is clear that there are challenges verifying yellow-billed cuckoo breeding at a site. Cuckoos are very secretive, difficult to detect, and move over large areas. Thus, verifying that cuckoos are breeding in a particular patch requires finding young, a nest, or copulating adult - all of which can sometimes present difficulties. This reality makes it safe to assume that we did not observe all breeding activities that occurred in 2006 or 2007. For example, some repetitive activities like food carries were certainly missed. We are also aware that more nests were present in our study sites than just those we were able to locate. All fledglings were found in areas with high concentrations of cuckoo activity where nests were likely located, but only three fledglings were found in close proximately to a nest. Given this knowledge, the number of breeding activities recorded at a site should be interpreted as a minimum of breeding activity that occurred. However, all of our documented breeding activities took place at the Bill Williams River NWR, indicating that this area has more and/or better breeding habitat than the other survey locations.

\section{Other Riparian Bird Detections}

We detected and documented 160 additional species during our surveys in 2007, including local breeders and many Neotropical migrants (Table 2.31; Appendix 6). These species were observed before, during, or after our yellow-billed cuckoo surveys. Because the focus of our efforts was on detecting cuckoos, no effort was made to quantify abundance of these additional species, nor to track down and verify any species that were not readily identifiable or obvious to the surveyors.

Of the 160 species detected, nine species were focal species under the Lower Colorado River Multi-Species Conservation Program (Table 2.32). The willow flycatcher (Empidonax traillii), Bell's vireo (Vireo bellii), and yellow warbler (Dendroica petechia) were the most widespread species. 
Table 2.31. Number of bird species detected at each site and totaled by yellow-billed cuckoo survey area within the Lower Colorado River Multi-Species Conservation Program Area, 2007.

\begin{tabular}{lll}
\hline \multicolumn{1}{c}{ YBCU-LCR-MCSB Survey Area/Site Name } & Number of Bird Species \\
\hline Pahranagat NWR & 35 \\
Overton WMA & 29 \\
Grand Canyon NP/Lake Mead NRA & 39 \\
Havasu NWR & 68 \\
Bill Williams River NWR & 127 \\
Ahakhav Tribal Preserve & 55 \\
Cibola NWR & 46 \\
Picacho SRA & 23 \\
Imperial NWR & 17 \\
Mittry Lake WMA/Pratt Restoration & 31 \\
Gila/Colorado River Confluence & 42 \\
Yuma West Wetlands & 38 \\
Limitrophe Division & 62 \\
Quigley Pond WMA & 31 \\
\hline
\end{tabular}


Table 2.32. Lower Colorado River Multi-Species Conservation Program focal bird species detected by LCR MSCP geographic area, 2007.

\begin{tabular}{|c|c|}
\hline LCR MSCP Geographic Area & LCR MSCP Focal Species \\
\hline \multirow[t]{2}{*}{ Pahranagat NWR } & Willow Flycatcher \\
\hline & Yellow Warbler \\
\hline \multirow[t]{2}{*}{ Overton WMA } & Willow Flycatcher \\
\hline & Yellow Warbler \\
\hline \multirow[t]{4}{*}{ Grand Canyon NP/Lake Mead NRA } & Willow Flycatcher \\
\hline & Bell's Vireo \\
\hline & Summer Tanager \\
\hline & Yellow Warbler \\
\hline \multirow[t]{3}{*}{ Havasu NWR } & Gilded Flicker \\
\hline & Bell's Vireo \\
\hline & Yellow Warbler \\
\hline \multirow[t]{5}{*}{ Bill Williams River NWR } & Black Rail \\
\hline & Least Bittern \\
\hline & Gilded Flicker \\
\hline & Willow Flycatcher \\
\hline & Vermillion Flycatcher \\
\hline \multirow[t]{6}{*}{ Ahakhav Tribal Preserve } & Bell's Vireo \\
\hline & Summer Tanager \\
\hline & Yellow Warbler \\
\hline & Willow Flycatcher \\
\hline & Vermillion Flycatcher \\
\hline & Yellow Warbler \\
\hline \multirow[t]{4}{*}{ Cibola NWR } & Willow Flycatcher \\
\hline & Bell's Vireo \\
\hline & Yellow Warbler \\
\hline & Vermillion Flycatcher \\
\hline Picacho SRA & Bell's Vireo \\
\hline \multirow[t]{3}{*}{ Imperial NWR } & Least Bittern \\
\hline & Bell's Vireo \\
\hline & Summer Tanager \\
\hline Mittry Lake WMA & Bell's Vireo \\
\hline Gila/Colorado River Confluence & Willow Flycatcher \\
\hline
\end{tabular}


Table 2.32. Lower Colorado River Multi-Species Conservation Program focal bird species detected by LCR MSCP geographic area, 2007.-Continued

\begin{tabular}{ll}
\hline \multicolumn{1}{c}{ LCR MSCP Geographic Area } & \multicolumn{1}{c}{ LCR MSCP Focal Species } \\
\hline Yuma West Wetlands & Bell's Vireo \\
& Yellow Warbler \\
Limitrophe Division & Willow Flycatcher \\
& Vermillion Flycatcher \\
Quigley Pond WMA & Yellow Warbler \\
& Willow Flycatcher \\
& Vermillion Flycatcher \\
& Bell's Vireo \\
& Yellow Warbler \\
\hline
\end{tabular}


This page intentionally left blank 


\section{Chapter 3: Survey Methodology}

The basic approach of this survey protocol - the use of broadcast vocalizations to elicit a response by resident yellow-billed cuckoos-was established in California in 1965 (Hamilton and Hamilton 1965). Since then, the protocol has evolved as biologists have learned more about the cuckoo's breeding biology and behavior (Gaines 1974; Gaines 1977; Gaines and Laymon 1984; Laymon and Halterman 1985, 1987a, 1987b, 1989; Halterman 2005; Halterman et al. 2006). Refinements to the protocol have helped to maximize the likelihood of detecting cuckoos while minimizing survey time and costs. Although our current project was not intended to serve as a full evaluation and test of the cuckoo survey protocol, our results might be used to help further refine and develop specific experiments of the method that can be tested in the future.

Tape broadcast survey techniques have proven advantageous in eliciting responses from many bird species, especially those that are secretive or nocturnal. It often increases the total number of birds seen or heard for a given species in comparison to a conventional census (Johnson et al. 1981), especially for species with low song activity (Robbins 1978). Broadcasting has also been helpful in estimating population size and investigating avian social behavior and territoriality. Broadcast surveys have been used primarily during the breeding season to study the presence and distribution of species (Glahn 1974, Griese et al. 1980, Sogge et al. 1997), but they also have been employed on wintering grounds (Koronkiewicz et al. 2006). However, the use of broadcast recordings can sometimes have unexpected consequences. Robbins (1978) found that the use of tape recordings during repeated visits over the breeding season can bias results, as birds might alter their habits or their territorial boundaries if they believe that there are competing conspecifics holding a territory nearby. Studies of the use of broadcast recordings to survey spotted owls (Strix occidentalis) suggest that, if surveyed too often, some individuals and/or species might become less responsive (Forsman et al. 1977). Also, the use of broadcast recordings can attract some individuals away from their territories, as in elegant trogons (Trogon elegans; Taylor 1978), resulting in inflated population density estimates. To date, we are not aware of any adverse impact of tape broadcast survey techniques to yellow-billed cuckoos or estimates of their population size. As with other monitoring techniques, an assumption of broadcast surveys techniques is a constant probability of detection over time and space (Pollock et al. 2002). Violation of this assumption can confound efforts to compare results among different areas or studies.

The use of broadcast recordings in surveys of western yellow-billed cuckoos has increased the number of detections of this elusive and easily overlooked species (Hamilton and Hamilton 1965, Halterman et al. 2006). Cuckoos do not sing to defend territory and they vocalize relatively infrequently. Little is known about the functions of the cuckoo's various calls, but the kowlp call might function as a spacing mechanism and as a means to communicate between mated individuals (Hughes 1999). Studies, mostly of eastern yellow-billed cuckoos (Coccyzus americanus americanus), have found that calls are most frequent during pair formation and nest building; calls continue through nesting, then become infrequent after the last young fledge (Hughes 1999). Unfortunately, little is known about whether frequency of vocalization is related to mating status (paired or 
unpaired) or to population density. Lack of this information complicates the interpretation of survey results.

Assessing the use of broadcast recordings for surveys to determine the presence and distribution of yellow-billed cuckoos can be challenging, especially due to the difficulty in finding and following individuals. As with any field survey protocol, there is no way to be absolutely certain that an area with no detections is unoccupied. This might be a particular challenge with yellow-billed cuckoos, which we have long suspected have a fairly low response rate; the standard survey method of using broadcast recordings might fail to detect all birds present in an area. In fact, it has been observed that some individuals known to be present in the area sometimes do not respond to the recordings (Halterman 2004, Johnson et al. 2006b, Johnson et al. 2007). During a test of broadcast survey methods using adult cuckoos with radio transmitters, Halterman (2005) found that only 30 to 50 percent of radio-transmitted birds were detected when solicited through broadcast recordings.

In our evaluation of the survey protocol in 2006, we found that the majority (72 percent) of cuckoo detections were solicited through broadcast at all study sites. The number of solicited detections peaked during the first half of July and then declined as the breeding season progressed, while the number of unsolicited detections (cuckoos heard calling before broadcast was initiated) remained fairly constant. The majority (64 percent) of cuckoo detections, solicited or unsolicited, were aural; 27 percent were both heard and seen and nine percent were visual detections only. We found that cuckoos in areas with the largest populations had the highest rate of vocalizations before the broadcast or after the first broadcast. In contrast, more than half the responses at sites with fewer cuckoos (with $<10$ detections per site) first occurred after three or more broadcast recordings.

In 2007, we continued to examine the cuckoo survey protocol and specifically continued to collect baseline information that will be used to help refine the survey protocol, and to create experiments that can serve as the foundation for a full-scale evaluation and optimization of this survey technique.

\section{Methods}

To gain a better understanding of the efficacy of the yellow-billed cuckoo survey protocol, we continued to compare cuckoo responses to tape broadcasts among sites and within the breeding season. We summarized the number of broadcasts needed to solicit a response, how the cuckoos responded, and the cuckoo's distance from survey points. We also summarized the number of cuckoo detections across survey periods to examine the minimum number of surveys needed to determine occupancy and breeding status of a site.

Our survey method involved one minute of listening for spontaneously calling cuckoos, followed by five consecutive broadcasts of the cuckoo kowlp call spaced one minute apart. Broadcasts were ceased at a survey point once a cuckoo was detected. Cuckoo detections were categorized as either "unsolicited" if birds called before initiation of the broadcast or "solicited" if they occurred after a broadcast (i.e., in response to the broadcast). Cuckoo detections were also classified as "aural" if individuals were heard calling but were never seen, "visual" if birds were seen but not heard, or "both" if birds were heard and seen. See Chapter 2 for a complete description of the methods used to survey for yellow-billed cuckoos during this study. 


\section{Results}

Almost 85 percent of solicited and 88 percent of unsolicited responses were at Bill Williams River NWR; the other solicited responses were Havasu NWR, Ahakhav Tribal Reserve, Cibola NWR, Imperial NWR, Gila/Colorado Confluence, Limitrophe Division and Quigley Pond WMA (Fig. 3.1). The other unsolicited responses occurred at Cibola NWR, Imperial NWR, and Gila/Colorado Confluence.

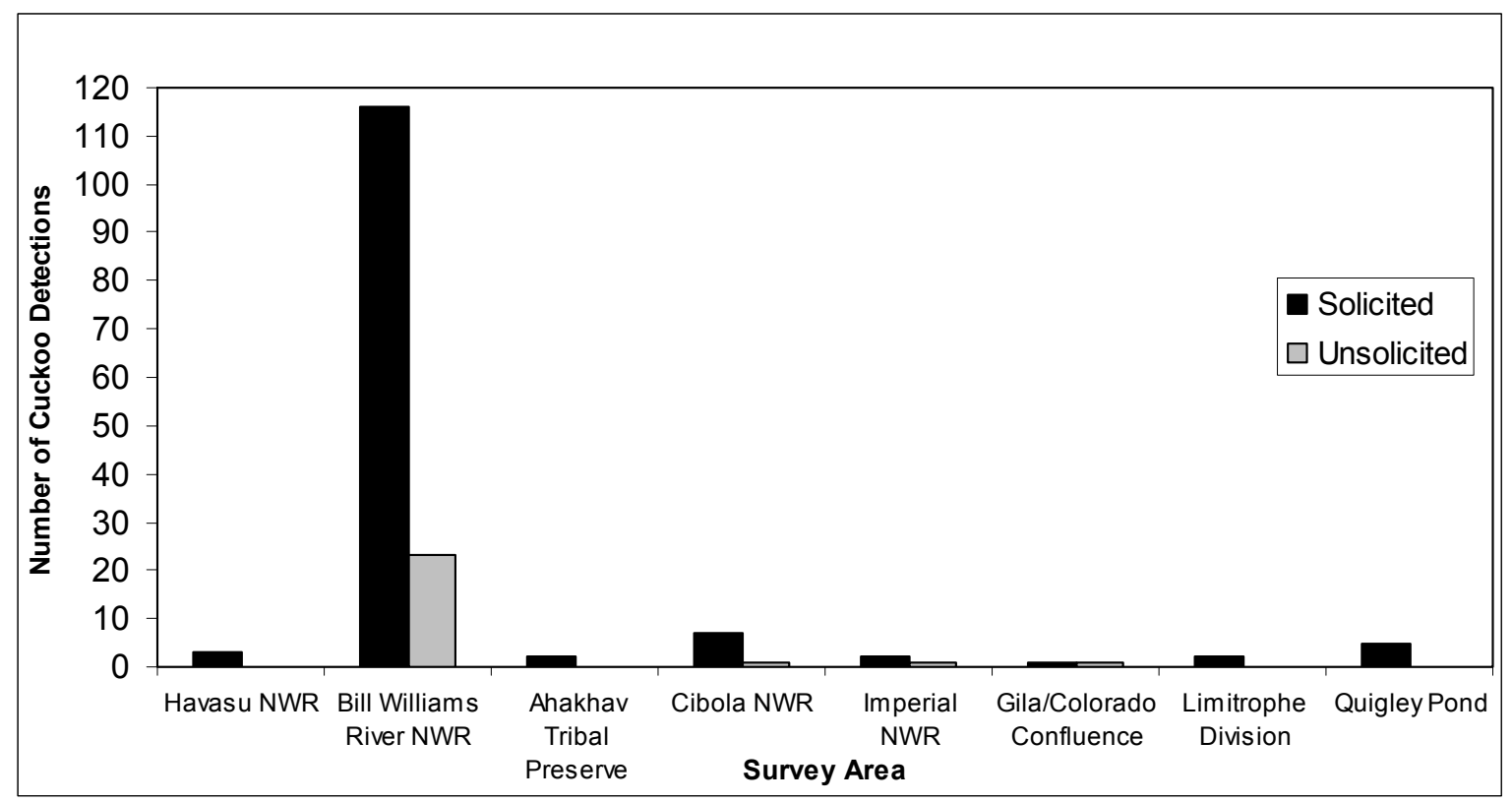

Figure 3.1. Number of unsolicited initial responses and post-broadcast responses by yellow-billed cuckoo in each geographical area.

We found that 66 percent of all detections occurred before the third broadcast was played (Fig. 3.2). We also found that timing of initial responses differed slightly between areas with $>10$ detections (i.e., Bill Williams River NWR) and areas with $<10$ detections (i.e., Limitrophe Division; Fig. 3.3). Yellow-billed cuckoos responded more readily (in earlier surveys) to broadcasts in areas with lower overall detections (73 percent of detections) than in areas with higher overall detections (68 percent of detections; Fig. 3.2). The actual density of cuckoos per area is unknown, but it appears that cuckoo's respond more readily to playback broadcasts in areas with estimated lower densities than areas with higher densities. We also found that 50 percent of all initial responses were almost evenly split between the first and second broadcast at sites with $>10$ detections while 45 percent of responses occurred after a single broadcast at the areas with $<10$ detections. 


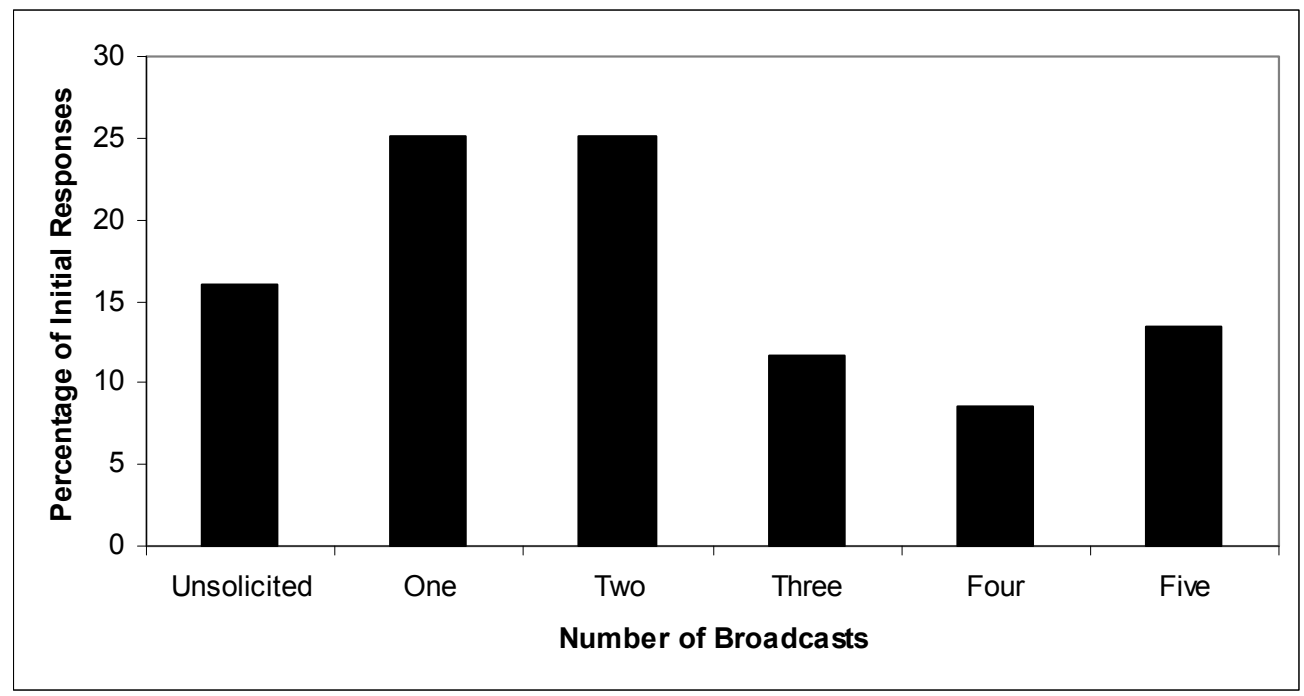

Figure 3.2. Percentage of initial yellow-billed cuckoo responses to survey broadcasts, based on sequential order of broadcast $(n=163)$. All data collected within the LCR MSCP boundary area, 2007.

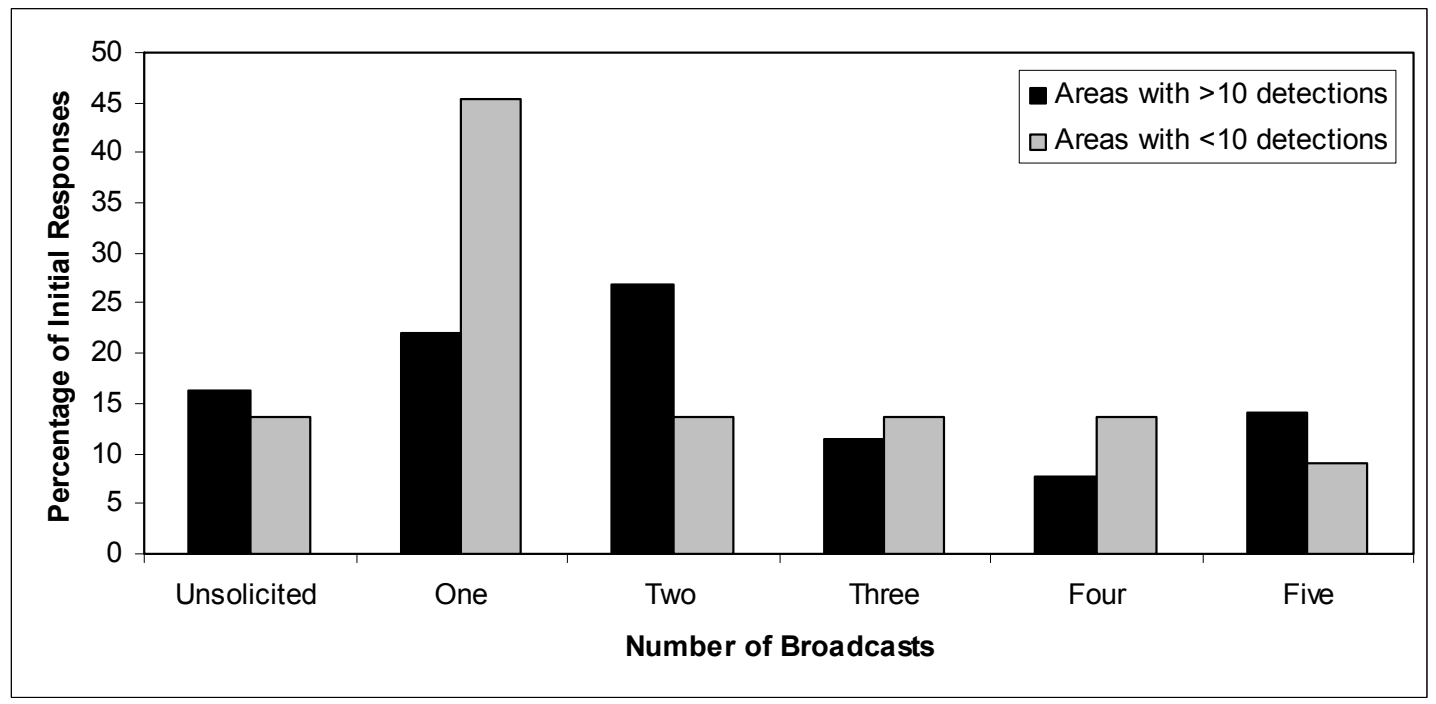

Figure 3.3. Percentage of initial yellow-billed cuckoos responses to broadcasts at geographical areas with $>10$ detections $(n=139)$ and all areas with $<10$ detections $(n=24)$ based on sequential order of response. All data collected within the LCR MSCP boundary area, 2007.

Solicited detections were highest in the month of June and declined throughout rest of the breeding season (Fig. 3.4). Contrastingly, unsolicited detections remained fairly constant through 11 August. After this time, no unsolicited survey detections occurred. The percentage of unsolicited initial responses was slightly higher in areas with $>10$ detections (17 percent) than in areas with $<10$ detections ( 13 percent). 


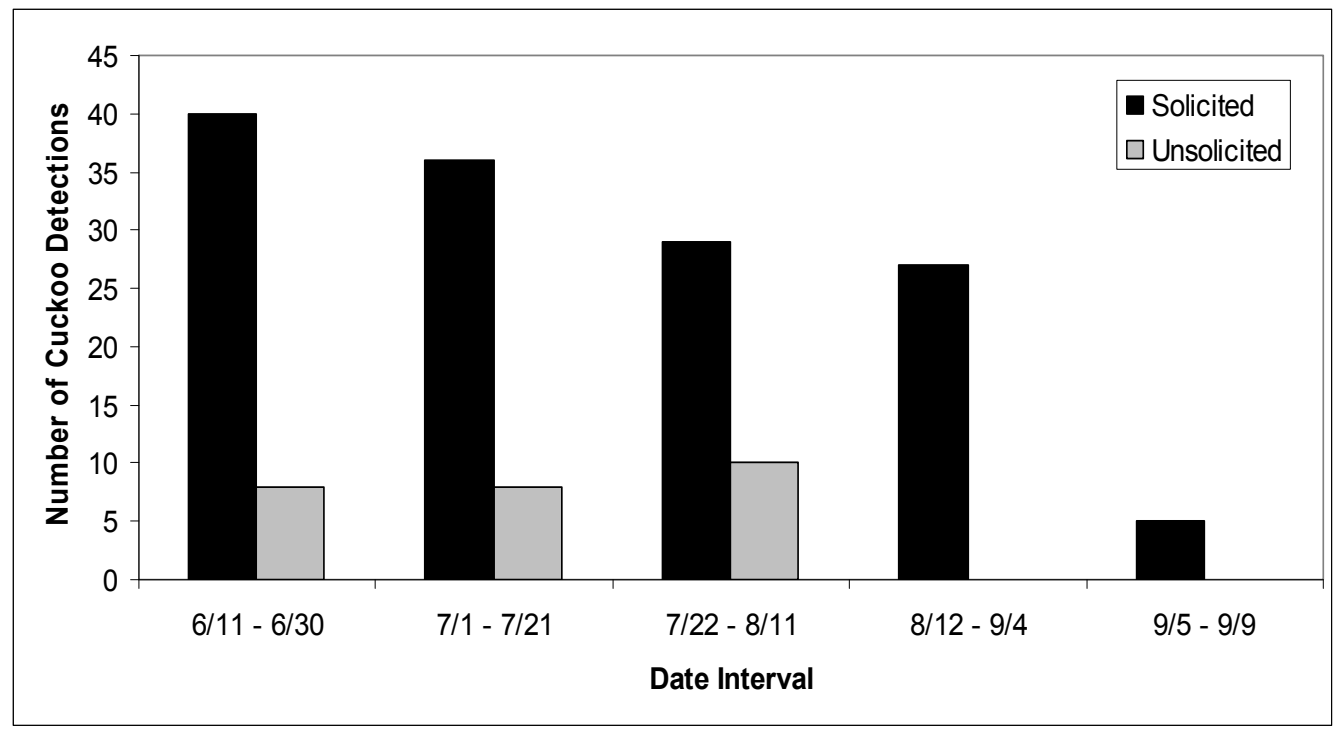

Figure 3.4. Number of yellow-billed cuckoo detections (solicited vs. unsolicited) by time period, from 11 June to 9 September. All data collected within the LCR MSCP boundary area, 2007.

For the entire study area, the total number of cuckoo detections declined as the season progressed (Fig. 3.5). We saw the biggest drop in areas with $<10$ detections. Detections in these areas made up 16 percent of the total in the first survey period, 7 percent in the second period and only 2 percent in the third. After this point, no detections were made in areas with apparent low populations $(<10$ detections). In contrast, detections at the areas with higher populations ( $>10$ detections) remained fairly constant up until the third survey period, then decreasing later in the season. 


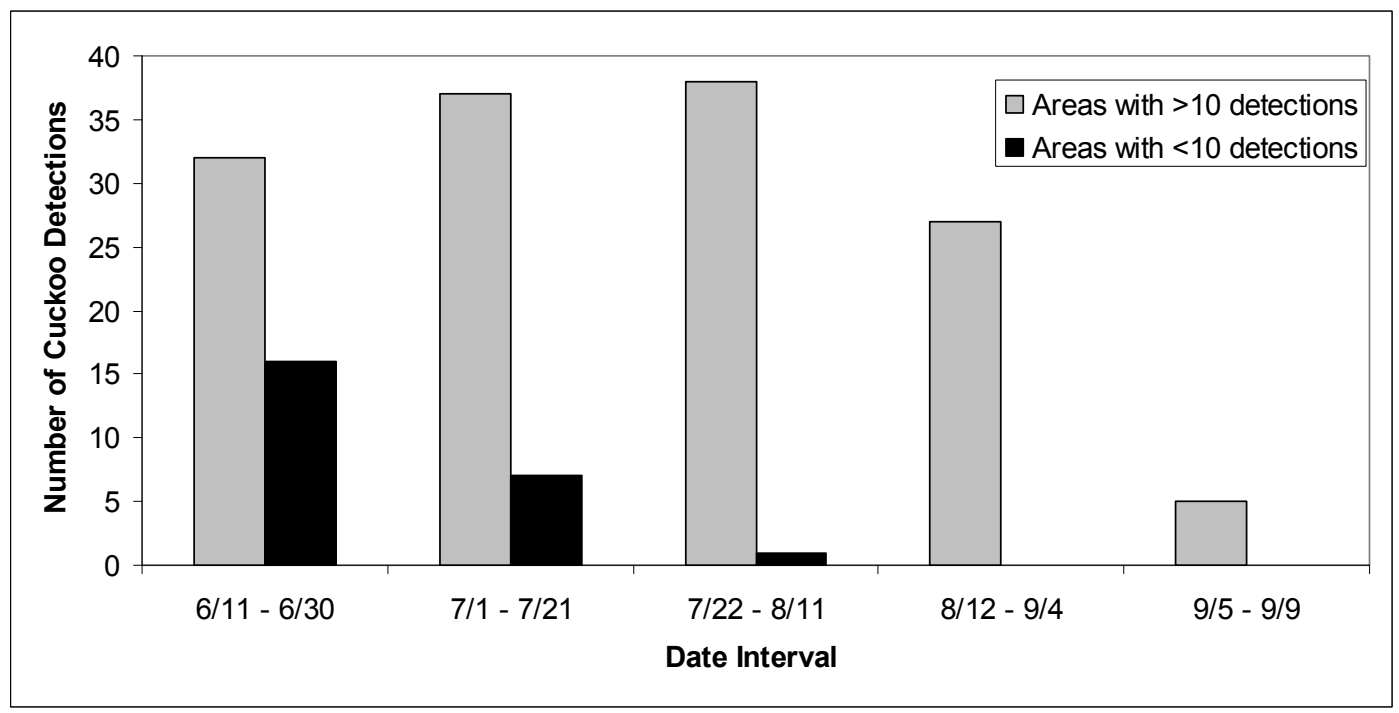

Figure 3.5. Number of yellow-billed cuckoo detections by time period, from 11 June to 9 September, in areas with $>10$ detections vs. areas with $<10$ detections. All data collected within the LCR MSCP boundary area, 2007.

Over the course of the breeding season, 66 percent of total survey detections were aural, 23 percent were both heard and seen, and 11 percent were visual only (Fig. 3.6). During the first survey period, the ratio of aural-only to visual-only and visual/aural detections was nearly even. However, during the second survey period, the cuckoos were seen less frequently and the proportion of visual detections declined. By the third survey period, aural-only detections were five times more prevalent than visual detections.

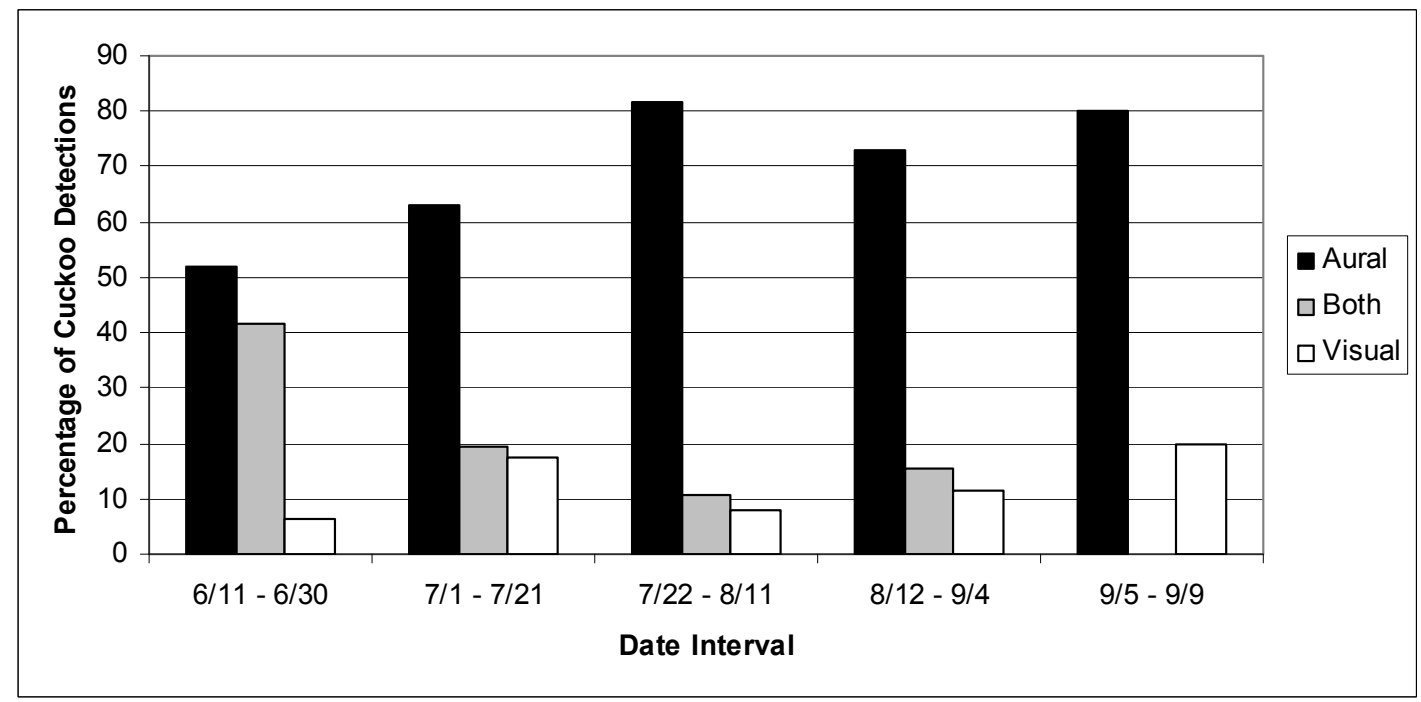

Figure 3.6. Percent of yellow-billed cuckoo aural, both aural and visual, and visual detections by time period, from 11 June to 9 September. All data collected within the LCR MSCP boundary area, 2007. 


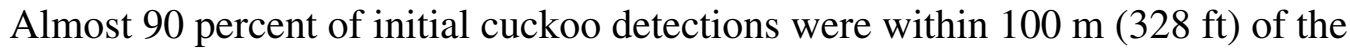
observer (Fig. 3.7) and only 1 percent were at distances greater than $200 \mathrm{~m}(656 \mathrm{ft})$. Twothirds of cuckoos were initially detected from less than $51 \mathrm{~m}(167 \mathrm{ft})$ away.

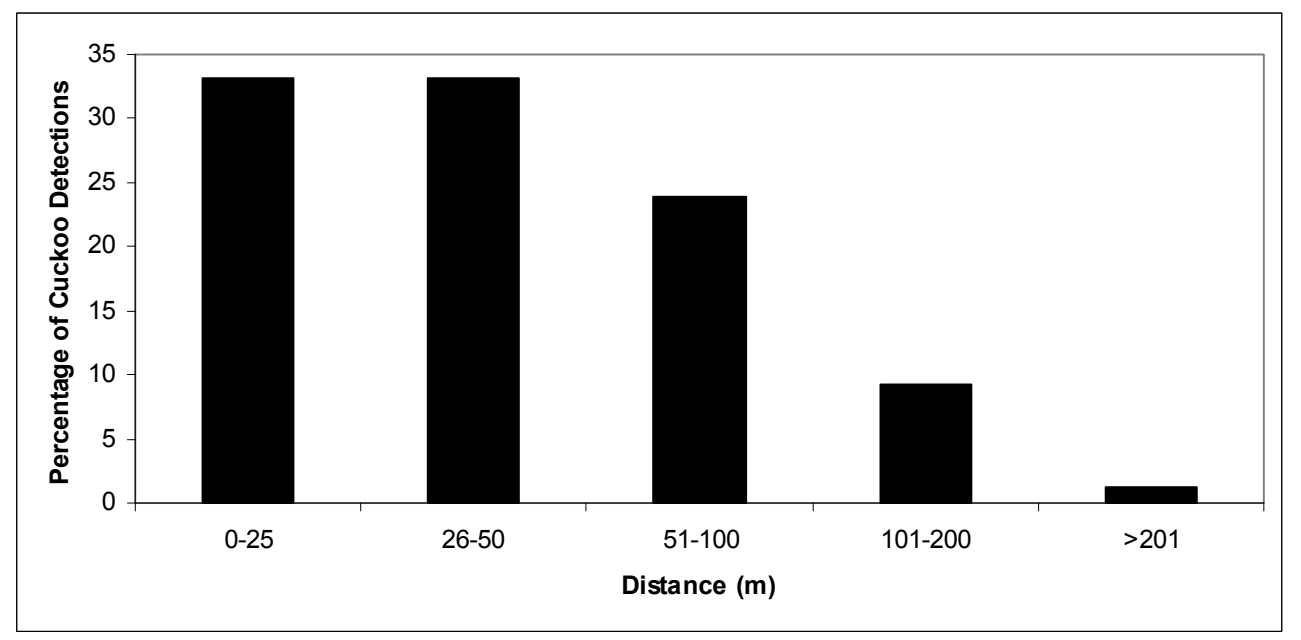

Figure 3.7. Percentage of yellow-billed cuckoos detected within categories of distance from the survey point. All data collected within the LCR MSCP boundary area, 2007.

\section{Discussion}

Results from our study indicate that the number of broadcasts required to elicit a response may be influenced by cuckoo abundance (nearest-neighbor distances), as has been found in other species (Penteriani et al. 2002). Birds were detected earlier when found in smaller populations than when in larger populations. Individuals in the former might be displaying a heightened reaction (responding after the first broadcast) to the presence of other cuckoos.

In 2007, we also observed that over 13 percent of cuckoo detections across all sites were made after the fifth broadcast. Therefore, repeated broadcasts at each point, at least to the point of five, continues to increase the probability of a cuckoo being detected.

It has been observed that birds might be less likely to vocalize in response to a broadcast after nesting has started (Sogge et al. 1997, Legare et al. 1999, Bogner and Baldassarre 2002). Laymon and Halterman (1985) found that yellow-billed cuckoos were fairly vocal during pair formation, nest building, and the nestling stage, and less vocal during incubation. However, Halterman (2005) found no noticeable decrease in vocalization frequency after nesting for two yellow-billed cuckoos that were tracked via telemetry throughout their nesting cycles. We found that the total number of detections peaked in late June, just before observed breeding activity peaked (See Chapter 2:

Breeding Activity), then declined as the season progressed. However, across all sites there was declining trend in the mean timing of initial response, as one would expect if breeding stage does indeed affect responsiveness to the broadcast. Potentially, staggered breeding by individual cuckoos and the presence of non-breeders could produce this result.

Yellow-billed cuckoos have been documented breeding in late August and even into September (Halterman 2002). Sites were confirmed as occupied by the end of the third survey period (see Chapter 2, Table 2.3). However, previous surveys at the Bill 
Williams River NWR detected several new pairs in mid-August (Halterman 2002, Johnson et al. 2007). Additionally, 22 percent of our observed breeding activities $(n=27)$ took place during the fourth survey period (August) and breeding activity was not observed at one of the seven breeding sites until the fourth survey period (See Chapter 2: Yellow-billed Cuckoo Breeding Surveys). This demonstrates the value of continuing surveys through August and even the first half of September to verify cuckoo occupancy.

The survey protocol we utilized requires broadcasts to be conducted every $100 \mathrm{~m}$ $(328 \mathrm{ft})$ on transects separated by $200 \mathrm{~m}(656 \mathrm{ft})$ of habitat. If a cuckoo is detected, the surveyor must move $300 \mathrm{~m}$ before conducting the next survey point. This protocol assumes that a yellow-billed cuckoo $100 \mathrm{~m}$ away will be able to hear the broadcast and respond, and that the response is heard by the observer. It also assumes that a cuckoo $>300 \mathrm{~m}(984 \mathrm{ft})$ away will not respond to a broadcast. Halterman (2005) found that yellow-billed cuckoos called 14 percent of the time when a survey point was completed $300 \mathrm{~m}$ (984 ft) away, but surveyors heard this response only 4 percent of the time. In 2007, almost 90 percent of our detections were within $100 \mathrm{~m}(328 \mathrm{ft})$ of the survey point and no yellow-billed cuckoos were detected at a distance greater than $250 \mathrm{~m}(820 \mathrm{ft})$ from the survey point. This suggests the distances we currently utilize represent appropriate intervals for the spacing of survey points and transects. 


\section{Chapter 4. Habitat Vegetation Characteristics}

To design an effective habitat restoration program under the Lower Colorado River Multi-Species Conservation Program, information is needed regarding yellowbilled cuckoo habitat requirements in this region. We currently know relatively little about the cuckoos' specific breeding habitat requirements along the lower Colorado River. In the arid Southwest, yellow-billed cuckoos are primarily restricted to densely wooded rivers and streams and damp thickets with relatively high humidity (Corman and Wise-Gervais 2005, Johnson et al. 2007, Holmes et al. 2008).

Western yellow-billed cuckoos generally breed in large blocks of riparian habitat, particularly woodlands with cottonwoods and willows (Ehrlich et al. 1988, USFWS 2002). Nesting cuckoos along the Sacramento River in California were estimated to need riparian habitat patches ranging from 10-40 ha (25-100 acres) (Gaines 1974, Laymon et al. 1997, Halterman 1991).

Within riparian patches in California, dense understory foliage appears to be an important factor in cuckoo nest site selection, while cottonwood trees are an important foraging habitat (Laymon et al. 1997, USFWS 2002). Cuckoo surveys in Arizona from 1998 and 1999 (Corman and Magill 2000) found that occupancy rates (i.e., the percentage of sites surveyed that were occupied) were highest in cottonwood (Populus spp.) -willow (Salix spp.) -ash (Fraxinus spp.) -mesquite (Prosopis spp.) habitat with less than 75 percent tamarisk (Tamarix spp.). Mesquite bosque-hackberry (Celtus spp.) habitat also had a relatively high occupancy rate. Yellow-billed Cuckoos were much less common in sycamore (Platanus spp.) -cottonwood (46 percent occupancy), sycamorealder (Alnus spp.; 33 percent occupancy), and habitats comprised of more than 75 percent tamarisk (33 percent occupancy). Surveys conducted by the Arizona Breeding Bird Atlas (Corman and Wise-Gervais 2005) found that 68 percent of the Yellow-billed Cuckoo observations were in lowland riparian woodlands, often containing a variable combination of Fremont cottonwood (Populus fremontii), willow, velvet ash (Fraxinus velutina), Arizona walnut (Juglans major), mesquite, and tamarisk.

Our preliminary efforts to characterize the habitat vegetation characteristics in 2006 (Johnson et al. 2007) were primarily focused on comparing occupied and unoccupied habitats within Grand Canyon NP/Lake Mead NRA, Bill Williams River NWR, and Cibola NWR. Across these study sites the dominant tree species were cottonwood, willow, and tamarisk. Tamarisk was the most common tree due to the abundance of trees in the smallest size class $(<8 \mathrm{~cm}[<3.2$ inches $]$ diameter at breast height $[\mathrm{DBH}])$ and variation among the different study sites was driven by these trees. In general we found that occupied sites had canopies dominated by cottonwood and willow, with greater total canopy cover compared to unoccupied sites due to the denser mid- and low strata layers. The habitats where we detected cuckoos in 2006 had lower total tree density, particularly of tamarisk in the smallest size class, compared to unoccupied habitats. Our objective in this chapter is to build upon last year's work to refine the current knowledge of yellow-billed cuckoo habitat requirements specifically within the LCR MSCP study area by characterizing riparian habitat at the site-patch level. We sampled occupied and unoccupied sites within the entire study area in order to describe vegetation composition and structure, including characteristics of the canopy and the 
distribution and density of woody species based on the occupancy of status of sites from 2007 and vegetation measurements made in 2007.

\section{Methods}

In 2007, we refined our characterization of vegetation based on results from our 2006 pilot year and a review of sample designs and measurement techniques typically used in western riparian bird-habitat studies. Based on previous experience, yellow-billed cuckoo use fairly large areas (10-40 ha; 25-100 acres), are not territorial, are present in low numbers, and have nests that are difficult to locate (Gaines 1974, Laymon et al. 1997, Halterman 1991, Johnson et al. 2007). We reviewed vegetation sampling designs and found that the majority of studies used point-based sampling associated with songbird territories or nest sites (e.g., James and Shugart 1970, Noon 1981, Strong and Bock 1990, Martin et al. 1997, Saab 1999, Powell and Steidl 2000, Miller et al. 2003). Therefore, we selected point-based sampling measures but sampled in a manner to characterize riparian habitat at the survey site-patch level rather than at the territory or nest scale. This provides more general and appropriately scaled information to guide riparian restoration efforts along the lower Colorado River. We based our evaluated measurement techniques on our understanding of cuckoo habitat use and the physical features that might be most important in characterizing breeding cuckoo habitat. Overall, we selected measures to provide data on vegetation composition and structure: the numbers and identities of plant species present in a sample site, and the relative abundance or importance of riparian woody species. We also documented general vegetation characteristics within sites by taking photographs at each vegetation plot (Appendix 5). Our measurement of vegetation characteristics covers multiple spatial scales. The smallest scale includes the $5 \mathrm{~m}$ and $11.3 \mathrm{~m}$ vegetation sampling plots located within survey site. The mean values of all vegetation sampling plots comprise the vegetation characteristics of what we refer to as the site/patch level—our survey sites. The total or mean values of all measurements at the site/patch level make up the vegetation characteristics of an entire study site/area, these are the large scale geographic area that we conducted this study along the lower Colorado River (Table 4.1).

\section{Vegetation Sampling Design}

During the 2007 study season, we were primarily interested in characterizing vegetation at the site-patch level and in comparing vegetation characteristics between occupied and unoccupied sites, among different geographic areas, and among survey sites within the Bill Williams River NWR. The entire survey region was stratified north to south from the Grand Canyon to the United States/Mexican International border (Table 4.1). For the vegetation analyses presented in this chapter, we focused on the Grand Canyon NP/Lake Mead NRA, Havasu NWR, Bill Williams River NWR, Cibola NWR, and Yuma Restoration Sites.

We attempted to sample vegetation plots in both occupied and unoccupied survey sites within each study area. Sites were categorized as occupied if cuckoos were detected during two or more survey periods, and unoccupied if cuckoos were detected during only one or no survey periods. We classified sites prior to the 2007 field season as occupied or unoccupied based on 2005 and 2006 yellow-billed cuckoo surveys (Johnson et al. 2006b, Johnson et al. 2007). However, yellow-billed cuckoo detections were not evenly distributed across the geographic extent of the study in 2007. Our vegetation sampling 
plots corresponded to microclimate and soil moisture sampling locations. So in 2007 when we detected cuckoos at nearly all sites within the Bill Williams River NWR and at none of the sites with the Grand Canyon NP/Lake Mead NRA, we continued our vegetation sampling at the locations pre-established in our protocol, because data collection had already started for microclimate and soil moisture parameters. Most vegetation sampling plots in the Bill Williams River NWR in 2006 were also in occupied habitats (26 of 28 plots). At Grand Canyon NP/Lake Mead NRA in 2006 there were plots in both occupied and unoccupied habitats in contrast to 2007 when there were none. This sampling design resulted in 60 percent of all occupied and 55 percent of all unoccupied vegetation sampling plots being located in the Bill Williams River NWR and Grand Canyon NP/Lake Mead NRA, respectively. One result of this approach is that the data from the Bill Williams River NWR and Grand Canyon NP/Lake Mead NRA likely drove vegetation characteristics of occupied and unoccupied habitats, respectively. Because there were so few unoccupied sites within the Bill Williams River NWR we could not characterize unoccupied habitat within this otherwise heavily occupied study area.

Table 4.1. Vegetation and microclimate study areas along the lower Colorado River and tributaries, 2007. Geographic areas marked with an asterisk $\left({ }^{*}\right)$ have been lumped together as "Yuma Restoration Sites" geographic area for comparative purposes. The number of randomly selected vegetation plots at occupied and unoccupied sites at each geographic study area is indicated.

\begin{tabular}{lll}
\hline \multicolumn{1}{c}{ Study Areas } & Plots in Occupied Sites & Plots in Unoccupied Sites \\
\hline Pahranagat NWR & 0 & 0 \\
Overton WMA & 0 & 0 \\
Grand Canyon NP/Lake Mead NRA & 0 & 57 \\
Havasu NWR & 10 & 10 \\
Bill Williams River NWR & 62 & 0 \\
CRIT Reservation & 0 & 0 \\
Cibola NWR & 10 & 20 \\
Picacho SRA & 0 & 0 \\
Imperial NWR* & 10 & 0 \\
Pratt Restoration* & 0 & 10 \\
Yuma West Wetlands* & 0 & 6 \\
Limitrophe & 0 & 0 \\
Gila/Colorado Rivers Confluence & 0 & 0 \\
Quigley Pond* & 12 & 0 \\
Total & 104 & 103 \\
\hline
\end{tabular}

To identify sampling points we used orthorectified aerial photographs for each study site to identify habitat boundaries. We then created a numbered list of Geographic Information System (GIS)-generated random locations (Universal Transverse Mercator [UTM] coordinates) for each site. Sampling locations were assigned to these random 
UTM coordinates. These points were then located in the field using a handheld Global Positioning System (GPS) unit and, in cases where random UTM locations were inaccessible or located in inappropriate habitat, such as marsh, an alternate random location was selected by choosing the next point on the list for that site. In addition to randomly-placed sampling plots, plots were established at each yellow-billed cuckoo nest site when the nest became inactive (i.e., when the nest fails or the nestlings fledge and leave the area of the nest).

\section{Vegetation Measures and Measurement Techniques}

\section{Characteristics of the Canopy}

We sampled vegetation characteristics for horizontal canopy cover and vertical stem density within both $5 \mathrm{~m}(16.5 \mathrm{ft})$ and $11.3 \mathrm{~m}(37.3 \mathrm{ft})$ radius plot (centered on the same point). The vegetation cover layers described below are meant to be flexible enough to describe a range of habitats of varying structural complexity. Cover was estimated as the vertical projection of vegetation from the ground, as viewed from above. We estimated cover and height measures for following horizontal vegetation strata from highest to lowest layer in the canopy: "high canopy," was defined as only that portion of the canopy >5 m (16.5 ft) tall; we defined "canopy," as the top-most continuous layer of the canopy (of any height), this is what we described as the main canopy layer; "subcanopy" layer was a distinct layer of cover below the main canopy; and we defined "shrub/saplings," as the lowest distinct layer of vegetation closest to the ground. We describe the high canopy and canopy layers together as canopy overstory. We describe the cover of sub-canopy and shrub/sapling layer together as the understory. Average canopy height was measured for each canopy layer using a clinometer based on a point in the canopy that represented the estimated average height of that layer within the $11.3 \mathrm{~m}$ $(37.3 \mathrm{ft})$ plot; lone trees that emerged far above the main canopy were not considered when estimating this average (although these trees did contribute to high canopy measurements). We used a spherical densiometer to measure cover at each layer covering

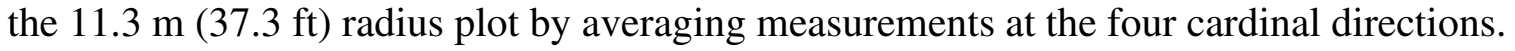
Counts from the densiometer were converted, after the field season, using the formula:

$$
\frac{\text { number of covered dots }}{96} \times 100=\text { percentcanopycover }
$$

We also determined the dominant plant species in each stratum except the high canopy. A plant was defined as dominant if it accounted for at least 40 percent of the particular vegetation layer. Two plant species were considered co-dominant when each accounted for $\geq 40$ percent of the high canopy. If no single plant species comprised $\geq 40$ percent of the high canopy, there were no dominant species. In some sites, only a single tree layer or shrub layer might be present. In others, one layer or another might be entirely absent from the site.

\section{Density of Woody Species}

To characterize the distribution and density of woody plant species, we counted the number of trees in four different DBH size classes: $<8 \mathrm{~cm}$ ( $<3.2$ inches), $8-23 \mathrm{~cm}$ (3.2-9.2 inches), 23-38 cm (9.2-15.2 inches), and $>38 \mathrm{~cm}$ (15.2 inches). Hereafter, we 
describe these four size classes as smallest, small, large, and largest, respectively. We counted trees in the two smaller size classes within the 5-m $(16.5 \mathrm{ft})$ radius plot and trees in the two larger size classes within the $11.3-\mathrm{m}(37.3 \mathrm{ft})$ radius plot. We also counted the number of shrubs and saplings by species within the $5-\mathrm{m}(16.5 \mathrm{ft})$ radius and the number of snags by species within the $11.3-\mathrm{m}(37.3 \mathrm{ft})$ radius plot. We classified live vertical stems less than $1.4 \mathrm{~m}$ (4.6 ft) in height as shrubs/saplings and those greater than $1.4 \mathrm{~m}$ as trees. We present stem count by species for the main riparian tree species: Fremont cottonwood, Goodding's willow, and tamarisk (plus honey mesquite within the Bill Williams River NWR sites). For summary purposes, we presented all tree, shrub/sapling, and snag species in total counts. For the two smaller tree size classes, we present the number of Fremont cottonwood, Goodding's willow, and tamarisk (and include honey mesquite within the Bill Williams River NWR sites) in an effort to characterize potential recruitment of these species. All sampling plots were a fixed size; thus, mean abundance also represents the relative density of each area.

Our analyses focused on comparing patterns in woody plant structure and density and the different canopy layers in occupied and unoccupied sites, among the different geographic study areas, and among sites within the Bill Williams River NWR. Vegetation sampling was conducted during August and September of 2007.

\section{Results}

\section{Yellow-billed Cuckoo Vegetation by Occupancy Status}

There were 104 vegetation plots within occupied yellow-billed cuckoo sites and 103 in unoccupied sites. Most of the occupied plots were within the Bill Williams River NWR (62 of 104; 60 percent), thus many of the patterns we observed in occupied sites were driven by the vegetation characteristics there. Most unoccupied plots were within Grand Canyon NP/Lake Mead NRA (57 of 103; 55 percent), so vegetation characteristics of unoccupied sites primarily reflect the habitat conditions there.

\section{Characteristics of the Canopy}

We detected several differences in the canopy cover and canopy plant species composition between occupied and unoccupied sites. Occupied sites had nearly twice the high canopy cover (canopy $>5 \mathrm{~m}$ in height) compared to unoccupied sites $\left(\mathrm{t}_{205}=5.0\right.$, $\mathrm{p}<0.0001$; Fig 4.1). However, there was no difference between occupied and unoccupied sites in canopy cover $\left(\mathrm{t}_{205}=0.1, \mathrm{p}=0.91\right.$; Fig. 4.1$)$ or sub-canopy cover $\left(\mathrm{t}_{205}=1.7, \mathrm{p}=\right.$ 0.08; Fig 4.1). While the shrub/sapling canopy layer was sparse compared to the high canopy, canopy, and sub-canopy layers; cover in the shrub layer was over four times greater in unoccupied sites compared to occupied sites $\left(\mathrm{t}_{205}=-4.1, \mathrm{p}<0.001\right.$; Fig 4.1). Corresponding to the differences in high canopy cover between occupied and unoccupied sites, we also found that total tree height was 70 percent higher at occupied sites compared to unoccupied sites $\left(\mathrm{t}_{205}=8.0 ; \mathrm{p}<0.001\right.$; Fig. 4.2). In general, occupied sites appear to have more developed over-stories and sparser under-stories compared to unoccupied sites, indicating the possible importance of these layers to yellow-billed cuckoos. 
While we did not record the plant species making up the high canopy layer, most species taller than $5 \mathrm{~m}(16.5 \mathrm{ft})$ across the study area were native species (cottonwood and willow; Johnson et al. pers. obs.), so high canopy was likely dominated by natives. But in the canopy layer, plots in both occupied (77 percent) and unoccupied (74 percent) sites were dominated by native species such as Fremont cottonwood and Goodding's willow. Tamarisk was the dominant canopy species at only a few occupied and unoccupied sites, 12 percent and 8 percent, respectively. At occupied sites the subcanopy was dominated by tamarisk ( 36 of 88 plots; 41 percent) or Goodding's willow (25 of 88 plots; 28 percent), while the sub-canopy of unoccupied sites was mostly tamarisk (41 of 70 plots; 59 percent). A shrub/sapling layer was relatively rare at occupied sites (17 of 104; 16 percent), but 76 percent of plots with a shrub/sapling canopy layer at occupied sites were dominated by arrowweed or seep willow. At unoccupied sites a shrub/sapling layer was more common (46 of 103; 45 percent) and most of these were dominated by tamarisk (63 percent). Based on these results, it appears that overstories made up of native Freemont cottonwood and Goodding's willow with mixed willow tamarisk sub-canopies are widespread throughout the LCR MSCP area. Habitats occupied by cuckoos were less likely to have a shrub/sapling layer. If cuckoos were in a habitat with a dense shrub/sapling layer it was typically dominated by native species (arrowweed or seep willow); cuckoos do not appear to be found in habitats with dense tamarisk shrub/sapling layer.

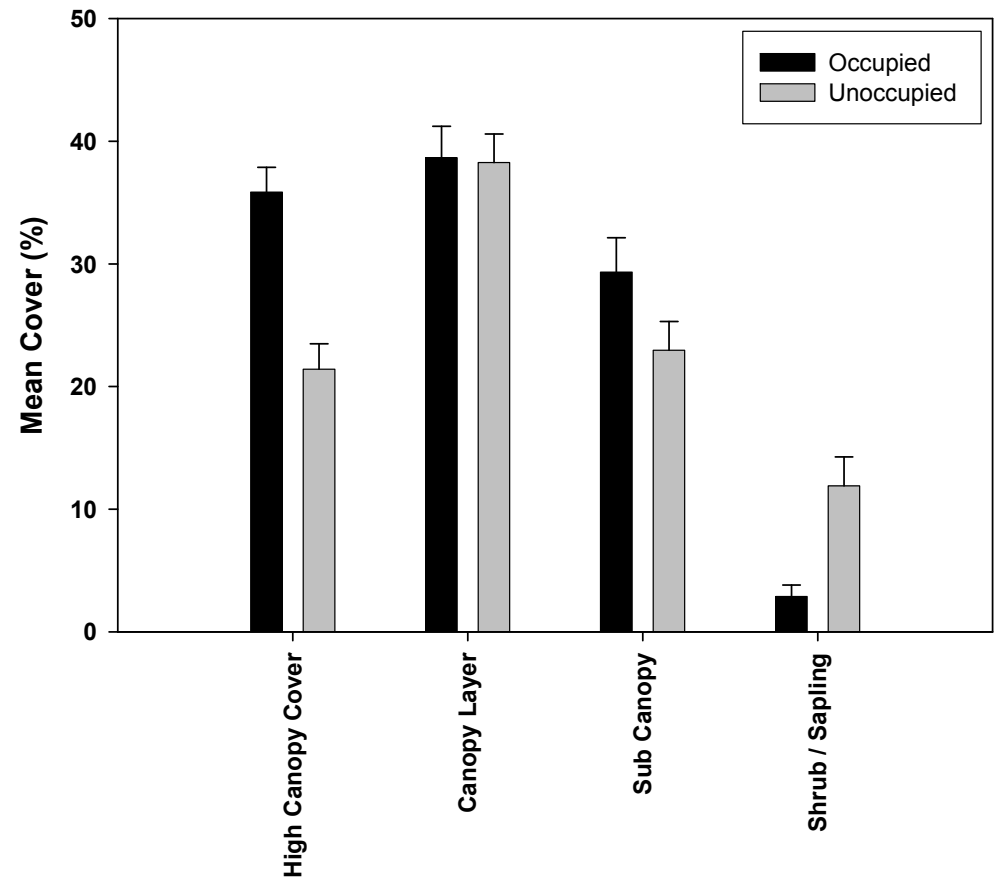

Strata Layer

Figure 4.1. Percent cover at different layers in the canopy between occupied and unoccupied sites within the LCR MSCP boundary area, 2007. Error bars represent one standard error of the mean. 


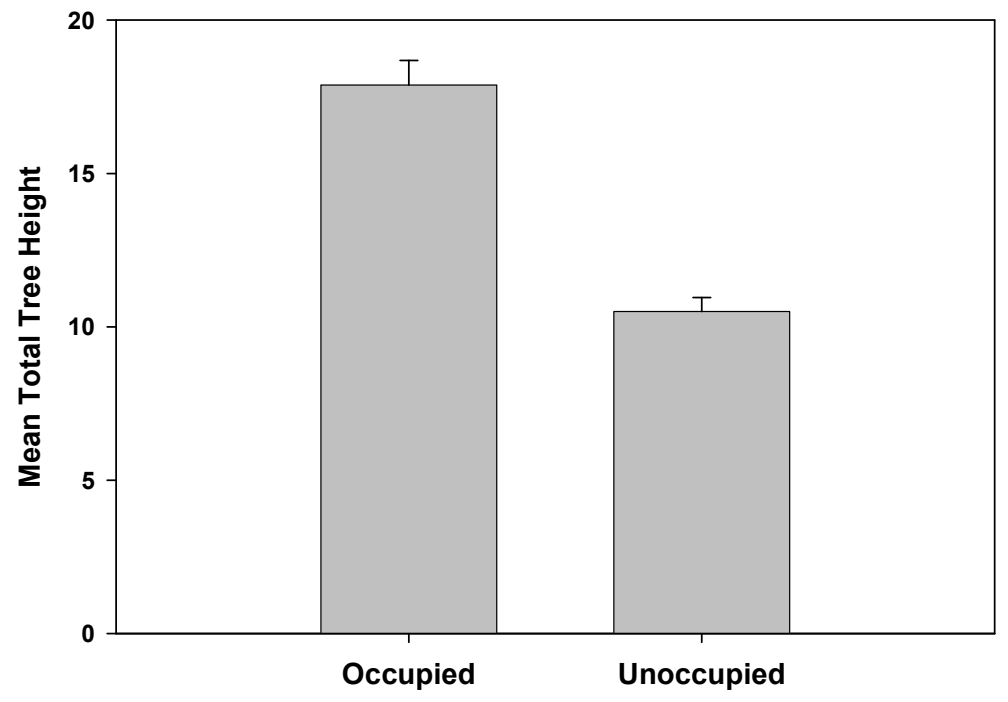

Figure 4.2. Total tree height (in meters) for occupied and unoccupied sites within the LCR MSCP boundary area, 2007. Error bars represent one standard error of the mean.

\section{Density of Woody Species}

We detected many differences in the density and composition of woody species between occupied and unoccupied sites that corresponded to some characteristics of the canopy layers. The mean density of all stems (tree, shrubs/saplings, and snags combined) was over twice as great at sites unoccupied versus occupied $\left(\mathrm{t}_{205}=-3.0 ; \mathrm{p}=0.003\right.$; Fig 4.3). Considering trees of all sizes and species and all shrub and sapling species, we found greater density at unoccupied sites (trees: $\mathrm{t}_{205}=-2.9, \mathrm{p}=0.004$; shrubs/saplings: $\mathrm{t}_{205}$ $=-2.9, \mathrm{p}=0.004$; Fig 4.3 ); however, snag density was not significantly different between occupied and unoccupied sites $\left(\mathrm{t}_{205}=-1.6, \mathrm{p}=0.11 ;\right.$ Fig 4.3$)$. 


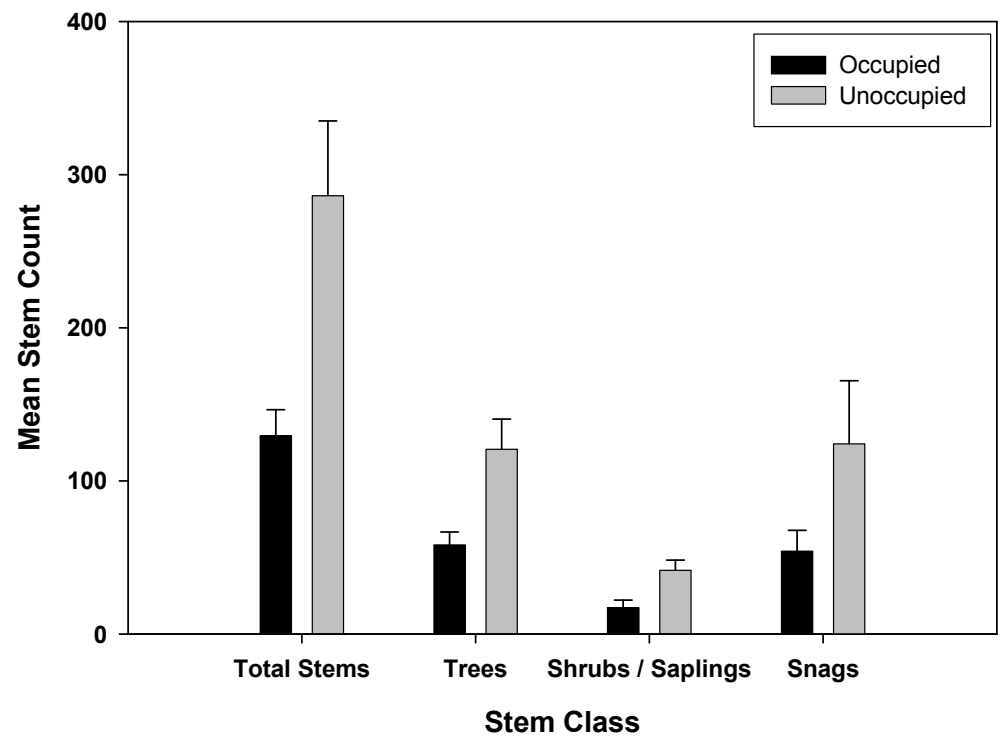

Figure 4.3. Mean total stem count at occupied and unoccupied sites within the LCR MSCP boundary area, 2007. Trees with $\mathrm{DBH}<23 \mathrm{~cm}$ and shrubs and saplings were counted within the $5 \mathrm{~m}$ plot and trees $>23 \mathrm{~cm} \mathrm{DBH}$ and snags were counted within the $11.3 \mathrm{~m}$ plot. Error bars represent one standard error of the mean.

We found that trees in the smallest size class accounted for 86 percent of total tree density in occupied sites and 94 percent at sites unoccupied, while trees in the large and largest size classes accounted for 6 percent of all trees at occupied sites and only $<1$ percent at unoccupied sites. We found that unoccupied sites had more than twice the stem density of the smallest class trees $(<8 \mathrm{~cm} \mathrm{DBH} ; 3.2$ inches $)$ as occupied sites $\left(\mathrm{t}_{205}=-3.0 ; \mathrm{p}\right.$ $=0.004 ;$ Fig. 4.4). The greater density of trees in the smallest size class in unoccupied sites is consistent with the greater cover of the shrub/sapling layer at unoccupied sites as these smaller trees likely to contribute to some of the understory cover. However, sites occupied by cuckoos had three times greater stem counts of trees in the large $(23-38 \mathrm{~cm}$ DBH; 9.2-15.2 inches) and more than twice the density of trees in the largest $(>38 \mathrm{~cm}$ DBH; 15.2 inches) size classes (large: $\mathrm{t}_{205}=5.8 ; \mathrm{p}<0.001$; largest: $\mathrm{t}_{205}=2.3 ; \mathrm{p}=0.02$; Fig. 4.4). The greater density of trees in these bigger size classes in occupied sites might correspond to differences in the characteristics of the high canopy between occupied and unoccupied sites. The stem density of small trees (8-23 cm DBH; 3.2-9.2 inches) was not different between occupied and unoccupied sites $\left(\mathrm{t}_{205}=-1.4, \mathrm{p}=0.17\right.$; Fig. 4.4).

Although the occupancy status of sites is confounded by the distribution of vegetation sampling points among the different geographic areas, it appears that the density of trees in different size classes could be a useful predictor of yellow-billed cuckoo habitat use. We did not find cuckoos using sites with high density of the smallest trees (leading to dense understory cover) but we did detect cuckoos in sites with more trees in the large and largest size classes (likely with dense high canopies). Since most of the tree density occurred in the smallest and small classes trees, we presented the stem count of three common riparian tree species (cottonwood, willow and tamarisk) for only the smallest ( $<8 \mathrm{~cm} \mathrm{DBH;} 3.2$ inches) and small ( $8-23 \mathrm{~cm} \mathrm{DBH} ; 3.2-9.2$ inches) tree size 
class. Also these young trees are the new recruits and thus likely indicate the future vegetation composition of a plot. For the smallest size class ( $<8 \mathrm{~cm} \mathrm{DBH} ; 3.2$ inches), Freemont cottonwood stem count was higher in occupied sites $\left(\mathrm{t}_{205}=2.2, \mathrm{p}=0.02\right.$; Fig. 4.5 ), while Goodding's willow and tamarisk were higher in unoccupied sites (willow: $t_{205}$ $=-2.5, \mathrm{p}=0.01$; tamarisk: $\mathrm{t}_{205}=-2.8, \mathrm{p}=0.006$; Fig. 4.5).

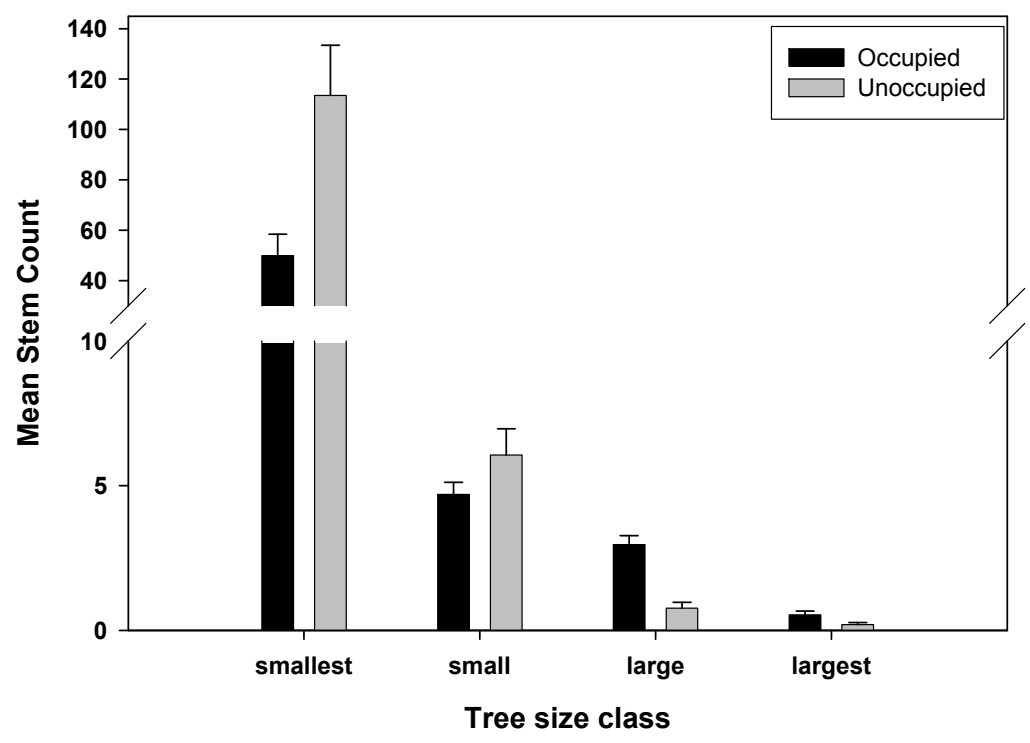

Figure 4.4. Total tree count by size class for occupied and unoccupied sites within the LCR MSCP boundary area, 2007. Note the break in the y-axis from 10-30. Trees in the smallest and small size classes were counted within the $5 \mathrm{~m}$ plot and tress in the large and largest size classes were counted within the $11.3 \mathrm{~m}$ plot. Error bars represent one standard error of the mean.

In the small size class (8-23 cm DBH; 3.2-9.2 inches), Freemont cottonwood stem count was over twice as high in unoccupied sites $\left(t_{205}=-2.3, p=0.02\right.$; Fig. 4.6), willow density was the same in occupied and unoccupied $\left(t_{205}=-0.6, p=0.53\right.$; Fig. 4.6), and mean stem count of small tamarisk trees was over 20 times higher in occupied sites $\left(\mathrm{t}_{205}=4.3, \mathrm{p}<0.001 ;\right.$ Fig. 4.6). Trees in the large and largest size class were mostly Goodding's willow at both occupied and unoccupied sites, accounting for 57 percent and 44 percent of total trees in these size classes, respectively.

In summary, these finding suggest that occupied sites have a distinct vegetative composition. Specifically, occupied cuckoo sites include (1) a tall, dense overstory composed of native tree species, where native cottonwoods and willows dominate the larger size classes; (2) a sub-canopy composed of both native and exotic species; and (3) a dense understory dominated by tamarisk in the smaller classes. 


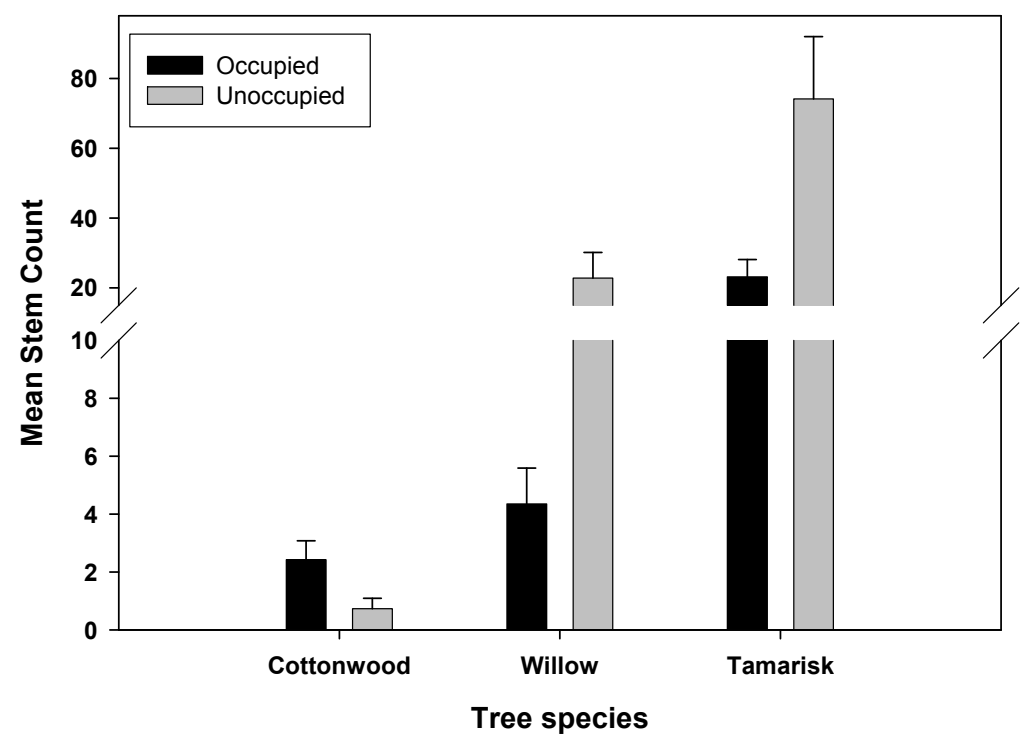

Figure 4.5. Mean stem count of smallest trees $(<8 \mathrm{~cm} \mathrm{DBH})$, in occupied versus unoccupied sites within the LCR MSCP boundary area, 2007. Note the break in the $y$-axis from 10-15. Trees in the smallest size class were counted within the $5 \mathrm{~m}$ plot. Error bars represent one standard error of the mean.

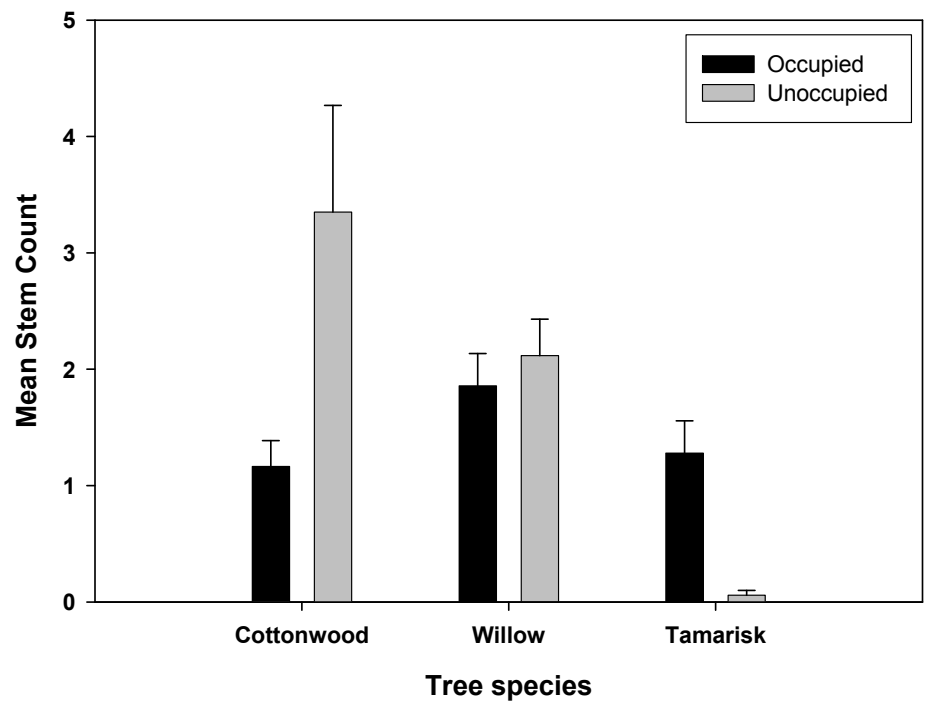

Figure 4.6. Mean stem count of small trees $(8-23 \mathrm{~cm} \mathrm{DBH})$ in occupied versus unoccupied sites within the LCR MSCP boundary area, 2007. Trees in the small size class were counted within the $5 \mathrm{~m}$ plot. Error bars represent one standard error of the mean. 


\section{Yellow-billed Cuckoo Vegetation by Geographic Area}

To examine potential geographic variation in vegetation characteristics, we measured vegetation plots at five Geographic Study Areas; Grand Canyon NP/Lake Mead NRA (57 plots), Havasu NWR (20 plots), Bill Williams River NWR (62 plots), Cibola NWR (30 plots), and the Yuma Restoration Sites (38 plots). All of the plots at the Bill Williams River NWR were occupied, none of the plots at Grand Canyon NP/Lake Mead NRA were occupied, and the other Geographic Areas had plots in both occupied and unoccupied sites (Table 4.1).

\section{Characteristics of the Canopy}

We found some differences in cover and composition of the canopy but also considerable overlap in the canopy structure among the different Geographic Study Areas. Consistent with its occupied status, cover of the high canopy $(>5 \mathrm{~m} ; 16.5 \mathrm{ft})$ was significantly greatest at Bill Williams River NWR compared to Grand Canyon NP/Lake Mead NRA, Cibola NWR, and the Yuma Restoration sites; however, the high canopy cover at Havasu NWR was not statistically different from the other Geographic Areas $\left(\mathrm{F}_{4,202}=11.8, \mathrm{p}<0.0001\right.$; Fig. 4.7). Because there were no differences in the cover of the canopy or sub-canopy layer between occupied or unoccupied sites, these variables might not be important in distinguishing suitable habitats for yellow-billed cuckoos; however, we found differences among the study areas in both of these parameters. The only differences in canopy cover among study areas were between the Cibola NWR and Grand Canyon NP/Lake Mead NRA $\left(\mathrm{F}_{4,202}=2.6 ; \mathrm{p}=0.03\right.$; Fig. 4.7). The sub-canopy cover at the Grand Canyon NP -Lake Mead NRA and Bill Williams River NWR sites was significantly greater than at the Havasu and Cibola NWR sites $\left(\mathrm{F}_{4,202}=9.8 ; \mathrm{p}<0.001\right.$; Fig. 4.7). Grand Canyon NP/Lake Mead NRA and Havasu NWR had the highest shrub/sapling cover $\left(\mathrm{F}_{4,202}=8.1, \mathrm{p}<0.0001\right.$; Fig. 4.7), but all other study areas were statistically indistinguishable in total shrub cover.

Examining the different Geographic Study Areas from northernmost (Grand Canyon NP/Lake Mead NRA) to the southernmost (Yuma Restoration Sites), we did not detect any consistent pattern in the vegetation composition of the different canopy strata layers. The canopy layer was dominated by primarily by Goodding's willow, Athel tamarisk, or Freemont cottonwood. We found tamarisk or Goodding's willow as the dominant species in the sub-canopy layer although many plots did not have a developed sub-canopy layer. Overall shrub/sapling layers were not well developed across all study areas, but the dominance of tamarisk cover in the understory of Grand Canyon NP/Lake Mead NRA was an exception (Table 4.2).

Mean total tree height varied by Geographic Area $\left(\mathrm{F}_{4,202}=42.3, \mathrm{p}<0.0001\right.$; Fig. 4.8), with the tallest trees found at Bill Williams River NWR. Larger trees were usually Freemont cottonwoods or Goodding's willows, probably due to their morphology. 


\section{Density of Woody Species}

We found large differences among Geographic Study Areas in the density of woody species, primarily driven by the high stem counts at Grand Canyon NP/Lake Mead NRA. Grand Canyon NP/Lake Mead NRA had significantly greater total stem count (over 3.5 times greater) compared to all other areas, while all other areas were not statistically different from one another $\left(\mathrm{F}_{4,202}=11.8 ; \mathrm{p}<0.0001 ;\right.$ Fig 4.9). Grand Canyon NP/Lake Mead NRA had twice the mean tree density as other study areas $\left(\mathrm{F}_{4,202}=9.6\right.$, $\mathrm{p}<0.0001$; Fig. 4.10) and nearly 3.5 times the shrub/sapling density $\left(\mathrm{F}_{4,202}=8.4, \mathrm{p}<0.001\right.$; Fig. 4.9). We found that the density of snags at Grand Canyon NP/Lake Mead NRA was over six times greater than Bill Williams River NWR and the Yuma Restoration Sites $\left(\mathrm{F}_{4,202}=3.8, \mathrm{p}=0.005\right.$; Fig. 4.9). There were no significant differences in snag density among the other study areas. The greater number of snags at Grand Canyon NP/Lake Mead NRA is probably due to the high number of dead trees due to the lower water levels in 2007.

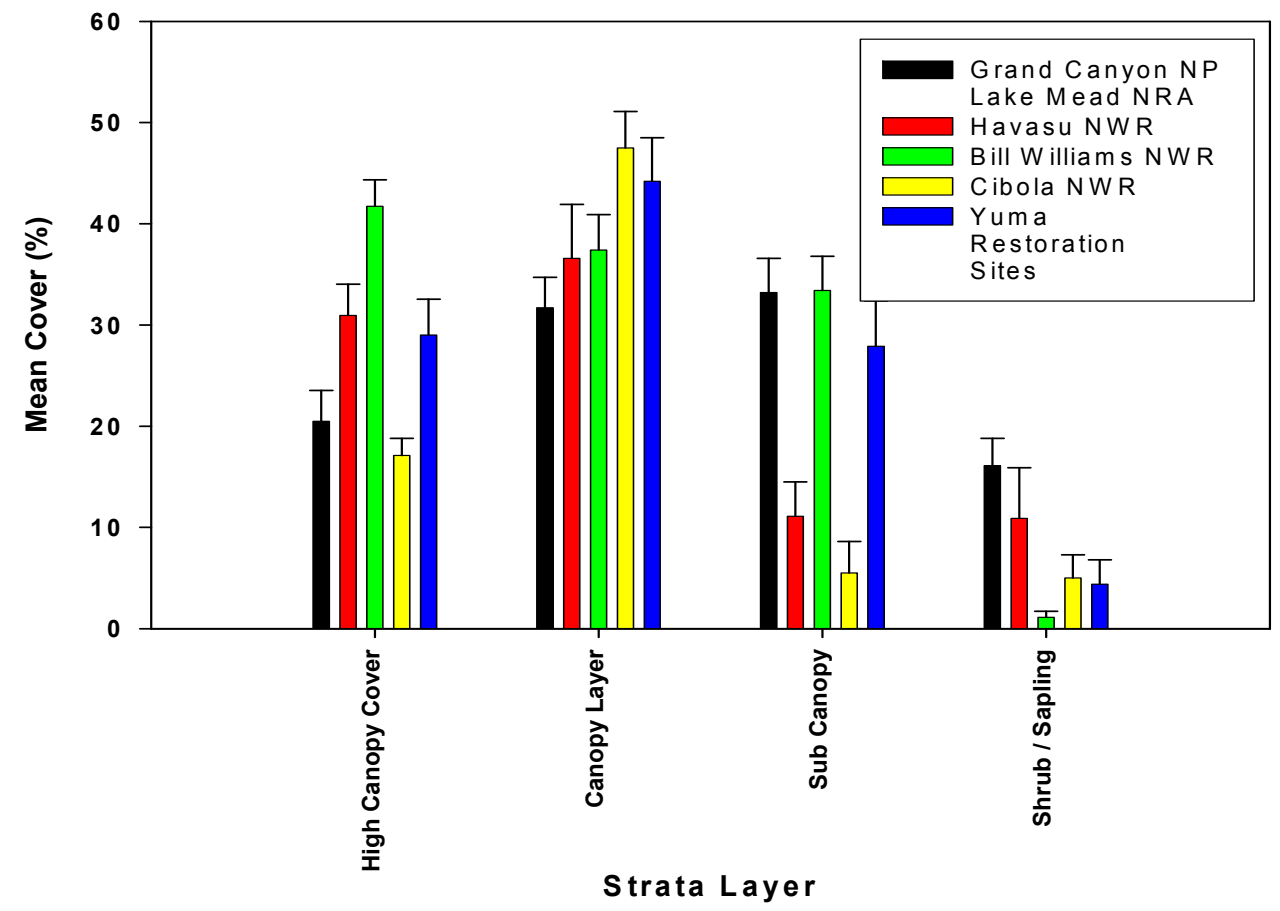

Figure 4.7. Canopy cover for high canopy $>5 \mathrm{~m}$, canopy layer, sub canopy, and shrub/sapling layer at each Geographic Area (Grand Canyon NP/Lake Mead NRA, Havasu NWR, Bill Williams River NWR, Cibola NWR and Yuma Restoration Sites), 2007. Error bars represent one standard error of the mean. 
Table 4.2. Dominant species by layer among geographic areas. Values indicate the percent of total plots within study areas that had indicated species as the dominant species.

\begin{tabular}{|c|c|c|c|}
\hline Site & Canopy & Sub-canopy & Shrub/sapling \\
\hline $\begin{array}{l}\text { Grand Canyon NP/Lake } \\
\text { Mead NRA }\end{array}$ & $\begin{array}{l}\text { Goodding's willow } \\
(74 \%)\end{array}$ & Tamarisk $(76 \%)$ & Tamarisk $(76 \%)$ \\
\hline Havasu NWR & $\begin{array}{l}\text { Freemont cottonwood } \\
(40 \%) \text { Athel tamarisk } \\
(39 \%)\end{array}$ & $\begin{array}{l}\text { Equally dominated by } \\
\text { Athel tamarisk, } \\
\text { Goodding's willow, } \\
\text { Screwbean and honey } \\
\text { mesquite }\end{array}$ & $\begin{array}{l}\text { Only } 50 \% \text { of plots had } \\
\text { layer }\end{array}$ \\
\hline $\begin{array}{l}\text { Bill Williams River } \\
\text { NWR }\end{array}$ & $\begin{array}{l}\text { Goodding's willow } \\
(66 \%)\end{array}$ & $\begin{array}{l}\text { Tamarisk (59\%) } \\
\text { Goodding's willow } \\
(28 \%)\end{array}$ & $\begin{array}{l}\text { Only } 5 \% \text { of plots had } \\
\text { layer }\end{array}$ \\
\hline Cibola NWR & $\begin{array}{l}\text { Freemont cottonwood } \\
\text { and Goodding's willow } \\
(67 \%)\end{array}$ & $\begin{array}{l}\text { Only } 20 \% \text { of plots had } \\
\text { layer }\end{array}$ & $\begin{array}{l}\text { Only } 23 \% \text { of plots had } \\
\text { layer }\end{array}$ \\
\hline Yuma Restoration Sites & $\begin{array}{l}\text { Freemont cottonwood } \\
(67 \%)\end{array}$ & $\begin{array}{l}\text { Only } 40 \% \text { of plots had } \\
\text { layer }\end{array}$ & $\begin{array}{l}\text { Only } 13 \% \text { of plots had } \\
\text { layer }\end{array}$ \\
\hline
\end{tabular}

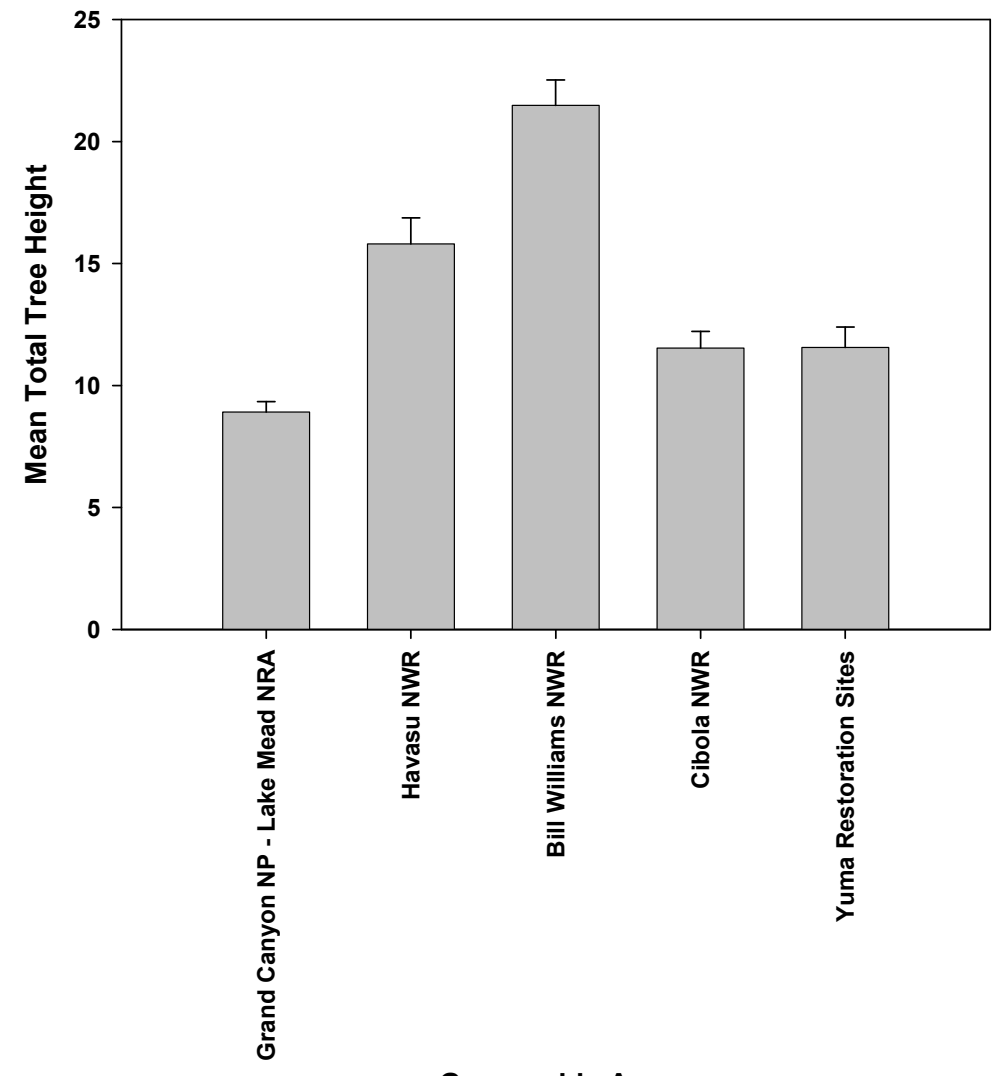

Geographic Area

Figure 4.8. Mean total tree height (in meters) by Geographic Area (Grand Canyon NP/Lake Mead NRA, Havasu NRA, Bill Williams River NWR, Cibola NWR and Yuma Restoration Sites), 2007. Error bars represent one standard error of the mean. 


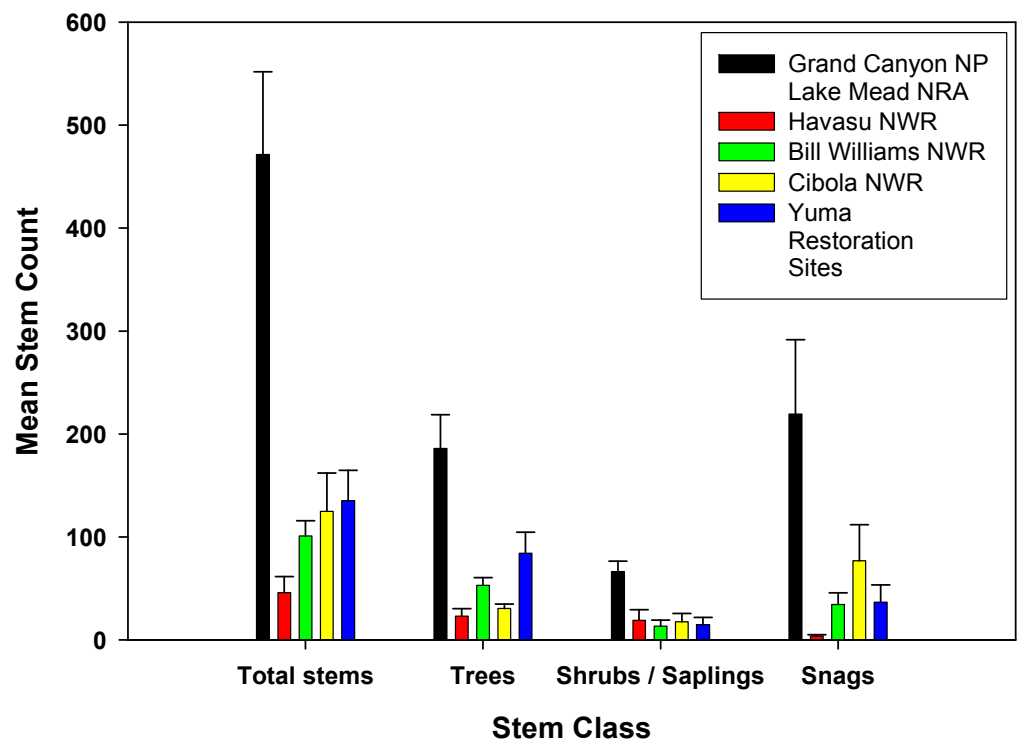

Figure 4.9. Mean stem count by total stems, trees, shrubs/saplings, and snags for all five Geographic Areas (Grand Canyon NP/Lake Mead NRA, Havasu NRA, Bill Williams River NWR, Cibola NWR and Yuma Restoration Sites), 2007. Trees with DBH $<23 \mathrm{~cm}$ and shrubs and saplings were counted within the $5 \mathrm{~m}$ plot and trees $>23 \mathrm{~cm} \mathrm{DBH}$ and snags were counted within the $11.3 \mathrm{~m}$ plot. Error bars represent one standard error of the mean.

Trees in the smallest and small size classes made up most of the tree density at all Geographic Areas (Fig 4.10). We examined the mean density of cottonwoods, willows, and tamarisk trees in these size classes. Recruitment of new trees into the different study areas can be best examined in the smallest and small size classes. The mean number of cottonwoods varied among Geographic Areas for the smallest $(\mathrm{F} 4,202=3.2, \mathrm{p}=0.01$; Fig. 4.11) and small (F4,202 = 19.9, p $<0.001$; Fig 4.12) size classes. For the smallest size class of cottonwoods, density at the Bill Williams River NWR and Yuma Restoration Sites was greater than at the Grand Canyon NP/Lake Mead NRA sites; but mean density of the smallest size class cottonwoods was not statistically different at other sites. The Cibola NWR had over 5-times the density of cottonwood trees in the small size class compared to other study areas. However, because cottonwoods were relatively rare on the landscape (especially compared to willow and tamarisk), cottonwood density was not well represented in the measurements of cover at any layer.

The mean number of Goodding's willow also varied by Geographic Area in the smallest $\left(\mathrm{F}_{4,202}=4.5, \mathrm{p}=0.002\right.$; Fig. 4.11) and small $\left(\mathrm{F}_{4,202}=4.6, \mathrm{p}=0.001\right.$; Fig. 4.12) tree size classes. The density of the smallest size class of willow trees was greater at Grand Canyon NP/Lake Mead NRA compared to Bill Williams River NWR, Cibola NWR, and Yuma Restoration Sites; but Havasu NWR was not statistically different from any Geographic Area. There were more willows in the small size class at Grand Canyon NP/Lake Mead NRA compared to Havasu and Cibola NWR, but there was no difference among the other Geographic Areas. Because willows are present at all sites in the smallest and small size classes, the potential exists that as these trees mature, the 
vegetation structure at any of these sites might become suitable for yellow-billed cuckoos, if in fact tall willow over-stories prove to be important for this species.

Tamarisk in the smallest size class were almost four-times as dense at Grand Canyon NP/Lake Mead NRA compared to other Geographic Areas $\left(\mathrm{F}_{4,202}=8.1, \mathrm{p}<0.0001\right.$; Fig. 4.11) and tamarisk in the small size class were over five-times as dense at the Bill Williams River NWR compared to other Geographic Areas $\left(\mathrm{F}_{4,202}=8.2, \mathrm{p}<0.0001\right.$; Fig 4.12). Although there we no cuckoos detected at any of the Grand Canyon NP/Lake Mead NRA sites in 2007, it is not clear that this was because of the high density of tamarisk in the smallest size class and associated dense cover of the shrub/sapling layer. It appears that cuckoos tolerate and maybe favor some tamarisk component based on the high density of small sized class tamarisk at the Bill Williams River NWR and the high degree of use of that study area by yellow-billed cuckoos.

The dominant tree species in the large and largest size classes also varied among Geographic Area. At the Grand Canyon NP/Lake Mead NRA all trees in the large and largest size classes were Goodding's willow. At Havasu NWR 70 percent of trees in the large and largest size classes were Athel tamarisk. At the Bill Williams River NWR 69 percent of trees in the large and largest size classes were Goodding's willow, and at both Cibola NWR and Yuma Restoration sites Fremont cottonwood were the dominant trees in the large and largest size classes making up 81 percent and 74 percent of trees in these sizes classes at these two areas, respectively. In general trees of the large and largest size classes corresponded to the dominant tree species and the high canopy and canopy layer of each study area indicating the role trees of these sizes play in determining vegetation structure. 


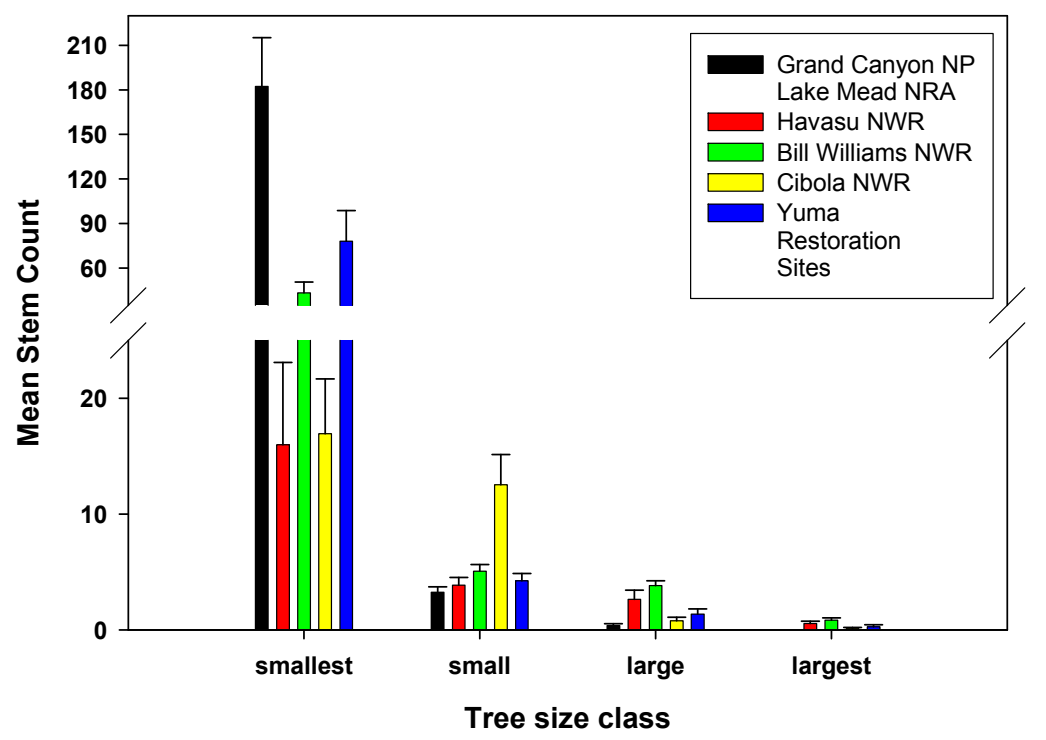

Figure 4.10. Total tree count by size class by Geographic Area (Grand Canyon NP/Lake Mead NRA, Havasu NRA, Bill Williams River NWR, Cibola NWR and Yuma Restoration Sites), 2007. Note the break in the $y$-axis between 25-35. Trees in the smallest and small size classes were counted within the $5 \mathrm{~m}$ plot and tress in the large and largest size classes were counted within the $11.3 \mathrm{~m}$ plot. Error bars represent one standard error of the mean. 


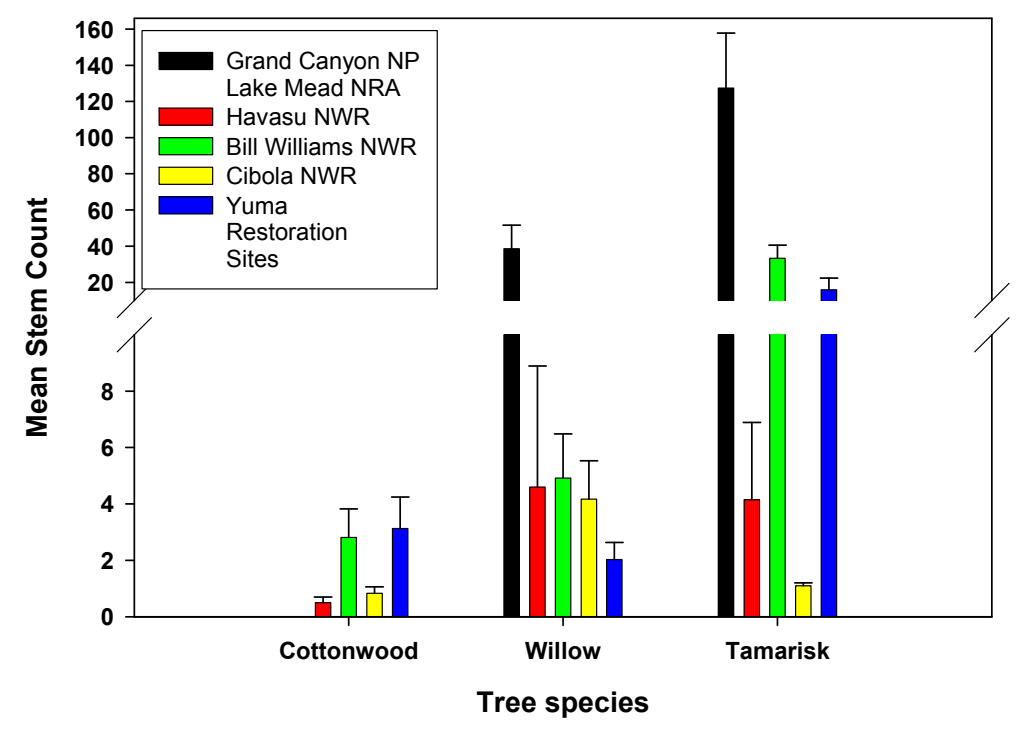

Figure 4.11. Mean stem count of smallest trees by Geographic Area. (Grand Canyon NP/Lake Mead NRA, Havasu NRA, Bill Williams River NWR, Cibola NWR and Yuma Restoration Sites), 2007. Note the break in the $y$-axis at 10 and the different scales above and below the break. Trees in the smallest size class were counted within the $5 \mathrm{~m}$ plot. Error bars represent one standard error of the mean.

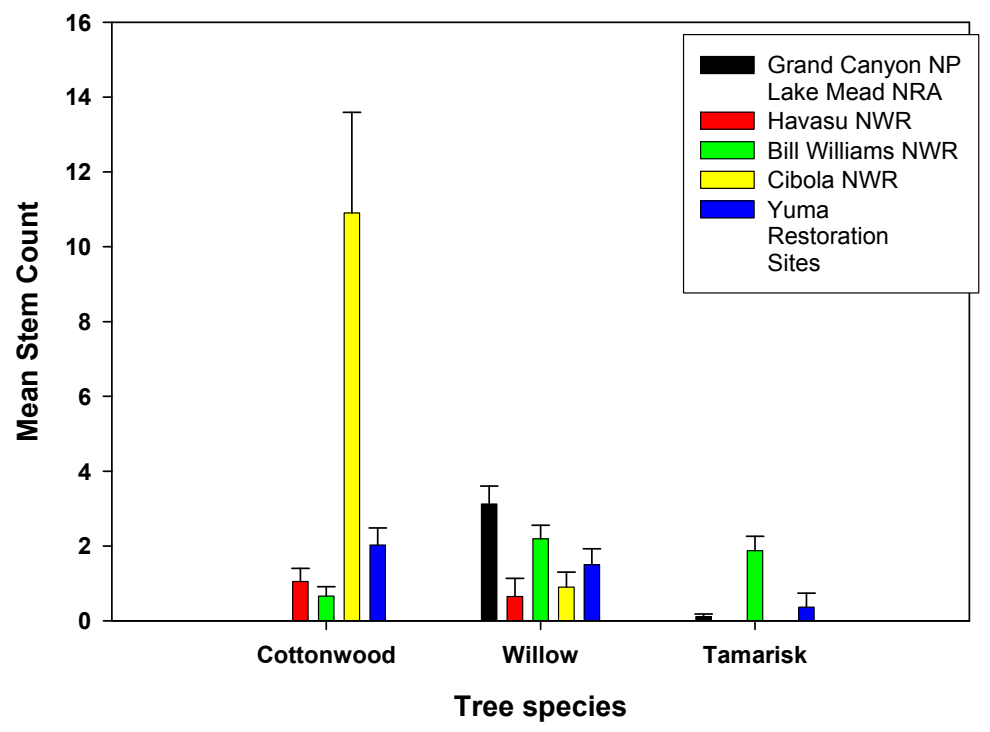

Figure 4.12. Mean stem count of small trees by Geographic Area. (Grand Canyon NP/Lake Mead NRA, Havasu NRA, Bill Williams River NWR, Cibola NWR and Yuma Restoration Sites), 2007. Trees in the small size class were counted within the $5 \mathrm{~m}$ plot. Error bars represent one standard error of the mean. 


\section{Yellow-billed Cuckoo Vegetation at Bill Williams River NWR Sites}

At the Bill Williams River NWR we measured the vegetation characteristics of three sites_- Mineral Wash $(\mathrm{n}=20)$, Big Bend $(\mathrm{n}=21)$, and Sandy Wash $(\mathrm{n}=18)$ - in order to examine the variation within the Geographic Study Area that accounted for the majority of cuckoo detections. All of these sites were considered occupied at high density by yellow-billed cuckoos and together accounted for 44 percent of all survey detections at Bill Williams River NWR.

\section{Characteristics of the Canopy}

There was no difference among sites in mean canopy height $\left(\mathrm{F}_{2.56}=0.4, \mathrm{p}=0.66\right.$; Fig 4.13), which ranged from $20.5 \mathrm{~m}-22.8 \mathrm{~m}$. High canopy cover ( $>5 \mathrm{~m}$ high) varied among the three sites, with Mineral Wash and Sandy Wash both having significantly greater high canopy cover compared to Big Bend $\left(\mathrm{F}_{2,56}=8.1, \mathrm{p}=0.008\right.$; Fig. 4.14). Canopy cover at Mineral Wash was significantly greater than Big Bend, but the canopy cover at Sandy Wash was not statistically different from either site $\left(\mathrm{F}_{2,56}=5.9, \mathrm{p}=0.005\right.$; Fig. 4.14). Mean cover in the sub-canopy layer differed among the three sites $\left(\mathrm{F}_{2,56}=5.8\right.$, $\mathrm{p}=0.005$; Fig. 4.14), with the sub-canopy cover of Sandy Wash over twice that of Big Bend, but Mineral Wash was not statistically different in sub-canopy cover from either site. There were no differences in the mean cover of the shrub layer among the different sites at the Bill Williams River NWR $\left(\mathrm{F}_{2,56}=1.4, \mathrm{p}=0.25\right.$; Fig. 4.14). Because these three sites account for 57 percent of vegetation plots in occupied sites, the mean values of the canopy characteristics were similar to overall mean values of all occupied sites.

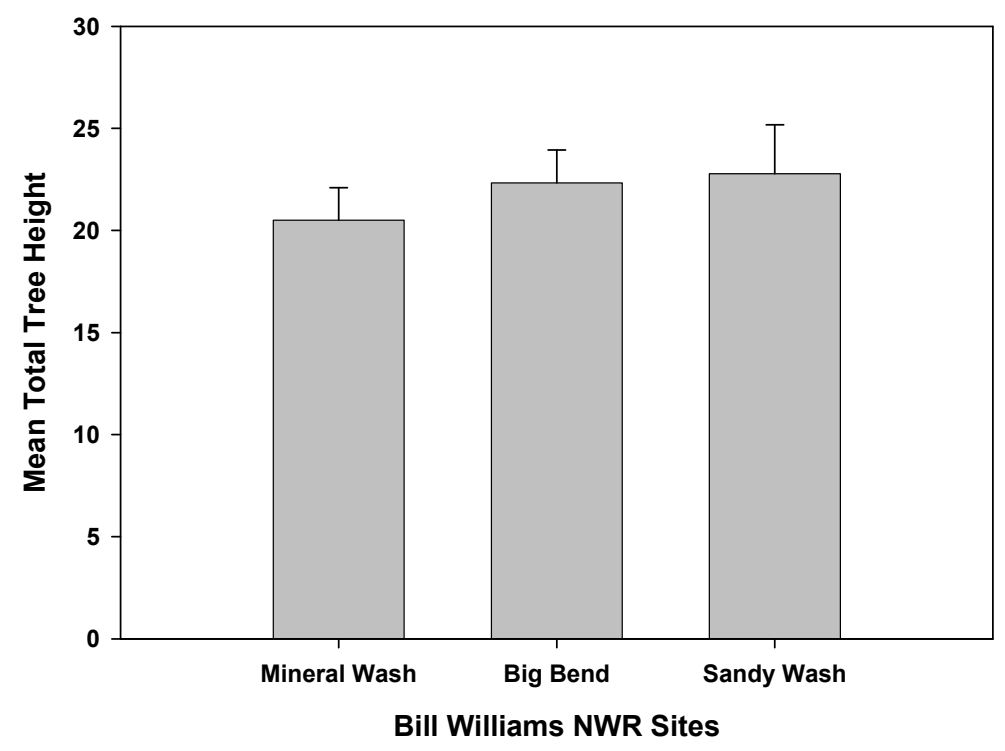

Figure 4.13. Mean total tree height (in meters) at Bill Williams River NWR sites (Mineral Wash, Big Bend and Sandy Wash), 2007. Error bars represent one standard error of the mean. 


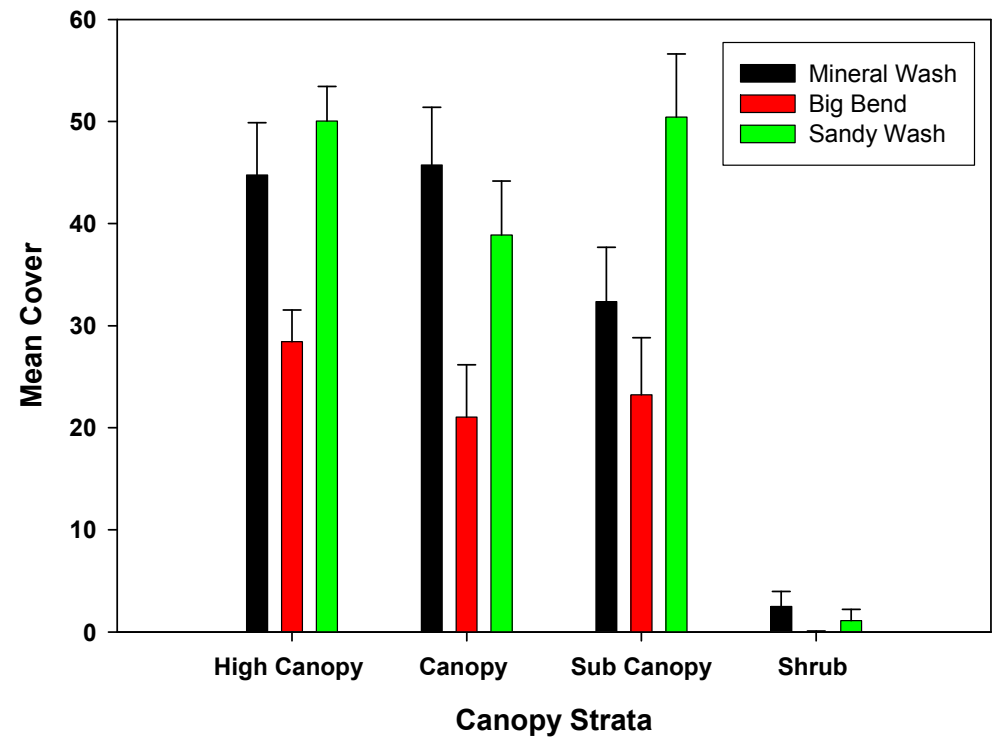

Figure 4.14. Mean percent canopy cover of different layer of canopy strata at Bill Williams River NWR sites (Mineral Wash, Big Bend and Sandy Wash), 2007. Error bars represent one standard error of the mean.

At all Bill Williams River NWR sites the canopy layer was dominated by Goodding's willow, like most sites in the entire study area and accounted for the dominant species at 70 percent of plots at Mineral Wash, 57 percent of plots at Big Bend, and 72 percent of plots at Sandy Wash. The sub-canopy layer at Mineral Wash had tamarisk as the dominant species on 50 percent of plots. The sub-canopy at Big Bend was approximately equally dominated by tamarisk and Goodding's willow on 43 percent and 38 percent of plots, respectively. Almost all plots at Sandy Wash had tamarisk as the dominant sub-canopy species (94 percent). The shrub layer was absent on most plots within the Bill Williams River NWR (a distinct shrub layer was only present on 3 of the 62 total plots; 5 percent). The presence of tamarisk in the sub-canopy at these sites that account for many of the cuckoo detections at the Bill Williams River NWR indicates that cuckoos are able to use habitats with some exotic component, although the dense overstories of tall Goodding's willow and sparse under-stories might be important factors in yellow-billed cuckoo habitat selection.

\section{Density of Woody Species}

We detected differences in the total density of woody species, but it was primarily driven by the high number of snags at Sandy Wash. Total stem density at Sandy Wash was over three-times as great as Big Bend, but stem density at Mineral Wash was not statistically different from either site $\left(\mathrm{F}_{2,56}=5.6, \mathrm{p}=0.006\right.$; Fig. 4.15). Density of trees and shrub/saplings were not significantly different among the three sites (trees: $\mathrm{F}_{2,56}=1.0$, $p=0.38$; shrubs/saplings: $F_{2,56}=1.1, p=0.32$; Fig. 4.15). However, Sandy Wash had almost 10-times the snag density as Mineral Wash and Big Bend $\left(\mathrm{F}_{2,56}=7.2, \mathrm{p}=0.002\right.$; Fig. 4.15). 


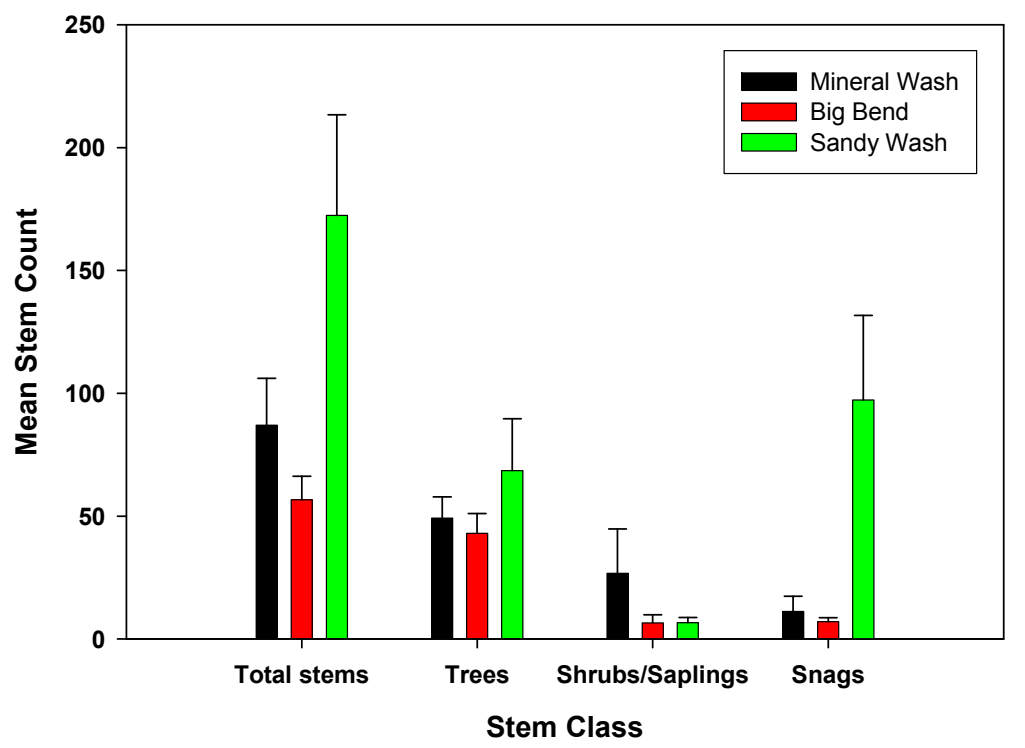

Figure 4.15. Mean stem count by stem class at Bill Williams River NWR sites (Mineral Wash, Big Bend and Sandy Wash), 2007. Trees with DBH $<23 \mathrm{~cm}$ and shrubs and saplings were counted within the $5 \mathrm{~m}$ plot and trees $>23 \mathrm{~cm}$ DBH and snags were counted within the $11.3 \mathrm{~m}$ plot. Error bars represent one standard error of the mean.

The mean density of trees in the four different size classes did not vary among the sites (smallest trees: $\mathrm{F}_{2,56}=0.9, \mathrm{p}=0.41$; small trees: $\mathrm{F}_{2,56}=0.1, \mathrm{p}=0.89$; large trees: $\mathrm{F}_{2,56}$ $=0.1, \mathrm{p}=0.87$; largest trees: $\mathrm{F}_{2.56}=0.9, \mathrm{p}=0.42 ;$ Fig. 4.16). Much like the other study sites, most trees were in the smallest and small size classes' at all three sites. At Mineral Wash 91 percent of trees were either in the smallest or small size classes, 89 percent of trees at Big Bend fell into the smallest and small size classes, and at Sandy Wash 93 percent of trees were in the smallest and small size classes. Of trees that were in the large and largest size classes, most of these were Goodding's willow at all sites: 82 percent at Mineral Wash, 72 percent at Big Bend, and 56 percent at Sandy Wash.

We found no significant differences in the stem density of the most common tree species (cottonwood, Goodding's willow, honey mesquite, and tamarisk) in the smallest size class among the three Bill Williams River NWR sites (cottonwood: $\mathrm{F}_{2,56}=1.1, \mathrm{p}=$ 0.35; willow: $\mathrm{F}_{2,56}=1.0, \mathrm{p}=0.37$; mesquite: $\mathrm{F}_{2,56}=0.3, \mathrm{p}=0.77$; tamarisk: $\mathrm{F}_{2.56}=1.6, \mathrm{p}=$ 0.21 ; Fig. 4.17, or in the small size class (cottonwood: $F_{2.56}=1.3, p=0.28$; willow: $F_{2.56}=$ $0.8, p=0.45$; mesquite: $F_{2.56}=0.7, p=0.50$; tamarisk: $F_{2.56}=1.7, p=0.19$; Fig. 4.18) The similarity in the density of trees in different size classes and different species might be in part due to the geographic proximity. 


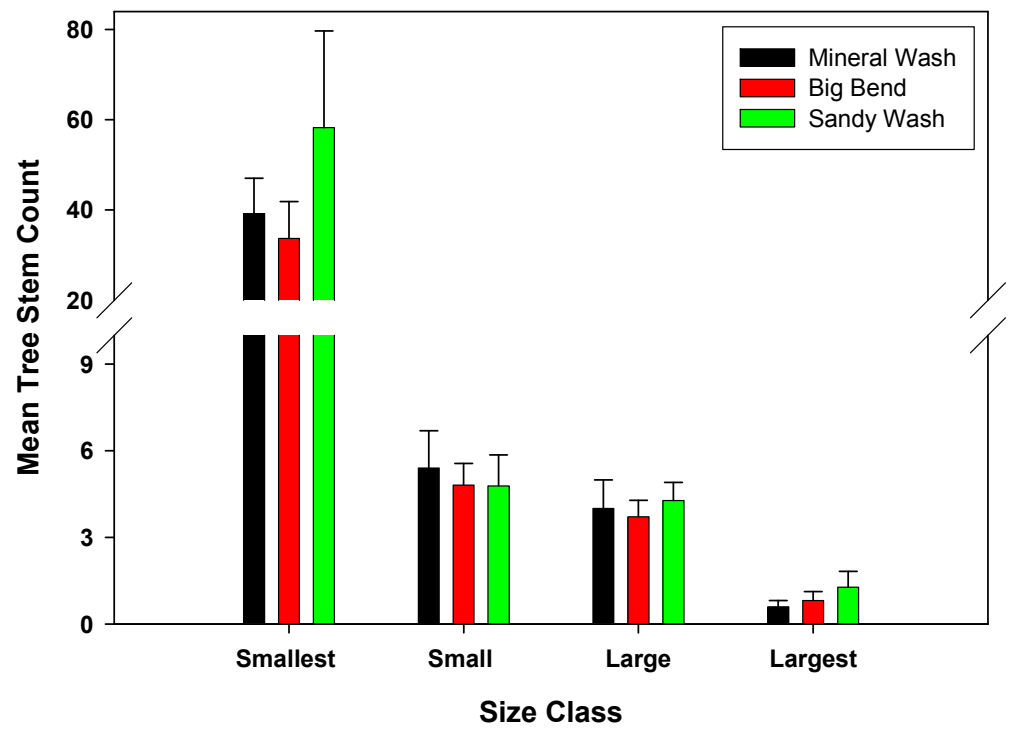

Figure 4.16. Total tree count by size class at Bill Williams River NWR sites (Mineral Wash, Big Bend and Sandy Wash), 2007. Note the break in the y-axis between 10-20. Trees in the smallest and small size classes were counted within the $5 \mathrm{~m}$ plot and tress in the large and largest size classes were counted within the $11.3 \mathrm{~m}$ plot. Error bars represent one standard error of the mean. 


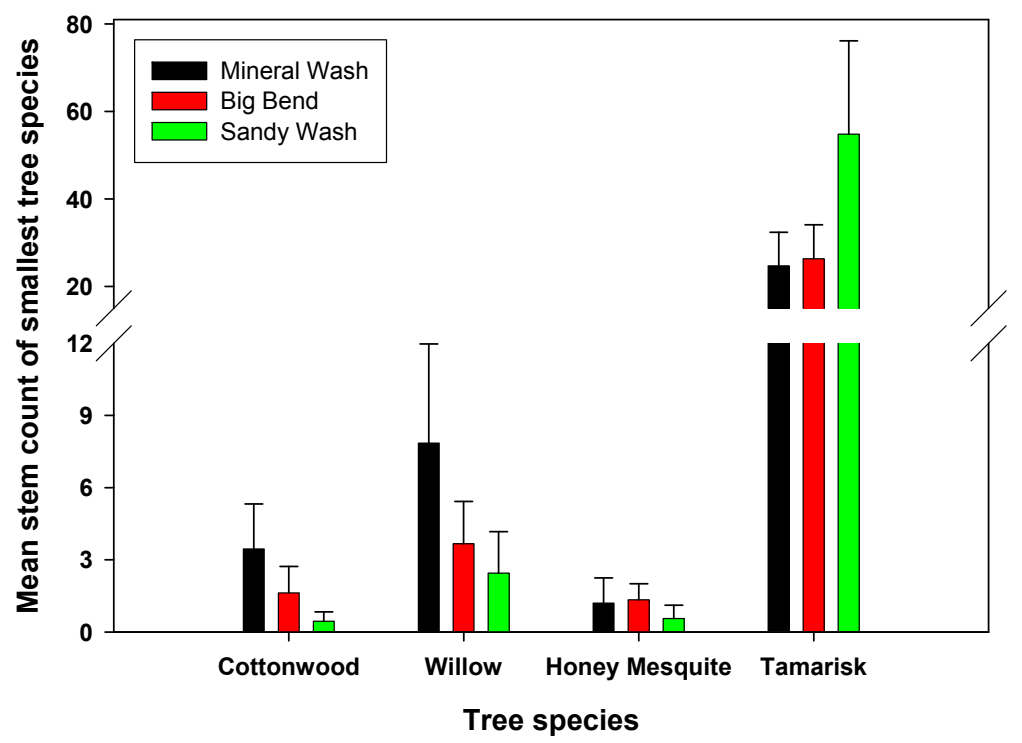

Figure 4.17. Mean stem count by of trees in the smallest size class at Bill Williams River NWR sites (Mineral Wash, Big Bend and Sandy Wash), 2007. Note the break in the y-axis between 12-20 and the different scales above and below the break. Trees in the smallest size class were counted within the $5 \mathrm{~m}$ plot. Error bars represent one standard error of the mean.

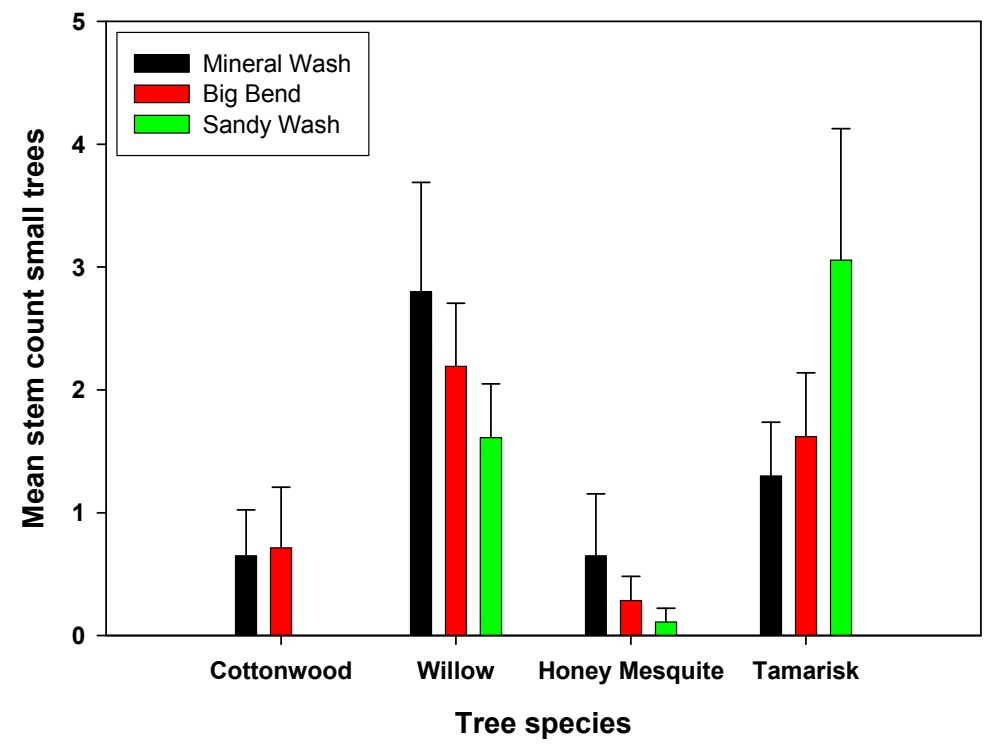

Figure 4.18. Mean stem count by major tree species in small size class at Bill Williams River NWR (Mineral Wash, Big Bend and Sandy Wash), 2007. Trees in the small size class were counted within the $5 \mathrm{~m}$ plot. Error bars represent one standard error of the mean. 


\section{Discussion}

Our characterization of vegetation at yellow-billed cuckoo survey sites for 2007 was a follow up to our preliminary analysis conducted in 2006 . We were able to refine our methods in order to more accurately represent the vegetation characteristics of yellow-billed cuckoo habitat. In 2007, we compared habitat characteristics in: (1) yellowbilled cuckoo occupied areas versus unoccupied, (2) Geographic Areas (e.g. Cibola NWR) of the study area, and (3) more closely investigated the characteristics of sites within the heavily occupied Bill Williams River NWR. The dominant tree species at our cuckoo survey sites were cottonwood, willow, and tamarisk. Tamarisk was the most common tree due to the abundance of trees in the smallest size class. Trees in large and larger size classes were usually cottonwoods or willows. Mesquite was not regularly encountered at most sites we sampled.

\section{Vegetation by Cuckoo Occupancy Status}

We attempted to stratify vegetation sampling plots across the different Geographic Areas to include sites occupied by yellow-billed cuckoos and those that did not have cuckoos. We based this on occupancy patterns observed in 2006. Unfortunately, yellow-billed cuckoo detection patterns in 2007 were not consistent with previous years, resulting in most of our occupied sampling plot being within the Bill Williams River NWR and most of our unoccupied sampling plots within the Grand Canyon NP/Lake Mead NRA. While this might have skewed the vegetation characteristic statistics towards these two areas, we were able to observe some general patterns between occupied and unoccupied sites.

Sites that were occupied by yellow-billed cuckoos in 2007 in general had higher canopies, denser cover in the upper layers of the canopy, and sparse shrub layers compared to unoccupied sites. This could indicate that cuckoos prefer areas with tall dense canopies for nesting with an open understory for foraging activities. Also areas with open under-stories may have fewer terrestrial predators. The upper layer of the canopy was consistently dominated by native riparian tree species (Fremont cottonwood and Goodding's willow) at both occupied and unoccupied habitats. The sub-canopy of occupied sites was typically either tamarisk or Goodding's willow. A distinct shrub/sapling layer was rare at occupied sites, but when present, this layer was dominated by native arrowweed or seep willow. At unoccupied sites the sub-canopy and shrub layers were consistently dominated by dense tamarisk.

The density of woody species was consistently higher at unoccupied sites, except for stems in the snag class, which we found in equal numbers in occupied and unoccupied sites. For trees, the greater density in the unoccupied sites was driven by trees in the smallest size class, and trees in this class were the most abundant across the entire study area. Trees in the large and largest size classes were more numerous in occupied sites, and consistent with the dominant canopy layer across all occupancy classes, these trees were generally Goodding's willow. However, in both occupied and unoccupied sites there was a mosaic of native and exotic tree species in the smallest and small size classes, indicating that cuckoos are able to use habitats that have exotic components.

In 2006, occupied sites had greater canopy cover driven by denser low and midcanopies (Johnson et al. 2007). However, we found in 2007 that the differences between canopies in occupied and unoccupied sites were due to difference at higher canopy strata. Also in 2007, the canopies at both occupied and unoccupied sites were dominated by 
native species, while in 2006 only occupied sites were more consistently dominated by native species. Consistent between the two years was the greater tree density in unoccupied sites. Some of the difference we observed between years might be due to difference in the refined vegetation sampling methodology we used in 2007 and the different sites we measured due to changes in their occupancy status. Additional research examining characteristics of sites occupied by yellow-billed cuckoos and sites unoccupied is necessary to determine consistent annual patterns of vegetation characteristics in these riparian habitats.

\section{Vegetation by Geographic Area}

Among the different Geographic Study Areas, we found some differences in the cover at various canopy strata, but also instances of considerable overlap. The canopy layers among Geographic Areas were dominated by different tree species, likely driven by the histories of the study areas and also the degree of vegetation management that occurs at some sites (i.e., native plant restoration and tamarisk removal). The large differences in the density of woody species among the different study areas was largely due to the high number of stems counted on vegetation plots with the Grand Canon NP/Lake Mead NRA compared to other study areas. At all of the study sites the most numerous trees were those in the smallest and small size classes and there was high variation in the specific composition of the dominant riparian tree species among the different areas. In general, the species of the dominant trees in the large and largest size class corresponded to the dominant species in the upper canopy layer at each study area. The wide variety of canopy structures present within the LCR MSCP boundary area indicates that yellow-billed cuckoos have a wide range of habitats to select from when arriving on the breeding grounds. However in 2007, the majority of detections were within the Bill Williams River NWR, suggesting that within the LCR MSCP boundary, habitats with tall dense over-stories of Goodding's willow and Freemont Cottonwood, sub-canopies with willow and tamarisk components, and sparse under-stories are most suitable for yellow-billed cuckoos.

In 2006, we compared the vegetation characteristics among Grand Canyon NP/Lake Mead NRA, Bill Williams River NWR, and Cibola NWR. Generally speaking the characterization among these study areas was consistent between the two years of the study. Bill Williams River NWR had larger Goodding's willow, Grand Canyon NP/Lake Mead NRA was dominated by willows and tamarisk in the smallest size class, and the row planting of native tree species at Cibola NWR distinguished it from other more "natural" riparian habitats. While the species and size class composition of trees at the Grand Canyon NP/Lake Mead NRA was consistent between the two years, in 2007 it contained no occupied sites after having three occupied sites in 2006 (Cuckoo Beach, Iceberg Ridge, and Chuckwalla Cove). One factor possibly contributing to this change in occupancy at Grand Canyon NP/Lake Mead NRA was the declining water levels of Lake Mead. This water stress on the plant communities in the deposited sediments along the river can be examined by the proportion of snags in total stem density. Snags accounted for 46 percent of all stem density in 2007 compared to only 14 percent in 2006, indicating that large tracts of riparian habitat that had been occupied by cuckoos in 2007 had died over the past survey season. It remains to be seen if this trend continues and what recruitment of young trees leads to habitat conditions appropriate for yellow-billed cuckoos at Grand Canyon NP/Lake Mead NRA. 


\section{Vegetation among Occupied Sites at Bill Williams River NWR}

We studied the vegetation characteristics within three sites at the Bill Williams River NWR in order to examine the degree of variation among habitats in the area with the greatest number of cuckoo detections across the entire study. Since the three sites at the Bill Williams River NWR accounted for 62 vegetation sampling plots of the 104 vegetation sampling plots in occupied patches across the LCR MSCP study area, it is not surprising that habitat characteristics of occupied habitats across the LCR MSCP and the Bill Williams River NWR are similar. Although Mineral Wash, Big Bend, and Sandy Wash were the sites with the greatest number of cuckoo detections, we were still able to detect substantial variation in the cover of the different strata. In general Big Bend had sparser cover at all layers. The sites within the Bill Williams River NWR all had Goodding's willow as the dominant species of the canopy layer, but there was variation in the sub-canopy layer with tamarisk the dominant sub-canopy species at about half the plots in Mineral Wash and Big Bend (50 percent and 43 percent, respectively) and almost all the plots at Sandy Wash (94 percent). The composition of the canopy and sub-canopy layers could represent a range of "ideal" habitat conditions necessary for cuckoo occupancy, although there are certainly hydrologic conditions unique to the Bill Williams River NWR that might contribute to occupancy in these areas. All the Bill Williams River NWR had sparse shrub layers, which was also apparent in occupied sites in general and might indicate the importance of an open understory to cuckoos. The density of different riparian trees species did not differ among Mineral Wash, Big Bend, and Sandy Wash, although Sandy Wash did have a higher density of snags. It appears that there is some density threshold that provides the most suitable habitat structure to yellow-billed cuckoos. It is possible that the proximity of a diverse mosaic of habitat types present within the Bill Williams River NWR was a positive factor influencing cuckoos relatively high detection rates within some of these sites. Future sampling efforts should consider vegetation characteristics within a gradient of low to high cuckoo occupancy; however, based on two years of survey results, the habitat at the Bill Williams River NWR is the only location within the study area where this kind of effort would be possible.

Because our data are derived from only two years of study, further research is key to determining the degree to which these are general patterns and to capture a potentially wider degree of natural variation than we have quantified to date. Ultimately a multivariate model would be a useful tool to use in order to determine the factors most important in yellow-billed cuckoo habitat selection. Identifying such characteristics is a key to effective restoration efforts for yellow-billed cuckoo habitat. 
This page intentionally left blank 


\section{Chapter 5. Microclimate Characteristics}

Large-scale transformation of the riparian ecosystem along the lower Colorado River has produced extensive areas that are no longer suitable for breeding yellow-billed cuckoos. Because of this, previous surveys (e.g., Corman and Magill 2000, Johnson et al. 2006b, Johnson et al. 2007) were conducted only in habitat that appeared suitable for cuckoos based on the "look see" method described in Chapter 2. Within suitable sites, however, occupation likely depends on both the presence of appropriate habitat structure and suitable microclimatic conditions. The Lower Colorado River Multi-Species Conservation Program calls for the creation of 1639 ha (4,050 acres) of yellow-billed cuckoo breeding habitat, including 546 ha (1,350 acres) created specifically for cuckoos (Lower Colorado River Multi-Species Conservation Program 2004).

Characterization of vegetation within currently occupied sites will help guide cuckoo habitat restoration and creation. However, cuckoos might select breeding habitat or nest sites based on specific microclimatic conditions such as relative humidity (Hamilton and Hamilton 1965) or temperature, which along the lower Colorado River approach $50^{\circ} \mathrm{C}\left(122^{\circ} \mathrm{F}\right)$, subjecting birds and their nestlings to severe heat loading. There could be a range of suitable microclimate conditions that determine where nests will likely be constructed. Therefore, we designed a method to characterize the microclimate at occupied and unoccupied yellow-billed cuckoo survey sites in five areas that span much of the lower Colorado River. Additionally we characterized microclimate at three sites within the Bill Williams River NWR, the area with the greatest concentration of yellow-billed cuckoos.

We used microclimate data collected in 2006 to guide our efforts in 2007 to further characterize aspects of yellow-billed cuckoo habitat microclimate at the habitat patch scale. In 2006 we found that occupied habitats were generally cooler and more humid than unoccupied habitats at Grand Canyon NP/Lake Mead NRA and Bill Williams River NWR, but at occupied sites in Cibola NWR only mean nocturnal temperate was lower than unoccupied sites (Johnson et al. 2007). Cuckoos have been observed using fairly large areas compared to typical songbird territories (Laymon 1999, Halterman 2005, Johnson et al. 2006b, Johnson et al. 2007), so we selected point-based sampling measures that characterize riparian habitat at the survey site/patch level rather than at the nest or territory scale (i.e., multiple random samples within a site/patch are taken to describe the patch/site). We examined microclimate characteristics at the site/patch level rather than the nest site in order to provide information relevant to riparian patch restoration and not nest placement. We measured mean diurnal and nocturnal temperature and relative humidity, in addition to mean soil moisture at sampling locations across all study areas. Also, we took vegetation measurements (described in Chapter 4) at microclimate sampling locations in order to relate microclimate variables to vegetation structure and species composition.

\section{Methods}

We conducted microclimate analyses to investigate the correlation between cuckoo presence and microclimatic conditions and also to characterize the range of 
microclimate conditions across the entire study area. Due to logistical considerations, we stratified our LCR MSCP survey region from north to south and selected seven areas from the total list based on the presence of cuckoos and/or feasibility for the placement of microclimate data loggers (Table 5.1). We collected microclimate data at both occupied and unoccupied study sites. Sites were initially selected and classified based on 2006 yellow-billed cuckoo surveys (Johnson et al. 2007). Sites were classified as occupied if cuckoos were detected during two or more survey periods in 2006 and unoccupied if one or fewer cuckoos were found. Sites with only a single detection were categorized as unoccupied because we believe that the cuckoos found at these sites were likely foraging away from their breeding sites, or were migrants or "wanderers" that did not breed within the detection area. Also, these single detections frequently occurred at sites where the habitat did not have the general characteristics considered important for breeding cuckoos.

Loggers were placed in the field in early June and were removed in late September. Each logger was programmed to record an event (T/RH reading) every 15 minutes for 80 days. Most data loggers were placed within the Grand Canyon NP/Lake Mead NRA and Bill Williams River NWR, with fewer at Havasu NWR, Cibola NWR, and the Yuma Restoration Sites (Table 5.1). At both occupied and unoccupied sites, data loggers $(n=95)$ were typically placed in mixed native-exotic habitat or exotic habitat within the riparian floodplain. Aerial photographs for each study site were used to identify habitat boundaries, and data logger locations were assigned to random UTM coordinates. These coordinates were located in the field with GPS, and a logger within a protective housing was then deployed within vegetation at 2-m high. In cases where random UTM locations were inaccessible or located in inappropriate habitat such as marsh, an alternate was selected by choosing a random compass bearing and a random distance to a new location. If the random distance could not be reached, the data logger was deployed at the first suitable patch of vegetation along that compass bearing.

\section{Temperature and Relative Humidity}

Temperature $(\mathrm{T})$ and relative humidity $(\mathrm{RH})$ were both recorded with HOBO Pro $\mathrm{RH} /$ Temp data loggers (Onset Computer Corporation, Pocasset, MA). HOBO loggers can be programmed to collect $\mathrm{T}\left(-30^{\circ} \mathrm{C}\right.$ to $50^{\circ} \mathrm{C}$; accurate to $\pm 0.2^{\circ} \mathrm{C}$ at $21^{\circ} \mathrm{C} ;-22^{\circ} \mathrm{F}$ to $\left.122^{\circ} \mathrm{F}\right)$ and $\mathrm{RH}(0-100$ percent, accurate to \pm 3 percent $)$ data at specified intervals. To protect each data logger from direct solar radiation, HOBOs were deployed in the field using a cost-effective method developed by McLeod et al. (2005). Each logger, operating under identical field conditions, was housed in a small, inverted plastic container with a sheet of shade cloth covering the top. The open bottom of the bowl was also covered with shade cloth to ensure that the HOBO was sampling free-flowing air, and thus could accurately measure T/RH. To ensure accuracy, we compared readings from HOBOs within our housings to those from the data loggers housed within Onset's Solar Radiation Shields; we found almost no detectable difference between data loggers in these two housings. Therefore, all data loggers were deployed within our homemade housings. At each data logger we measured (1) mean diurnal and nocturnal temperatures: we used local sunrise and sunset times to delineate cutoff times between night and day and (2) mean diurnal and nocturnal relative humidity over 80 days from mid-June to early September. We used the canopy cover data collected at each data logger location to in an effort to investigate possible influence on microclimate conditions. 
Table 5.1. Microclimate study areas within the lower Colorado River, Multi-Species Conservation boundary area and adjacent locations, 2007. Sites with an asterisk (*) indicate sites that were analyzed as "Yuma Restoration Sites." The table indicates the number of data loggers ( $\mathrm{HOBO}$ ) and soil moisture arrays that were placed within each study area in both occupied and unoccupied habitat.

\begin{tabular}{lll}
\hline \multicolumn{1}{c}{ Study Areas } & \multicolumn{1}{c}{$\begin{array}{c}\text { Occupied sites } \\
\text { HOBO / Soil Moisture }\end{array}$} & \multicolumn{1}{c}{$\begin{array}{c}\text { Unoccupied sites: } \\
\text { HOBO / Soil Moisture }\end{array}$} \\
\hline Pahranagat NWR & 0 & 0 \\
Overton WMA & 0 & 0 \\
Grand Canyon NP/Lake Mead NRA & 0 & $24 / 25$ \\
Havasu NWR & $5 / 2$ & $5 / 8$ \\
Bill Williams River NWR & $33 / 31$ & 0 \\
CRIT Reservation & 0 & 0 \\
Cibola NWR & $5 / 5$ & $10 / 10$ \\
Picacho SRA & 0 & 0 \\
Imperial NWR* & $5 / 5$ & 0 \\
Pratt Restoration* & 0 & $5 / 5$ \\
Yuma West Wetlands* & 0 & $3 / 3$ \\
Limitrophe & 0 & 0 \\
Gila/Colorado Rivers Confluence & 0 & 0 \\
Quigley Pond* & $0 / 6$ & 0 \\
Total & $48 / 50$ & $47 / 51$ \\
\hline
\end{tabular}

\section{Soil Moisture}

We used an ML2x ThetaProbe with a type HH2 ThetaMeter type (Delta-T

Devices Ltd., Cambridge, UK) to measure soil percent volumetric content to an accuracy of \pm 1 percent once every survey period. Soil moisture sampling locations were centered at cuckoo nests and data logger locations (Table 5.1). At each sampling location we measured soil moisture directly under the data logger or nest and also took measurements at $1 \mathrm{~m}, 2 \mathrm{~m}$, and $3 \mathrm{~m}(3.3 \mathrm{ft}, 6.6 \mathrm{ft}$, and $9.9 \mathrm{ft})$ in the four cardinal directions from the center point. We calculated a mean value for each cluster of 13 measurements averaged across the four survey periods. In some cases we were not able to collect all 13 measurements during each survey period due to dense vegetation or hard soil and based the mean value on fewer values. Soil type on the ThetaMeter was set to mineral soil, and measurements were taken at a depth of $60 \mathrm{~mm}$ (2.4 inches). McLeod et al. (2005) noted that for very high or very low voltage readings, the ThetaMeter reports volumetric soil moisture as above or below the table, respectively. To eliminate these qualitative readings, we recorded soil moisture in terms of voltage $(\mathrm{mV})$, and later converted these values to percent soil moisture. 


\section{Results}

During the 2007 breeding season we deployed 95 data loggers to sample the mean diurnal and nocturnal temperature and relative humidity across the entire study area. Microclimate was sampled from 19 June to 6 September, when data loggers were simultaneously collecting information for all deployed loggers. We compared the diurnal and nocturnal mean temperature and relative humidity by occupancy status (occupied versus unoccupied), among the Geographic Study Areas, and among three sites within the Bill Williams River NWR.

\section{Temperature and Relative Humidity by Yellow-billed Cuckoo Occupancy Status}

We collected information from 48 data loggers in occupied sites and 47 in unoccupied sites. We found that unoccupied sites were significantly warmer than occupied sites during the day $\left(\mathrm{t}_{93}=-4.0 ; \mathrm{p}<0.0001 ;\right.$ Fig. 5.1) but not at night $\left(\mathrm{t}_{93}=-0.9 ; \mathrm{p}\right.$ $=0.37$; Fig. 5.1). Diurnal temperatures in unoccupied sites averaged $2.5^{\circ} \mathrm{C}\left(4.5^{\circ} \mathrm{F}\right)$ higher than occupied sites. Relative humidity values in occupied sites during both diurnal $\left(\mathrm{t}_{93}=\right.$ 4.4; $\mathrm{p}<0.0001$; Fig. 5.1) and nocturnal $\left(\mathrm{t}_{93}=5.3 ; \mathrm{p}<0.0001\right.$; Fig. 5.1) periods was approximately 10 percent higher than unoccupied sites. Consistent difference in relative humidity between occupied and unoccupied sites could indicate a more favorable microclimate regime in the occupied sites. Comparison of microclimate variables between occupied and unoccupied sites are confounded by geography because 67 percent of data loggers in occupied sites were from the Bill Williams River NWR and 50 percent of data loggers in unoccupied sites were from the Grand Canyon NP/Lake Mead NRA study area.

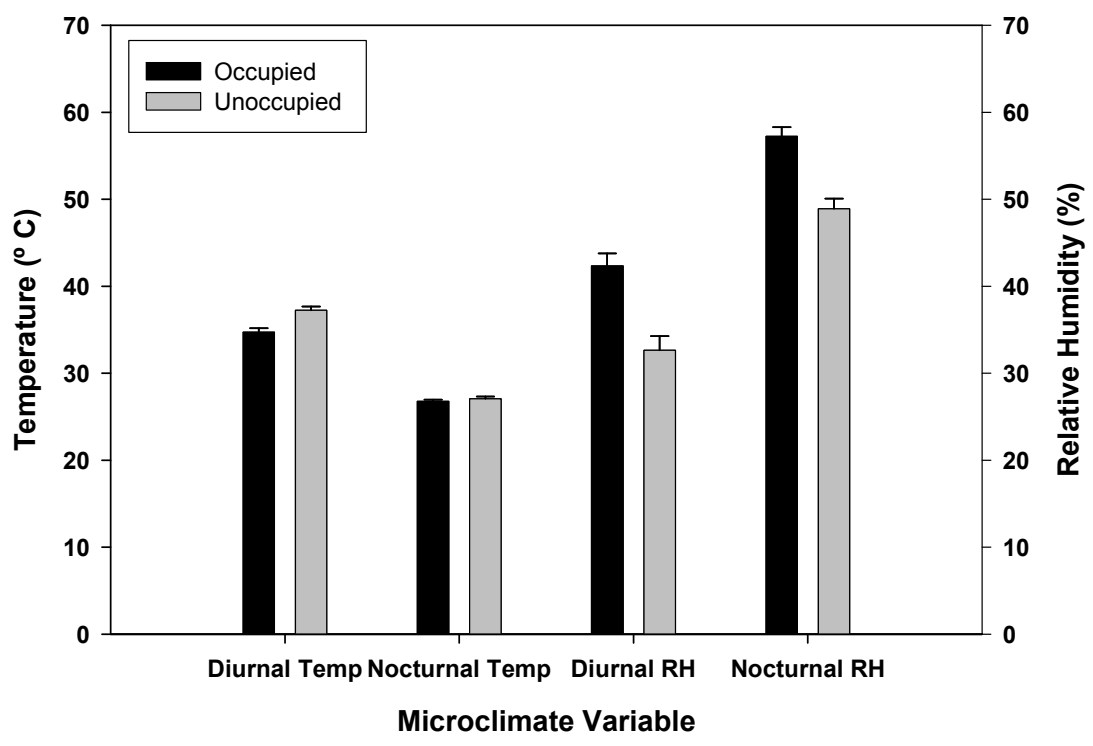

Figure 5.1. Mean diurnal and nocturnal temperature and relative humidity of areas occupied by yellow-billed cuckoos and areas unoccupied within the LCR MSCP boundary area, 2007. Error bars represent one standard error of the mean. 


\section{Temperature and Relative Humidity by Geographic Area}

We found differences in the microclimate characteristics among the different Geographic Study Areas. However, the distribution of data loggers across the different areas was not uniform (Table 5.1). The number of data loggers at each study area roughly corresponded to the size of the area. For example, Bill Williams River NWR is approximately 2,500 ha (6175 acres) and so we placed more data loggers there compared to Pratt Restoration Site (6 ha; 14.8 acres) within the Yuma Restoration Sites. We recorded the lowest daytime temperatures at the Bill Williams River NWR study area, and the mean of $32.9^{\circ} \mathrm{C}\left(91.2^{\circ} \mathrm{F}\right)$ was significantly lower than for the other study areas (range: $36.8-38.4^{\circ} \mathrm{C} ; \mathrm{F}_{4,90}=22.1, \mathrm{p}<0.0001 ;$ Fig. 5.2). Mean nighttime temperatures were greatest at Havasu NWR and the Yuma Restoration Sites $\left(\mathrm{F}_{4,90}=14.9, \mathrm{p}<0.0001\right.$; Fig. 5.2), although the magnitude of the difference in nighttime temperatures among study areas was not as great as diurnal temperatures. We found that relative humidity was highest in the Bill Williams River NWR during both diurnal $\left(\mathrm{F}_{4,90}=19.2, \mathrm{p}<0.0001\right.$; Fig. 5.2) and nocturnal $\left(\mathrm{F}_{4,90}=23.2, \mathrm{p}<0.0001\right.$; Fig. 5.2) periods. The diurnal relative humidity in the Bill Williams River NWR averaged 48.1 percent, significantly greater than the other study areas (which were not significantly different; range: $27.3-33.4$ percent). The mean nocturnal relative humidity of the Bill Williams NWR (60.3 percent) was significantly greater than other study areas and was nearly 20 percent greater than Havasu NWR (41.1 percent), the site with the lowest nighttime relative humidity. The mean relative humidity at night in other study areas (Cibola NWR, Grand Canyon NP/Lake Mead NRA, and Yuma Restoration Areas) were not significantly different from one another (range: $48.7-53.8$ percent), although they were lower than Bill Williams River NWR and greater than Havasu NWR. 


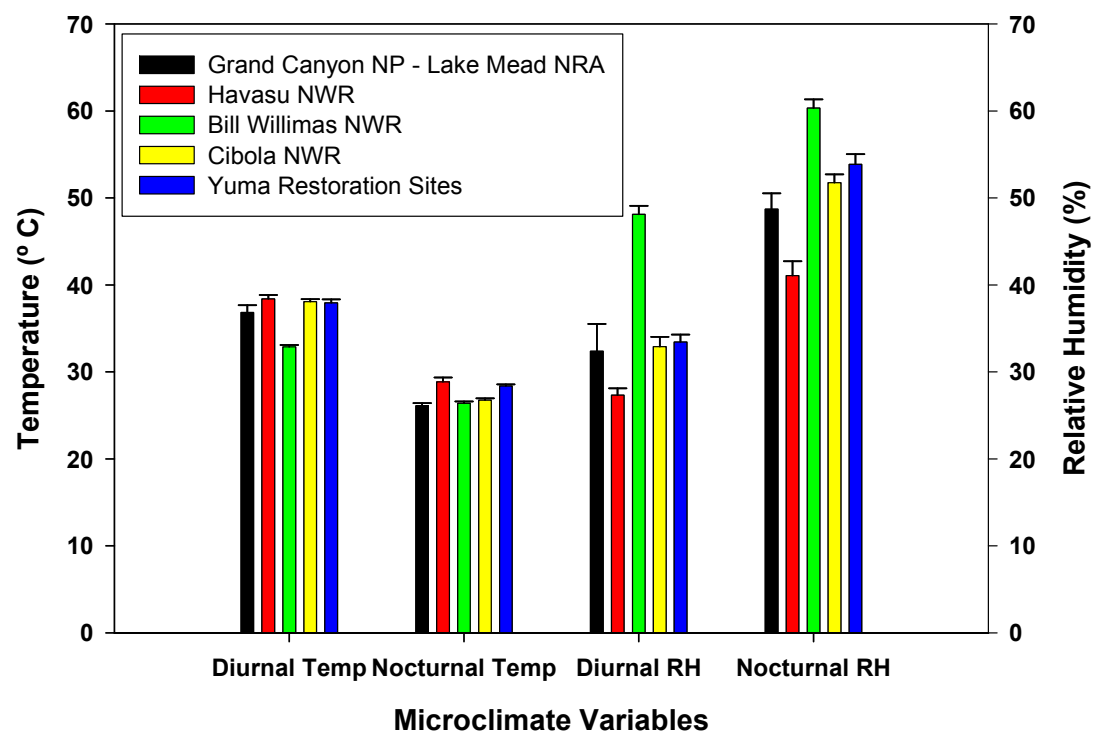

Figure 5.2. Mean diurnal and nocturnal temperature and relative humidity among yellow-billed cuckoo Geographic Study Areas within the LCR MSCP boundary area, 2007. Error bars represent one standard error of the mean.

\section{Temperature and Relative Humidity at Bill Williams River NWR Study Sites}

We detected yellow-billed cuckoos most frequently at the Bill Williams River NWR; therefore to understand the range of microclimate variation suitable for cuckoos, we examined the microclimate characteristics within three of the most heavily occupied sites within the refuge: Mineral Wash, Big Bend, and Sandy Wash. We analyzed a total of 30 data loggers at these three sites; 10 at Mineral Wash, 11 at Big Bend, and 9 at Sandy Wash. We found that the diurnal mean temperature was significantly cooler at Big Bend $\left(\mathrm{F}_{2,27}=15.7, \mathrm{p}<0.0001\right.$; Fig. 5.3), while Mineral Wash was the hottest at nighttime $\left(\mathrm{F}_{2,27}=9.0, \mathrm{p}<0.001 ;\right.$ Fig. 5.3). However, these within site differences in diurnal and nocturnal temperature were smaller than the variation we observed across the Geographic Study Areas. Consistent with being the coolest site, Big Bend had the highest diurnal relative humidity $\left(\mathrm{F}_{2,27}=12.7, \mathrm{p}<0.0001\right.$; Fig. 5.3). The nighttime relative humidity in Big Bend and Sandy Wash was greater than Mineral Wash $\left(\mathrm{F}_{2,27}=7.2\right.$, $\mathrm{p}<0.003$; Fig. 5.3). 


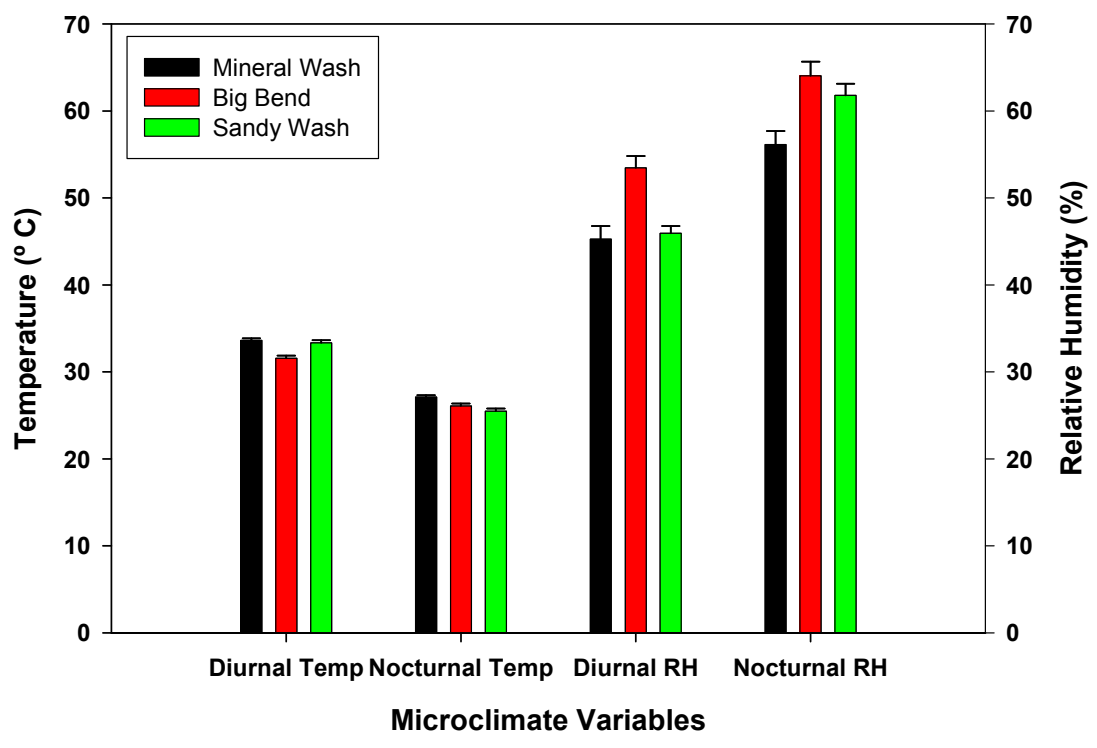

Figure 5.3. Mean diurnal and nocturnal temperature and relative humidity among sites within the Bill Williams River NWR, 2007. Error bars represent one standard error of the mean.

\section{Microclimate and Canopy Cover}

We suspected that mean diurnal temperature would be influenced by the amount of shading at a site, perhaps best represented by average canopy cover. However, we detected no relationship between the mean diurnal temperature and mean canopy cover at identical microclimate and vegetation sampling locations across the entire study area $(\mathrm{n}=$ $92 ; F_{1,91}=0.3, r^{2}=0.004 ; p=0.57 ;$ Fig 5.4). When we examined the relationship of temperature and canopy cover grouping points according to occupancy status, there was no correlation between these variables (occupied: $\mathrm{n}=41 ; \mathrm{F}_{1,45}=0.2, \mathrm{r}^{2}=0.005 ; \mathrm{p}=0.64$; unoccupied: $\left.\mathrm{n}=45 ; \mathrm{F}_{1,43}=1.9, \mathrm{r}^{2}=0.04 ; \mathrm{p}=0.18\right)$. Among the different Geographic Study Areas, there appeared to be an inverse relationship between temperature and canopy cover at the Cibola NWR; however, this pattern was not consistent between occupied and unoccupied sites and might have been driven by the small number of data loggers used at the study area. Additionally there was not a relationship between mean soil moisture and mean canopy cover across the entire study area $\left(n=91 ; \mathrm{F}_{1,89}=3.3, \mathrm{r}^{2}=\right.$ $0.04 ; \mathrm{p}=0.07)$. It is likely that there are more complex factors involved in determining the microclimate regime of riparian habitats along the lower Colorado River. 


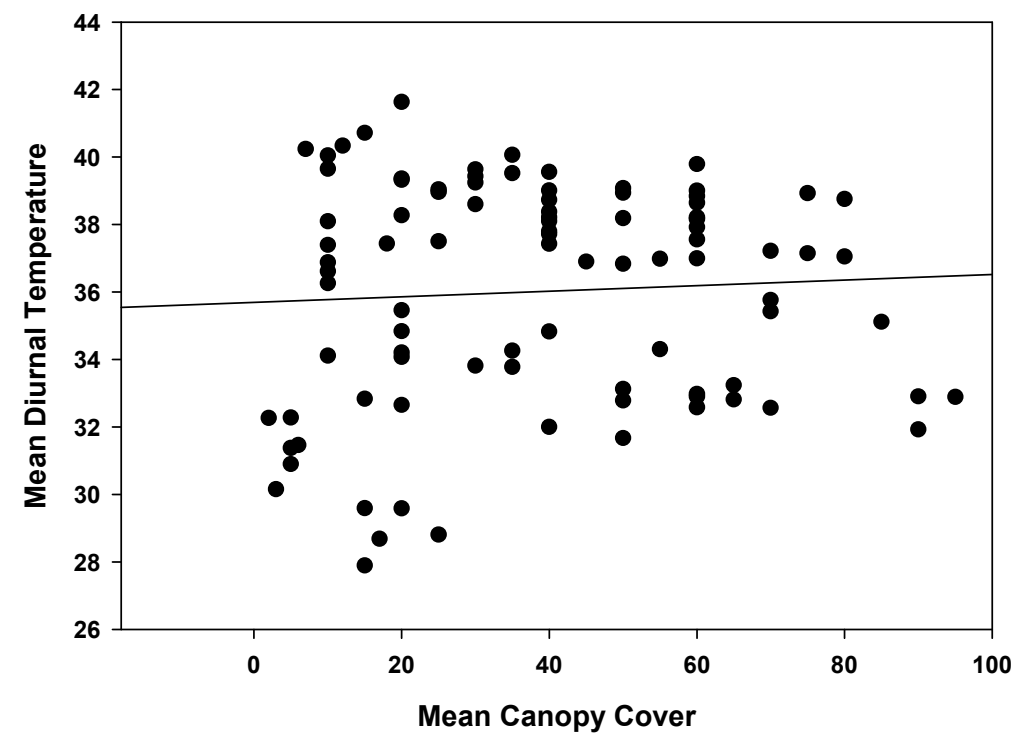

Figure 5.4. Mean diurnal temperature versus mean canopy cover and linear regression line for all yellow-billed cuckoo sampled areas within the LCR MSCP boundary area.

\section{Soil Moisture}

We collected soil moisture data from 101 locations across the entire study area. Mean soil moisture was 9 percent. We found no difference in mean soil moisture between occupied $(n=50)$ and unoccupied $(n=51)$ sites $\left(t_{99}=-0.2, p=0.80\right)$. While soil moisture measurements were not evenly distributed across the study area, we did detect difference in soil moisture among the different study areas $\left(\mathrm{F}_{4,96}=2.5, \mathrm{p}=0.04\right.$; Fig. 5.5). For example, mean soil moisture at Cibola NWR more than 10-times greater then Havasu NWR; all other study areas were statistically equivalent. Within the Bill Williams River NWR, soil moisture at Big Bend was nearly 10-times greater than Sandy Wash $\left(\mathrm{F}_{2,26}=\right.$ $6.2, p=0.006$; Fig. 5.6), but Mineral Wash was not significantly different from either site. 


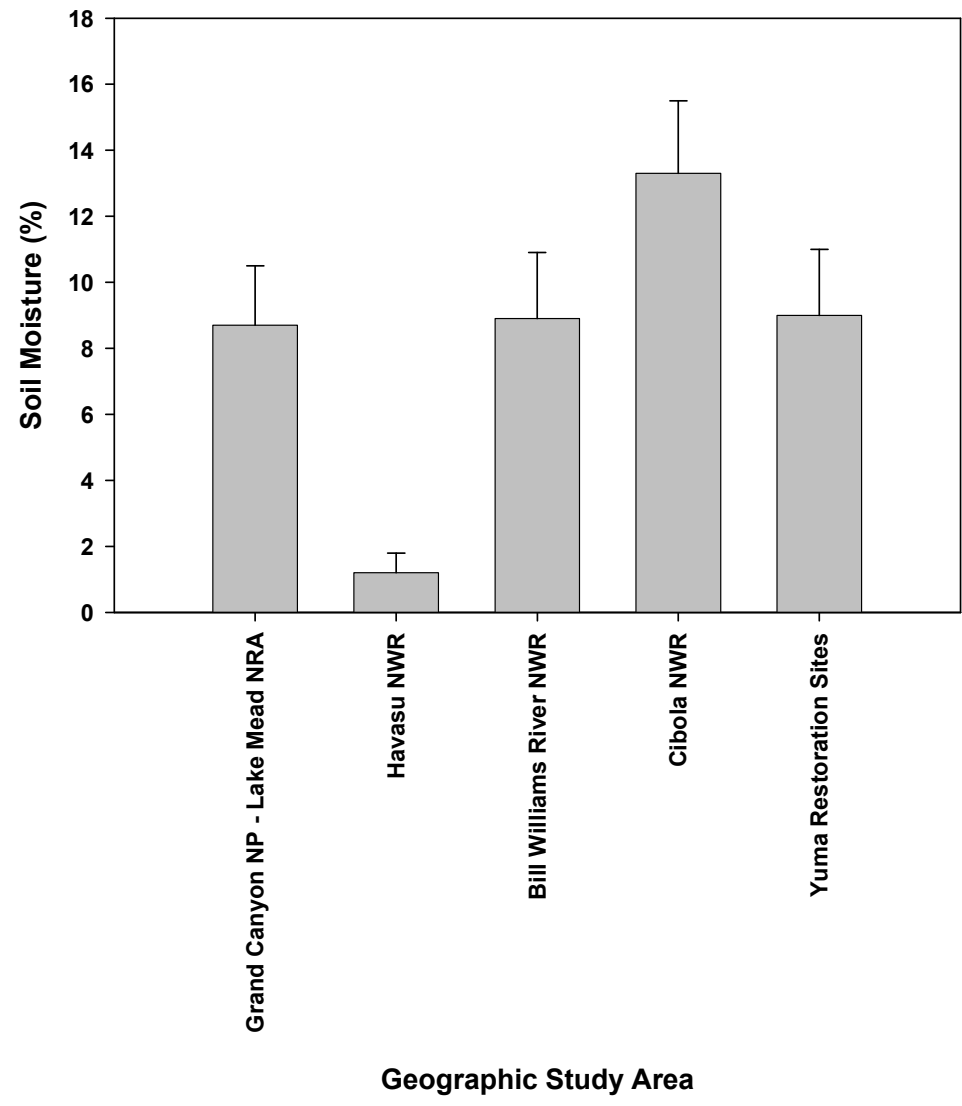

Figure 5.5. Mean soil moisture among yellow-billed cuckoo Geographic Study Areas within the LCR MSCP boundary area, 2007. Error bars represent one standard error of the mean. 


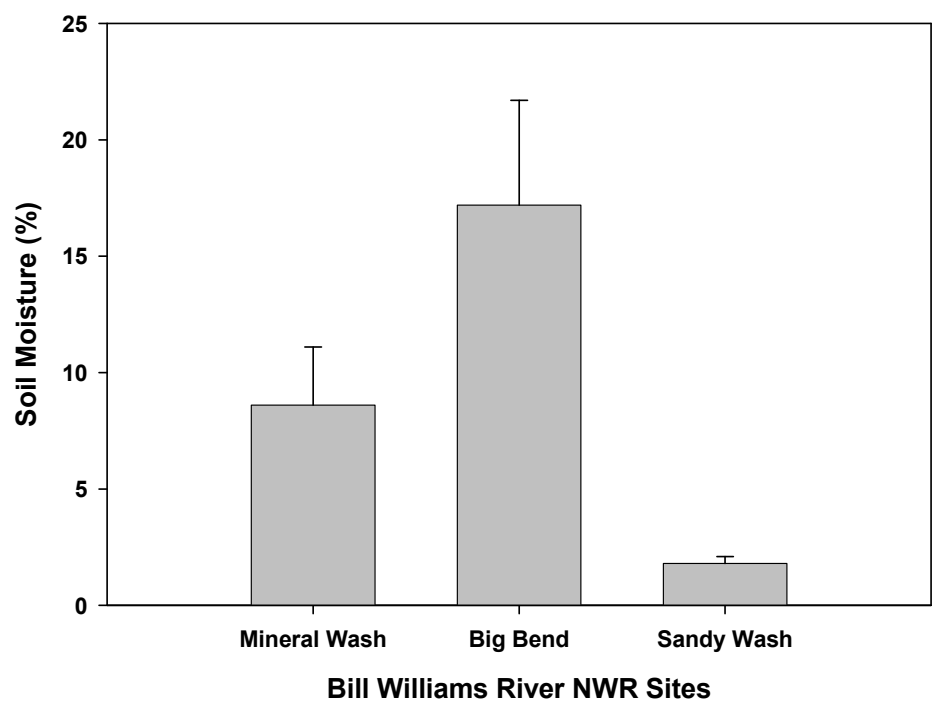

Figure 5.6. Mean soil moisture among sites within the Bill Williams River NWR, 2007. Error bars represent one standard error of the mean.

\section{Discussion}

We were able to detect some differences in microclimate conditions based on occupancy status, study area, and comparisons of sites within one study area. However, the mechanisms explaining the differences in microclimate regimes remain unclear. Factors such as nest predation and food limitation undoubtedly affect nest site selection (Martin 1995). The non-random distribution of nests in dense vegetation highlights the possible importance of microclimate, as nest placement will determine the extent of protection from wind and excess diurnal heat gain from solar radiation (Walsberg 1985, Gloutney and Clark 1997). Hamilton and Hamilton (1965) suggested that yellow-billed cuckoo nests in the Southwest are restricted to river bottoms because these areas are humid. Walsberg (1985) also noted that egg dehydration is sensitive to the microclimate to which the egg is exposed, and is primarily determined by nest humidity. Ultimately, factors such as predation, foraging sites, and favorable microclimate are not mutually exclusive and might interact in the selection of nest sites (Holway 1991).

In 2007, occupied sites were consistently cooler during the day and more humid during all other times of the day and night compared to unoccupied sites across the entire study area. It appears that these findings are consistent with other studies indicating suitable cuckoo breeding habitat having a more benign microclimate regime compared to other habitats (Hamilton and Hamilton 1965, Walsberg 1985). However, the cooler and more humid conditions of occupied sites did not correspond with greater soil moisture; there was no difference in soil moisture between occupied and unoccupied habitats. Occupied sites in 2007 were primarily represented by the microclimate characteristics of the Bill Williams River NWR in terms of temperature and relative humidity because 67 percent of data loggers were located there.

The cooler and more humid microclimate conditions characteristic of occupied sites were also prevalent at the Bill Williams River NWR compared to other study areas. However, it is unclear whether these microclimate conditions at the Bill Williams River 
NWR were the driving force resulting in the majority of yellow-billed cuckoo detections occurring here. Even within the Bill Williams NWR, there were differences in the microclimate of the most densely occupied sites, but these differences were small compared to those observed across different study areas. Because the Bill Williams River NWR is so heavily populated with cuckoos, it is possible that the range of microclimate measured at sites in the Bill Williams NWR represent a range of suitable microclimate conditions for breeding activities. Diurnal temperatures at sites in Bill Williams River NWR averaged $31.6-33.6^{\circ} \mathrm{C}\left(88.9-92.5^{\circ} \mathrm{F}\right)$ and minimum relative humidity was 45 percent and 56 percent for diurnal and nocturnal periods respectively. However, diurnal temperatures in occupied habitats at Havasu NWR, Cibola NWR, and the Yuma Restoration Sites ranged from $37-42^{\circ} \mathrm{C}\left(98.6-107.6^{\circ} \mathrm{F}\right)$, and minimum diurnal humidity in these sites ranges from 25-38 percent, suggesting that cuckoos are able to tolerate microclimate regimes less favorable than those found at the Bill Williams River NWR.

While there was substantial variation in soil moisture of locations at both the site and study area scale, there was no apparent relationship of soil moisture with cuckoo occupancy. All sites within the Bill Williams River NWR had numerous cuckoo detections but soil moisture varied by almost 10-fold. Likewise, sites at both Cibola NWR and Havasu NWR were occupied but there was a 10-fold difference in the mean soil moisture between these areas. These preliminary results are based on just one year of data, and further research would be valuable in more fully characterizing the suitable microclimate conditions for yellow-billed cuckoos

We also expected that microclimate conditions are in part driven by the vegetation composition and characteristics of the habitat patch. However, we did not find a relationship between mean canopy cover and mean diurnal temperature or mean soil moisture. There was also no relationship of these factors when comparing occupancy status, Geographic Study Area, or sites differences within the Bill Williams River NWR. It is likely that more complicated factors are involved in determining the microclimate regime of a patch including canopy height and complexity, dominant tree species, proximity to water, the nature of surrounding habitat, or many other variables. While yellow-billed cuckoos could respond to microclimate conditions in regards to nest placement, their decision to use one habitat and not another, or to focus their activities in one part of a habitat might be determined by coarser climatic conditions, broad vegetation characteristics, or the suitability of food resources. Any comparison of microclimate patterns between 2006 and 2007 will be limited based on the sparse data collected in 2006; however, further investigation in all of these factors is warranted in order to understand yellow-billed cuckoo habitat requirements and thus could be important in managing for riparian restoration goals. 
This page intentionally left blank 


\section{Chapter 6. Management and Research Considerations}

\section{Yellow-billed Cuckoo Presence/Absence Surveys}

The Lower Colorado River Multi-Species Conservation Plan of 2004 calls for surveys to identify areas that cuckoos use and to collect information necessary to better define the species' habitat requirements. This information will then be used to design and maintain riparian habitat suitable for yellow-billed cuckoos in the LCR MSCP planning area, which should help reduce the likelihood of future federal listing of this species. In order to have high confidence in the surveys and the resultant data, we recommend that four cuckoo surveys be conducted each year at all sites with suitable habitat within the MSCP boundary area. we also recommend evaluating habitat within the lower Colorado River watershed and expanding cuckoo surveys to areas where adequate cuckoo habitat may come available. The areas we recommend evaluating each year include sites along the Gila River in Arizona, and the Virgin and Muddy Rivers in Southern Nevada and southern Utah.

\section{Evaluation of Survey Protocol for Yellow-Billed Cuckoos}

One of the most important factors affecting the accuracy and precision of any survey method is detection probability $\left(P_{\text {detect }}\right.$; the probability that an observer will record a bird that is present during a survey; Pendleton 1995). To effectively determine an index of population size, detection probability should be both robust (high detection probability) and precise (low temporal variation in detection probability) (Johnson 1995).

The tape broadcast survey technique has proven advantageous in eliciting responses from many bird species, especially those that are secretive or nocturnal. It often increases the total number of birds seen or heard for a given species in comparison to a conventional census (Johnson et al. 1981), especially for species with low song activity (Robbins 1978). Broadcast also has been helpful in estimating population size and investigating avian social behavior and territoriality. Broadcast surveys have been used primarily during the breeding season to study the presence and distribution of many species (Glahn 1974, Griese et al. 1980, Sogge et al. 1997), but also have been employed on wintering grounds (Koronkiewicz et al. 2006).

The use of broadcast recordings in surveys of western yellow-billed cuckoos has increased the number of detections of this elusive and easily overlooked species (Hamilton and Hamilton 1965, Halterman et al. 2007). Studies, mostly of eastern yellowbilled cuckoos (Coccyzus americanus americanus), have found that calls are most frequent during pair formation and nest building; calls continue through nesting, and then become infrequent after the last young fledge (Hughes 1999). Unfortunately, little is known about whether cuckoos call more frequently when paired or unpaired, or if they call more frequently when solitary versus when they occur in higher densities. This lack of information complicates the interpretation of survey results.

As with any field survey protocol, there is no way to be absolutely certain that an area with no detections is unoccupied. This might be especially true for yellow-billed 
cuckoos, which have a fairly low response rate; the standard survey method of using broadcast recordings might fail to detect all birds present in an area. In fact, it has been observed that some individuals known to be present in the area sometimes do not respond to broadcasted recordings (Halterman 2005, Johnson et al. 2006b, Johnson et al. 2007; and Holmes et al. in review). The extent to which call-broadcast surveys increase detection probability in comparison with passive surveys is currently not known for yellow-billed cuckoos. Likewise, whether broadcast surveys decrease temporal variation in detection probability is also not known.

Therefore, in order to evaluate the effectiveness of the current yellow-billed cuckoo survey protocol, we recommend estimating detection probability and variance in detection probability associated with auditory and broadcast surveys, and using these estimates to evaluate the efficacy of broadcast surveys of yellow-billed cuckoos.

\section{Evaluating Survey Protocol}

In order to conduct this survey evaluation, we recommend surveying for cuckoos within the Bill Williams River NWR beginning in mid-June and continuing through lateAugust (the breeding season for most yellow-billed cuckoos; Halterman et al. 2007). We recommend conducting replicate surveys ( 1 every 3 weeks) along three survey routes in the Bill Williams River NWR. The design of this study has been used with other species, such as buff-breasted flycatchers (Empidonax fulvifrons; Conway and Kirkpatrick 2001), burrowing owls (Athene cunicularia; Conway and Simon 2003) and band-tailed pigeons (Patagioenas fasciata; Kirkpatrick et al. 2007). Therefore, we recommend adapting study designs for each of these studies to yellow-billed cuckoos.

In order to evaluate the effectiveness of broadcast surveys relative to auditory (i.e., listening only) surveys, we recommend conducting a 5-minute auditory survey for each survey point followed immediately by a 5-minute call-broadcast survey (10 minutes total at each survey point). This paired survey design will increase the power of statistical tests and increase the ability to detect differences between the two survey methods. During the paired auditory and broadcast survey at each survey point, record each yellow-billed cuckoo detected on a separate line of a data sheet and record the type number of detection(s): visually flying, visual perched, kowlp call, coo-call, or kuk, kuk, $k u k$ call during discrete time intervals within the 10-minute survey period. Divide the 5minute auditory survey into five 1-minute intervals and the 5-minute call-broadcast survey into five 1-minute intervals (a 15-20-sec broadcast interval followed by a 60 -sec silent interval with this pattern repeated 5 times). Estimating the distance $(\mathrm{m})$ to each cuckoo and record whether each cuckoo was a repeat detection (i.e., a cuckoo that was also detected earlier during the survey at a previous survey point) will eliminate repeat detections from the analyses.

\section{Estimating Detection Probability}

The probability of detecting birds auditorily during surveys $\left(P_{\text {detect }}\right)$ is the product of two components: (1) the probability that a bird within the survey area sings $\left(P_{\text {sings }}\right)$; and (2) the probability that a bird is heard given that it sings $\left(P_{\text {heard }}\right)$. Estimating $P_{\text {sings }}$ and $P_{\text {heard }}$ for both auditory and call-broadcast surveys should use the following methods. For each cuckoo that is detected during surveys, create a detection history by recording when the cuckoo first vocalized during the discrete time intervals in the auditory survey period and 
in the call-broadcast survey period. Use these detection histories to estimate $P_{\text {sings }}$ (Farnsworth et al. 2002).

We also recommend conducting a 10 double-observer trials in which pairs of observers independently record cuckoos during auditory and call-broadcast surveys along survey routes. The data from these double-observer trials (using only those surveys where $\geq 1$ cuckoo was detected by at least one observer) can be used to estimate $P_{\text {heard }}$ (Nichols et al. 2000, Conway and Simon 2003).

\section{Habitat Vegetation Characteristics}

Our study of vegetation characteristics within the LCR MSCP boundary in 2007 indicated that occupied cuckoo habitat consists of riparian habitats with a tall, dense overstory dominated by native cottonwoods and willow, a subcanopy with both willow and tamarisk components, and a sparse understory. Although unoccupied habitats also were dominated by a cottonwood-willow overstory, the subcanopy and understory were consistently dominated by dense tamarisk. However, in some cases, cuckoos did use habitats with tamarisk-dominated subcanopies. While we detected general patterns of occupied cuckoo habitat, occupied and unoccupied habitats were not evenly distributed across the entire LCR MSCP study area and were overrepresented at the Bill Williams River NWR and Grand Canyon NP/Lake Mead NRA, respectively. Declining water levels in Lake Mead likely resulted in a greater than 3-fold increase in the proportions of snags at the Grand Canyon NP/Lake Mead NRA sites between 2006 and 2007. The lack of cuckoo detection at the Grand Canyon NP/Lake Mead NRA sites in 2007 might be due to the loss of suitable habitat. We are not aware of the long-term occupancy of cuckoos at sites within Grand Canyon NP/Lake Mead NRA, but additional monitoring of habitat conditions and studying of yellow-billed cuckoo colonization patterns could provide information on the suitability of these areas for breeding cuckoos. Because vegetation characteristics of occupied habitats was not entirely consistent between 2006 and 2007, further research is needed to determine the degree of temporal and spatial consistency [variation?] in the vegetation patterns we have observed. Ultimately, a multivariate model would be useful in determining the factors most important in yellow-billed cuckoo habitat selection. Identification of such factors is a key to effective restoration efforts for yellowbilled cuckoo habitat.

\section{Microclimate}

Across the entire LCR MSCP study area, soil moisture was not useful in predicting yellow-billed cuckoo habitat use. However, yellow-billed cuckoos did use habitats that were consistently cooler during the day and more humid at all times compared to unoccupied habitats. Although the sites at the Bill Williams River NWR generally corresponded to these favorable microclimate conditions, cuckoos used hotter and dryer habitats at Havasu NWR, Cibola NWR, and the Yuma Restoration Sites, suggesting that cuckoos are able to tolerate a wider range of microclimate regimes than would be evident based only on the Bill Williams River NWR. The mechanisms explaining the differences in microclimate regimes remain unclear; we did not find a relationship between vegetation characteristics and microclimate. While yellow-billed cuckoos might respond to microclimate conditions in regards to nest placement, their use of one habitat and not another or their focus of activities in one part of a habitat might be determined by coarser climatic conditions, broad vegetation characteristics, or the 
suitability of food resources. Comparison of microclimate patterns between 2006 and 2007 were limited based on the sparse data collected in 2006; therefore, further investigation of all of these factors will be important in order to understand yellow-billed cuckoo habitat requirements and thus what end results might be important to manage for in terms of riparian restoration goals.

\section{Identifying Core Yellow-billed Cuckoo Breeding Habitat}

Within this landscape, the LCR MSCP calls for the Bureau of Reclamation to restore 5,940 acres of cottonwood (Populus spp.) - willow (Salix spp.) habitat, including 4,050 acres specifically for the yellow-billed cuckoo. Consequently, there is a need to identify core breeding habitat areas and their characteristics for use as a basis for future habitat expansion through riparian habitat restoration efforts. To define core breeding habitat as those areas upon which yellow-billed cuckoos depend for breeding, we define core habitat as the highest quality yellow-billed cuckoo habitat available in the region.

Radio telemetry has been used to determine core use areas of several passerines (e.g., Cardinal 2005; Vega Rivera et al. 1999, 2003; Bayne and Hobson 2001). Although yellow-billed cuckoo radio telemetry studies have been successful in determining the sex of individual birds, and can aid in locating nests and observing breeding behavior (Halterman 2005), capturing individual cuckoos is extremely time consuming and expensive, even in areas where they occur in relatively high densities (Johnson and Holmes pers. comm., Halterman pers. comm.). In addition, because cuckoos move large distances during the breeding season, tracking such wide-ranging birds can be extremely difficult (Laymon 1998, Hughes 1999, Halterman 2005).

Given the challenges and relative expense of using radio telemetry to identify core breeding habitat, we recommend an alternative approach of using occupancy as a surrogate for habitat quality. Habitat quality has been considered to be the ability of the environment to provide conditions appropriate for individual and population persistence (Hall et al. 1997), and both territory occupancy and density have often been used as a measure of habitat quality. Sergio and Newton (2003), in a review of the use of occupancy as a measure of territory quality, report that the quality of a territory has been mainly measured as: (1) the quality and quantity of its resources (e.g., food or safe nest sites), based on knowledge of the species requirements; (2) the duration of its occupation, under the assumption or knowledge that territories occupied for longer are more profitable; (3) its capability to sustain high levels of survival or reproduction; (4) its date of occupation during the seasonal sequence of settlement, assuming that better territories are occupied earlier within any given year; and (5) the predictability of breeding success in that territory, which might be of value for a settling individual, and which is usually measured as the coefficient of variation of reproductive success (Ferrer and Donazar 1996).

Sergio and Newton (2003) also found, in their review of 22 studies of territory occupancy in 17 species, that occupancy was always correlated with productivity and/or with some other measure of territory or habitat quality. They suggest that occupancy might be a reliable method of habitat quality assessment, especially for populations in which not all territories are always occupied, and for species in which checking occupancy is easier than finding nests. Yellow-billed cuckoos are just such a species. 


\section{Using Occupancy Patterns to Identify Core Yellow-billed Cuckoo Habitat}

Many species that are rare or difficult to detect are monitored by estimating trends in site occupancy as opposed to trends in numbers of animals detected (MacKenzie et al. 2002). Therefore, site occupancy estimation may be a suitable and very effective approach for monitoring yellow-billed cuckoo core habitat use within the Lower Colorado River Multi-Species Conservation Program Area.

Currently, survey sites are classified as either unoccupied (a site with no yellowbilled cuckoo detections), or occupied (a yellow-billed cuckoo had been detected at a site during at least two survey periods). These criteria were developed because individual cuckoos are known to wander, even within the breeding season, and there are numerous examples of cuckoos observed in obvious non-breeding habitat (Johnson et al. 2007). Consequently, a single detection of a cuckoo at a site does not indicate settling, pairing, or breeding at that location (i.e., occupied), so we classified sites as occupied if cuckoos were detected there during two or more survey periods.

For the purpose of using occupancy to identify core cuckoo breeding habitat, we recommend refining the classification of occupied sites based on their duration of occupancy, i.e., the number of survey periods (out of four total survey periods) in which cuckoos are detected at the site. Using this approach, core breeding sites would be those with the longest duration of occupancy throughout the breeding season and over multiple years. We also recommend testing whether these sites would also be identified as core breeding habitat based on: (1) density of detections; (2) indication of breeding activity based on breeding confirmation, nest presence, and behavior; (3) habitat characteristics (see Chapter 4; Johnson et al. in prep.); and (4) follow-up survey results (described below).

\section{Methods for Yellow-billed Cuckoo Follow-up Visits}

Compared to the time and monetary expense of telemetry, we believe that a more cost-effective method to determine yellow-billed cuckoo habitat use is to conduct followup visits after cuckoos are detected during formal cuckoo surveys. The follow-up visits do not follow the formal survey guidelines, but involve thorough walk-through searches of the area where cuckoos were detected during the formal survey. During these followup visits, surveyors mainly observe cuckoo behavior and movements and use cuckoo song broadcasts sparingly (when cuckoos are not detected). During each of these followup surveys, we recommend estimating numbers of individual cuckoos detected, recording UTM coordinates of observed cuckoo locations, recording breeding activity and habitat use (i.e., tree species, height cuckoo is observed in the tree), and continually looking for nests. After each visit to known cuckoo locations, cuckoo detections should then be entered into a database and mapped on aerial photos. Copies of aerial photos should be taken into the field during each follow-up visit and updated with all new cuckoo detections. The addition of follow-up surveys will improve our ability to determine cuckoo habitat use, the number of individuals in the habitat patch, obtain breeding observations (e.g., interactions between individuals, copulation, food carry), and record additional cuckoo locations within the known patch. 


\section{Identifying Yellow-billed Cuckoo Habitat Model Variables}

Despite concern over its conservation future (USFWS 2002), few aspects of the yellow-billed cuckoo's life history have been adequately studied, particularly in the Southwest, where its habitat selection patterns are largely unknown. Knowledge of habitat selection patterns and identification of potential breeding habitat is essential to guide conservation efforts (Laymon 1998, Hughes 1999).

To meet this information need, concomitant with future cuckoo surveys, we recommend additional habitat characterization, including measures of plant species composition and vegetation structure within riparian patches, riparian patch size, and the surrounding landscape matrix, along the lower Colorado River and throughout the cuckoo's western breeding range. These habitat data from multiple spatial scales could be used to construct a habitat model to determine associations between riparian habitat characteristics and Yellow-billed Cuckoo breeding-season occurrences. This information can then be used to construct a predictive model for yellow-billed cuckoo breeding season occurrences. This knowledge of habitat selection patterns and identification of potential breeding habitat can be used to guide conservation efforts, including prioritization of areas for conservation and restoration, identification of areas for future surveys, and areas for monitoring changes in habitat distribution and quality over time. Additionally, information regarding yellow-billed cuckoo habitat needs can help predict the effects of management options such as riparian restoration.

Currently, two habitat models for yellow-billed cuckoos have been developed, both based on habitat measurements taken along the Kern and Sacramento Rivers in California. As the riparian vegetation structure and composition along these river drainages differ from the lower Colorado River and cuckoo habitat requirements might vary geographically, these models should be used with caution in other river drainages. The model by Gaines and Laymon (1984) showed that willow-cottonwood habitat of any age with high humidity and a habitat width of $325 \mathrm{ft}(100 \mathrm{~m})$ was necessary for suitable yellow-billed cuckoo habitat. Additional research based on occupancy rates allowed for refinement of the model; Laymon and Halterman (1989) and Laymon 1998 concluded that sites $>80$ ha (200 acres) in extent and wider than $600 \mathrm{~m}$ (1950 ft) were most optimal for yellow-billed cuckoos, sites 41-80 ha (101-200 acres) in extent and wider than $200 \mathrm{~m}$ $(650 \mathrm{ft})$ were suitable, sites $20-40 \mathrm{ha}(50-100$ acres) in extent and 100-200 $\mathrm{m}$ (325-650

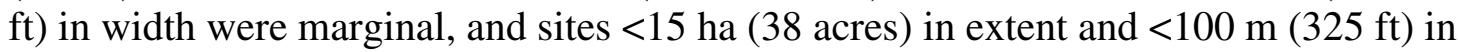
width were unsuitable.

Additional work by Launer et al. (1990) also recommends that, in relation to protection of existing habitat, restoration efforts should be concentrated in areas adjacent to existing habitat patches, or in areas of sufficient extent to create comparatively large tracts of habitat (a minimum of $100 \mathrm{ha}$ ). Again, geographic considerations appear to be very important, and Launer et al. (1990) suggest that restoration efforts in the southern portion of the cuckoo nesting range should have first priority.

In addition to affecting vegetation structure and composition, efforts to restore native riparian areas along the lower Colorado River also might influence another habitat component - avian food resources. Many bird species that breed in riparian habitats are insectivorous and the lush vegetation associated with riparian zones provides abundant arthropod food resources, especially when compared to surrounding upland habitats (Strong and Bock 1990). A particular food resource, the Apache cicada (Deceroprocta apache), has been suggested as a keystone species in the lower Colorado riverine 
ecosystem through their herbivory (Karban 1980, Anderson 1987, Anderson 1994) and their importance as a prey species for birds and mammals, especially during the breeding season (Rosenberg et al. 1982, Krohne et al. 1991).

In the Southwest, yellow-billed cuckoo habitat use appears to be linked to cicadas. In cottonwood-willow habitat in the Colorado River Valley, Rosenberg et al. (1982) found cuckoos concentrated on cicadas, a superabundant, seasonally predictable resource (Strong and Bock 1990). The relatively late nesting period of the western population of cuckoo is thought to be an adaptation to the typical timing of cicada emergence (Rosenberg et al. 1982). In New Mexico, cuckoo nesting coincides with peak cicada (Tibicen dealbatus) emergence in unburned plots along the Rio Grande (Howe 1986). Emergence of cicadas prior to the cuckoo breeding season could be detrimental to the cuckoo's nesting success (Andersen 1994). There is evidence in New Mexico (Smith et al. 2005) that cottonwood density and cottonwood canopy cover are important factors in cicada ( $T$. dealbatus) emergence density and phenology; age and health of a cottonwood stand have a smaller effect on emergence density. Cottonwood canopy was correlated with lower soil temperatures, which are associated with later emergence dates (Smith et al. 2005). These findings suggest that the recovery and sustainability of yellow-billed cuckoo populations in the Southwest might depend on sustaining cicada populations. Riparian restoration that is designed to provide conditions that promote cicada emergence in densities and at times that provide the greatest benefits to cuckoos may prove to especially effective in managing for the cuckoo. Studies are needed to understand the relationships between vegetation associations and cicadas, the effects of vegetation structure and climate on cicada emergence density and phenology in riparian habitats along the lower Colorado River. 
This page intentionally left blank 


\section{Chapter 7. 2006-2007 LCR MSCP Yellow-billed Cuckoo Research Summary}

This chapter summarizes the two years of yellow-billed cuckoo research conducted by the U.S. Geological Survey for the Lower Colorado River Multi-Species Conservation Plan (LCR MSCP). The LCR MSCP of 2004 calls for the identification of areas used by yellow-billed cuckoos through surveys and the collection of information necessary to better define the species' habitat requirements. This information will then be used to design and maintain riparian habitat suitable for yellow-billed cuckoos in the LCR MSCP planning area, which should help reduce the likelihood of future federal listing of this species. We conducted research on the distribution, abundance, and habitat use of yellow-billed cuckoos within the boundaries of the LCR MSCP in 2006 and 2007.

The objectives of this project were to document the distribution, abundance, and habitat use of yellow-billed cuckoos in riparian areas of the lower Colorado River, and to provide information relevant to the Habitat Conservation Plan measures. Yellow-billed cuckoo surveys provide information on their status and distribution, and establish baseline data that can be used for continued monitoring of cuckoo populations and riparian vegetation under the MSCP. There are four specific project objectives.

1. Conduct comprehensive, repeatable surveys in all potentially suitable habitat types within the MSCP project boundary. This work contributes to baseline information on yellow-billed cuckoo populations within these areas. All other avian species encountered within riparian habitats are also recorded.

2. Evaluate the effectiveness of the current yellow-billed cuckoo breeding season survey protocol (Halterman et al. 2006) and refine it to use over the term of the MultiSpecies Conservation Plan.

3. Determine breeding habitat selection and preferences in the areas of concern. This includes identifying the characteristics of habitats used during the breeding season, and comparing characteristics between occupied and unoccupied sites to identify factors that may influence habitat selection by cuckoos.

4. Identify core yellow-billed cuckoo breeding habitat to use as a basis for future habitat expansion through restoration efforts.

This chapter presents year-by-year summaries of our cuckoo breeding surveys, evaluation of the cuckoo survey methodology, habitat vegetation characteristics, microclimate analysis, and detection of other riparian bird species. Unless stated otherwise, all 2006 data are from Johnson et al. (2007).

\section{Yellow-Billed Cuckoo Presence/Absence Surveys}

Yellow-billed cuckoos have historically been considered a common breeding species within extensive riparian forests throughout the lower Colorado River Basin (Swarth 1905, Visher 1910, Phillips et al. 1964). In 1976, the estimated number of breeding cuckoo pairs along the lower Colorado River and its five tributaries was 846 (Groschupf 1987). Later studies found a 93 percent decline along the lower Colorado 
River between 1976 and 1986 and an estimated 71 to 75 percent decline on the Bill Williams River delta during the same period (Rosenburg et al. 1991).

We conducted our yellow-billed cuckoo presence/absence surveys in 2006 and 2007 at most areas that were historically surveyed throughout the lower Colorado River Basin. The exact number of cuckoos present at our survey sites is not known since there was no way to tell whether detections on separate surveys represented the same or different individuals. Thus, the detections should not be interpreted as a count of the number of cuckoos present or as the number of birds breeding at a site.

During formal cuckoo surveys, we documented 180 and 163 cuckoo detections in 2006 and 2007, respectively. In 2006, we conducted 243 surveys that covered 521 hours at 55 sites. In 2007 we conducted only 169 surveys that covered 312 hours at 40 sites. The difference in survey effort between the two years was made up by supplemental (follow-up) surveys in 2007. During these supplemental surveys we focused on areas where cuckoos were detected during formal surveys and at sites with the highest likelihood for cuckoo presence and breeding activity. We conducted 93 follow-up surveys, mostly at the Bill Williams River NWR, that covered 204 hours and accounted for 253 additional yellow-billed cuckoo detections. Also likely due to the supplemental survey effort, we detected 27 breeding events at seven sites in 2007 compared to only five breeding events at three sites in 2006. While many of the 253 cuckoo detections on supplemental surveys were likely from the same individuals, we were able to obtain finer details of cuckoos behavior and habitat use from these observations (Appendix 2), therefore we consider these follow up visits invaluable in studying the biology of the yellow-billed cuckoo.

The Bill Williams River NWR accounted for the majority of cuckoo detections during both years; 68 percent and 85 percent in 2006 and 2007, respectively. This area represents the largest stand and highest quality of suitable yellow-billed cuckoo habitat on the lower Colorado River (Figure 7.1).

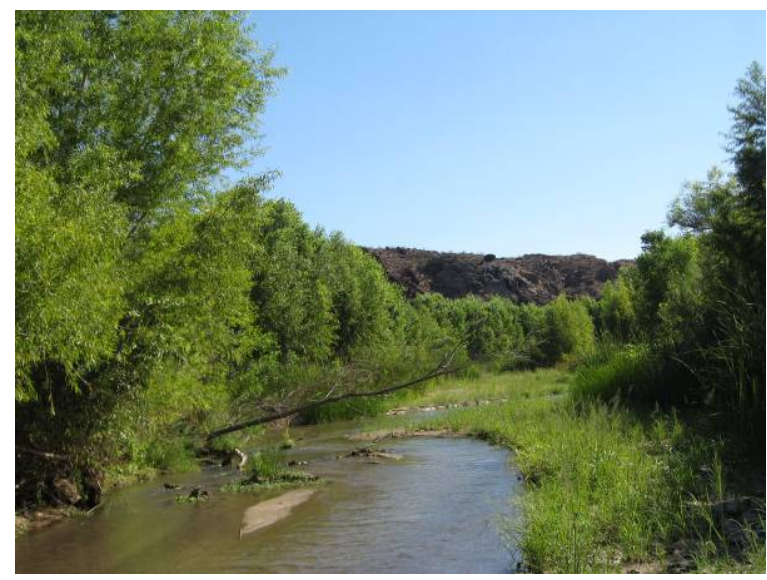

Bill Williams River NWR, Honeycomb Bend

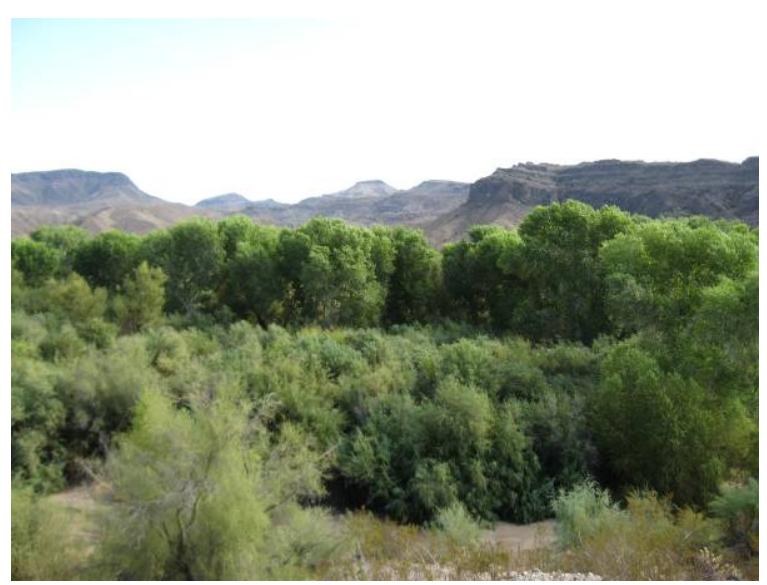

Bill Williams River NWR, Mosquito Flats

Figure 7.1. Lower Colorado River-Multi-Species Conservation Program, Yellow-billed cuckoo survey sites along the Bill Williams River NWR, AZ, 2007. 
Because of differences in survey methods, specific areas surveyed, and probable differences in the criteria used to estimate the number of individuals, it is difficult to make direct comparisons between our results and estimates of cuckoo numbers from previous studies. However, we can compare the occupancy of yellow-billed cuckoos between our 2006 and 2007 surveys. In doing so it is important to keep in mind that some survey sites change as new habitat became suitable or old habitat unsuitable, and the boundaries of some survey sites were changed for logistical reasons. At Pahranagat National Wildlife Refuge, Overton Wildlife Management Area, Havasu National Wildlife Refuge, Cibola National Wildlife Refuge and among the Yuma, AZ sites (Colorado/Gila Confluence, Pratt Restoration Site, Yuma Wetlands, Limitrophe Division, and Quigley Pond Wildlife Management Area) we observed high variation between years (Table 7.1) in the number of cuckoos detected, sites occupied, and the number breeding confirmations. Grand Canyon NP/Lake Mead NRA showed the greatest differences between years. In 2006, we had 29 detections in three occupied sites (Chuckwalla Cove, Iceberg Ridge and Cuckoo Beach) and confirmed breeding at Chuckwalla Cove, in 2007, we had zero yellow-billed cuckoo detections presumably due to the drought conditions as detailed below. At Bill Williams River National Wildlife Refuge, we consistently detected cuckoo during both years. In 2006, we had eight occupied sites and confirmed breeding at two sites; in 2007, we had ten occupied sites with confirmed breeding at seven (Table 7.1). At Imperial National Wildlife Refuge we also consistently detected cuckoos at Imperial South restoration site, which was an occupied site in both 2006 and 2007, yet breeding was not confirmed for either year.

Table 7.1. Summary of yellow-billed cuckoo detections, number of occupied sites and number of breeding cuckoos in 2006 and 2007 at all areas and sites along the Muddy, Virgin and White Rivers in Nevada and the Colorado, Bill Williams, and Gila Rivers in Arizona and California.

\begin{tabular}{lrrrrrrr}
\hline \multicolumn{1}{c}{ Survey Area } & \multicolumn{2}{c}{ YBCU Detections } & \multicolumn{2}{c}{$\begin{array}{c}\text { \# of YBCU } \\
\text { Occupied Sites }\end{array}$} & \multicolumn{2}{c}{$\begin{array}{c}\text { YBCU Breeding } \\
\text { Detections }\end{array}$} \\
& 2006 & 2007 & 2006 & 2007 & 2006 & 2007 \\
\hline Pahranagat NWR & 1 & 0 & 0 & 0 & 0 & 0 \\
Overton WMA & 7 & 0 & 2 & 0 & 0 & 0 \\
Grand Canyon NP/Lake Mead NRA & 29 & 0 & 3 & 0 & 1 & 0 \\
Havasu NWR & 1 & 3 & 0 & 1 & 0 & 0 \\
Bill Williams River NWR & 117 & 139 & 8 & 2 & 10 & 7 \\
Ahakhav Tribal Preserve - CRIT & NA & 2 & NA & 0 & 0 & 0 \\
Cibola NWR & 3 & 7 & 1 & 1 & 0 & 0 \\
Picacho State Recreation Area & 1 & 0 & 0 & 0 & 0 & 0 \\
Imperial NWR & 3 & 3 & 1 & 1 & 0 & 0 \\
Pratt Restoration Area & 0 & 0 & 0 & 0 & 0 & 0 \\
Gila-Colorado River Confluence & 9 & 2 & 1 & 0 & 0 & 0 \\
Yuma West Wetlands & 0 & 0 & 0 & 0 & 0 & 0 \\
Limitrophe Division & 6 & 2 & 1 & 0 & 0 & 0 \\
Quigley Pond WMA & 1 & 5 & 1 & 0 & 0 & 0 \\
\hline
\end{tabular}


So overall, with the exception of Bill Williams River NWR, there was a high degree of annual variation in site and yearly cuckoo detections, occupancy patterns and breeding conformations at all sites surveyed in 2006 and 2007. As habitat becomes more or less suitable, cuckoos likely respond by occupying those habitats that are most suitable for their breeding needs in any given year. Thus this annual variation in cuckoo distribution, abundance, and habitat use may be the norm for much of the lower Colorado River.

\section{Variation in Yellow-billed Cuckoo Detections, Occupied Sites and Habitat}

During the two years of this study we observed variation in the number of cuckoos detected, sites occupied and the quality of habitat they were detected and bred in. The changes in the number of cuckoo detections at the Grand Canyon NP/Lake Mead NRA area was the most striking difference between the two years. These differences as noted above are quite evident, which maybe due to the lake levels of Lake Mead, that

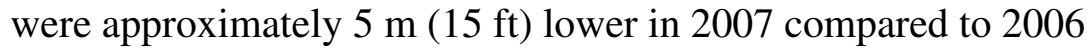
(http://www.usbr.gov/lc/region/g4000/hourly/mead-elv.html) due to long-term drought conditions in the Colorado River watershed. The greatest impact to the riparian habitat may be due to the declining lake levels ultimately affecting tree mortality (Figure 7.2), which was evident in the dramatic increase in the proportion of snags we detected in vegetation sampling plots between the two years.

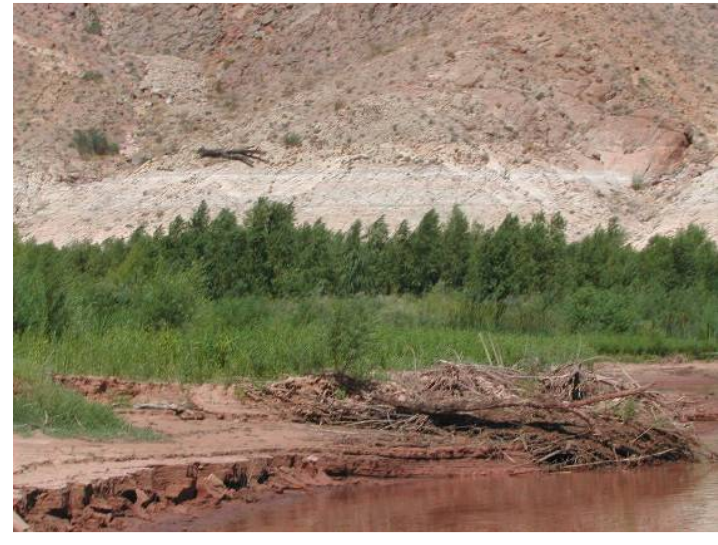

Iceberg Ridge, Lake Mead NRA, 2006

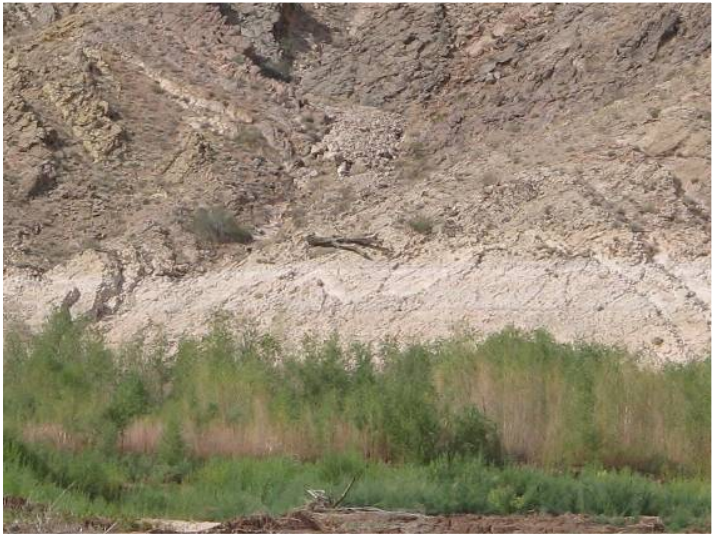

Iceberg Ridge, Lake Mead NRA, 2007

Figure 7.2. Lower Colorado River-Multi-Species Conservation Program, Yellow-billed cuckoo survey sites along the Colorado River at Lake Mead National Recreation Area, Ariz., 2007.

In 2007, snags made up 46 percent of the entire woody vegetation, but accounted for only 14 percent in 2006 (Figure 7.3). 


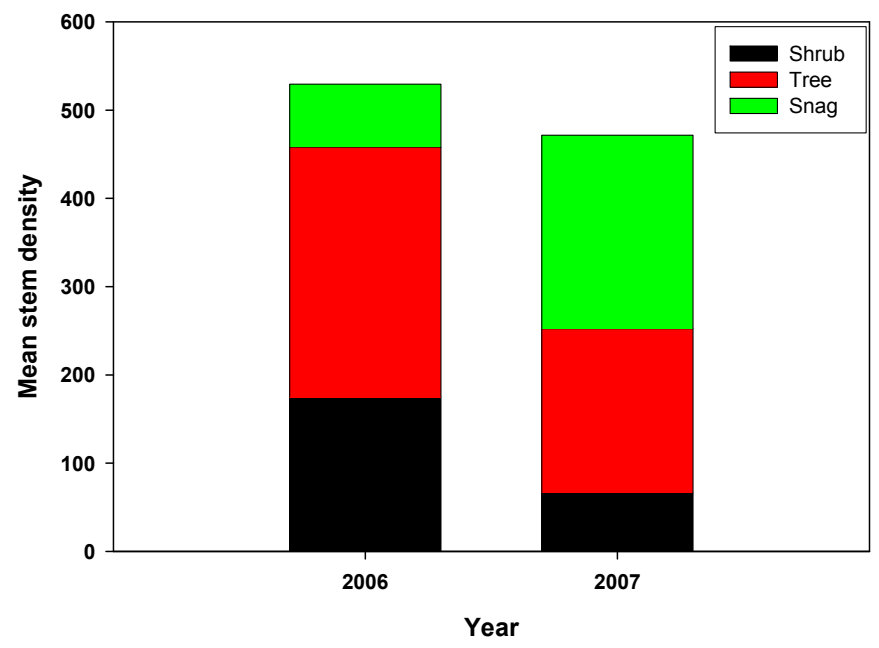

Figure 7.3. Lower Colorado River-Multi-Species Conservation Program, vegetation mean density for shrubs, trees and snags along the Colorado River, Lake Mead National Recreation Area, AZ, 2007.

These differences in habitat structure were also reflected when we examined microclimate characteristics at Grand Canyon NP/Lake Mead NRA between 2006 and 2007. We found that mean diurnal temperatures were nearly 17 percent greater in 2007 compared to $2006\left(\mathrm{U}_{6,24}=-2.4, \mathrm{p}=0.02\right)$ while diurnal relative humidity was 10 percent greater in 2006 than $2007\left(\mathrm{U}_{6,24}=1.9, \mathrm{p}=0.05\right.$; Figure 7.3). Likewise, nocturnal temperature was nearly 13 percent greater in 2007 compared to $2006\left(\mathrm{U}_{6,24}=-3.1, \mathrm{p}=\right.$ $0.002)$, but there was not a significant difference in nocturnal relative humidity between the two years $\left(\mathrm{U}_{6,24}=0.7, \mathrm{p}=0.48\right)$. 


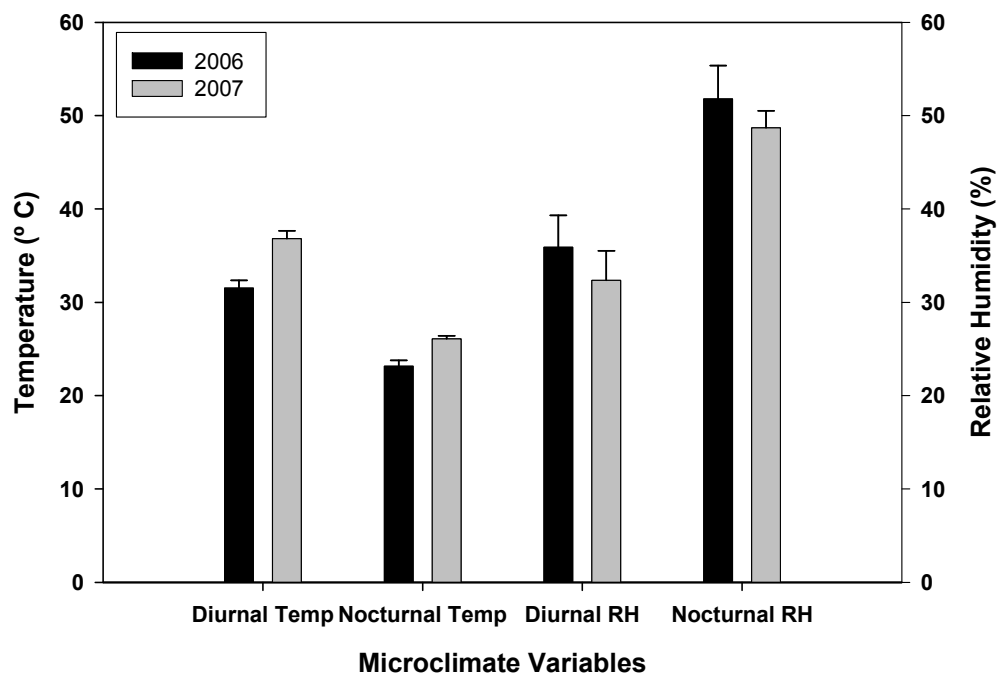

Figure 7.4. Lower Colorado River-Multi-Species Conservation Program, microclimate measurements (diurnal temperature, nocturnal temperature, diurnal relative humidity and nocturnal relative humidity) along the Colorado River, Lake Mead National Recreation Area, AZ.

However, this apparent drought induced stress on the vegetation was not evidenced in soil moisture readings. The soil moisture readings at Grand Canyon NP/Lake Mead NRA in 2007 (9 percent) where we had no presence of cuckoos was identical to values at the Bill Williams River NWR that was densely occupied by yellowbilled cuckoos. Thus, soil moisture may not be useful in predicting patterns of cuckoo occupancy.

We are not aware of the long-term patterns of cuckoo occupancy at sites within Grand Canyon NP/Lake Mead NRA. Sites along the lower Colorado River have likely historically been exposed to periodic drought and disturbance, and further study of yellow-billed cuckoo colonization patterns would be a useful guide for habitat restoration efforts in terms of the larger landscape decisions such as selecting the most suitable location for long-term cuckoo occupancy.

\section{Yellow-billed Cuckoo Breeding Verification}

From our results it is obvious that it is challenging to confirm yellow-billed cuckoo breeding at a site. Cuckoos are very secretive, difficult to detect, and move over large areas (Laymon 1998, Hughes 1999, Halterman 2005, Johnson et al. 2007). Verifying that cuckoos are breeding in a particular patch thus requires finding young, a nest, or copulating adults; observing these behaviors can sometimes be difficult. This reality makes it safe to assume that we did not observe all breeding activities that occurred in 2006 or 2007 . We know that more nests were present in our study sites than just the ones we were able to locate, because we found more fledglings than could be accounted for by nearby nests. Given this, the number of breeding activities recorded at a site should be interpreted as a minimum of breeding activity that occurred. However, all of our documented breeding activities were from the Bill Williams River NWR, 
indicating that this site has more and/or better breeding habitat than the other study sites on the lower Colorado River with the exception of Chuckwalla Cove in 2006. The difficulty of confirming cuckoo breeding highlights the importance of supplemental follow-up surveys. Total survey effort in both years was just over 500 hours, but when we used supplemental surveys in 2007 we detected 27 breeding events compared to only five breeding events in 2006 without the use of supplemental surveys.

\section{Survey Methodology Evaluation}

In both years of this study we evaluated the playback survey methodology, refining many of the methodologies in the second year. Notable changes between the two years include the adoption of supplemental follow-up surveys in 2007. These supplemental surveys were focused in areas where cuckoo presence had been confirmed during formal surveys. They are designed to determine the continued presence of cuckoos detected during formal surveys, and provide opportunities to observe breeding behavior and search for nests. These surveys also better defined yellow-billed cuckoo use of the habitat and site. Because of the supplemental survey effort, we did not conduct as many protocol surveys in 2007 as we did in 2006; however, the number of sites where we detected cuckoos and total number of survey hours remained constant. Thus we were able to obtain more detailed information at each occupied cuckoo site and at the same time we abandoned survey effort at sites that had no probability of detecting cuckoos.

The ways by which cuckoos were detected remained fairly constant across the two years, with 60 percent of detections made aurally, 10 percent visually, and 25 percent both aurally and visually. The number of broadcasts required to elicit a response from a yellow-billed cuckoo was variable. The abundance of cuckoos in a survey area may influence their response to playback, but response to playback was not consistent between the two years. At sites with the most detections, cuckoos were frequently detected unsolicited (prior to initial playback) or following the first playback in 2006. In 2007, most detections at these dense sites occurred following the first or second playback, and unsolicited detections were no different than surveys in areas with few cuckoo detections. We also found that at sites with fewer than 10 cuckoo detections, detections occurred later in the playback sequence (third, forth, and fifth playback) in 2006 (Johnson et al. 2007); in contrast in 2007 most detections in these areas occurred following the initial playback. The inconsistencies in cuckoos response warrants further investigation in order to develop the most effective survey protocol to detect yellowbilled cuckoos. Nevertheless since cuckoos continue to be detected after a fifth playback and also late in the breeding season, longer survey bouts over more survey periods appear to increase cuckoo's detection probability.

\section{Habitat Vegetation Characteristics}

Another important change between years was the method used to identify plots to characterize vegetation and microclimate of occupied cuckoo habitat. In 2006 we based vegetation and microclimate sampling plots on the location of the 2005 and 2006 cuckoo

detections. Rather than continue to describe the vegetation and microclimate of occupied habitats based on a cuckoo detection or a cuckoo nest, in 2007 we randomly placed vegetation and microclimate plots within occupied habitats to characterize the riparian habitat at the survey site-patch scale. The reason for the change in how vegetation plots were located was an issue of scale. Instead of looking the nest site or detection scale we 
wanted to examine it at a broader scale such as the patch scale. Any differences between the two years of this study should be interpreted in light of these methodological changes. In addition, vegetation sampling in 2006 was based on a center plot and three sub-plots, while in 2007 we only used a single plot. Differences in sampling methodology between the two years may confound some patterns in the characterization of yellow-billed cuckoo habitat.

We found that the dominant riparian tree species across 2006 and 2007 at occupied yellow-billed cuckoo survey sites remained cottonwood, willow, and tamarisk. In 2006, occupied sites had greater canopy cover driven by denser low and mid-canopies. However, we found in 2007 that the differences between occupied and unoccupied canopies were due to difference at higher canopy strata. Also in 2007, the canopies at both occupied and unoccupied sites were dominated by native species while in 2006 only occupied sites were more consistently dominated by native species. In 2006 and 2007, we found trees in the large and largest size classes were more numerous in occupied sites, and consistent with the dominant canopy layer across all occupancy sites, these trees were generally Goodding's willow. Consistent across both years was also the greater tree density in unoccupied sites. The density of woody species was consistently higher at unoccupied sites, except for stems in the snag class, which we found in equal numbers in the two occupancy statuses. For trees, the greater density in the unoccupied sites was driven by trees in the smallest size class, the most abundant size class across the entire study area. This could be a possible indication that cuckoos prefer areas with high dense canopies for nesting with an open understory for movement and foraging activities. Additional research can help determine consistent annual patterns of vegetation characteristics in these riparian habitats.

Generally speaking, the characterization of vegetation patterns among these study areas was consistent between the two years of the study. Bill Williams River NWR had a greater number of large Goodding's willow, Grand Canyon NP/Lake Mead NRA was dominated by willows and tamarisk in the smallest size class, and the row planting of native tree species at Imperial NWR, Cibola NWR, Pratt Restoration, Yuma West Wetlands and Quigley Pond WMA distinguished it from other more "natural" riparian habitats.

\section{Microclimate Characteristics}

We were able to measure the microclimate characteristics of riparian habitats during the entire yellow-billed cuckoo breeding season (covering 80 days) across a broad rage of habitats in 2007 compared to the late deployment (covering only 45 days), uneven distribution, and limited sampling size of microclimate analysis in 2006. However, in both years occupied habitats were more humid than unoccupied habitats. Although there were few temperature differences between occupied and unoccupied habitat in 2006, occupied habitats were cooler than unoccupied ones during the day in 2007. In 2006 occupied habitats had greater soil moisture, but in 2007 the cooler and more humid conditions of occupied sites did not correspond with greater soil moisture. While most cuckoo detections were at the Bill Williams River NWR and, at least in 2007, cooler and more humid conditions were prevalent there. Yellow-billed cuckoos are able to use drier and hotter habitats than those at Bill Williams River NWR. Sample size by study area was not sufficient in 2006 to be able to draw inferences by study area across the two years of the study. Any differences between the two years may have been due to 
difference in the timing and placement of $\mathrm{HOBO}$ sensors and soil moisture probes in 2006 and 2007.

In 2007, we expected that microclimate conditions were in part driven by the vegetation composition and characteristics of the habitat patch. However, we did not find a relationship between mean canopy cover and mean soil moisture in either year. It is likely that more complicated factors are involved in determining the microclimate regime of a patch including canopy height and complexity, dominant tree species, proximity to water, the nature of surrounding habitat, or many other variables. While yellow-billed cuckoos may respond to microclimate conditions in regards to nest placement, their decision to use one habitat and not another, or to focus their activities in one part of a habitat may be determined by coarser climatic conditions, broad vegetation characteristics, or the suitability of food resources. The mechanisms explaining the differences in microclimate regimes remain unclear and further investigation in all of these factors is necessary in order to understand yellow-billed cuckoo habitat requirements and thus may be important in managing for in terms of riparian restoration goals.

\section{Other Riparian Bird Detections}

During the 2006 and 2007 yellow-billed cuckoo field seasons we documented other bird species at or near our survey sites. Most species were observed before, during, or after our yellow-billed cuckoo surveys. Because the focus of our efforts was on detecting cuckoos, we did not attempt to quantify abundance of these additional species, nor to track down and verify any species that were not readily identifiable or obvious to the surveyors. We documented 190 bird species in 2006 and 160 species in 2007. While a decline of 30 species detections may appear substantial, the focus of research over these two years was on the yellow-billed cuckoo and the detection of other bird species was likely not consistent between the two years because of the time spent detecting non-target species. Thus this decline should not be viewed as a real loss of avian diversity.

Of the 190 total species detected in 2006 and 2007, nine were among the designated focal species under the Lower Colorado River Multi-Species Conservation Plan for both years. The composition of these nine species varied across our survey areas, but many were observed at Bill Williams River NWR. The willow flycatcher (Empidonax traillii), Bell's vireo (Vireo bellii), and yellow warbler (Dendroica petechia) were the most widespread species.

\section{What Have We Learned?}

Over the past two years we have undertaken the complex task of studying yellowbilled cuckoos along the lower Colorado River within the Multi-Species Conservation Planning area. This project had many challenges and obstacles, yet we have learned a tremendous amount about yellow-billed cuckoo habitat use and behavior. Below we will summarize some of the main points of increased understanding.

Because this study has only been conducted for the last two years, it is challenging to elucidate large-scale patterns. But there are some general conclusions we can draw from this research, particularly lessons from two important study areas; the Bill Williams River NWR and Grand Canyon NP/Lake Mead NRA. The Bill Williams River NWR appears to be the most important riparian habitat for yellow-billed cuckoos along the lower Colorado River. The majority of cuckoo detections and breeding activity 
occurred at this site during both years of the study. The riparian habitat at the Bill Williams River NWR appears to be ideal cuckoo habitat, with a tall dense overstory of native Goodding's willow and Fremont cottonwood and a cool, moist microclimate. We found that trees in the larger size classes were also more numerous in occupied sites, and consistent with the dominant canopy layer across all occupancy sites, these trees were generally native. We also learned that greater tree density occurs in unoccupied sites, and is driven by trees in the smallest size class. This suggests that cuckoos prefer areas with high dense canopies for nesting with a less dense understory for foraging activities.

The mechanisms explaining the differences in microclimate regimes remain unclear in yellow-billed cuckoo use of habitat and/or a site. The cuckoo's decision to use one habitat and not another, or to focus their activities in one part of a habitat may be determined by coarser climatic conditions, broad vegetation characteristics, or the suitability of food resources. Therefore, further investigation of all of these factors is warranted in order to understand yellow-billed cuckoo habitat requirements, which will be important for accomplishing riparian restoration goals. Ultimately a multivariate model would be a useful tool to use in order to determine the factors most important in yellow-billed cuckoo habitat selection. Identifying such characteristics is a key to effective restoration efforts for cuckoo habitat.

We also witnessed at the Grand Canyon NP/Lake Mead NRA site the effects of a long-term drought and associated tree mortality, which likely led to decreased live vegetation and an increase in the proportion of snags at this study area. We believe this led to the absence of cuckoo detections and breeding activity in 2007. This illustrates that rapid changes in habitat can have detrimental effect of local cuckoo populations, and other occupied sites could face the same fate if they are exposed to the same degree of environmental change. It remains to be seen if the riparian habitat at Grand Canyon NP/Lake Mead NRA will continue to be unsuitable for yellow-billed cuckoos in the nearterm. It is also unclear whether riparian restoration efforts along the lower Colorado River could result in an area rapidly becoming suitable for yellow-billed cuckoo breeding activity. Continued cuckoo surveys and monitoring of habitat conditions over the longterm would be essential to determine how natural and managed changes to riparian habitat influences yellow-billed cuckoo populations.

We were also constantly reminded that this species is very secretive and elusive and the amount of information one can gather can be limited due to its behavior. However, we found that supplementing our formal surveys with supplemental (followup) surveys has helped obtain finer details of cuckoos behavior and habitat use, and consider these follow up visits invaluable in studying the biology of the yellow-billed cuckoo.

And finally, we believe that continued monitoring of yellow-billed cuckoo population and habitat along the lower Colorado River is necessary to elucidate long-term patterns in their distribution, abundance, and habitat use in order best guide efforts to restore riparian habitat suitable for cuckoos along the lower Colorado River, and ultimately prevent the listing of yellow-billed cuckoos.

\section{Acknowledgments}

This project was made possible by the support and cooperation of many persons, agencies and private companies. Funding was provided by the Bureau of Reclamation in Boulder City, Nevada, under the Multi-Species Conservation Plan, and the USGS 
Southwest Biological Science Center in Flagstaff, Arizona. In particular, we thank Lorri Gray (Bureau of Reclamation) for her support of this project. The coordination and land access permission from the Bureau of Land Management and the Arizona Game and Fish Department was of particular importance. We also want to thank Greg Clune (Bureau of Reclamation) for administrative assistance and assisting the field crew. We would also like to thank Hira Walker and Carol Beardmore for their valuable peer review of this report. The success of the project is ultimately due to the efforts of the field personnel on the 2006 and 2007 USGS field crews: Chris Calvo, Ivan Samuels, Laura Riley, Geoffrey

Bland, Brent Campos, Shawn Carroll, Julia Fromfeld, Mary Davis, Samantha Dorr, Sarah Brown and Ken Etzel.

\section{References Cited}

American Ornithologists' Union. 1983. Check-list of North American birds: The species of birds of North America from the Artic through Panama, including the West Indies and Hawaiian Islands. American Ornithologists' Union: Washington, D.C. 877pp.

American Ornithologists' Union. 1998. Check-list of North American birds, 6th edition. American Ornithologists' Union, Washington, D.C.

Andersen, D.C. 1987. Below-ground herbivory in natural communities: A review emphasizing fossorial animals. Quarterly Review of Biology 62:261-286.

Andersen, D.C. 1994. Are cicadas (Diceroprocta apache) both a "keystone" and a "critical-link" species in lower Colorado River riparian communities? Southwestern Naturalist 39:26-33.

Arizona Game and Fish Department. 2002. Heritage Data Management System. http://www.gf.state.az.us/frames/fishwild/hdms.

Bayne, E.M., and K.A. Hobson. 2001. Effects of habitat fragmentation on pairing success of ovenbirds: importance of male age and floater behavior. Auk 118:380-388.

Bent, A.C. 1940. Life histories of North American cuckoos, goastsuckers, hummingbirds, and their allies. United States Natural History Museum Bulletin 176.

Bibby, C.J., N.D. Burgess, and D.A. Hill. 1992. Bird census techniques. Academic Press, New York. 257 pp.

Bogner, H.E., and G.A. Baldassarre. 2002. The effectiveness of call-response surveys for detecting least bitterns. Journal of Wildlife Management 66:976-984.

Braden, G.T., K. Carter, and M.R. Rathbun. 2005a. The status of Yuma clapper-rail and yellow-billed cuckoo along portions of Virgin River, Muddy River and Las Vegas Wash, southern Nevada, 2003. Prepared for U.S. Fish and Wildlife Service, Southern Nevada Field Office, and Southern Nevada Water Authority, Las Vegas, Nevada. 33 pp.

Braden, G.T., A. Miller, L. Crew and K. Carter. 2005b. The status of Yuma clapper-rail and yellow-billed cuckoo along portions of Virgin River, Muddy River and Las Vegas Wash, southern Nevada, 2004. Prepared for U.S. Fish and Wildlife Service, Southern Nevada Field Office, and Southern Nevada Water Authority, Las Vegas, Nevada. 73 pp. 
Cardinal, S.N. 2005. Conservation of southwestern willow flycatchers: Home range and habitat use by an endangered passerine. Masters Thesis, Northern Arizona University. $55 \mathrm{pp}$.

Conway C. J., Kirkpatrick C. 2001. Population status, detection probability, and effects of fire on buff-breasted flycatchers. Arizona Game and Fish Department. Phoenix, USA.

Conway C. J., Simon J. C. 2003. Comparison of detection probability associated with burrowing owl survey methods. Journal of Wildlife Management 67:501-511.

Corman, T.E., and R.T. Magill. 2000. Western yellow-billed cuckoo in Arizona: 1998 and 1999 survey report. Arizona Game and Fish, Technical Report 150. 49 pp.

Corman, T.E. and C. Wise-Gervais. 2005. Arizona breeding bird atlas. "University of New Mexico Press."

Dawson, D.G. 1981. Experimental design when counting birds. Studies in Avian Biology 6:392-398.

Durst, S.L. 2004. Southwestern willow flycatcher potential prey base and diet in native and exotic habitats. Masters thesis, Northern Arizona University, Flagstaff, AZ. 86 pp.

Ehrlich, P.R., D.S. Dobkin, and D. Wheye. 1988. The birders handbook: A field guide to the natural history of North American birds. Simon and Schuster, New York.

Ehrlich, P.R., D.S. Dobkin, and D. Wheye. 1992. Birds in jeopardy. "Stanford University Press."

Farnsworth, G. L., Pollack K. H., Nichols J. D., Simons T. S., Hines J. E., Sauer J. R. 2002. A removal model for estimating detection probabilities from point count surveys. Auk 119: 414-425 [http://www.bioone.org/perlserv/?request=getpdf\&doi $=10.1642 \% 2 \mathrm{~F} 0004-$ 8038\%282002\%29119\%5B0414\%3AARMFED\%5D2.0.CO\%3B2].

Ferrer, M., and J. A. Donázar. 1996. Density-dependent fecundity by habitat heterogeneity in an increasing population of Spanish Imperial Eagles. Ecology 77:69-74.

Forsman, E.D., E.C. Meslow, and M.J. Strub. 1977. Spotted owl abundance in young versus old-growth forest, Oregon. Wildlife Society Bulletin 5:43-47.

Franzreb, K. 1987. Perspectives on managing riparian ecosystems for endangered bird species. Western Birds 18:10-13.

Furtek, B., C.R. Tomlinson, and F. Griego. 2002. Breeding status and surveys for the Southwestern Willow Flycatcher and Yellow-billed Cuckoo at various sites in southern Nevada. Program Activities report, Nevada Division of Wildlife, Southern Region, Nongame Program.

Gaines, D. 1974. Review of the status of the yellow-billed cuckoo in California: Sacramento Valley populations. The Condor 76:204-209.

Gaines, D. 1977. Current status and habitat requirements of the yellow-billed cuckoo in California. Red Bluff, California. 67 pp. 
Gaines, D., and S.A. Laymon. 1984. Decline, status, and preservation of the yellow-billed cuckoo in California. Western Birds 15: 49-80.

Glahn, J.F. 1974. Study of breeding rails recorded calls in north central Colorado. Wilson Bulletin 86:206-214.

Gloutney, M.L., and R.G. Clark. 1997. Nest-site selection by mallards and blue-winged teal in relation to microclimate. Auk 114:381-395.

Griese, H.J., R.A. Ryder, and C.E. Braun. 1980. Spatial and temporal distribution of rails in Colorado. Wilson Bulletin 92:96-102.

Grinnell, J. 1915. A distributional list of the birds of California. Pacific Coast Avifauna $11: 75$.

Grinnell, J., and A. Miller. 1944. The distribution of the birds of California Pacific Coast. Avifauna.

Groschupf, K. 1987. Status of the yellow-billed cuckoo (Coccyzus americanus occidentalis) in Arizona and west Texas. Report prepared for the U.S. Fish and Wildlife Service. $34 \mathrm{pp}$.

Hall, L.S., P.R. Krausman, and M.L. Morrison. 1997. Habitat concept and a plea for standard terminology. Wildlife Society Bulletin 25;173-182.

Halterman, M.D. 1991. Distribution and habitat use of the yellow-billed cuckoo (Coccyzus americanus occidentalis) on the Sacramento River, California, 198790. Masters' thesis, California State University, Chico. 49 pp.

Halterman, M.D. 1998. Population status, site tenacity, and habitat requirements of the yellow-billed cuckoo at the Bill Williams River, Arizona: Summer 1998. United States Bureau of Reclamation, Lower Colorado River Region, Boulder City.13 pp.

Halterman, M.D. 2001. Population status of the yellow-billed cuckoo at the Bill Williams River NWR and Alamo Dam, Arizona, and Southern Nevada: Summer 2000. Bureau of Reclamation and U.S. Department of Interior Fish and Wildlife Service. Boulder City Nevada. 19 pp.

Halterman, M.D. 2002. Surveys and life history studies of the yellow-billed cuckoo: Summer 2001. USDI Bureau of Reclamation. Boulder City. 19 pp.

Halterman, M.D. 2003. Surveys and life history studies of the yellow-billed cuckoo: Summer 2002. Bureau of Reclamation and Bureau of Land Management. Boulder City Nevada. 21 pp.

Halterman, M.D. 2004. Surveys and life history studies of the yellow-billed cuckoo: Summer 2003. Draft report to the Bureau of Reclamation, Boulder City. 19 pp.

Halterman M.D. 2005. Surveys and life history studies of the yellow-billed cuckoo: Summer 2004. Administrative report to the Bureau of Reclamation, Boulder City. $20 \mathrm{pp}$. 
Halterman, M.D., and S.A. Laymon. 1994. Population status, site tenacity, and habitat requirements of the yellow-billed cuckoo at the Bill Williams River, Arizona: Summer 1993. Report 1448-00002-93-022 for U.S. Department of Interior, Fish and Wildlife Service, Bill Williams River National Wildlife Refuge, Parker, Arizona. 18 pp.

Halterman, M.D., and S.A. Laymon. 1995. Population status, site tenacity, and habitat requirements of the yellow-billed cuckoo at the Bill Williams River, Arizona: Summer 1994. Report 1448-00002-94-022 for U.S. Department of Interior, Fish and Wildlife Service, Bill Williams River National Wildlife Refuge, Parker, Arizona. $19 \mathrm{pp}$.

Halterman, M.D., M.J. Johnson, and J.A. Holmes. 2006. Western yellow-billed cuckoo natural history summary and survey methodology. Unpublished report, Southern Sierra Research Station, Weldon, California.

Hamilton, W.J. III, and M.E. Hamilton. 1965. Breeding characteristics of the yellowbilled cuckoo in Arizona. Proceedings of the California Academy of Sciences, 4th Series, 32:405-432.

Holmes, J.A., M.J. Johnson and C. Calvo. 2008. Yellow Billed Cuckoo distribution, habitat use and breeding ecology in the Verde Watershed of Arizona, 2003-2004. Final Report, Arizona Game and Fish Heritage Program, Phoenix, Arizona, 174 pp.

Holway, D.A. 1991. Nest-site selection and the importance of nest concealment in the black-throated blue warbler. Condor 93:575-581.

Howe, W.H. 1986. Status of the yellow-billed cuckoo in New Mexico, final report. New Mexico Department of Game and Fish, Share with Wildlife Program, Santa Fe, 25 pp.

Howell, S.N.G., and S. Webb. 1995. A guide to the birds of Mexico and northern Central America. Oxford University Press, New York.

Hughes, J.M. 1999. Yellow-billed cuckoo (Coccyzus americanus). In A. Poole and F. Gill (eds.), The Birds of North America. The Birds of North America, Inc., Philadelphia.

James, F.C., and H.H. Shugart. 1970. A quantitative method of habitat description. American Birds 24:727-736.

Johnson, D.H. 1995. Point counts of birds: What are we estimating? Pages 117-123 in Ralph C.J., Sauer J. R., Droege S. Monitoring bird populations by point counts. U.S. Forest Service General Technical Report PSW-GTR-149, Pacific Southwest Research Station. Berkeley, California, USA.

Johnson, R.R., B.T. Brown, L.T. Haight, and J.M. Simpson. 1981. Playback recordings as a special avian censusing technique. In C.J. Ralph and J.M. Scott (eds.), Estimating the numbers of terrestrial birds. Studies in Avian Biology 6:68-75.

Johnson, M.J., and C. O'Brien. 1998. Southwestern willow flycatcher and yellow-billed cuckoo surveys along the San Juan River, Utah (Four Corners Bridge-Mexican Hat): 1998. Final report to the Division of Wildlife Resources (Contract 976475). Colorado Plateau Field Station, Northern Arizona University, Flagstaff. 45 pp. 
Johnson, M. J., J. A. Holmes, and R. Weber. 2006a. Final report: Yellow-billed cuckoo distribution and abundance, habitat requirements, and breeding ecology in select habitats of the Roosevelt Habitat Conservation Plan, 2003-2006. Report submitted to Salt River Project (SRP), Phoenix, AZ; USGS, Southwest Biological Science Center-Colorado Plateau Research Station, Flagstaff. 41 pp.

Johnson, M.J., J.A. Holmes, R. Weber, and M. Dionne. 2006b. Yellow-billed cuckoo distribution, abundance and habitat use along the lower Colorado and Gila Rivers in La Paz and Yuma Counties, 2005. Report submitted to Arizona Game and Fish Heritage Program, Bureau of Land Management, Bureau of Reclamation, and Northern Arizona University, Flagstaff. 112 pp.

Johnson, M.J., J.A. Holmes, C. Calvo, I. Samuels, S. Krantz, and M.K. Sogge. 2007. Yellow-billed cuckoo distribution, abundance, and habitat use along the lower Colorado and tributaries, 2006 annual report: U.S. Geological Survey Open-File Report 2007-1097, 219 pp.

Karban, R. 1980. Periodical cicada nymphs impose periodical oak tree wood accumulation. Nature 287:326-327.

Kirkpatrick, C., C.J. Conway, K.M. Hughes, J.C. Devos Jr. Probability of detecting bandtailed pigeons during call-broadcast versus auditory surveys. Journal of Wildlife Management 71:231-237.

Kingery, H.E., ed. 1998. Colorado breeding bird atlas. Colorado Wildlife Heritage Foundation, Denver. 636 pp.

Koronkiewicz, T.J., M.K. Sogge, C. van Riper III, and E.H. Paxton. 2006. Territoriality, site fidelity, and survivorship of willow flycatchers wintering in Costa Rica. Condor 108:558-570.

Krohne, D.T., T.J. Couillard, and J.C. Riddle. 1991. Population responses of Permyscus leucopus and Blarina brevicauda to emergence of periodical cicadas. American Midland Naturalist 126:317-321.

Launer, A.E., D.D. Murphy, S.A. Laymon, and M.D. Halterman. 1990. 1990 distribution and habitat requirements of the yellow-billed cuckoo in California. Administrative Report to the Nature Conservancy. Stanford, $20 \mathrm{pp}$.

Laymon, S.A. 1998a. Yellow-billed cuckoo survey and monitoring protocol for California. Unpublished report. Weldon, California. 20 pp.

Laymon, S.A. 1998b. Yellow-billed cuckoo (Coccycus americanus). In The Riparian Bird Conservation Plan: A strategy for reversing the decline of riparian-associated birds in California. California Partners in Flight. http://www.prbo.org/calpif/htmldocs/riparian.

Laymon, S.A., and M.D. Halterman. 1985. Yellow-billed cuckoos in the Kern River Valley: 1985 population, habitat use, and management recommendations. Report to the Nature Conservancy, Kern River Preserve. Sacramento, CA. 29 pp.

Laymon, S.A., and M.D. Halterman. 1987a. Can the western subspecies of the yellowbilled cuckoo be saved from extinction? Western Birds 18: 19-25. 
Laymon, S.A., and M.D. Halterman. 1987b. Distribution and status of the yellow-billed cuckoo in California: 1986-1987. Report submitted to California Department of Fish and Game, Nongame Bird and Mammal Section. Sacramento. 35 pp.

Laymon, S.A., and M.D. Halterman. 1989. A proposed habitat management plan for yellow-billed cuckoos in California. U.S. Department of Agriculture Forest Service General Technical Report PSW-110, pp. 272-277.

Laymon, S.A, P.L. Williams, and M.D. Halterman. 1997. Breeding status of the yellowbilled cuckoo in the South Fork Kern River Valley, Kern County, California: Summary report 1985-1996. Prepared for U.S. Department of Agriculture, Forest Service, Sequoia National Forest, Cannell Meadow Ranger District. Challenge Cost-Share Grant 92-5-13.

Legare, M.L., W.R. Eddleman, P.A. Buckley, and C. Kelly. 1999. The effectiveness of tape playback in estimating black rail density. Journal of Wildlife Management 63:116-125.

Lower Colorado River Multi-Species Conservation Program (LCR MSCP). 2004. Lower Colorado River Multi-Species Conservation Program, Volume II: Habitat Conservation Plan. Final. December 17 (J\&S 00450.00.). Sacramento California.

MacKenzie, D.I., J.D. Nichols, G.B. Lachman, S. Droege, J.A. Royle, and C.A. Langtimm. 2002. Estimating site occupancy when detection probabilities are less than one. Ecology 83: 2248-2255.

Manolis, T., B. Webb, R. Spotts, S. Evans, B. Andrews, C. Brown, R. Schmidt, A Tura, and M.J. Palmer. 1986. Petition to list the western yellow-billed cuckoo as Endangered in a significant portion of its range. Letter to Frank H. Dunkle, Director, U.S. Fish and Wildlife Service. Federal Register, January 21, 1987.

Martin, T.E. 1995. Avian life history evolution in relation to nest sites, nest predation, and food. Ecological Monographs 65:101-127.

Martin, T.E., and G.R. Geupel. 1993. Methods for locating nests and monitoring success. Journal of Field Ornithology 64:438-449.

Martin, T.E., C.R. Paine, C.J. Conway, W.M. Hochachka, P. Allen, and W. Jenkins. 1997. BBIRD field protocol. Montana Cooperative Wildlife Research Unit, University of Montana, Missoula.

McLeod, M.A., T.J. Koronkiewicz, B.T. Brown, and S.W. Carothers. 2005. Southwestern willow flycatcher surveys, demography, and ecology along the lower Colorado River and tributaries, 2004. Annual report submitted to U.S. Bureau of Reclamation, Boulder City, NEVADA, by SWCA Environmental Consultants, Flagstaff. 155pp.

McKernan, R.L., and G.T. Braden. 2001. The status of Yuma clapper-rail and yellowbilled cuckoo along portions of Virgin River, Muddy River and Las Vegas Wash, southern Nevada, 2000. Prepared for U.S. Fish and Wildlife Service, Southern Nevada Field Office, and Southern Nevada Water Authority, Las Vegas, NV. 14 pp. 
Miller, J.R., J.A. Wiens, N.T. Hobbs, and D.M. Theobold. 2003. The effects of human settlement on bird communities in lowland riparian areas near Colorado's Front Range. Ecological Applications 13:1041-1059.

Mueller-Dombois, D., and H. Ellenberg. 1974. Aims and methods of vegetation ecology. John Wiley \& Sons, New York. 547 pp.

Navajo Nation. 2005. Navajo Endangered Species List. Navajo Fish and Wildlife Department. http://nnhp.navajofishandwildlife.org/nnhp_nesl.pdf.

Nevada Natural Heritage Program. 2004. Nevada Animal Species of Concern. Nevada Department of Conservation and Natural Resources http://heritage.nv.gov/lists/animls04.htm\#sensitive

Newton, I. 1980. The role of food in limiting bird numbers. Ardea 68:11-30.

Nichols, J. D., J. E. Hines, J. R. Sauer, F. W. Fallon, J. E. Fallon, and P. J. Heglund. 2000. A double-observer approach for estimating detection probability and abundance from point counts. Auk 117:393-408 [http://www.bioone.org/perlserv/?request=get-pdf\&doi=10.1642\%2F00048038\%282000\%29117\%5B0393\%3AADOAFE\%5D2.0.CO\%3B2].

Noon, B.R. 1981. Techniques for sampling avian habitat. In D.E. Capen (ed.), The use of multivariate statistics in studies of wildlife habitat. U.S. Department of Agriculture, Forest Service General Technical Report GTR-RM-87, Rocky Mountain Research Station, Fort Collins, Colorado.

Ohmart, R.D., B.W. Anderson, and W.C. Hunter. 1988. The ecology of the lower Colorado River from Davis Dam to the Mexico-United States International Boundary: A community profile. U.S. Fish and Wildlife Service Biological Report 85 (7.19). 296 pp.

Pendleton G. W. 1995. Effects of sampling strategy, detection probability, and independence of counts on the use of point counts. Pages 131-134 in Ralph C. J., Sauer J. R., Droege S. Monitoring bird populations by point counts. U.S. Forest Service General Technical Report PSW-GTR-149. Pacific Southwest Research Station. Berkeley, California, USA.

Penteriani, V., M. Gallardo, and H. Cazassus. 2002. Conspecific density biases passive auditory surveys. Journal of Field Ornithology 73:387-391.

Phillips, A., J. Marshall, and G. Monson. 1964. The birds of Arizona. "University of Arizona Press."

Pollock, K.H., J.D. Nichols, T.R. Simons, G.L. Farnsworth, L.L. Bailey, and J.R. Sauer. 2002. Large scale wildlife monitoring studies: Statistical methods for design and analysis. Environmetrics 13:105-119.

Powell, B.F., and R.J. Steidl. 2000. Nesting habitat and reproductive success of southwestern riparian songbirds. Condor 102:823-831.

Pyle, P., S.N.G. Howell, R.P. Yunick, and D.F. DeSante. 1997. Identification guide to North American passerines: Part 1. Slate Creek Press, Bolinas, California. 
Rathbun, M.R., and G.T. Braden. 2003. The status of Yuma clapper-rail and yellowbilled cuckoo along portions of the Virgin River and Muddy River in southern Nevada for 2002. Prepared for Southern Nevada Water Authority, Las Vegas, NV. 29 pp.

Robbins, C.S. 1978. Census techniques for forest birds. Pages 142-163 in R.M. DeGraff (tech. coord.), Proceeding of the workshop on management of southern forests for nongame birds. U.S. Forest Service General Technical Report WE-14, Asheville, North Carolina.

Rosenberg, K.V., R.D. Ohmart, and B.W. Anderson. 1982. Community organization of riparian breeding birds: Response to an annual resource peak. Auk 99:260-274.

Rosenberg, K.V., R.D. Ohmart, W.C. Hunter, and B.W. Anderson. 1991. Birds of the lower Colorado River valley. University of Arizona, Tucson.

Rourke, J.W., T.D. McCarthey, R.F. Davidson, and A.M. Santaniello. 1999.

Southwestern willow flycatcher nest monitoring protocol. Nongame and Endangered Wildlife Program Technical Report 144. Arizona Game and Fish Department, Phoenix, Arizona.

Russell, S.M., and G. Monson. 1998. The birds of Sonora. University of Arizona Press, Tucson.

Saab, V. 1999. Importance of spatial scale to habitat use by breeding birds in riparian forests: A hierarchical analysis. Ecological Applications 9:135-151.

Scott, M.L., M. E. Miller, and J.C. Schmidt. 2004. The structure and functioning of riparian ecosystems of the Colorado Plateau-Conceptual models to inform the vital-sign selection process. Prepared for National Park Service, Southern Colorado Plateau Network, Northern Arizona University, Flagstaff.

Sergio, F. and I. Newton. 2003. Occupancy as a measure of territory quality. Ecology 72:857-865.

Small, A. 1994. California birds: Their status and distribution. "Ibis Publishing Company."

Smith, D.M., J.F. Kelly, and D.M. Finch. 2006. Cicada emergence in southwestern riparian forest: Influences of wildfire and vegetation composition. Ecological Applications 16:1608-1618.

Sogge, M.K., R.M. Marshall, S.J. Sferra, and T.J. Tibbitts. 1997. A southwestern willow flycatcher natural history summary and survey protocol. National Park Service Technical Report NPS/NAUcprs/NRTR-97/12.

Stephens, F. 1903. Bird notes from eastern California to western Arizona. Condor 5:7578.

Strong, T.R., and C.E. Bock. 1990. Bird species distribution patterns in riparian habitats in southeastern Arizona. Condor 92: 866-885.

Swarth, H.S. 1905. Summer birds of the Papago Indian Reservation and of the Santa Rita Mountains, Arizona. Condor 7: 23-28, 47-50, 77-82. 
Swarth, H.S. 1914. A distributional checklist of the birds of Arizona. Pacific Coast Avifauna 10:1-33.

Taylor, R. 1978. The eared trogon in Arizona. Report by [?]Coronado National Forest, Tucson.

U.S. Fish and Wildlife Service. 1985. Sensitive species management plan for the western yellow-billed cuckoo. Portland, Oregon.

U.S. Fish and Wildlife Service. 2002. Yellow-billed cuckoo candidate listing on Endangered Species List. Federal Register 67:114.

Vega Rivera, J.H., W. J. McShea, J. H. Rappole, and C. A. Haas. 1999. Postbreeding movements and habitat use of adult wood thrushes in northern Virginia. Auk 116:458-466.

Vega River, J.H., W.J. McShea, and J.H. Rappole. 2003. Comparison of breeding and postbreeding movements and habitat requirements for the scarlet tanager (Piranga olivacea) in Virginia. Auk 120:632-644.

Veit, R., and W. Petersen. 1993. Birds of Massachusetts. Massachusetts Audubon Society, Lincoln, Massachusetts.

Visher, S.S. 1910. Notes on the birds of Pima County, Arizona. Auk 27:279-288.

Walsberg, G.E. 1985. Physiological consequences of microhabitat selection. Pages 389413 in M.L. Cody (ed.), Habitat selection in birds. Academic Press, Orlando, Florida. 
This page intentionally left blank 


\section{Appendixes 1-6}

The following appendixes provide a summary of Yellow-billed Cuckoo detections, a description of each Yellow-billed Cuckoo detection, incidental detections, habitat photos, and a list of other bird species observed during surveys. 
This page intentionally left blank 


\section{Appendix 1. Summary of Yellow-billed Cuckoo Detections by Survey Period, 2007}

Table 1-1. A summary of yellow-billed cuckoo detections by survey period in 2007 at all areas and sites along the Muddy and White rivers in Nevada and the Colorado, Bill Williams, and Gila Rivers in Arizona and California. Detections made on supplemental visits are displayed in parenthesis.

\begin{tabular}{|c|c|c|c|c|c|}
\hline Survey site name & Survey 1 & Survey 2 & Survey 3 & Survey 4 & Survey 5 \\
\hline \multicolumn{6}{|c|}{ Pahranagat NWR } \\
\hline Pahranagat North & 0 & 0 & 0 & 0 & N/A \\
\hline Pahranagat South & 0 & 0 & 0 & 0 & N/A \\
\hline Total & 0 & 0 & 0 & 0 & \\
\hline \multicolumn{6}{|c|}{ Overton WMA } \\
\hline Honeybee Pond & 0 & 0 & 0 & 0 & N/A \\
\hline Overton Wildlife & 0 & 0 & 0 & 0 & N/A \\
\hline Total & 0 & 0 & 0 & 0 & \\
\hline \multicolumn{6}{|c|}{ Grand Canyon NP/ Lake Mead NRA } \\
\hline RM 274.5 & 0 & 0 & 0 & 0 & N/A \\
\hline Cuckoo Beach & 0 & 0 & 0 & 0 & N/A \\
\hline Iceberg Ridge & 0 & 0 & 0 & 0 & N/A \\
\hline Chuckwalla Cove & 0 & 0 & 0 & 0 & N/A \\
\hline Big Horn Draw & 0 & 0 & 0 & 0 & N/A \\
\hline Total & 0 & 0 & 0 & 0 & \\
\hline \multicolumn{6}{|c|}{ Havasu NWR } \\
\hline Pintail Slough & 0 & 1 & 0 & 0 & N/A \\
\hline North Dike & 0 & $1(2)$ & 0 & 0 & N/A \\
\hline Topock Marsh Restoration & 1 & 0 & $0(7)$ & 0 & N/A \\
\hline Topock Tamarisk & 0 & 0 & 0 & 0 & N/A \\
\hline Total & 1 & $2(2)$ & $0(7)$ & 0 & \\
\hline \multicolumn{6}{|c|}{ Bill Williams River NWR } \\
\hline Teepee Trail & 0 & 0 & 1 & 0 & N/A \\
\hline Cottonwood Patch & $3(4)$ & $3(8)$ & $2(1)$ & 0 & 0 \\
\hline Cave Wash & $2(3)$ & $3(33)$ & $3(8)$ & 3 & 0 \\
\hline Honeycomb Bend & $5(9)$ & $3(6)$ & $2(5)$ & $1(4)$ & 0 \\
\hline Mineral Wash & $13(11)$ & 7 & $5(11)$ & $2(1)$ & 0 \\
\hline Big Bend & $4(7)$ & $7(14)$ & $2(5)$ & $6(16)$ & $1(1)$ \\
\hline Gibraltar Rock & $4(11)$ & $4(19)$ & $0(2)$ & 1 & 0 \\
\hline Sandy Wash & $0(1)$ & $3(11)$ & $6(18)$ & $3(6)$ & 2 \\
\hline Fox Wash & 0 & 1 & $1(1)$ & 0 & N/A \\
\hline Mosquito Flats & 0 & 3 & $6(12)$ & 4 & 2 \\
\hline Saguaro Slot & $0(1)$ & $2(3)$ & 4 & $2(8)$ & 0 \\
\hline North Burn & 0 & 1 & 2 & 2 & 0 \\
\hline
\end{tabular}


Table 1-1. A summary of yellow-billed cuckoo detections by survey period in 2007 at all areas and sites along the Muddy and White rivers in Nevada and the Colorado, Bill Williams, and Gila Rivers in Arizona and California. Detections made on supplemental visits are displayed in parenthesis.-Continued

\begin{tabular}{|c|c|c|c|c|c|}
\hline Survey site name & Survey 1 & Survey 2 & Survey 3 & Survey 4 & Survey 5 \\
\hline Bill Williams River Marsh & 1 & 0 & 4 & $3(3)$ & 0 \\
\hline Total & $32(47)$ & $37(94)$ & $38(63)$ & $27(38)$ & $5(1)$ \\
\hline \multicolumn{6}{|c|}{ Ahakhav Tribal Preserve-CRIT Restoration } \\
\hline $\begin{array}{l}\text { Ahakhav Tribal Preserve- } \\
\text { CRIT Restoration }\end{array}$ & 2 & 0 & 0 & 0 & N/A \\
\hline \multicolumn{6}{|c|}{ Cibola NWR } \\
\hline Cibola North Restoration & 0 & 0 & 1 & 0 & N/A \\
\hline $\begin{array}{l}\text { Cibola Nature Trail } \\
\text { Restoration }\end{array}$ & 2 & 0 & 0 & 0 & N/A \\
\hline $\begin{array}{l}\text { Cibola Eucalyptus } \\
\text { Restoration }\end{array}$ & 1 & 1 & 0 & 0 & N/A \\
\hline Cibola South Restoration & 0 & 2 & 0 & 0 & N/A \\
\hline Total & 3 & 3 & 1 & 0 & \\
\hline \multicolumn{6}{|c|}{ Picacho SRA } \\
\hline Picacho SRA & 0 & 0 & 0 & 0 & N/A \\
\hline \multicolumn{6}{|c|}{ Imperial NWR } \\
\hline Imperial South Restoration & 2 & 1 & 0 & 0 & N/A \\
\hline \multicolumn{6}{|c|}{ Mittry Lake WMA/Pratt Restoration } \\
\hline $\begin{array}{l}\text { Mittry Lake WMA/Pratt } \\
\text { Restoration }\end{array}$ & 0 & 0 & 0 & 0 & N/A \\
\hline \multicolumn{6}{|c|}{ Gila/Colorado River Confluence } \\
\hline Colorado River & 2 & 0 & 0 & 0 & N/A \\
\hline Gila River & 0 & 0 & 0 & 0 & N/A \\
\hline Total & 2 & 0 & 0 & 0 & \\
\hline \multicolumn{6}{|c|}{ Yuma West Wetlands } \\
\hline Yuma West Wetlands & 0 & 0 & 0 & 0 & N/A \\
\hline \multicolumn{6}{|c|}{ Limitrophe Division } \\
\hline Limitrophe Division North & 0 & 0 & 0 & 0 & N/A \\
\hline Limitrophe Division South & 2 & 0 & 0 & 0 & N/A \\
\hline Total & 2 & 0 & 0 & 0 & \\
\hline \multicolumn{6}{|c|}{ Gila River/Quigley Pond WMA } \\
\hline $\begin{array}{l}\text { Gila River/Quigley Pond } \\
\text { WMA }\end{array}$ & 4 & 1 & 0 & 0 & N/A \\
\hline Total All Areas & $48(47)$ & $44(96)$ & $39(70)$ & $27(38)$ & $5(1)$ \\
\hline
\end{tabular}




\section{Appendix 2. Narrative Descriptions of Each Yellow-billed Cuckoo Detection in the Lower Colorado River Watershed, 2007}

The following are descriptions of each yellow-billed cuckoo detection of each yellow-billed cuckoo detection in the lower Colorado River watershed along the Muddy River, Nevada, lower Colorado, Bill Williams, and Gila rivers, Arizona and California, 2007, made during the 2007 field season. Descriptions include how the bird was detected (solicited calls in response to playback recordings or unsolicited), the habitat the cuckoo was observed in, and behavioral observations such as vocalization type, courtship behavior, and breeding status.

We assigned breeding status based on observations of cuckoo behavior conducted across all five surveys and supplemental visits. Breeding was considered "confirmed" if an attended nest was found, copulation was observed, and/or recently fledged young were observed at a site. Detections where these activities were not observed were classified as "unconfirmed" as the breeding status of individuals present was not known.

\section{Pahranagat National Wildlife Refuge (White River)}

Pahranagat North

In 2007, no yellow-billed cuckoos were detected at this site.

Pahranagat South

In 2007, no yellow-billed cuckoos were detected at this site.

\section{Overton Wildlife Management Area (Muddy River)}

Honeybee Pond

In 2007, no yellow-billed cuckoos were detected at this site.

Overton Wildlife

In 2007, no yellow-billed cuckoos were detected at this site.

\section{Grand Canyon National Park/Lake Mead National Recreation Area (Colorado River and Lake Mead)}

RM 274.5

In 2007, no yellow-billed cuckoos were detected at this site.

Cuckoo Beach

In 2007, no yellow-billed cuckoos were detected at this site. 


\section{Iceberg Ridge}

In 2007, no yellow-billed cuckoos were detected at this site.

\section{Chuckwalla Cove}

In 2007, no yellow-billed cuckoos were detected at this site.

\section{Big Horn Draw}

In 2007, no yellow-billed cuckoos were detected at this site.

\section{Havasu National Wildlife Refuge (Colorado River)}

\section{Pintail Slough}

Pintail Slough Survey 2 - 07/03/2007, 0608, 726565 E, 3858609 N, 218\%/75 m. Yellowbilled cuckoo gave knocker call after the $5^{\text {th }}$ playback. The observer tracked the cuckoo to the North Dike survey site where it gave a kuk-kowlp call at 0620 from $726465 \mathrm{E}$, 3858486 N, $200^{\circ} / 40 \mathrm{~m}$. Aural detection only. Breeding classification: unconfirmed.

\section{North Dike}

North Dike Revisit 1 - 07/03/2007, 0628, 726127 E, 3858519 N, 0\%/0 m. Cuckoo1 gave an unsolicited, soft knocker call to which Cuckoo2 responded with a knocker call and a ping-pong call. Cuckoo2 then flew to a tall stringer of Fremont cottonwood located at 726147E, 3858754N in the Pintail Slough survey site while knocking. Cuckoo1 then flew across a field and joined Cuckoo2. After perching for several minutes, both cuckoos began to move east through the stringer, giving soft knocker calls. Aural and visual detection. Breeding classification: unconfirmed.

North Dike Survey 2 - 07/10/2007, 0651, 726345 E, 3858317 N, Cuckoo1 @ 160\%/30 m, Cuckoo2@30\% $/ 50 \mathrm{~m}$. Cuckoo1 seen flying through an open field into a patch of arrowweed near the road after the $4^{\text {th }}$ playback. Cuckoo 2 seen flying east behind us in open field into arrowweed patch. Ten minutes later, Cuckoo2 (?) gave a knocker-kowlp, then was seen flying through an open field and into the arrowweed. Aural and visual detection. Breeding classification: unconfirmed.

\section{Topock Marsh Restoration}

Topock Marsh Restoration Survey 1 - 06/12/2007, 0637, 723253 E, 3852176 N, 340¹5 $\mathrm{m}$. Yellow-billed cuckoo landed $6 \mathrm{~m}$ above the ground in a $10 \mathrm{~m}$ tall Fremont cottonwood after the $3^{\text {rd }}$ playback. The cuckoo then flew east and landed in an $18 \mathrm{~m}$ tall Fremont cottonwood. After two minutes it flew southeast into a patch of tamarisk/arrowweed. Visual detection only. Breeding classification: unconfirmed.

Topock Marsh Restoration Revisit 1- 07/26/2007, 0742, 723181 E, 3852289 N, 90/75 $\mathrm{m}$. Yellow-billed cuckoo gave unsolicited series of coo calls from $8 \mathrm{~m}$ above the ground in a $10 \mathrm{~m}$ tall Fremont cottonwood. Observers followed this cuckoo as it moved around the northwest corner of the site, cooing, until 0842. Aural and visual detection. Breeding classification: unconfirmed. 
Topock Marsh Restoration Revisit 1 - 07/26/2007, 0925, 723671 E, 3852202 N, 35\%/25 $\mathrm{m}$. Yellow-billed cuckoo gave an unsolicited kuk-kowlp call from $5 \mathrm{~m}$ above the ground in a $8 \mathrm{~m}$ tall Goodding's willow. The bird then flew $75 \mathrm{~m}$ southwest and gave two coo calls. Aural and visual detection. Breeding classification: unconfirmed.

Topock Marsh Restoration Revisit 1 - 07/26/2007, 1133, 723219 E, 3852230 N, $335 \% 125 \mathrm{~m}$. Yellow-billed cuckoo gave three unsolicited coo calls. Aural detection only. Breeding classification: unconfirmed.

Topock Marsh Restoration Revisit 2 - 07/27/2007, 0804, 723256 E, 3852296 N, 29060 m. Yellow-billed cuckoo gave an unsolicited kuk-kowlp call. Aural detection only. Breeding classification: unconfirmed.

\section{Bill Williams River National Wildlife Refuge (Bill Williams River)}

\section{Teepee Trail}

Teepee Trail Survey 3 - 07/28/2007, 0637, 229027 E, 3794701 N, 290\%/25 m. Yellowbilled cuckoo gave an unsolicited knocker-kowlp from a $4 \mathrm{~m}$ tall Fremont cottonwood. The cuckoo then flew $15 \mathrm{~m}$ southeast and called again. Aural and visual detection. Breeding classification: unconfirmed.

\section{Cottonwood Patch}

Cottonwood Patch Survey 1 - 06/26/2007, 0812, 227948 E, 3794132 N, Cuckoo1 and Cuckoo2@ $340 \% / 10 \mathrm{~m}$. Cuckoo1 responded to the $1^{\text {st }}$ playback with a kuk-kowlp call. At 0818, Cuckoo1 and Cuckoo2 gave a series of kuk-kowlp counter-calls about $20 \mathrm{~m}$ apart from one another. At 0827, Cuckoo1 (?) gave several kuk calls. Aural detection only. Breeding classification: unconfirmed.

Cottonwood Patch Survey 1 - 06/26/2007, 0835, 227636 E, 3794166 N, 22\%/100 m. Yellow-billed cuckoo responded to the $1^{\text {st }}$ playback with a kuk-kowlp call. Aural detection only. Breeding classification: unconfirmed.

Cottonwood Patch Revisit 1 - 06/28/2007, 0732, 227751 E, 3794257 N, 270\%/100 m. Yellow-billed cuckoo gave an unsolicited call. Aural detection only. Breeding classification: unconfirmed.

Cottonwood Patch Revisit 1 - 06/28/2007, 0821, 227596 E, 3794187 N, 65\%/15 m. Yellow-billed cuckoo gave an unsolicited coo call. Aural detection only. Breeding classification: unconfirmed.

Cottonwood Patch Revisit 1 - 06/28/2007, 0835, 227578 E, 3794201 N, Cuckoo1 @ 310\%100 m, Cuckoo2 (?) @ 260\%/80 m. Cuckoo1 gave several unsolicited kuk-kowlp calls. Then at 0840, Cuckoo2 (?) gave a kuk-kowlp call. Aural detection only. Breeding classification: unconfirmed.

Cottonwood Patch Revisit 2 - 07/01/2007, 0643, 227989 E, 3794111 N, 346\%/50 m. Yellow-billed cuckoo gave an unsolicited kuk-kowlp call. Aural detection only. Breeding classification: unconfirmed. 
Cottonwood Patch Survey 2 - 07/12/2007, 0717, 227911 E, 3794154 N, 302\%/15 m. Yellow-billed cuckoo responded to the $1^{\text {st }}$ playback with kuk-kowlp call. Aural detection only. Breeding classification: unconfirmed.

Cottonwood Patch Survey 2 - 07/12/2007, 0740, 227737 E, 3794221 N, Cuckoo1 @ 316\%/25 m, Cuckoo2 @ 24\%/15 m. Cuckoo1 gave an unsolicited kuk-kowlp call followed by kuks from Cuckoo2. At 0745, Cuckoo1 gave a series of very soft kuks. At 0753, an unspecified cuckoo flew into a $4 \mathrm{~m}$ high Goodding's willow $20 \mathrm{~m}$ to the northeast of the survey point and gave a kuk-kowlp call before flying to the southeast. At 0757, an unspecified cuckoo was seen near this last location, this time $8 \mathrm{~m}$ above the ground in a Fremont cottonwood. This cuckoo gave a kuk-kowlp call and several soft kuks. Aural and visual detection. Breeding classification: unconfirmed.

Cottonwood Patch Revisit 3 - 07/14/2007, 0635, 227691 E, 3794254 N, $86^{\circ} / 40$ m. Yellow-billed cuckoo responded to the $1^{\text {st }}$ playback with a kuk-kowlp call. This was soon followed by another kuk-kowlp call $30 \mathrm{~m}$ to the east. At 0639, soft knocker calls were heard from the second location. At 0647, a yellow-billed cuckoo was discovered sitting on a nest (CPNest1) $4 \mathrm{~m}$ above the ground in a $10 \mathrm{~m}$ tall Fremont cottonwood, right where the knocker calls had come from. Aural and visual detection. Breeding classification: confirmed.

Cottonwood Patch Revisit 4 - 07/16/2007, 0659, 227747 E, 3794239 N, Cuckoo1 and Cuckoo2@0\% m, Cuckoo3 @ 100\%/30 m. Observer arrived at CPNest1 at 0659 to find no adults on the nest. When the nest was mirror-poled, a nestling (Cuckoo1) gaped at the mirror. The observer felt there may have been two nestlings but was not certain. The nestling looked very young. Its black down/feathers looked slightly slick but there were no signs of eggshells. At 0706, Cuckoo2 landed three inches from the nest with a large green item, possibly a katydid. Cuckoo2 looked at the observer, gave several knocker calls, and then flew out of the nest area where it gave soft kuks and ping-pong calls from about $10 \mathrm{~m}$ away. The observer left but returned at 0730 to find a cuckoo sitting silently on the nest. At 0735, Cuckoo3 began to coo. The cuckoo on the nest responded with several soft, single kuks. Aural and visual detection. Breeding classification: confirmed.

Cottonwood Patch Revisit 5 - 07/18/2007, 0845, 227747 E, 3794239 N, 0 \% 0 m. Yellowbilled cuckoo sitting on CPNest1, observer was able to see the head of one nestling. The next time the nest was checked on 07/25/2007, no nestlings, fledges, or adults were observed in the nest area. Visual detection only. Breeding classification: confirmed.

Cottonwood Patch Survey 3 - 07/28/2007, 0728, 227972 E, 3794122 N, 325\%/25 m. Yellow-billed cuckoo responded to the $1^{\text {st }}$ playback with a knocker-kowlp call. Aural detection only. Breeding classification: unconfirmed.

Cottonwood Patch Survey 3 - 07/28/2007, 0747, 227683 E, 3794199 N, 75\%/75 m. Yellow-billed cuckoo responded to the $1^{\text {st }}$ playback with a knocker-kowlp call. The cuckoo then flew northwest to an area near CPNest1 and gave another knocker-kowlp. Aural and visual detection. Breeding classification: unconfirmed. 


\section{Cave Wash}

Cave Wash Survey 1 - 06/26/2007, 0634, 226683 E, 3794320 N, 27\%/25 m. Yellow-billed cuckoo responded to the $5^{\text {th }}$ playback with several $k u k$ calls from a stand of young Fremont cottonwoods on river right. At 0642, several kuk calls were given from the same location. At 0659 , the cuckoo responded to the $2^{\text {nd }}$ playback being done at the next survey point $300 \mathrm{~m}$ away with a kuk-kowlp call. At 0703 and again at 0711, kuk-kowlp calls were heard from further back in the stand of Fremont cottonwood. Aural detection only. Breeding classification: unconfirmed.

Cave Wash Revisit 1 - 06/26/2007, 0816,226555 E, 3794499 N, Cuckoo1 @ 80³0 m, Cuckoo2 @ 120\% $/ 70$ m. Cuckoo1 gave an unsolicited kuk-kowlp call. At 0820 and at 0826, Cuckoo1 (?) gave kuk-kowlp calls from approximately $20 \mathrm{~m}$ further northeast. At 0827, Cuckoo2 responded, also with a kuk-kowlp call. Aural detection only. Breeding classification: unconfirmed.

Cave Wash Revisit 1 - 06/26/2007, 0905, 226733 E, 3794395 N, 172\%/9 m. Yellow-billed cuckoo gave an unsolicited knocker call. One minute later it flew west from the top of an $8 \mathrm{~m}$ tall Fremont cottonwood. Aural and visual detection. Breeding classification: unconfirmed.

Cave Wash Revisit 2 -07/01/2007, 0538, 226789 E, 3794398 N, Cuckoo1@ 172\%/10 m, Cuckoo2@340\%/40 m, Cuckoo3 (?) @ 240\%/15 m, Cuckoo4 (?) @ 156\%/15 m. Cuckoo1 gave an unsolicited kuk-kowlp call, then moved west through a stand of Fremont cottonwood. At 0543, Cuckoo1 gave another kuk-kowlp call and flew off to the west. Cuckoo2 gave kuk-kowlp call at 0547. At 06:00, Cuckoo3 (?) gave a kuk-kowlp call and at 0601 and 0614, Cuckoo4 (?) gave rolling kowlp calls. The observer believed there were at least three birds in this area. Aural and visual detection. Breeding classification: unconfirmed.

Cave Wash Revisit 2 - 07/01/2007, 0632, 226800 E, 3794347 N, 54\%/15 m. Yellow-billed cuckoo gave an unsolicited rolling kowlp. Aural detection only. Breeding classification: unconfirmed.

Cave Wash Revisit 2 - 07/01/2007, 0639, 226831 E, 3794370 N, 90/7 m. Yellow-billed cuckoo observed unsolicited $7 \mathrm{~m}$ above the ground in a $9 \mathrm{~m}$ tall Fremont cottonwood.

The cuckoo foraged within a $5 \mathrm{~m}$ radius for two minutes, then flew $20 \mathrm{~m}$ to the southwest and gave several kuks. Aural and visual detection. Breeding classification: unconfirmed.

Cave Wash Revisit 2 - 07/01/2007, 0710, 226780 E, 3794339 N, 45/30 m. Yellow-billed cuckoo gave unsolicited kuk-kowlp calls at 0710 and 0726. Aural detection only. Breeding classification: unconfirmed.

Cave Wash Revisit 2 - 07/01/2007, 0800, 226766 E, 3794402 N, 143\%/15 m. Yellowbilled cuckoo gave an unsolicited kuk-kowlp call. At 0810, a cuckoo gave a knocker call $20 \mathrm{~m}$ to the southeast of this location from $8 \mathrm{~m}$ above the ground in an $11 \mathrm{~m}$ tall Fremont cottonwood. The cuckoo was observed perching until 0816 when it flew west $10 \mathrm{~m}$, disappeared into the vegetation, and gave a kuk-kowlp call. Aural and visual detection. Breeding classification: unconfirmed. 
Cave Wash Revisit 2 - 07/01/2007, 0830,226782 E, 3794380 N, Cuckoo1 @ 305\%/10 m, Cuckoo2@75\%/30 m, Cuckoo3 (?) @ 340/75 m, Cuckoo4 (?) @ 2\%/50 m. Cuckoo1 flew unsolicited into a Goodding's willow and gave a kuk call. Cuckoo2 responded immediately with a kuk call. At 0856, Cuckoo3 (?) gave a kuk-kowlp call and at 09:00, Cuckoo4 (?) gave a kuk-kowlp call. The observer felt there were at least three cuckoos at this location. Aural and visual detection. Breeding classification: unconfirmed.

Cave Wash Revisit 2 - 07/01/2007, 0845, 226600 E, 3794495 N, 290\%/80 m. Yellowbilled cuckoo gave an unsolicited coo call. Aural detection only. Breeding classification: unconfirmed.

Cave Wash Survey 2 - 07/12/2007, 0553, 226678 E, 3794323 N, 40\%/100 m. Yellowbilled cuckoo responded to the $2^{\text {nd }}$ playback with a kuk-kowlp call. At 0557 and 0632 , $k u k$-kowlp calls were given from the same location. Kuk-kowlp calls were given approximately every ten minutes until 0712 , after which time no additional calls were heard. Aural detection only. Breeding classification: unconfirmed.

Cave Wash Survey 2 - 07/12/2007, 0626, 227166 E, 3794407 N, 280³5 m. Yellowbilled cuckoo responded to the $5^{\text {th }}$ playback with a kuk-kowlp call from within a dense Fremont cottonwood/Goodding's willow thicket. Aural detection only. Breeding classification: unconfirmed.

Cave Wash Survey 2 - 07/12/2007, 0727, 227597 E, 3794576 N, 5\%/3 m. Yellow-billed cuckoo landed $5 \mathrm{~m}$ above the ground in an $8 \mathrm{~m}$ tall Fremont cottonwood after the $4^{\text {th }}$ playback. One minute later, the cuckoo flew $13 \mathrm{~m}$ east and landed $5 \mathrm{~m}$ above the ground in another Fremont cottonwood where it was observed eating a cicada. At 0738, the cuckoo flew $100 \mathrm{~m}$ to the south before it disappeared from view. The observer suspected the cuckoo was headed to Cottonwood Patch which is located about $400 \mathrm{~m}$ south of this survey point. Visual detection only. Breeding classification: unconfirmed.

Cave Wash Revisit 3 - 07/12/2007, 0813, 226821 E, 3794518 N, Cuckoo1 @ 100\%/50 m, Cuckoo2@350\%/75 m, Cuckoo3 (?) @ 210\%/60 m. Cuckoo1 gave an unsolicited kukkowlp call. One minute later, Cuckoo2 responded with a knocker call. Ten seconds later, Cuckoo3 (?) gave a kuk-kowlp call. The observer suspected these calls were given by three different individuals. Aural detection only. Breeding classification: unconfirmed.

Cave Wash Revisit 4 - 07/14/2007, 0820, 226799 E, 3794378 N, 115\%100 m. Yellowbilled cuckoo gave an unsolicited kuk-kowlp call. Aural detection only. Breeding classification: unconfirmed.

Cave Wash Revisit 4 - 07/14/2007, 0825, 226837 E, 3794353 N, 260\%10 m. Yellowbilled cuckoo gave an unsolicited knocker call three times from a Fremont cottonwood, then flew $50 \mathrm{~m}$ west and gave several kowlp calls. Aural and visual detection. Breeding classification: unconfirmed.

Cave Wash Revisit 4 - 07/14/2007, 0849, 226729 E, 3794343 N, 90/40 m. Yellow-billed cuckoo foraging unsolicited in a Fremont cottonwood. The cuckoo then flew into the vegetation and out of sight. Visual detection only. Breeding classification: unconfirmed. 
Cave Wash Revisit 4 - 07/14/2007, 0912, 226822 E, 3794345 N, 360\%/15 m. Yellowbilled cuckoo gave two kuk-kowlp calls from a Fremont cottonwood. Aural and visual detection. Breeding classification: unconfirmed.

Cave Wash Revisit 4 - 07/14/2007, 0940, 226831 E, 3794351 N, Cuckoo1 @ 0\% m, Cuckoo2@ 0\% m. Cuckoo1 gave an unsolicited knocker call 6m above the ground in an $8 \mathrm{~m}$ tall Fremont cottonwood. Cuckoo2, a fledgling, was observed perched $3.5 \mathrm{~m}$ above the ground in the lower branches of the same tree. The fledgling had a very short tail, no yellow on its bill, and no eye-ring. It was smaller than an adult but fully feathered. Cuckoo1 flew around giving knocker calls in an attempt to lead the observers away from the fledgling. Cuckoo1 was also observed carrying food about $10 \mathrm{~m}$ northeast of this location. Observers later located a nest (CWNest1) about $10 \mathrm{~m}$ to the north that they suspected was associated with this fledgling, however, they did not observe the adult or fledgling at the nest. Aural and visual detection. Breeding classification: confirmed.

Cave Wash Revisit 5 - 07/16/2007, 0811, 226827 E, 3794344 N, 340/30 m. Yellowbilled cuckoo gave an unsolicited knocker call. Aural detection only. Breeding classification: unconfirmed.

Cave Wash Revisit 5 - 07/16/2007, 0817, 226834 E, 3794368 N, 20\%/20 m. Yellow-billed cuckoo gave an unsolicited kuk-kowlp call. Aural detection only. Breeding classification: unconfirmed.

Cave Wash Revisit 5 - 07/16/2007, 0833, 226835 E, 3794358 N, 8\%/4 m. Fledgling yellow-billed cuckoo perched $4 \mathrm{~m}$ above the ground in an $8 \mathrm{~m}$ tall Fremont cottonwood, $1 / 4 \mathrm{~m}$ away from CWNest1. Fledgling did not move the entire time, no calls were heard after it was spotted. Visual detection only. Breeding classification: confirmed.

Cave Wash Revisit 6 - 07/18/2007, 0955, 226880 E, 3794385 N, Cuckoo1 and Cuckoo2 @ 260\% $/ 80 \mathrm{~m}$. Cuckoo1 gave an unsolicited knocker call from an $8 \mathrm{~m}$ tall Fremont cottonwood. Cuckoo2 responded immediately with another knocker call. Visual and aural detection. Breeding classification: unconfirmed.

Cave Wash Survey 3 - 07/25/2007, 0612, 226504 E, 3794332 N, 34\%/100 m. Yellowbilled cuckoo responded to the $1^{\text {st }}$ playback with a full kuk-kowlp call. Aural detection only. Breeding classification: unconfirmed.

Cave Wash Survey 3 - 07/25/2007, 0637, 226929 E, 3794341 N, 320\%/20 m. Yellowbilled cuckoo responded to the $2^{\text {nd }}$ playback with two knocker-kowlp calls. Ten minutes later, kowlp calls were heard from $25 \mathrm{~m}$ back in the vegetation. Aural detection only. Breeding classification: unconfirmed.

Cave Wash Survey 3 - 07/25/2007, 0655, 227223 E, 3794448 N, 276\%/40 m. Yellowbilled cuckoo responded to the $3^{\text {rd }}$ playback. Aural detection only. Breeding classification: unconfirmed.

Cave Wash Revisit 7 - 07/25/2007, 0942, 226841 E, 3794361 N, 300\%10 m. Yellowbilled cuckoo gave several unsolicited knocker calls when observer approached CWNest1. Aural detection only. Breeding classification: unconfirmed. 
Cave Wash Revisit 8 - 08/07/2007, 0758, 226827 E, 3794358 N, 270\%/10 m. Yellowbilled cuckoo gave an unsolicited knocker call. Aural detection only. Breeding classification: unconfirmed.

Cave Wash Revisit 8 - 08/07/2007, 0806, 226820 E, 3794380 N, 300\%/10 m. Yellowbilled cuckoo gave several unsolicited knocker call from the top of a $13 \mathrm{~m}$ tall Fremont cottonwood. The cuckoo flew east $20 \mathrm{~m}$ and gave another knocker call. Aural and visual detection. Breeding classification: unconfirmed.

Cave Wash Revisit 8 - 08/07/2007, 0831,226871 E, 3794336 N, Cuckoo1 @ 350\%/15 m, Cuckoo2@40\%30 m. Cuckoo1 observed moving around unsolicited in a Fremont cottonwood. Cuckoo1 then flew $5 \mathrm{~m}$ west and gave a kuk-kowlp call at 0906. Cuckoo2 responded immediately. Aural and visual detection. Breeding classification: unconfirmed.

Cave Wash Revisit 8 - 08/07/2007, 1003, 226820 E, 3794380 N, 60³0 m. Yellow-billed cuckoo gave an unsolicited knocker call. Aural detection only. Breeding classification: unconfirmed.

Cave Wash Revisit 8 - 08/07/2007, 1011, 226856 E, 3794381 N, 150\%10 m. Yellowbilled cuckoo gave several unsolicited knocker calls from $8 \mathrm{~m}$ above the ground in a $10 \mathrm{~m}$ tall Fremont cottonwood. Aural and visual detection. Breeding classification: unconfirmed.

Cave Wash Survey 4 - 08/14/2007, 0648, 226462 E, 3794397 N, 308\%/100 m. Yellowbilled cuckoo responded to the $1^{\text {st }}$ playback with a kowlp call. Aural detection only. Breeding classification: unconfirmed.

Cave Wash Survey 4 - 08/14/2007, 0705, 226757 E, 3794332 N, 320\%/17 m. Yellowbilled cuckoo was observed $6 \mathrm{~m}$ above the ground in a $10 \mathrm{~m}$ tall Fremont cottonwood at the edge of a thick Fremont cottonwood patch after the $5^{\text {th }}$ playback. The cuckoo stayed in view for one minute, the flew back into the patch towards CWNest1. Visual detection only. Breeding classification: unconfirmed.

Cave Wash Survey 4 - 08/14/2007, 0754, 227404 E, 3794595 N, 213\%/150 m. Yellowbilled cuckoo responded to the $1^{\text {st }}$ playback with a kuk-kowlp call. Aural detection only. Breeding classification: unconfirmed.

\section{Honeycomb Bend}

Honeycomb Bend Survey 1 - 06/19/2007, 0652, 225859 E, 3794653 N, 278\%/20 m. Yellow-billed cuckoo responded to the $2^{\text {nd }}$ playback with four rolling kowlps from a Goodding's willow. At 0726, a kuk-kowlp call was given by an unspecified cuckoo, $60 \mathrm{~m}$ downstream from a Goodding's willow. At 0730, this cuckoo flew upriver and gave a $k u k$-kowlp call within $20 \mathrm{~m}$ of the point. The cuckoo continued to move upstream and giving kuk-kowlp calls through 0742. Aural and visual detection. Breeding classification: unconfirmed.

Honeycomb Bend Survey 1 - 06/19/2007, 0712, 225552 E, 3794690 N, 286\%/5 m. Yellow-billed cuckoo flew into a dead tree after the $1^{\text {st }}$ playback and gave a kuk-kowlp 
call. At 0820, kuk-kowlp calls were heard near this location, then two cuckoos flew $100 \mathrm{~m}$ upstream together. Aural and visual detection. Breeding classification: unconfirmed.

Honeycomb Bend Survey 1- 06/19/2007, 0800, 225119 E, 3794413 N, Cuckoo1 @ $102^{\circ} / 20 \mathrm{~m}$, Cuckoo2 @ 226\%/10 m. Two cuckoos began to call five minutes after the $5^{\text {th }}$ playback. Cuckoo1 gave a series of soft kuks, Cuckoo2 gave a long kuk-kowlp call. At 0815, both cuckoos flew into a $12 \mathrm{~m}$ tall Fremont cottonwood, both gave several $k u k$ kowlp calls, then flew to the north side of the river and landed $20 \mathrm{~m}$ apart where they continued to call to one another. Starting at 0830, one cuckoo began to move downstream giving occasional kuk-kowlp calls. Aural and visual detection. Breeding classification: unconfirmed.

Honeycomb Bend Revisit 1 - 06/20/2007, 0625, 226474 E, 3794216 N, $320^{\circ} / 25$ m. Yellow-billed cuckoo gave an unsolicited rolling kowlps then a kuk-kowlp call. Aural detection only. Breeding classification: unconfirmed.

Honeycomb Bend Revisit 1 - 06/20/2007, 0715, 225873 E, 3794617 N, Cuckoo1, 2, and 3 @ 342\%/20 m, Cuckoo4 and 5 (?) @0\%/50 m. Cuckoo1, 2, and 3 flew unsolicited from a Goodding's willow on the north bank to a Goodding's willow on the south bank. At the same time, Cuckoo4 gave coo calls from the vegetation on the north bank. For the next seventy-five minutes, four cuckoos were observed flying back and forth across the river, sometimes in a group, sometimes singly. Rolling kowlps and kuk-kowlp calls were given frequently from both banks. At 0830, two pairs of cuckoos crossed the river near the survey point, then about one minute later, Cuckoo5 (?) gave a coo call. Aural and visual detection. Breeding classification: unconfirmed.

Honeycomb Bend Revisit 1 - 06/20/2007, 225199 E, 3794453 N, 200\%/15 m. Yellowbilled cuckoo located unsolicited in a Fremont cottonwood. At 0935, a kuk-kowlp call was heard and at 0952 an unspecified cuckoo was seen $15 \mathrm{~m}$ upstream from the point. Aural and visual detection. Breeding classification: unconfirmed.

Honeycomb Bend Revisit 2 - 06/29/2007, 0605, 225873E, 3794617N, 130\%100m. Yellow-billed cuckoo gave an unsolicited soft coo call. Aural detection only. Breeding classification: unconfirmed.

Honeycomb Bend Revisit 2 - 06/29/2007, 0737, 225143 E, 3794423 N, 352\%/10 m. Yellow-billed cuckoo gave an unsolicited ping-pong call. Twelve minutes later, a cuckoo gave two kuks followed by another ping-pong call. At 0800, observers saw a cuckoo about $75 \mathrm{~m}$ south of this location, $8 \mathrm{~m}$ above the ground in a Goodding's willow, picking off leaves and placing them in the tree. A second cuckoo joined the first, and gave a kukkowlp call; it too had leaves in its bill. After several minutes, Cuckoo 2 flew to a nearby tree and vanished. The first cuckoo began to preen, then flew northeast at 0813. At 0900, two cuckoos were spotted across the river in the same tree together, $100 \mathrm{~m}$ from the last sighting. Aural and visual detection. Breeding classification: unconfirmed.

Honeycomb Bend Survey 2 - 07/09/2007, 0715, 225586 E, 3794686 N, 62\%/25 m. Yellow-billed cuckoo flew from river right to river left after $5^{\text {th }}$ playback. Visual detection only. Breeding classification: unconfirmed. 
Honeycomb Bend Survey 2 - 07/09/2007, 0739, 225308E, 225308 E, 3794567 N, 230\%/30 $\mathrm{m}$. Yellow-billed cuckoo responded to the $2^{\text {nd }}$ playback with $k u k$ call. Aural detection only. Breeding classification: unconfirmed.

Honeycomb Bend Survey 2 - 07/09/2007, 0755, 225269 E, 3794526 N, Cuckoo1 @ $280 \% 10 \mathrm{~m}$, Cuckoo2 @ 100\%/12 m. Cuckoo1 observed $2 \mathrm{~m}$ above the ground in a Goodding's willow, carrying an unidentified food item. At the same time, Cuckoo2 flew into a Goodding's willow. Both cuckoos gave short calls to one another. After an hour of monitoring, a nest (HCNest1) was located in a Goodding's willow about $40 \mathrm{~m}$ west of the survey point. When the nest was mirror poled the next day the nestlings had fledged. No adults or juveniles were located on that day. Aural and visual detection. Breeding classification: confirmed.

Honeycomb Bend Revisit 6 - 07/12/2007, 0941, 225289 E, 3794497 N, $40 \% / 10$ m. Yellow-billed cuckoo observed unsolicited holding a cicada about $40 \mathrm{~m}$ south of HCNest1. The cuckoo gave a knocker call, looked directly at the observer, and then flew into the vegetation with the cicada still in its mouth. No juveniles were located and the adult was not detected again. Aural and visual detection. Breeding classification: unconfirmed.

Honeycomb Bend Revisit 7 - 07/14/2007, 0655, 225239 E, 3794527 N, 78\%/20 m. Yellow-billed cuckoo gave an unsolicited knocker call followed by a kuk-kowlp call near HCNest1. Another knocker call was heard at 0708. Aural detection only. Breeding classification: unconfirmed.

Honeycomb Bend Revisit 7 - 07/14/2007, 0742, 225273 E, 3794513 N, Cuckoo1 and Cuckoo2 @ 155\%/15 m. Cuckoo1 flew unsolicited across the river and landed $8 \mathrm{~m}$ above the ground in a 10m tall Goodding's willow. Cuckoo2 flew through this area at 0747, after which both birds disappeared. Visual detection only. Breeding classification: unconfirmed.

Honeycomb Bend Survey 3 - 08/07/2007, 0640, 226380 E, 3794325 N, $80^{\circ} / 30$ m. Yellow-billed cuckoo responded to the $3^{\text {rd }}$ playback with a kuk-kowlp call. At 0723, a cuckoo gave a kuk-kowlp call from the same location. Aural detection only. Breeding classification: unconfirmed.

Honeycomb Bend Survey 3 - 08/07/2007, 0816, 225315 E, 3794581 N, 4\%/25 m. Yellowbilled cuckoo located in a large Goodding's willow after the $5^{\text {th }}$ playback. The cuckoo was observed foraging in the tree then it began to slowly move upstream, foraging. Cuckoo was last seen about $150 \mathrm{~m}$ upstream. Visual detection only. Breeding classification: unconfirmed.

Honeycomb Bend Revisit 9 - 08/07/2007, 0725, 226433 E, 3794328 N, 8\%/15 m. Yellowbilled cuckoo gave an unsolicited $k u k$ call from a Fremont cottonwood/Goodding's willow patch, then again at 0750 . Aural detection only. Breeding classification: unconfirmed.

Honey Bend Revisit 9 - 08/07/2007, 1010, 225226 E, 3794522 N, 0\% m. Two fledgling yellow-billed cuckoos gave unsolicited, soft, hoarse versions of the adult kuk-kowlp call, 
both from within $15 \mathrm{~m}$ of HCNest1.A visual was obtained on one of the fledglings. It had a very short tail, a mostly black bill, and was small compared to an adult. This fledgling was actively calling and clumsily flying/hopping $4 \mathrm{~m}$ above the ground among the branches of a $9 \mathrm{~m}$ tall Goodding's willow. Aural and visual detection. Breeding classification: confirmed.

Honeycomb Bend Revisit 10 - 08/10/2007, 1045, 225256 E, 3794513 N, Cuckoo1 and Cuckoo2 @ 320\%/10 m. Cuckoo1, a fledgling, gave several unsolicited soft, hoarse kukkowlps near HCNest1. Cuckoo2, an adult, then gave a knocker call from the same location. At 1055, Cuckoo2 was seen flying back further into the vegetation. Aural and visual detection. Breeding classification: confirmed.

Honeycomb Bend Revisit 11 - 08/14/2007, 1037, 225265 E, 3794559 N, 340\%10 m. Yellow-billed cuckoo gave unsolicited knocker calls from $13 \mathrm{~m}$ above the ground in $17 \mathrm{~m}$ tall Fremont cottonwood. Aural and visual detection. Breeding classification: unconfirmed.

Honeycomb Bend Survey 3 - 08/23/2007, 0735, 225483 E, 3794678 N, 106\%/35 m. Yellow-billed cuckoo responded to $1^{\text {st }}$ playback with a kowlp call from a stand of $8 \mathrm{~m}$ tall Goodding's willow/Fremont cottonwood. Aural detection only. Breeding classification: unconfirmed.

Honeycomb Bend Revisit 12 - 08/23/2007, 0952, 225230 E, 3794516 N, $78^{\circ} / 50$ m. Yellow-billed cuckoo gave an unsolicited kuk-kowlp call across the river from HCNest1. Aural detection only. Breeding classification: unconfirmed.

Honeycomb Bend Revisit 12 - 08/23/2007, 0958, 225259 E, 3794521 N, 198\%15 m. Yellow-billed cuckoo responded immediately to the $1^{\text {st }}$ playback with kuk-kowlp calls and cooing from a $20 \mathrm{~m}$ tall Fremont cottonwood. The cuckoo then flew downstream and out of sight where it gave one more kuk-kowlp call. Aural and visual detection. Breeding classification: unconfirmed.

Honeycomb Bend Revisit 13 - 08/27/2007, 0725, 225242 E, 3794529 N, 9\%/45 m. Yellow-billed cuckoo gave unsolicited kuk-kowlp calls over a ten minute period while observers were measuring vegetation at HCNest1. Aural detection only. Breeding classification: unconfirmed.

\section{Mineral Wash}

Mineral Wash Survey 1 - 06/18/2007, 0550,775347 E, 3794446 N, Cuckoo1@ 60\%40 m, Cuckoo2 and Cuckoo3 (?) @ 90\%/45 m, Cuckoo4 (?) @ 90\%/150 m. Cuckoo1 gave unsolicited kuk calls. Later, Cuckoo2 and Cuckoo3 (?) were observed $45 \mathrm{~m}$ upstream, flying together across the river to the north bank. Cuckoo4 (?) was seen another $100 \mathrm{~m}$ upstream flying from the north to the south bank. Kuk-kowlp calls were heard from this area as well. Aural and visual detection. Breeding classification: unconfirmed.

Mineral Wash Survey 1 - 06/18/2007, 0615, 775787 E, 3794347 N, Cuckoo1 @ 128\%/50 m, Cuckoo2 (?) @ NA/5 m, Cuckoo3 (?) @ 90\%/50 m, Cuckoo4 (?) @ 275\%/60 m. Cuckoo1 responded to the $4^{\text {th }}$ playback with soft kuks. Cuckoo2 (?) gave a kuk-kowlp call 
a few minutes later from a large Goodding's willow. Cuckoo3 (?) then gave a kuk-kowlp from upriver, after which, Cuckoo4 (?) gave a kuk-kowlp call from downriver. All calls except that of Cuckool were within two minutes of one another. The observer believed there were at least two, likely three, birds here. The cuckoos continued to call from both upstream and downstream until the observer left the area at 0715 . Aural detection only. Breeding classification: unconfirmed.

Mineral Wash Survey 1 - 06/18/2007, 0641, 776092 E, 3794370 N, 332¹5 m. Yellowbilled cuckoo flew across river to the south bank where it perched in a Goodding's willow after the $1^{\text {st }}$ playback. The cuckoo then gave two kuk-kowlp calls before flying 10 $\mathrm{m}$ upriver to a clump of Goodding's willow at 0647. Aural and visual detection. Breeding classification: unconfirmed.

Mineral Wash Survey 1 - 06/18/2007, 0714, 223872 E, 3794425 N, 255\%/20 m. Yellowbilled cuckoo flew upriver into a Goodding's willow and gave a kuk-kowlp call after the $5^{\text {th }}$ playback. After a couple minutes, it flew $10 \mathrm{~m}$ upriver and landed in a Goodding's willow. At 0727, it flew upriver and out of view. At 0739, a kuk-kowlp" call was given from a clump of Fremont cottonwoods $10 \mathrm{~m}$ further upriver. Aural and visual detection. Breeding classification: unconfirmed.

Mineral Wash Survey 1 - 06/18/2007, 0754, 224174 E, 3794464 N, Cuckoo1 @ 28040 m, Cuckoo2 @ 280 /20 m, Cuckoo3 (?) @ 280\%/70 m. Cuckoo1 gave an unsolicited kuk-kowlp call from behind a stand of large Fremont cottonwoods. At 0801, Cuckoo2 flew in from downriver and landed about $20 \mathrm{~m}$ from the survey point. Cuckoo1 immediately gave a kuk-kowlp call which it repeated at 0809. At 0808, Cuckoo3 (?) was observed downriver from the survey point. Aural and visual detection. Breeding classification: unconfirmed.

Mineral Wash Survey 1 - 06/18/2007, 0826, 224458 E, 3794341 N, Cuckoo1 @ 350\%10 m, Cuckoo2 @ 290\%/65 m, Cuckoo3 @ 80\%/80 m. Cuckoo1 flew in from upriver after the $2^{\text {nd }}$ playback and gave a kuk-kowlp call. At 0832, it flew $30 \mathrm{~m}$ upriver. At 0835, Cuckoo2 gave two kuk-kowlp calls. Cuckoo1 and Cuckoo2 counter-called several times, then, at 0855, two cuckoos were seen sunning themselves in a Fremont cottonwood $20 \mathrm{~m}$ upstream from the survey point. At this time, Cuckoo3 flew in about $50 \mathrm{~m}$ upriver of the sunning cuckoos. Aural and visual detection. Breeding classification: unconfirmed.

Mineral Wash Survey 1 - 06/18/2007, 0912, 224708 E, 3794385 N, 44\%/40 m. Yellowbilled cuckoo gave an unsolicited kuk-kowlp call. Aural detection only. Breeding classification: unconfirmed.

Mineral Wash Survey 1 - 06/18/2007, 0939, 224947 E, 3794350 N, 40³0 m. Yellowbilled cuckoo gave an unsolicited kuk-kowlp call from back in the vegetation near a sandy wash. Aural detection only. Breeding classification: unconfirmed.

Mineral Wash Revisit 1 - 06/18/2007, 0631,775464 E, 3794446 N, Cuckoo1 @ 140\%14 m, Cuckoo2 @ 130\%12 m, Cuckoo3 (?) 180\%/9 m. Cuckoo1 gave an unsolicited kukkowlp call from $7 \mathrm{~m}$ above the ground in a $10 \mathrm{~m}$ tall willow. Cuckoo2 responded with a $k u k$ call. Cuckoo1 then flew toward Cuckoo2 and disappeared. At 0646, a cuckoo flew out of a Goodding's willow within $1 \mathrm{~m}$ of where Cuckoo2 called from, into the 
Goodding's willow Cuckoo1 had called from. Thirty seconds later, Cuckoo3 (?) flew from a tamarisk around the Goodding's willow where the other cuckoo was perched. Aural and visual detection. Breeding classification: unconfirmed.

Mineral Wash Revisit 1 - 06/18/2007, 0715, 775565 E, 3794439 N, 130\%/30 m. Yellowbilled cuckoo gave an unsolicited kuk-kowlp call. Aural detection only. Breeding classification: unconfirmed.

Mineral Wash Revisit 2 - 06/19/2007, 0536, 775470 E, 3794455 N, 240\%/11 m. Yellowbilled cuckoo flew unsolicited into a Goodding's willow and gave kuk-kowlp call. The cuckoo then moved to the back of the tree and out of sight. At 0541, it gave a kuk-kowlp call. Aural and visual detection. Breeding classification: unconfirmed.

Mineral Wash Revisit 2 - 06/19/2007, 0558, 775438 E, 3794384 N, Cuckoo1 and Cuckoo2@325\%/20 m, Cuckoo3 @ 325\%/50 m. Cuckoo1 and Cuckoo2 seen unsolicited together in a Goodding's willow. Cuckoo3 then gave a kuk-kowlp call from the other side of the river. Aural and visual detection. Breeding classification: unconfirmed.

Mineral Wash Revisit 3 - 06/29/2007, 0522, 775482 E, 3794477 N, $150^{\circ} / 30$ m. Yellowbilled cuckoo gave an unsolicited kuk-kowlp call. Aural detection only. Breeding classification: unconfirmed.

Mineral Wash Revisit 3 - 06/29/2007, 0744, 775787 E, 3794354 N, Cuckoo1 @ 315\%/75 m, Cuckoo2@65\%/20 m. Cuckoo1 gave an unsolicited kuk-kowlp call. Cuckoo2 responded with its own kuk-kowlp call from $8 \mathrm{~m}$ above the ground in a $13 \mathrm{~m}$ tall Goodding's willow. After calling, Cuckoo2 flew south into the vegetation. Aural and visual detection. Breeding classification: unconfirmed.

Mineral Wash Revisit 3 - 06/29/2007, 0759, 775886 E, 3794339 N, Cuckoo1 @ 60\%60 $\mathrm{m}$, Cuckoo2 @ 320\%/10 m. Cuckoo1 was seen unsolicited $5 \mathrm{~m}$ above the ground in a $7 \mathrm{~m}$ tall Goodding's willow. Cuckoo1 alternately preened and perched until Cuckoo2 gave a kuk-kowlp call at 0808. Cuckoo1 flew toward Cuckoo2 and as it passed, Cuckoo2 joined it in flight. The two birds then flew off together at a $310^{\circ}$ bearing. Aural and visual detection. Breeding classification: unconfirmed.

Mineral Wash Revisit 3 - 06/29/2007, 0830, 775669 E, 3794312 N, Cuckoo1 and Cuckoo2@0\% m. Cuckoo1 gave an unsolicited knocker calls from $6 \mathrm{~m}$ above the ground in an $18 \mathrm{~m}$ tall Fremont cottonwood. After about twenty minutes, Cuckoo1 and Cuckoo 2 flew out of the cottonwood and into some mesquite where they were observed foraging. Aural and visual detection. Breeding classification: unconfirmed.

Mineral Wash Survey 2 - 07/02/2007, 0620, 775774 E, 3794354 N, Cuckoo1 and Cuckoo2 @ 110\% $/ 35 \mathrm{~m}$. Cuckoo1 seen five minutes after the $5^{\text {th }}$ playback $8 \mathrm{~m}$ above the ground in a dead tree. At 0630, Cuckoo1 flew into a Goodding's willow $2 \mathrm{~m}$ away and gave a soft kuk call. At 0632, Cuckoo2 gave a kowlp call from a $10 \mathrm{~m}$ tall Goodding's willow $10 \mathrm{~m}$ from Cuckoo1. Aural and visual detection. Breeding classification: unconfirmed. 
Mineral Wash Survey 2 - 07/02/2007, 0648, 776081 E, 3794377 N, 8\%/100 m. Yellowbilled cuckoo gave coo calls for ten minutes following the $4^{\text {th }}$ playback from an area near a very large Fremont cottonwood surrounded by tamarisk and mesquite. Aural detection only. Breeding classification: unconfirmed.

Mineral Wash Survey 2 - 07/02/2007, 0712, 223857 E, 3794427 N, Cuckoo1 @ 40\%40 $\mathrm{m}$, Cuckoo2 (?) @ 22\% $/ 20 \mathrm{~m}$. Cuckoo1 responded to the $3^{\text {rd }}$ playback with a kuk-kowlp call. At 0733, Cuckoo2 (?) gave a kuk-kowlp call from a medium Goodding's willow. At 0742, Cuckoo2 (?) flew $20 \mathrm{~m}$ downstream where it gave two kuk-kowlp calls before flying back into the vegetation on the north bank. Several more calls were heard over the next 45 minutes, progressively further downstream. At 0851, a cuckoo was observed $\sim 100 \mathrm{~m}$ downstream from the survey point as it flew from a sandy wash on the south bank into the vegetation on the north bank. The cuckoo may have been carrying a food item, but the observer was not certain. Aural and visual detection. Breeding classification: unconfirmed.

Mineral Wash Survey 2 - 07/02/2007, 0755, 224264 E, 3794484 N, Cuckoo1 @ 56²0 m, Cuckoo2@ 90\%150 m, Cuckoo3 (?) @ 146\%/20 m. Cuckoo1 responded to the $1^{\text {st }}$ playback with a kuk-kowlp call. Later, Cuckoo 2 was seen perched in a dead tree.

Cuckoo3 (?) was then seen as it flew across the river to the south bank. Aural and visual detection. Breeding classification: unconfirmed.

Mineral Wash Survey 2 - 07/02/2007, 0850, 224852 E, 3794416 N, 128\%/15 m. Yellowbilled cuckoo responded to the $5^{\text {th }}$ playback with soft kowlp call from a Goodding's willow overhanging the river. Aural and visual detection. Breeding classification: unconfirmed.

Mineral Wash Revisit 6 - 07/24/2007, 0821,775565 E, 3794470 N, Cuckoo1 @ 320\%/45 m, Cuckoo2 (?) @ 320\%/90 m. Cuckoo1 gave an unsolicited rapid knocker call followed by several rolling kowlps. At 0830, a knocker call was given from the same location. Three minutes later, a Cuckoo2 (?) gave a knocker call. Aural detection only. Breeding classification: unconfirmed.

Mineral Wash Survey 3 - 07/30/2007, 0606, 775343 E, 3794453 N, 130/30 m. Yellowbilled cuckoo responded to the $1^{\text {st }}$ playback with a kuk-kowlp call. Aural detection only. Breeding classification: unconfirmed.

Mineral Wash Survey 3 - 07/30/2007, 0618, 775642 E, 3794387 N, Cuckoo1@ 250²0 m, Cuckoo2@100\%10 m, Cuckoo3 (?) @ 50\%/10 m. Cuckoo1 responded to the $3^{\text {rd }}$ playback with a kuk-kowlp call from a large Goodding's willow. Cuckoo2 responded from the other side of the river with a knocker-kowlp call. At 0623, Cuckoo1 (?) gave a knocker-kowlp call to which Cuckoo3 (?) responded with a kuk-kowlp call from a medium Goodding's willow. At 0630, Cuckoo1 gave a knocker call. Two minutes later, Cuckoo2 was seen flying from its initial location to a Goodding's willow about $10 \mathrm{~m}$ west. Aural and visual detection. Breeding classification: unconfirmed.

Mineral Wash Survey 3 - 07/30/2007, 0756, 224168E, 3794463 N, 100\%/50 m. Yellowbilled cuckoo responded to the $4^{\text {th }}$ playback with a kuk-kowlp call. At 0809, a knocker- 
kowlp was heard from the same tree. Aural detection only. Breeding classification: unconfirmed.

Mineral Wash Survey 3 - 07/30/2007, 0823, 224553 E, 3794353 N, 286\%/100 m. Yellowbilled responded to the $1^{\text {st }}$ playback with a kuk-kowlp call near the previous survey point. Aural detection only. Breeding classification: unconfirmed.

Mineral Wash Revisit 7-07/30/2007,0637,775659 E, 3794393 N, Cuckoo1@300³0 m, Cuckoo2 (?) @ 20\%/40 m. Cuckoo1 gave an unsolicited knocker-kowlp call. Cuckoo2 (?) gave a knocker-kowlp call at 0652. Aural detection only. Breeding classification: unconfirmed.

Mineral Wash Revisit 7 - 07/30/2007, 0640, 775482 E, 3794449 N, 136\%15 m. Observer was monitoring the 0606 survey detection and had not heard anything additional until this time. One playback was done to which a yellow-billed cuckoo responded with a kukkowlp call from a stand of medium Fremont cottonwood. Aural detection only. Breeding classification: unconfirmed.

Mineral Wash Revisit 7-07/30/2007,0655,775672 E, 3794385 N, Cuckoo1 @ 110³0 m, Cuckoo2 (?) @ 300\%/25 m. Cuckoo1 gave an unsolicited kuk-kowlp call. Three minutes later, Cuckoo2 (?) gave kuk-kowlp call. Aural detection only. Breeding classification: unconfirmed.

Mineral Wash Revisit 7 - 07/30/2007, 0659, 775596 E, 3794490 N, 242\%/10 m. Yellowbilled cuckoo gave an unsolicited knocker-kowlp from a large Goodding's willow. Aural detection only. Breeding classification: unconfirmed.

Mineral Wash Revisit 7 - 07/30/2007, 0832, 224477 E, 3794381 N, $50 \% 15$ m. Observer was monitoring the 0823 survey detection when a yellow-billed cuckoo gave an unsolicited kuk-kowlp call from a medium Fremont cottonwood in a wash north of the river. At 0836 and 0839, a cuckoo gave kuk-kowlp calls from the 0823 detection location. Aural detection only. Breeding classification: unconfirmed.

Mineral Wash Survey 4 - 08/13/2007, 0819,224403 E, 3794380 N, Cuckoo1@ 75\%/9 m, Cuckoo2@138\%/85 m. Cuckoo1 landed 6m above the ground in an $8 \mathrm{~m}$ tall Goodding's willow after the $5^{\text {th }}$ playback and gave six $k u k$ calls. Cuckoo 2 responded with a $k u k$ call. At 0827, Cuckoo1 gave another kuk call and Cuckoo2 responded again with a kuk call. Cuckoo1 then flew over a clump of tamarisk toward Cuckoo2 and disappeared. At 0850, a cuckoo was sighted in a tamarisk tree, 9 m east of Cuckool's initial location where it perched for four minutes before flying away to the east. Aural and visual detection. Breeding classification: unconfirmed.

\section{Big Bend}

Big Bend Survey 1- 06/12/2007, 0545, 775342 E, 3794448 N, 320\%/50 m. Yellow-billed cuckoo responded to the $2^{\text {nd }}$ playback with a kuk-kowlp call from $8 \mathrm{~m}$ above the ground in a dead section of a $12 \mathrm{~m}$ tall Goodding's willow. The cuckoo then flew east $20 \mathrm{~m}$, disappearing over a bank of tamarisk. At 0630, a yellow-billed cuckoo gave a kuk-kowlp 
call within $15 \mathrm{~m}$ of this last location. Aural and visual detection. Breeding classification: unconfirmed.

Big Bend Survey 1- 06/12/2007, 0623, 774911 E, 3794742 N, 140\%/15 m. Yellow-billed cuckoo responded to the $1^{\text {st }}$ playback with a kuk-kowlp call. Called again from across the river and was observed perched $5 \mathrm{~m}$ above ground in a tamarisk tree. Cuckoo called three times total, moving further upstream with each successive call. Aural and visual detection. Breeding classification: unconfirmed.

Big Bend Survey 1 - 06/12/2007, 0803, 774317E, 3795688 N, 152\%/25 m. Yellow-billed cuckoo responded to the $5^{\text {th }}$ playback with a series of very quiet $k u k s$ from a Goodding's willow. Aural detection only. Breeding classification: unconfirmed.

Big Bend Survey 1 - 06/12/2007, 1000, 773570 E, 3795166 N, Cuckoo1 @ 106\%/5 m, Cuckoo2 (?) @ 250\% $/ 50 \mathrm{~m}$. Cuckoo1 silently flew upstream after the $1^{\text {st }}$ playback and landed $7 \mathrm{~m}$ above the ground in a $10 \mathrm{~m}$ tall Goodding's willow. Cuckoo1 then flew into a second Goodding's willow one meter away where it preened for fifteen minutes. At 1018, Cuckoo1 flew east into a $10 \mathrm{~m}$ tall Goodding's willow and disappeared. At 1030, Cuckoo2 (?) gave a kuk-kowlp call then at 1035 Cuckoo2 (?) flew across the river and disappeared into the same willow thicket as Cuckoo1. Aural and visual detection. Breeding classification: unconfirmed.

Big Bend Revisit 1 - 06/15/2007, 0545, 775258 E, 3794542 N, 100\%/35 m. Yellow-billed cuckoo gave an unsolicited kuk-kowlp call. Aural detection only. Breeding classification: unconfirmed.

Big Bend Revisit 1 - 06/15/2007, 0735, 775258 E, 3794502 N, 52\%/18 m. Yellow-billed cuckoo flew unsolicited from an $8 \mathrm{~m}$ tall Goodding's willow northwest $40 \mathrm{~m}$ to an $18 \mathrm{~m}$ tall Fremont cottonwood. The cuckoo was observed foraging within the top five meters of this tree. At 0739, the cuckoo flew northwest and out of sight. Visual detection only. Breeding classification: unconfirmed.

Big Bend Revisit 1 - 06/15/2007, 0819, 775028 E, 3794639 N, 325\%/40 m. Yellow-billed cuckoo flew unsolicited from $10 \mathrm{~m}$ above the ground in a $16 \mathrm{~m}$ tall Fremont cottonwood, downstream and out of sight. Visual detection only. Breeding classification: unconfirmed.

Big Bend Revisit 1 - 06/15/2007, 1125, 775104 E, 3794574 N, 155\%/50 m. Yellow-billed cuckoo flew unsolicited downstream to the northwest about $40 \mathrm{~m}$ and disappeared around a bend in the river. Visual detection only. Breeding classification: unconfirmed.

Big Bend Re-visit 2 - 06/20/2007, 0953,775249 E, 3794563 N, Cuckoo1@ 0\%/0 m, Cuckoo2@270\%/20 m, Cuckoo3@180\%/5 m. Cuckoo1 gave unsolicited knocker calls. Cuckoo2 was seen and Cuckoo3 called while observer was monitoring Cuckoo1. Aural and visual detections. Breeding classification: unconfirmed.

Big Bend Survey 2 - 07/02/2007, 0552, 775199 E, 3794502 N, 332\%/150 m. Yellowbilled cuckoo responded to the $2^{\text {nd }}$ playback with a quiet knocker call from river right. Aural detection only. Breeding classification: unconfirmed. 
Big Bend Survey 2 - 07/02/2007, 0625, 774755 E, 3794908 N, 95\%/27 m. Yellow-billed cuckoo responded to the $2^{\text {nd }}$ playback with a kuk-kowlp call. Fifteen seconds later it gave a single coo call followed by several coo calls ten seconds later. Aural detection only. Breeding classification: unconfirmed.

Big Bend Survey 2 - 07/02/2007, 0700, 774386 E, 3795360 N, 81\%/31 m. Yellow-billed cuckoo seen flying across the river after the $1^{\text {st }}$ playback. The cuckoo landed $8 \mathrm{~m}$ above the ground in a $10 \mathrm{~m}$ tall Fremont cottonwood, then moved south along the river through a stand of Fremont cottonwood/Goodding's willow where it gave a loud knocker call. Aural and visual detection. Breeding classification: unconfirmed.

Big Bend Survey 2 - 07/02/2007, 0738, 774225 E, 3795831 N, 18\%/19 m. Yellow-billed cuckoo gave an unsolicited coo call from river right. Aural detection only. Breeding classification: unconfirmed.

Big Bend Survey 2 - 07/02/2007, 0817, 773803 E, 3795626 N, Cuckoo1 @ 145\%/40 m, Cuckoo2 (?) @ 188\%/90 m, Cuckoo3 (?) @ 350 $/ 50 \mathrm{~m}$. Cuckoo1 responded to the $1^{\text {st }}$ playback with a loud knocker call from a patch of Honey Mesquite. At 8:20, Cuckoo2 (?) gave a kuk-kowlp call downstream of Cuckoo1. At 0829, Cuckoo3 (?) gave a coo call from a large Fremont cottonwood 50 m north of the survey point. This bird then flew 45 $\mathrm{m}$ upstream and gave several coo calls. It then flew further upstream and gave coo calls $232 \mathrm{~m}$ from its initial location. Aural and visual detection. Breeding classification: unconfirmed.

Big Bend Survey 2 - 07/02/2007, 0830, 773731 E, 3795336 N, 15\%/40 m. Yellow-billed cuckoo responded to the $2^{\text {nd }}$ playback with a loud kuk-kowlp call. Aural detection only. Breeding classification: unconfirmed.

Big Bend Survey 2 - 07/02/2007, 0848, 773531 E, 3795101 N, 212\%/35 m. Yellow-billed cuckoo flew towards survey point from these coordinates after the $2^{\text {nd }}$ playback. The cuckoo landed $9 \mathrm{~m}$ above the ground in a $14 \mathrm{~m}$ tall Goodding's willow. At 0850, it gave a kuk-kowlp call, then at 0853, flew across the river and perched $12 \mathrm{~m}$ above ground in a $16 \mathrm{~m}$ tall Fremont cottonwood. The cuckoo preened for three minutes then gave a kukkowlp call. Aural and visual detection. Breeding classification: unconfirmed.

Big Bend Revisit 4 - 07/17/2007, 0602, 773735 E, 3795409 N, 330²5 m. Yellow-billed cuckoo gave unsolicited knocker-kowlp calls. Aural detection only. Breeding classification: unconfirmed.

Big Bend Revisit 4 - 07/17/2007, 0618, 773764 E, 3795395 N, Cuckoo $1 @ 30 \% / 90$ m, Cuckoo2 @ 295\%10 m, Cuckoo3 (?) @ NA. Cuckoo1 gave an unsolicited kuk-kowlp. One minute later, Cuckoo2 responded. Cuckoo2 then flew toward the waypoint, where it landed $7 \mathrm{~m}$ above the ground in an $8 \mathrm{~m}$ tall Goodding's willow. It raised its tail methodically seven or eight times before Cuckoo3 (?), unseen before this time, hopped onto Cuckoo2's back from $0.5 \mathrm{~m}$ above with a cicada in its mouth. Both cuckoos held the cicada with their bills while copulating for twenty seconds. Cuckoo3 (?) then flew toward where Cuckoo1 was detected. Cuckoo2 stayed in the willow for ten minutes more, during which time it swallowed the cicada, before flying upstream $100 \mathrm{~m}$ and out of sight. Aural and visual detection. Breeding classification: confirmed. 
Big Bend Revisit 4 - 07/17/2007, 0635, 773776 E, 3795448 N, 20\%/40 m. Yellow-billed cuckoo gave an unsolicited knocker-kowlp call. Aural detection only. Breeding classification: unconfirmed.

Big Bend Revisit 4- 07/17/2007, 0639, 773781 E, 3795474 N, 230\%/50 m. Unsolicited yellow-billed cuckoo seen carrying food. Visual detection only. Breeding classification: unconfirmed.

Big Bend Revisit 4 - 07/17/2007, 0646, 773765 E, 3795468 N, Cuckoo1 @90\%/75 m, Cuckoo2@340\% 5 m. Cuckoo1 gave an unsolicited knocker-kowlp call. Cuckoo2 immediately responded, and then flew northeast. Aural and visual detection. Breeding classification: unconfirmed.

Big Bend Revisit 4 - 07/17/2007, 0748, 773740 E, 3795426 N, Cuckoo1, 2, and 3 (?) @ $0 \% \mathrm{~m}$. Cuckoo1 flew in unsolicited from the north with food, landing $10 \mathrm{~m}$ above ground in a $12 \mathrm{~m}$ high Goodding's willow. Gave a knocker-kowlp call, then flew down into the vegetation. At 0903, a cuckoo gave unsolicited, rapid, and prolonged knocker calls from the same willow. A potential but unconfirmed nest was later found in this tree. At 0910, a juvenile (Cuckoo2) was spotted $8 \mathrm{~m}$ above ground on a curving, horizontal branch in a $10 \mathrm{~m}$ tall Goodding's willow, attended by Cuckoo3 (?). Aural and visual detection. Breeding classification: confirmed.

Big Bend Survey 3 - 07/25/2007, 0942, 773826 E, 3795660 N, 250\%/15 m. Yellow-billed cuckoo gave an unsolicited coo call, then flew across the river. Aural and visual detection. Breeding classification: unconfirmed.

Big Bend Survey 3 - 07/15/2007, 0956, 773744 E, 3795367 N, 170\%/10 m. Yellow-billed cuckoo responded to the $1^{\text {st }}$ playback with a $k u k$ call, then flew west across the river. At 1010 and 1015 more $k u k$ calls were heard in this area. Aural and visual detection. Breeding classification: unconfirmed.

Big Bend Revist 5 - 07/29/2007, 0648, 773778 E, 3795383 N, Cuckoo1 @ 132\%/30 m, Cuckoo2 (?) @ 20\%/20 m. Cuckoo1 responded to $1^{\text {st }}$ playback with a kuk-kowlp call. At 0653 and again at 0705 an unsolicited knocker-kowlp call was given by Cuckoo2 (?). Aural detection only. Breeding classification: unconfirmed.

Big Bend Revisit 6 - 08/07/2007, 0900, 774286 E, 3795801 N, 00 m. Yellow-billed cuckoo gave an unsolicited, soft knocker call. On a subsequent visit a potential but unconfirmed nest was located within $3 \mathrm{~m}$ of this location. Aural detection only. Breeding classification: unconfirmed.

Big Bend Revisit 7 - 08/09/2007, 0920, 773801 E, 3795597 N, 70\%/10 m. Yellow-billed cuckoo flew in unsolicited and landed $10 \mathrm{~m}$ above the ground in a Goodding's willow. The cuckoo foraged for a couple minutes, and then gave a very quiet kowlp call ten times. The cuckoo then moved down two branches, spread both wings and raised its tail, remaining in this position for ten minutes, after which time, the cuckoo flew about $50 \mathrm{~m}$ northeast into the vegetation and knocked softly three separate times. Aural and visual detection. Breeding classification: unconfirmed. 
Big Bend Revisit 7 - 08/09/2007, 0919, 773613 E, 3795188 N, 0²0 m. Yellow-billed cuckoo flew unsolicited from river left to river right and landed in a young Fremont cottonwood. It then flew to a mature Fremont cottonwood, stayed still for two minutes and flew off. Visual detection only. Breeding classification: unconfirmed.

Big Bend Survey 4 - 08/13/2007, 0640, 774865 E, 3794777 N, Cuckoo1 @ 20¹5 m, Cuckoo2 @ 104\% $/ 20 \mathrm{~m}$. Cuckoo1, a fledgling, responded to the $4^{\text {th }}$ playback with very hoarse, off-sounding coo calls. Cuckoo2, an adult, responded with knocker calls from a medium Goodding's willow. At 0645, Cuckoo1 gave hoarse kowlp calls which Cuckoo2 responded to with a kuk-kowlp call. At 0705 kuk-kowlp calls were heard approximately $30 \mathrm{~m}$ downstream. Aural and visual detection. Breeding classification: confirmed.

Big Bend Survey 4 - 08/13/2007, 0743, 774370 E, 3795432 N, 2\%/40 m. Yellow-billed cuckoo responded to the $3^{\text {rd }}$ playback with knocker calls then flew to a medium Goodding's willow $15 \mathrm{~m}$ upstream on river left. At 0830, a nest (BBNest1) was located on river left right across from where the cuckoo was first detected. The nest was $4.5 \mathrm{~m}$ above ground in a tamarisk tree and had "something" inside it. A yellow-billed cuckoo gave a knocker call when the nest was approached. The observer left the area at 0835 but returned at 1100 to find an adult yellow-billed cuckoo sitting on the nest. A second adult gave knocker calls nearby. Aural and visual detection. Breeding classification: confirmed.

Big Bend Survey 4 - 08/13/2007, 0904, 773791 E, 3795584 N, 126\%10 m. Yellow-billed cuckoo responded to the $4^{\text {th }}$ playback with a knocker call. The cuckoo then flew from a medium Goodding's willow to a medium Fremont cottonwood on river left and knocked again before flying back across the river and knocking again from its original location. More knocker calls were heard from this Goodding's willow at 0923. Aural and visual detection. Breeding classification: unconfirmed.

Big Bend Survey 4 - 08/13/2007, 0923, 773714 E, 3795302 N, 10\%40 m. Yellow-billed cuckoo responded to the $1^{\text {st }}$ playback with a kuk-kowlp call. Aural detection only. Breeding classification: unconfirmed.

Big Bend Survey 4 - 08/13/2007, 0949, 773518 E, 3795075 N, 250\%10 m. Yellow-billed cuckoo flew in from the north after the $1^{\text {st }}$ playback. It landed $8 \mathrm{~m}$ above ground in a $10 \mathrm{~m}$ tall Goodding's willow and gave a kowlp call. The cuckoo then disappeared into the vegetation. Aural and visual detection. Breeding classification: unconfirmed.

Big Bend Revisit 8 - 08/13/2007, 0751, 774358 E, 3795465 N, Cuckoo1 @ 15\%15 m, Cuckoo2 @ 100\%10 m. Cuckoo1 gave an unsolicited, high pitched kuk-kowlp call from a large Fremont cottonwood on river left, followed by a knocker-kowlp given by Cuckoo2 from a $10 \mathrm{~m}$ tall Goodding's willow on river left. Cuckoo2 then flew across the river and gave a kuk-kowlp call. Aural and visual detection. Breeding classification: unconfirmed.

Big Bend Revisit 8 - 08/13/2007, 0815, 774350 E, 3795428 N, 210\%10 m. Yellow-billed cuckoo seen unsolicited, $6 \mathrm{~m}$ above the ground in a $12 \mathrm{~m}$ tall Goodding's willow on river right holding a cicada. It sat still, knocked at the observer, then ate the cicada and cleaned its bill. The cuckoo then flew south across the river and landed $8 \mathrm{~m}$ above the ground in a Goodding's willow. Here it gave a knocker call before flying back across the river and knocking again. The 0751 and 0815 Revisit1 detections were both made in the area of the 
0743 survey detection and should not be considered independent events. Aural and visual detection. Breeding classification: unconfirmed.

Big Bend Revisit 9 - 08/14/2007, 1100, 774359 E, 3795439 N, 0\% m. Observers mirrorpoled BBNest1 and discovered a nestling yellow-billed cuckoo sitting on the rim. The nestling's feathers had burst and it had a short tail. Streaks of skin could still be seen around its bill. Its back was very dark and had no dandruff. Upon seeing the mirror pole, the nestling began to gape. It then jumped to a nearby branch, flapping its wings. It struggled to grasp the branch but held on. Observers estimated the nestling's age to be approximately seven or eight days based on feather development. While observers were mirror-poling the nest, an adult yellow-billed cuckoo gave several knocker calls. Aural and visual detection. Breeding classification: confirmed.

Big Bend Revisit 10 - 8/22/2007, 0652, 774355 E, 3795432 N, Cuckoo1@ @0\%/50 m, Cuckoo2 (?) @ $15 \mathrm{~m} / 350^{\circ}$, Cuckoo3 @ 37\%/75 m. Cuckoo1 gave an unsolicited kukkowlp call while observer checking BBNest1. At 0754, Cuckoo2 (?) gave a kuk-kowlp call, then flew across the river from a Gooding's willow carrying a large (potentially orthopteran) prey item. Upon landing, Cuckoo2 (?) gave a "kuk-kowlp call. At 0757, it flew back towards the nest, disappearing $8 \mathrm{~m}$ above ground in a Goodding's willow $6 \mathrm{~m}$ north of the nest. At 0816, Cuckoo2 (?) gave a kuk call. Cuckoo3 responded with a kukkowlp call. Cuckoo2 (?) responded immediately to Cuckoo3 with a kuk-kowlp call, then flew into view with no prey in its bill. At 0818, Cuckoo2 (?) looked directly at the observer and gave five knocker calls within the next two minutes. Cuckoo3 responded one time with a kowlp call. Cuckoo2(?) was observed moving about the Goodding's willows near the nest for the next five minutes, after which it flew off to the southeast. No eggs, nestlings, or fledges were located, however, based on adult behavior, fledgling(s) suspected to be near the nest. No cuckoos detected here at the next nest check on 08/25/2007. Aural and visual detection. Breeding classification: confirmed.

Big Bend Survey 5 - 09/06/2007, 0914, 773926 E, 3795881 N, 346\%/10 m. Yellow-billed cuckoo flew northeast across the river after the $2^{\text {nd }}$ playback from a Fremont cottonwood into a Goodding's willow/Fremont cottonwood stringer on river right. The cuckoo moved northeast, foraging along the stringer for ten minutes, after which time it disappeared into the vegetation. Visual detection only. Breeding classification: unconfirmed.

Big Bend Revisit 12 - 09/06/2007, 1012, 7738224 E, 3795454 N, 196\%/30 m. Yellowbilled cuckoo gave an unsolicited kuk-kowlp call. No detections were made at this location when the survey came through just thirty minutes earlier. Aural detection only. Breeding classification: unconfirmed.

\section{Gibraltar Rock}

Gibraltar Rock Survey 1 - 06/13/2007, 0625, 772082 E, 3795855 N, 3\%/200 m. Yellowbilled cuckoo responded to the $3^{\text {rd }}$ playback with a kuk-kowlp call and coo calls from the location of the cuckoo detected in Sandy Wash at 0602. Aural detection only. Breeding classification: unconfirmed.

Gibraltar Rock Survey 1 - 06/13/2007, 0715, 772647 E, 3795585 N, 284\%/200 m. Yellow-billed cuckoo responded to the $1^{\text {st }}$ playback with a series of "coo" calls. At 0724 , 
the cuckoo was seen at this location $6 \mathrm{~m}$ above the ground in a $9 \mathrm{~m}$ tall Goodding' $\mathrm{s}$ willow giving coo and kuk-kowlp calls. The cuckoo flew upstream from clump to clump of Goodding's willows, cooing as it went, until it landed behind some tamarisk about 20 $\mathrm{m}$ from the survey point. The cuckoo continued to give coo calls and was last heard at 0748, $200 \mathrm{~m}$ upstream from the survey point. Observer believed this to be the same individual detected at 0625. Aural and visual detection. Breeding classification: unconfirmed.

Gibraltar Rock Survey 1 - 06/13/2007, 0844, 773184 E, 3794899 N, Cuckoo1 @ 352\%/10 $\mathrm{m}$, Cuckoo2@252\%/20 m. Two yellow-billed cuckoos flew in silently after the $2^{\text {nd }}$ playback. Cuckoo1 landed in a patch of tamarisk, Cuckoo 2 in a clump of $8 \mathrm{~m}$ tall Goodding's willow. Cuckoo1 immediately flew over to Cuckoo2's location. They remained here until 0849, when they both flew downriver and behind a wall of tamarisk. Visual detection only. Breeding classification: unconfirmed.

Gibraltar Rock Revisit 2 - 06/25/2007, 0638, 773180 E, 3794925 N, $108^{\circ} / 50$ m. Yellowbilled cuckoo gave two unsolicited kuk-kowlp calls fifteen seconds apart. Aural detection only. Breeding classification: unconfirmed.

Gibraltar Rock Revisit 2 - 06/25/2007, 0711, 773183 E, 3794895 N, 98\%/70 m. Yellowbilled cuckoo gave an unsolicited kowlp call followed by a kuk call. Aural detection only. Breeding classification: unconfirmed.

Gibraltar Rock Revisit 2 - 06/25/2007, 0740, 773294 E, 3794856 N, 270\%/50 m. Yellowbilled cuckoo gave an unsolicited kuk-kowlp call. Aural detection only. Breeding classification: unconfirmed.

Gibraltar Rock Revisit 3 - 06/30/2007, 0535, 773212 E, 3794921 N, 80\%/150 m. Yellowbilled cuckoo gave an unsolicited kuk-kowlp call. Aural detection only. Breeding classification: unconfirmed.

Gibraltar Rock Revisit 3 - 06/30/2007, 0550, 773276 E, 3794914 N, 39/74 m. Yellowbilled cuckoo gave an unsolicited knocker call. Aural detection only. Breeding classification: unconfirmed.

Gibraltar Rock Revisit 3 -06/30/2007, 0611,773317 E, 3794928 N, Cuckoo1 @ 53\%/30 m, Cuckoo2 (?) @ 178\%15 m. Cuckoo1 gave a single, unsolicited, soft, rolling kuk from a thin stringer of Goodding's willow. Five minutes later, Cuckoo2 (?) gave a knocker call. Aural detection only. Breeding classification: unconfirmed.

Gibraltar Rock Revisit 3 - 06/30/2007, 0618, 773422 E, 3794974 N, 270\%/100 m. Yellow-billed cuckoo gave an unsolicited kuk-kowlp call. Aural detection only. Breeding classification: unconfirmed.

Gibraltar Rock Revisit 3 -06/30/2007, 0621,773345 E, 3794839 N, Cuckoo1 @ 253/7 m, Cuckoo2@279\%10 m. Cuckoo1 and Cuckoo2 gave a series of unsolicited contact calls from a clump of Fremont cottonwoods. Cuckoo1 remained stationary and gave rolling kowlps while Cuckoo 2 moved around the cottonwoods and responded with kukkowlp calls. Aural detection only. Breeding classification: unconfirmed. 
Gibraltar Rock Survey 2 - 07/03/2007, 0711, 772784 E, 3795523 N, 100\%40 m. Yellowbilled cuckoo responded to the $2^{\text {nd }}$ playback with a kuk-kowlp call from a $15 \mathrm{~m}$ tall, yellowing Fremont cottonwood. Aural detection only. Breeding classification: unconfirmed.

Gibraltar Rock Survey 2 -07/03/2007, 0731, 772827 E, 3795216 N, Cuckoo1 @ 36\%/40 m, Cuckoo2@90\%/30 m. Cuckoo1 responded to the $2^{\text {nd }}$ playback with a kuk-kowlp call. At 0740, Cuckoo1 gave another kuk-kowlp call to which Cuckoo2 responded. At 0742, Cuckool gave one more kuk-kowlp call. Aural detection only. Breeding classification: unconfirmed.

Gibraltar Rock Survey 2 - 07/03/2007, 0817, 773107 E, 3794926 N, 226²0 m. Yellowbilled cuckoo gave an unsolicited kuk-kowlp call from a stringer of $8 \mathrm{~m}$ tall Goodding's willows. Two more kuk-kowlp calls were heard between 0820 and 0927 . Aural detection only. Breeding classification: unconfirmed.

Gibraltar Rock Revisit 4- 07/13/2007, 0600, 773006 E, 3794884 N, 0\%/0 m. Yellowbilled cuckoo gave unsolicited coo calls from $11 \mathrm{~m}$ above the ground in a Fremont cottonwood, then flew off. Aural and visual detection. Breeding classification: unconfirmed.

Gibraltar Rock Revisit 4 - 07/13/2007,0607, 773183 E, 3794879 N, Cuckoo1 @ 45\%/5 $\mathrm{m}$, Cuckoo2@270\%/30 m. Cuckoo1 landed unsolicited $2 \mathrm{~m}$ above the ground in a $3 \mathrm{~m}$ tall Fremont cottonwood and gave a kuk-kowlp call. Cuckoo 2 immediately responded with a kuk-kowlp from the direction of the cuckoo detected at 0600. Cuckoo1 then flew $30 \mathrm{~m}$ southeast and gave a kuk-kowlp call. Aural and visual detection. Breeding classification: unconfirmed.

Gibraltar Rock Revisit 4 - 07/13/2007, 0627, 773141 E, 3794831 N, 277\%/50 m. Yellowbilled cuckoo gave an unsolicited kuk-kowlp call. Aural detection only. Breeding classification: unconfirmed.

Gibraltar Rock Revisit 4 - 07/13/2007, 0630, 773006 E, 3794884 N, Cuckoo1 and Cuckoo2@0\% m. Cuckoo1 flew unsolicited to the Fremont cottonwood the cuckoo was detected in at 0600 and landed $11 \mathrm{~m}$ above the ground. Cuckoo2 was perched $1 \mathrm{~m}$ below and behind Cuckoo1. Cuckoo1 flew to a branch $1 \mathrm{~m}$ below Cuckoo2 and gave five tail pumps. Cuckoo2 landed on Cuckoo1 and copulation occurred for two seconds. Cuckoo2 then flew away. Cuckoo1 remained for five minutes then flew off. Visual detection only. Breeding classification: confirmed.

Gibraltar Rock Revisit 4-07/13/2007, 0635, 773044 E, 3794855 N, Cuckoo1 @ 170\%/45 m, Cuckoo2@85\%/100 m. Cuckoo1 gave an unsolicited kuk-kowlp call to which Cuckoo2 responded with six series of coo calls. Aural detection only. Breeding classification: unconfirmed.

Gibraltar Rock Revisit 4 - 07/13/2007, 0657, 773251 E, 3794864 N, 65\%/70 m. Yellowbilled cuckoo gave an unsolicited kuk-kowlp call. Aural detection only. Breeding classification: unconfirmed. 
Gibraltar Rock Revisit 4 - 07/13/2007, 0721, 773293 E, 3794853 N, 7060 m. Yellowbilled cuckoo gave an unsolicited kuk-kowlp call. Aural detection only. Breeding classification: unconfirmed.

Gibraltar Rock Revisit 4- 07/13/2007, 0745, 772926 E, 3794849 N, Cuckoo1 and Cuckoo2 @ 0\% $/ 0$. Two yellow-billed cuckoos were seen unsolicited in the top canopy giving soft knocker and coo calls. Cuckoo1 flew north to a large Fremont cottonwood where it caught and ate an unidentified food item. Cuckool then flew to the west along the river. Cuckoo2 remained where it was first located and called until 0800. Aural and visual detection. Breeding classification: unconfirmed.

Gibraltar Rock Revisit 5 - 07/16/2007, 0552, 772953 E, 3794896 N, Cuckoo1 @ 350²0 m, Cuckoo2 and Cuckoo3 @ 230\%15 m. Cuckoo1 gave unsolicited soft kowlps to which Cuckoo2 immediately responded with a kuk-kowlp call. Cuckoo3 immediately responded to Cuckoo2 with a knocker call. The observer later located three cuckoos foraging in the $14 \mathrm{~m}$ tall Fremont cottonwood Cuckoo2 and Cuckoo3 had called from. At 0657, a yellow-billed cuckoo gave a kuk-kowlp call, and at 0747 a ping-pong call came from this same Fremont cottonwood. Aural and visual detection. Breeding classification: unconfirmed.

Gibraltar Rock Revisit 5 - 07/16/2007, 0828, 772910 E, 3794876 N, 0\%0 m. Unsolicited yellow-billed cuckoo seen flying with food from near the river to an area $20 \mathrm{~m}$ west of the Fremont cottonwood cuckoos were detected in at 0552. Upon landing, the cuckoo gave a harsh kuk-kowlp call followed by several knocks. Aural and visual detection. Breeding classification: unconfirmed.

Gibraltar Rock Revisit 6 - 07/29/2007, 0818, 772919 E, 3794873 N, $320^{\circ} / 5$ m. Yellowbilled cuckoo gave an unsolicited knocker-kowlp. At 0827, a knocker-kowlp was given 20 $\mathrm{m}$ further west. Aural detection only. Breeding classification: unconfirmed.

Gibraltar Rock Revisit 7 - 08/09/2007, 0654, 772927 E, 3794857 N, 21050 m. Yellowbilled cuckoo gave an unsolicited kowlp call. Aural detection only. Breeding classification: unconfirmed.

Gibraltar Rock Survey 4 - 08/15/2007, 0847, 773027 E, 3794918 N, 210\%/8 m. Yellowbilled cuckoo fledgling responded to the $3^{\text {rd }}$ playback with an immature call; a combination of a $k u k$ and a coo. The fledgling was fully feathered including its tail and had yellow on its bill but it appeared to lack an eye ring. Aural and visual detection. Breeding classification: confirmed.

\section{Sandy Wash}

Sandy Wash Revisit 1 - 06/13/2007, 0602, 771859 E, 3796073 N, 20³0 m. Yellowbilled cuckoo gave an unsolicited kuk-kowlp call followed by coo calls for the next two minutes. Kuk-kowlp calls and rolling kowlps were given after that. Aural detection only. Breeding classification: unconfirmed. 
Sandy Wash Survey 2 - 07/11/2007, 0555, 771266 E, 3796325 N, $40^{\circ} / 70$ m. Yellowbilled cuckoo gave unsolicited coo calls from an $18 \mathrm{~m}$ tall Fremont cottonwood. Aural detection only. Breeding classification: unconfirmed.

Sandy Wash Survey 2 - 07/11/2007, 0726, 771748 E, 3796616 N, Cuckoo1 @ 4²0 m, Cuckoo2 (?) @ 352\%100 m. Cuckoo1 responded to the $1^{\text {st }}$ playback with soft kuks. At 0737, Cuckoo2 (?) began to coo. Aural detection only. Breeding classification: unconfirmed.

Sandy Wash Survey 2 - 07/11/2007, 0857, 771466 E, 3796612 N, Cuckoo1 @ 324\%15 m, Cuckoo2 (?) @ 58\% $/ 40$ m. Cuckoo1 gave unsolicited kuks from a $17 \mathrm{~m}$ tall Fremont cottonwood, then again at 0904. Two minutes later, Cuckoo2 (?) gave a series of kuks from another large Fremont cottonwood. Aural detection only. Breeding classification: unconfirmed.

Sandy Wash Revisit 3 - 07/11/2007, 0800, 771761 E, 3796743 N, 236²0 m. Yellowbilled cuckoo gave unsolicited kuks from a clump of small Goodding's willows. Then at 0826, a kuk-kowlp call was given. Aural detection only. Breeding classification: unconfirmed.

Sandy Wash Revisit 3 - 07/11/2007, 0806, 771739 E, 3796757 N, 290/30 m. Yellowbilled cuckoo gave unsolicited coo calls from two $17 \mathrm{~m}$ tall Fremont cottonwoods for four minutes, and then gave kuks at 0813 . Aural detection only. Breeding classification: unconfirmed.

Sandy Wash Revisit 3 - 07/11/2007, 0821, 771703 E, 3796779 N, 290²5 m. Yellowbilled cuckoo gave an unsolicited kuk-kowlp call from a clump of medium Goodding's willows. At 0834 and 0835 , kuks were given from this location. Aural detection only. Breeding classification: unconfirmed.

Sandy Wash Revisit 3 - 07/11/2007, 0832, 771659 E, 3796732 N, 226³0 m. Yellowbilled cuckoo gave an unsolicited kuk-kowlp call from a clump of large Fremont cottonwoods. At 0840, a kowlp call was given here. The survey detection at 0726 and the revisit detections for this date were all close to one another and should not be viewed as independent events. Aural detection only. Breeding classification: unconfirmed.

Sandy Wash Revisit 4 - 07/15/2007, 0628, 771894 E, 3796283 N, 200\%/40 m. Yellowbilled cuckoo flew in and gave an unsolicited kuk-kowlp call. Aural and visual detection. Breeding classification: unconfirmed.

Sandy Wash Revisit 4 - 07/15/2007, 0920, 771644 E, 3796738 N, 333/50 m. Yellowbilled cuckoo gave several unsolicited coo calls before flying across a wash into a large Fremont cottonwood. Here it gave rolling kowlps then two knocker calls. Aural and visual detection. Breeding classification: unconfirmed.

Sandy Wash Revisit 5 - 07/17/2007, 0602, 771892 E, 3796216 N, 15050 m. Yellowbilled cuckoo gave an unsolicited knocker-kowlp. Aural detection only. Breeding classification: unconfirmed. 
Sandy Wash Revisit 5 - 07/17/2007, 0636, 771956E, 3796250N, 150²0m. Yellowbilled cuckoo gave an unsolicited "knocker-kowlp" call. Aural detection only. Breeding classification: unconfirmed.

Sandy Wash Revisit 5 - 07/17/2007, 0751, 771637 E, 3796830 N, Cuckoo1 and Cuckoo2 @ 170\%50 m. Cuckoo1, a juvenile, gave an unsolicited grr-brr call, which Cuckoo2, an adult, followed with a knocker-kowlp call. After the adult called, the juvenile gave another grr-brr call. Aural detection only. Breeding classification: confirmed.

Sandy Wash Survey 3 - 07/26/2007, 0643, 771705 E, 3796102 N, 205\%/10 m. Yellowbilled cuckoo seen unsolicited in a medium Goodding's willow after the $2^{\text {nd }}$ playback. The cuckoo took flight, caught an unidentified insect, and brought it back to a large Fremont cottonwood $20 \mathrm{~m}$ northeast of its original location. Visual detection only. Breeding classification: unconfirmed.

Sandy Wash Survey 3 - 07/26/2007, 0710, 771890 E, 3796336 N, Cuckoo1 @ 5\%/75 m, Cuckoo2@ 25\%/45 m, Cuckoo3 (?) @ 5\%/40 m. Cuckoo1 responded to the $2^{\text {nd }}$ playback with a knocker-kowlp call. Cuckoo2 immediately responded to Cuckoo1 with a knockerkowlp call. Cuckoo1 responded to this with another knocker-kowlp call. Cuckoo1 called several more times and was last heard at 0735 . Cuckoo3 (?) called at 0739. Aural detection only. Breeding classification: unconfirmed.

Sandy Wash Survey 3 - 07/26/2007, 0826, 771692 E, 3796682 N, 100/75 m. Yellowbilled cuckoo responded to the $2^{\text {nd }}$ playback with a knocker-kowlp call. Over the next 45 minutes, Cuckoo1 called a total of three more times from the same location, one of which was followed shortly afterwards by a call from the cuckoo detected at 0830 on Revisit 6 . After Cuckoo1's last call, a cuckoo flew east from this location. A food carry was later observed as a cuckoo flew west across the wash toward Cuckoo1's original location. Activity primarily centered on an area of several emergent Fremont cottonwoods with an understory of dense tamarisk. Aural and visual detection. Breeding classification: unconfirmed.

Sandy Wash Survey 3 - 07/26/2007, 1005, 771403 E, 3796578 N, 90\%/40 m. Yellowbilled cuckoo responded to the $2^{\text {nd }}$ playback with three minutes of coo calls. Nineteen minutes later, more coo calls were heard approximately $60 \mathrm{~m}$ to the north. Aural detection only. Breeding classification: unconfirmed.

Sandy Wash Revisit 6 - 07/26/2007, 0804, 771878 E, 3796437 N, $30^{\circ} / 50$ m. Yellowbilled cuckoo gave unsolicited kowlps. Aural detection only. Breeding classification: unconfirmed.

Sandy Wash Revisit 6 - 07/26/2007, 0830, 771796 E, 3796543 N, 180/50 m. Yellowbilled cuckoo gave a response to calls given by the cuckoo detected on the survey at 0826. Aural detection only. Breeding classification: unconfirmed.

Sandy Wash Revisit 6 - 07/26/2007, 0838, 771735 E, 3796604 N, 152/30 m. Yellowbilled cuckoo gave unsolicited kuks. Aural detection only. Breeding classification: unconfirmed. 
Sandy Wash Revisit 6 - 07/26/2007, 0845, 771653 E, 3796750 N, 30³0 m. Yellowbilled cuckoo gave unsolicited kuks. At 0855, a kuk-kowlp call was heard $15 \mathrm{~m}$ to the north. Then at 0909 and 0923 , kuk-kowlp calls were given $20 \mathrm{~m}$ west of the initial detection. Aural detection only. Breeding classification: unconfirmed.

Sandy Wash Revisit 7 - 07/29/2007, 0555, 771770 E, 3796576 N, Cuckoo1 @ 25\%/30 m, Cuckoo2 (?) @ 20\%/50 m, Cuckoo3 (?) @ 175\% m. Cuckoo1 gave two series of unsolicited kuks followed by a knocker-kowlp call at 0606. At 0615, Cuckoo2 (?) gave a knocker-kowlp. Cuckoo 3 (?) gave a knocker-kowlp five minutes later. Aural detection only. Breeding classification: unconfirmed.

Sandy Wash Revisit 7 - 07/29/2007, 0642, 771735 E, 3796632 N, 4050 m. Yellowbilled cuckoo responded to the $1^{\text {st }}$ playback with a knocker-kowlp call. Aural detection only. Breeding classification: unconfirmed.

Sandy Wash Revisit 7 - 07/29/2007, 0710, 771637 E, 3796882 N, 100²5 m. Yellowbilled cuckoo responded to the $1^{\text {st }}$ playback with a knocker-kowlp call from the north side of a small pond. Aural detection only. Breeding classification: unconfirmed.

Sandy Wash Revisit 7 - 07/29/2007, 0720, 771633 E, 3796891 N, 170²5 m. Yellowbilled cuckoo gave an unsolicited kuk-kowlp call from a large Fremont cottonwood. Aural detection only. Breeding classification: unconfirmed.

Sandy Wash Revisit 7 - 07/29/2007, 0726, 771628 E, 3796855 N, 27040 m. Yellowbilled cuckoo gave an unsolicited kuk-kowlp call. At 0737, it gave the same call again. Aural detection only. Breeding classification: unconfirmed.

Sandy Wash Revisit 7 - 07/29/2007, 0834, 771762 E, 3796586 N, 350\%15 m. Yellowbilled cuckoo gave an unsolicited kuk-kowlp call from a small Goodding's willow. The cuckoo then flew approximately $40 \mathrm{~m}$ southwest to a patch of large Fremont cottonwoods where it gave a kuk-kowlp call at 0847. Aural and visual detection. Breeding classification: unconfirmed.

Sandy Wash Revisit 7 - 07/29/2007, 0928, 771740 E, 3796531 N, Cuckoo1 @ 270³5 $\mathrm{m}$, Cuckoo2 @ 310\% $/ 25 \mathrm{~m}$. Yellow-billed cuckoo responded to the $3^{\text {rd }}$ playback with two knocker-kowlps from a large Fremont cottonwood, followed by a knocker-kowlp from Cuckoo2. Aural detection only. Breeding classification: unconfirmed.

Sandy Wash Revisit 8 - 08/08/2007, 0904, 771754 E, 3796627 N, 1050 m. Yellowbilled cuckoo gave unsolicited kuks from a clump of $4 \mathrm{~m}$ tall Goodding's willow. At 0923, a kuk-kowlp call was given from the same location. Aural detection only. Breeding classification: unconfirmed.

Sandy Wash Revisit 8 - 08/08/2007, 0952, 771778 E, 3796648 N, 40³0 m. Yellowbilled cuckoo responded to the $1^{\text {st }}$ playback with a kuk-kowlp call. Aural detection only. Breeding classification: unconfirmed. 
Sandy Wash Revisit 8 - 08/08/2007, 1003, 771779 E, 3796663 N, 26050 m. Yellowbilled cuckoo gave an unsolicited kuk-kowlp call. Aural detection only. Breeding classification: unconfirmed.

Sandy Wash Revisit 8 - 08/08/2007, 1031, 771273 E, 3796322 N, 125\%/15 m. Yellowbilled cuckoo gave an unsolicited knocker call from $12 \mathrm{~m}$ above the ground in a $15 \mathrm{~m}$ tall Fremont cottonwood. The cuckoo was observed for thirty seconds before flying to the north. Aural and visual detection. Breeding classification: unconfirmed.

Sandy Wash Revisit 8 - 08/08/2007, 1043, 771817 E, 3796657 N, 335\%/15 m. Yellowbilled cuckoo responded to the $2^{\text {nd }}$ playback with a kuk-kowlp call. When observers approached its location, it began to knock. It was later spotted by observers as it flew out of sight. Aural and visual detection. Breeding classification: unconfirmed.

Sandy Wash Survey 4 - 08/15/2007, 0631, 771375 E, 3796249 N, 84\%/8 m. Yellow-billed cuckoo responded to the $1^{\text {st }}$ playback with kuks from $10 \mathrm{~m}$ above the ground in a Fremont cottonwood. It then flew to the southwest. Aural and visual detection. Breeding classification: unconfirmed.

Sandy Wash Survey 4 - 08/15/2007, 0720, 771834 E, 3796429 N, 50¹00 m. Yellowbilled cuckoo responded to the $4^{\text {th }}$ playback with a kuk-kowlp call. Aural detection only. Breeding classification: unconfirmed.

Sandy Wash Survey 4 - 08/15/2007, 0744, 771642 E, 3796778 N, 264\%/100 m. Yellowbilled cuckoo responded to the $5^{\text {th }}$ playback with coo calls. Aural detection only. Breeding classification: unconfirmed.

Sandy Wash Revisit 10 - 08/26/2007, 0805, 771707 E, 3796689 N, 106²0 m. Yellowbilled cuckoo gave an unsolicited kuk-kowlp call from a stand of Goodding's willow. Aural detection only. Breeding classification: unconfirmed.

Sandy Wash Revisit 11 - 08/27/2007, 0625, 771821 E, 3796123 N, 0\% / m. A fledgling yellow-billed cuckoo was seen, unsolicited, on the edge of a wash, $3 \mathrm{~m}$ above the ground in a $6 \mathrm{~m}$ tall Goodding's willow. The bird had no yellow on its bill, a tail of full length, and was almost completely feathered. Pin feathers were apparent between the nape, cheek, and supra loral region. The cuckoo pumped its tail a few times, hopped around the willow's branches, and after 20 seconds flew north into the vegetation. It was very agile and maneuverable. The fledgling moved through the willow like an adult bird would. Visual detection only. Breeding classification: confirmed.

Sandy Wash Revisit 12 - 08/28/2007, 0736, 771870 E, 3796399 N, 316\%60 m. Yellowbilled cuckoo gave an unsolicited kuk-kowlp call. Aural detection only. Breeding classification: unconfirmed.

Sandy Wash Revisit 12 - 08/28/2007, 0803, 771788 E, 3796424 N, $40^{\circ} / 80$ m. Yellowbilled cuckoo gave an unsolicited kuk-kowlp call, then kuks at 0808. Aural detection only. Breeding classification: unconfirmed. 
Sandy Wash Revisit 12 - 08/28/2007, 0835, 771876 E, 3796461 N, 258\%/70 m. Yellowbilled cuckoo gave several unsolicited kuk-kowlp calls and knocker calls. Aural detection only. Breeding classification: unconfirmed.

Sandy Wash Revisit 13 - 08/29/2007, 0700, 771722 E, 3796743 N, 150/35 m. Yellowbilled cuckoo gave unsolicited knocker calls while flying successively closer to where observers were measuring vegetation. At 0712, the cuckoo was spotted $5 \mathrm{~m}$ above the ground in a $10 \mathrm{~m}$ tall Goodding's willow about $15 \mathrm{~m}$ away from the observers. The cuckoo fell silent at 0720 and was not heard from again. Aural detection only. Breeding classification: unconfirmed.

Sandy Wash Survey 5 - 09/07/2007, 0759, 771666 E, 3796708 N, 254\%/50 m. Yellowbilled cuckoo responded to the $4^{\text {th }}$ playback with kuk-kowlp and coo calls from a patch of Fremont cottonwoods. Aural detection only. Breeding classification: unconfirmed.

\section{Fox Wash}

Fox Wash Survey 2 - 07/03/2007, 0824, 770846 E, 3797861 N, 208\%/90 m. Yellow-billed cuckoo gave an unsolicited kuk-kowlp call. Observer stayed in area until 0900 and did not detect the cuckoo again. Aural detection only. Breeding classification: unconfirmed.

Fox Wash Survey 3 - 08/11/2007, 0730, 770980 E, 3797401 N, 285\%/250 m. Yellowbilled cuckoo responded to the $2^{\text {nd }}$ playback with a series of coo calls. At 0711, the cuckoo moved into a stand of $14 \mathrm{~m}$ tall Fremont cottonwoods $20 \mathrm{~m}$ south of the survey point and continued to coo. Aural detection only. Breeding classification: unconfirmed.

\section{Mosquito Flats}

Mosquito Flats Survey 2 - 07/11/2007, 0735, 770624 E, 3797065 N, 52\%/100 m. Yellowbilled cuckoo responded to the $2^{\text {nd }}$ playback with three series of coo calls. Aural detection only. Breeding classification: unconfirmed.

Mosquito Flats Survey 2 - 07/11/2007, 0753, 770866 E, 3796866 N, 340\%120 m. Yellow-billed cuckoo responded to the $5^{\text {th }}$ playback with a series of $c o 0$ calls. Observer suspected this was the same bird detected at 0735. Aural detection only. Breeding classification: unconfirmed.

Mosquito Flats Survey 2 - 07/11/2007, 0832, 771178 E, 3796647 N, 335\%/120 m. Yellow-billed cuckoo responded to the $4^{\text {th }}$ playback with a kuk-kowlp call. Aural detection only. Breeding classification: unconfirmed.

Mosquito Flats Survey 3 - 08/08/2007, 0614, 769838 E, 3797115 N, $30^{\circ} / 100$ m. Yellowbilled cuckoo responded to the $3^{\text {rd }}$ playback with a knocker call. Aural detection only. Breeding classification: unconfirmed.

Mosquito Flats Survey 3 - 08/08/2007, 0650, 770142 E, 3797051 N, 60\%50 m. Yellowbilled cuckoo responded to the $2^{\text {nd }}$ playback. Aural detection only. Breeding classification: unconfirmed. 
Mosquito Flats Survey 3 - 08/08/2007, 0705, 770386 E, 3796995 N, 340³0 m. Yellowbilled cuckoo gave an unsolicited knocker call. Aural detection only. Breeding classification: unconfirmed.

Mosquito Flats Survey 3 - 08/08/2007, 0720, 770447 E, 3796936 N, 1070 m. Yellowbilled cuckoo gave an unsolicited coo call. Aural detection only. Breeding classification: unconfirmed.

Mosquito Flats Survey 3 - 08/08/2007, 0808, 770866 E, 3795880 N, $290^{\circ} / 250 \mathrm{~m}$. Yellow-billed cuckoo responded to the $3^{\text {rd }}$ playback with four series of coo calls. Aural detection only. Breeding classification: unconfirmed.

Mosquito Flats Survey 3 - 08/08/2007, 0827, 771091 E, 3796678 N, 55²5 m. Yellowbilled cuckoo responded to the $2^{\text {nd }}$ playback with a kuk-kowlp call. Aural detection only. Breeding classification: unconfirmed.

Mosquito Flats Revisit 2 - 08/08/2007, 0640, 769927 E, 3797163 N, 120\%40 m. Yellowbilled cuckoo gave an unsolicited soft knocker call. Aural detection only. Breeding classification: unconfirmed.

Mosquito Flats Revisit 2 - 08/08/2007, 0655, 769927 E, 3797163 N, 47/75 m. Yellowbilled cuckoo gave unsolicited soft knocker calls and a kowlp call from the same area as the bird detected at 0640 . Aural detection only. Breeding classification: unconfirmed.

Mosquito Flats Revisit 2 -08/08/2007, 0730,769969 E, 3797221 N, Cuckoo1 @ 346³5 m, Cuckoo2 @ 40\%30 m, Cuckoo3 (?) @ 75\%100 m. Cuckoo1 gave an unsolicited soft kowlp call. Cuckoo2 responded with a soft knocker call. Cuckoo3 (?) gave a coo call at 0805. Aural detection only. Breeding classification: unconfirmed.

Mosquito Flats Revisit 3 - 08/11/2007, 0600, 769918 E, 3797290 N, Cuckoo1 @ 45\%30 m, Cuckoo2 @ 260\%/50 m, Cuckoo3 (?) @ 130\%100 m. Cuckoo1 gave an unsolicited kukkowlp call to which Cuckoo2 responded with its own kuk-kowlp call. At 0610, Cuckoo3 (?) gave a coo call. Aural detection only. Breeding classification: unconfirmed.

Mosquito Flats Revisit 3 - 08/11/2007, 0710, 769921 E, 3797333 N, Cuckoo1 @ 200\%15 m, Cuckoo2 (?) @ 156\% /20 m. Cuckoo1 gave unsolicited knocker calls. At 0817, Cuckoo2 (?) gave a knocker call. Aural detection only. Breeding classification: unconfirmed.

Mosquito Flats Revisit 3 - 08/11/2007, 0832, 769918E, 3797293N, Cuckoo1 @ 137\% $/ 20 \mathrm{~m}, 127^{\circ} / 10 \mathrm{~m}$. Cuckoo1 gave an unsolicited "kuk-kowlp" call. At 0837, a "kukkowlp" call was heard from Cuckoo2(?). Aural detection only. Breeding classification: unconfirmed.

Mosquito Flats Revisit 3 - 08/11/2007, 0947, 769983 E, 3797356 N, Cuckoo1 @ 170²0 m, Cuckoo2 @ 20\%20 m. Cuckoo1 gave an unsolicited knocker call, to which Cuckoo2 responded with a kuk-kowlp call. Cuckoo1 then gave another knocker call. Aural detection only. Breeding classification: unconfirmed. 
Mosquito Flats Survey 4 - 08/21/2007, 0623, 769867 E, 3797162 N, $49^{\circ} / 50$ m. Yellowbilled cuckoo responded to the $3^{\text {rd }}$ playback with a knocker call, then rolling kowlps. Aural detection only. Breeding classification: unconfirmed.

Mosquito Flats Survey 4 -08/21/2007, 0648, 770235 E, 3797014 N, $43^{\circ} / 70$ m. Yellowbilled cuckoo responded to the $3^{\text {rd }}$ playback with ten kowlps. This was repeated two minutes later. Aural detection only. Breeding classification: unconfirmed.

Mosquito Flats Survey 4 - 08/21/2007, 0702, 770532 E, 3796943 N, Cuckoo1 330³0 $\mathrm{m}$, Cuckoo2@15\%/50 m. Cuckoo1 responded to the $3^{\text {rd }}$ playback with a knocker-kowlp call to which Cuckoo2 responded with its own knocker-kowlp. Cuckoo1 gave two more of the same call over the next six minutes. Aural detection only. Breeding classification: unconfirmed.

Mosquito Flats Survey 5 - 09/07/2007, 0658, 770237 E, 3797039 N, Cuckoo1 @ 38\%/45 $\mathrm{m}$, Cuckoo2 @ 320\%100 m. Cuckoo1 responded to the $2^{\text {nd }}$ playback with a rapid kukkowlp call. Cuckoo2 responded with a coo call. Aural detection only. Breeding classification: unconfirmed.

\section{Saguaro Slot}

Saguaro Slot Revisit 1 - 06/27/2007, 0840, 769567 E, 3797523 N, 90\%/50 m. Yellowbilled cuckoo gave two unsolicited kuk-kowlp calls within five minutes of one another. Aural detection only. Breeding classification: unconfirmed.

Saguaro Slot Survey 2 - 07/11/2007, 0544, 769509 E, 3797585 N, Cuckoo1 @ 332\%/50 $\mathrm{m}$, Cuckoo2 (?) @ 320\%/15 m. Cuckoo1 responded to the $5^{\text {th }}$ playback with kuk-kowlp call. At 0807, Cuckoo2 (?) gave a kuk-kowlp call, then another at 0817. Aural detection only. Breeding classification: unconfirmed.

Saguaro Slot Survey 2 - 07/11/2007, 0610, 769348 E, 3797766 N, 44\%/55 m. Yellowbilled cuckoo responded to the $5^{\text {th }}$ playback with a kuk-kowlp call. Aural detection only. Breeding classification: unconfirmed.

Saguaro Slot Revisit 2 - 07/15/2007, 0701, 769504 E, 3797593 N, 120\%/100 m. Yellowbilled cuckoo gave a series of unsolicited coo calls, followed by a kuk-kowlp call at 0706, and a $k u k$ call at 0712. Aural detection only. Breeding classification: unconfirmed.

Saguaro Slot Revisit 2 - 07/15/2007, 0748, 769615 E, 3797444 N, 100\%/75 m. Yellowbilled cuckoo gave an unsolicited kuk-kowlp call. Aural detection only. Breeding classification: unconfirmed.

Saguaro Slot Revisit 2 - 07/15/2007, 0810, 769596E, 3797375N, 35\%/100m. Yellowbilled cuckoo gave an unsolicited "kuk-kowlp" call. Aural detection only. Breeding classification: unconfirmed.

Saguaro Slot Survey 3 - 08/01/2007, 0545, 769502 E, 3797591 N, Cuckoo1 @ 110²5 $\mathrm{m}$, Cuckoo2 @ 100\%/150 m. Cuckoo1 responded to the $3^{\text {rd }}$ playback with a knocker-kowlp 
call. Cuckoo2 responded a giving several coo calls. Aural detection only. Breeding classification: unconfirmed.

Saguaro Slot Survey 3 - 08/01/2007, 0603, 769350 E, 3797770 N, 45\%/25 m. Yellowbilled cuckoo responded to the $2^{\text {nd }}$ playback with two knocker calls. Aural detection only. Breeding classification: unconfirmed.

Saguaro Slot Survey 3 - 08/01/2007, 0703, 769790 E, 3797356 N, 358\%/50 m. Yellowbilled cuckoo responded to the $1^{\text {st }}$ playback with a kuk-kowlp call. Aural detection only. Breeding classification: unconfirmed.

Saguaro Slot Survey 4 - 08/21/2007, 0630, 769513 E, 3797628 N, 40\%/65 m. Yellowbilled cuckoo responded to the $5^{\text {th }}$ playback with two $k u k$ calls from a clump of tall Goodding's willow. At 0646, 0707, and 0708, kuk-kowlp calls were given from this same location. Aural detection only. Breeding classification: unconfirmed.

Saguaro Slot Survey 4 - 08/21/2007, 0801, 769619 E, 3797336 N, 90¹00 m. Yellowbilled cuckoo responded to the $1^{\text {st }}$ playback with $k u k$ calls from a clump of large Goodding's willow. Aural detection only. Breeding classification: unconfirmed.

Saguaro Slot Revisit 3 - 08/21/2007, 0638, 769503 E, 3797588 N, 90\%/80 m. Yellowbilled cuckoo gave an unsolicited kuk-kowlp call. Aural detection only. Breeding classification: unconfirmed.

Saguaro Slot Revisit 3 - 08/21/2007, 0822, 769747 E, 3797322 N, Cuckoo1@ @196\%20 m, Cuckoo2 (?) @ 330\%/80 m. Cuckoo1 gave an unsolicited kuk call from $13 \mathrm{~m}$ above the ground in a $17 \mathrm{~m}$ tall, stressed Goodding's willow. The cuckoo was working on getting the wings off a Microcentrum katydid, and then it hopped behind a clump of leaves and out of sight. At 0851, the observer did one playback to which Cuckoo2 (?) responded with rolling kowlps. At 0857, a fast, high-pitched kuk-kowlp was heard from the same location. Aural detection only. Breeding classification: unconfirmed.

Saguaro Slot Revisit 4 - 08/27/2007, 0709, 769522 E, 3797572 N, 2/30 m. Yellowbilled cuckoo did not respond to five plays of survey tape but did respond to one play of recorded coo call with a kuk-kowlp call from a clump of large Goodding's willow. The cuckoo gave knocker calls at 0727 and 0730 from the same location. At 0750, knocker calls came from some low, bushy Goodding's willows in the same area. At 0823, another coo call was played and a cuckoo responded with knocks from a medium Goodding's willow. At 0841, a cuckoo flew $50 \mathrm{~m}$ west to some large Goodding's willows and gave three knocker calls in the next minute. Aural detection only. Breeding classification: unconfirmed.

Saguaro Slot Revisit 4-08/27/2007, 0947, 769718 E, 3797312 N, Cuckoo1 @ 40\%120 m, Cuckoo2 @ NA/50 m. Cuckoo1 responded to coo calls with a series of coo calls that lasted until 0952. It then gave two knocker-kowlps and several rolling knocker-kowlps. After this, Cuckoo2 began to coo $50 \mathrm{~m}$ west of Cuckoo1. At 1008, Cuckoo1 flew south through the high canopy. Aural and visual detection. Breeding classification: unconfirmed. 


\section{North Burn}

North Burn Survey 2 - 07/17/2007, 0919, 770276 E, 3798127 N, 203\%/30 m. Yellowbilled cuckoo responded to the $2^{\text {nd }}$ playback with hard $k u k s$ from a stand of dense, medium-sized Goodding's willow. Aural detection only. Breeding classification: unconfirmed.

North Burn Survey 3 - 08/08/2007, 0843, 770033 E, 3798393 N, 156\%/80 m. Yellowbilled cuckoo gave unsolicited coo calls from a stand of large Fremont cottonwoods. Over the next fifteen minutes, the cuckoo continued to coo while moving south and west through the patch. Aural detection only. Breeding classification: unconfirmed.

North Burn Survey 3 - 08/08/2007, 0905, 770253 E, 3798163 N, 256\%/90 m. Yellowbilled cuckoo gave unsolicited coo calls from some large Fremont cottonwoods. The cuckoo was still cooing when the observers left the area at 0920. Aural detection only. Breeding classification: unconfirmed.

North Burn Survey 4 - 08/26/2007, 0900, 770187 E, 3798244 N, 160/75 m. Yellowbilled cuckoo responded to the $1^{\text {st }}$ playback with a kuk-kowlp call from a stand of $10-15 \mathrm{~m}$ tall Fremont cottonwoods. Aural detection only. Breeding classification: unconfirmed.

North Burn Survey 4 - 08/26/2007, 0915, 770423 E, 3798050 N, 200\%/130 m. Yellowbilled cuckoo responded to the $2^{\text {nd }}$ playback with a kuk-kowlp call from a stand of 10-15 $\mathrm{m}$ tall Fremont cottonwoods. Aural detection only. Breeding classification: unconfirmed.

\section{Bill Williams Marsh}

Bill Williams Marsh Survey 1 - 06/14/2007, 0710, 769178 E, 3798091 N, 108\%60 m. Yellow-billed cuckoo responded to the $5^{\text {th }}$ playback with a kuk-kowlp call. Aural detection only. Breeding classification: unconfirmed.

Bill Williams Marsh Survey 3 - 08/01/2007, 0650, 769087 E, 3798176 N, Cuckoo1 @ 15\%/40 m, Cuckoo2@ 42\%/30 m, Cuckoo3 (?) @ 280\%/100 m. Cuckoo1 gave an unsolicited kuk-kowlp call from river right followed by coo calls for the next seven minutes. Cuckoo 2 responded with several coo calls at 0654. At 0658 Cuckoo3 (?) called from an $11 \mathrm{~m}$ tall Goodding's willow on river left. Aural detection only. Breeding classification: unconfirmed.

Bill Williams Marsh Survey 3 - 08/01/2007, 0708, 769311 E, 3797975 N, 125\%/120 m. Yellow-billed cuckoo gave an unsolicited kuk-kowlp call once at 0708 and again at 0711. Aural detection only. Breeding classification: unconfirmed.

Bill Williams Marsh Survey 4 - 08/24/2007, 0710, 768990 E, 3798191 N, Cuckoo1 @ $185^{\circ} / 30 \mathrm{~m}$, Cuckoo2@130\%/20 m. Cuckoo1 gave a quick kuk-kowlp call after the $2^{\text {nd }}$ playback. At 0734, Cuckoo1 (?) flew from river right to a tamarisk on river left with prey in its bill. An observer entered the vegetation near Cuckoo1 (?) to nest/juvenile search and the cuckoo knocked upon her approach. By the time the observer obtained a visual on the cuckoo at 0735, it no longer was carrying prey. At 0736, the cuckoo flew back across the river and into the vegetation on river right. At 0759, Cuckoo1 (?) again flew back 
across to river left, this time with an enormous moth in its bill. Upon landing, it began to knock at the observer who was still inside the habitat. The cuckoo flew further into the vegetation, towards a mesquite patch on the outer edge of the riparian zone giving knocker calls. Cuckoo1 (?) then jumped back into the vegetation, out of view with the moth still in its bill. At 0815 and again at 0829 , Cuckool (?) gave kuk-kowlp calls from river right. In addition to these observations, at 0734 and again 0750, a Cuckoo2 gave a $k u k$-kowlp call from near the Saguaro Slot survey route. Aural and visual detection. Breeding classification: unconfirmed.

Bill Williams Marsh Survey 4 - 08/24/2007, 0911, 769536 E, 3797753 N, Cuckoo1 @ $142 \% / 80 \mathrm{~m}$, Cuckoo2 (?) @ NA/40m. Cuckoo1 responded to the $1^{\text {st }}$ playback with a kukkowlp call from river right. At 0915, Cuckoo2 (?) gave a kuk-kowlp call from river left from about $40 \mathrm{~m}$ back in the vegetation. At 0917, an unspecified cuckoo gave a $k u k$ kowlp from river right about $70 \mathrm{~m}$ upstream of the survey point. Additional kuk-kowlp and knocker calls were heard from this area over the next half hour. Aural detection only. Breeding classification: unconfirmed.

\section{Ahakhav Tribal Preserve (Colorado River)}

\section{Ahakhav Tribal Preserve}

Ahakhav Tribal Preserve Survey 1 - 06/16/2007, 0600, 745877 E, 3779802 N, $212^{\circ} / 70$ $\mathrm{m}$. Yellow-billed cuckoo responded to the $4^{\text {th }}$ playback with five $k u k s$ from $12 \mathrm{~m}$ above the ground in a Fremont cottonwood. Aural detection only. Breeding classification: unconfirmed.

Ahakhav Tribal Preserve Survey 1 - 06/16/2007, 0620, 745918 E, 3779499 N, 24\%140 $\mathrm{m}$. Yellow-billed cuckoo responded to the $2^{\text {nd }}$ playback with five $k u k s$ from a patch of young Goodding's willows. Observer felt this may have been the same bird detected at 0600. Aural detection only. Breeding classification: unconfirmed.

\section{Cibola National Wildlife Refuge (Colorado River)}

\section{North Restoration}

North Restoration Survey 3 - 07/27/2007, 0618, 715867 E, 3695242 N, 170 /75 m. Yellow-billed cuckoo gave a quiet knocker-kowlp call after the $1^{\text {st }}$ playback. Aural detection only. Breeding classification unconfirmed.

\section{Nature Trail Restoration}

Nature Trail Restoration Survey 1 - 06/16/2007, 0607, 716124 E, 3694449 N, 190\%20 m. Yellow-billed cuckoo flew in after the $2^{\text {nd }}$ playback from the northwest and landed in the top of a $20 \mathrm{~m}$ tall Fremont cottonwood. The cuckoo flew southeast and out of sight, then gave a knocker-kowlp call $30 \mathrm{~m}$ away. Aural and visual detection. Breeding classification: unconfirmed.

Nature Trail Restoration Survey 1 -06/16/2007, 0625, 715898 E, 3694379 N, 150\%/50 $\mathrm{m}$. Yellow-billed cuckoo gave a knocker-kowlp after the $2^{\text {nd }}$ playback. The call came from 
an area of mostly mesquite and arrowweed. Aural detection only. Breeding classification: unconfirmed.

Nature Trail Restoration Revisit 1 - 07/02/2007, 716117 E, 3694428 N. Yellow-billed cuckoo flew unsolicited into a $15 \mathrm{~m}$ high tree and out of view. Visual detection only. Breeding classification: unconfirmed.

\section{Eucalyptus Restoration}

Eucalyptus Restoration Survey 2 - 07/02/2007, 0733, 713781 E, 3693750 N, 298\%10 m. Yellow-billed cuckoo flew in from previous survey point and perched $10 \mathrm{~m}$ above the ground in a eucalyptus. The cuckoo perched here for a couple minutes, and then flew south into another eucalyptus. Visual detection only. Breeding classification: unconfirmed.

\section{South Restoration}

South Restoration Survey 1 - 06/16/2007, 0858, 715917 E, 3684645 N, 290\%/50 m. Yellow-billed cuckoo responded to the $5^{\text {th }}$ playback with a knocker-kowlp call. This area of the patch contains the largest Fremont cottonwoods. Aural detection only. Breeding classification: unconfirmed.

South Restoration Survey 2 - 07/02/07, 0734, 716008 E, 3684633 N, 180\%/75 m. Yellowbilled cuckoo responded to the $1^{\text {st }}$ playback with a knocker-kowlp call. Aural detection only. Breeding classification: unconfirmed.

\section{Picacho State Recreation Area (Colorado River)}

In 2007, no yellow-billed cuckoos were detected at this site.

\section{Imperial National Wildlife Refuge (Colorado River)}

\section{Imperial South Restoration}

Imperial South Restoration Survey 1 - 06/27/2007, 0530, 734354 E, 3653848 N, 240\%/50 $\mathrm{m}$. Yellow-billed cuckoo responded to the $1^{\text {st }}$ playback with two knocker-kowlp calls. Several minutes later, another knocker-kowlp call was heard. Aural detection only. Breeding classification unconfirmed.

Imperial South Restoration Survey 1 - 06/27/2007, 0601, 734370 E, 3653848 N, 75\%/50 m. Yellow-billed cuckoo gave an unsolicited knocker-kowlp after the survey was complete. Aural and visual detection. Breeding classification: unconfirmed.

Imperial South Restoration Survey 2 - 07/18/2007, 0603, 734245 E, 3653885 N, 230\%/50 $\mathrm{m}$. Yellow-billed cuckoo responded to the $1^{\text {st }}$ playback with a knocker-kowlp call, then flew into a Fremont cottonwood. The cuckoo gave another knocker-kowlp call, flew out of sight, and gave one more knocker-kowlp. Aural and visual detection. Breeding classification: unconfirmed. 


\section{Mittry Lake Wildlife Management Area/Pratt Restoration (Colorado River)}

In 2007, no yellow-billed cuckoos were detected at this site.

\section{Gila/Colorado River Confluence (Gila and Colorado Rivers)}

Colorado Confluence

Colorado Confluence Survey 1 - 06/26/2007, 0817, 729869 E, 3623200 N, 300\%/50 m.

Yellow-billed cuckoo responded to the $1^{\text {st }}$ playback with a $k u k$ call. It then gave a knocker-kowlp call followed by several minutes of coo calls. All calls came from the California side of the river. Aural detection only. Breeding classification: unconfirmed.

Colorado Confluence Survey 1 - 06/26/2007, 0840, 729495 E, 3623057 N, 40\%/20 m. Yellow-billed cuckoo gave unsolicited knocker calls from the California side of the river. Aural detection only. Breeding classification: unconfirmed.

Gila Confluence

In 2007, no yellow-billed cuckoos were detected at this site.

\section{Yuma West Wetlands (Colorado River)}

In 2007, no yellow-billed cuckoos were detected at this site.

\section{Limitrophe Division (Colorado River)}

\section{Limitrophe Division North}

In 2007, no yellow-billed cuckoos were detected at this site.

\section{Limitrophe Division South}

Limitrophe Division South Survey 1 - 06/13/2007, 0535, 707416 E, 3604314 N, 320\%/50 $\mathrm{m}$. Yellow-billed cuckoo responded to $3^{\text {rd }}$ playback with soft knocker-kowlp calls. Aural detection only. Breeding classification: unconfirmed.

Limitrophe Division South Survey 1 - 06/13/2007, 0558, 707299 E, 3603923 N, 300\%/100 $\mathrm{m}$. Yellow-billed cuckoo flew unsolicited toward survey point, landed out of view, and gave a knocker-kowlp call. The observer believed this cuckoo to be the same individual detected at 0535 . Five minutes later, a cuckoo was seen $10 \mathrm{~m}$ above the ground in a Goodding's willow. After two minutes, the cuckoo flew west and out of sight. Aural and visual detection. Breeding classification: unconfirmed.

\section{Quigley Pond Wildlife Management Area (Gila River)}

\section{Quigley Pond Wildlife Management Area}

Quigley Pond WMA Survey 1 - 06/12/2007, 0537, 222632 E, 3625566 N, 210\%/100 m. Yellow-billed cuckoo responded immediately to the $1^{\text {st }}$ playback with a knocker-kowlp call. It then flew $50 \mathrm{~m}$ northeast, landing in a top of a $20 \mathrm{~m}$ tall Fremont cottonwood. The 
cuckoo vocalized, and then flew southeast to the opposite side of the patch where it continued to call. Aural and visual detection. Breeding classification: unconfirmed.

Quigley Pond WMA Survey 1 - 06/12/2007, 0631, 222392 E, 3625494 N, 300²00 m. Yellow-billed cuckoo responded to $3^{\text {rd }}$ playback with a slow knocks from an area of Goodding's willow/tamarisk with scattered Fremont cottonwoods. Aural detection only. Breeding classification: unconfirmed.

Quigley Pond WMA Survey 1 - 06/12/2007, 0730, 222204 E, 3625813 N, 110²0 m. Yellow-billed cuckoo observed as it perched in a $10 \mathrm{~m}$ tall Goodding's willow after the survey was complete. The bird flew off towards the middle of the patch. A couple minutes later, a soft knocker call was heard outside the patch. Aural and visual detection. Breeding classification: unconfirmed.

Quigley Pond WMA Survey 2 - 07/09/2007, 0644, 222619 E, 3625363 N, $315^{\circ} / 50$ m. Yellow-billed cuckoo responded to the $4^{\text {th }}$ playback with a knocker-kowlp call from the top of a Goodding's willow. It then flew off to the southwest. Aural and visual detection. Breeding classification: unconfirmed. 


\section{Appendix 3. Incidental Yellow-billed Cuckoo Observations in the Lower Colorado River Watershed, 2007}

Throughout the 2007 field season yellow-billed cuckoos were occasionally detected independent of USGS surveys in the lower Colorado River watershed along the Virgin River, Nevada, lower Colorado, Bill Williams and Gila Rivers, Arizona, 2007. These incidental sightings were made by staff of SWCA consulting firm while conducting field research on southwestern willow flycatchers, a species that has extensive habitat overlap with yellow-billed cuckoos. With the exception of Mormon Mesa, NV, and Imperial NWR/Great Blue Heron, AZ all of the locations where incidental sightings occurred were also surveyed by USGS employees this year, and many of these same birds were likely detected on our surveys. Please refer to Table 2.1 for site name overlap.

\begin{tabular}{|c|c|c|c|c|c|c|}
\hline Date & Time & Observer & Number & Location & UTM* & Comments \\
\hline $7 / 16 / 2007$ & NA & SWCA & 1 & Mormon Mesa, NV & NA & $\begin{array}{l}\text { Individual heard } \\
\text { calling. }\end{array}$ \\
\hline $7 / 27 / 2007$ & NA & BOR & 1 & Havasu NWR & NA & At Beal Lake calling. \\
\hline $7 / 28 / 2007$ & NA & BOR & 1 & Havasu NWR & NA & $\begin{array}{l}\text { At Beal Lake calling in } \\
\text { mesquite. }\end{array}$ \\
\hline $6 / 26 / 2007$ & NA & SWCA & NA & $\begin{array}{l}\text { Bill Williams River } \\
\text { NWR/Site } 5\end{array}$ & NA & Calls heard. \\
\hline $7 / 2 / 2007$ & NA & SWCA & 1 & $\begin{array}{l}\text { Bill Williams River } \\
\text { NWR/Site } 3\end{array}$ & NA & $\begin{array}{l}\text { Individual heard } \\
\text { calling. }\end{array}$ \\
\hline $7 / 13 / 2007$ & NA & SWCA & 1 & $\begin{array}{l}\text { Bill Williams River } \\
\text { NWR/Mineral Wash }\end{array}$ & NA & $\begin{array}{l}\text { Individual heard } \\
\text { calling. Individual } \\
\text { observed to the North. }\end{array}$ \\
\hline $7 / 25 / 2007$ & NA & SWCA & 1 & $\begin{array}{l}\text { Bill Williams River } \\
\text { NWR/Beaver Pond/Site } \\
8\end{array}$ & NA & $\begin{array}{l}\text { Individual heard } \\
\text { calling, between beaver } \\
\text { pond site and Site } 8 \text {. }\end{array}$ \\
\hline $7 / 3 / 2007$ & NA & SWCA & 1 & $\begin{array}{l}\text { Imperial NWR/Imperial } \\
\text { Nursery }\end{array}$ & NA & $\begin{array}{l}\text { Individual heard } \\
\text { calling. }\end{array}$ \\
\hline $7 / 24 / 2007$ & NA & SWCA & 2 & $\begin{array}{l}\text { Imperial NWR/Great } \\
\text { Blue Heron }\end{array}$ & NA & $\begin{array}{l}2 \text { individuals heard } \\
\text { counter calling. }\end{array}$ \\
\hline $7 / 11 / 2007$ & NA & SWCA & 1 & Gila Confluence North & NA & $\begin{array}{l}\text { Individual heard } \\
\text { calling. }\end{array}$ \\
\hline $7 / 19 / 2007$ & NA & SWCA & 1 & Gadsen & NA & $\begin{array}{l}\text { Individual captured in } \\
\text { mist net. }\end{array}$ \\
\hline
\end{tabular}


This page intentionally left blank 


\section{Appendix 4. Aerial Photographs of Yellow-billed Cuckoo Survey Points and Detections According to Survey Period, 2007}

Figures 4-1 through 4-13 are aerial photographs of yellow-billed cuckoo survey points and detections according to survey period, as well as supplemental visit detections on separate maps at sites along the White and Muddy Rivers, Nevada, lower Colorado and Gila Rivers, Arizona and California, 2007.

Figure 4-1A. Orthorectified aerial photo display Pahranagat National Wildlife Refuge, NV, yellow-billed cuckoo survey area, 2007.

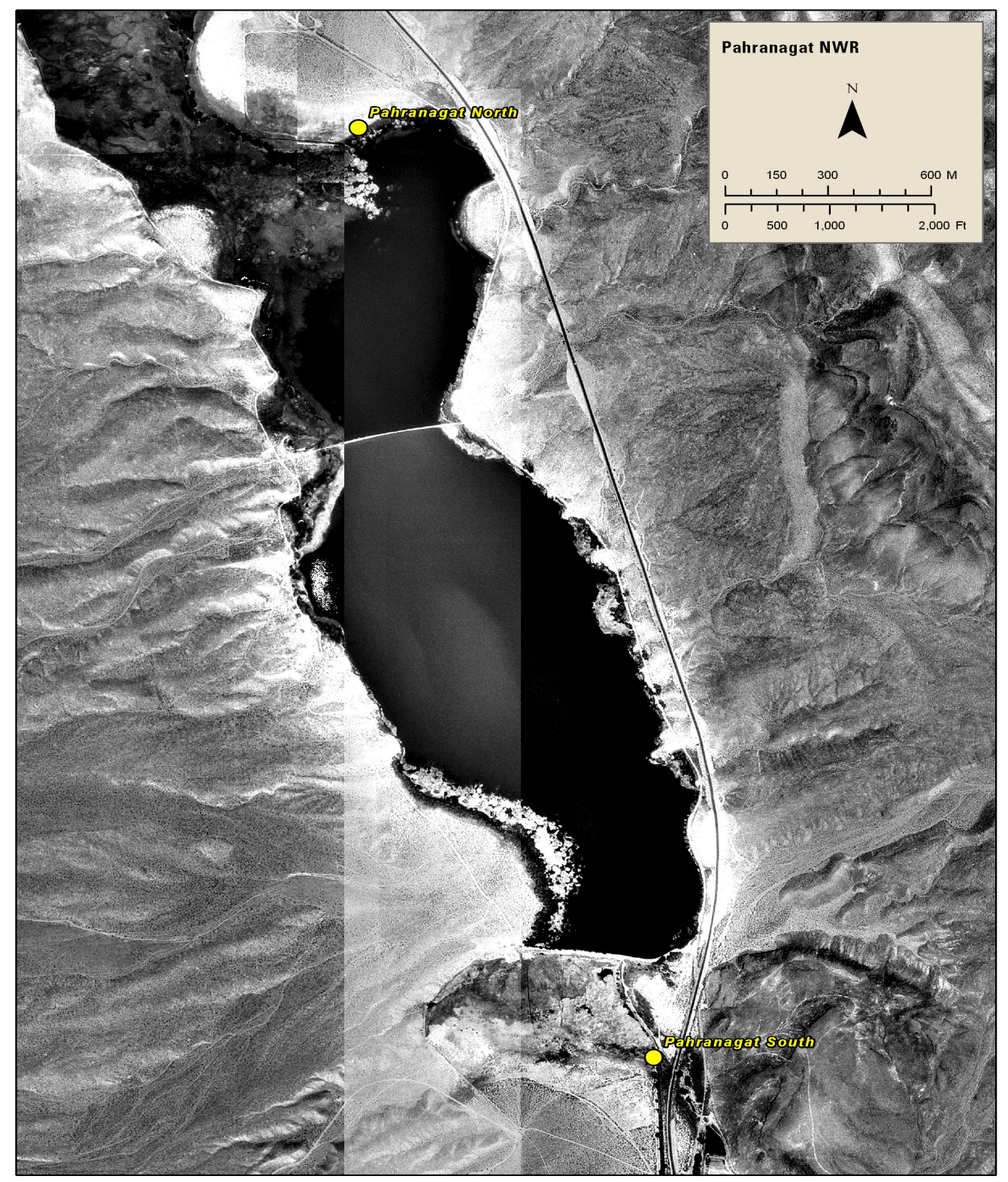


Figure 4-1B. Orthorectified aerial photo display yellow-billed cuckoo survey points at Pahranagat National Wildlife Refuge, NV, Pahranagat North, 2007. No cuckoos were detected at this site in 2007. Red boundary line represents yellow-billed cuckoo survey habitat patch.

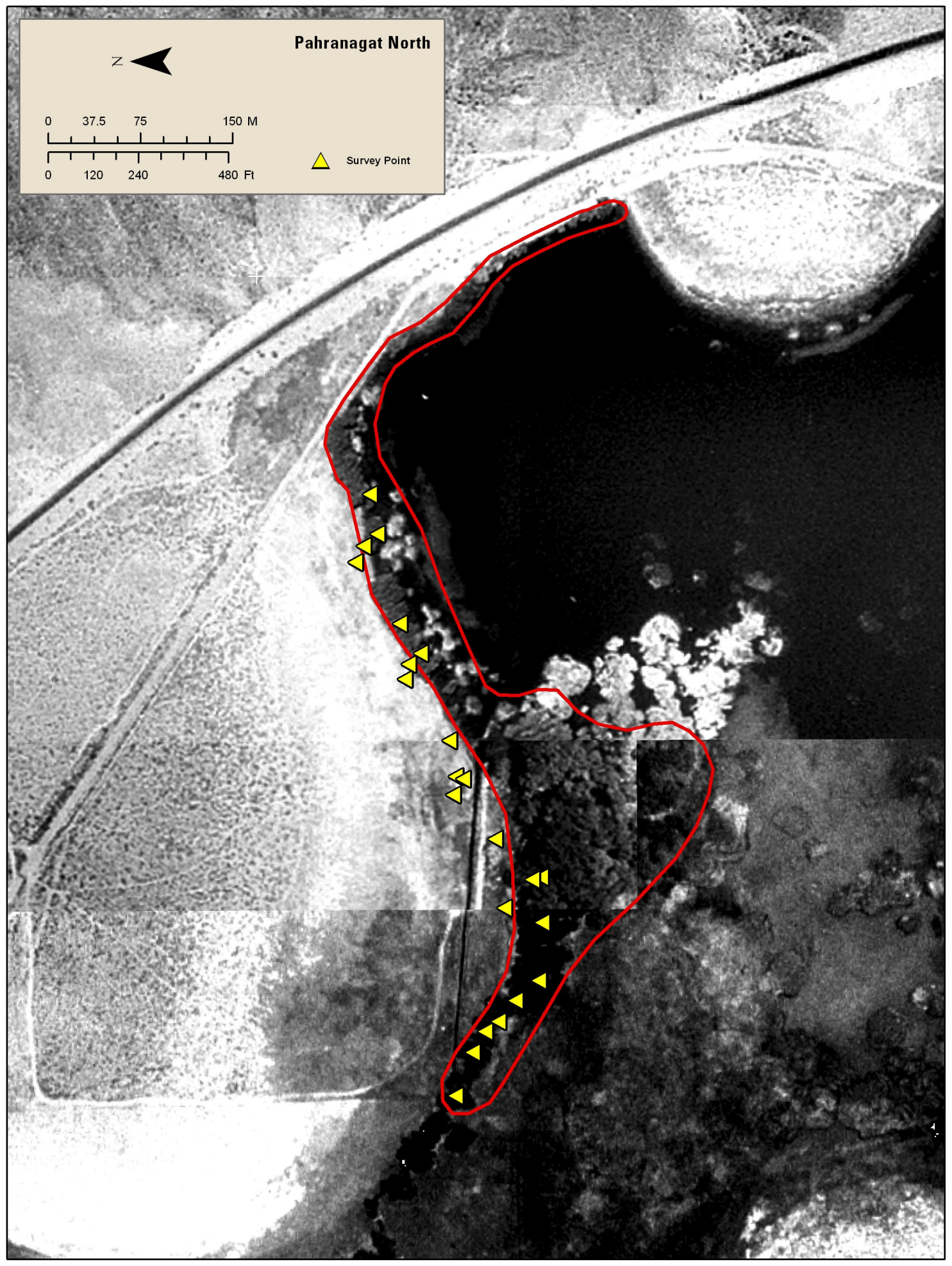


Figure 4-1C. Orthorectified aerial photo display yellow-billed cuckoo survey points at Pahranagat National Wildlife Refuge, NV, Pahranagat South, 2007. No cuckoos were detected at this site in 2007. Red boundary line represents yellow-billed cuckoo survey habitat patch.

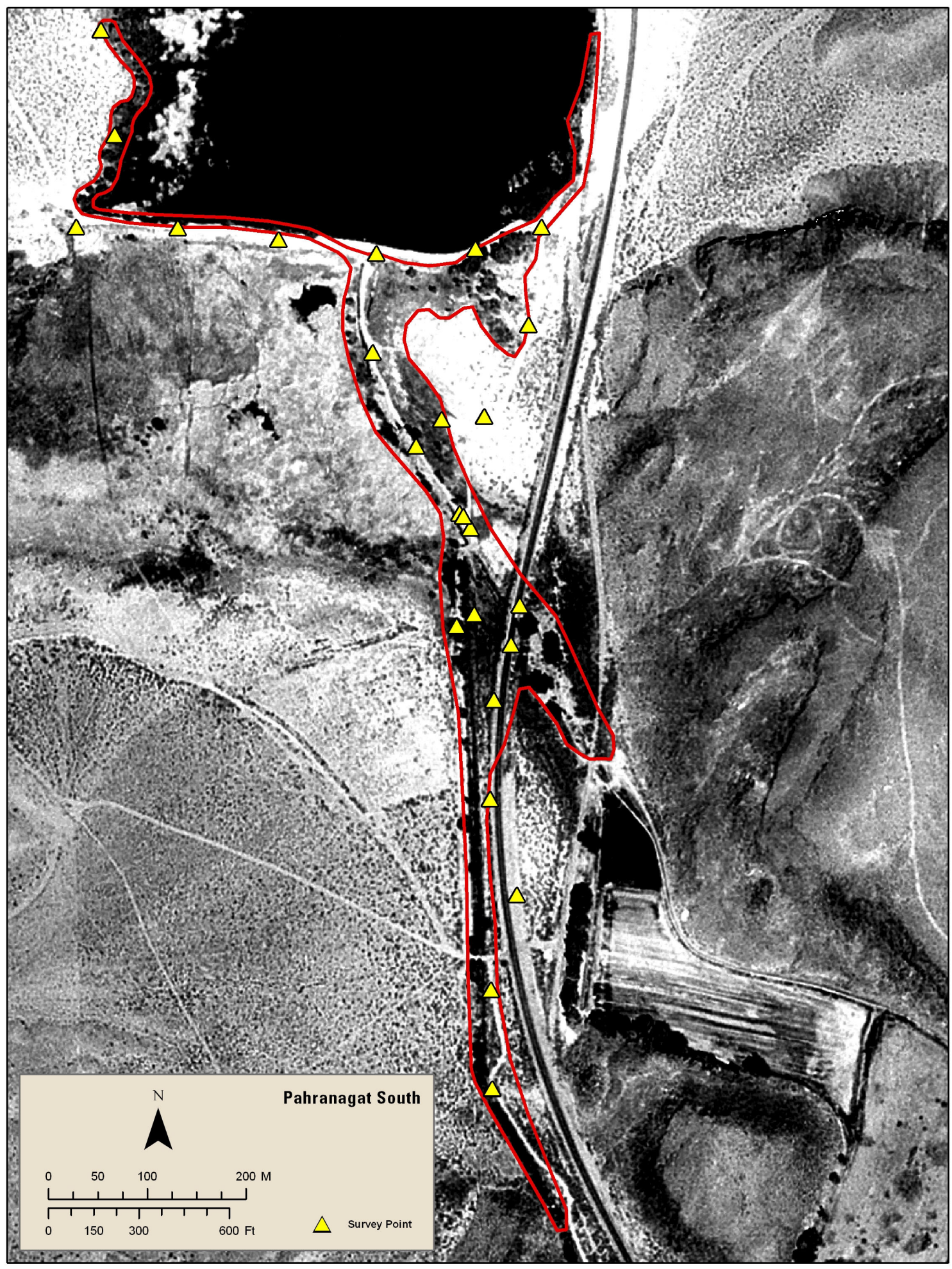


Figure 4-2A. Orthorectified aerial photo display Overton Wildlife Management Area, NV, yellow-billed cuckoo survey area, 2007.

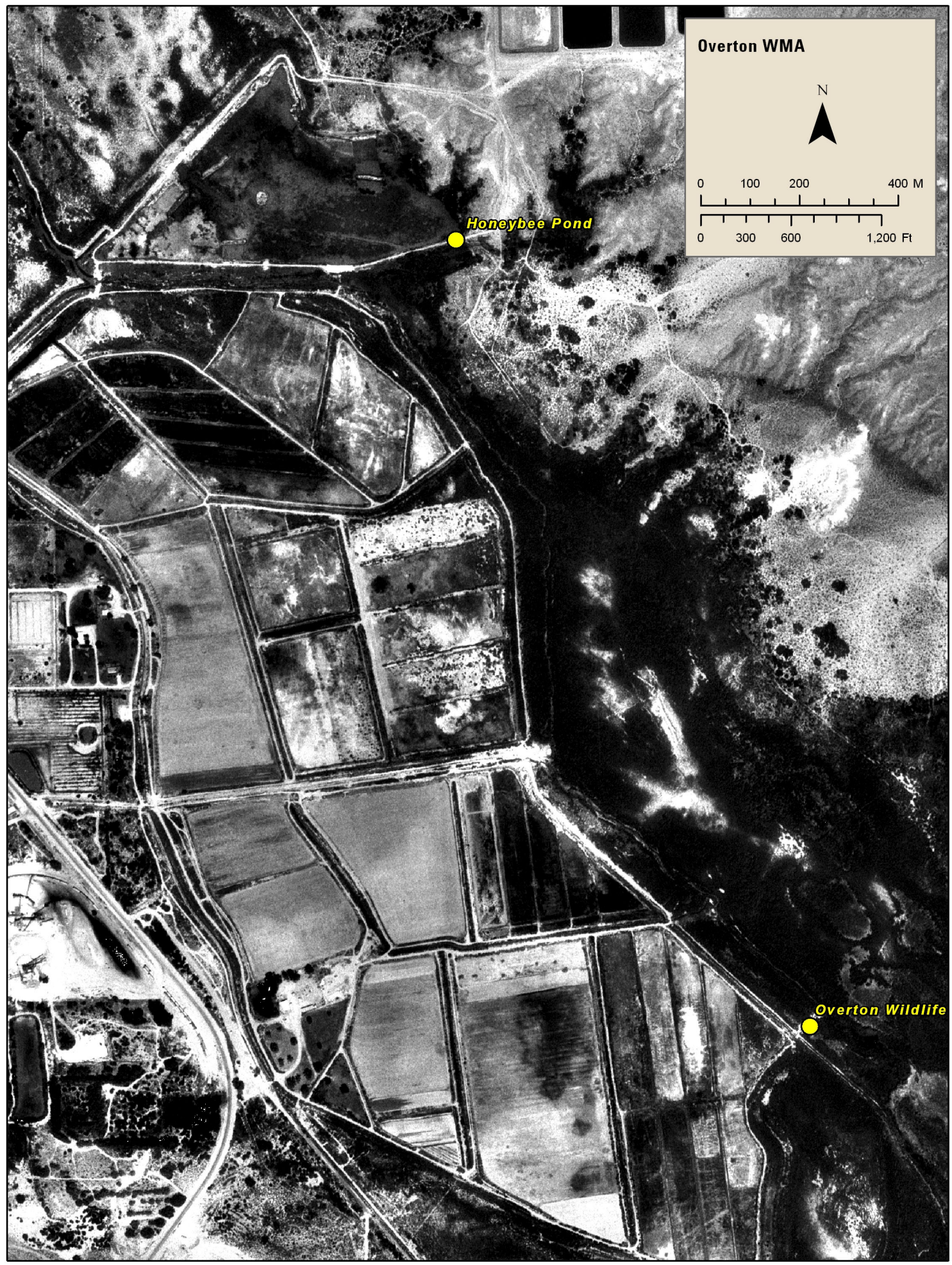


Figure 4-2B. Orthorectified aerial photo display yellow-billed cuckoo survey points at Overton Wildlife Management Area, NV, Honeybee Pond, 2007. No cuckoos were detected at this site in 2007. Red boundary line represents yellow-billed cuckoo survey habitat patch.

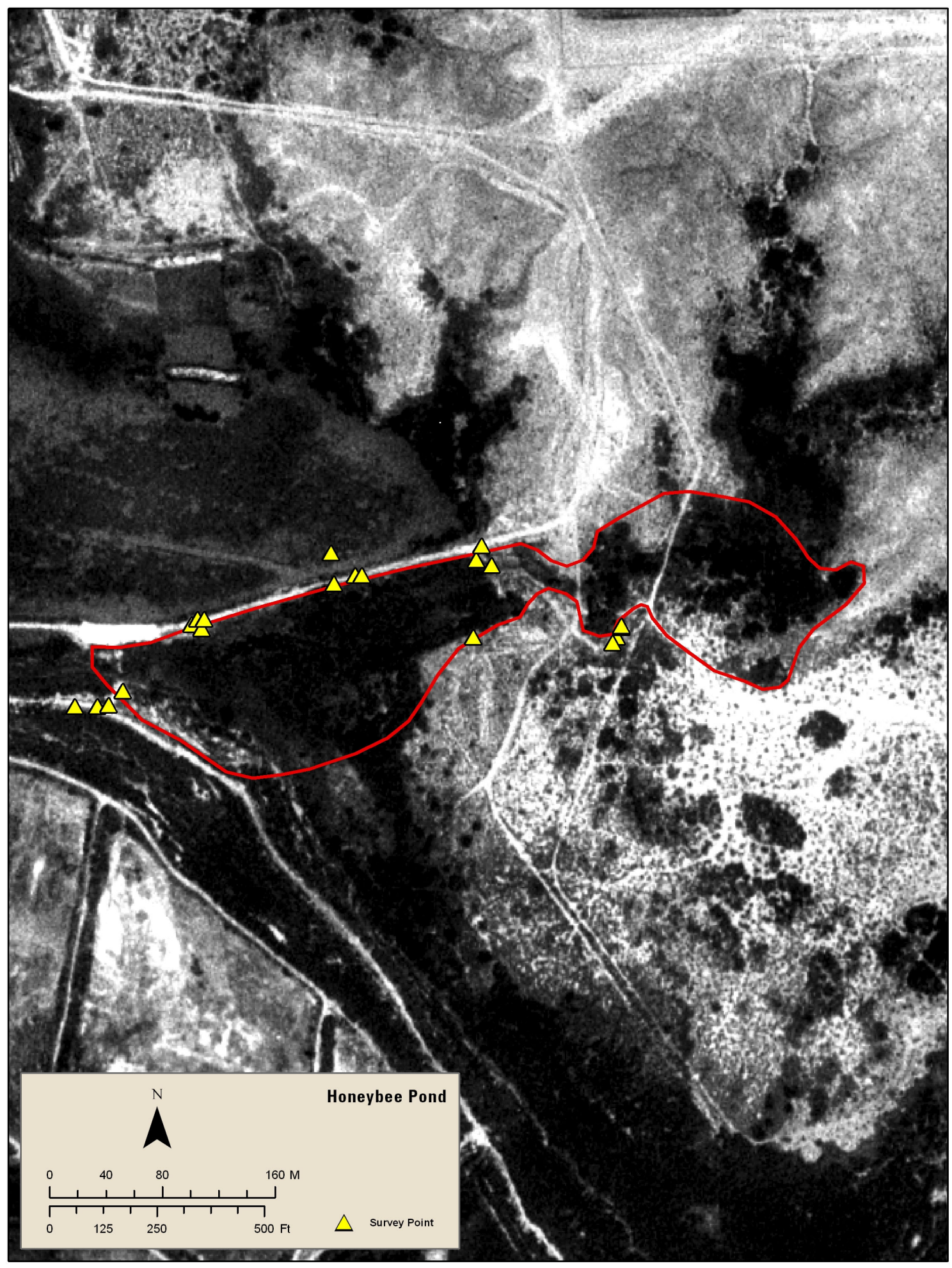


Figure 4-2C. Orthorectified aerial photo display yellow-billed cuckoo survey points at Overton Wildlife Management Area, NV, Overton Wildlife, 2007. No cuckoos were detected at this site in 2007. Red boundary line represents yellow-billed cuckoo survey habitat patch.

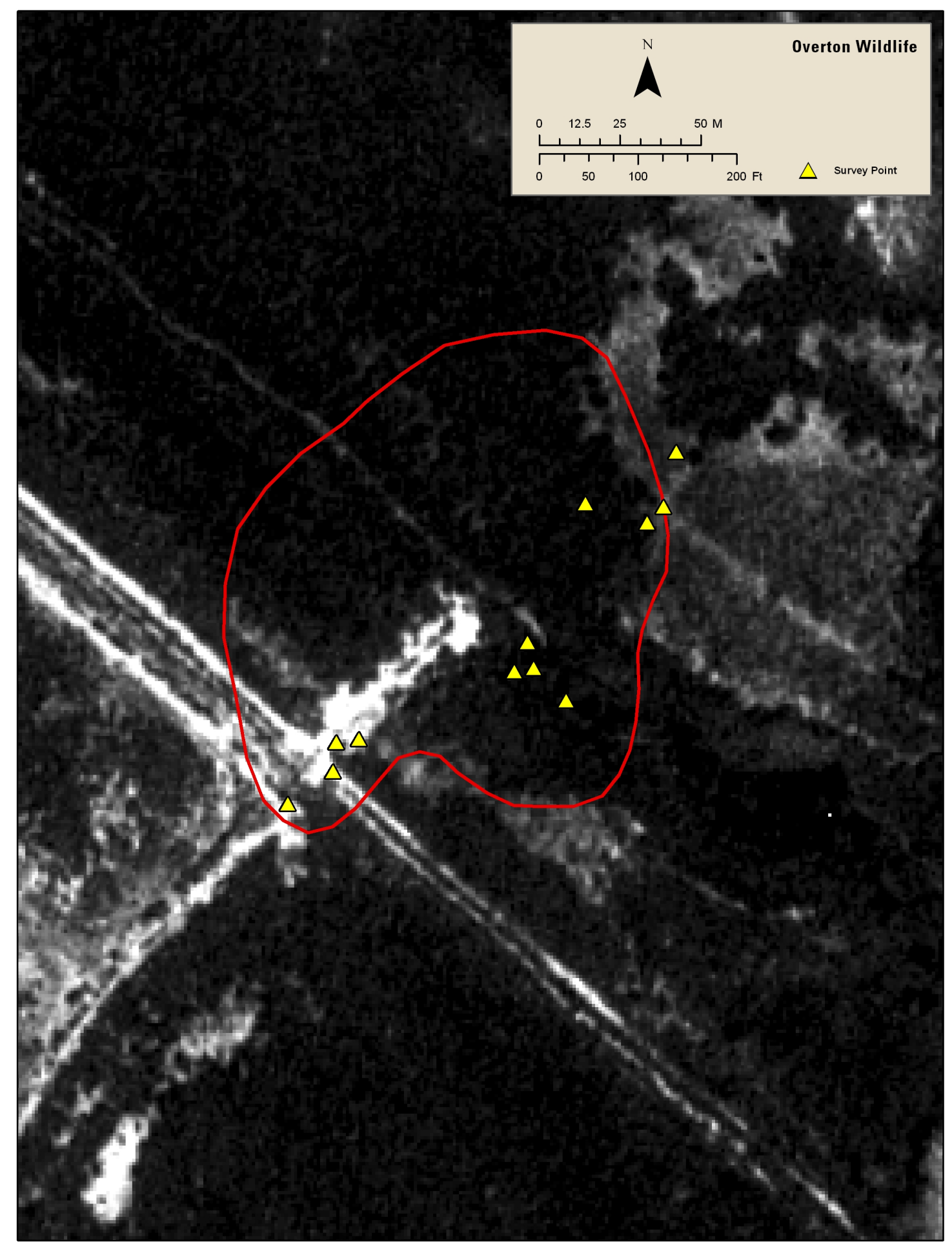


Figure 4-3A. Orthorectified aerial photo display Grand Canyon National Park/ Lake Mead National Recreation Area, AZ, yellow-billed cuckoo survey area, 2007.

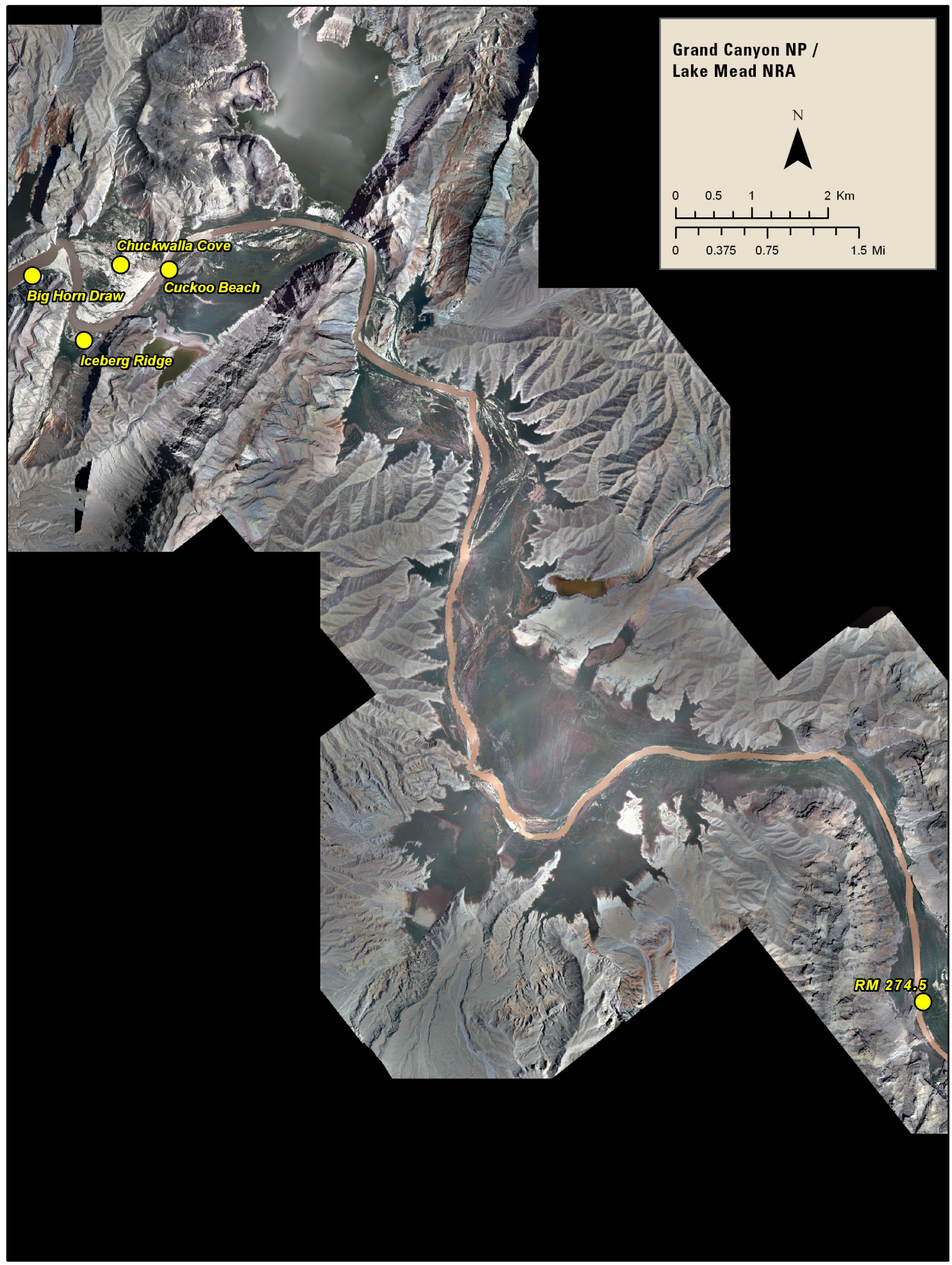


Figure 4-3B. Orthorectified aerial photo display yellow-billed cuckoo survey points at Grand Canyon National Park/Lake Mead National Recreation Area, AZ, RM 274.5, 2007. No cuckoos were detected at this site in 2007. Red boundary line represents yellow-billed cuckoo survey habitat patch.

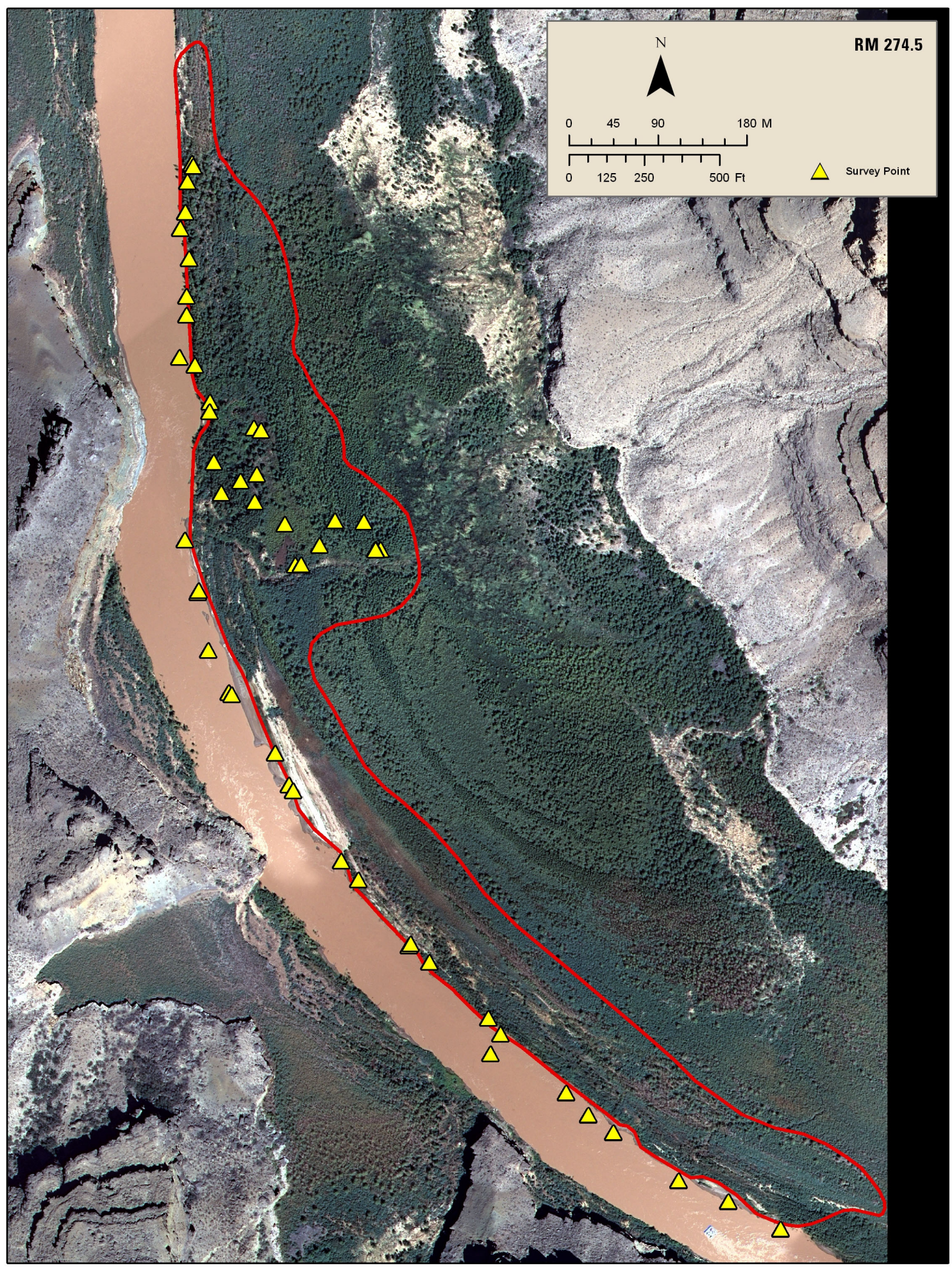


Figure 4-3C. Orthorectified aerial photo display yellow-billed cuckoo survey points at Grand Canyon National Park/Lake Mead National Recreation Area, AZ, Cuckoo Beach, 2007. No cuckoos were detected at this site in 2007. Red boundary line represents yellowbilled cuckoo survey habitat patch.

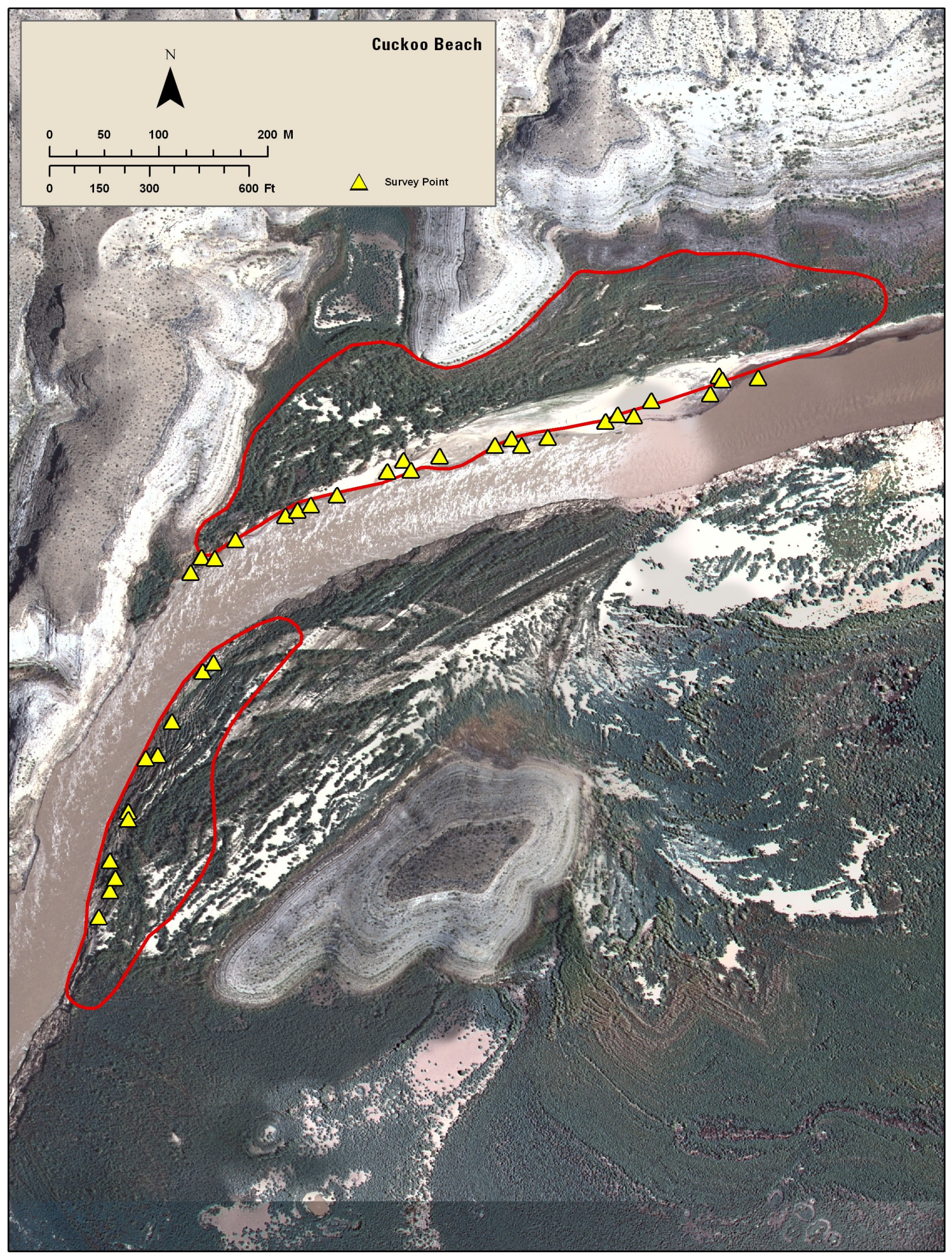


Figure 4-3D. Orthorectified aerial photo display yellow-billed cuckoo survey points at Grand Canyon National Park/Lake Mead National Recreation Area, AZ, Iceberg Ridge, 2007. No cuckoos were detected at this site in 2007. Red boundary line represents yellowbilled cuckoo survey habitat patch.

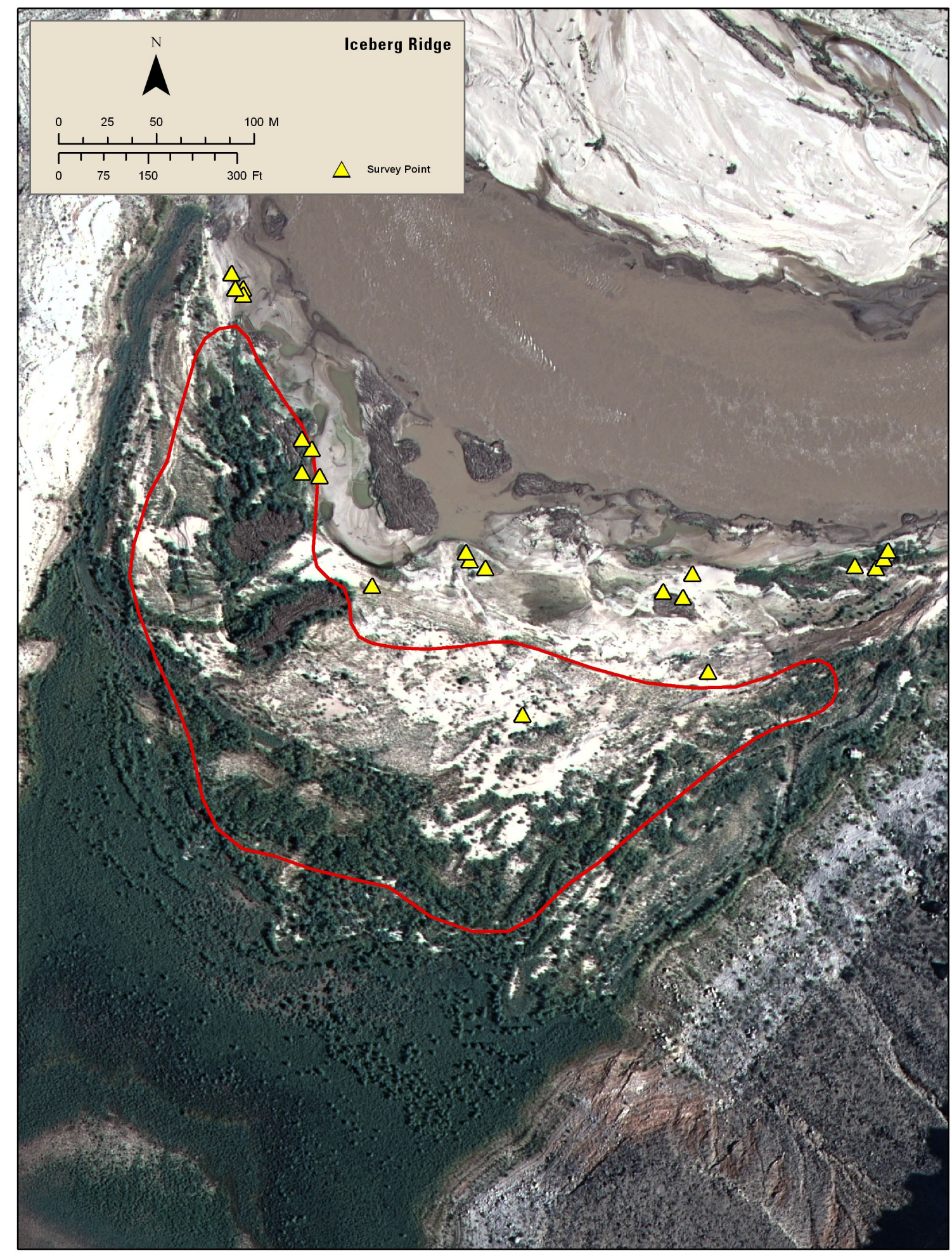


Figure 4-3E. Orthorectified aerial photo display yellow-billed cuckoo survey points at Grand Canyon National Park/Lake Mead National Recreation Area, AZ, Chuckwalla Cove, 2007. No cuckoos were detected at this site in 2007. Red boundary line represents yellowbilled cuckoo survey habitat patch.

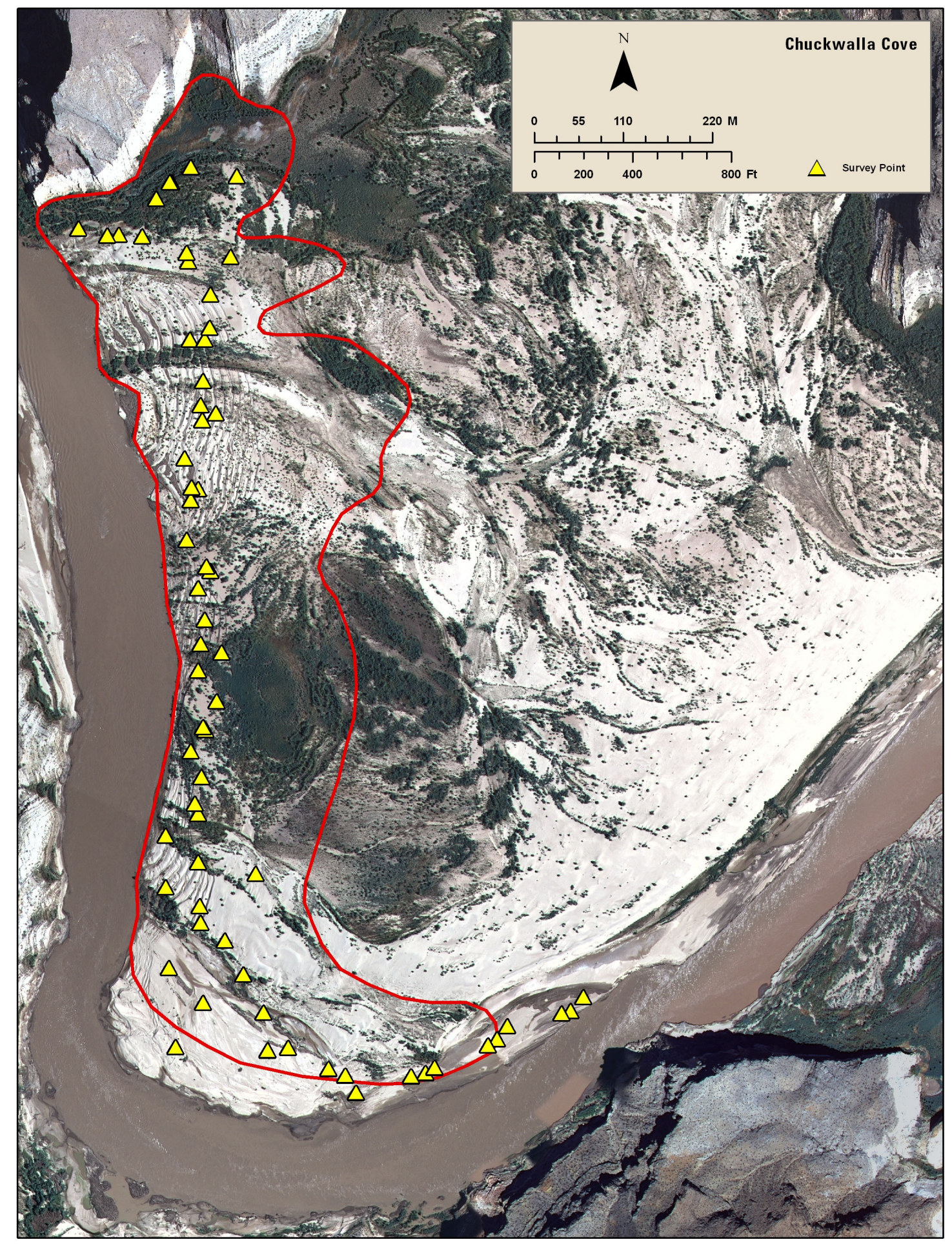


Figure 4-3F. 0 rthorectified aerial photo display yellow-billed cuckoo survey points at Grand Canyon National Park/Lake Mead National Recreation Area, AZ, Big Horn Draw, 2007. No cuckoos were detected at this site in 2007. Red boundary line represents yellowbilled cuckoo survey habitat patch.

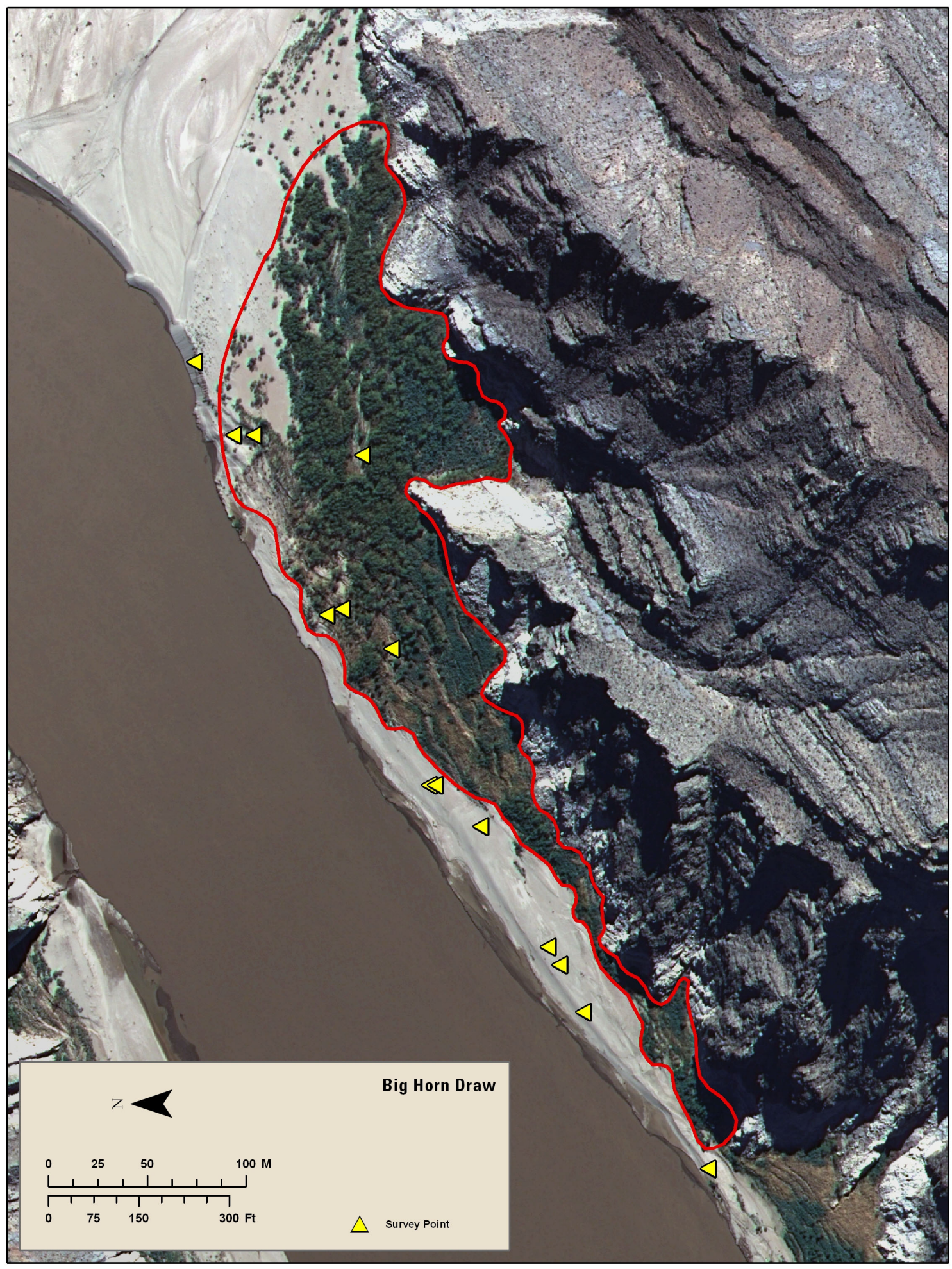


Figure 4-4A. Orthorectified aerial photo display Havasu National Wildlife Refuge, $A Z$, yellow-billed cuckoo survey area, 2007.

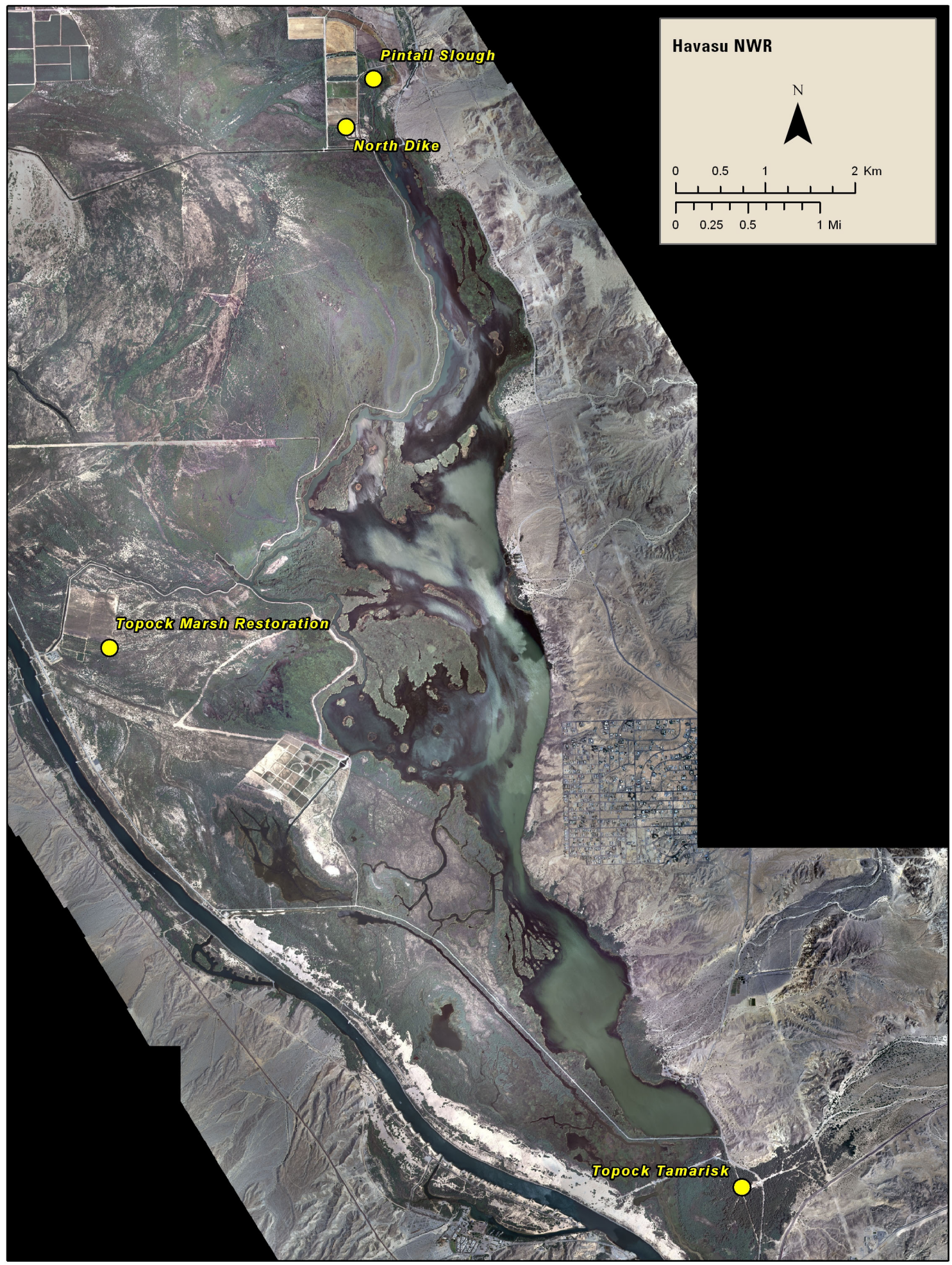


Figure 4-4B. $\quad 0$ rthorectified aerial photo display yellow-billed cuckoo survey points and detection locations at Havasu National Wildlife Refuge area, AZ, Pintail Slough, 2007. Red boundary line represents yellow-billed cuckoo survey habitat patch.

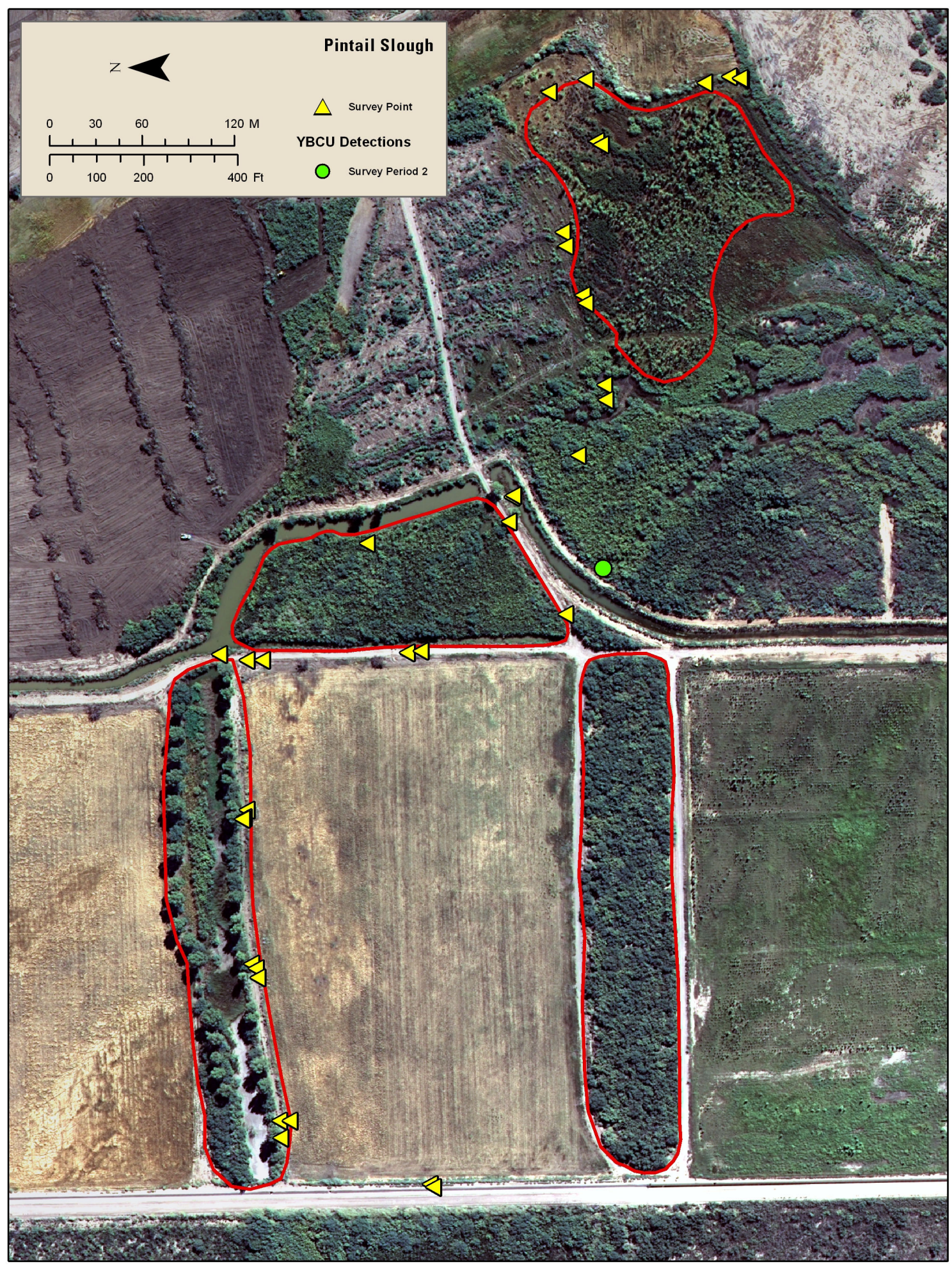


Figure 4-4C. Orthorectified aerial photo display yellow-billed cuckoo survey points and detection locations at Havasu National Wildlife Refuge area, AZ, North Dike, 2007. Red boundary line represents yellow-billed cuckoo survey habitat patch.

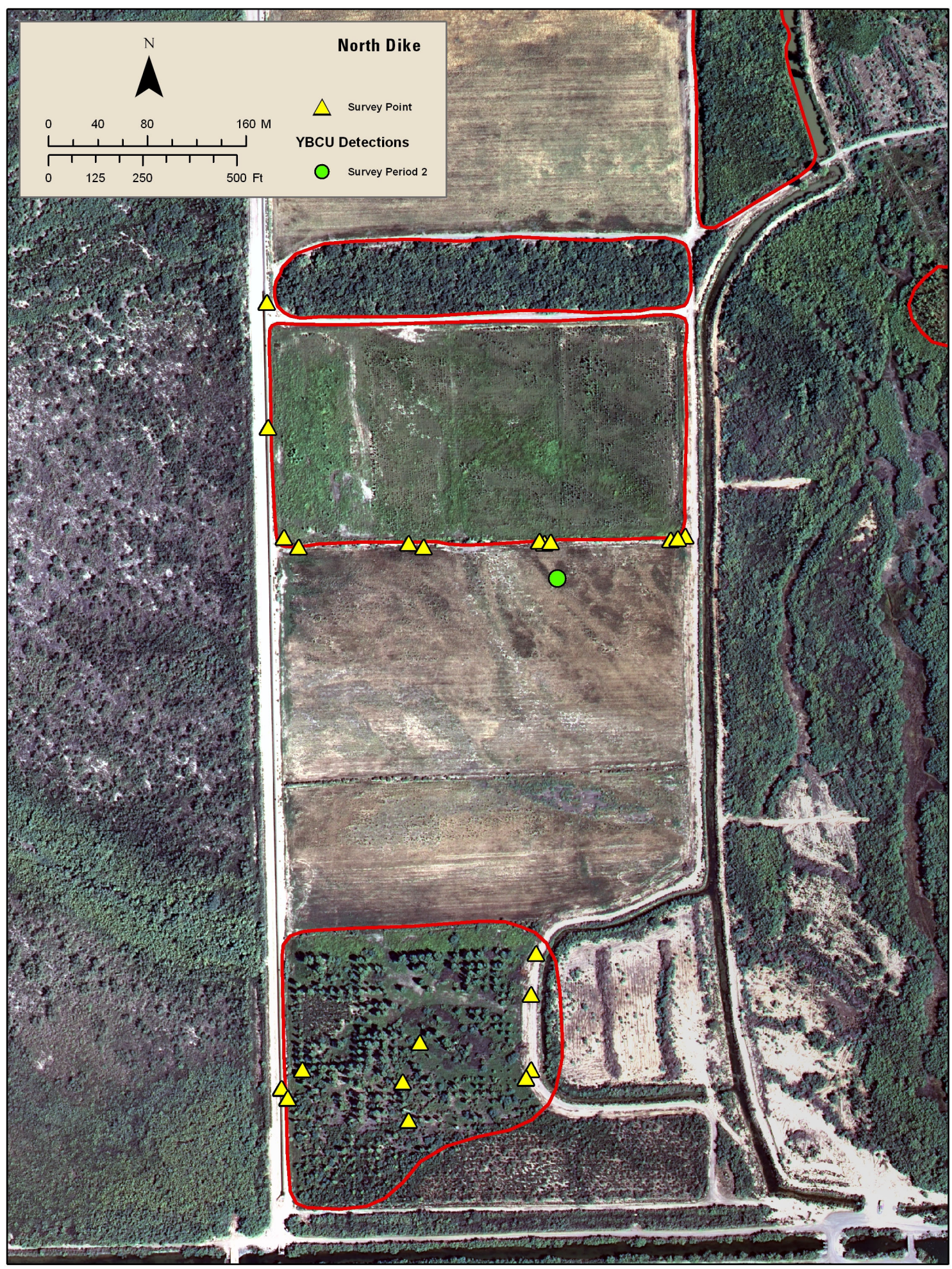


Figure 4-4D. Orthorectified aerial photo display the yellow-billed cuckoo follow-up survey detection location at Havasu National Wildlife Refuge area, AZ, North Dike, 2007.

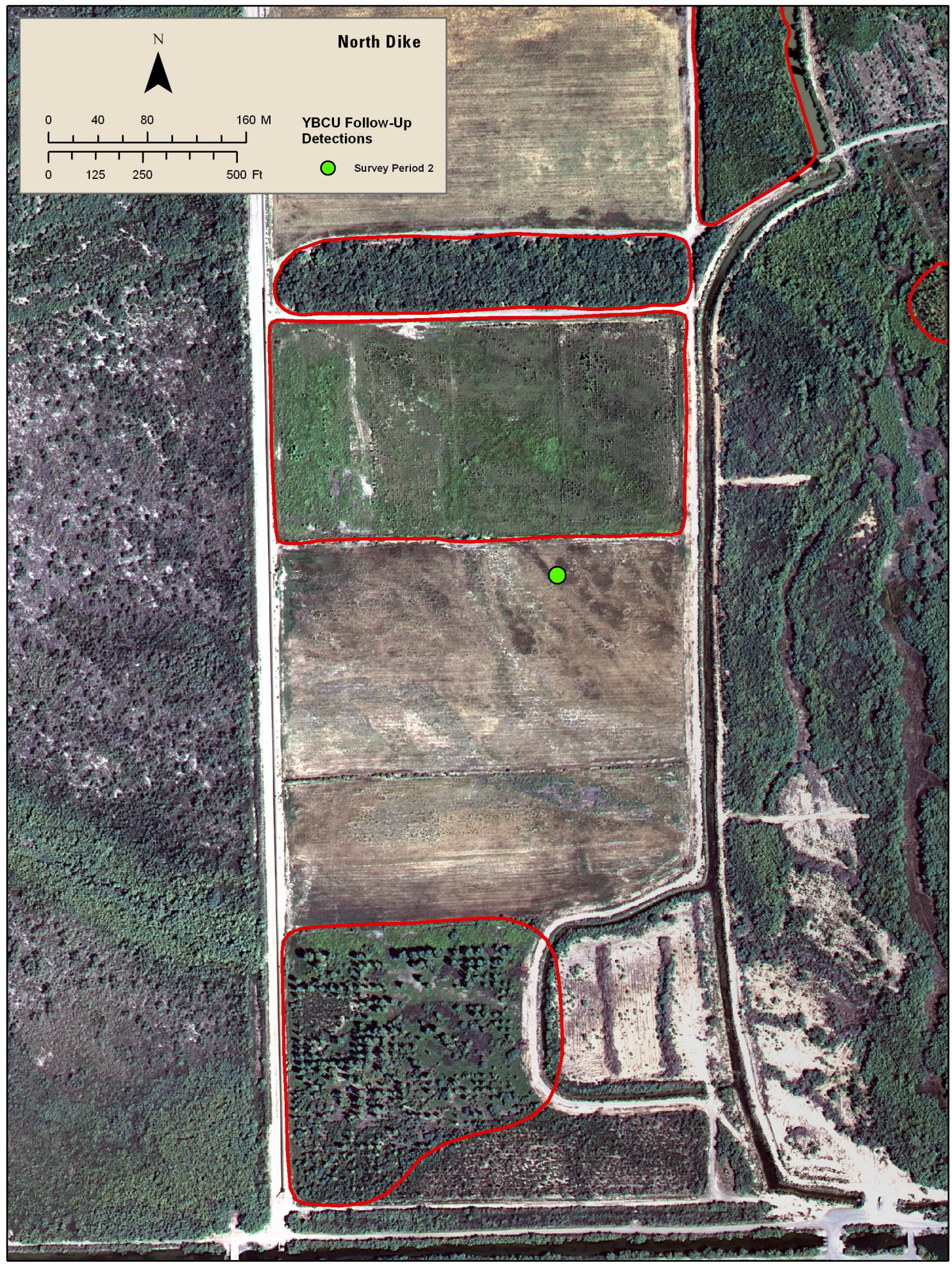


Figure 4-4E. Orthorectified aerial photo display yellow-billed cuckoo survey points and detection locations at Havasu National Wildlife Refuge area, AZ, Topock Marsh Restoration, 2007. Red boundary line represents yellow-billed cuckoo survey habitat patch.

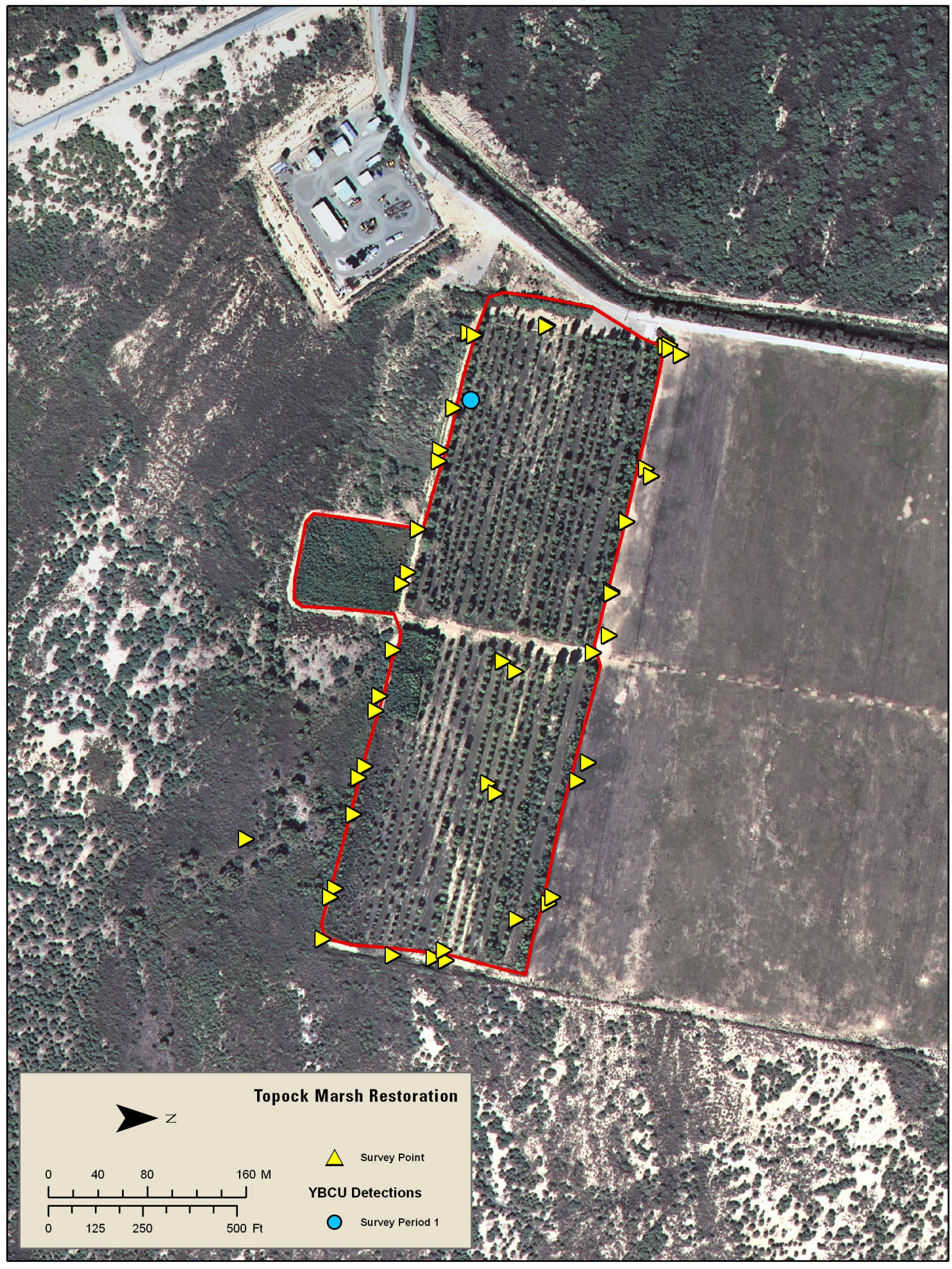


Figure 4-4F. Orthorectified aerial photo display yellow-billed cuckoo follow-up survey detection locations at Havasu National Wildlife Refuge area, AZ, Topock Marsh Restoration, 2007.

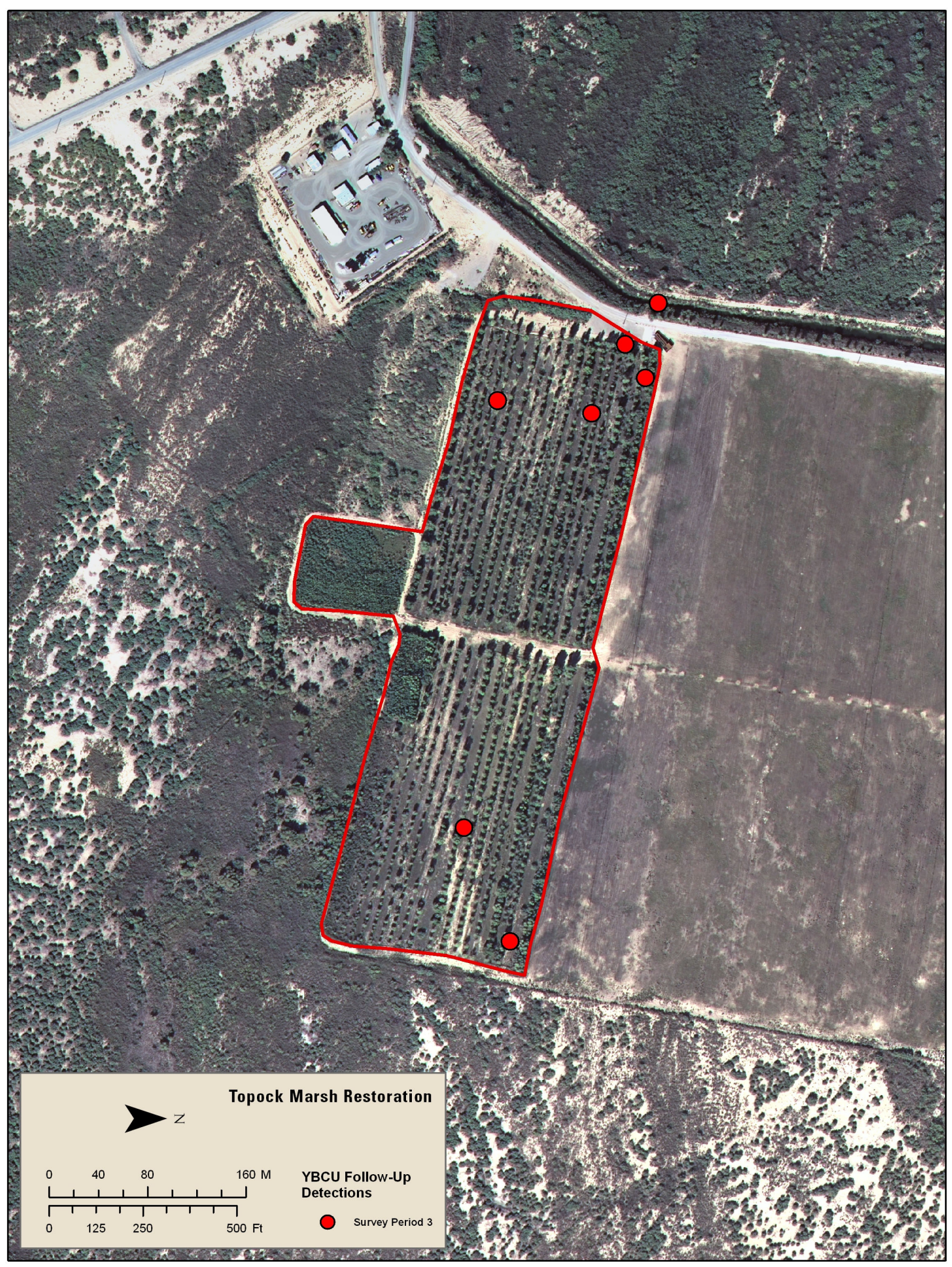


Figure 4-4G. Orthorectified aerial photo display yellow-billed cuckoo survey points at Havasu National Wildlife Refuge area, AZ, Topock Tamarisk, 2007. No cuckoos were detected at this site in 2007. Red boundary line represents yellow-billed cuckoo survey habitat patch.

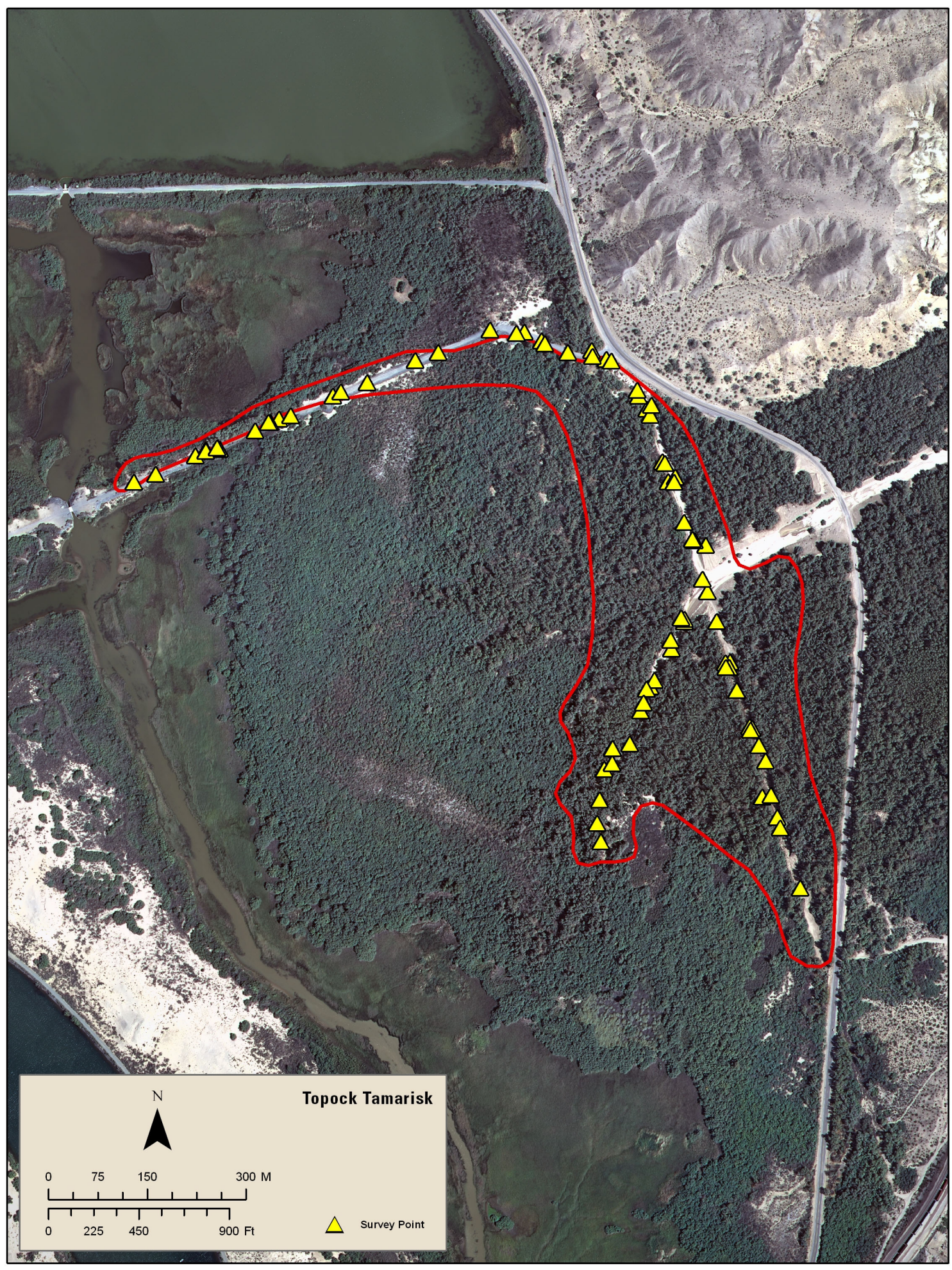


Figure 4-5A. Orthorectified aerial photo display Bill Williams National Wildlife Refuge, AZ, survey, 2007.

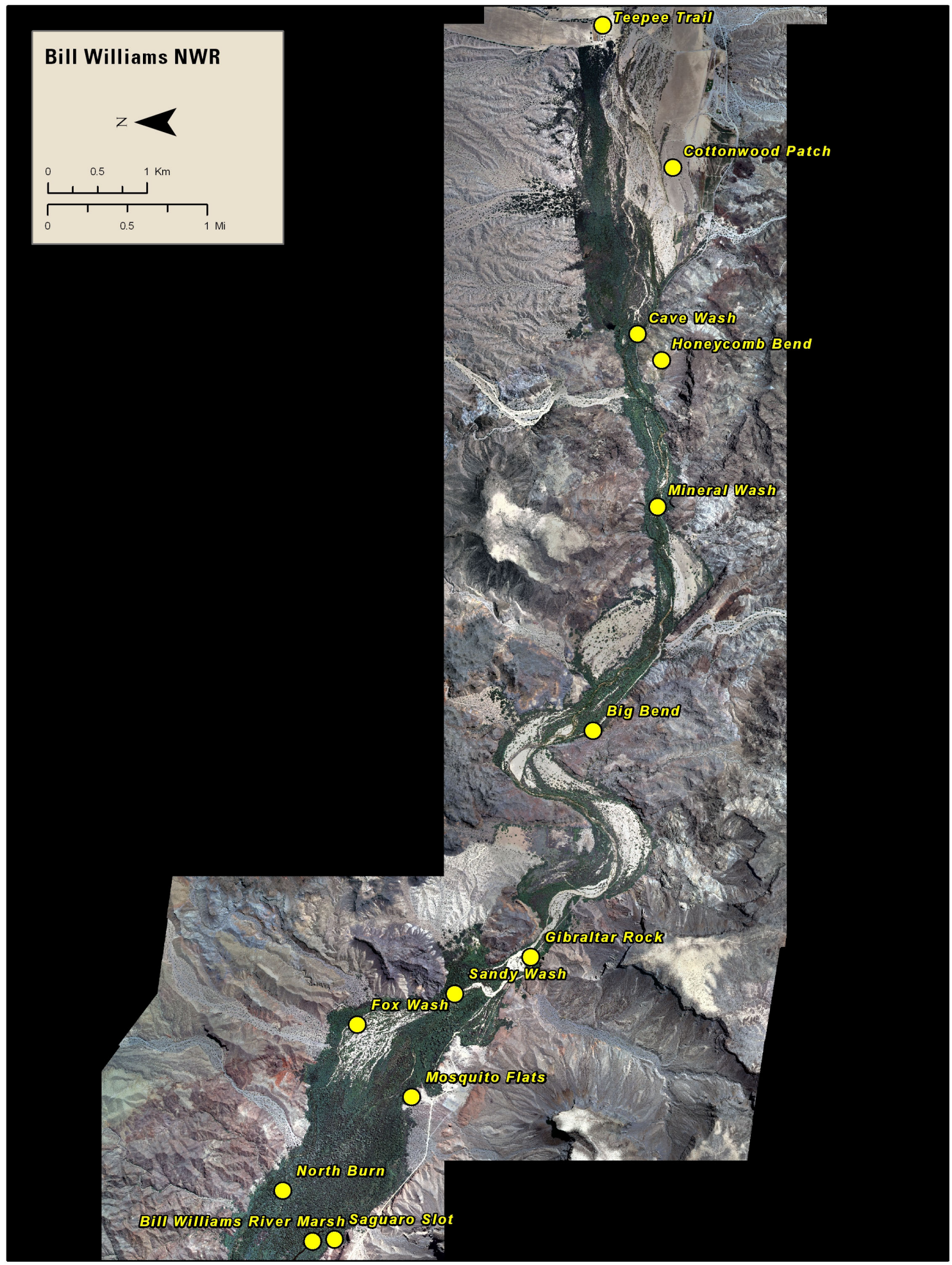


Figure 4-5B. Orthorectified aerial photo display yellow-billed cuckoo survey points and detection locations at Bill Williams National Wildlife Refuge, AZ, Teepee Trail, 2007.

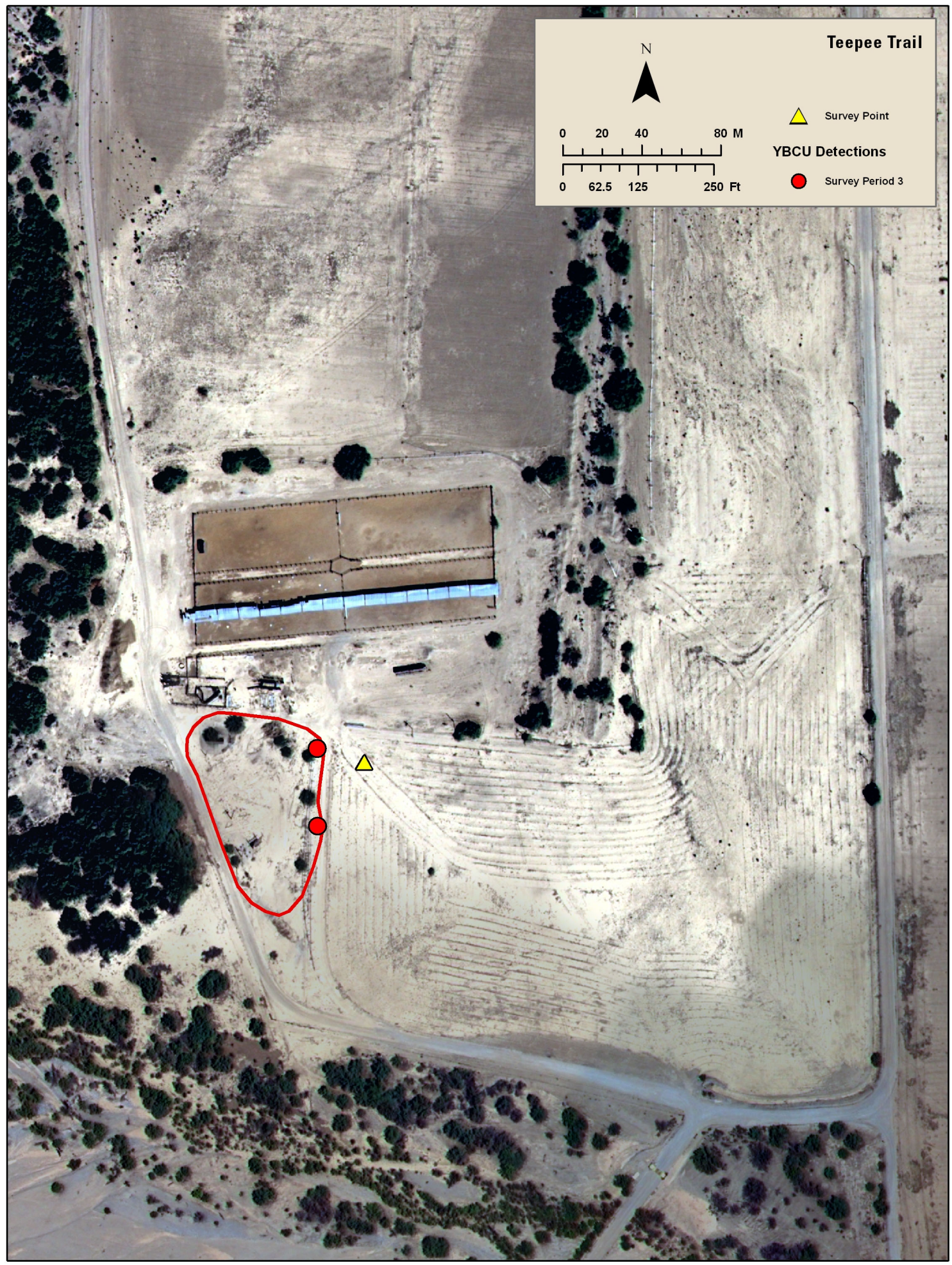


Figure 4-5C. Orthorectified aerial photo display yellow-billed cuckoo survey points and detection locations at Bill Williams National Wildlife Refuge, AZ, Cottonwood Patch, 2007.

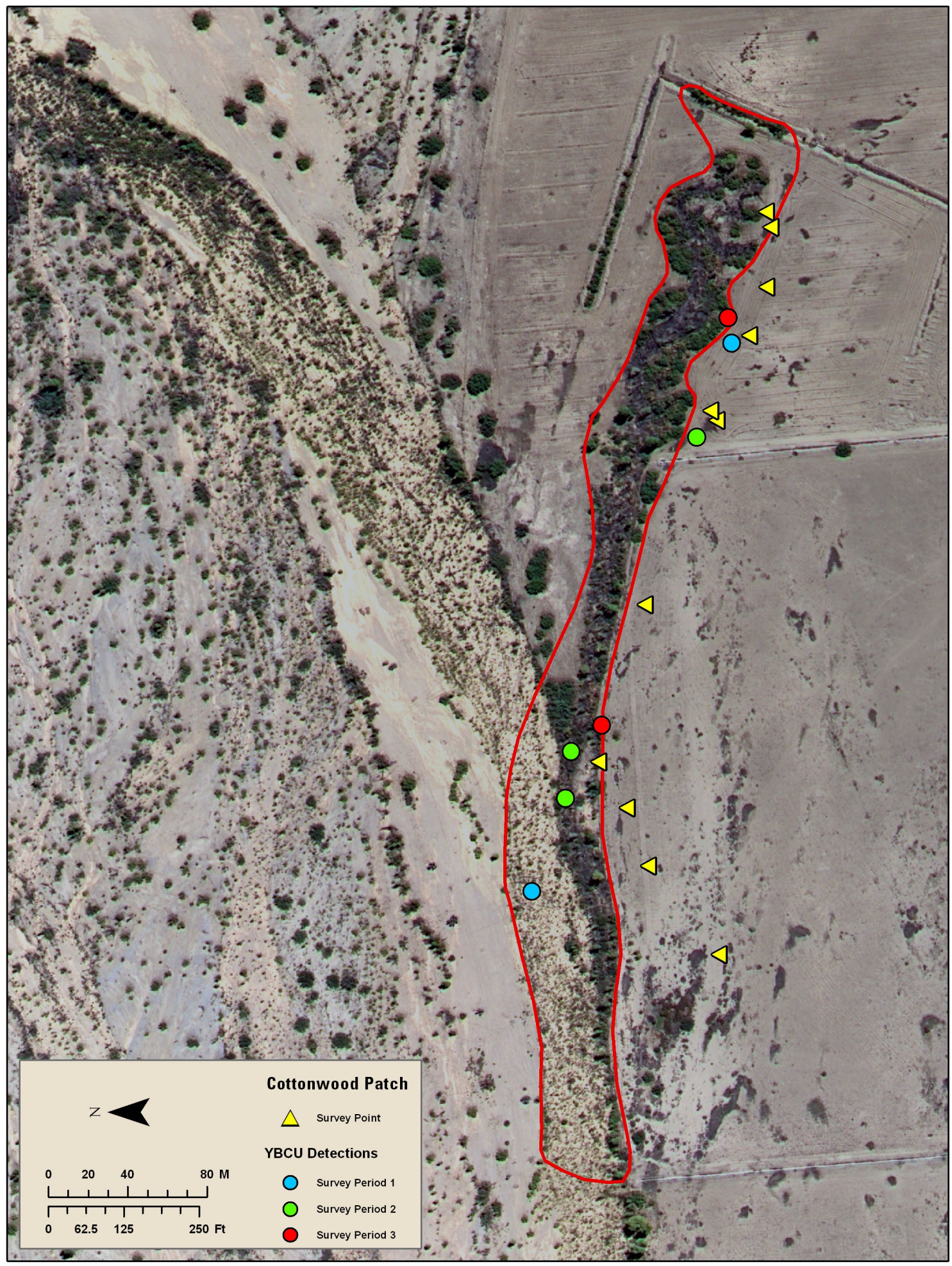


Figure 4-5D. Orthorectified aerial photo display yellow-billed cuckoo follow-up survey detection locations at Bill Williams National Wildlife Refuge, AZ, Cottonwood Patch, 2007.

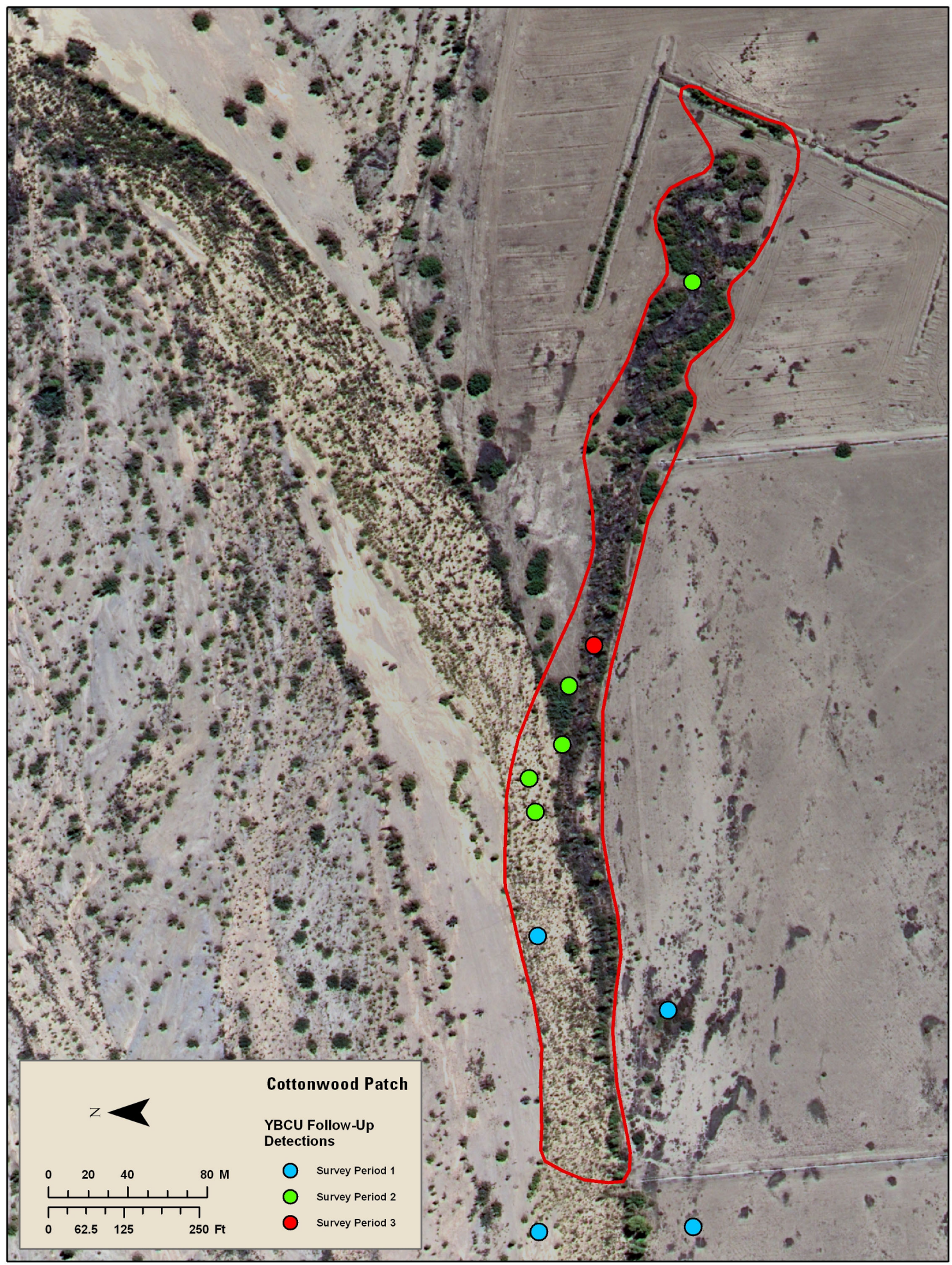


Figure 4-5E. Orthorectified aerial photo display yellow-billed cuckoo survey points and detection locations at Bill Williams National Wildlife Refuge, AZ, Cave Wash, 2007. Red boundary line represents yellow-billed cuckoo survey habitat patch.

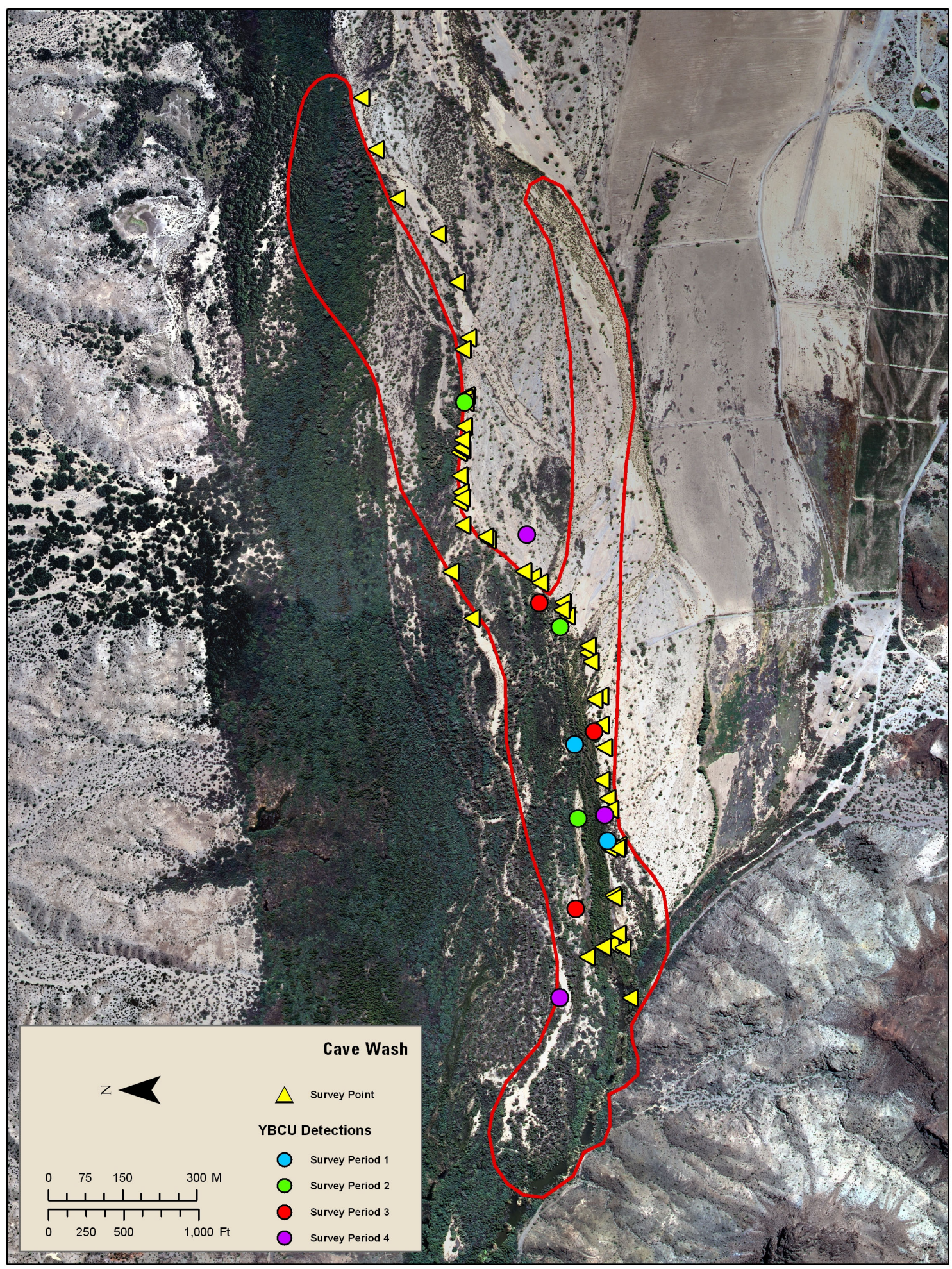


Figure 4-5F. Orthorectified aerial photo display yellow-billed cuckoo follow-up survey detection locations at Bill Williams National Wildlife Refuge, AZ, Cave Wash, 2007.

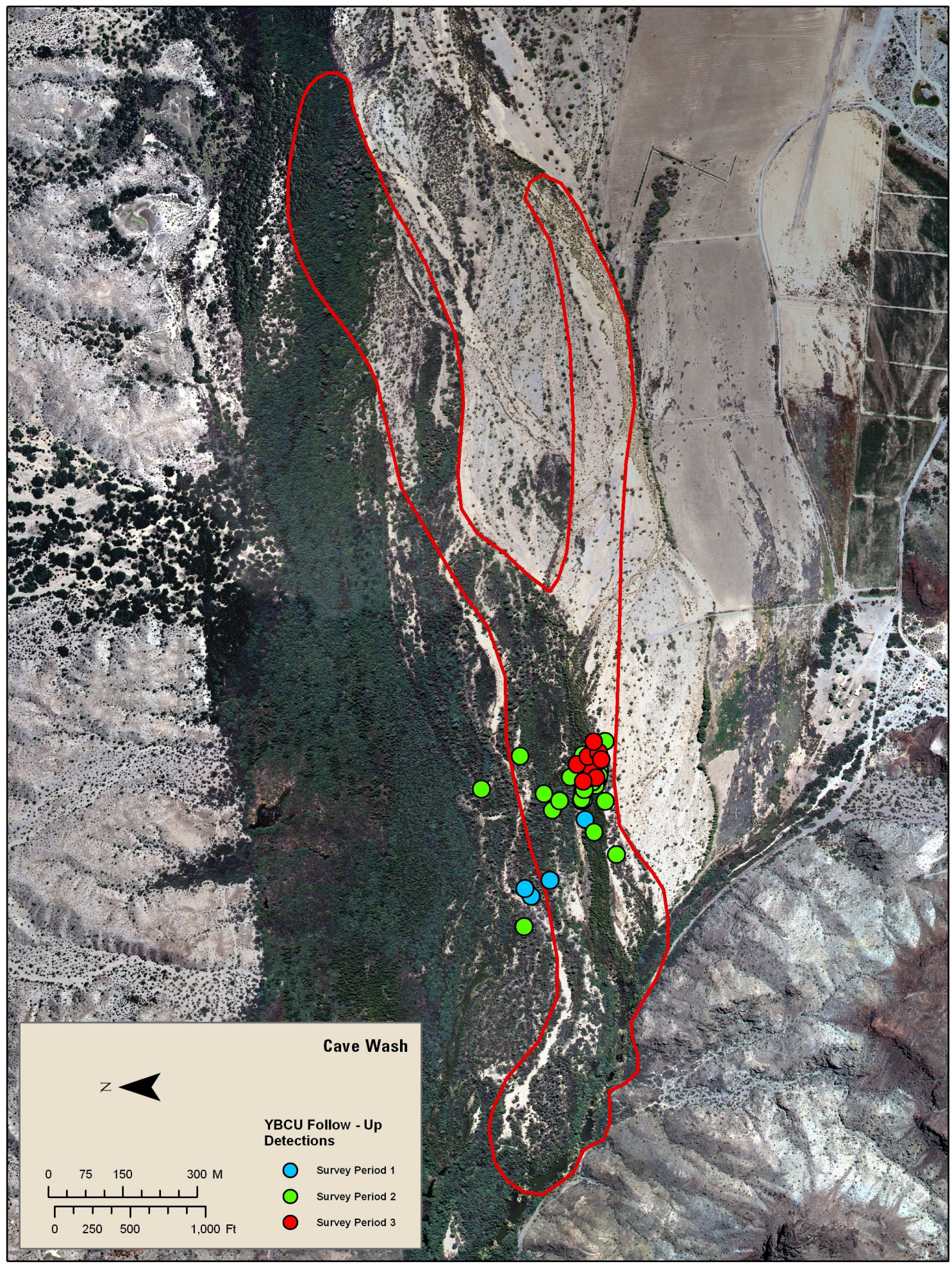


Figure 4-5G. Orthorectified aerial photo display yellow-billed cuckoo survey points and detection locations at Bill Williams National Wildlife Refuge, AZ, Honeycomb Bend, 2007.

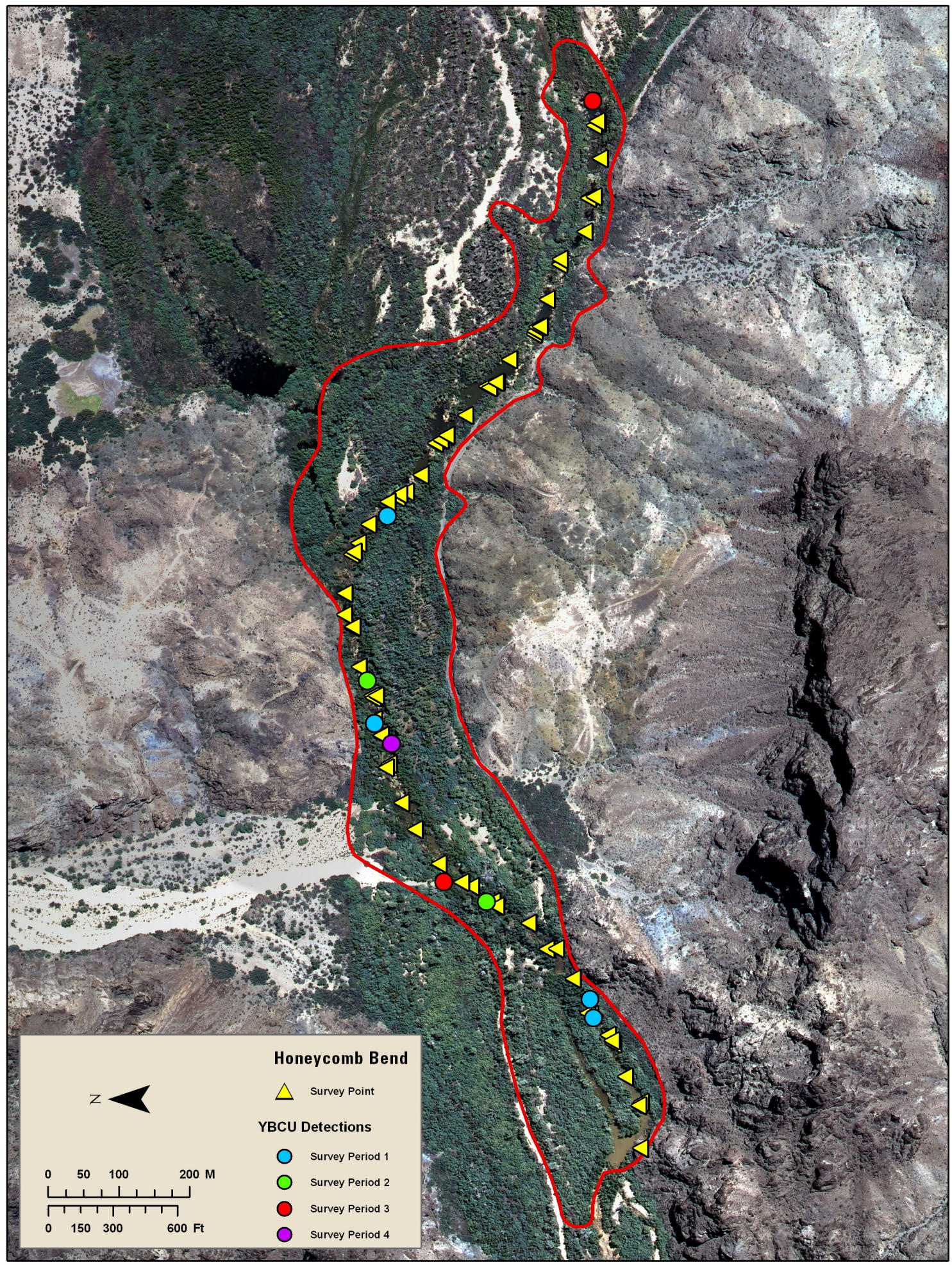


Figure 4-5H. Orthorectified aerial photo display yellow-billed cuckoo follow-up survey detection locations at Bill Williams National Wildlife Refuge, AZ, Honeycomb Bend, 2007.

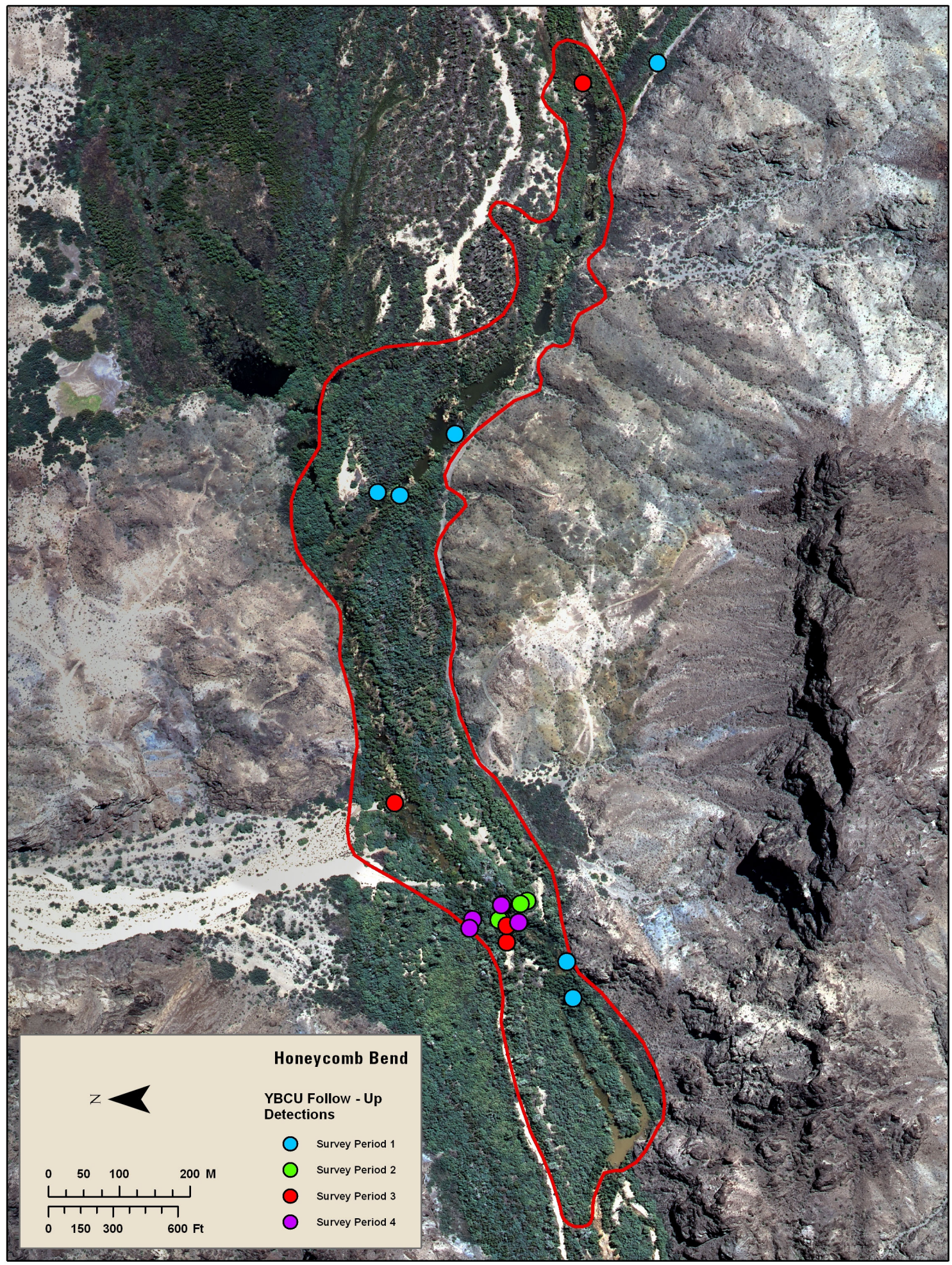


Figure 4-5l. Orthorectified aerial photo display yellow-billed cuckoo survey points and detection locations at Bill Williams National Wildlife Refuge, AZ, Mineral Wash, 2007. Red boundary line represents yellow-billed cuckoo survey habitat patch.

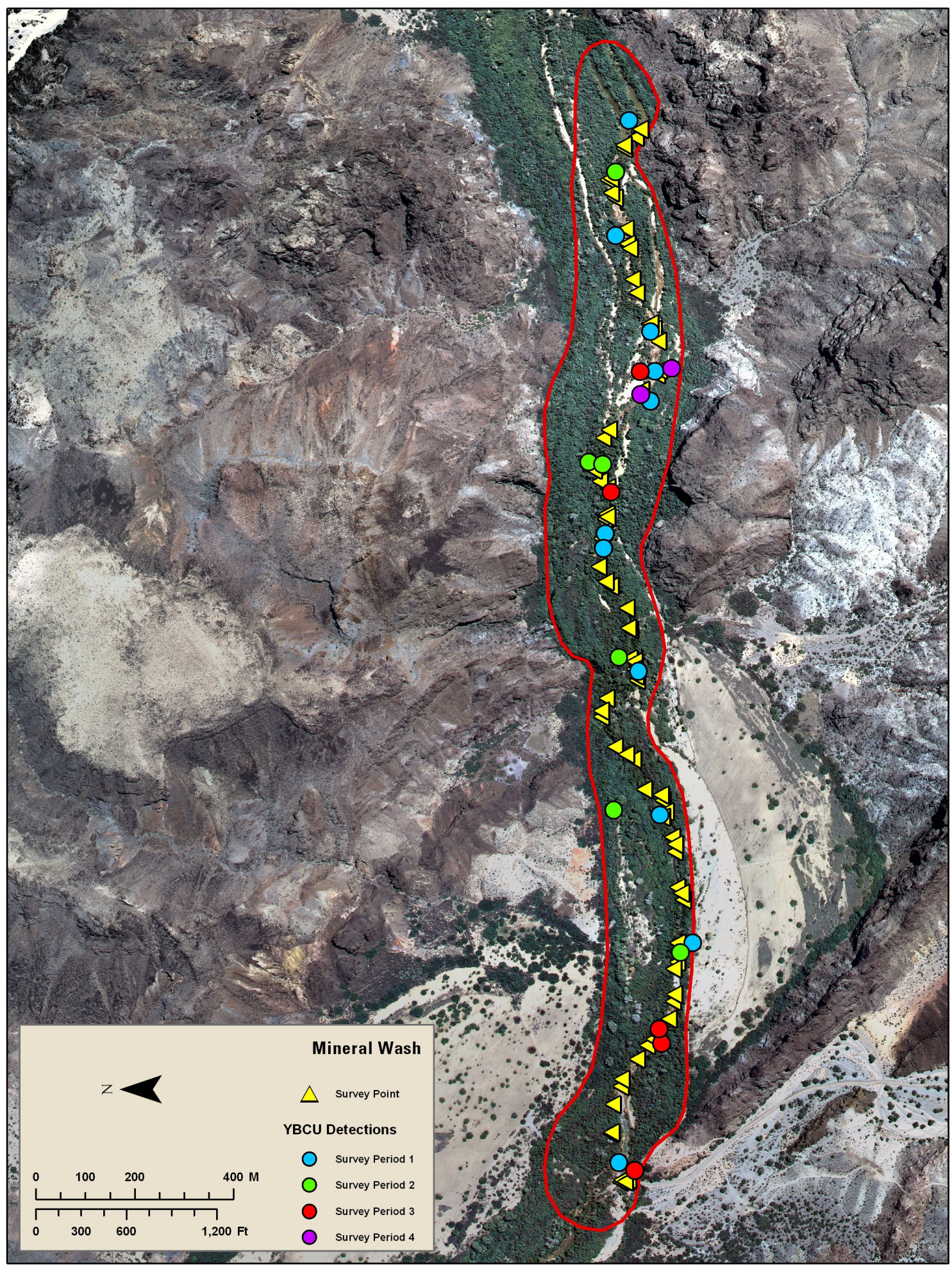


Figure 4-5J. Orthorectified aerial photo display yellow-billed cuckoo follow-up survey detection locations at Bill Williams National Wildlife Refuge, AZ, Mineral Wash, 2007.

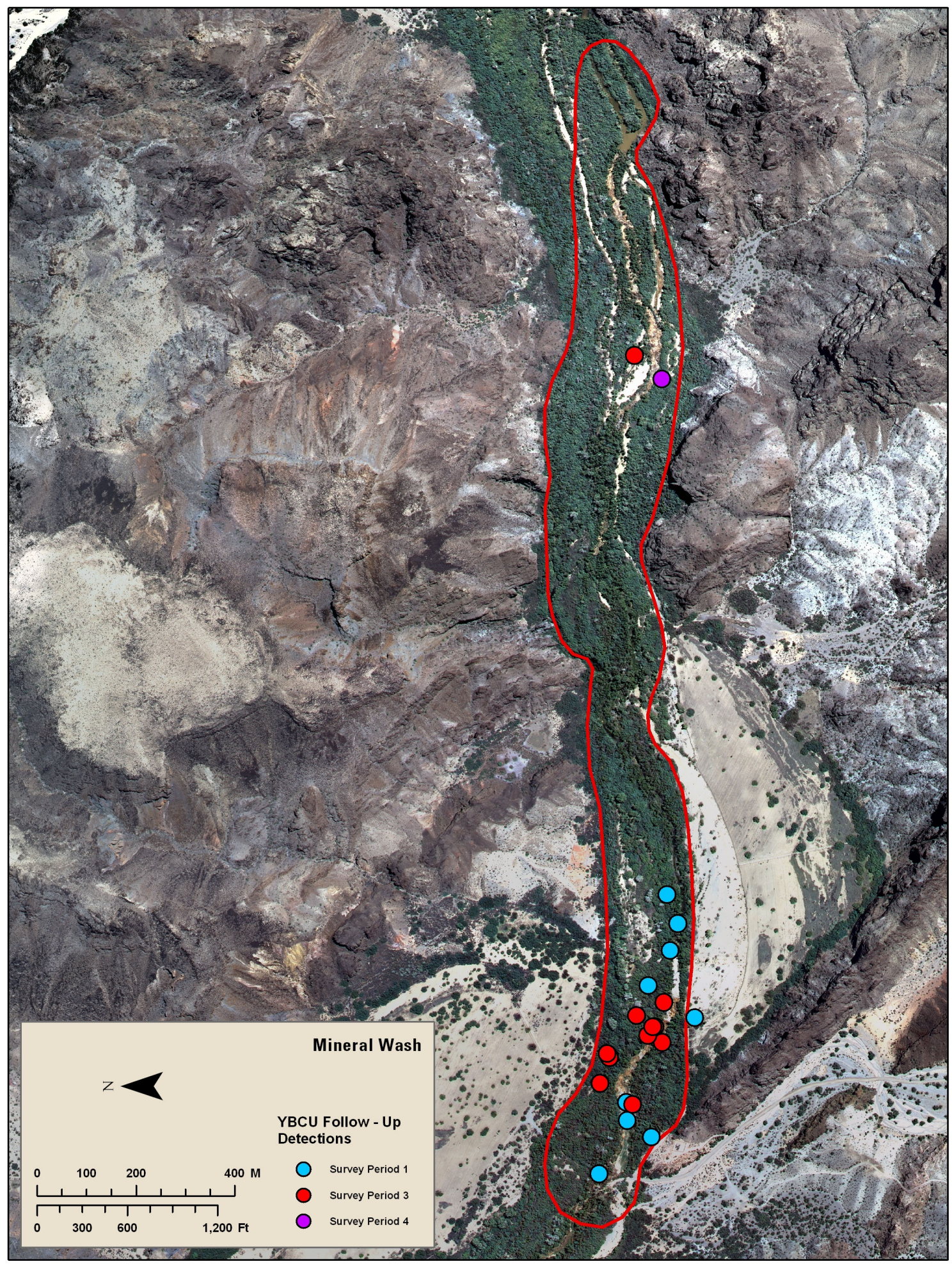


Figure 4-5K. Orthorectified aerial photo display yellow-billed cuckoo survey points and detection locations at Bill Williams National Wildlife Refuge, AZ, Big Bend, 2007. Red boundary line represents yellow-billed cuckoo survey habitat patch.

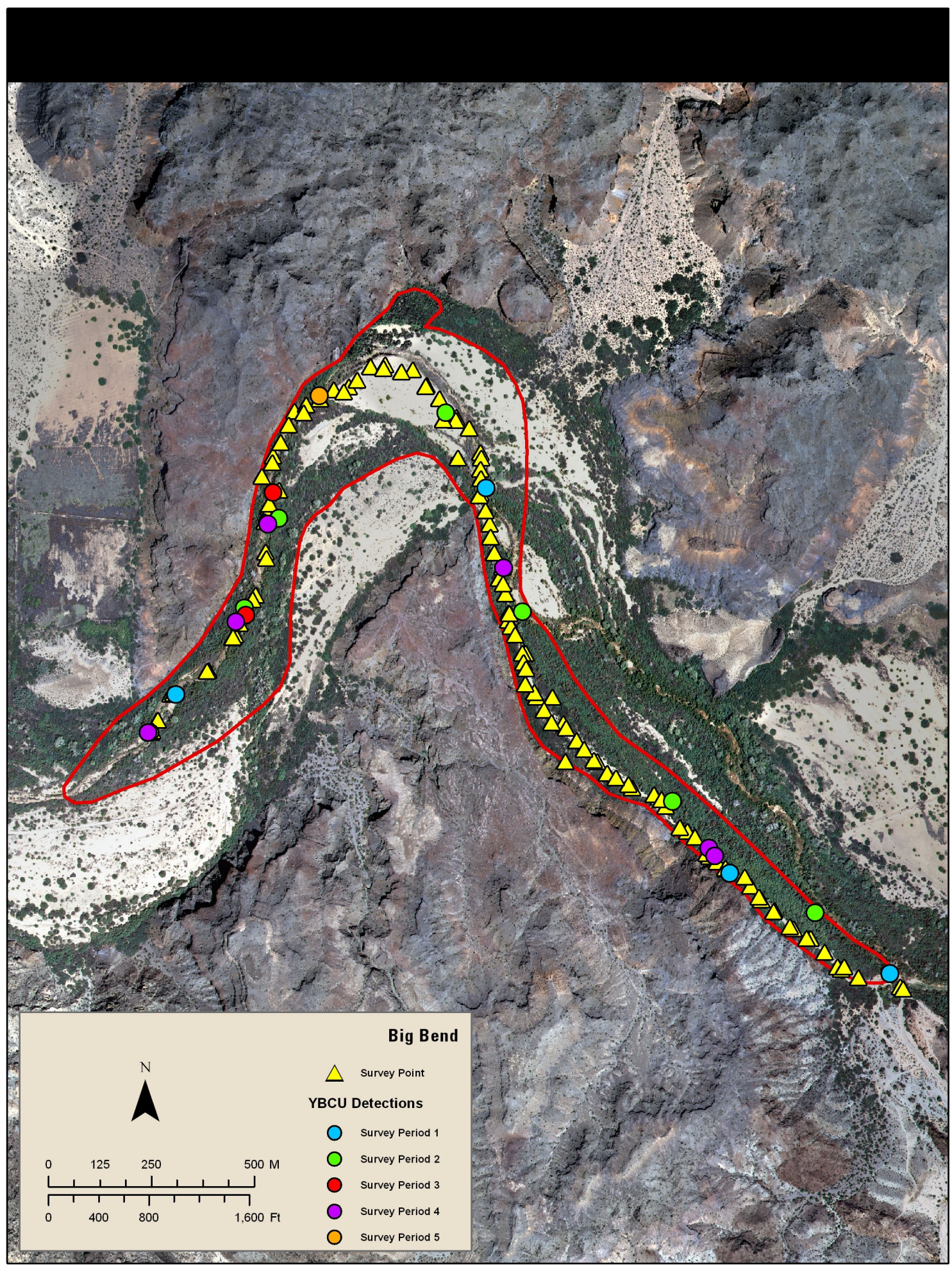


Figure 4-5L. Orthorectified aerial photo display yellow-billed cuckoo follow-up survey detection locations at Bill Williams National Wildlife Refuge, AZ, Big Bend, 2007.

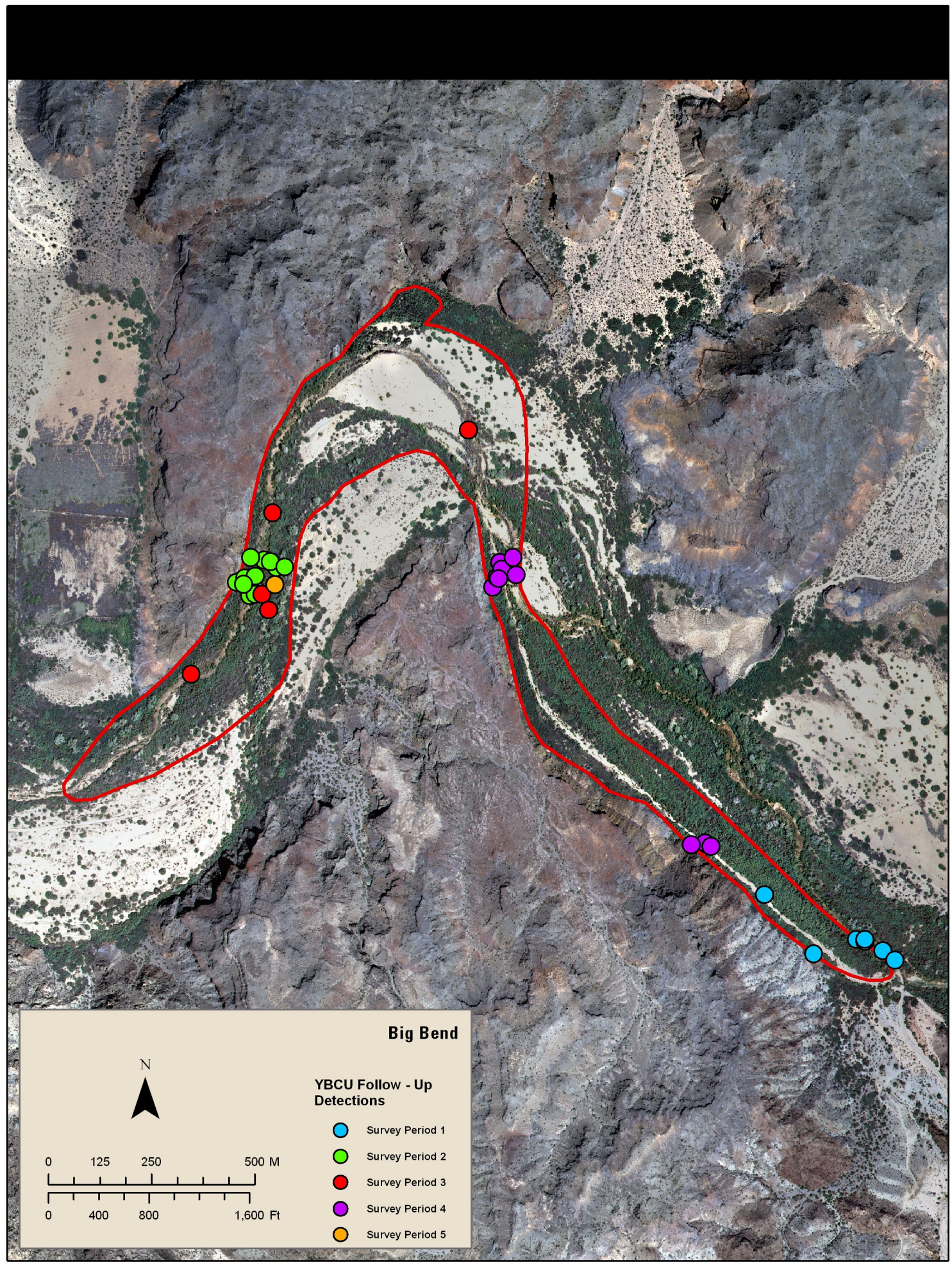


Figure 4-5M. Orthorectified aerial photo display yellow-billed cuckoo survey points and detection locations at Bill Williams National Wildlife Refuge, AZ, Gibraltar Rock, 2007. Red boundary line represents yellow-billed cuckoo survey habitat patch.

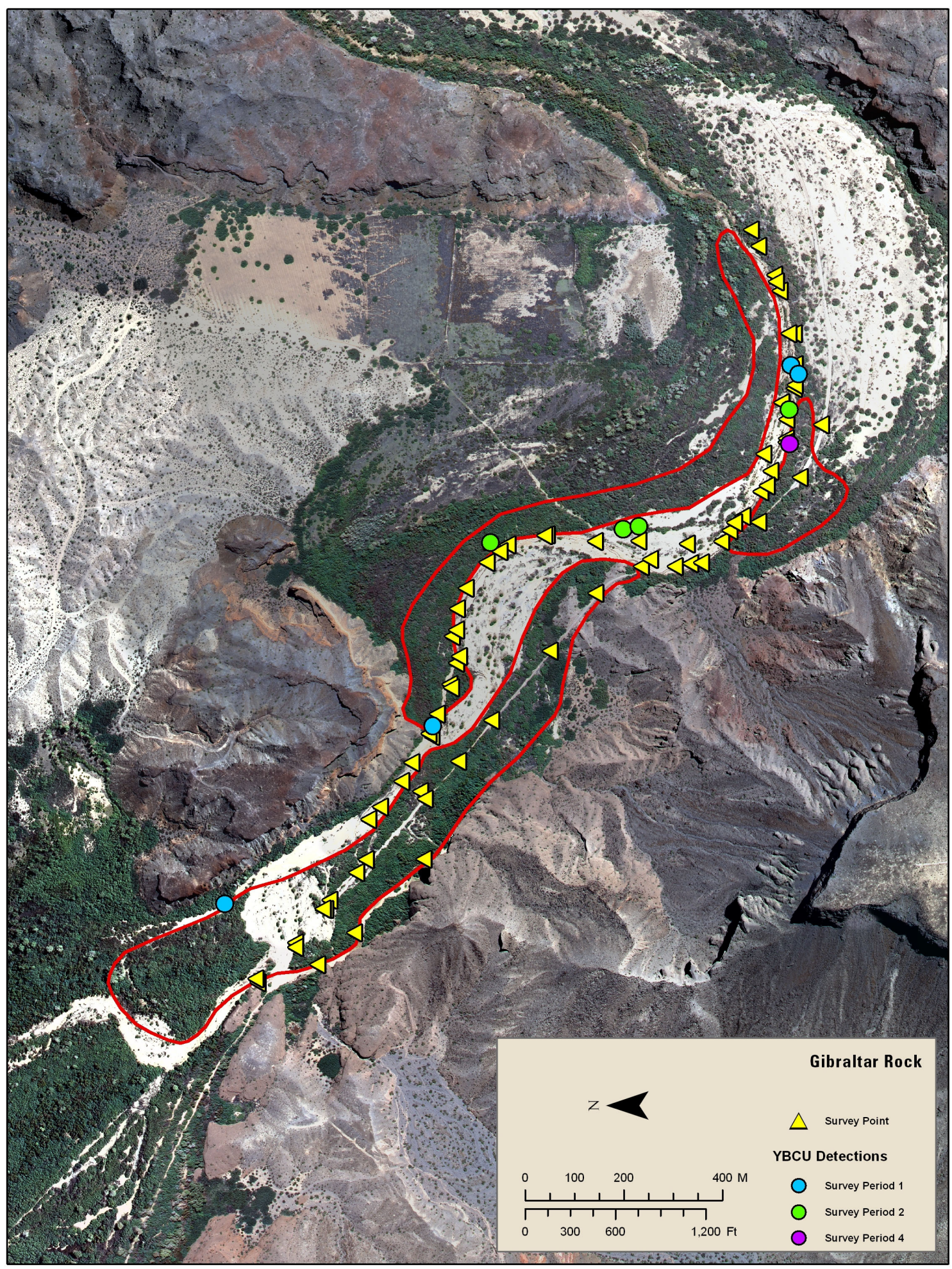


Figure 4-5N. Orthorectified aerial photo display yellow-billed cuckoo follow-up survey detection locations at Bill Williams National Wildlife Refuge, AZ, Gibraltar Rock, 2007.

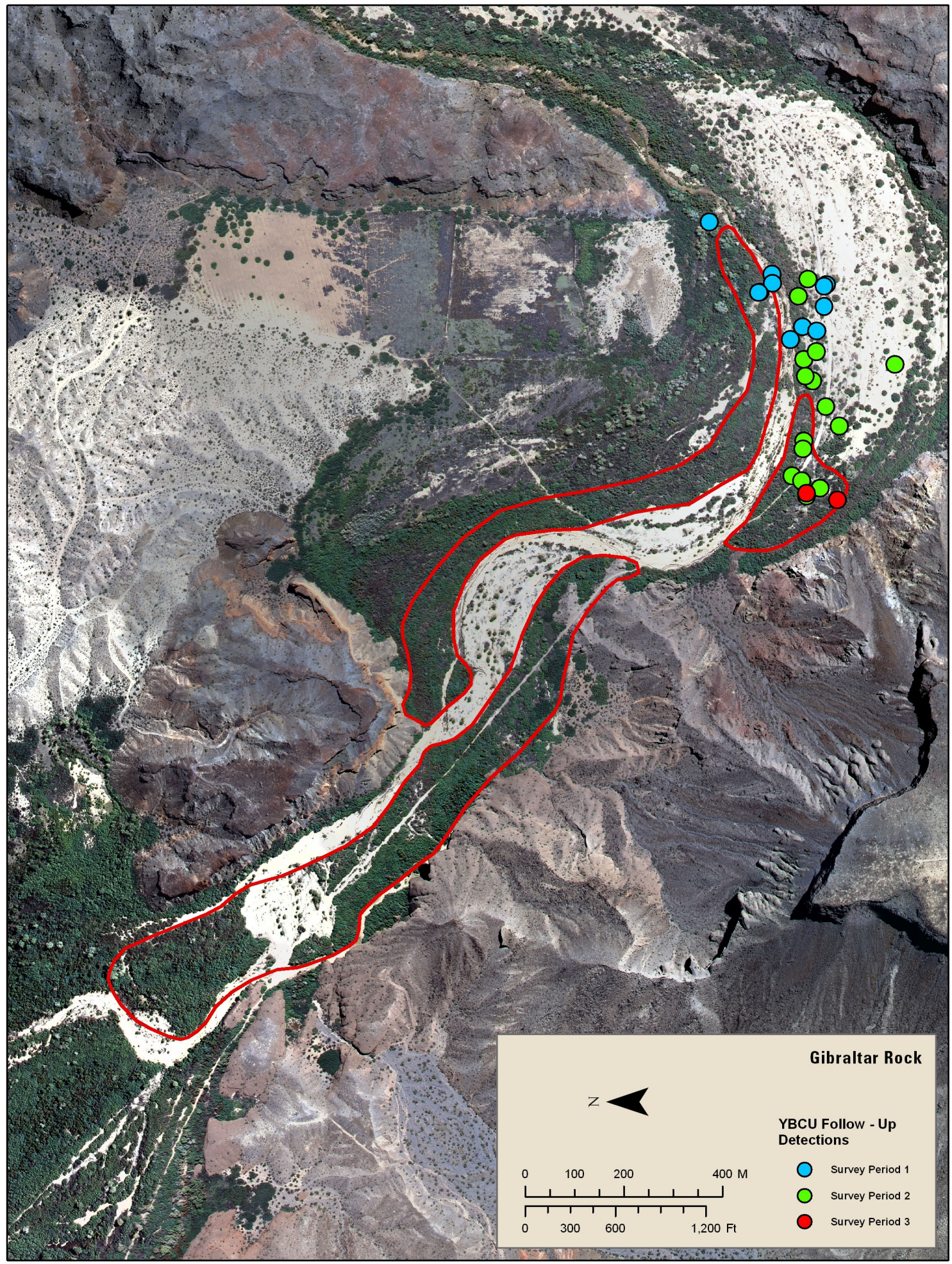


Figure 4-50. Orthorectified aerial photo display yellow-billed cuckoo survey points and detection locations at Bill Williams National Wildlife Refuge, AZ, Sandy Wash, 2007. Red boundary line represents yellow-billed cuckoo survey habitat patch.

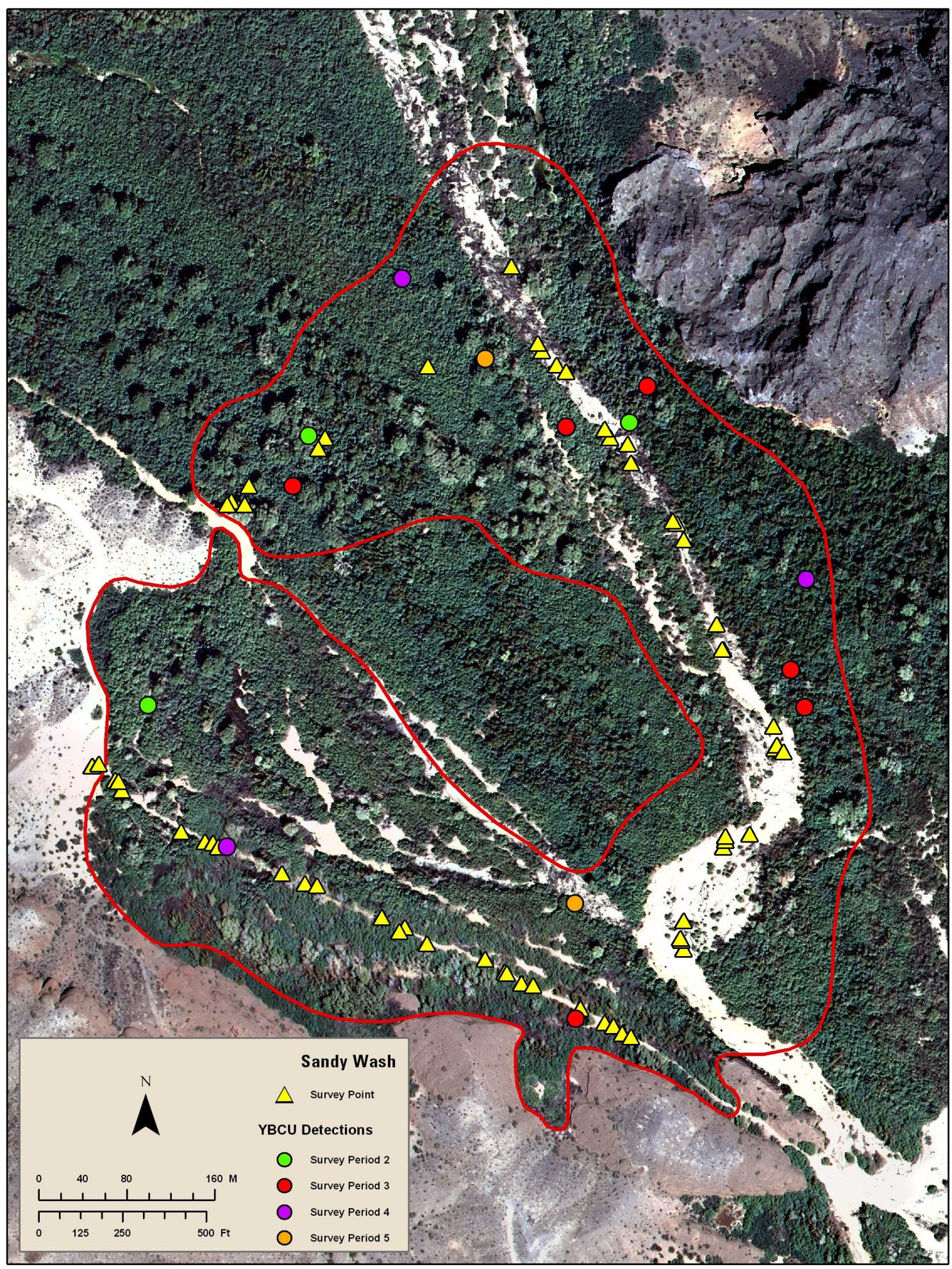


Figure 4-5P. Orthorectified aerial photo display yellow-billed cuckoo follow-up survey detection locations at Bill Williams National Wildlife Refuge, AZ, Sandy Wash, 2007.

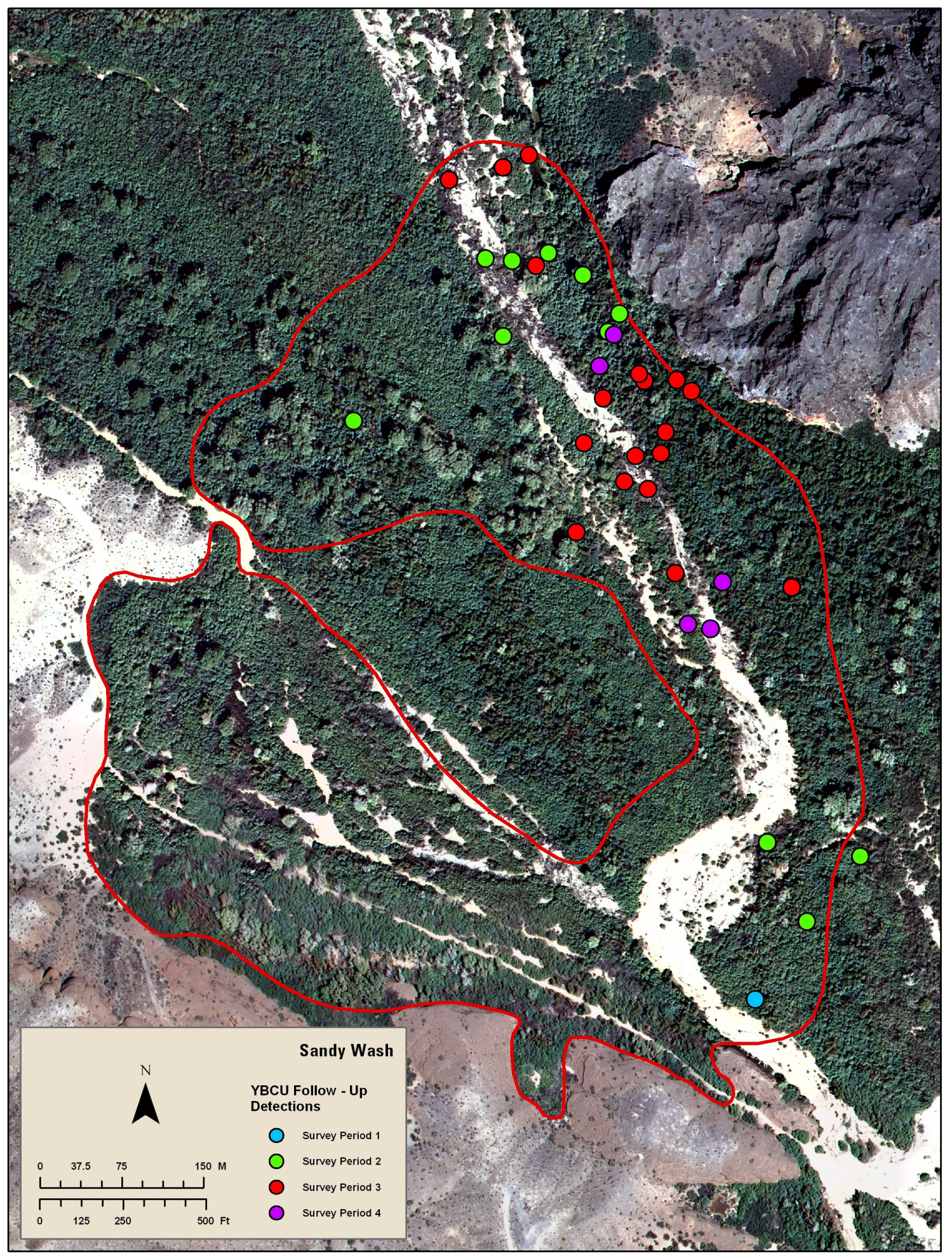


Figure 4-50. Orthorectified aerial photo display yellow-billed cuckoo survey points and detection locations at Bill Williams National Wildlife Refuge, AZ, Fox Wash, 2007. Red boundary line represents yellow-billed cuckoo survey habitat patch.

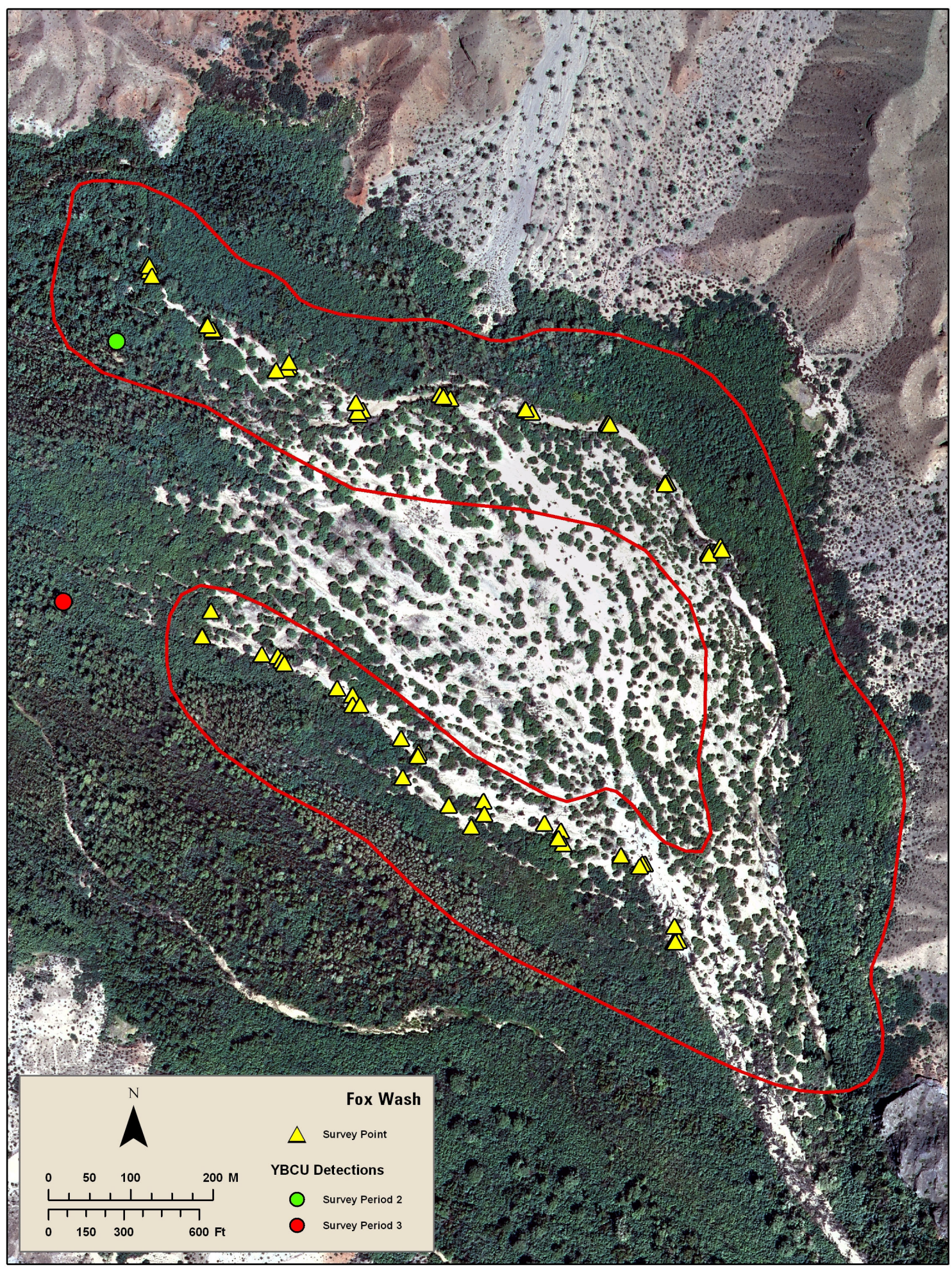


Figure 4-5R. Orthorectified aerial photo display yellow-billed cuckoo follow-up survey detection locations at Bill Williams National Wildlife Refuge, AZ, Fox Wash, 2007.
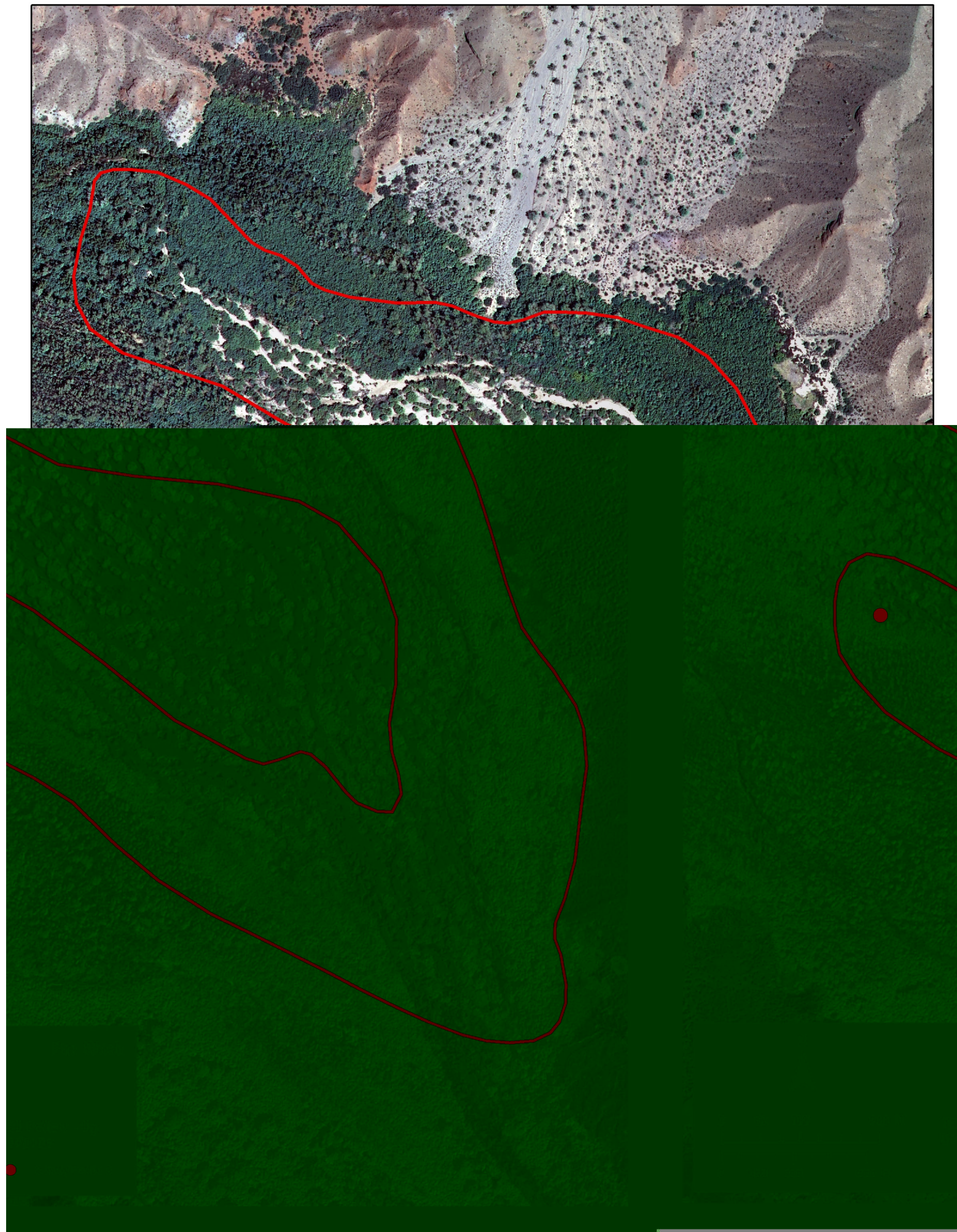
Figure 4-5S. Orthorectified aerial photo display yellow-billed cuckoo survey points and detection locations at Bill Williams National Wildlife Refuge, AZ, Mosquito Flats, 2007. Red boundary line represents yellow-billed cuckoo survey habitat patch.

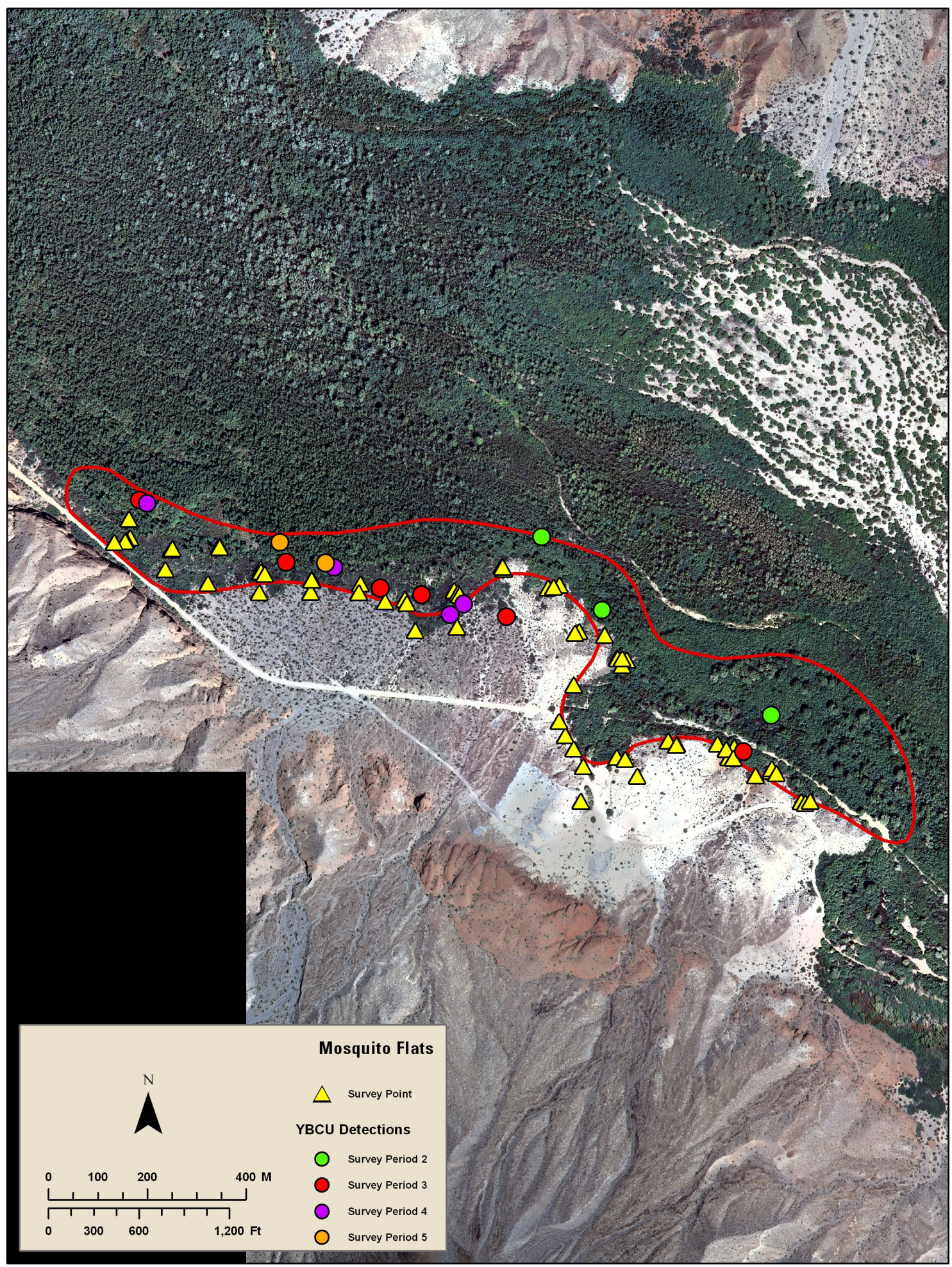


Figure 4-5T. Orthorectified aerial photo display yellow-billed cuckoo follow-up survey detection locations at Bill Williams National Wildlife Refuge, AZ, Mosquito Flats, 2007.

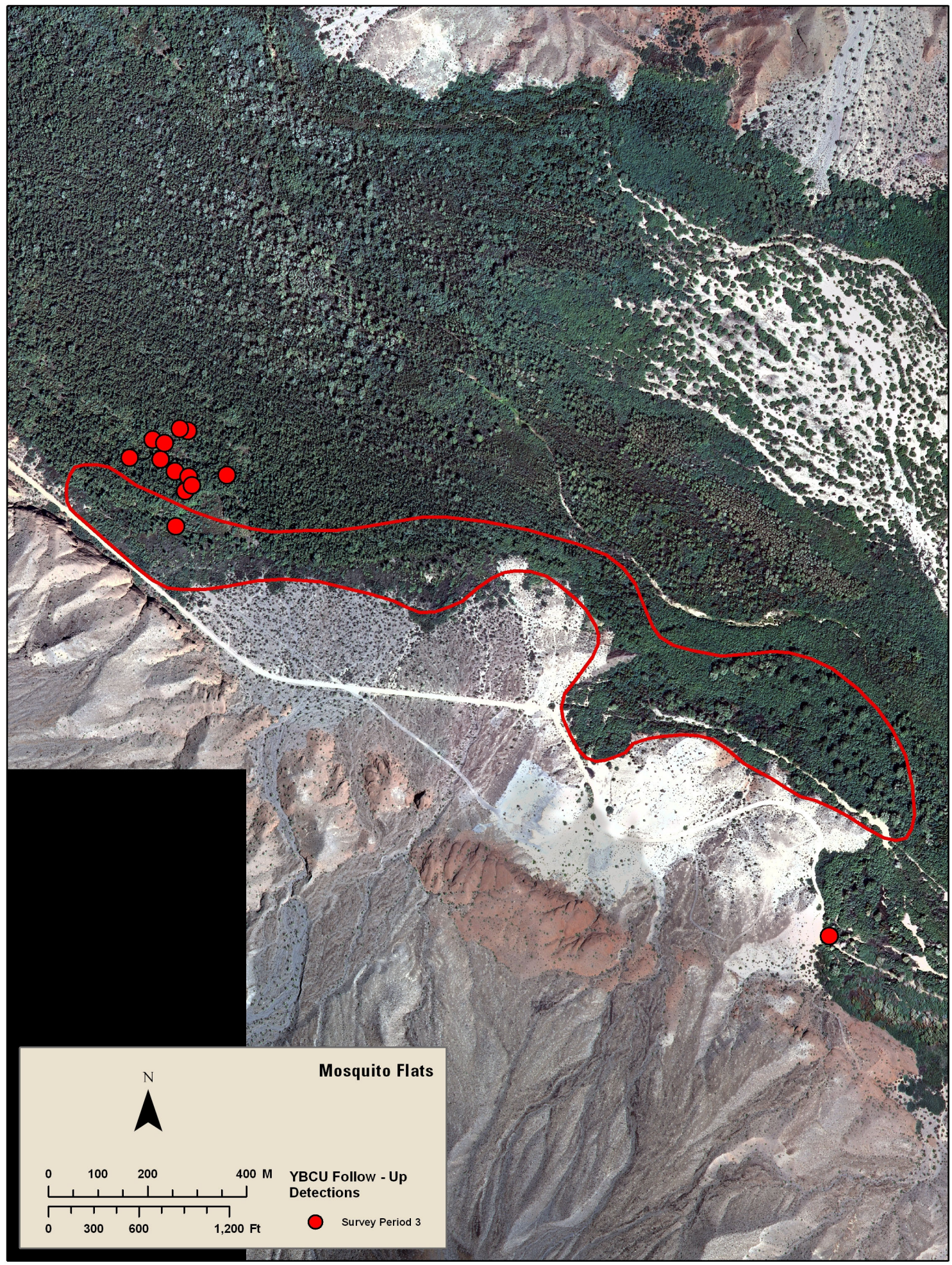


Figure 4-5U. Orthorectified aerial photo display yellow-billed cuckoo survey points and detection locations at Bill Williams National Wildlife Refuge, AZ, Saguaro Slot, 2007. Red boundary line represents yellow-billed cuckoo survey habitat patch.

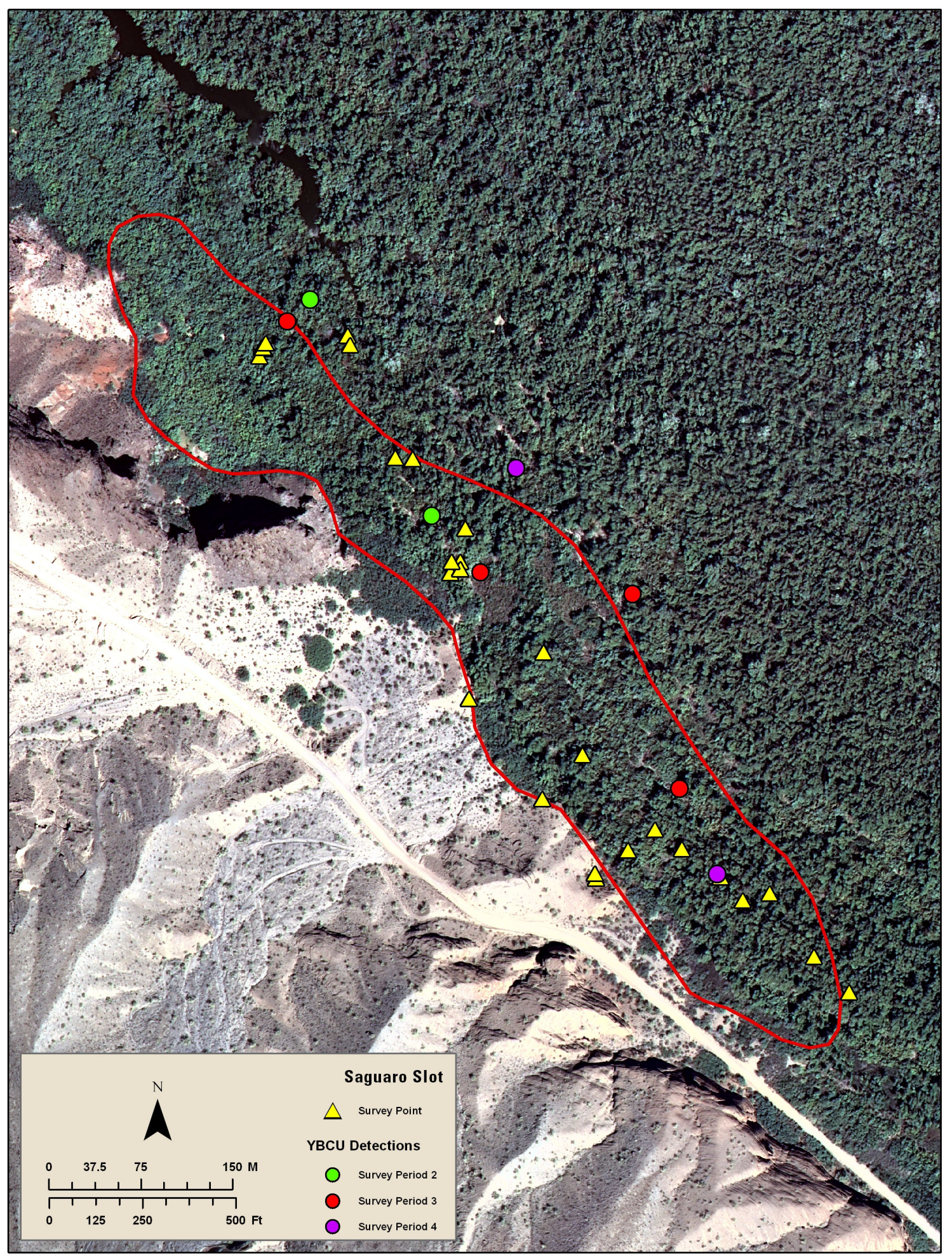


Figure 4-5V. Orthorectified aerial photo display yellow-billed cuckoo follow-up survey detection locations at Bill Williams National Wildlife Refuge, AZ, Saguaro Slot, 2007.

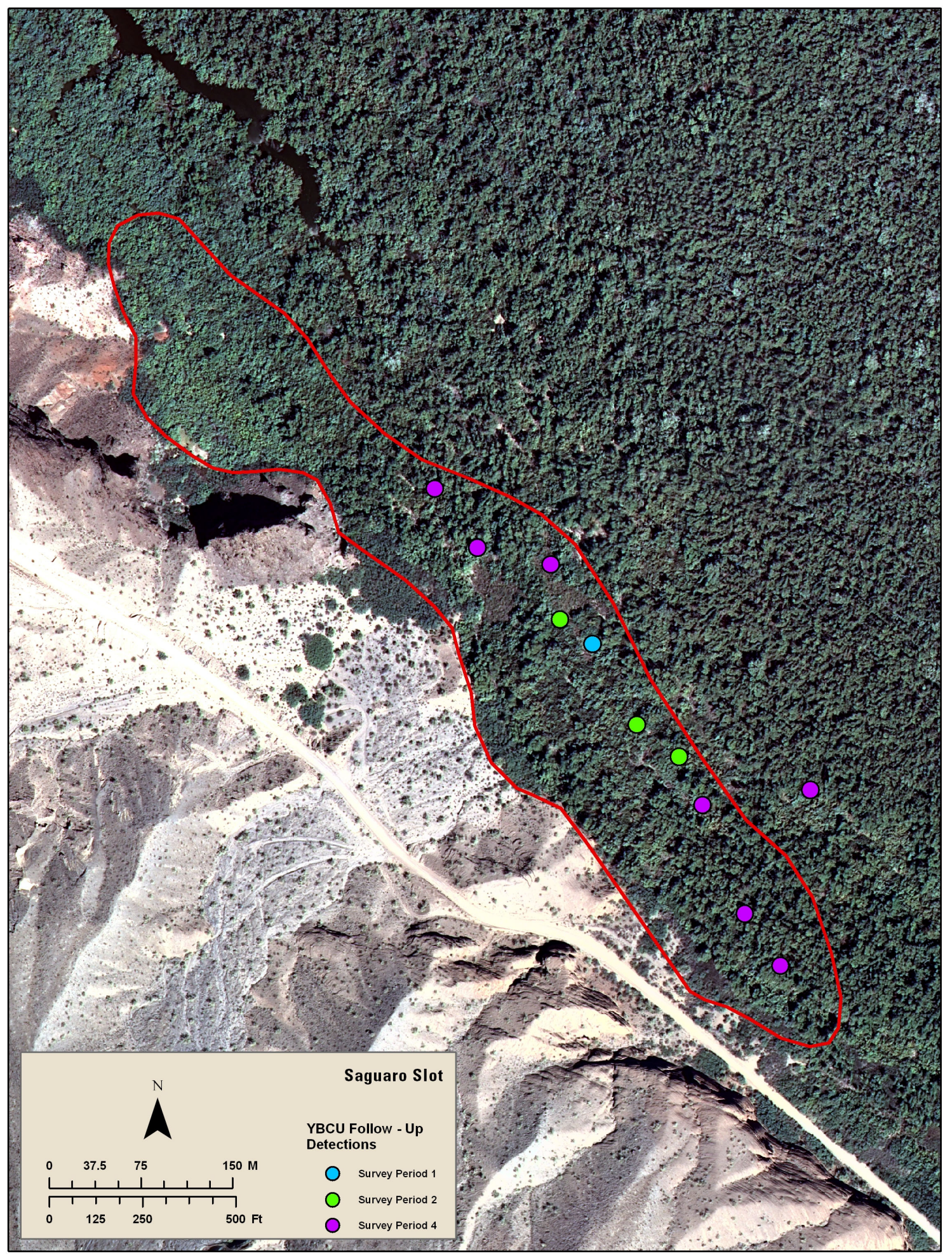


Figure 4-5W. Orthorectified aerial photo display yellow-billed cuckoo survey points and detection locations at Bill Williams National Wildlife Refuge, AZ, North Burn, 2007.

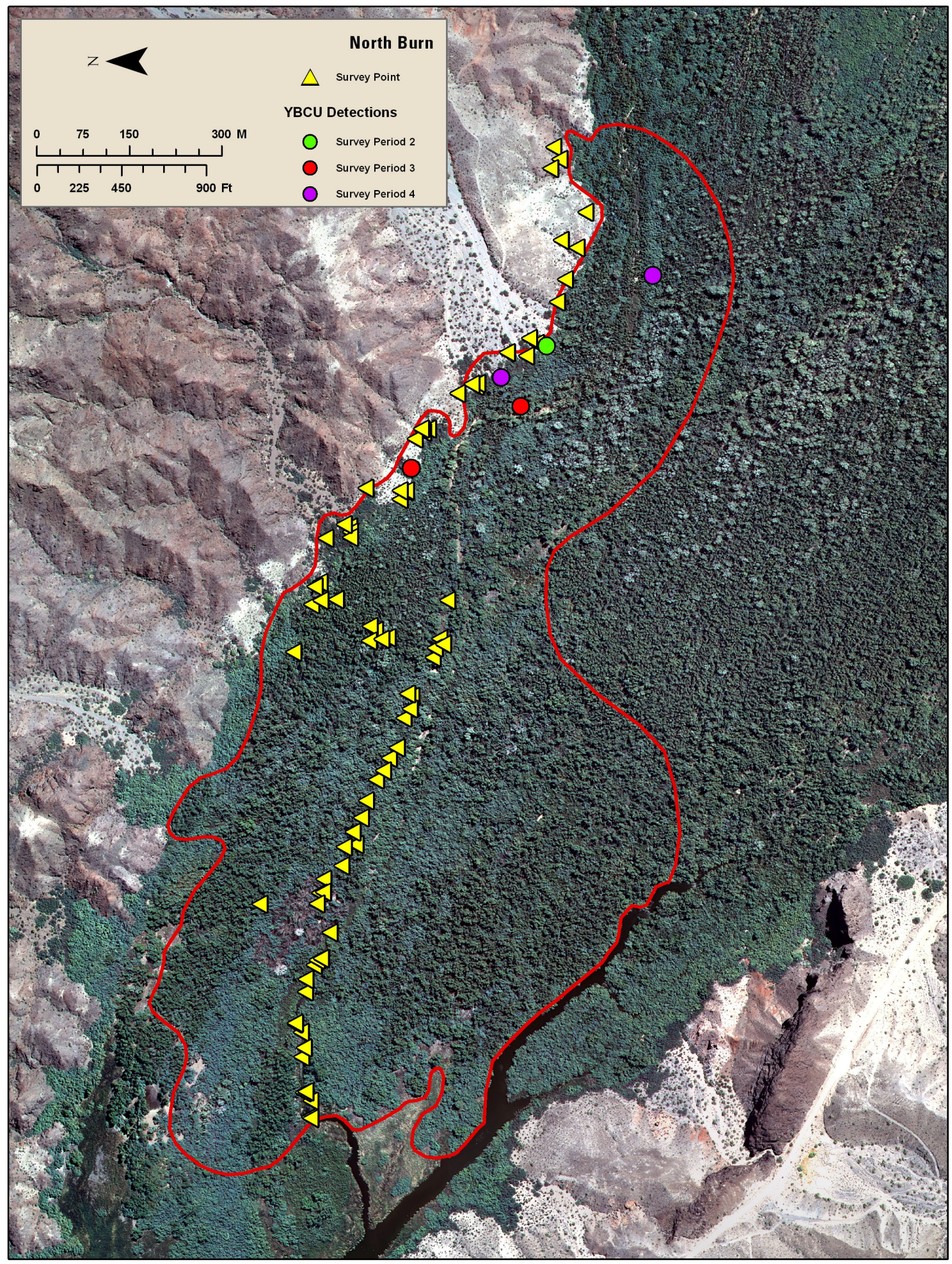


Figure 4-5X. Orthorectified aerial photo display yellow-billed cuckoo survey points and detection locations at Bill Williams National Wildlife Refuge, AZ, Bill Williams River Marsh, 2007. Red boundary line represents yellow-billed cuckoo survey habitat patch.

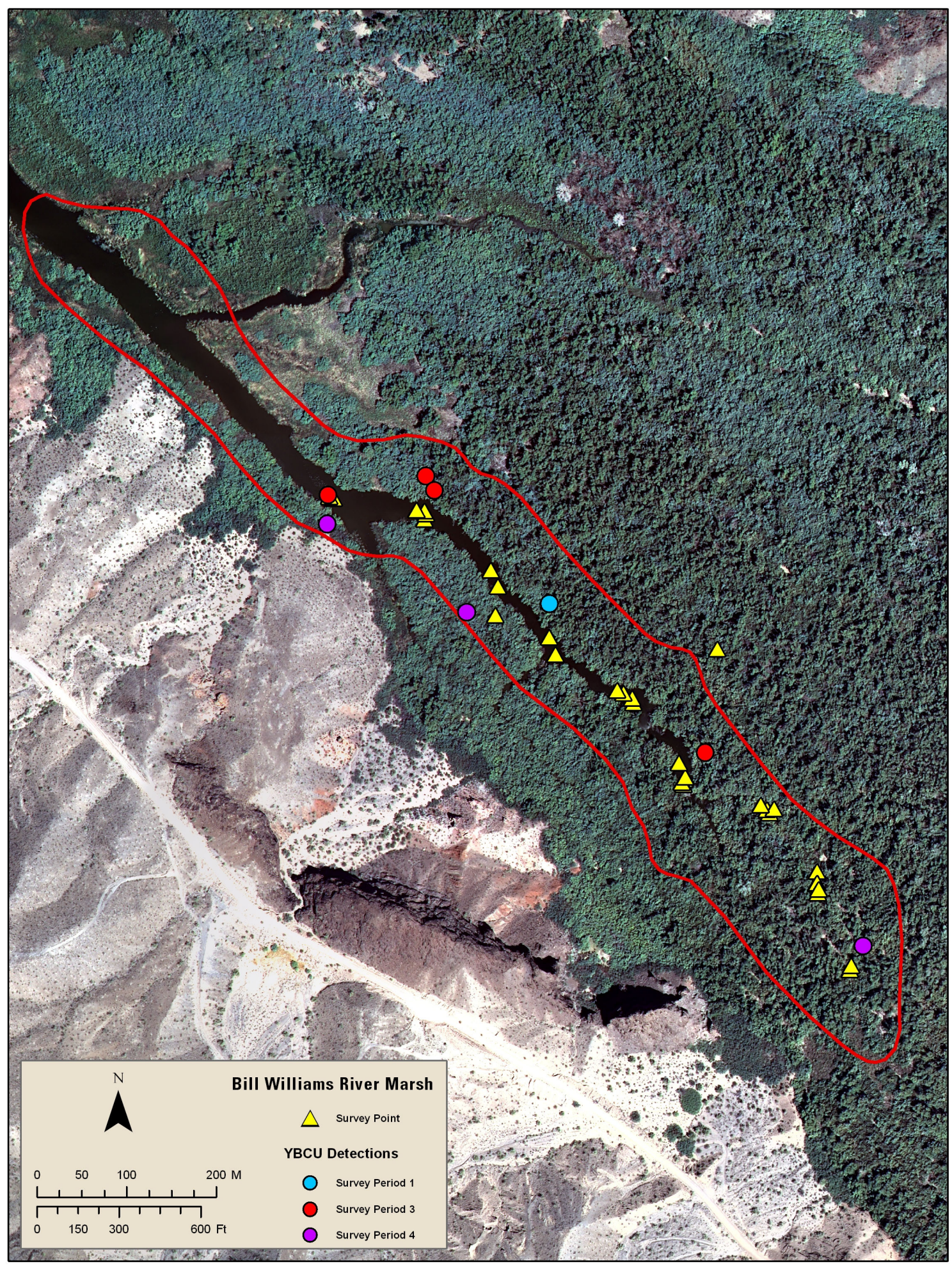


Figure 4-5Y. Orthorectified aerial photo display yellow-billed cuckoo follow-up survey detection locations at Bill Williams National Wildlife Refuge, AZ, Bill Williams River Marsh, 2007.

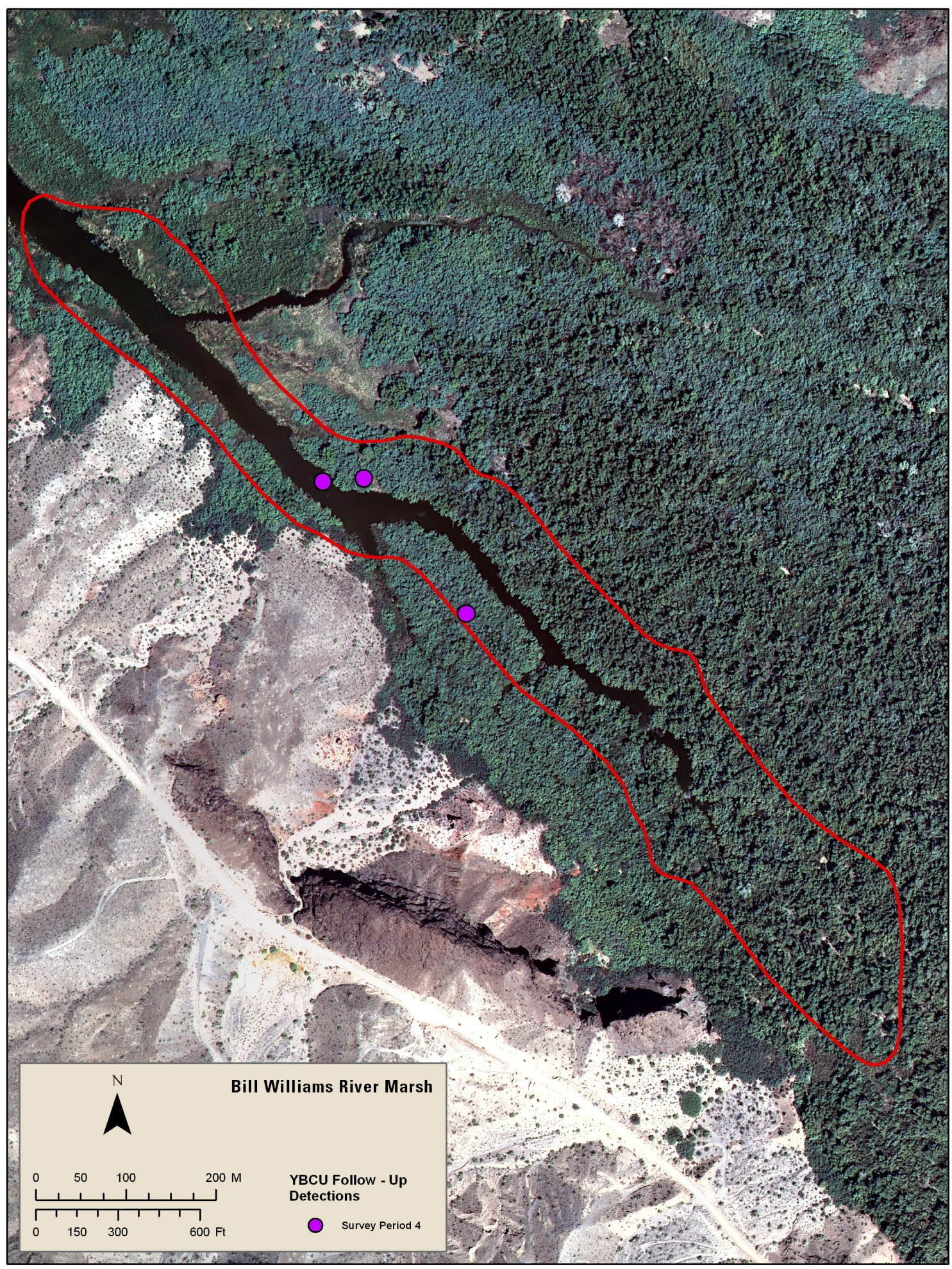


Figure 4-6A. Orthorectified aerial photo display Ahakhav Tribal Preserve area, AZ yellow-billed cuckoo survey, 2007.

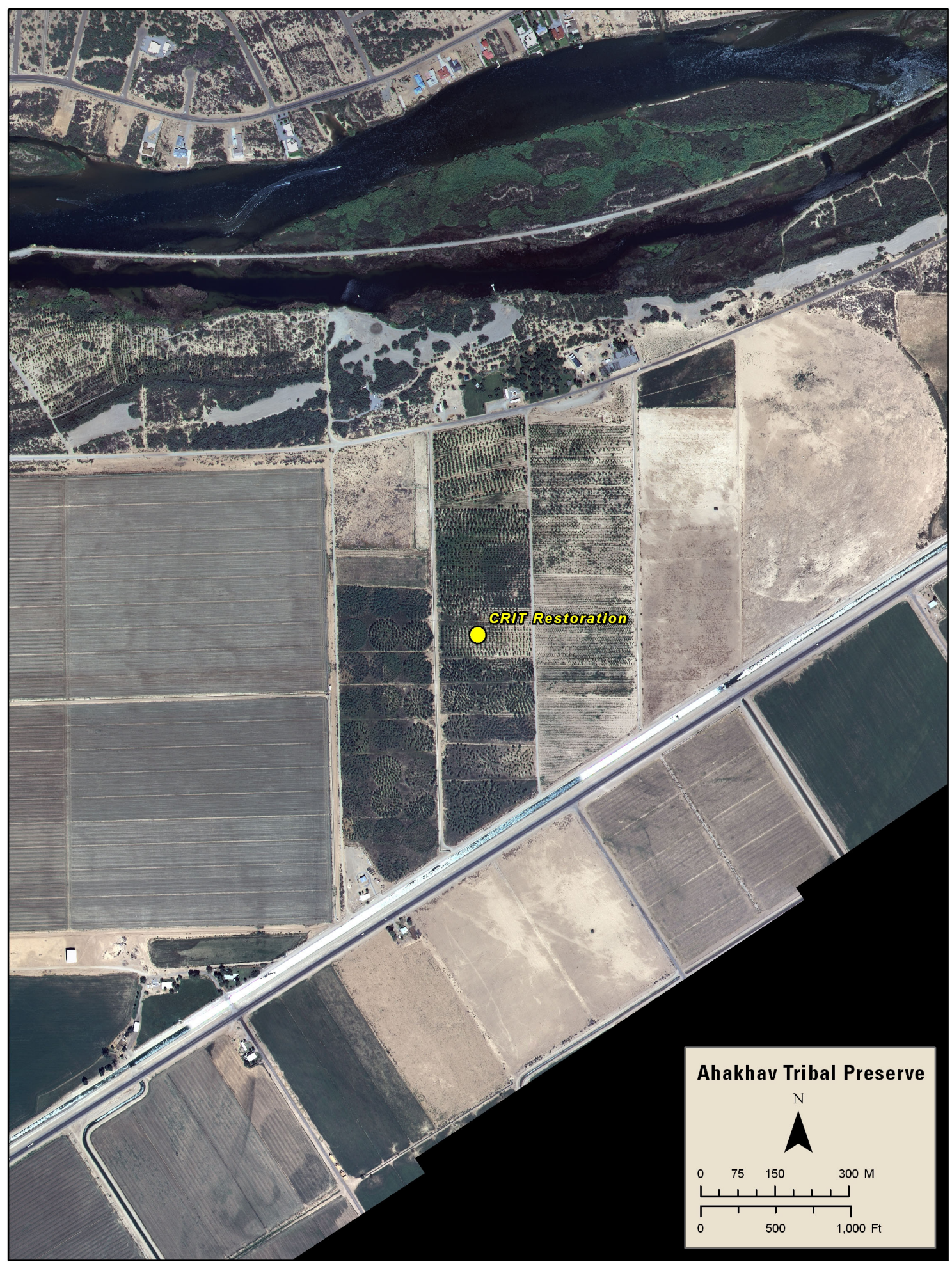


Figure 4-6B. Orthorectified aerial photo display yellow-billed cuckoo survey points at Ahakhav Tribal Preserve, AZ, 2007.

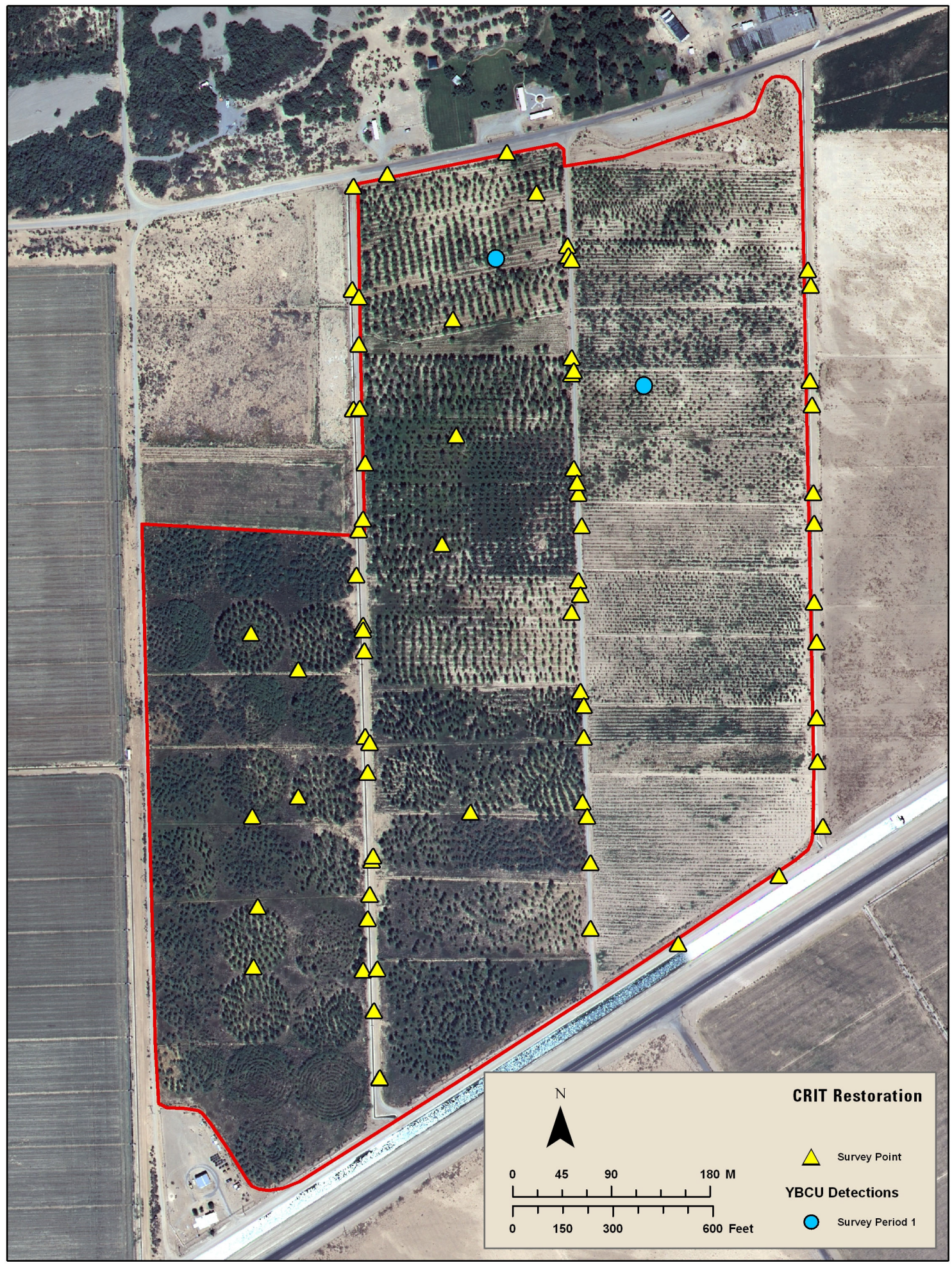


Figure 4-7A. Orhorectified aerial photo display Cibola National Wildlife Refuge area, AZ, yellow-billed cuckoo survey, 2006.

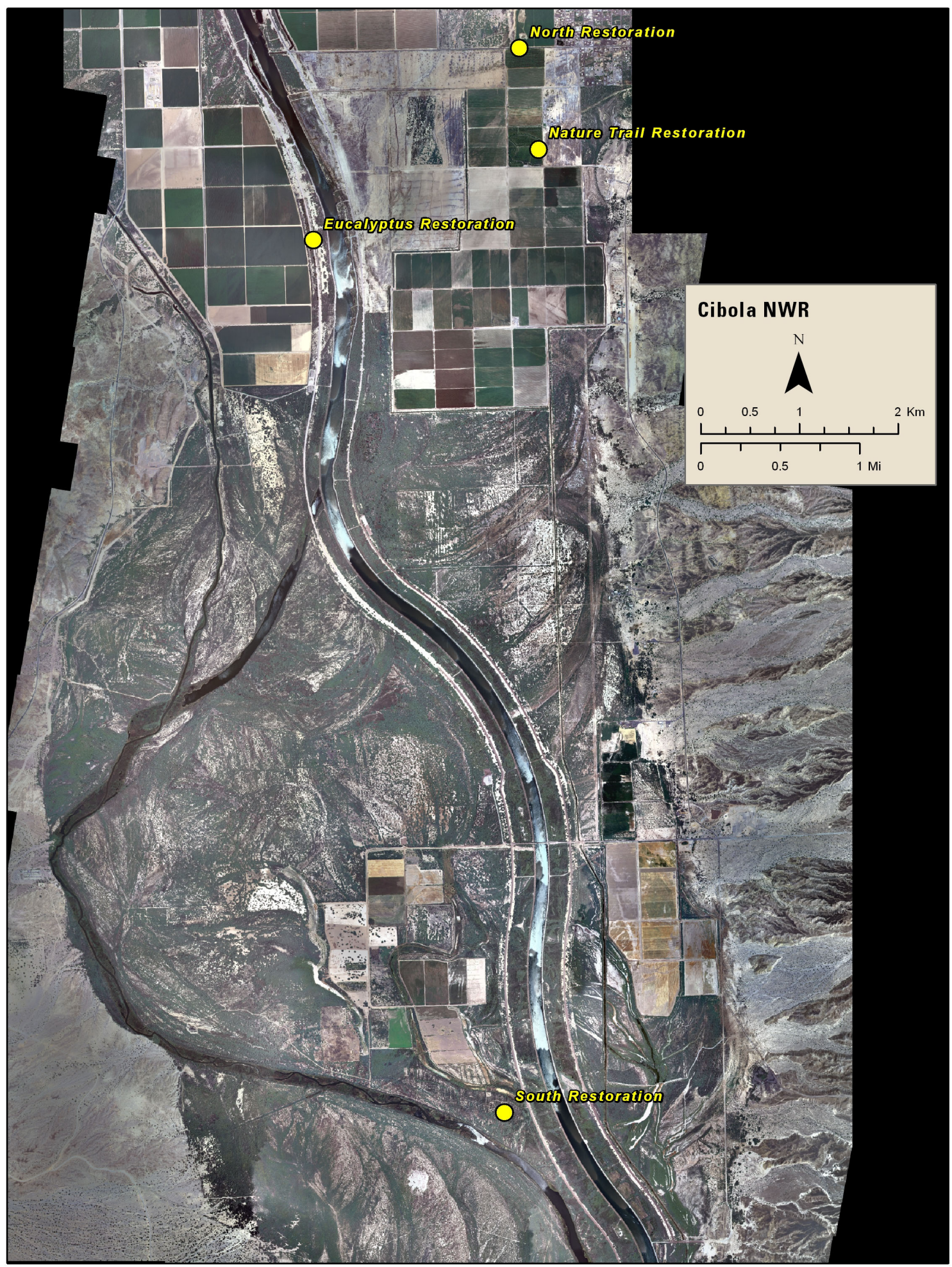


Figure 4-7B. Orthorectified aerial photo display yellow-billed cuckoo survey points and detection locations at Cibola National Wildlife Refuge area, AZ, Cibola North Restoration, 2007. Red boundary line represents yellow-billed cuckoo survey habitat patch.

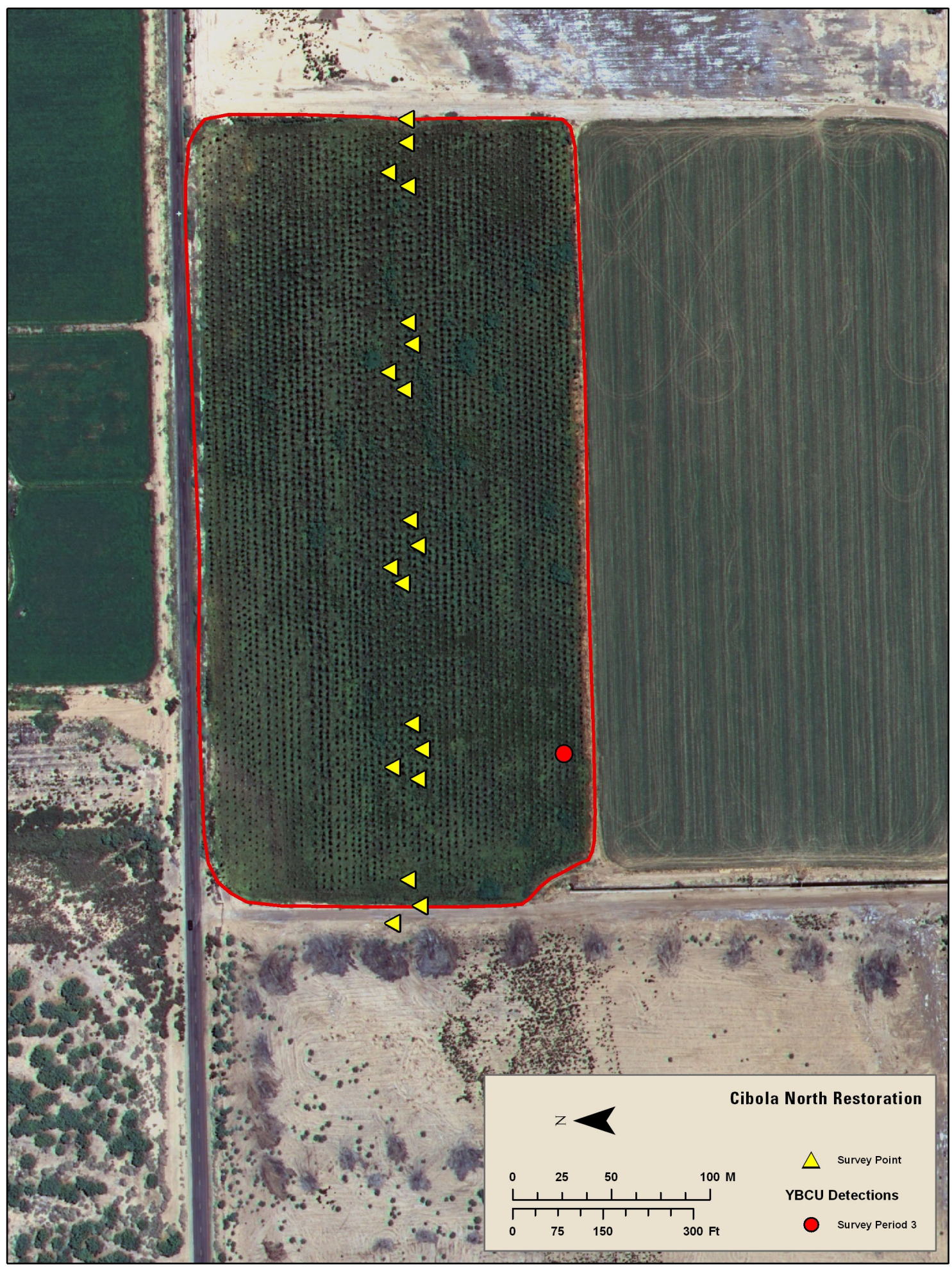


Figure 4-7C. Orthorectified aerial photo display yellow-billed cuckoo survey points and detection locations at Cibola National Wildlife Refuge area, AZ, Cibola Nature Trail Restoration, 2007. Red boundary line represents yellow-billed cuckoo survey habitat patch.

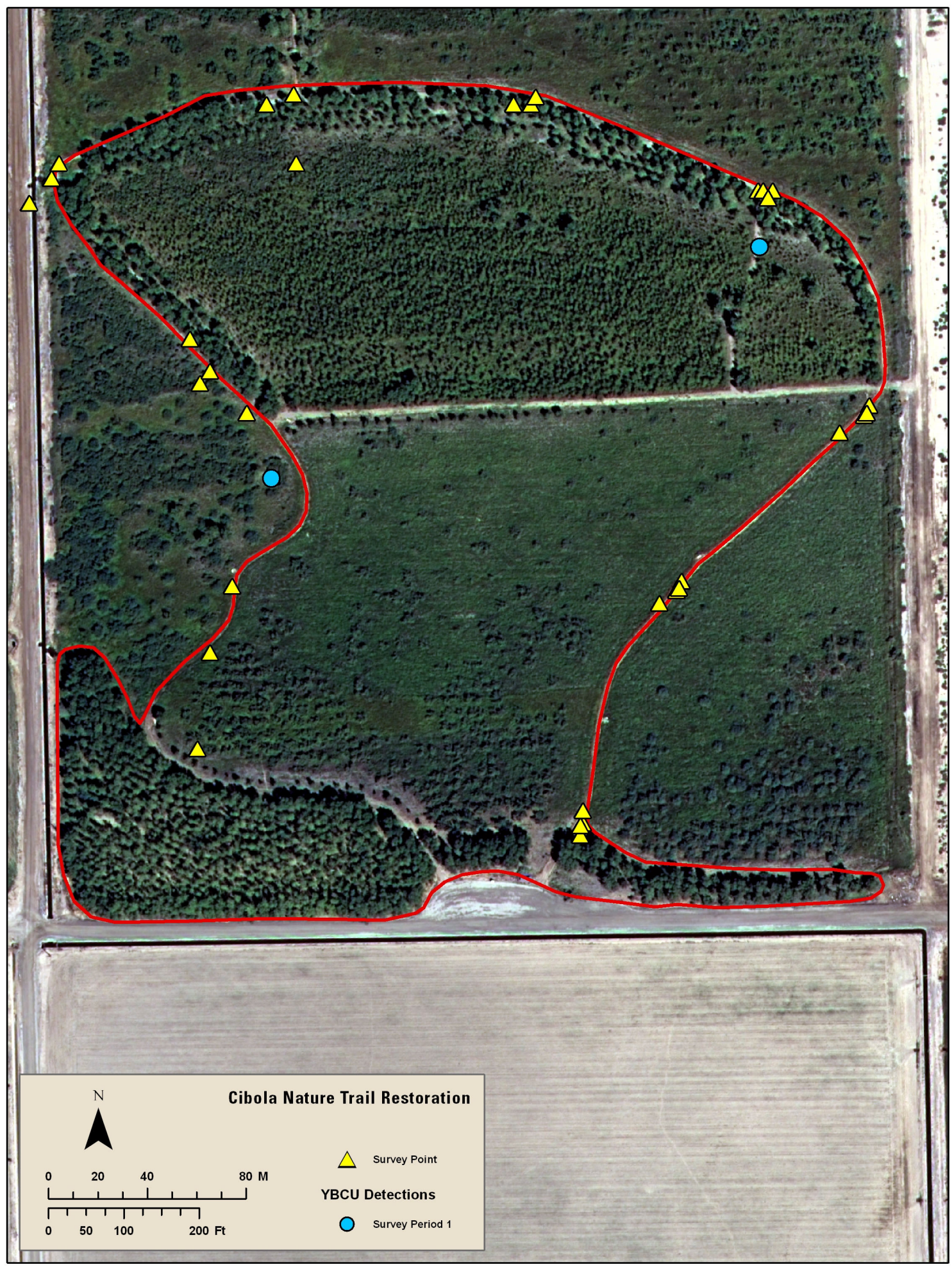


Figure 4-7D. Orthorectified aerial photo display yellow-billed cuckoo survey points and detection locations at Cibola National Wildlife Refuge area, AZ, Cibola Eucalyptus Restoration, 2007. Red boundary line represents yellow-billed cuckoo survey habitat patch.

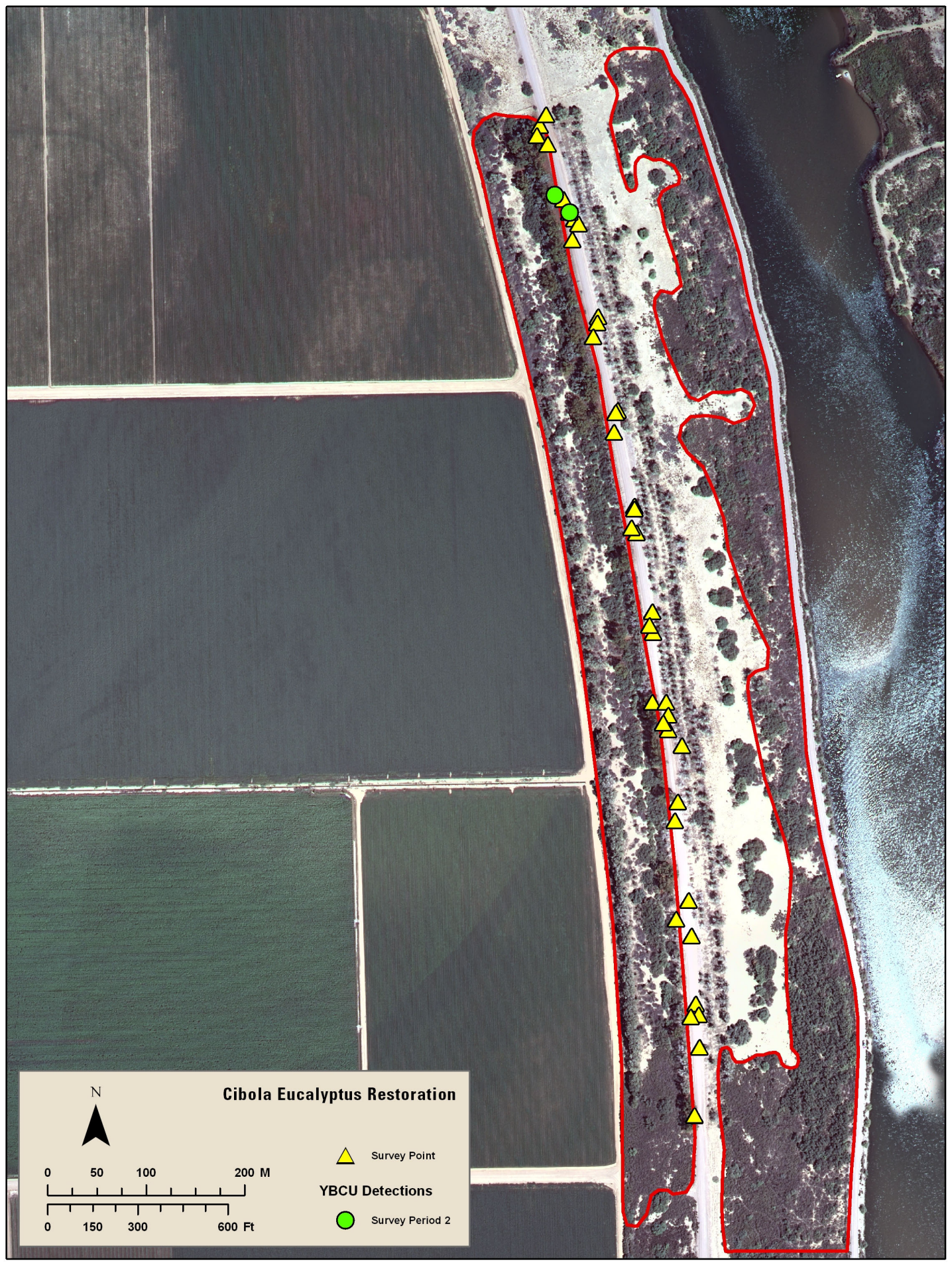


Figure 4-7E. Orthorectified aerial photo display yellow-billed cuckoo survey points and detection location at Cibola National Wildlife Refuge area, AZ, Cibola South Restoration, 2007. Red boundary line represents yellow-billed cuckoo survey habitat patch.

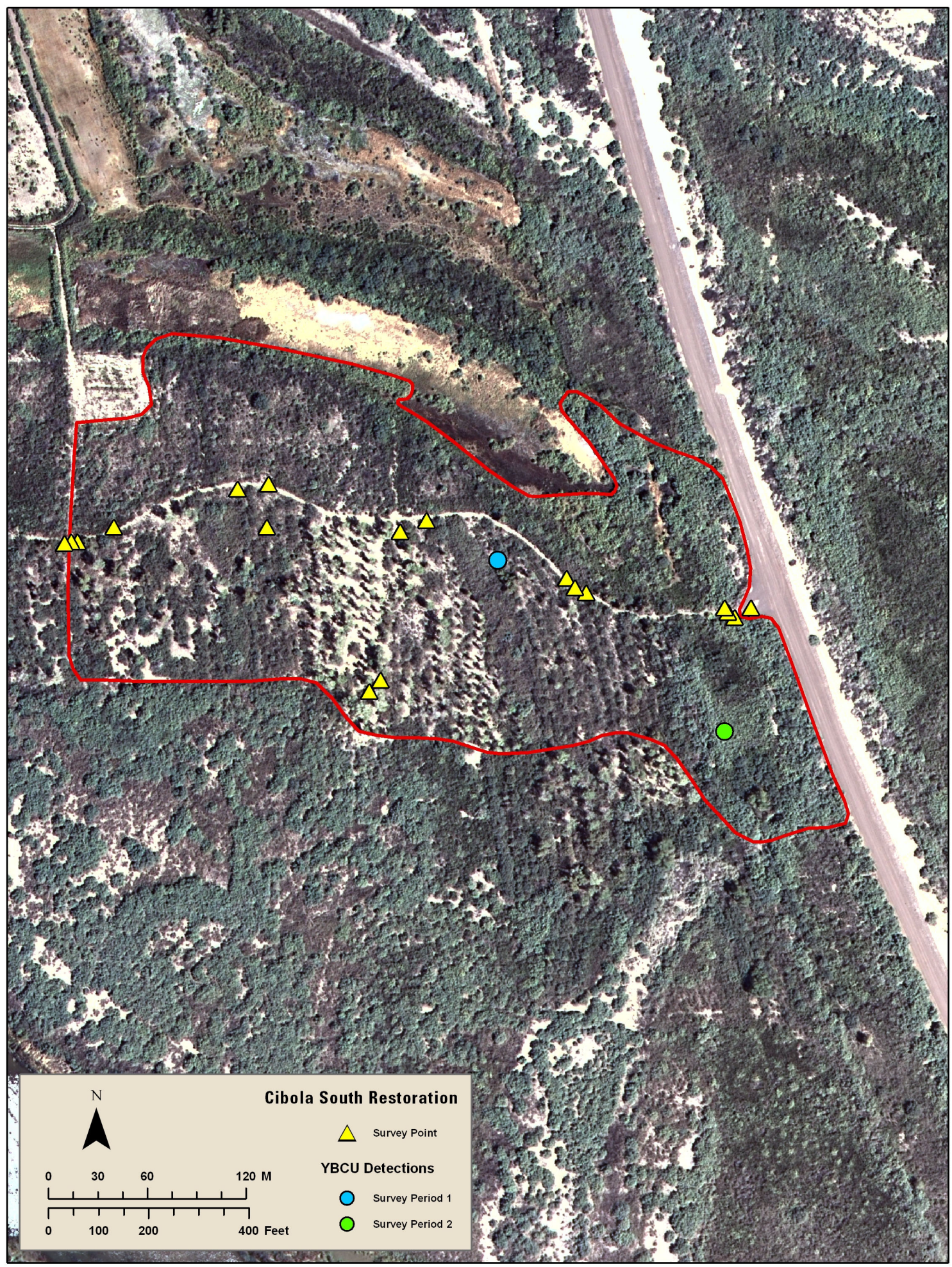


Figure 4-8A. Orthorectified aerial photo display Picacho SRA, CA, yellow-billed cuckoo survey, 2007.

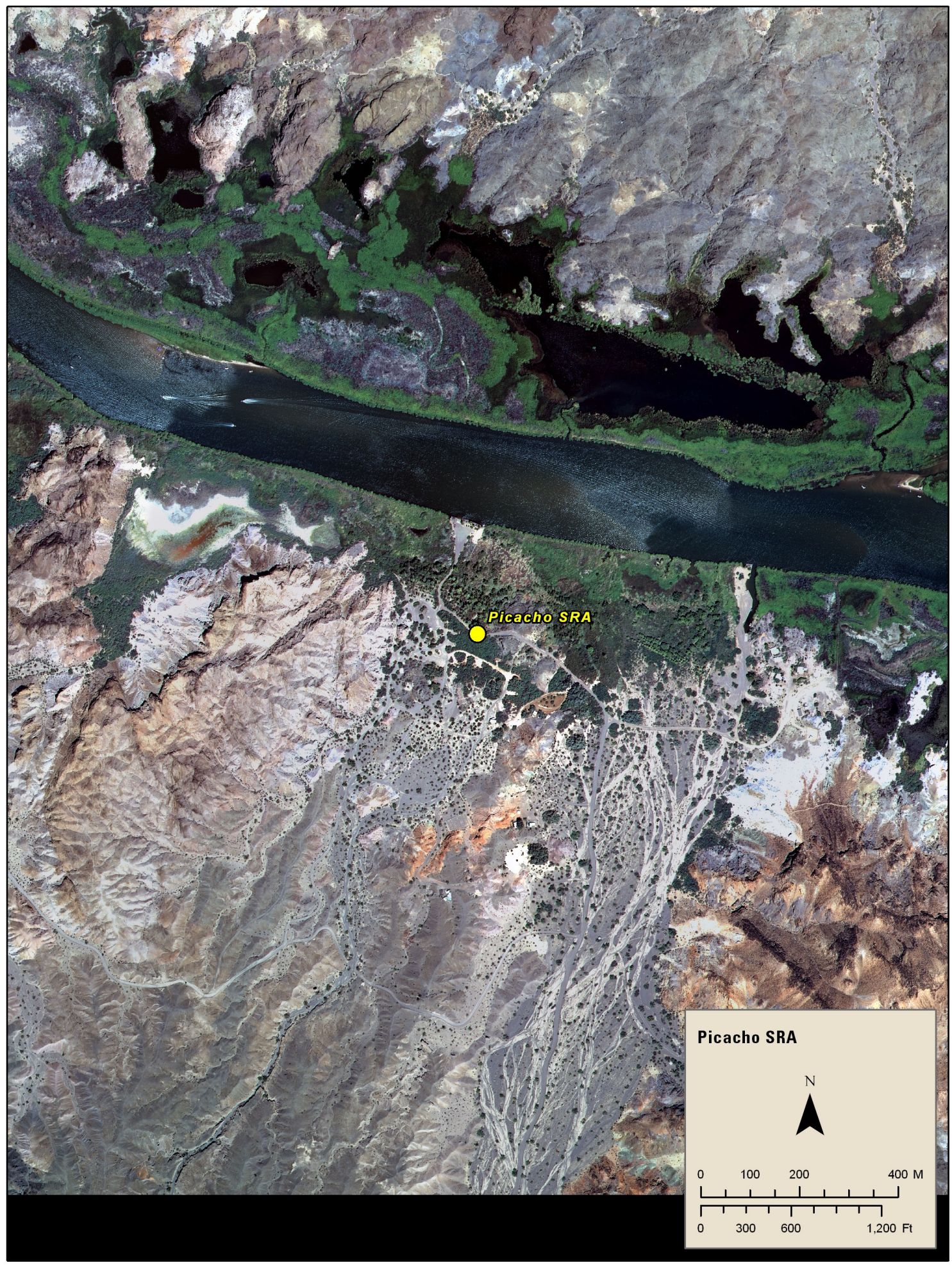


Figure 4-8B. Orthorectified aerial photo display yellow-billed cuckoo survey points at Picacho SRA, CA along the lower Colorado River, CA, 2007. No cuckoos were detected at this site in 2007. Red boundary line represents yellow-billed cuckoo survey habitat patch.

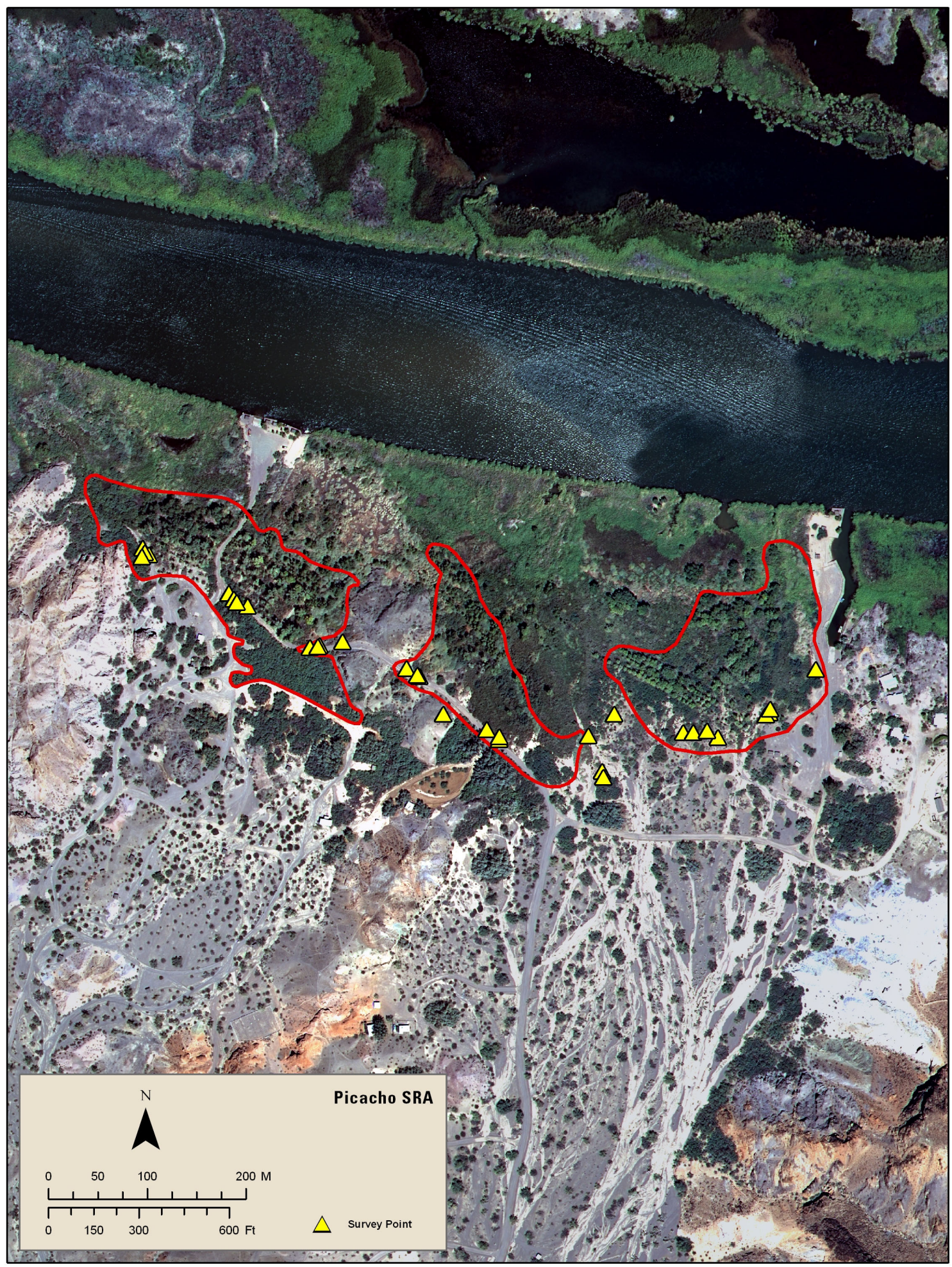


Figure 4-9A. Orthorectified aerial photo display Imperial National Wildlife Refuge, AZ yellow-billed cuckoo survey area, 2007.

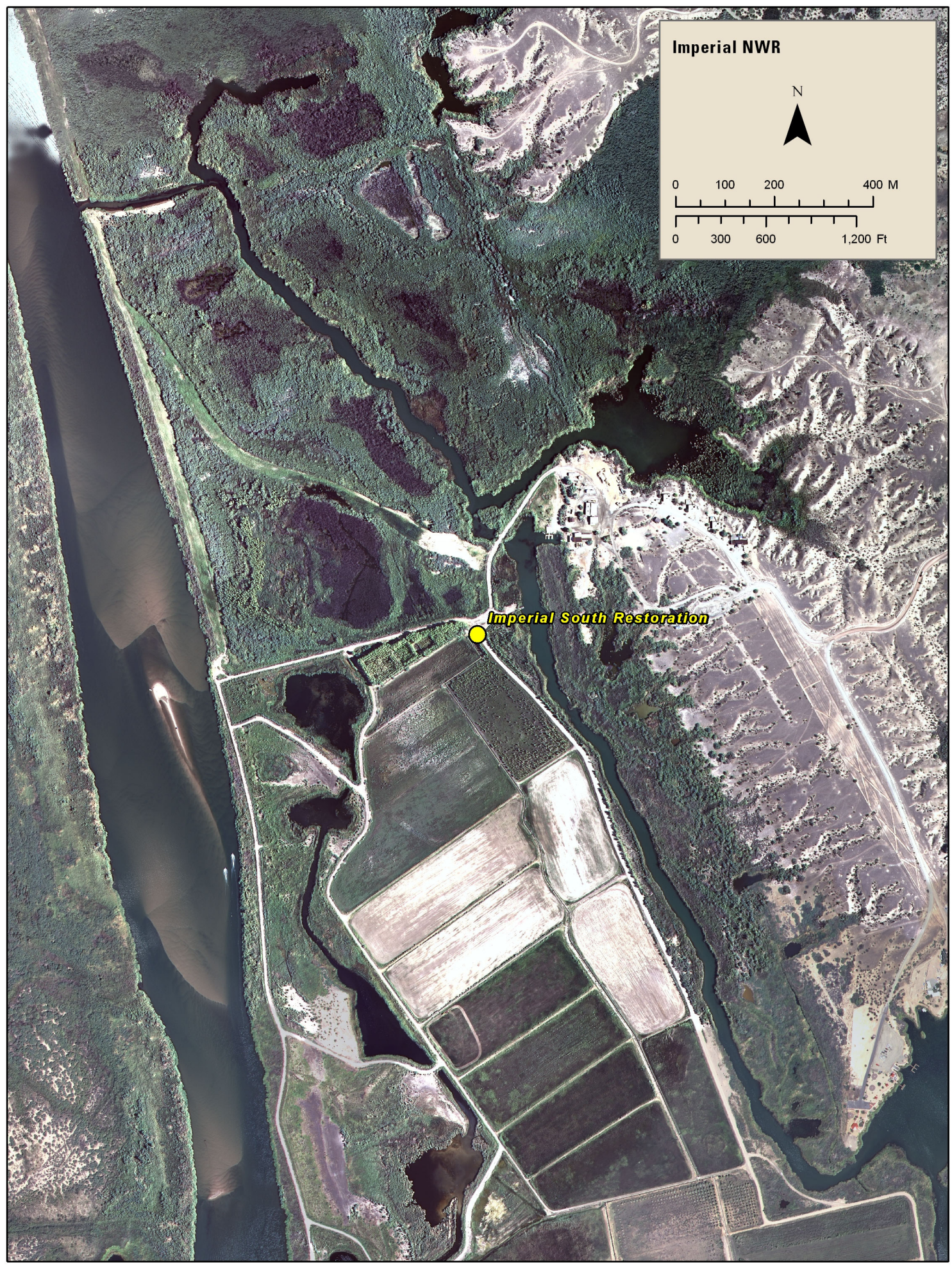


Figure 4-9B. Orthorectified aerial photo display yellow-billed cuckoo survey points and detection locations at Imperial National Wildlife Refuge, AZ, Imperial South Restoration, 2007. Red boundary line represents yellow-billed cuckoo survey habitat patch.

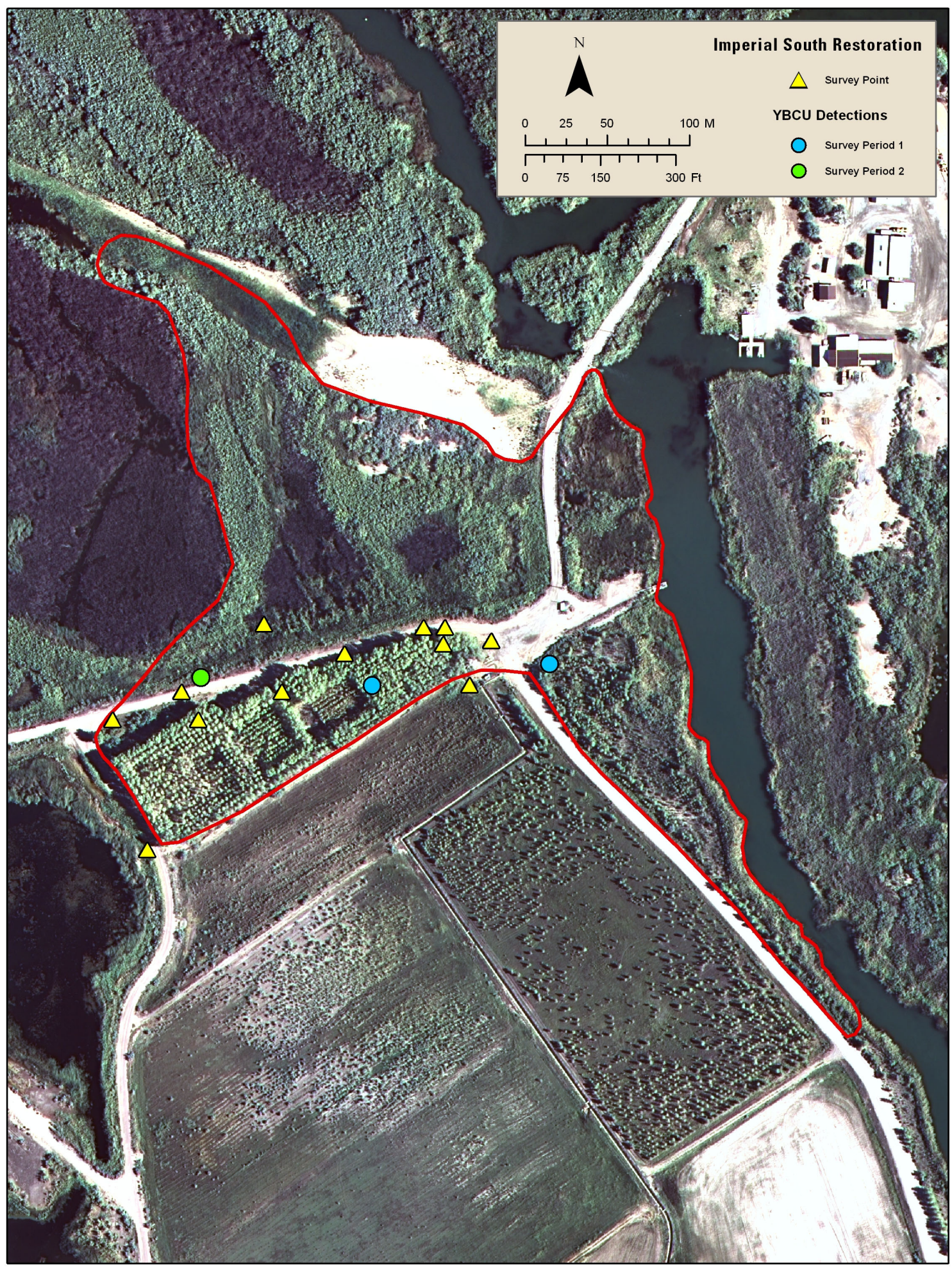


Figure 4-10A. Orthorectified aerial photo display Mittry Lake WMA/Pratt Restoration, AZ yellow-billed cuckoo survey area, 2007.

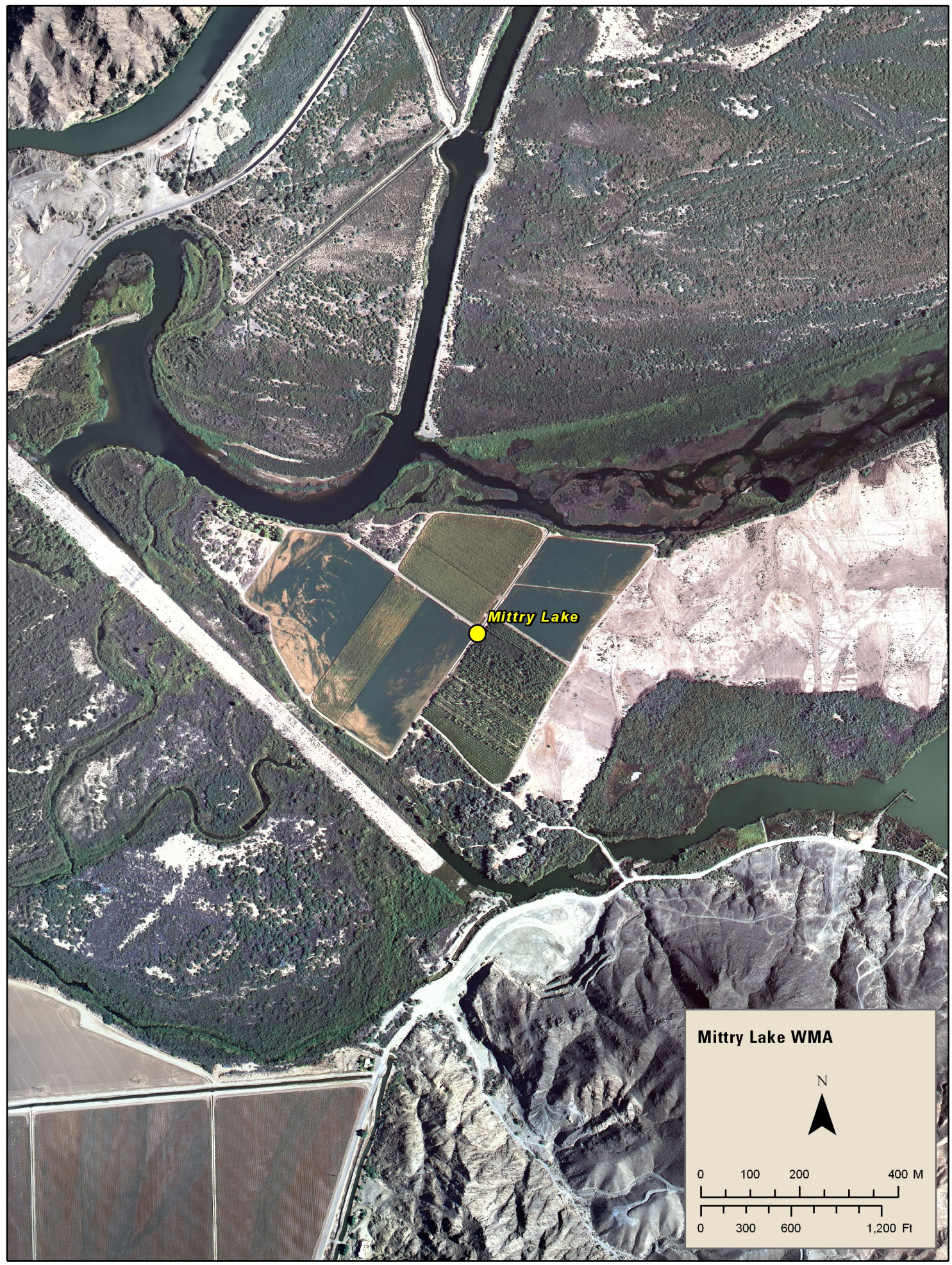


Figure 4-10B. Orthorectified aerial photo display yellow-billed cuckoo survey points at Mittry Lake WMA/Pratt Restoration, AZ, 2006. No cuckoos were detected at this site in 2007. Red boundary line represents yellow-billed cuckoo survey habitat patch.

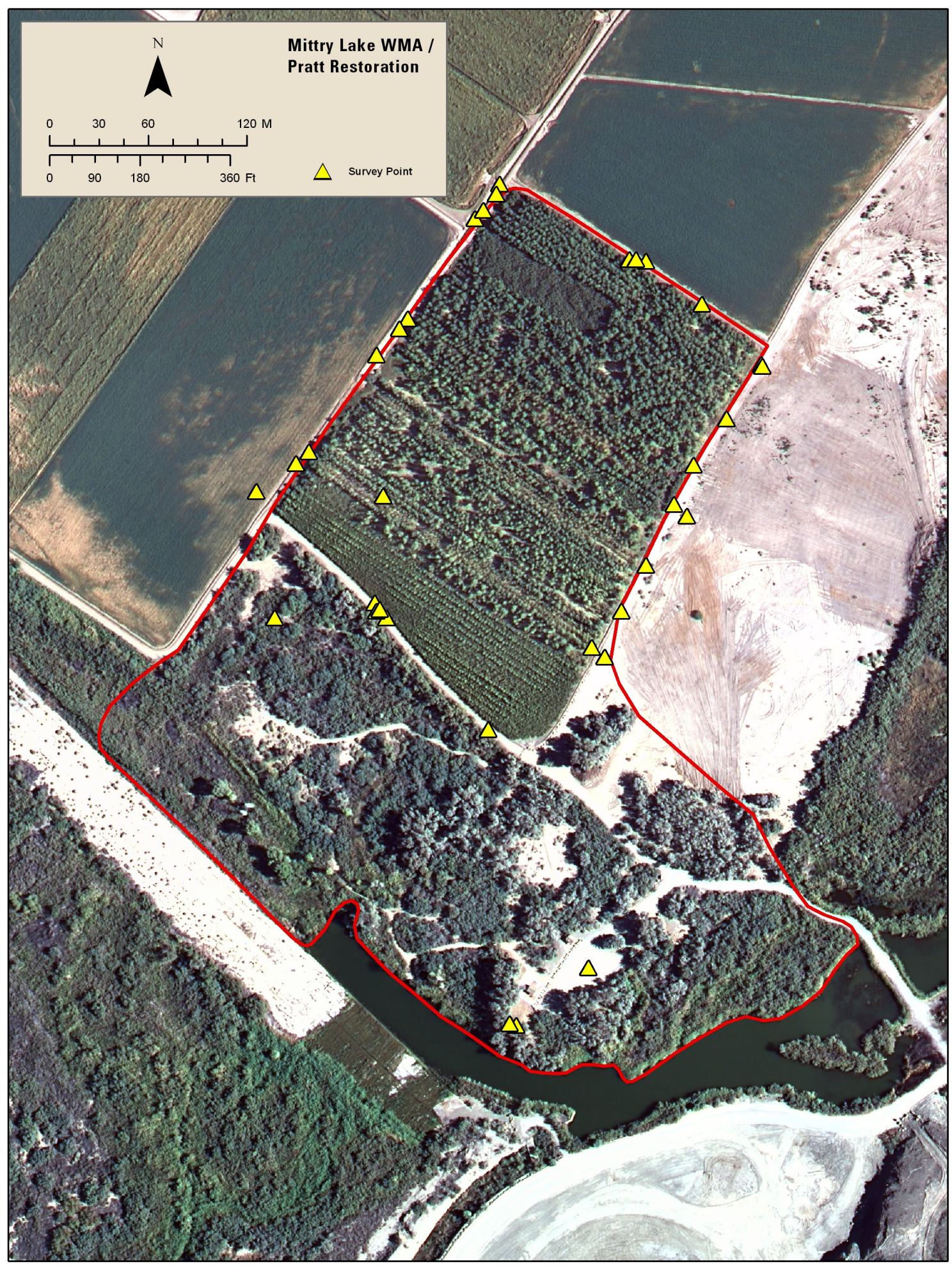


Figure 4-11A. Orthorectified aerial photo display Gila/Colorado River Confluence, AZ yellow-billed cuckoo survey area, 2007.

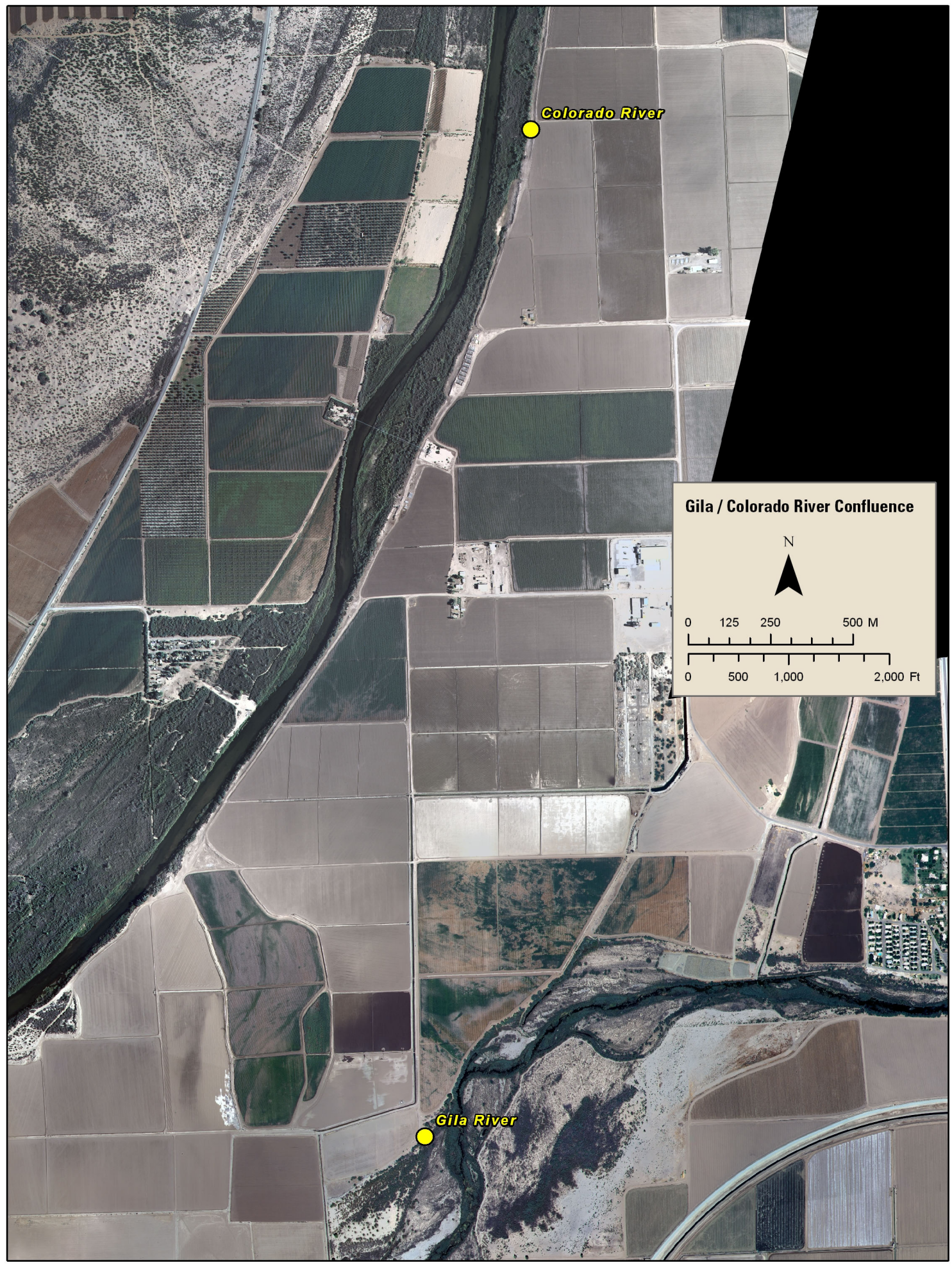


Figure 4-11B. Orthorectified aerial photo display yellow-billed cuckoo survey points and detection locations at Gila/Colorado River Confluence, AZ, Colorado River, 2007. Red boundary line represents yellow-billed cuckoo survey habitat patch.

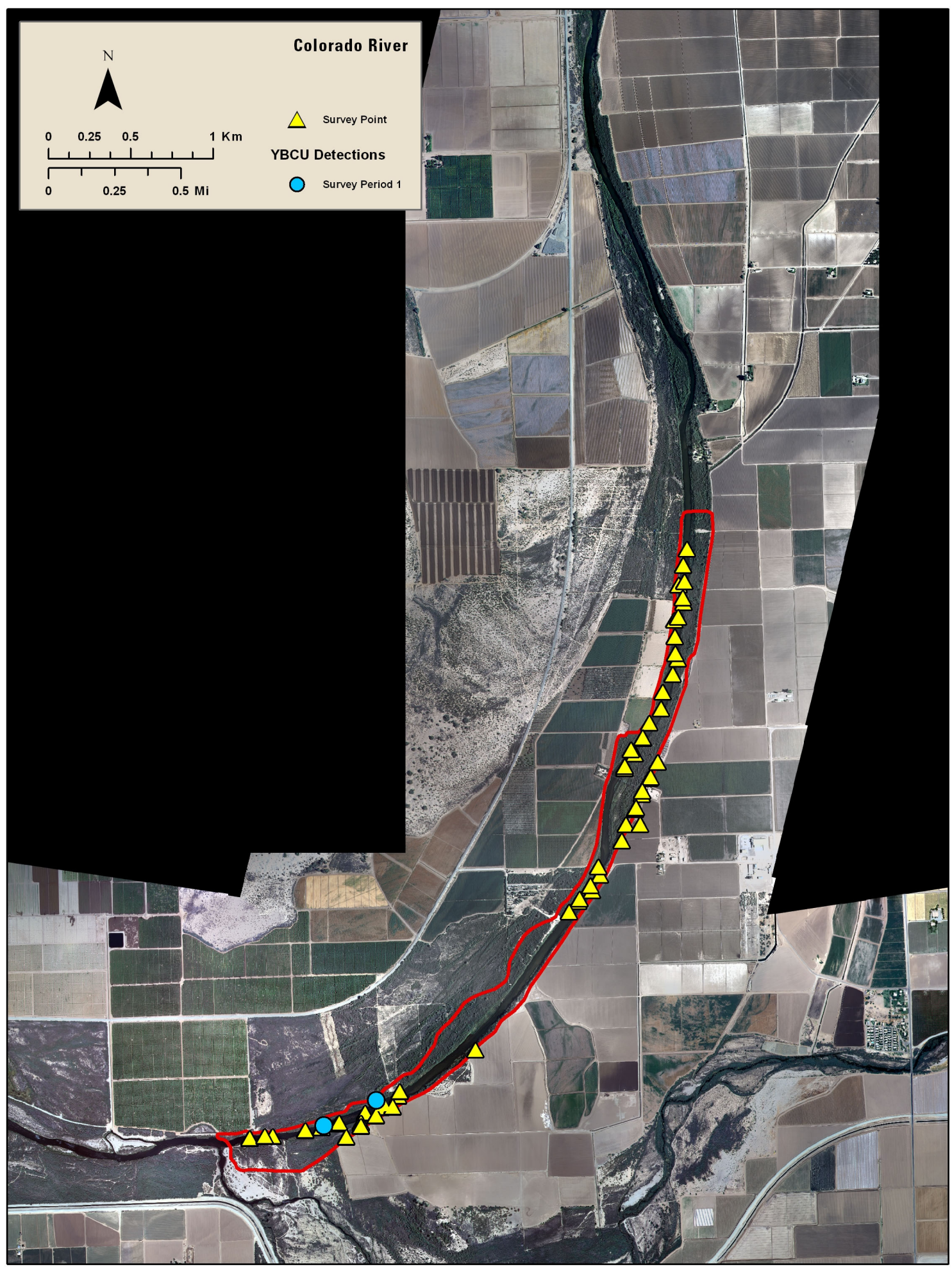


Figure 4-11C. Orthorectified aerial photo display yellow-billed cuckoo survey points at Gila/Colorado River Confluence, AZ, Gila River, 2007. No cuckoos were detected at this site in 2007. Red boundary line represents yellow-billed cuckoo survey habitat patch.

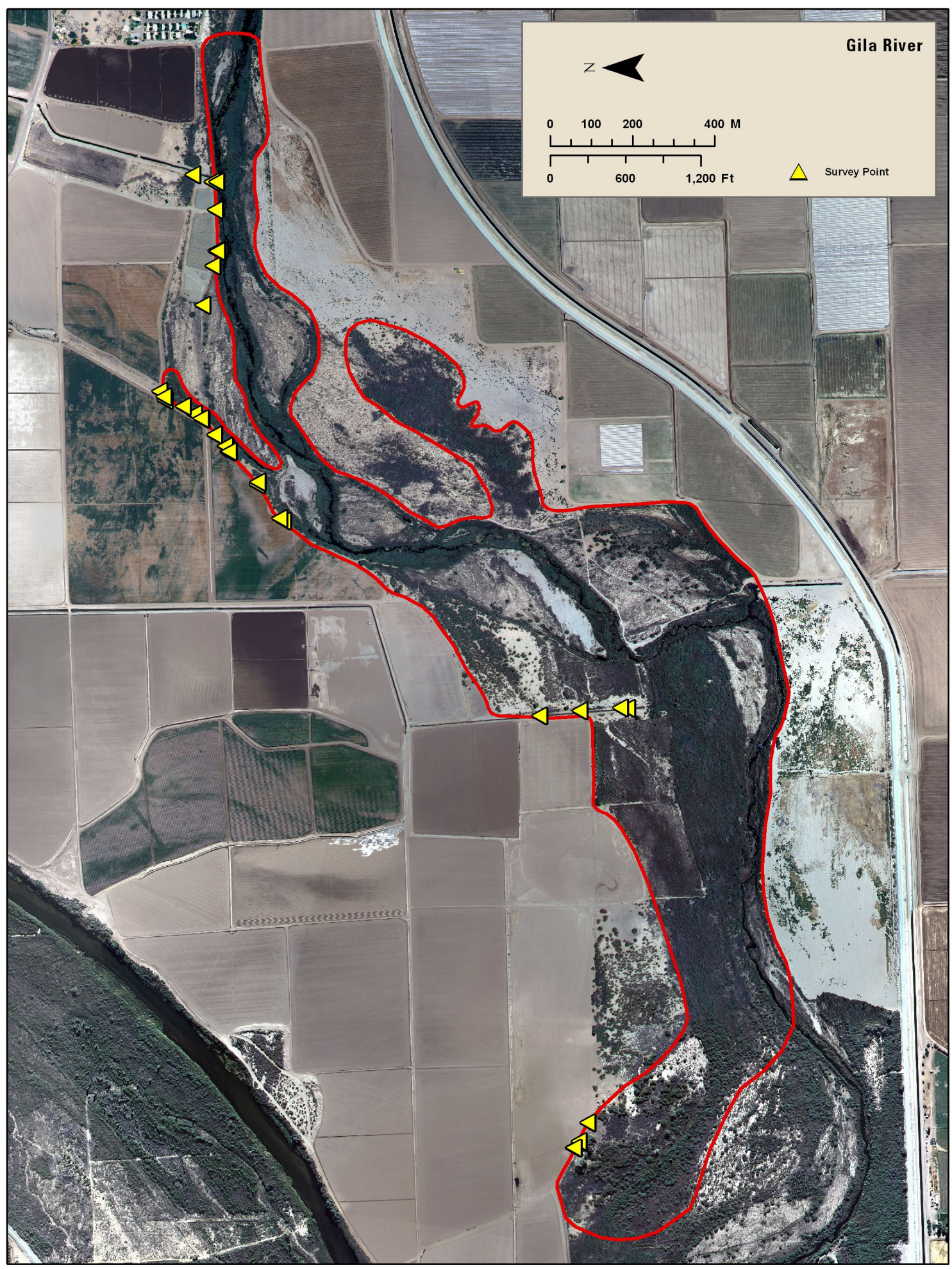


Figure 4-12A. Orthorectified aerial photo display Yuma West Wetlands, AZ, yellow-billed cuckoo survey area, 2006.

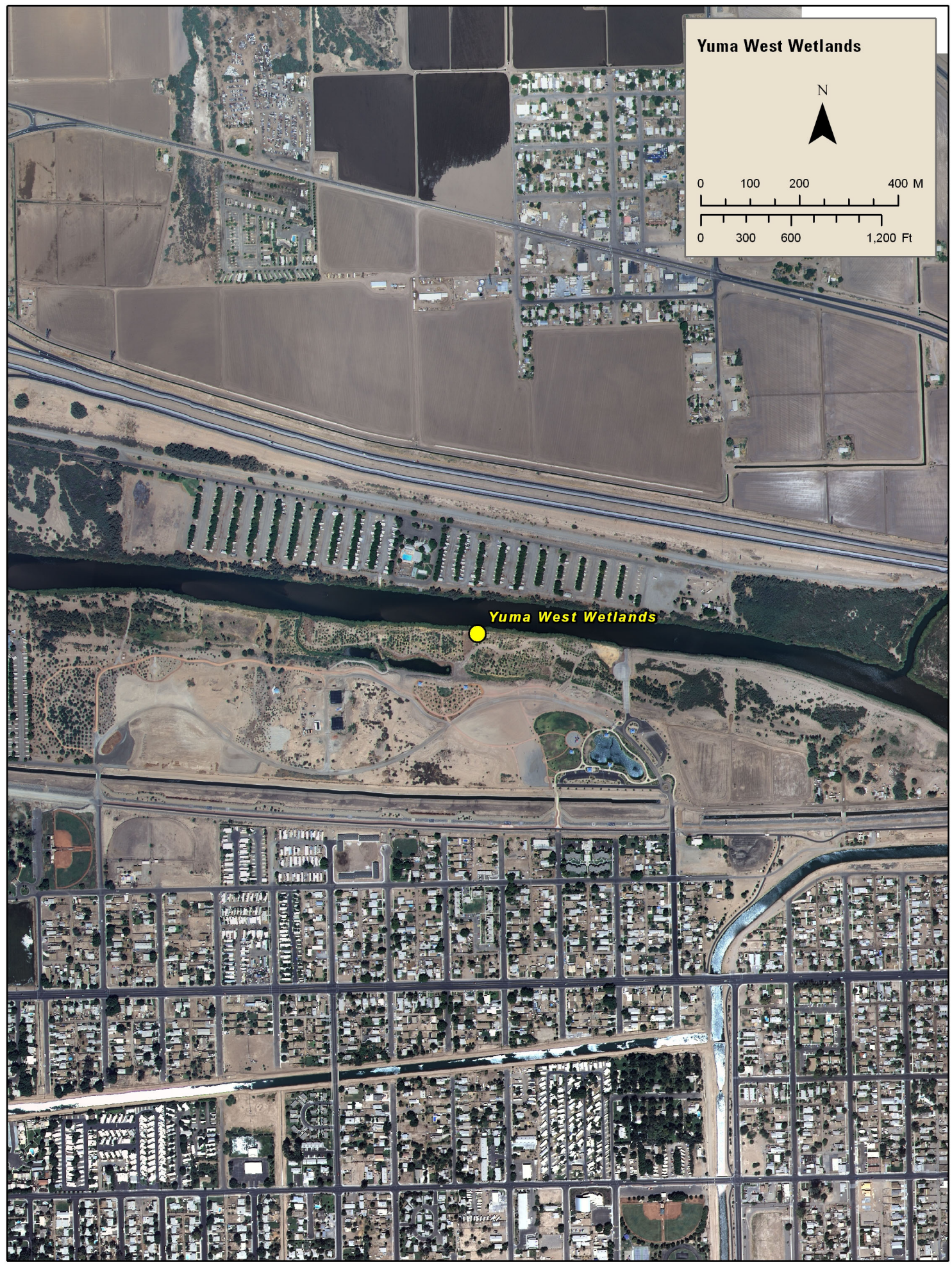


Figure 4-12B. Orthorectified aerial photo display yellow-billed cuckoo survey points at Yuma West Wetlands, AZ, 2007. No cuckoos were detected at this site in 2007. Red boundary line represents yellow-billed cuckoo survey habitat patch.

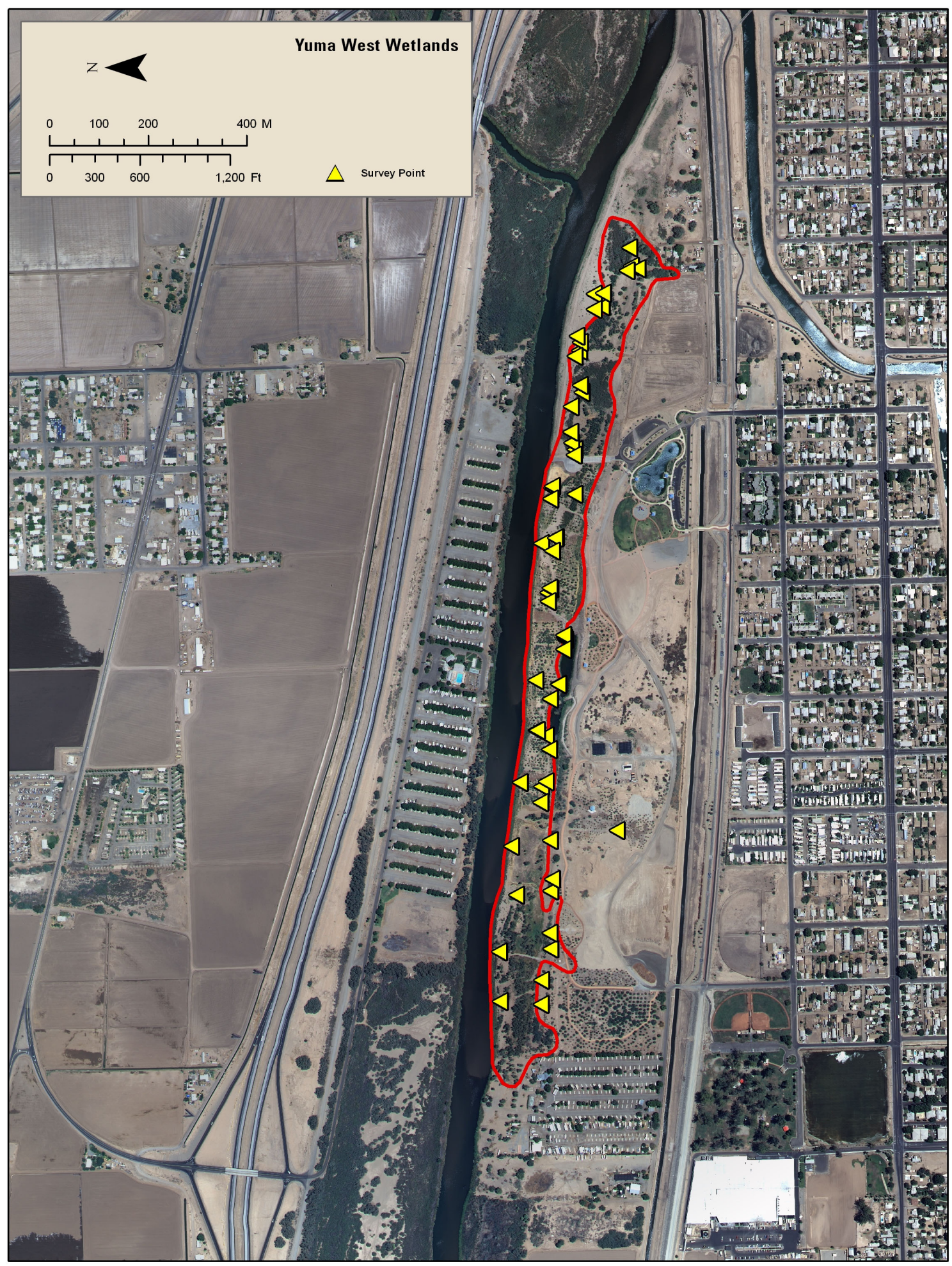


Figure 4-13A. Orthorectified aerial photos display Limitrophe Division, AZ yellow-billed cuckoo survey area, 2007.

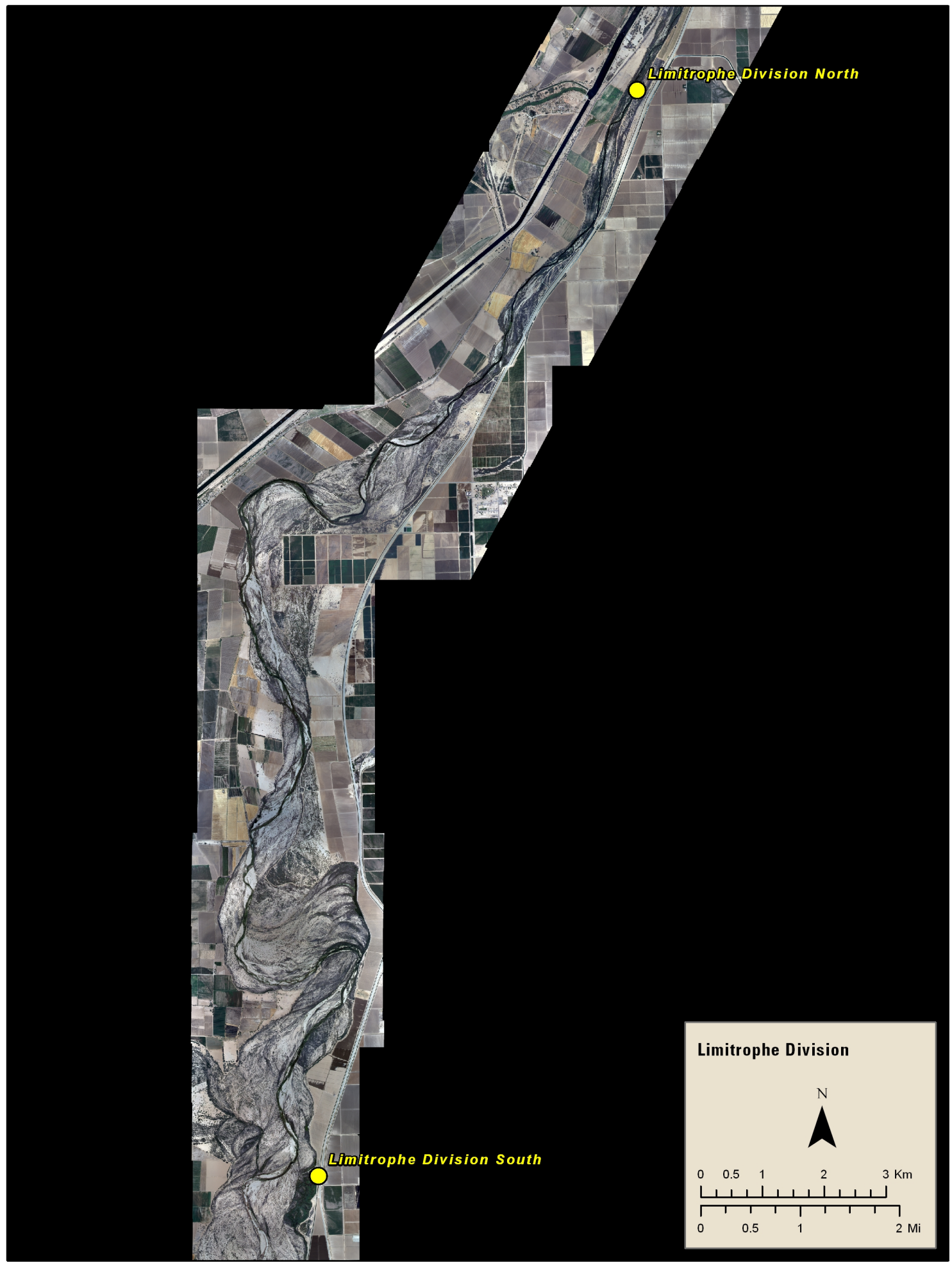


Figure 4-13B. Orthorectified aerial photos display yellow-billed cuckoo survey points at Limitrophe Division, AZ, Limitrophe Division North, 2007. No cuckoos were detected at this site in 2007. Red boundary line represents yellow-billed cuckoo survey habitat patch.

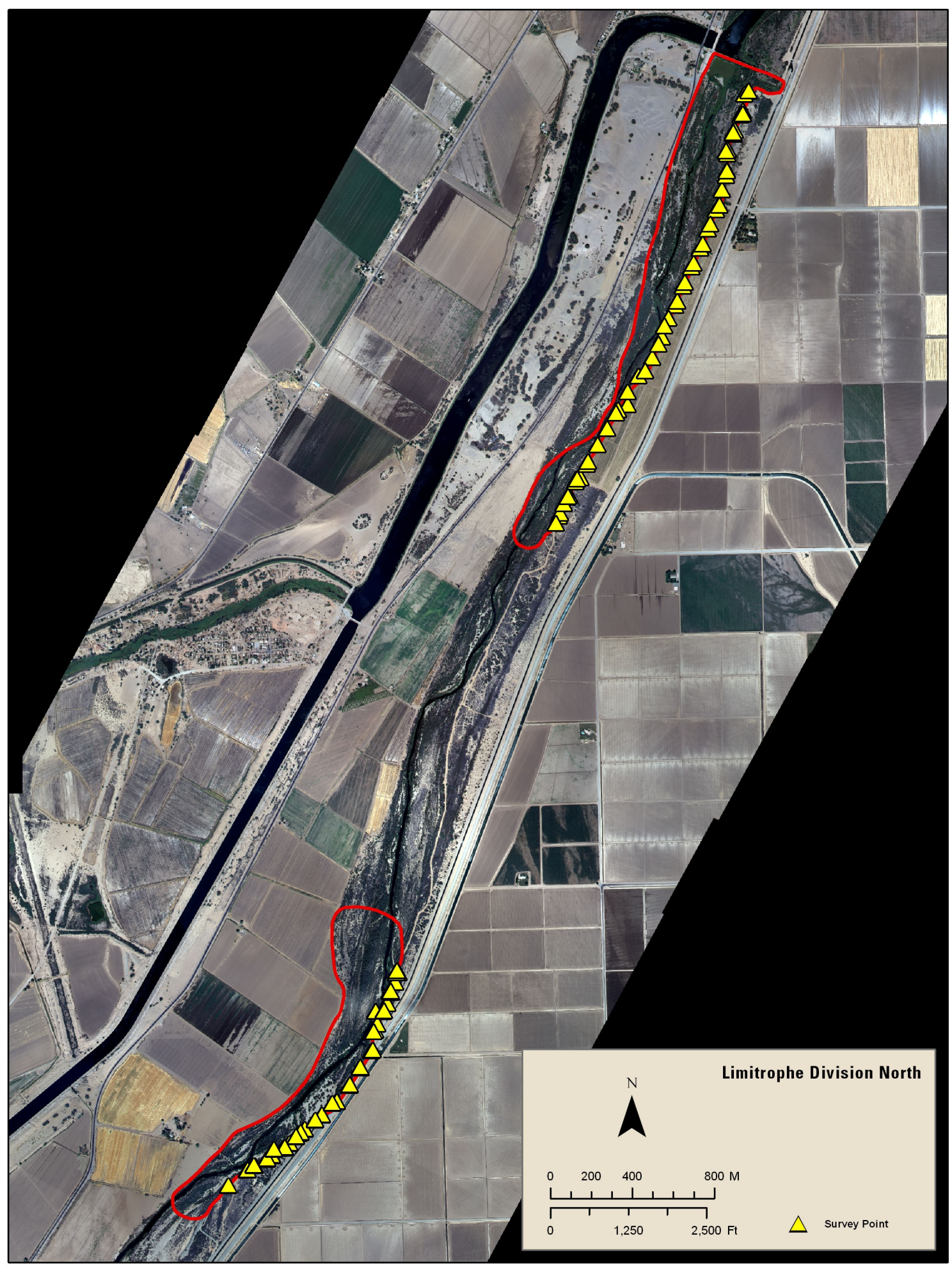


Figure 4-13C. Orthorectified aerial photos display yellow-billed cuckoo survey points and detection locations at Limitrophe Division, AZ, Limitrophe Division South, 2007. Red boundary line represents yellow-billed cuckoo survey habitat patch.

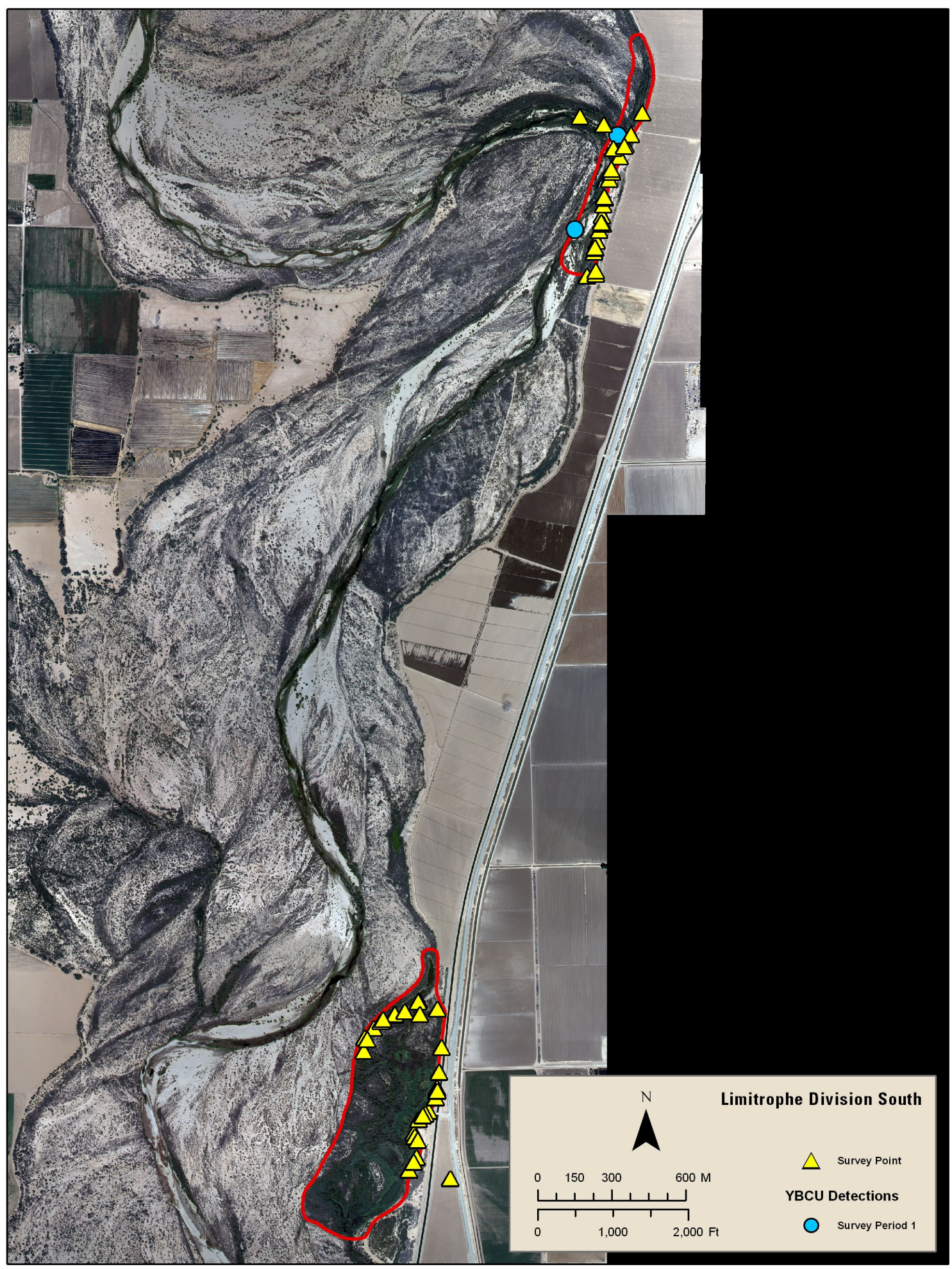


Figure 4-14A. Orthorectified aerial photo display Gila River/Quigley Pond WMA, AZ yellow-billed cuckoo survey area along the Gila River, 2007.

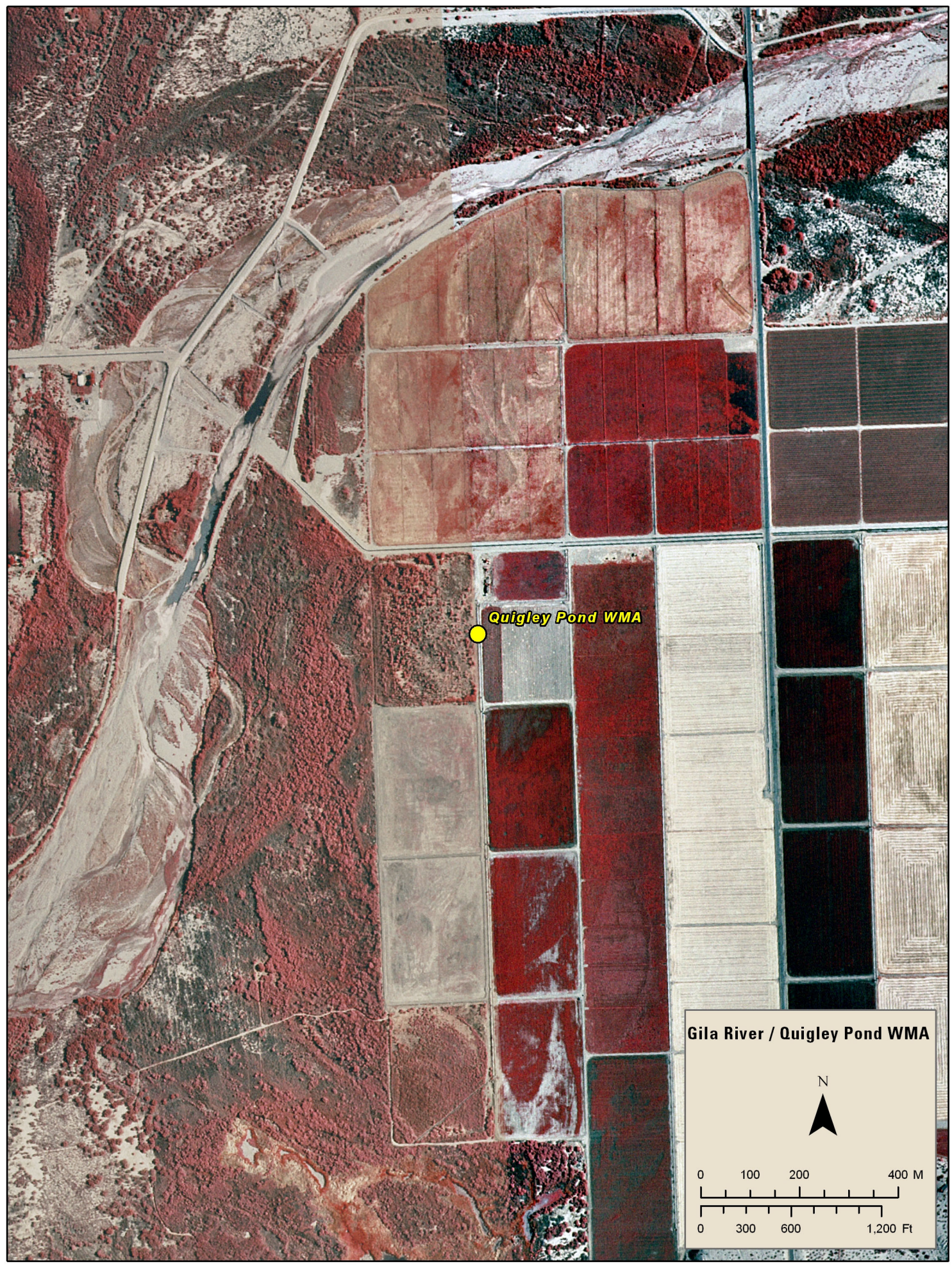


Figure 4-14B. Orthorectified aerial photo display yellow-billed cuckoo survey points and cuckoo detection location at Gila River/Quigley Pond WMA, AZ, along the Gila River, 2007. Red boundary line represents yellow-billed cuckoo survey habitat patch.

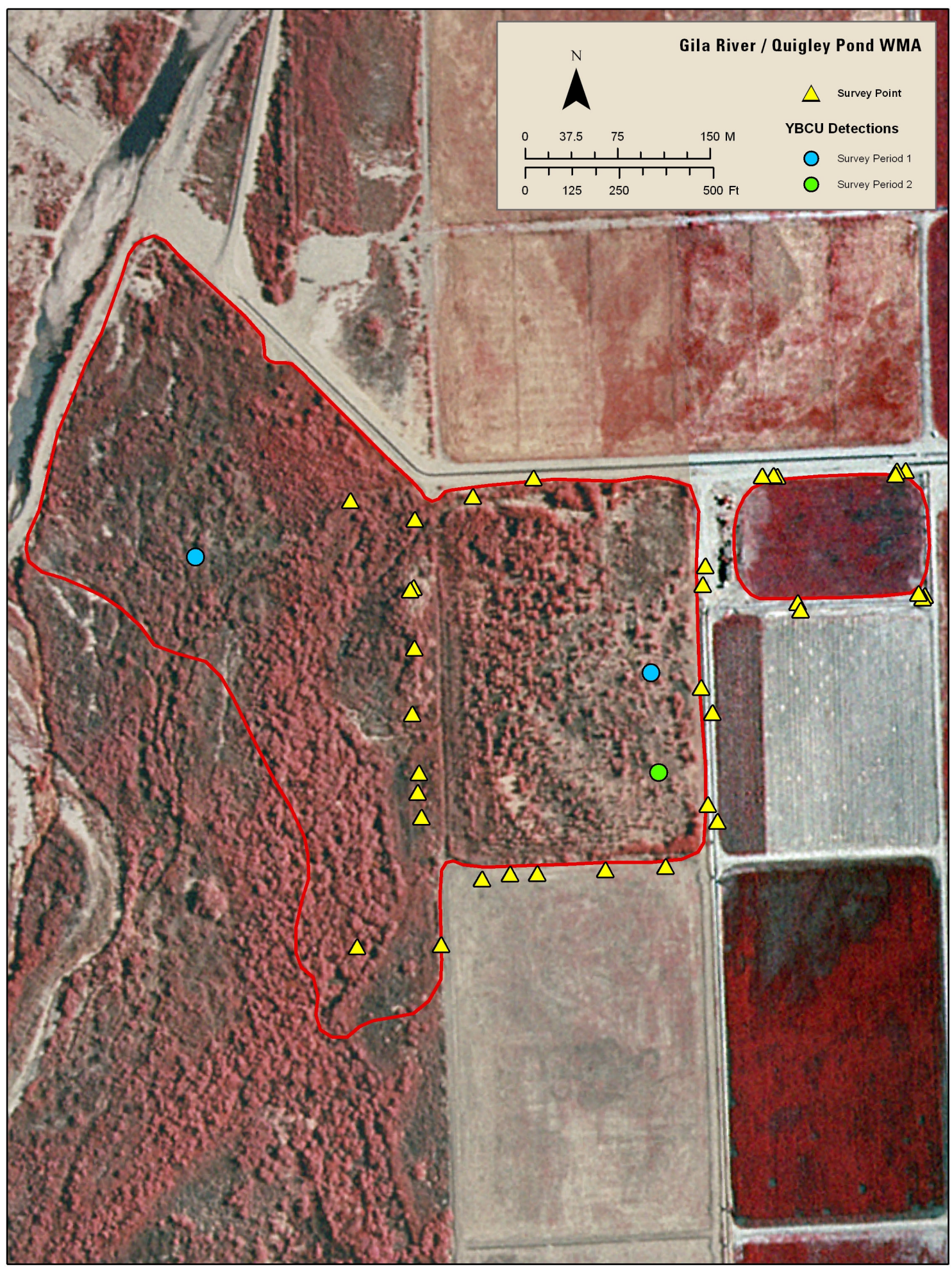


This page intentionally left blank 


\section{Appendix 5. Habitat photos of yellow-billed cuckoo survey areas and sites in the lower Colorado River Watershed, 2007}

Habitat photos of yellow-billed cuckoo survey areas and sites in the lower Colorado River watershed along the Muddy River, Nevada, lower Colorado, Bill Williams and Gila Rivers, Arizona and California, 2007. Listed with each photo are area name and site name when applicable.

\section{Pahranagat National Wildlife Refuge, NV}

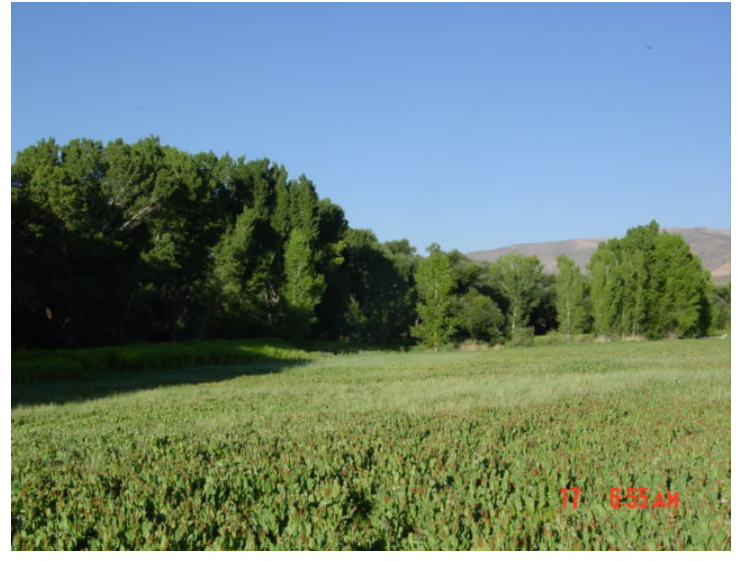

Pahranagat NWR, Pahranagat North

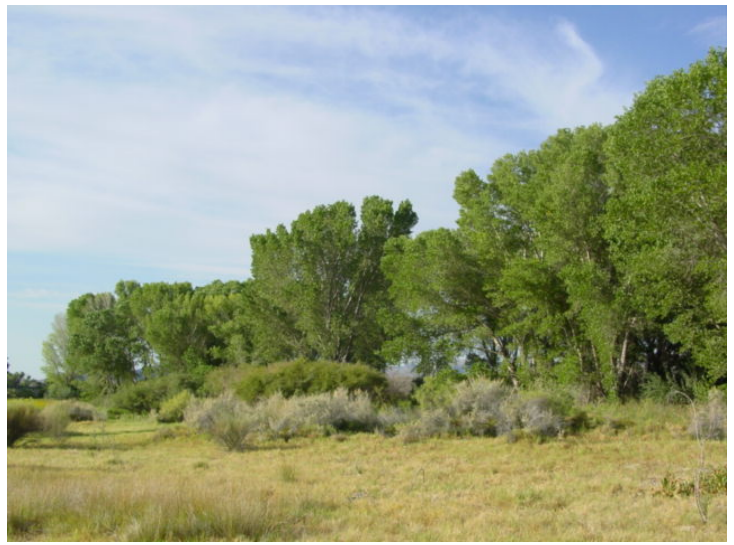

Pahranagat NWR, Pahranagat South

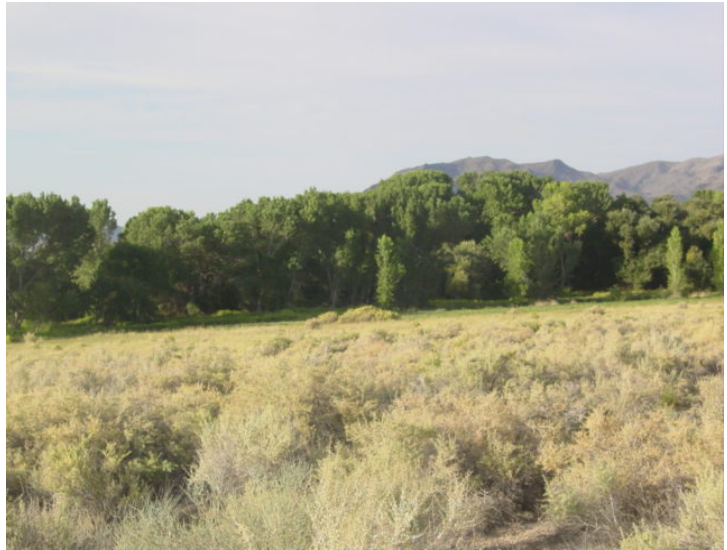

Pahranagat NWR, Pahranagat North

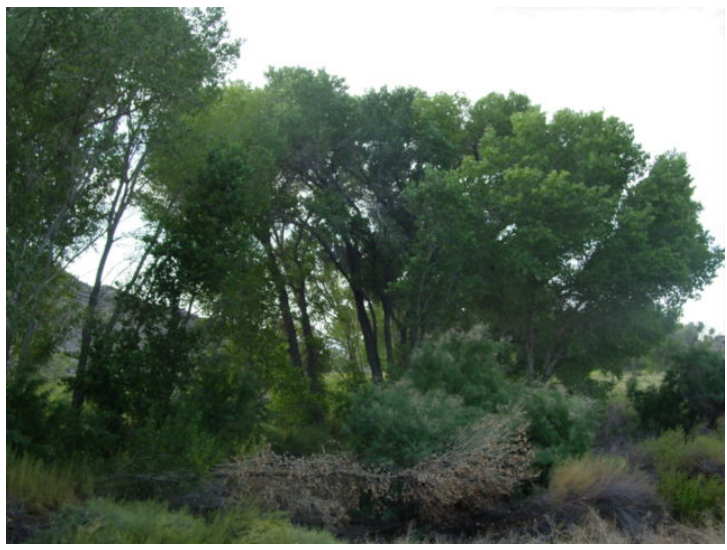

Pahranagat NWR, Pahranagat South 


\section{Overton Wildlife Management Area, NV}

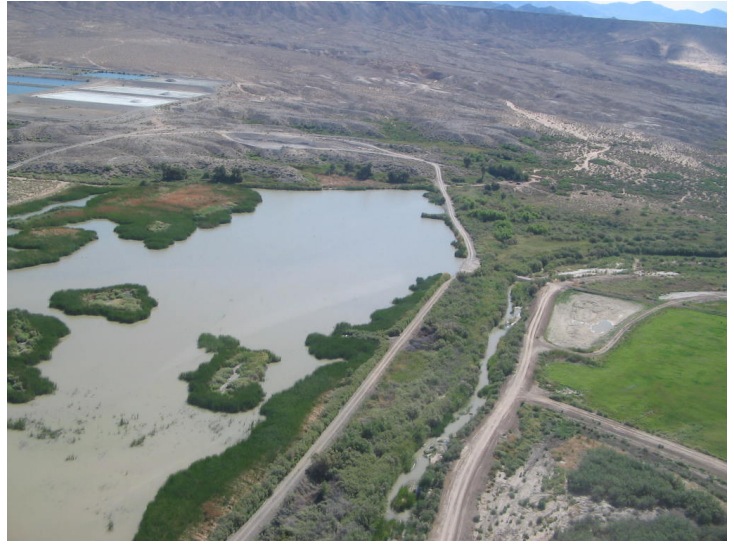

Overton WMA, Honey Bee Pond.

Photo taken from helicopter.

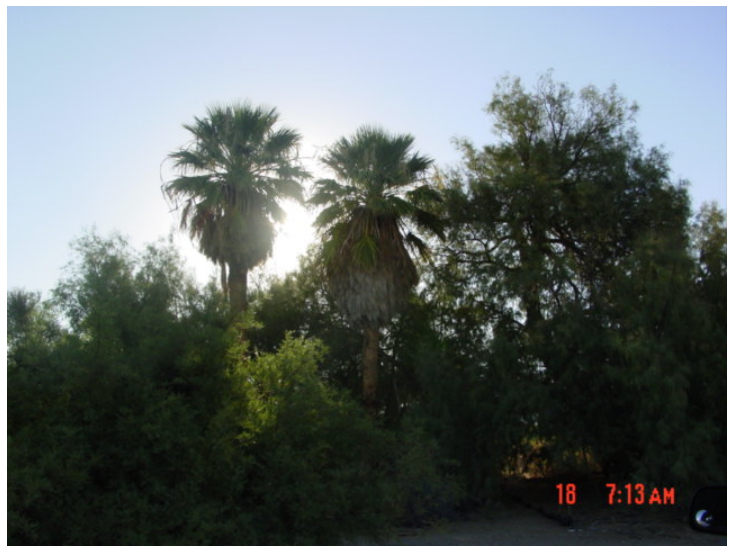

Overton WMA, Honey Bee Pond

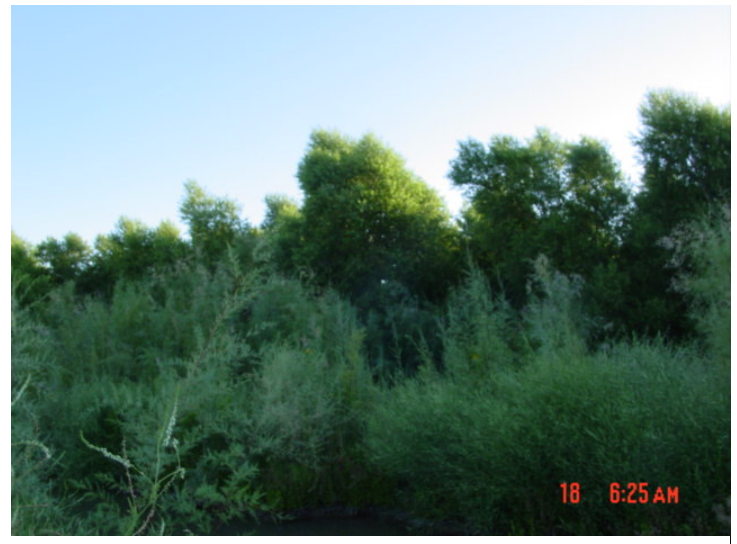

Overton WMA, Overton Wildlife

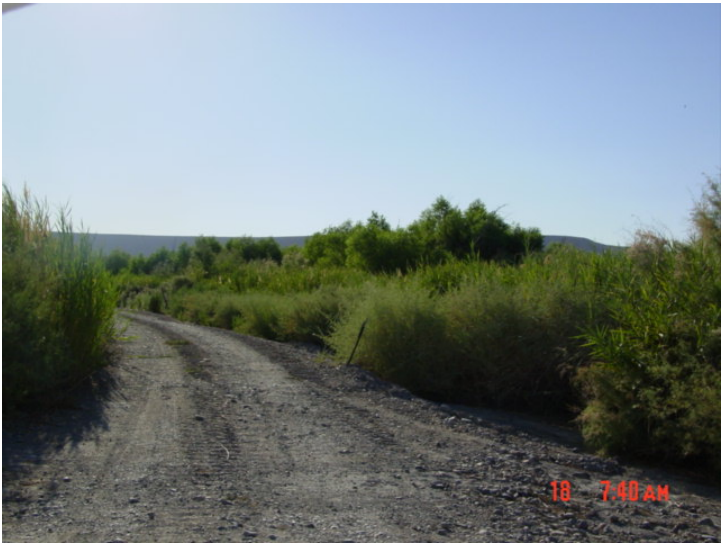

Overton WMA, Honey Bee Pond

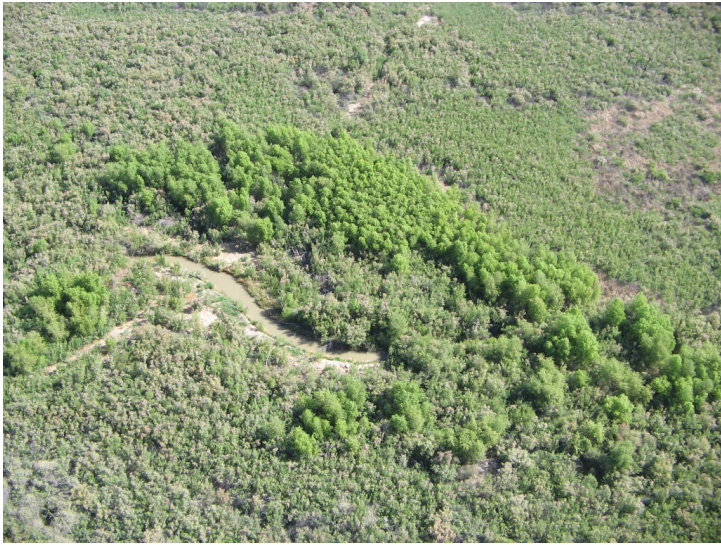

Overton WMA, Overton Wildlife.

Photo taken from helicopter.

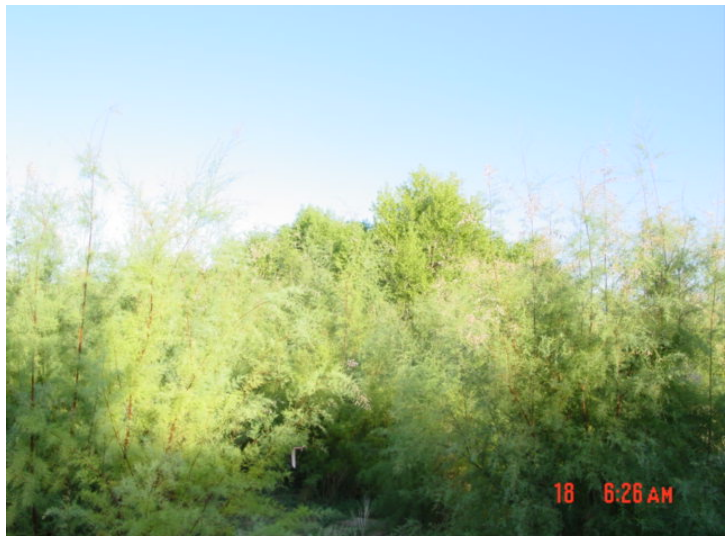

Overton WMA, Overton Wildlife 


\section{Grand Canyon National Park/Lake Mead National Recreation Area, AZ}

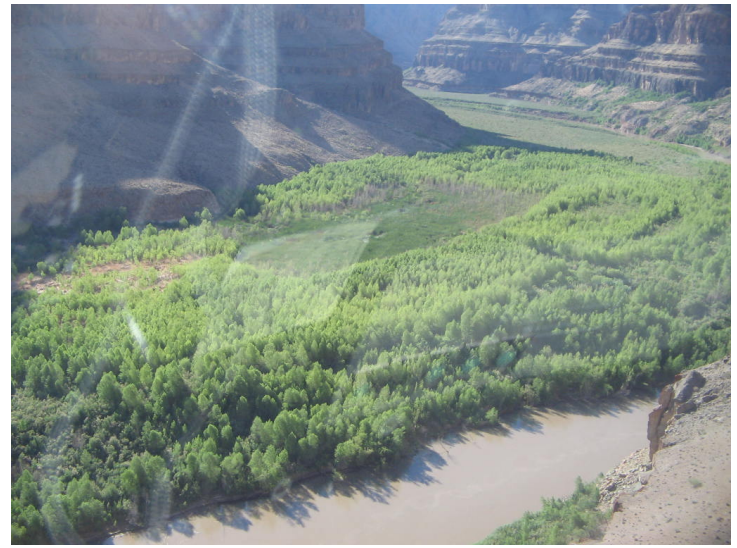

Grand Canyon NP, River Mile 274. Photo taken from helicopter.

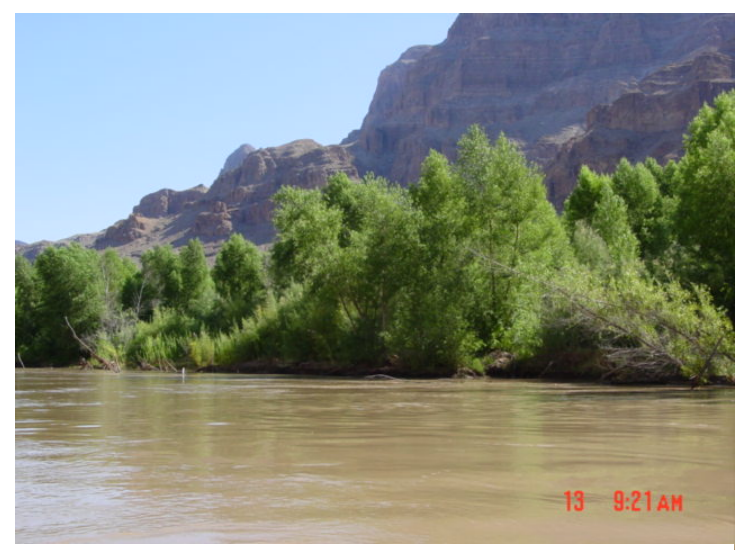

Grand Canyon NP, River Mile 274

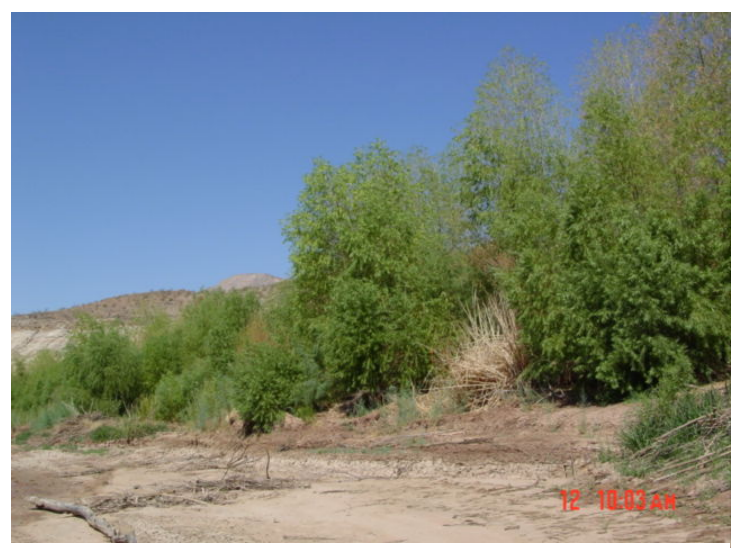

Lake Mead NRA, Cuckoo Beach

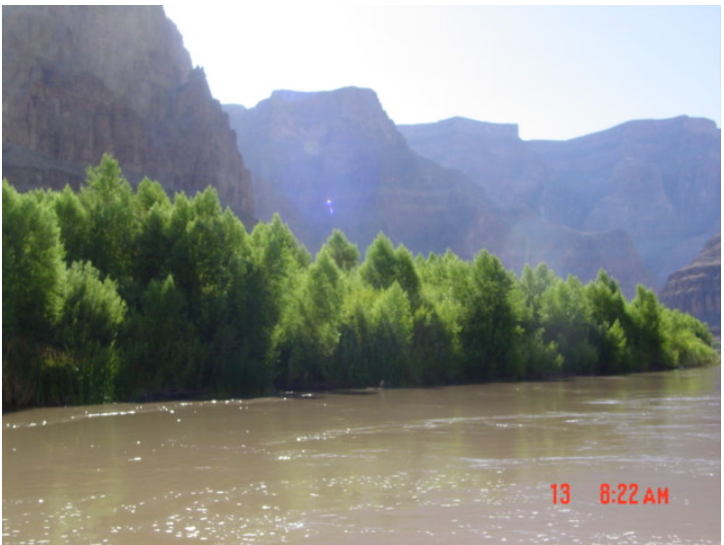

Grand Canyon NP, River Mile 274

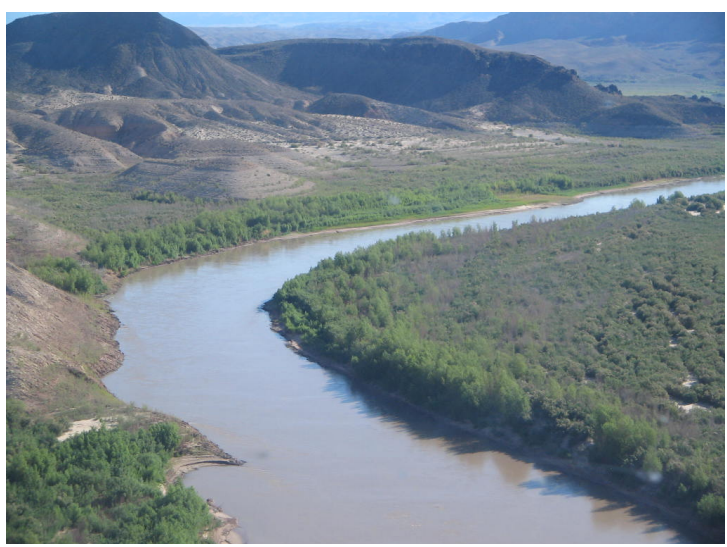

Lake Mead NRA, Cuckoo Beach. Photo taken from helicopter.

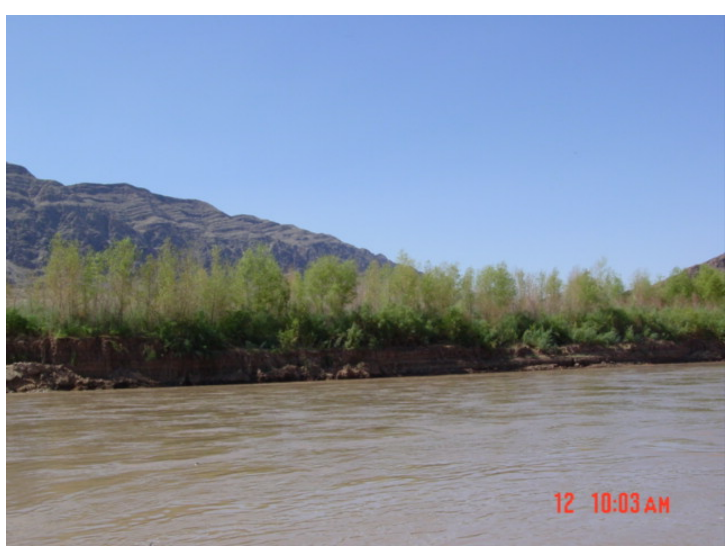

Lake Mead NRA, Cuckoo Beach 


\section{Grand Canyon National Park/Lake Mead National Recreation Area, AZ (continued)}

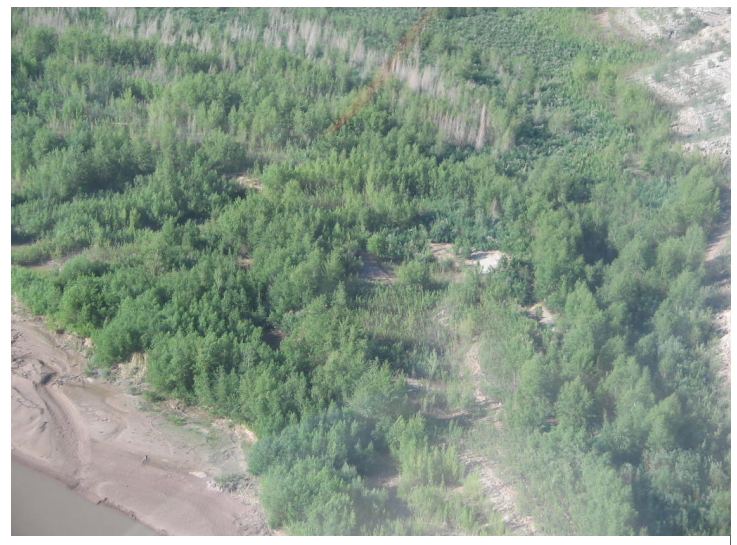

Lake Mead NRA, Iceberg Ridge.

Photo taken from helicopter.

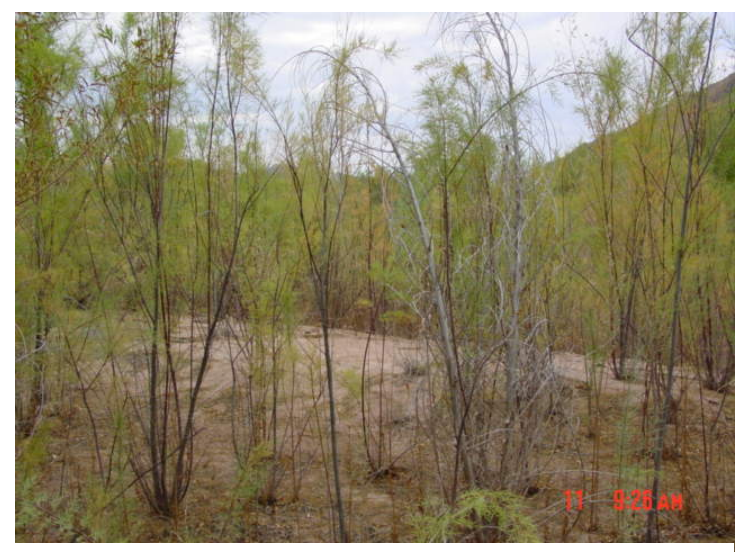

Lake Mead NRA, Iceberg Ridge

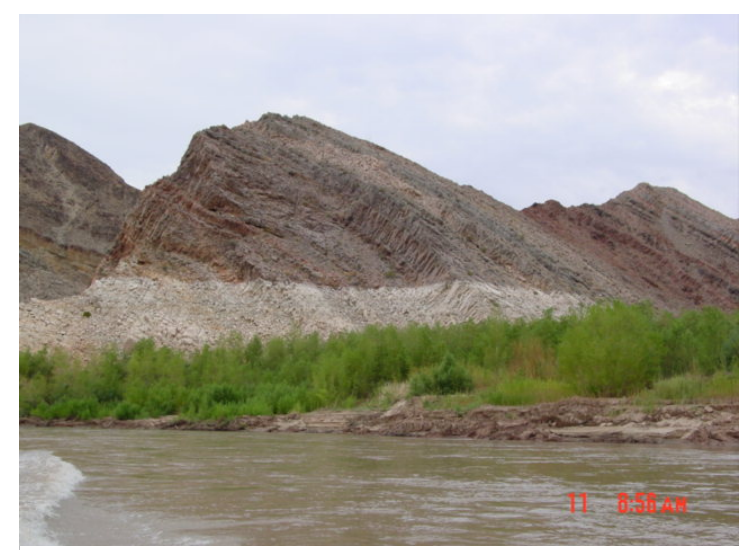

Lake Mead NRA, Chuckwalla Cove

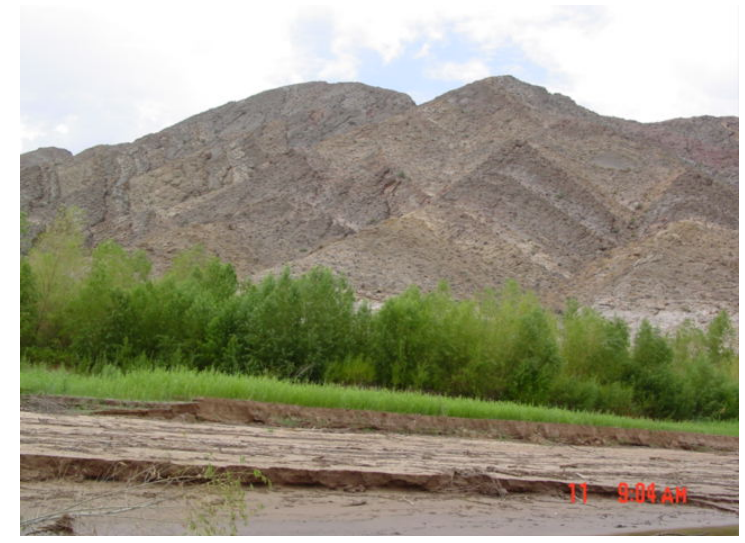

Lake Mead NRA, Iceberg Ridge

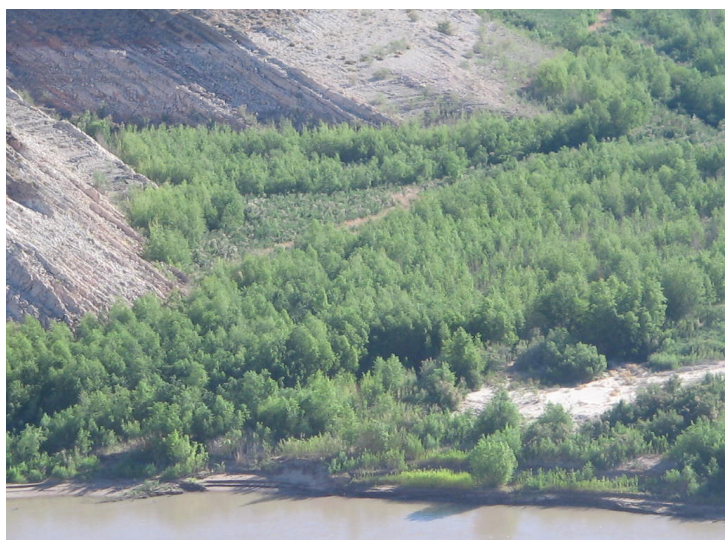

Lake Mead NRA, Chuckwalla Cove. Photo taken from helicopter.

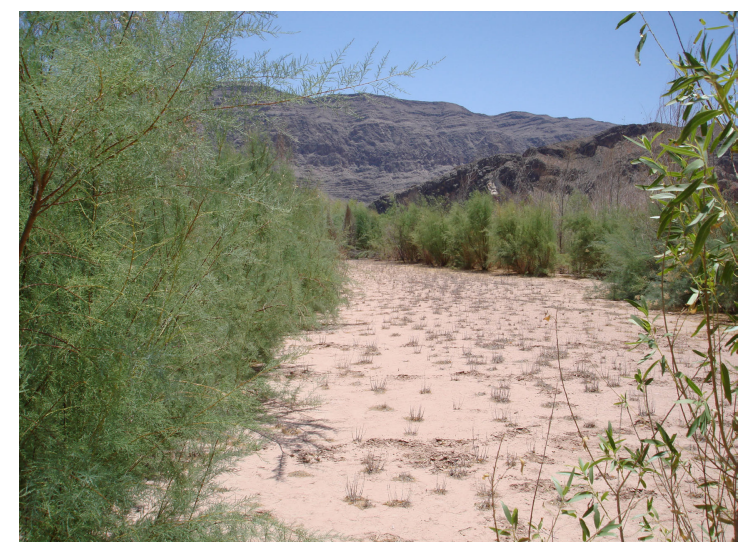

Lake Mead NRA, Chuckwalla Cove 


\section{Grand Canyon National Park/Lake Mead National Recreation Area, AZ (continued)}

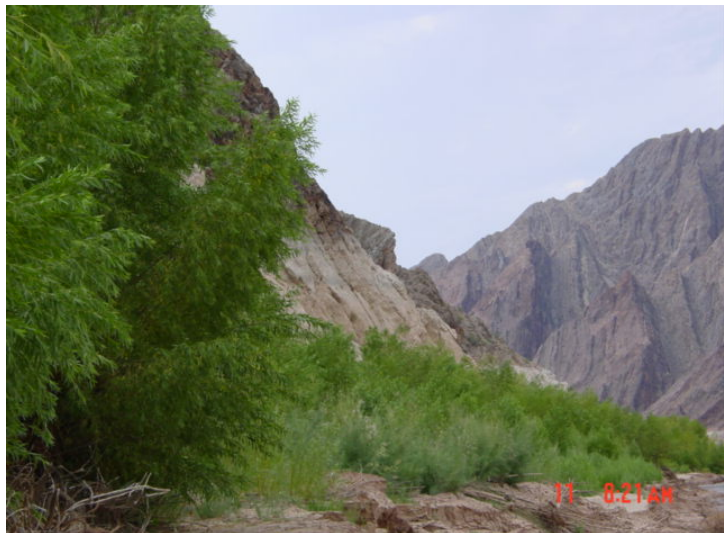

Lake Mead NRA, Big Horn Draw

\section{Havasu National Wildlife Refuge, AZ}

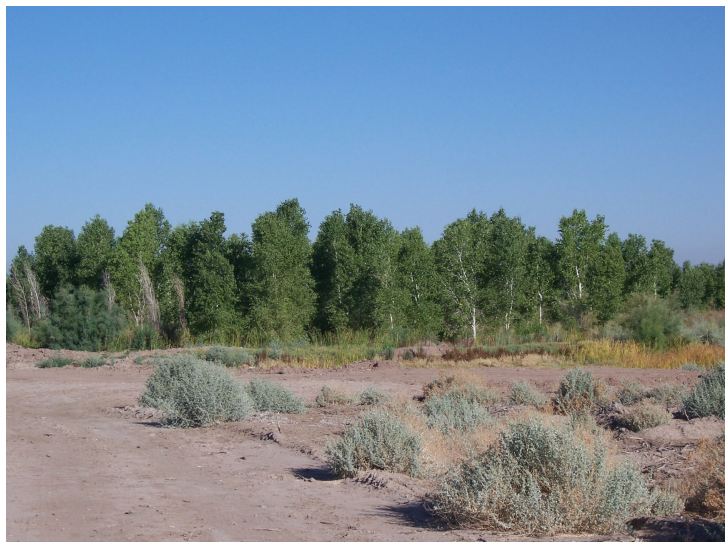

Havasu NWR, Pintail Slough

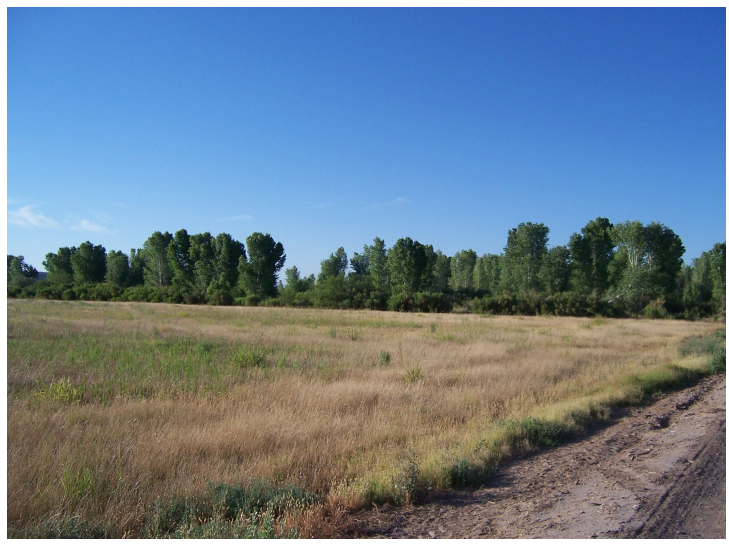

Havasu NWR, North Dike

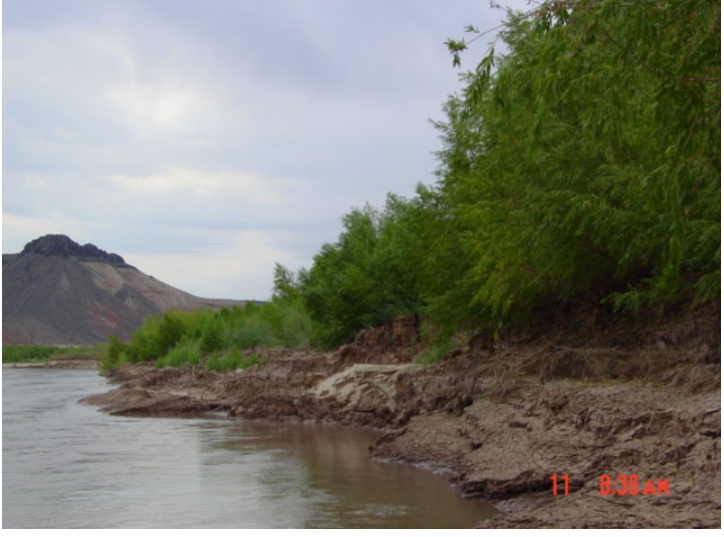

Lake Mead NRA, Big Horn Draw

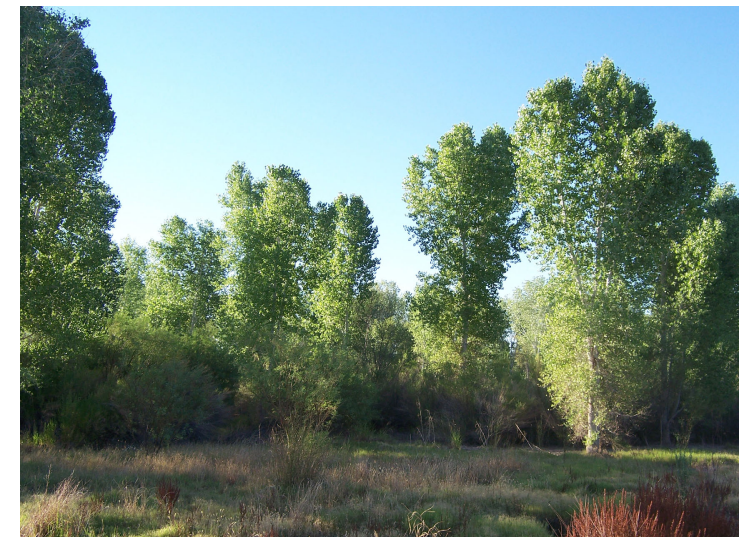

Havasu NWR, North Dike

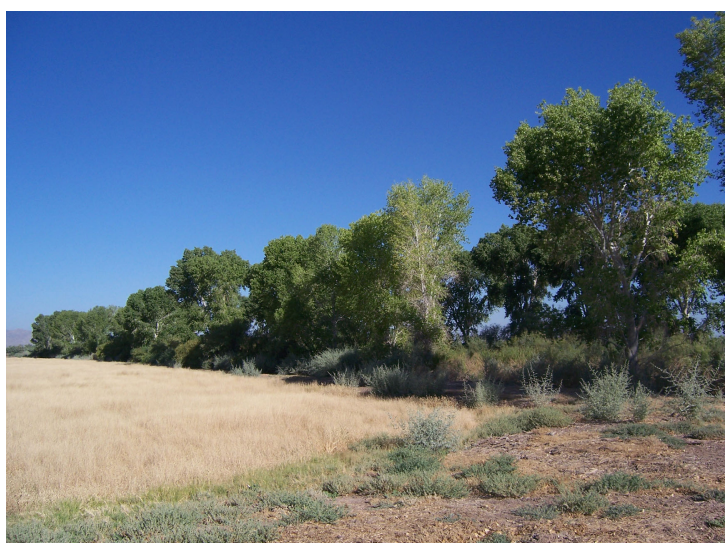

Havasu NWR, Pintail Slough 


\section{Havasu National Wildlife Refuge, AZ (continued)}

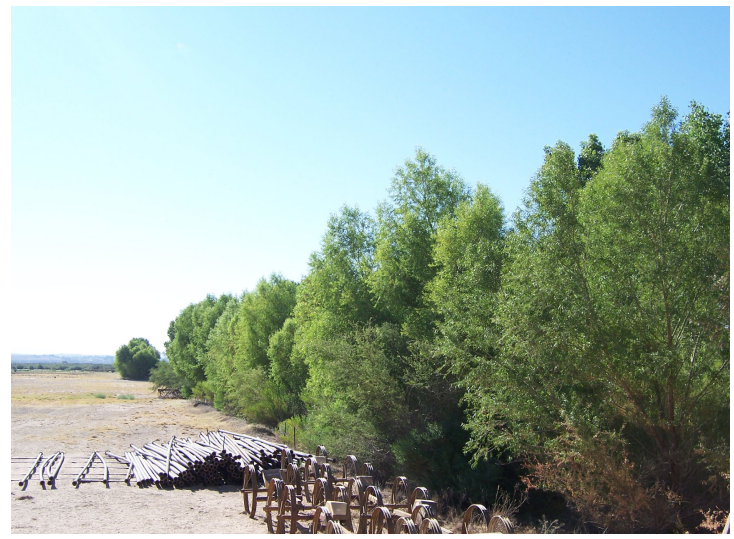

Havasu NWR, Topock Marsh Restoration

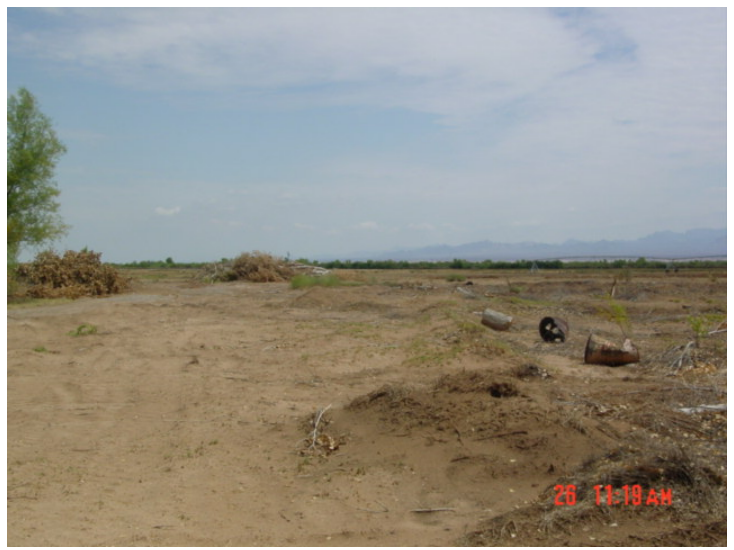

Havasu NWR, Topock Marsh Restoration. Area of 2007 tree maintenance.

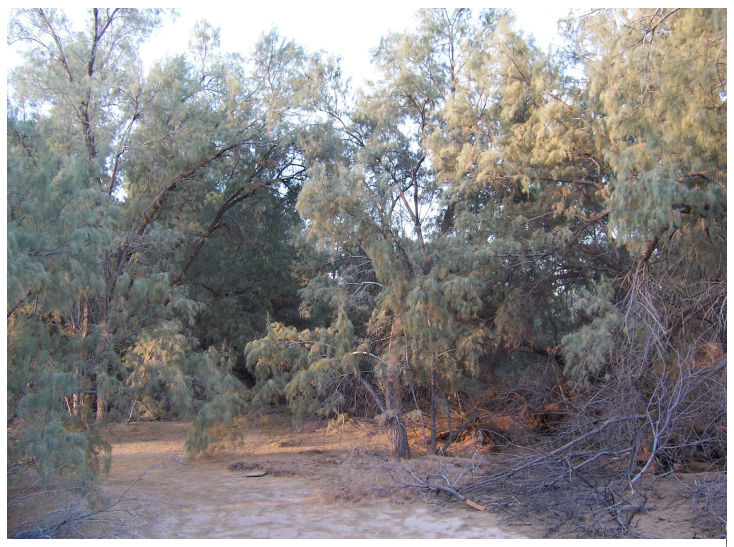

Havasu NWR, Topock Tamarisk

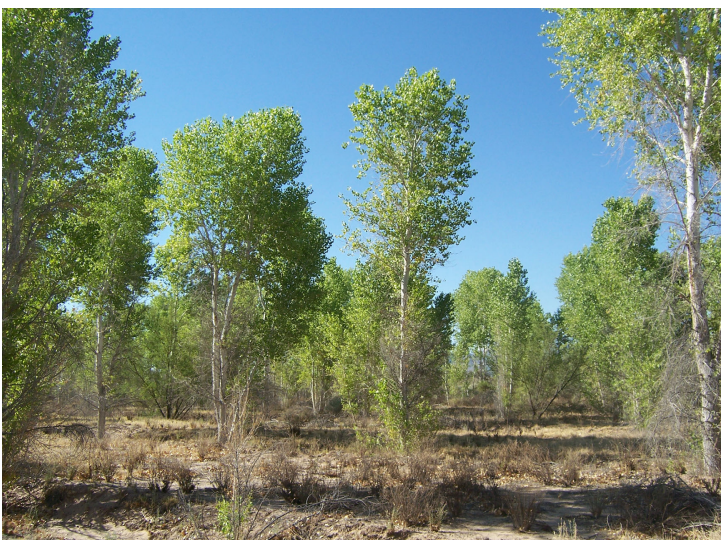

Havasu NWR, Topock Marsh Restoration

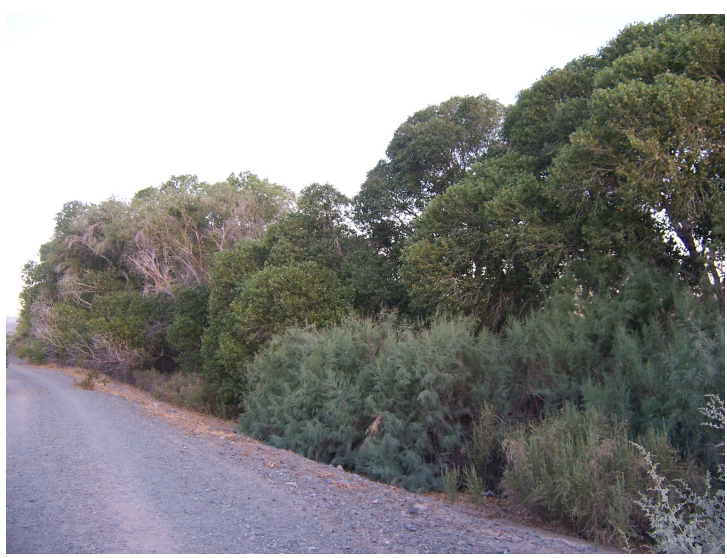

Havasu NWR, Topock Tamarisk

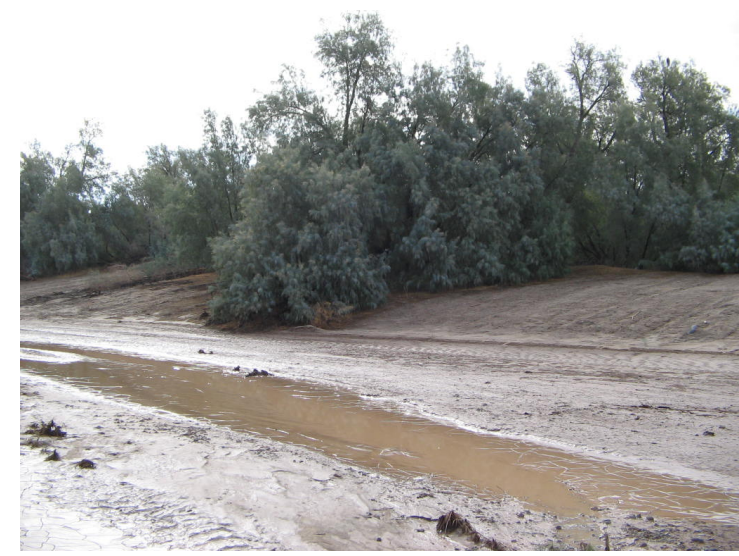

Havasu NWR, Topock Tamarisk. After monsoon flooding. 


\section{Bill Williams River National Wildlife Refuge, AZ}

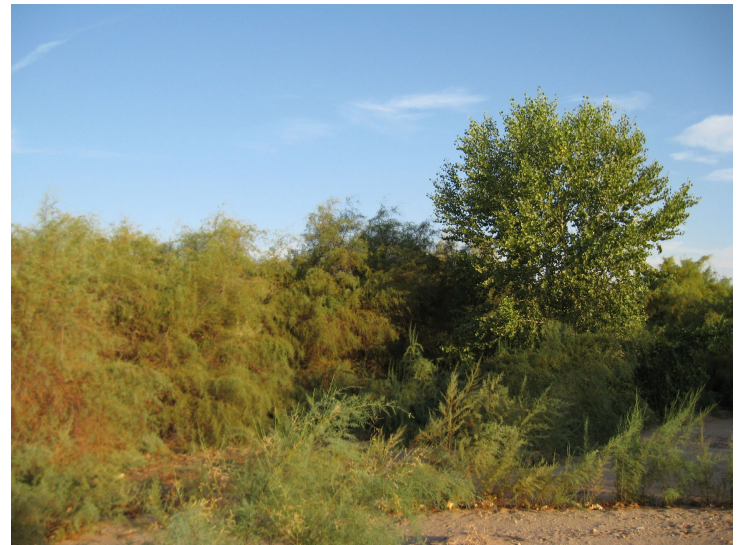

Bill Williams River NWR, Teepee Trail

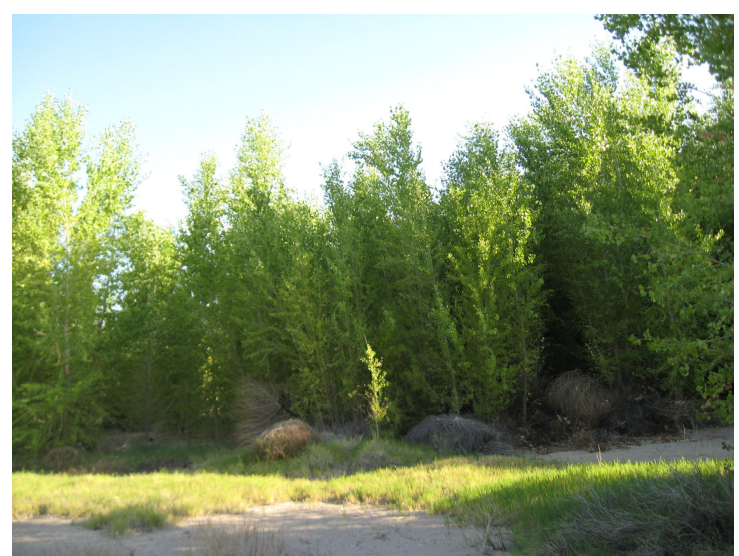

Bill Williams River NWR, Cottonwood Patch

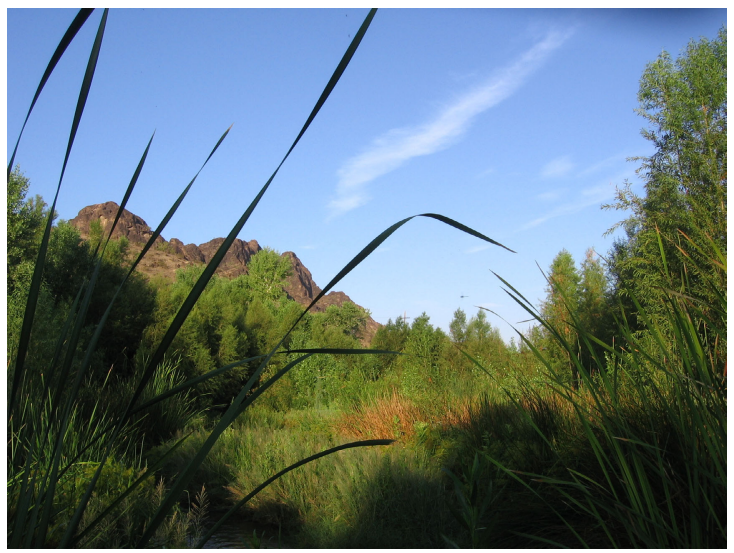

Bill Williams River NWR, Cave Wash

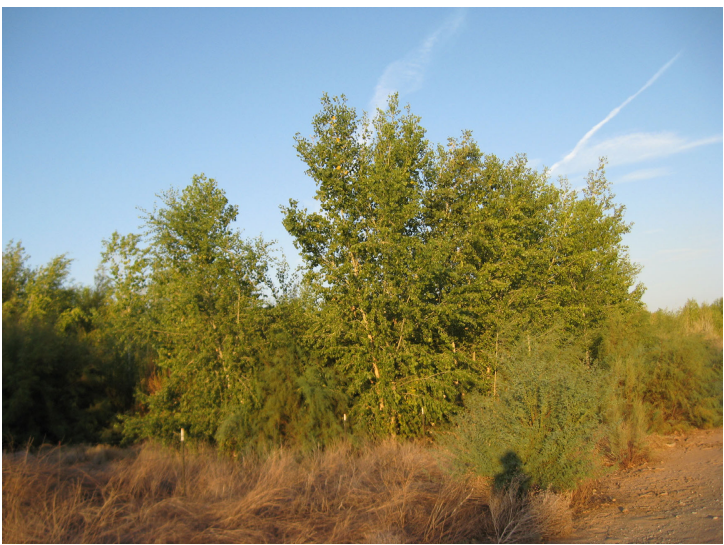

Bill Williams River NWR, Teepee Trail

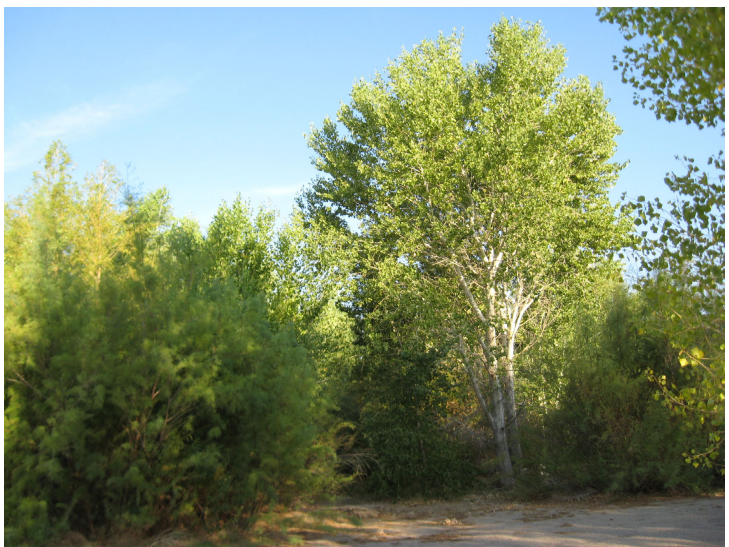

Bill Williams River NWR, Cottonwood Patch

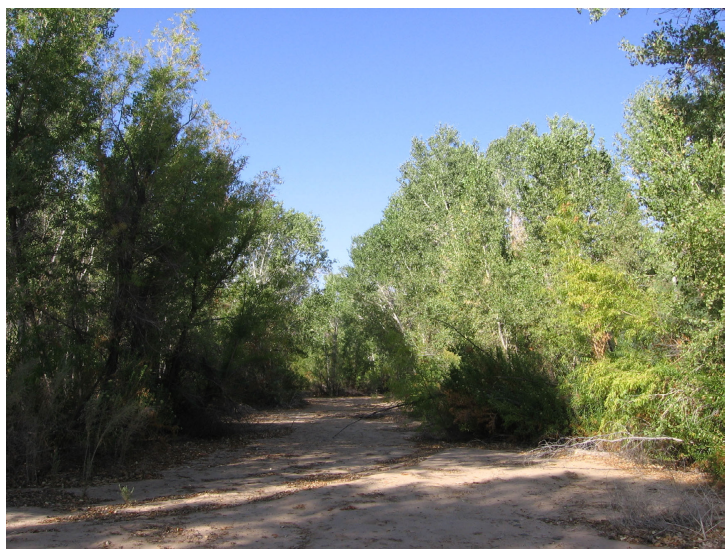

Bill Williams River NWR, Cave Wash 


\section{Bill Williams River National Wildlife Refuge, AZ (continued)}

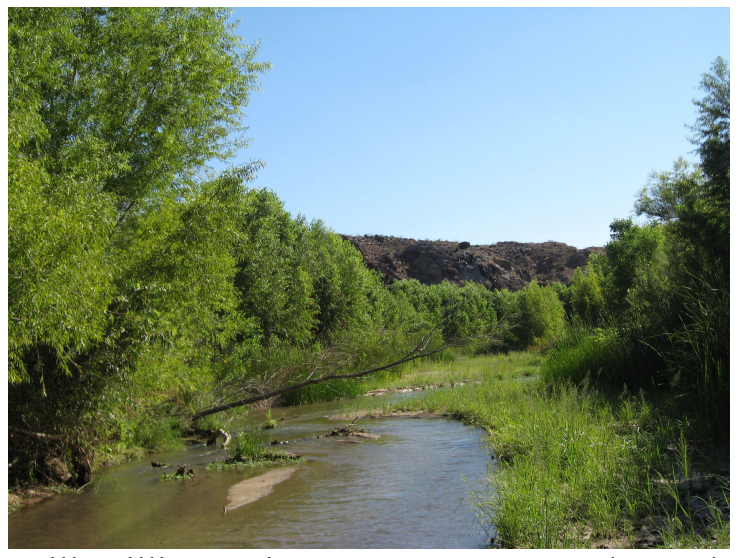

Bill Williams River NWR, Honeycomb Bend

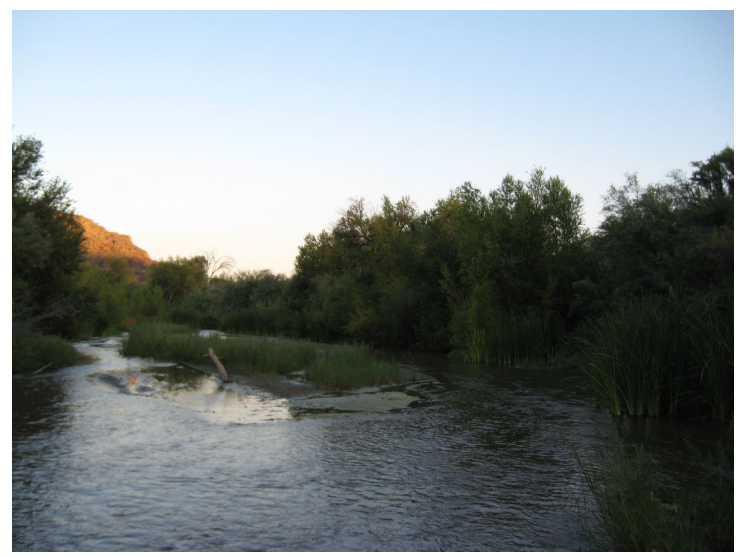

Bill Williams River NWR, Mineral Wash

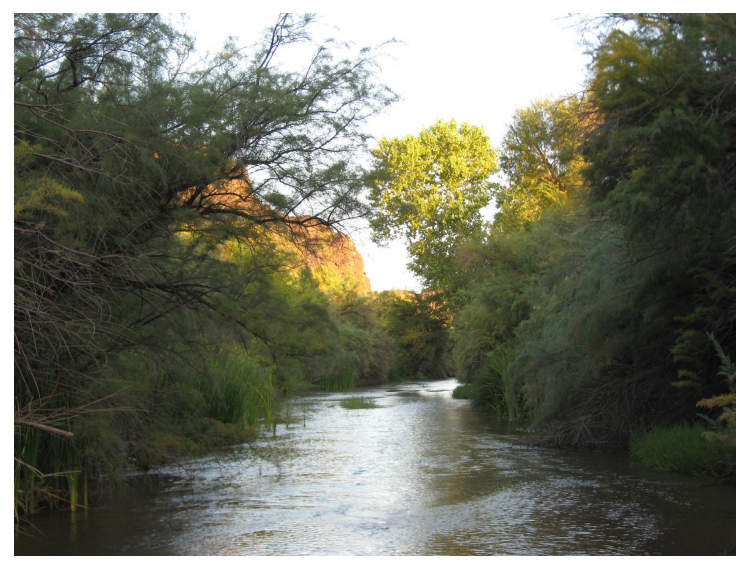

Bill Williams River NWR, Big Bend

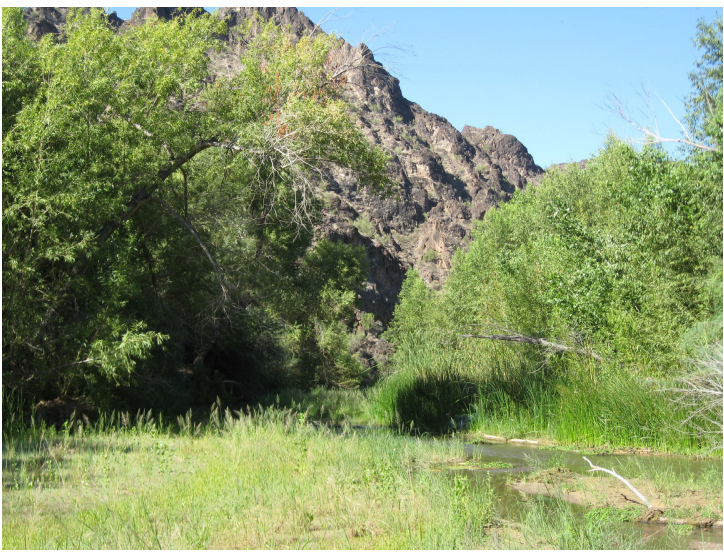

Bill Williams River NWR, Honeycomb Bend

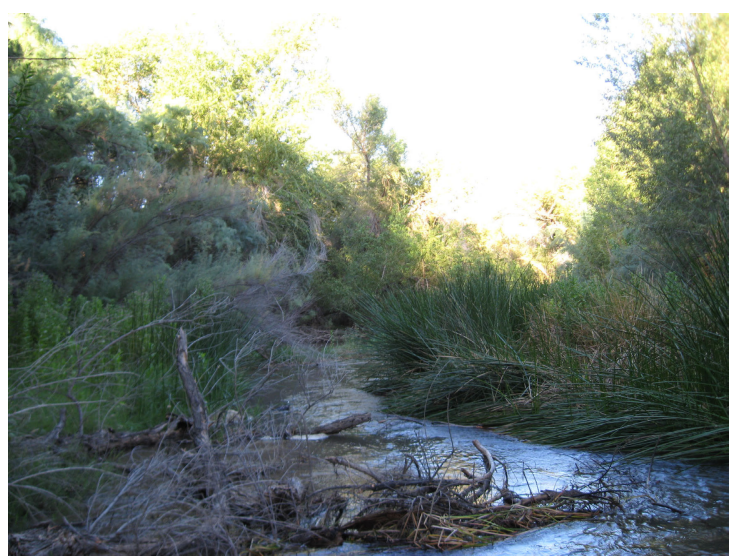

Bill Williams River NWR, Mineral Wash

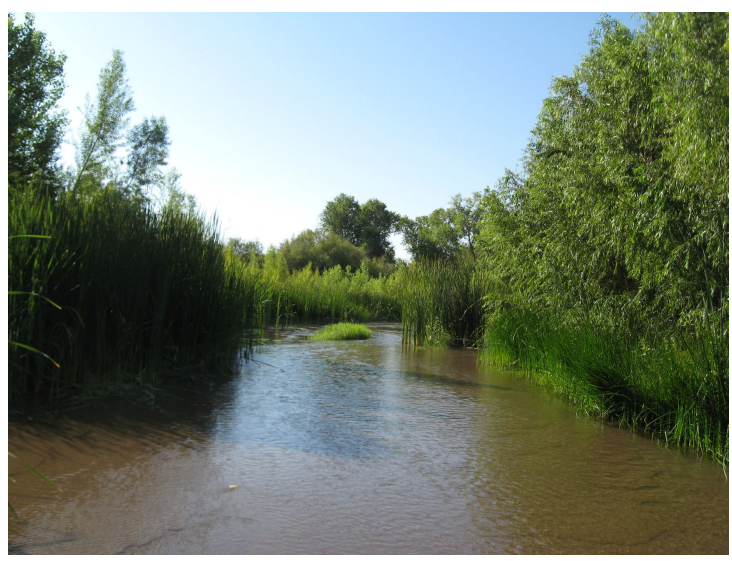

Bill Williams River NWR, Big Bend 


\section{Bill Williams River National Wildlife Refuge, AZ (continued)}

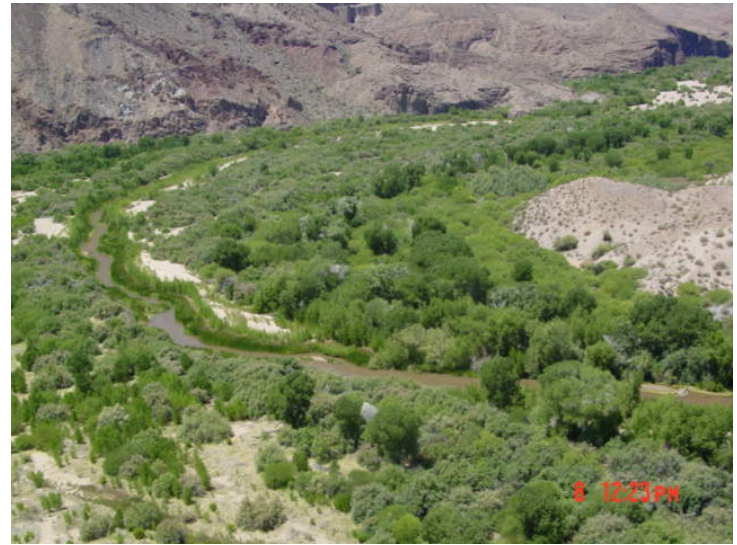

Bill Williams River NWR, Big Bend. Photo taken from helicopter.

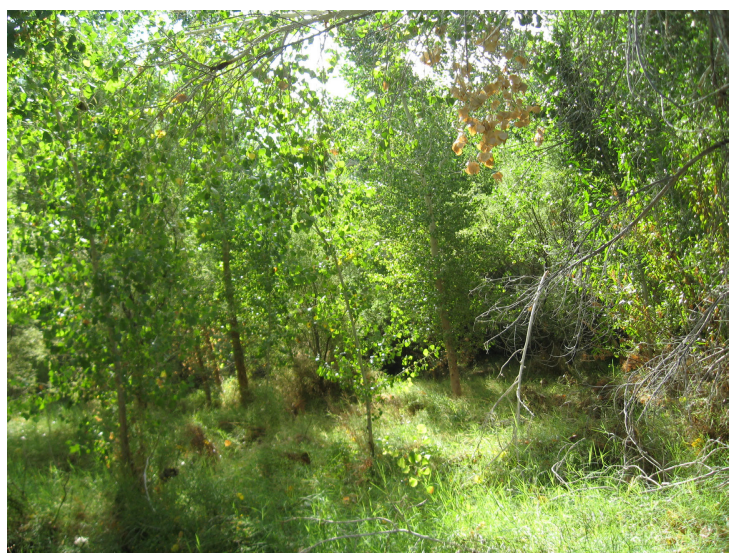

Bill Williams River NWR, Gibraltar Rock

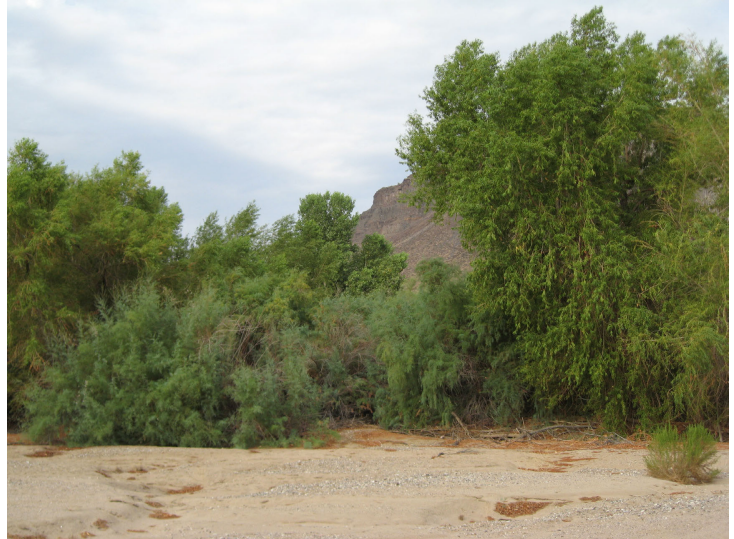

Bill Williams River NWR, Sandy Wash

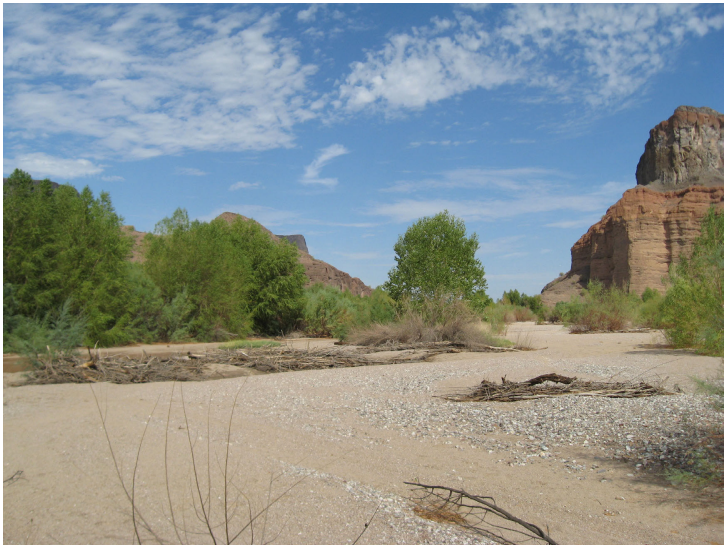

Bill Williams River NWR, Gibraltar Rock

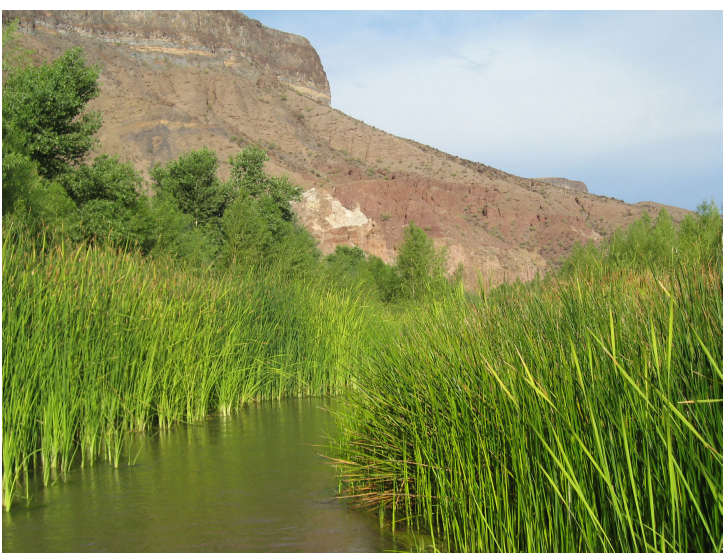

Bill Williams River NWR, Gibraltar Rock

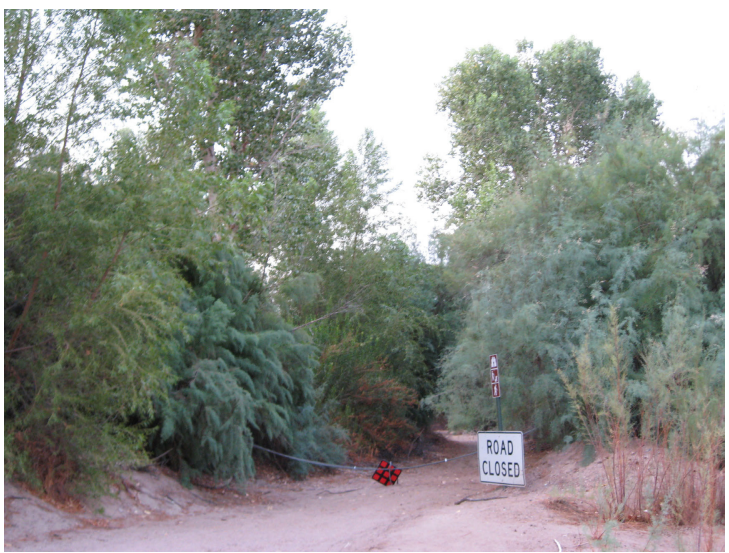

Bill Williams River NWR, Sandy Wash 


\section{Bill Williams River National Wildlife Refuge, AZ (continued)}

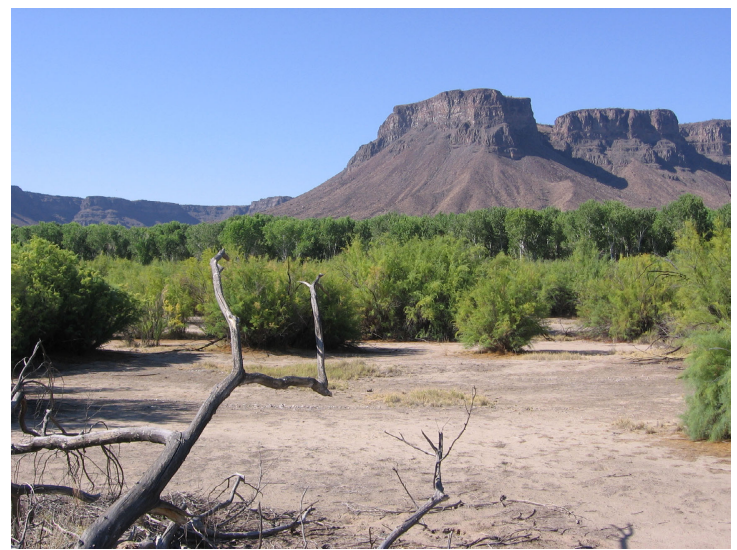

Bill Williams River NWR, Fox Wash

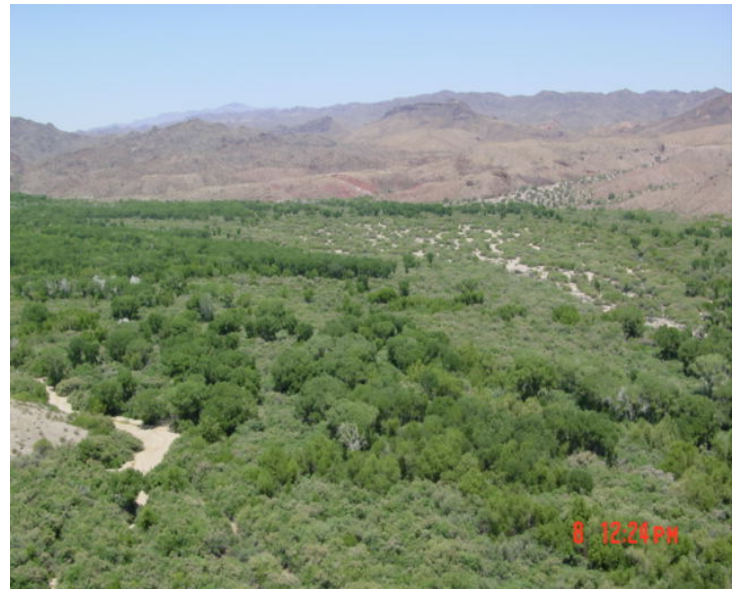

Bill Williams River NWR, Fox Wash

Photo taken from helicopter.

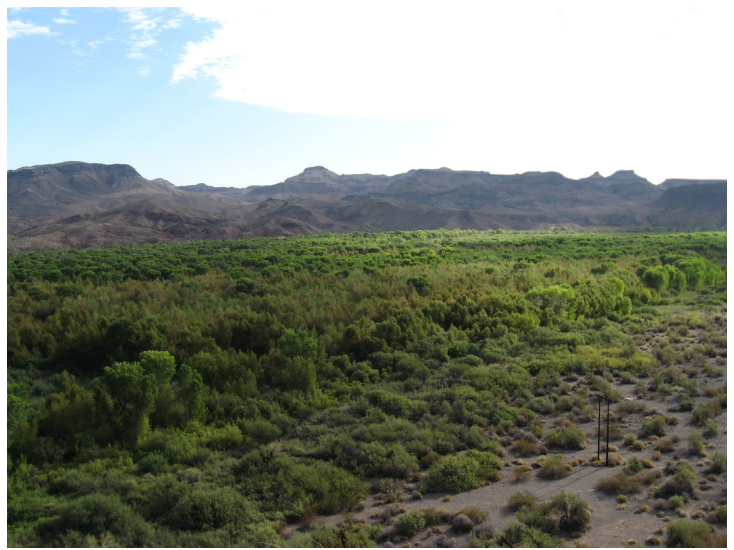

Bill Williams River NWR, Mosquito Flats

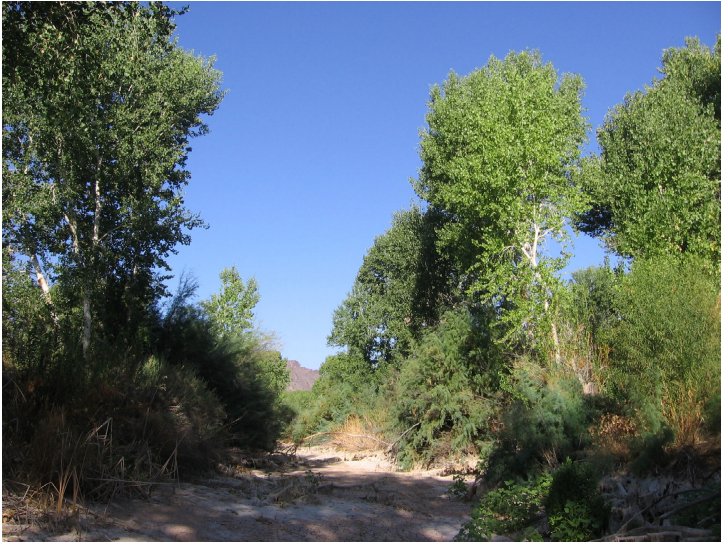

Bill Williams River NWR, Fox Wash

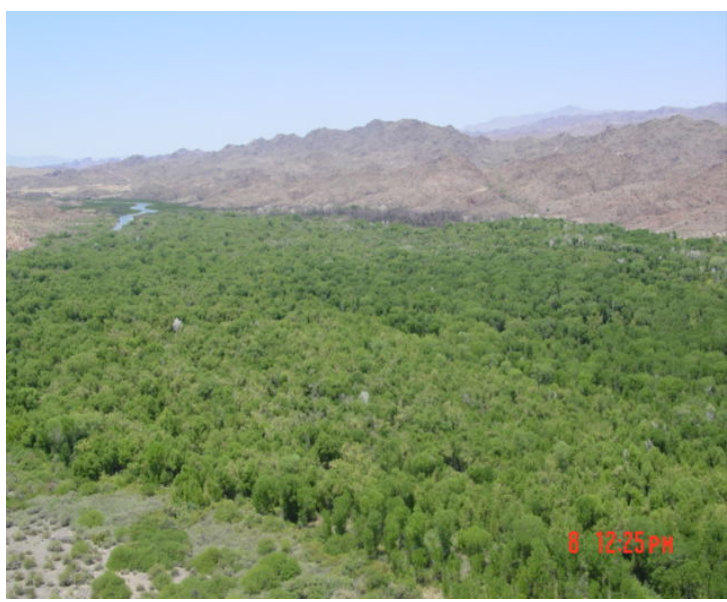

Clockwise from top middle, North Burn, Mosquito Flats, Saguaro Slot, Bill Williams Marsh.

Photo taken from helicopter

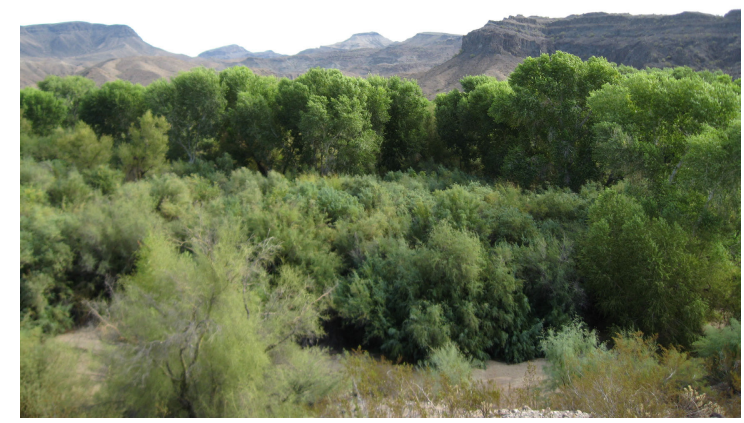

Bill Williams River NWR, Mosquito Flats 


\section{Bill Williams River National Wildlife Refuge, AZ (continued)}

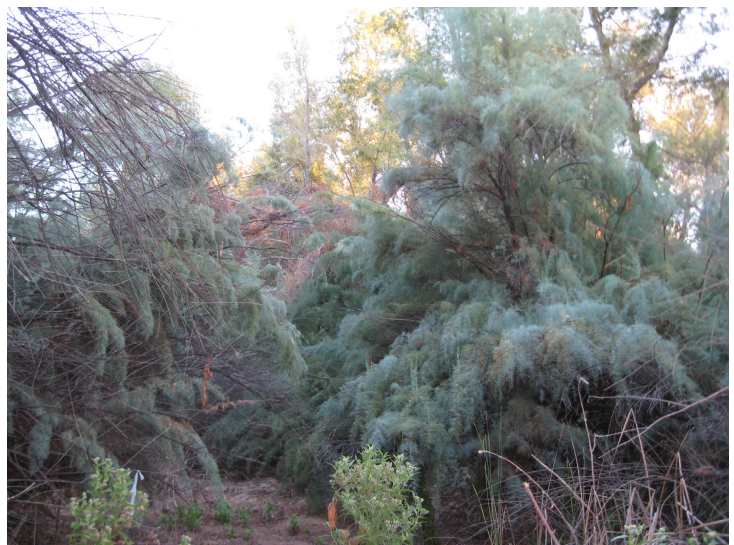

Bill Williams River NWR, Saguaro Slot

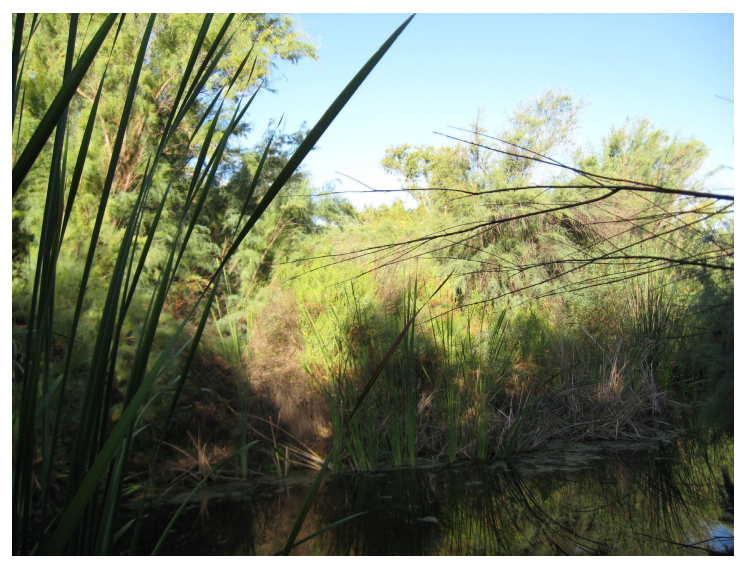

Bill Williams River NWR, North Burn

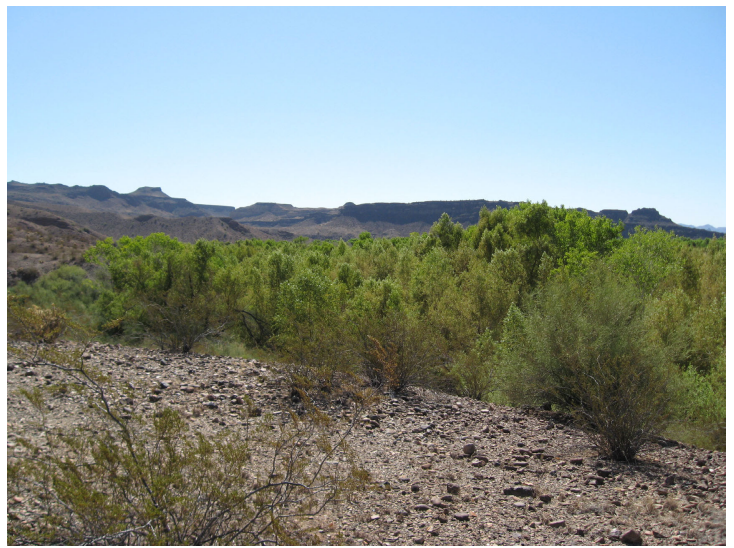

Bill Williams River NWR, North Burn

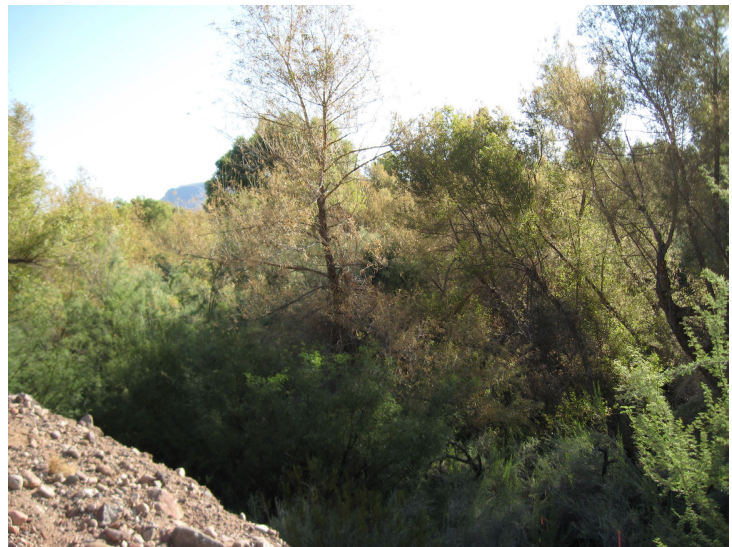

Bill Williams River NWR, Saguaro Slot

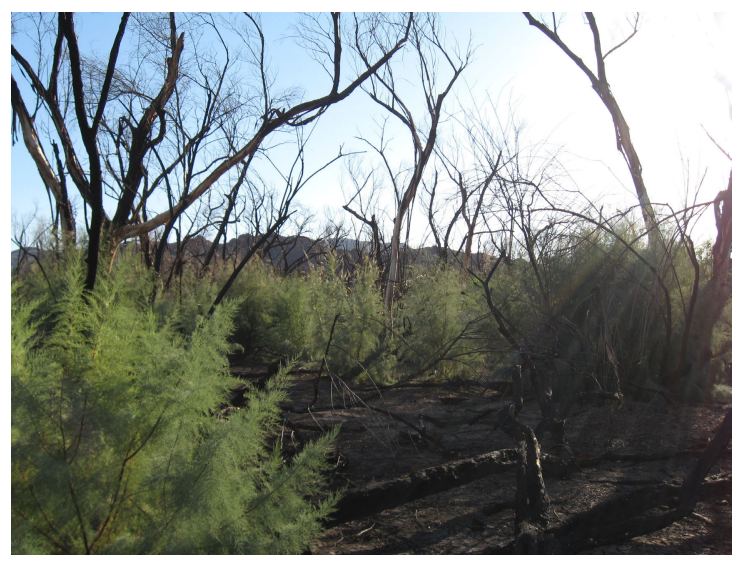

Bill Williams River NWR, North Burn

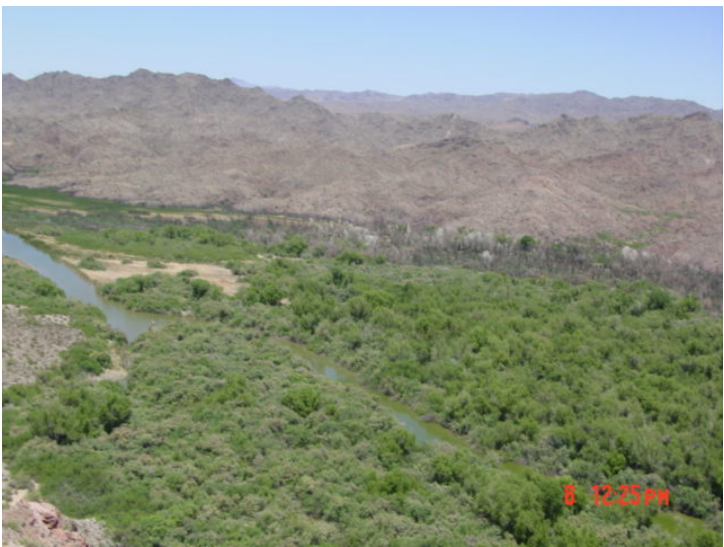

Bill Williams River NWR, Bill Williams Marsh

Photo taken from helicopter. 


\section{Ahakhav Tribal Preserve, AZ}

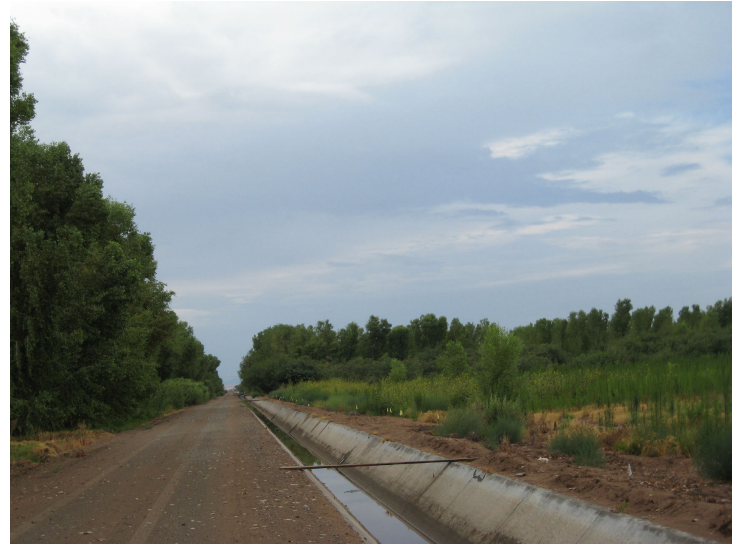

Colorado River Indian Tribes Restoration

Cibola National Wildlife Refuge, AZ

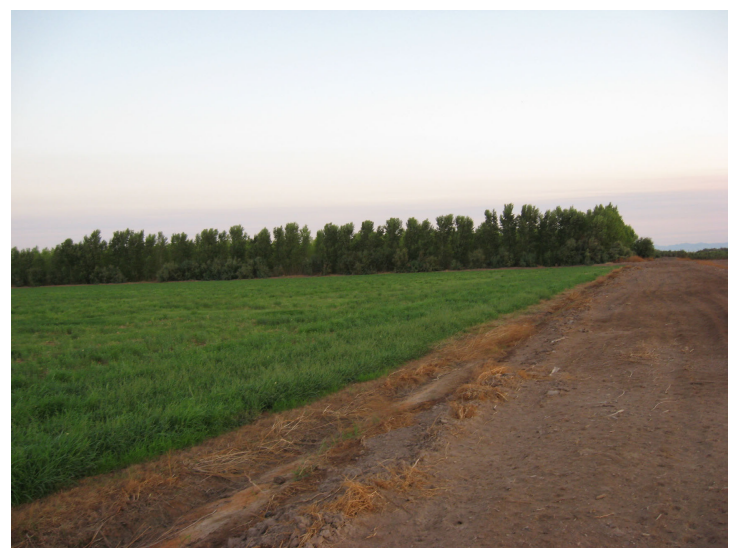

Cibola NWR, North Restoration

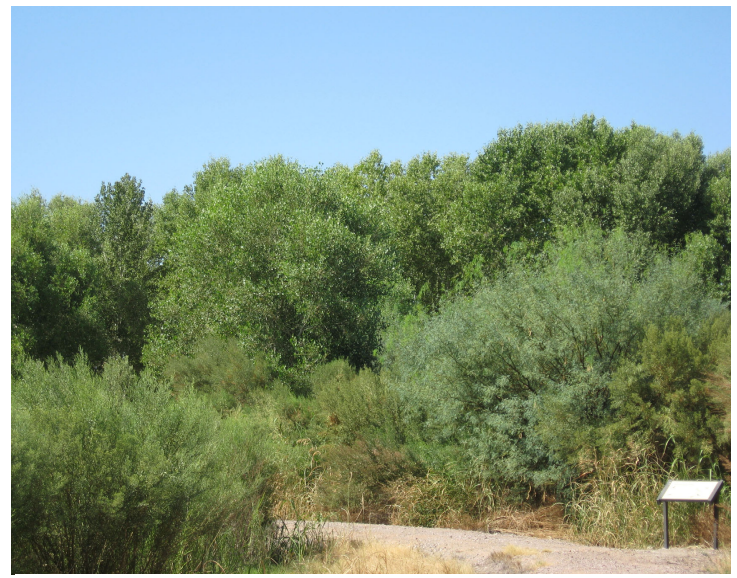

Cibola NWR, Nature Trail Restoration

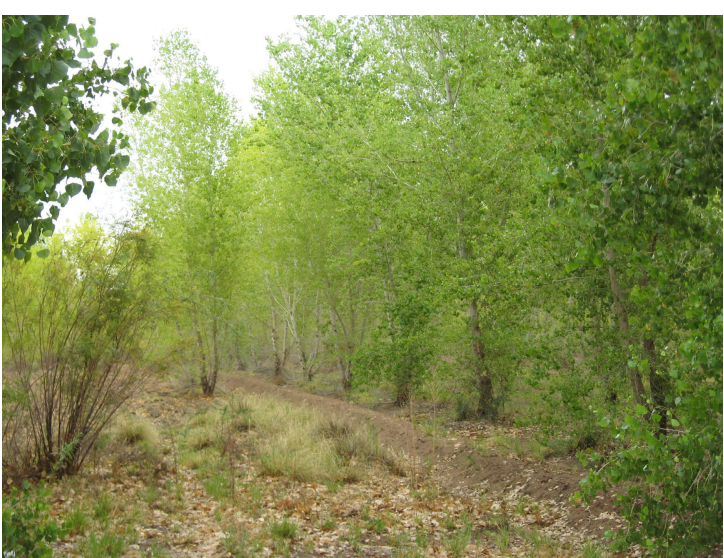

Colorado River Indian Tribes Restoration

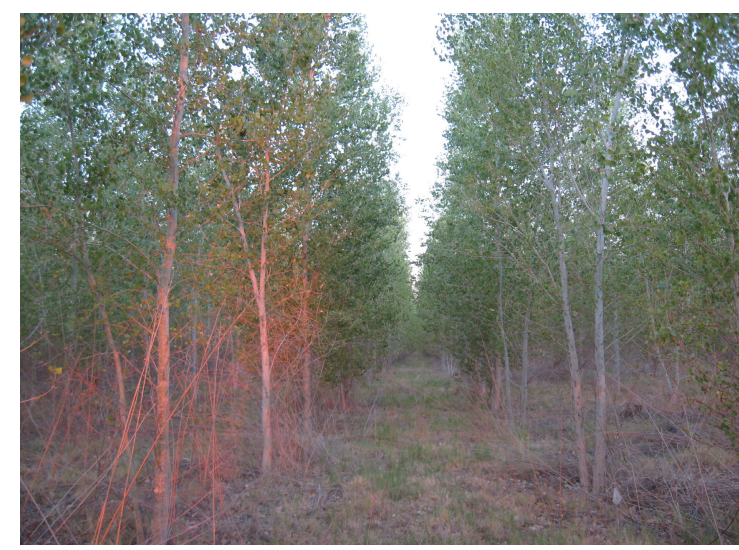

Cibola NWR, North Restoration

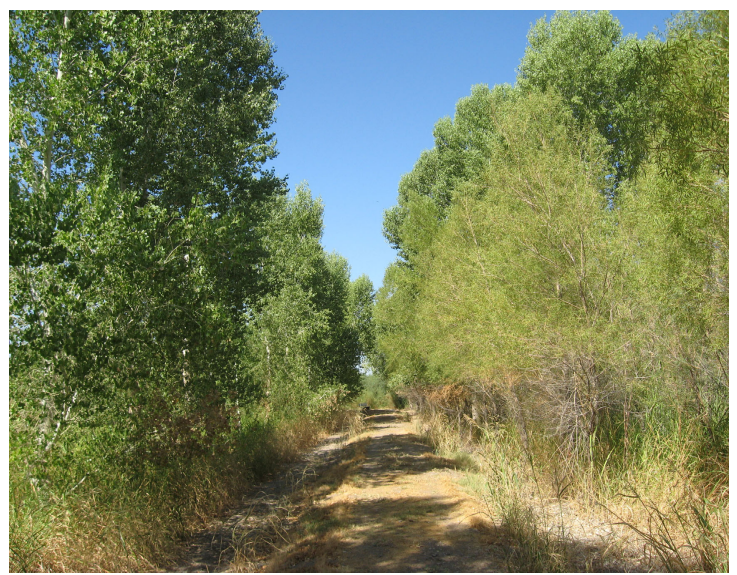

Cibola NWR, Nature Trail Restoration 


\section{Cibola National Wildlife Refuge, AZ (continued)}

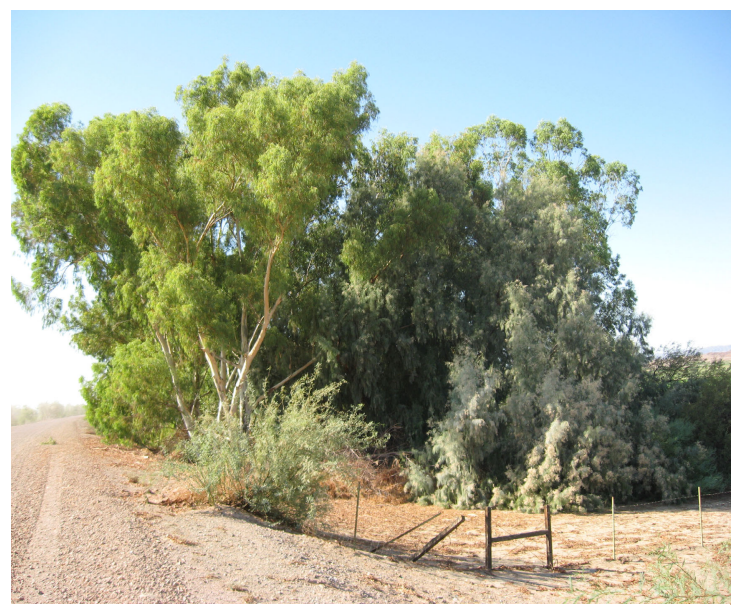

Cibola NWR, Eucalyptus Restoration

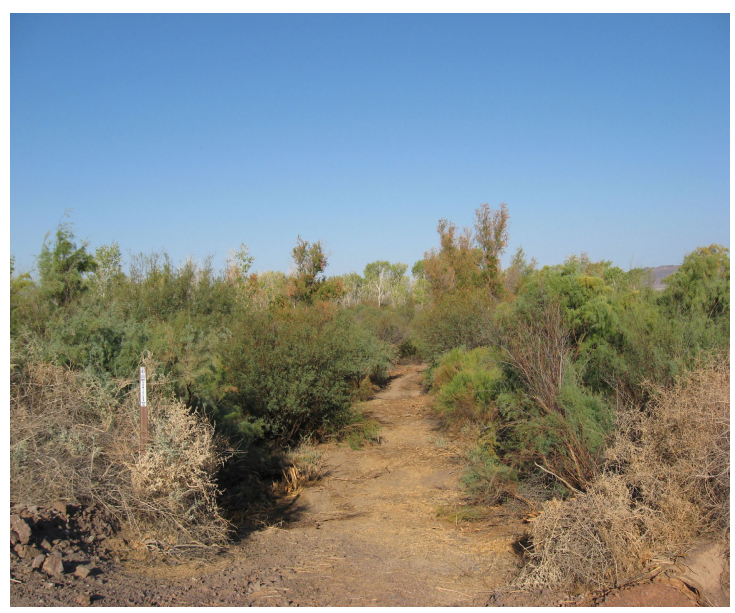

Cibola NWR, South Restoration

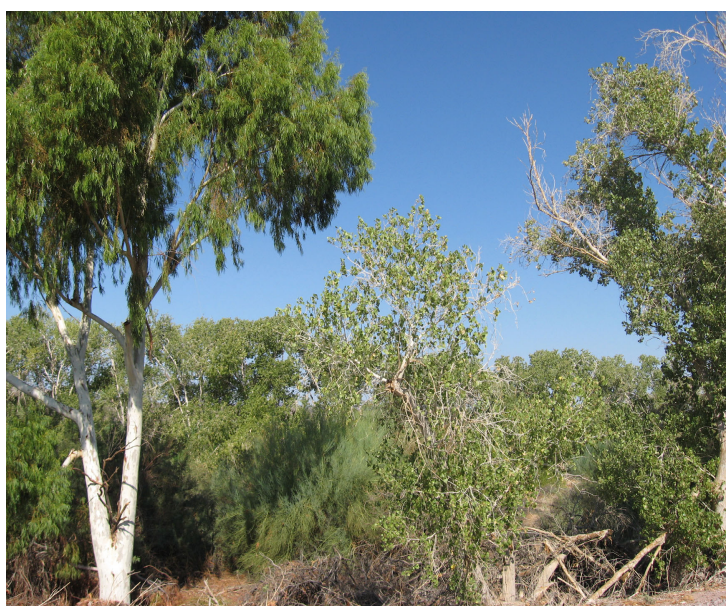

Cibola NWR, Eucalyptus Restoration

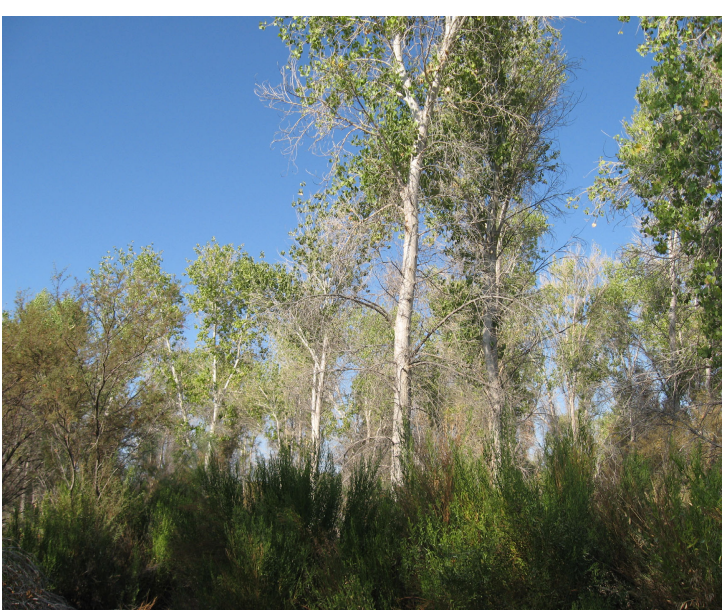

Cibola NWR, South Restoration

\section{Picacho State Recreation Area, CA}

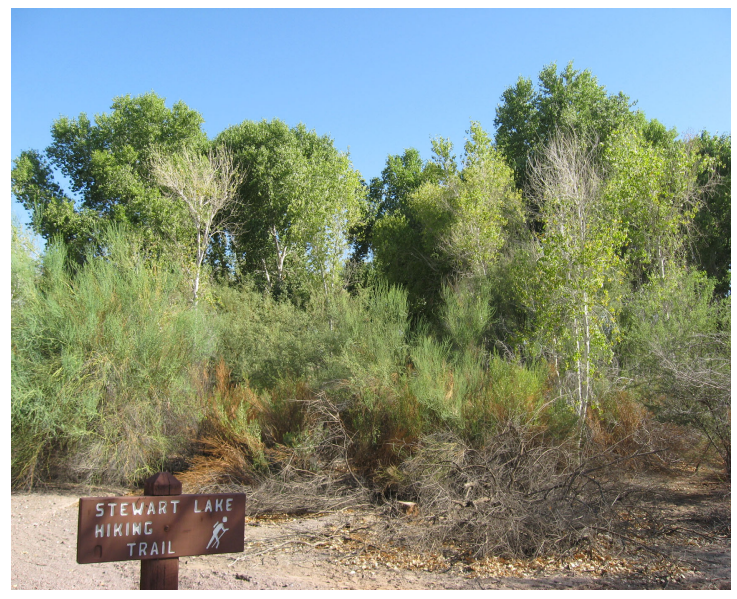

Picacho SRA

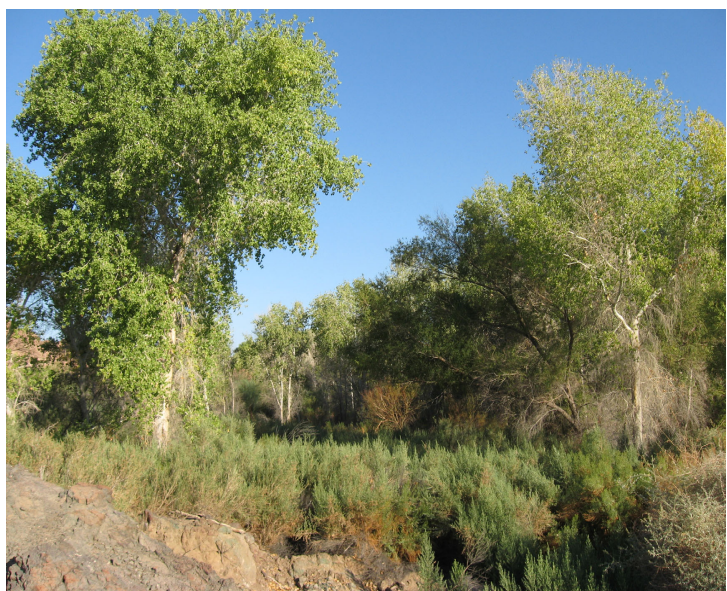

Picacho SRA 


\section{Imperial National Wildlife Refuge, AZ}

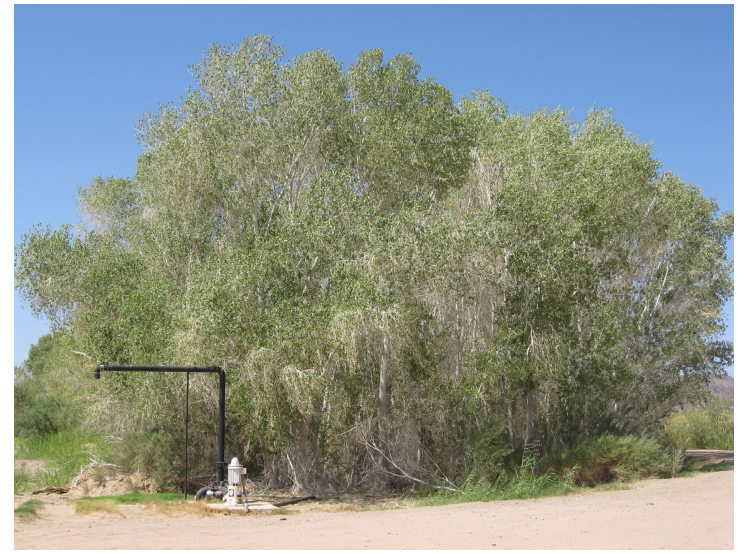

Imperial NWR, Imperial South Restoration

\section{Mittry Lake Wildlife Management Area}

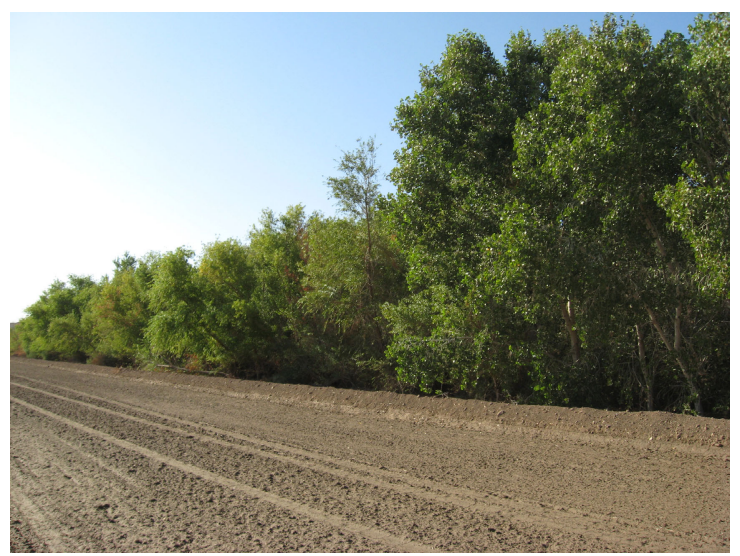

Pratt Restoration

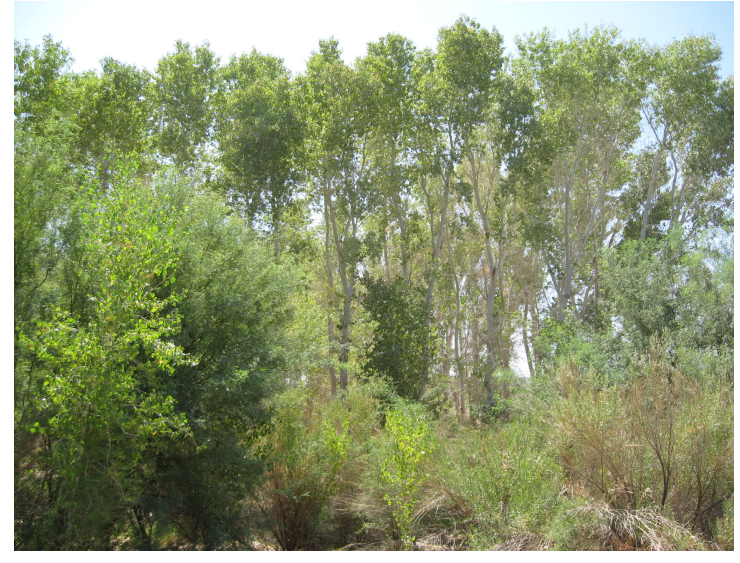

Imperial NWR, Imperial South Restoration

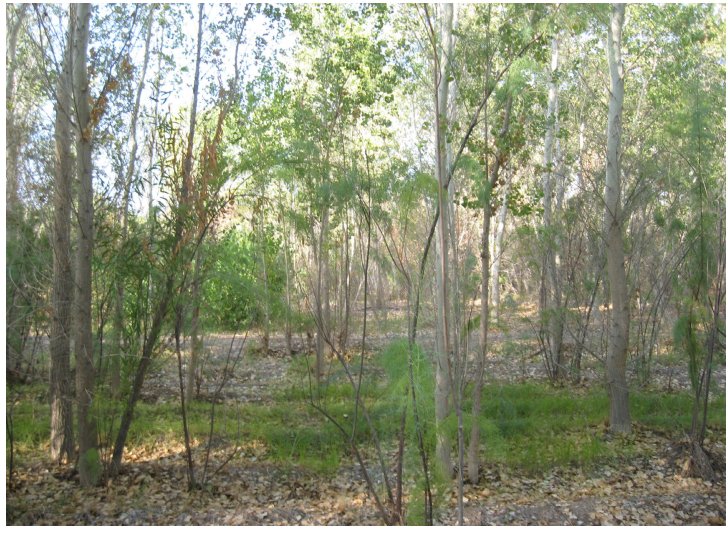

Pratt Restoration

\section{Gila/Colorado River Confluence, AZ and CA}

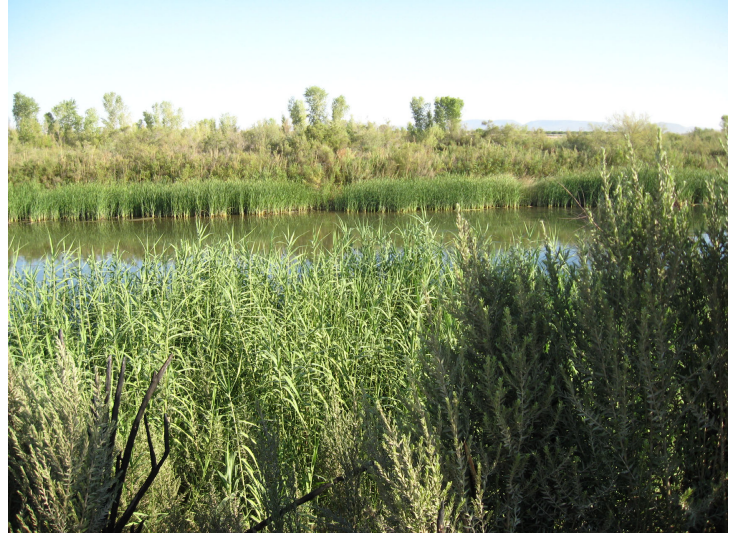

Gila/Colorado River Confluence, Colorado River

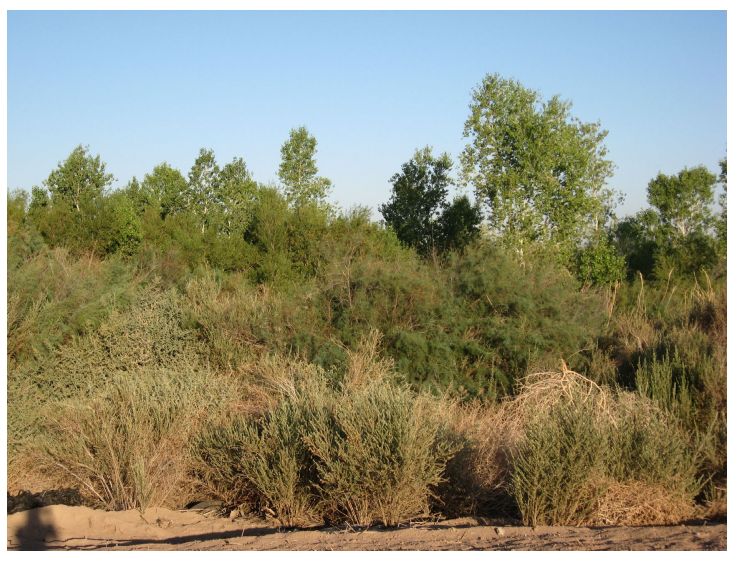

Gila/Colorado River Confluence, Colorado River 


\section{Gila/Colorado River Confluence, AZ and CA (continued)}

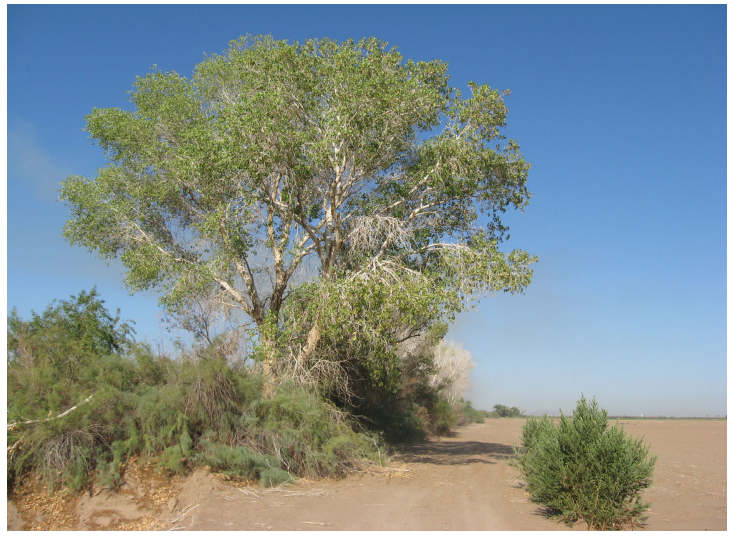

Gila/Colorado River Confluence, Gila River

\section{Yuma West Wetlands, AZ}

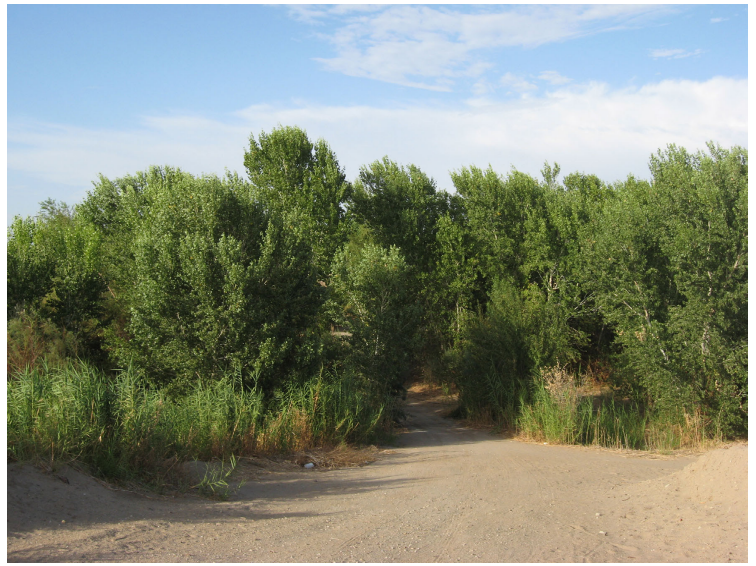

Yuma West Wetlands

\section{Limitrophe Division, AZ}

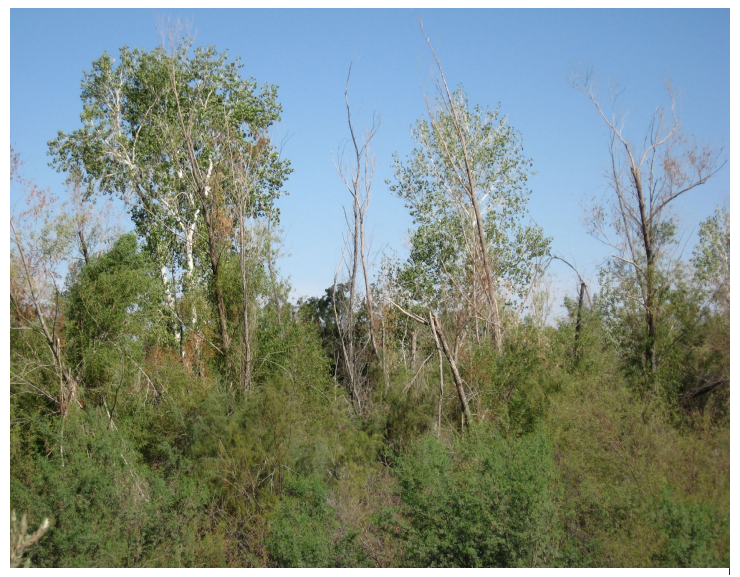

Limitrophe Division North

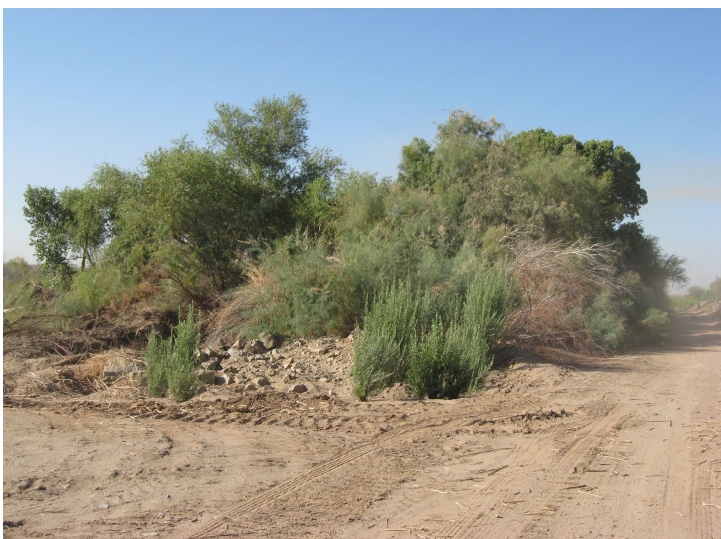

Gila/Colorado River Confluence, Gila River

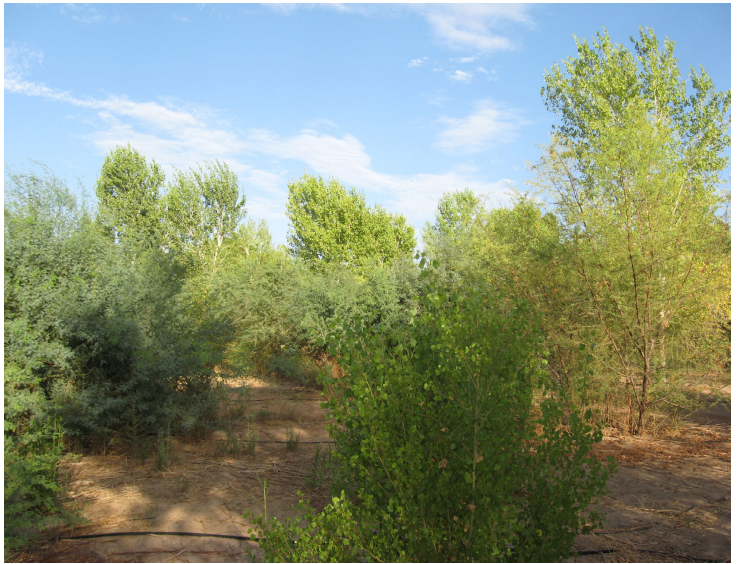

Yuma West Wetlands

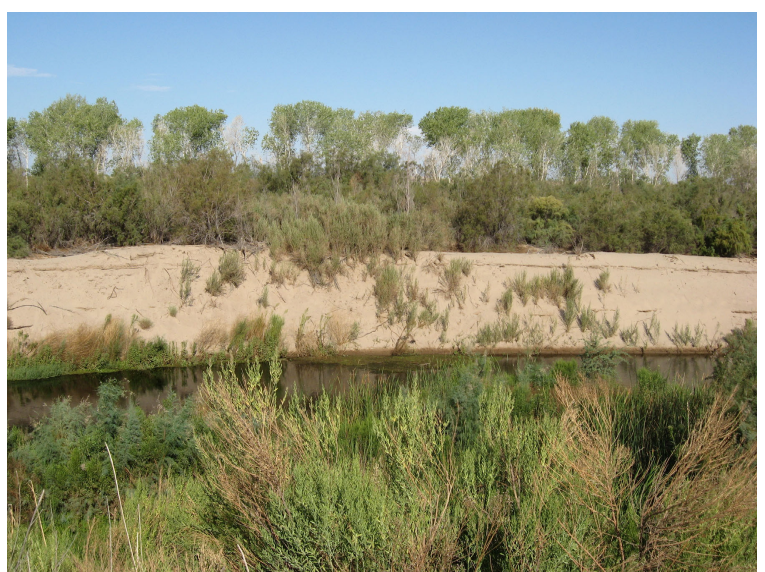

Limitrophe Division North 


\section{Limitrophe Division, AZ (continued)}

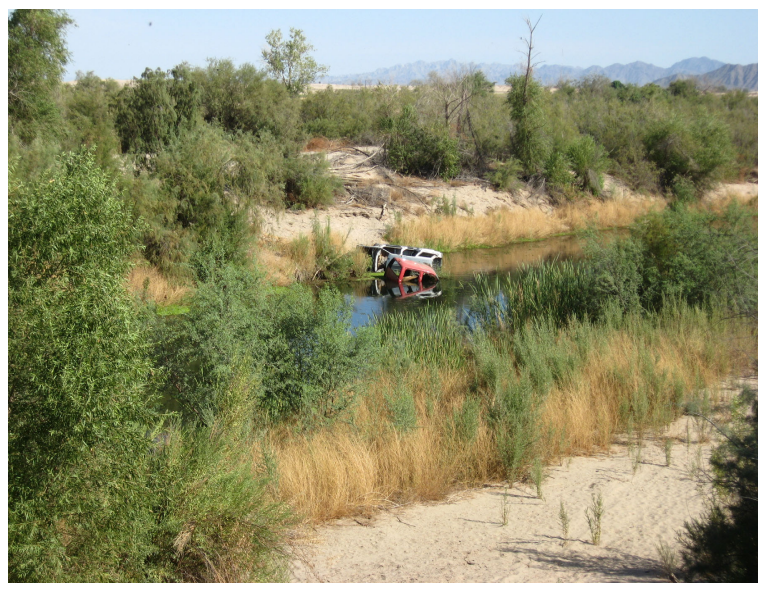

Limitrophe Division North

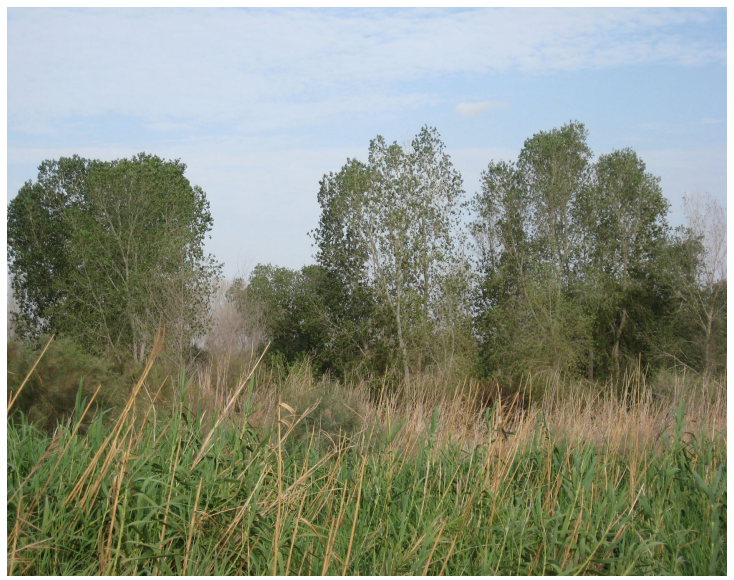

Limitrophe Division South

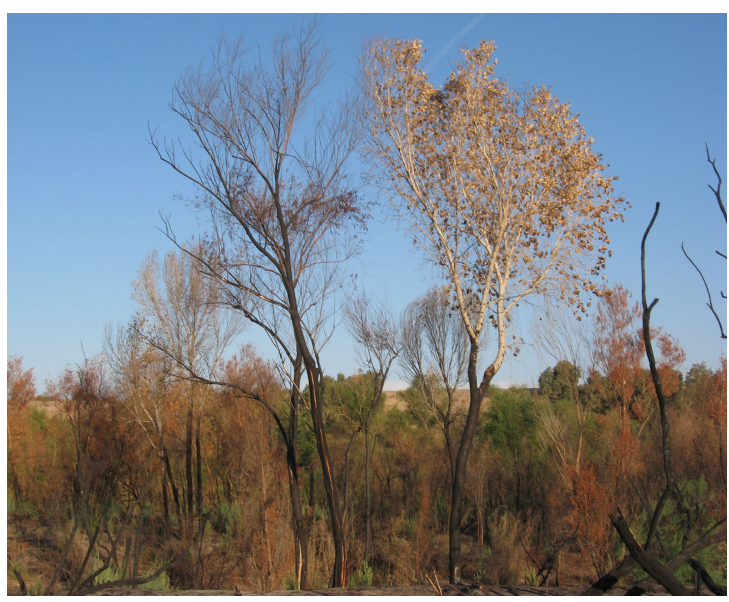

Limitrophe Division North burn

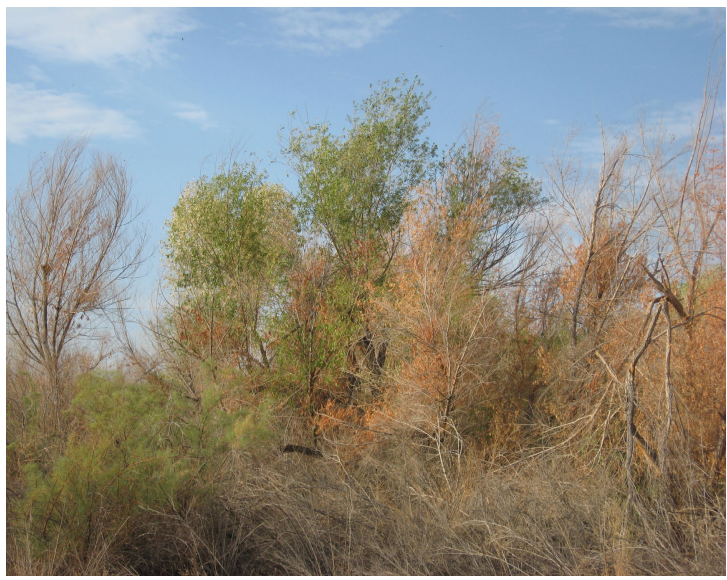

Limitrophe Division South 


\section{Gila River/Quigley Pond Wildlife Management Area, AZ}

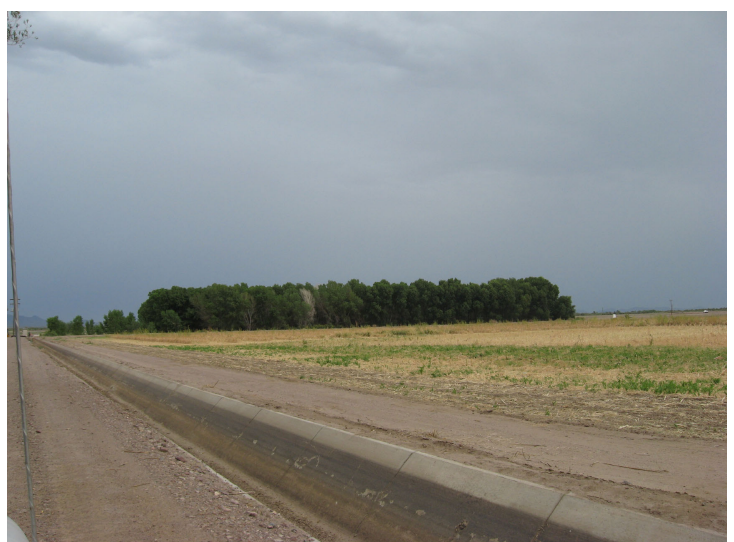

Gila River/Quigley Pond WMA

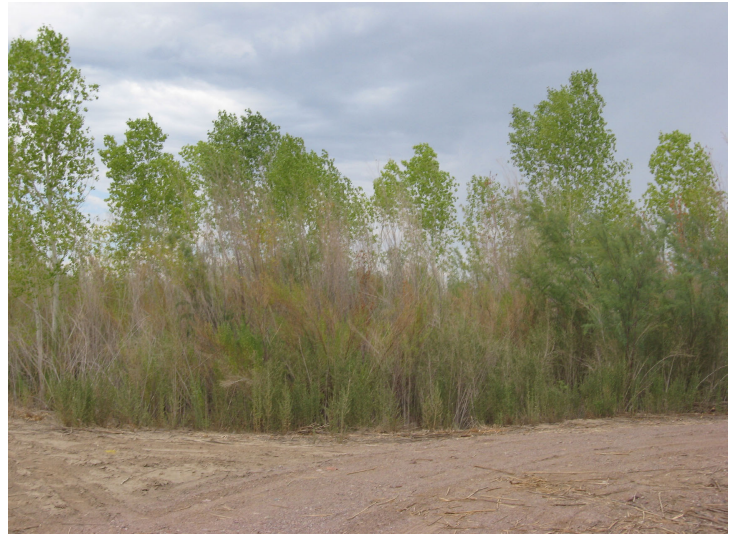

Gila River/Quigley Pond WMA

Gila River/Quigley Pond Wildlife Management Area, AZ

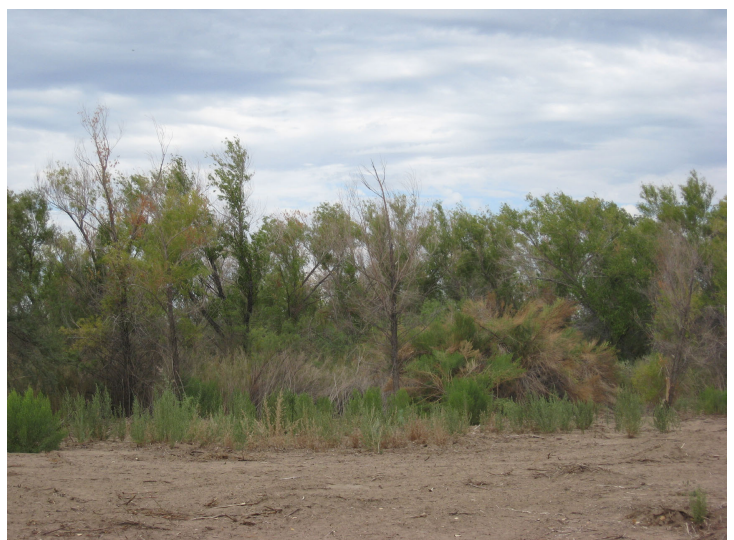

Gila River/Quigley Pond WMA

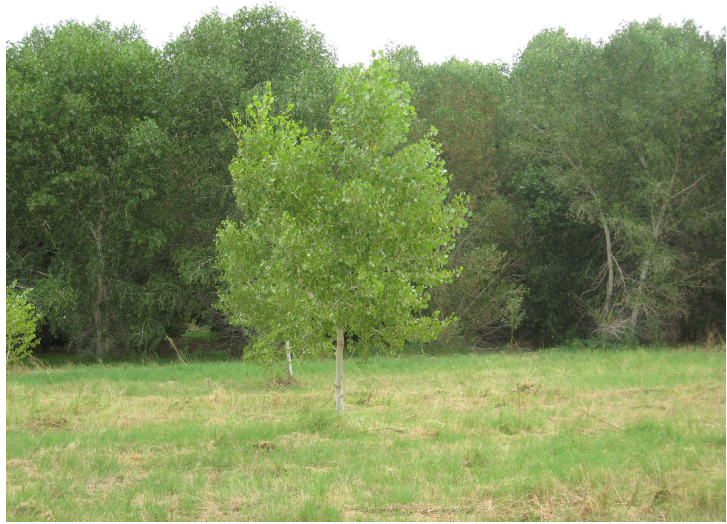

Gila River/Quigley Pond WMA 
This page intentionally left blank 


\section{Appendix 6. List of Other Bird Species Observed During Yellow-billed Cuckoo Surveys in the Lower Colorado River Watershed}

Table 6-1. List of other bird species observed during 2007 yellow-billed cuckoo surveys, in the lower Colorado River watershed along the White and Muddy Rivers, Nevada, lower Colorado, Bill Williams and Gila Rivers, Arizona and California.

\begin{tabular}{|c|c|c|c|c|c|c|}
\hline Common name & Scientific name & $\begin{array}{c}\text { Survey } \\
1\end{array}$ & $\begin{array}{c}\text { Survey } \\
2\end{array}$ & $\begin{array}{c}\text { Survey } \\
\mathbf{3}\end{array}$ & $\begin{array}{c}\text { Survey } \\
4\end{array}$ & $\begin{array}{c}\text { Survey } \\
\mathbf{5}\end{array}$ \\
\hline \multicolumn{7}{|c|}{ Pahranagat National Wildlife Refuge (White River) } \\
\hline Clarks's Grebe & Aechmophorus clarkii & - & - & $\mathrm{X}$ & $\mathrm{X}$ & \\
\hline American White Pelican & Pelecanus erythrorhynchos & - & - & $\mathrm{X}$ & - & \\
\hline Great Blue Heron & Ardea herodias & $\mathrm{X}$ & $\mathrm{X}$ & $\mathrm{X}$ & - & \\
\hline Great Egret & Ardea alba & - & - & $\mathrm{X}$ & - & \\
\hline Turkey Vulture & Cathartes aura & $\mathrm{X}$ & - & - & $\mathrm{X}$ & \\
\hline Canada Goose & Branta canadensis & $\mathrm{X}$ & $\mathrm{X}$ & $\mathrm{X}$ & - & \\
\hline Osprey & Pandion haliaetus & - & - & $\mathrm{X}$ & - & \\
\hline American Kestrel & Falco Sparverius & - & - & $\mathrm{X}$ & - & \\
\hline Virginia Rail & Rallus limicola & - & - & $\mathrm{X}$ & - & \\
\hline American Coot & Fulica americana & $\mathrm{X}$ & - & $\mathrm{X}$ & $\mathrm{X}$ & \\
\hline Spotted Sandpiper & Actitus macularia & - & - & $\mathrm{X}$ & - & \\
\hline Belted Kingfisher & Ceryle alcyon & - & - & - & $\mathrm{X}$ & \\
\hline Nuttall's Woodpecker & Picoides nuttallii & - & - & $\mathrm{X}$ & - & \\
\hline Willow Flycatcher & Empidonax traillii & $\mathrm{X}$ & - & $\mathrm{X}$ & - & \\
\hline Brown-crested Flycatcher & Myiarchus tyrannulus & $\mathrm{X}$ & $\mathrm{X}$ & $\mathrm{X}$ & - & \\
\hline Warbling Vireo & Vireo gilvus & - & - & $\mathrm{X}$ & - & \\
\hline Common Raven & Corvus corax & - & - & $\mathrm{X}$ & - & \\
\hline Violet-green Swallow & Tachycineta thalassina & - & - & $\mathrm{X}$ & - & \\
\hline Cliff Swallow & Petrochelidon pyrrhonota & - & - & $\mathrm{X}$ & - & \\
\hline Bewick's Wren & Thryomanes bewickii & - & - & $\mathrm{X}$ & - & \\
\hline Marsh Wren & Cistothorus palustris & - & - & $\mathrm{X}$ & - & \\
\hline Lucy's Warbler & Vermivora luciae & - & - & $\mathrm{X}$ & - & \\
\hline Townsend's Warbler & Dendroica townsendi & - & - & $\mathrm{X}$ & - & \\
\hline Yellow Warbler & Dendroica petechia & $\mathrm{X}$ & $\mathrm{X}$ & $\mathrm{X}$ & - & \\
\hline Common Yellowthroat & Geothlypis trichas & - & - & $\mathrm{X}$ & - & \\
\hline Yellow-breasted Chat & Icteria virens & $\mathrm{X}$ & - & $\mathrm{X}$ & - & \\
\hline Western Tanager & Piranga ludoviciana & - & - & $\mathrm{X}$ & - & \\
\hline Song Sparrow & Melospiza melodia & - & - & $\mathrm{X}$ & - & \\
\hline
\end{tabular}


Table 6-1. List of other bird species observed during 2007 yellow-billed cuckoo surveys, in the lower Colorado River watershed along the White and Muddy Rivers, Nevada, lower Colorado, Bill Williams and Gila Rivers, Arizona and California.-Continued

\begin{tabular}{|c|c|c|c|c|c|c|}
\hline Common name & Scientific name & $\begin{array}{c}\text { Survey } \\
1\end{array}$ & $\begin{array}{c}\text { Survey } \\
2\end{array}$ & $\begin{array}{c}\text { Survey } \\
3 \\
\end{array}$ & $\begin{array}{c}\text { Survey } \\
4\end{array}$ & $\begin{array}{c}\text { Survey } \\
5\end{array}$ \\
\hline Lazuli Bunting & Passerina amoena & - & - & $\mathrm{X}$ & - & \\
\hline Red-winged Blackbird & Agelaius phoeniceus & - & - & $\mathrm{X}$ & - & \\
\hline Great-tailed Grackle & Quiscalus mexicanus & - & - & $\mathrm{X}$ & - & \\
\hline Brown-headed Cowbird & Molothrus ater & $\mathrm{X}$ & - & - & - & \\
\hline Bullock's Oriole & Icterus bullockii & - & - & $\mathrm{X}$ & - & \\
\hline House Finch & Carpodacus mexicanus & - & - & $\mathrm{X}$ & - & \\
\hline Lesser Goldfinch & Carduelis psaltria & - & - & $\mathrm{X}$ & - & \\
\hline \multicolumn{7}{|c|}{ Overton Wildlife Management Area (Muddy River) } \\
\hline Clarks's Grebe & Aechmophorus clarkii & - & $\mathrm{X}$ & $\mathrm{X}$ & - & \\
\hline Double-crested Cormorant & Phalacrocorax auritus & - & $\mathrm{X}$ & - & - & \\
\hline American Bittern & Botaurus lentiginosus & - & $\mathrm{X}$ & - & - & \\
\hline Great Blue Heron & Ardea herodias & $\mathrm{X}$ & $\mathrm{X}$ & $\mathrm{X}$ & - & \\
\hline Cattle Egret & Bubulcus ibis & - & $\mathrm{X}$ & - & - & \\
\hline Black-crowned Night Heron & Nycticorax nycticorax & - & - & $\mathrm{X}$ & - & \\
\hline Canada Goose & Branta canadensis & - & $\mathrm{X}$ & $\mathrm{X}$ & $\mathrm{X}$ & \\
\hline Mallard & Anas platyrhynchos & - & - & $\mathrm{X}$ & - & \\
\hline Cooper's Hawk & Accipiter cooperii & - & - & $\mathrm{X}$ & - & \\
\hline American Kestrel & Falco Sparverius & - & $X$ & - & - & \\
\hline Wild Turkey & Meleagris gallopavo & $\mathrm{X}$ & $\mathrm{X}$ & - & - & \\
\hline Gambel's Quail & Callipepla gambellii & - & $\mathrm{X}$ & $\mathrm{X}$ & - & \\
\hline Virginia Rail & Rallus limicola & - & - & - & $\mathrm{X}$ & \\
\hline American Coot & Fulica americana & - & - & $X$ & - & \\
\hline Spotted Sandpiper & Actitus macularia & - & - & $\mathrm{X}$ & - & \\
\hline White-winged Dove & Zenaida asiatica & - & $\mathrm{X}$ & - & - & \\
\hline Mourning Dove & Zenaida macroura & $\mathrm{X}$ & $\mathrm{X}$ & $\mathrm{X}$ & - & \\
\hline Greater Roadrunner & Geococcyx californianus & - & $\mathrm{X}$ & $\mathrm{X}$ & $\mathrm{X}$ & \\
\hline Great Horned Owl & Bubo virginianus & - & - & - & $\mathrm{X}$ & \\
\hline Willow Flycatcher & Empidonax traillii & $\mathrm{X}$ & $\mathrm{X}$ & - & - & \\
\hline Common Raven & Corvus corax & - & - & $X$ & - & \\
\hline $\begin{array}{l}\text { Northern Rough-winged } \\
\text { Swallow }\end{array}$ & Stelgidopteryx serripennis & $\mathrm{X}$ & - & - & - & \\
\hline Yellow Warbler & Dendroica petechia & $\mathrm{X}$ & $\mathrm{X}$ & $X$ & $X$ & \\
\hline
\end{tabular}


Table 6-1. List of other bird species observed during 2007 yellow-billed cuckoo surveys, in the lower Colorado River watershed along the White and Muddy Rivers, Nevada, lower Colorado, Bill Williams and Gila Rivers, Arizona and California.-Continued

\begin{tabular}{|c|c|c|c|c|c|c|}
\hline Common name & Scientific name & $\begin{array}{c}\text { Survey } \\
1\end{array}$ & $\begin{array}{c}\text { Survey } \\
2\end{array}$ & $\begin{array}{c}\text { Survey } \\
3 \\
\end{array}$ & $\begin{array}{c}\text { Survey } \\
4\end{array}$ & $\begin{array}{c}\text { Survey } \\
5\end{array}$ \\
\hline Common Yellowthroat & Geothlypis trichas & $\mathrm{X}$ & $\mathrm{X}$ & $\mathrm{X}$ & - & \\
\hline Yellow-breasted Chat & Icteria virens & $\mathrm{X}$ & $\mathrm{X}$ & $\mathrm{X}$ & - & \\
\hline Song Sparrow & Melospiza melodia & $\mathrm{X}$ & - & $\mathrm{X}$ & - & \\
\hline Red-winged Blackbird & Agelaius phoeniceus & $\mathrm{X}$ & - & $\mathrm{X}$ & $\mathrm{X}$ & \\
\hline Great-tailed Grackle & Quiscalus mexicanus & - & - & $\mathrm{X}$ & - & \\
\hline Brown-headed Cowbird & Molothrus ater & $\mathrm{X}$ & $\mathrm{X}$ & - & - & \\
\hline \multicolumn{7}{|c|}{ Grand Canyon National Park/Lake Mead National Recreation Area (Colorado River) } \\
\hline Brown Pelican & Pelecanus occidentalis & - & - & $\mathrm{X}$ & - & \\
\hline Great Blue Heron & Ardea herodias & $\mathrm{X}$ & $\mathrm{X}$ & - & $\mathrm{X}$ & \\
\hline Snowy Egret & Egretta thula & - & $\mathrm{X}$ & - & - & \\
\hline Black-crowned Night-heron & Nycticorax nycticorax & - & - & $\mathrm{X}$ & - & \\
\hline White-Faced Ibis & Plegadis chihi & $\mathrm{X}$ & - & $\mathrm{X}$ & - & \\
\hline Turkey Vulture & Cathartes aura & $\mathrm{X}$ & $\mathrm{X}$ & - & $\mathrm{X}$ & \\
\hline Sharp-shinned Hawk & Accipiter striatus & - & $\mathrm{X}$ & - & - & \\
\hline Red-tailed Hawk & Buteo jamaicensis & - & $\mathrm{X}$ & $\mathrm{X}$ & - & \\
\hline Perigrine Falcon & Falco peregrinus & - & - & $\mathrm{X}$ & - & \\
\hline Gambel's Quail & Callipepla gambellii & - & - & $\mathrm{X}$ & - & \\
\hline Spotted Sandpiper & Actitus macularia & $\mathrm{X}$ & - & - & $\mathrm{X}$ & \\
\hline Ring-billed Gull & Larus delewarensis & - & - & $\mathrm{X}$ & - & \\
\hline Mourning Dove & Zenaida macroura & - & - & $\mathrm{X}$ & - & \\
\hline White-throated Swift & Aeronautes saxatalis & - & $\mathrm{X}$ & $\mathrm{X}$ & $\mathrm{X}$ & \\
\hline Greater Roadrunner & Geococcyx californianus & - & $\mathrm{X}$ & - & - & \\
\hline Western Wood-Pewee & Contopus sordidulus & $\mathrm{X}$ & - & - & - & \\
\hline Willow Flycatcher & Empidonax traillii & $\mathrm{X}$ & - & - & - & \\
\hline Black Phoebe & Sayornis nigricans & $\mathrm{X}$ & - & - & $\mathrm{X}$ & \\
\hline Ash-throated Flycatcher & Myiarchus cinerascens & $\mathrm{X}$ & $\mathrm{X}$ & - & - & \\
\hline Bell's Vireo & Vireo bellii & $\mathrm{X}$ & $\mathrm{X}$ & $\mathrm{X}$ & $\mathrm{X}$ & \\
\hline Plumbeous Vireo & Vireo plumbeus & $\mathrm{X}$ & - & - & - & \\
\hline Common Raven & Corvus corax & $\mathrm{X}$ & $\mathrm{X}$ & $\mathrm{X}$ & - & \\
\hline Violet-Green Swallow & Tachycineta thalassina & $\mathrm{X}$ & - & - & - & \\
\hline $\begin{array}{l}\text { Northern Rough-winged } \\
\text { Swallow }\end{array}$ & Stelgidopteryx serripennis & $\mathrm{X}$ & - & - & - & \\
\hline
\end{tabular}


Table 6-1. List of other bird species observed during 2007 yellow-billed cuckoo surveys, in the lower Colorado River watershed along the White and Muddy Rivers, Nevada, lower Colorado, Bill Williams and Gila Rivers, Arizona and California.-Continued

\begin{tabular}{|c|c|c|c|c|c|c|}
\hline Common name & Scientific name & $\begin{array}{c}\text { Survey } \\
1\end{array}$ & $\begin{array}{c}\text { Survey } \\
2 \\
\end{array}$ & $\begin{array}{c}\text { Survey } \\
\mathbf{3} \\
\end{array}$ & $\begin{array}{c}\text { Survey } \\
4 \\
\end{array}$ & $\begin{array}{c}\text { Survey } \\
5 \\
\end{array}$ \\
\hline Bushtit & Psaltriparus minimus & $\mathrm{X}$ & - & - & - & \\
\hline Rock Wren & Salpinctes obsoletus & - & - & $\mathrm{X}$ & - & \\
\hline Canyon Wren & Catherpes mexicanus & $\mathrm{X}$ & $\mathrm{X}$ & $\mathrm{X}$ & $\mathrm{X}$ & \\
\hline Bewick's Wren & Thryomanes bewickii & $\mathrm{X}$ & - & $\mathrm{X}$ & - & \\
\hline Blue-gray Gnatcatcher & Polioptila caerulea & $\mathrm{X}$ & - & - & - & \\
\hline Yellow Warbler & Dendroica petechia & $\mathrm{X}$ & $\mathrm{X}$ & $\mathrm{X}$ & $\mathrm{X}$ & \\
\hline Yellow-rumped Warbler & Dendroica coronata & - & - & $\mathrm{X}$ & - & \\
\hline Common Yellowthroat & Geothlypis trichas & - & $\mathrm{X}$ & $\mathrm{X}$ & $\mathrm{X}$ & \\
\hline Yellow-breasted Chat & Icteria virens & $\mathrm{X}$ & $\mathrm{X}$ & $\mathrm{X}$ & $\mathrm{X}$ & \\
\hline Summer Tanager & Piranga rubra & - & - & $\mathrm{X}$ & - & \\
\hline Western Tanager & Piranga ludoviciana & $\mathrm{X}$ & - & $\mathrm{X}$ & - & \\
\hline Black-throated Sparrow & Amphispiza bilineata & - & $\mathrm{X}$ & - & - & \\
\hline Song Sparrow & Melospiza melodia & $\mathrm{X}$ & $\mathrm{X}$ & $\mathrm{X}$ & $\mathrm{X}$ & \\
\hline Blue Grosbeak & Guiraca caerulea & - & - & $\mathrm{X}$ & - & \\
\hline Lazuli Bunting & Passerina amoena & $\mathrm{X}$ & $\mathrm{X}$ & $\mathrm{X}$ & - & \\
\hline Red-winged Blackbird & Agelaius phoeniceus & $\mathrm{X}$ & $\mathrm{X}$ & $\mathrm{X}$ & - & \\
\hline Brown-headed Cowbird & Molothrus ater & $\mathrm{X}$ & $\mathrm{X}$ & $\mathrm{X}$ & - & \\
\hline Bullock's Oriole & Icterus bullockii & - & $\mathrm{X}$ & - & - & \\
\hline House Finch & Carpodacus mexicanus & - & - & $\mathrm{X}$ & - & \\
\hline \multicolumn{7}{|c|}{ Havasu National Wildlife Refuge (Colorado River) } \\
\hline Eared Grebe & Podiceps nigricollis & $X$ & - & - & - & \\
\hline Western Grebe & Aechmophorus occidentalis & $\mathrm{X}$ & - & - & - & \\
\hline Clarks's Grebe & Aechmophorus clarkii & - & $\mathrm{X}$ & - & - & \\
\hline Double-crested Cormorant & Phalacrocorax auritus & - & - & $X$ & - & \\
\hline Great Blue Heron & Ardea herodias & - & $\mathrm{X}$ & - & - & \\
\hline Great Egret & Ardea alba & - & $\mathrm{X}$ & - & $\mathrm{X}$ & \\
\hline Green Heron & Butorides virescens & - & - & $\mathrm{X}$ & $\mathrm{X}$ & \\
\hline Black-crowned Night Heron & Nycticorax nycticorax & - & $X$ & - & - & \\
\hline White-faced Ibis & Plegadis chihi & - & $\mathrm{X}$ & - & $\mathrm{X}$ & \\
\hline Turkey Vulture & Cathartes aura & $X$ & $\mathrm{X}$ & $X$ & $X$ & \\
\hline Canada Goose & Branta canadensis & - & - & - & $\mathrm{X}$ & \\
\hline Cinnamon Teal & Anas cyanoptera & - & - & - & $X$ & \\
\hline
\end{tabular}


Table 6-1. List of other bird species observed during 2007 yellow-billed cuckoo surveys, in the lower Colorado River watershed along the White and Muddy Rivers, Nevada, lower Colorado, Bill Williams and Gila Rivers, Arizona and California.-Continued

\begin{tabular}{|c|c|c|c|c|c|c|}
\hline Common name & Scientific name & $\begin{array}{c}\text { Survey } \\
1\end{array}$ & $\begin{array}{c}\text { Survey } \\
2 \\
\end{array}$ & $\begin{array}{c}\text { Survey } \\
\mathbf{3} \\
\end{array}$ & $\begin{array}{c}\text { Survey } \\
4 \\
\end{array}$ & $\begin{array}{c}\text { Survey } \\
5 \\
\end{array}$ \\
\hline Cooper's Hawk & Accipeter cooperii & $\mathrm{X}$ & - & - & - & \\
\hline Common Black Hawk & Buteogallus anthracinus & - & - & $\mathrm{X}$ & - & \\
\hline Red-tailed Hawk & Buteo jamaicensis & $\mathrm{X}$ & - & - & - & \\
\hline American Kestrel & Falco Sparverius & - & - & $\mathrm{X}$ & $\mathrm{X}$ & \\
\hline Gambel's Quail & Callipepla gambellii & $\mathrm{X}$ & $\mathrm{X}$ & $\mathrm{X}$ & $\mathrm{X}$ & \\
\hline Virginia Rail & Rallus limicola & - & - & $\mathrm{X}$ & - & \\
\hline American Coot & Fulica americana & $\mathrm{X}$ & $\mathrm{X}$ & $\mathrm{X}$ & - & \\
\hline Killdeer & Charadrius vociferus & - & - & $\mathrm{X}$ & - & \\
\hline Greater Yellowlegs & Tringa melanoleuca & - & - & - & $\mathrm{X}$ & \\
\hline Spotted Sandpiper & Actitus macularia & - & - & $\mathrm{X}$ & - & \\
\hline Western Sandpiper & Calidris mauri & - & - & - & $\mathrm{X}$ & \\
\hline White-winged Dove & Zenaida asiatica & $\mathrm{X}$ & $\mathrm{X}$ & $\mathrm{X}$ & $\mathrm{X}$ & \\
\hline Mourning Dove & Zenaida macroura & $\mathrm{X}$ & $\mathrm{X}$ & $\mathrm{X}$ & $\mathrm{X}$ & \\
\hline Yellow-billed Cuckoo & Coccyzus americanus & $\mathrm{X}$ & $\mathrm{X}$ & $\mathrm{X}$ & - & \\
\hline Greater Roadrunner & Geococcyx californianus & $\mathrm{X}$ & $\mathrm{X}$ & - & $\mathrm{X}$ & \\
\hline Great Horned Owl & Tyto alba & - & $\mathrm{X}$ & - & - & \\
\hline Lesser Nighthawk & Chordeiles acutipennis & $\mathrm{X}$ & $\mathrm{X}$ & - & - & \\
\hline Black-chinned Hummingbird & Archilochus alexandri & $\mathrm{X}$ & $\mathrm{X}$ & - & - & \\
\hline Broad-tailed Hummingbird & Selasphorus platycercus & $\mathrm{X}$ & - & - & - & \\
\hline Gila Woodpecker & Melanerpes uropygialis & - & $\mathrm{X}$ & $\mathrm{X}$ & $\mathrm{X}$ & \\
\hline Ladder-backed Woodpecker & Picoides scalaris & - & $\mathrm{X}$ & $\mathrm{X}$ & - & \\
\hline Pacific-slope Flycatcher & Empidonax difficilis & - & - & $\mathrm{X}$ & - & \\
\hline Black Phoebe & Sayornis nigricans & - & $\mathrm{X}$ & $\mathrm{X}$ & $\mathrm{X}$ & \\
\hline Say's Phoebe & Sayornis saya & $\mathrm{X}$ & - & - & - & \\
\hline Ash-throated Flycatcher & Myiarchus cinerascens & $\mathrm{X}$ & $\mathrm{X}$ & $\mathrm{X}$ & $\mathrm{X}$ & \\
\hline Brown-crested Flycatcher & Myiarchus tyrannulus & - & - & $\mathrm{X}$ & - & \\
\hline Cassin's Kingbird & Tyrannus vociferans & $\mathrm{X}$ & - & - & - & \\
\hline Western Kingbird & Tyrannus verticalis & $\mathrm{X}$ & $\mathrm{X}$ & $\mathrm{X}$ & $\mathrm{X}$ & \\
\hline Bell's Vireo & Vireo bellii & $\mathrm{X}$ & $X$ & $\mathrm{X}$ & - & \\
\hline Warbling Vireo & Vireo gilvus & - & $\mathrm{X}$ & $\mathrm{X}$ & - & \\
\hline Common Raven & Corvus corax & - & - & $\mathrm{X}$ & $\mathrm{X}$ & \\
\hline
\end{tabular}


Table 6-1. List of other bird species observed during 2007 yellow-billed cuckoo surveys, in the lower Colorado River watershed along the White and Muddy Rivers, Nevada, lower Colorado, Bill Williams and Gila Rivers, Arizona and California.-Continued

\begin{tabular}{|c|c|c|c|c|c|c|}
\hline Common name & Scientific name & $\begin{array}{c}\text { Survey } \\
1\end{array}$ & $\begin{array}{c}\text { Survey } \\
2\end{array}$ & $\begin{array}{c}\text { Survey } \\
3\end{array}$ & $\begin{array}{c}\text { Survey } \\
4\end{array}$ & $\begin{array}{l}\text { Survey } \\
5\end{array}$ \\
\hline $\begin{array}{l}\text { Northern Rough-winged } \\
\text { Swallow }\end{array}$ & Stelgidopteryx serripennis & - & - & $\mathrm{X}$ & - & \\
\hline Cliff Swallow & Petrochelidon pyrrhonota & - & $\mathrm{X}$ & $\mathrm{X}$ & - & \\
\hline Verdin & Auriparus flaviceps & - & - & $\mathrm{X}$ & $\mathrm{X}$ & \\
\hline Marsh Wren & Cistothorus palustris & - & $\mathrm{X}$ & - & - & \\
\hline Blue-gray Gnatcatcher & Polioptila caerulea & $\mathrm{X}$ & - & - & - & \\
\hline Black-tailed Gnatcatcher & Polioptila melanura & - & - & $\mathrm{X}$ & - & \\
\hline Northern Mockingbird & Mimus polyglottos & $\mathrm{X}$ & - & $\mathrm{X}$ & - & \\
\hline Crissal Thrasher & Toxostoma crissale & - & - & - & $\mathrm{X}$ & \\
\hline Nashville Warbler & Vermivora ruficapilla & - & - & $\mathrm{X}$ & - & \\
\hline Lucy's Warbler & Vermivora luciae & $\mathrm{X}$ & - & $\mathrm{X}$ & - & \\
\hline Yellow Warbler & Dendroica petechia & - & - & - & $\mathrm{X}$ & \\
\hline Common Yellowthroat & Geothlypis trichas & $\mathrm{X}$ & - & - & $\mathrm{X}$ & \\
\hline Yellow-breasted Chat & Icteria virens & $\mathrm{X}$ & $\mathrm{X}$ & $\mathrm{X}$ & - & \\
\hline Western Tanager & Piranga ludoviciana & - & - & $\mathrm{X}$ & - & \\
\hline Abert's Towhee & Pipilo aberti & $\mathrm{X}$ & $\mathrm{X}$ & $\mathrm{X}$ & $\mathrm{X}$ & \\
\hline Song Sparrow & Melospiza melodia & $\mathrm{X}$ & - & $\mathrm{X}$ & - & \\
\hline Black-headed Grosbeak & Pheucticus melanocephalus & - & $\mathrm{X}$ & $\mathrm{X}$ & - & \\
\hline Blue Grosbeak & Guiraca caerulea & $\mathrm{X}$ & $\mathrm{X}$ & $\mathrm{X}$ & $\mathrm{X}$ & \\
\hline Red-winged Blackbird & Agelaius phoeniceus & $\mathrm{X}$ & $\mathrm{X}$ & $\mathrm{X}$ & $\mathrm{X}$ & \\
\hline Yellow-headed Blackbird & Xanthocephalus xanthocephalus & - & $\mathrm{X}$ & - & - & \\
\hline Great-tailed Grackle & Quiscalus mexicanus & $\mathrm{X}$ & $\mathrm{X}$ & $\mathrm{X}$ & $\mathrm{X}$ & \\
\hline Brown-headed Cowbird & Molothrus ater & $\mathrm{X}$ & $\mathrm{X}$ & $\mathrm{X}$ & - & \\
\hline Hooded Oriole & Icterus cucullatus & - & - & $\mathrm{X}$ & - & \\
\hline Bullock's Oriole & Icterus bullockii & $\mathrm{X}$ & $\mathrm{X}$ & $\mathrm{X}$ & - & \\
\hline House Finch & Carpodacus mexicanus & $\mathrm{X}$ & - & $\mathrm{X}$ & $\mathrm{X}$ & \\
\hline
\end{tabular}

Bill Williams River National Wildlife Refuge (Bill Williams River)

\begin{tabular}{|c|c|c|c|c|c|c|}
\hline Pied-billed Grebe & Podilymbus podiceps & - & - & $X$ & $\mathrm{X}$ & $\mathrm{X}$ \\
\hline Eared Grebe & Podiceps nigricollis & - & - & - & $\mathrm{X}$ & - \\
\hline Western Grebe & Aechmophorus occidentalis & $\mathrm{X}$ & $\mathrm{X}$ & $\mathrm{X}$ & $\mathrm{X}$ & $\mathrm{X}$ \\
\hline Clark's Grebe & Aechmophorus clarkii & $\mathrm{X}$ & $\mathrm{X}$ & $\mathrm{X}$ & $\mathrm{X}$ & $\mathrm{X}$ \\
\hline Double-crested Cormorant & Phalacrocorax auritus & - & $\mathrm{X}$ & $\mathrm{X}$ & - & $\mathrm{X}$ \\
\hline
\end{tabular}


Table 6-1. List of other bird species observed during 2007 yellow-billed cuckoo surveys, in the lower Colorado River watershed along the White and Muddy Rivers, Nevada, lower Colorado, Bill Williams and Gila Rivers, Arizona and California.-Continued

\begin{tabular}{|c|c|c|c|c|c|c|}
\hline Common name & Scientific name & $\begin{array}{c}\text { Survey } \\
1\end{array}$ & $\begin{array}{c}\text { Survey } \\
2 \\
\end{array}$ & $\begin{array}{c}\text { Survey } \\
\mathbf{3} \\
\end{array}$ & $\begin{array}{c}\text { Survey } \\
4 \\
\end{array}$ & $\begin{array}{c}\text { Survey } \\
5 \\
\end{array}$ \\
\hline Magnificent Frigatebird & Fregata magnificens & - & - & - & - & $\mathrm{X}$ \\
\hline Least Bittern & Ixobrychus exilis & - & $\mathrm{X}$ & $\mathrm{X}$ & $\mathrm{X}$ & $\mathrm{X}$ \\
\hline Great Blue Heron & Ardea herodias & $\mathrm{X}$ & $\mathrm{X}$ & $\mathrm{X}$ & $\mathrm{X}$ & $\mathrm{X}$ \\
\hline Great Egret & Ardea alba & - & $\mathrm{X}$ & $\mathrm{X}$ & $\mathrm{X}$ & $\mathrm{X}$ \\
\hline Snowy Egret & Egretta thula & $\mathrm{X}$ & $\mathrm{X}$ & - & $\mathrm{X}$ & $\mathrm{X}$ \\
\hline Green Heron & Butorides virescens & $\mathrm{X}$ & $\mathrm{X}$ & $\mathrm{X}$ & $\mathrm{X}$ & $\mathrm{X}$ \\
\hline Black-crowned Night Heron & Nycticorax nycticorax & - & $\mathrm{X}$ & - & $\mathrm{X}$ & $\mathrm{X}$ \\
\hline White-faced Ibis & Plegadis chihi & $\mathrm{X}$ & $\mathrm{X}$ & $\mathrm{X}$ & $\mathrm{X}$ & $\mathrm{X}$ \\
\hline Turkey Vulture & Cathartes aura & $\mathrm{X}$ & $\mathrm{X}$ & $\mathrm{X}$ & $\mathrm{X}$ & $\mathrm{X}$ \\
\hline Greater White-fronted Goose & Anser albifrons & - & - & - & - & $\mathrm{X}$ \\
\hline Gadwall & Anas strepera & - & - & - & - & $\mathrm{X}$ \\
\hline Mallard & Anas platyrhynchos & $\mathrm{X}$ & $\mathrm{X}$ & $\mathrm{X}$ & $\mathrm{X}$ & $X$ \\
\hline Cinnamon Teal & Anas cyanoptera & - & - & - & $\mathrm{X}$ & $\mathrm{X}$ \\
\hline Northern Shoveler & Anas clypeta & - & - & - & - & $\mathrm{X}$ \\
\hline Green-winged Teal & Anas creeca & - & - & $\mathrm{X}$ & - & - \\
\hline Sharp-shinned Hawk & Accipiter striatus & - & - & - & - & $\mathrm{X}$ \\
\hline Cooper's Hawk & Accipiter cooperii & $\mathrm{X}$ & - & - & $\mathrm{X}$ & $\mathrm{X}$ \\
\hline Red-tailed Hawk & Buteo Jamaicensis & $\mathrm{X}$ & $\mathrm{X}$ & $\mathrm{X}$ & $\mathrm{X}$ & - \\
\hline American Kestrel & Falco sparverius & - & $\mathrm{X}$ & - & $\mathrm{X}$ & - \\
\hline Peregrine Falcon & Falco peregrinus & - & $\mathrm{X}$ & $\mathrm{X}$ & $\mathrm{X}$ & - \\
\hline Gambel's Quail & Callipepla gambelli & $\mathrm{X}$ & $\mathrm{X}$ & $\mathrm{X}$ & $\mathrm{X}$ & $\mathrm{X}$ \\
\hline Black Rail & Laterallus jamaicensis & $\mathrm{X}$ & $\mathrm{X}$ & $\mathrm{X}$ & - & - \\
\hline Clapper Rail & Rallus longirostris & $\mathrm{X}$ & - & $\mathrm{X}$ & - & - \\
\hline Virginia Rail & Rallus limicola & $\mathrm{X}$ & $\mathrm{X}$ & $\mathrm{X}$ & $\mathrm{X}$ & $\mathrm{X}$ \\
\hline Sora & Porzana carolina & - & - & $\mathrm{X}$ & $\mathrm{X}$ & - \\
\hline Common Moorhen & Gallinula chloropus & - & - & $\mathrm{X}$ & $\mathrm{X}$ & $\mathrm{X}$ \\
\hline American Coot & Fulica americana & $\mathrm{X}$ & - & $\mathrm{X}$ & $\mathrm{X}$ & $\mathrm{X}$ \\
\hline Long-billed Curlew & Numenius americanus & $\mathrm{X}$ & $\mathrm{X}$ & - & - & - \\
\hline Killdeer & Charadrius vociferus & $\mathrm{X}$ & $\mathrm{X}$ & $\mathrm{X}$ & $\mathrm{X}$ & - \\
\hline American Avocet & Recurvirostra americana & - & - & - & $\mathrm{X}$ & $\mathrm{X}$ \\
\hline Black-necked Stilt & Himantopus mexicanus & - & - & - & - & $\mathrm{X}$ \\
\hline Spotted Sandpiper & Actitus macularia & - & $\mathrm{X}$ & $\mathrm{X}$ & - & - \\
\hline
\end{tabular}


Table 6-1. List of other bird species observed during 2007 yellow-billed cuckoo surveys, in the lower Colorado River watershed along the White and Muddy Rivers, Nevada, lower Colorado, Bill Williams and Gila Rivers, Arizona and California.-Continued

\begin{tabular}{|c|c|c|c|c|c|c|}
\hline Common name & Scientific name & $\begin{array}{c}\text { Survey } \\
1\end{array}$ & $\begin{array}{c}\text { Survey } \\
2 \\
\end{array}$ & $\begin{array}{c}\text { Survey } \\
\mathbf{3} \\
\end{array}$ & $\begin{array}{c}\text { Survey } \\
4 \\
\end{array}$ & $\begin{array}{c}\text { Survey } \\
5 \\
\end{array}$ \\
\hline Least Sandpiper & Tachycineta bicolor & - & $\mathrm{X}$ & - & $\mathrm{X}$ & - \\
\hline Ring-billed Gull & Larus delewarensis & - & - & $\mathrm{X}$ & $\mathrm{X}$ & $\mathrm{X}$ \\
\hline Caspian Tern & Sterna caspia & - & - & - & - & $\mathrm{X}$ \\
\hline Forster's Tern & Sterna forsteri & - & - & - & $\mathrm{X}$ & $\mathrm{X}$ \\
\hline Rock Dove & Columba livia & - & - & - & $\mathrm{X}$ & - \\
\hline Mourning Dove & Zenaida macraura & $\mathrm{X}$ & $\mathrm{X}$ & $\mathrm{X}$ & $\mathrm{X}$ & $\mathrm{X}$ \\
\hline White-winged Dove & Zenaida asiatica & $\mathrm{X}$ & $\mathrm{X}$ & $\mathrm{X}$ & $\mathrm{X}$ & - \\
\hline Common Ground-Dove & Columbina passerina & - & $\mathrm{X}$ & - & $\mathrm{X}$ & - \\
\hline Greater Roadrunner & Geococcyx californianus & $\mathrm{X}$ & $\mathrm{X}$ & $\mathrm{X}$ & $\mathrm{X}$ & $\mathrm{X}$ \\
\hline Great Horned Owl & Bubo virginianus & $\mathrm{X}$ & $\mathrm{X}$ & - & $\mathrm{X}$ & $\mathrm{X}$ \\
\hline Lesser Nighthawk & Chordeiles acutipennis & $\mathrm{X}$ & $\mathrm{X}$ & $\mathrm{X}$ & $\mathrm{X}$ & $\mathrm{X}$ \\
\hline Common Nighthawk & Chordeiles acutipennis & $\mathrm{X}$ & - & - & - & - \\
\hline White-throated Swift & Aeronautes saxatalis & $\mathrm{X}$ & $\mathrm{X}$ & - & $\mathrm{X}$ & - \\
\hline Black-chinned Hummingbird & Archilochus alexandri & $\mathrm{X}$ & $\mathrm{X}$ & - & $\mathrm{X}$ & - \\
\hline Anna's Hummingbird & Calypte anna & - & $\mathrm{X}$ & $\mathrm{X}$ & - & $\mathrm{X}$ \\
\hline Costa's Hummingbird & Calypte costae & $\mathrm{X}$ & - & - & - & - \\
\hline Belted Kingfisher & Ceryle alcyon & - & - & - & $\mathrm{X}$ & $X$ \\
\hline Gila Woodpecker & Melanerpes uropygialis & $\mathrm{X}$ & $\mathrm{X}$ & $\mathrm{X}$ & $\mathrm{X}$ & $\mathrm{X}$ \\
\hline Ladder-backed Woodpecker & Picoides scalaris & $\mathrm{X}$ & $\mathrm{X}$ & $\mathrm{X}$ & $\mathrm{X}$ & $\mathrm{X}$ \\
\hline Hairy Woodpecker & Dendrocopos villosus & - & $\mathrm{X}$ & - & - & - \\
\hline Gilded Flicker & Colaptes chrysoides & - & - & - & - & $\mathrm{X}$ \\
\hline Northern Flicker & Colaptes auratus & - & - & $\mathrm{X}$ & $\mathrm{X}$ & - \\
\hline Western Wood-Pewee & Contopus sordidulus & $\mathrm{X}$ & - & - & $\mathrm{X}$ & $\mathrm{X}$ \\
\hline Willow Flycatcher & Empidonax traillii & $\mathrm{X}$ & $\mathrm{X}$ & - & $\mathrm{X}$ & $\mathrm{X}$ \\
\hline Western Flycatcher & Empidonax difficilis & - & $\mathrm{X}$ & - & $\mathrm{X}$ & - \\
\hline Pacific-slope Flycatcher & Empidonax difficilis & - & $\mathrm{X}$ & $\mathrm{X}$ & $\mathrm{X}$ & $\mathrm{X}$ \\
\hline Black Phoebe & Sayornis nigricans & $\mathrm{X}$ & $\mathrm{X}$ & $\mathrm{X}$ & $\mathrm{X}$ & $\mathrm{X}$ \\
\hline Say's Phoebe & Sayornis saya & $\mathrm{X}$ & $\mathrm{X}$ & $\mathrm{X}$ & - & - \\
\hline Vermillion Flycatcher & Pyrocephalus rubinus & $\mathrm{X}$ & $\mathrm{X}$ & - & $\mathrm{X}$ & - \\
\hline Ash-throated Flycatcher & Myiarchus cinerascens & $X$ & $\mathrm{X}$ & $\mathrm{X}$ & $\mathrm{X}$ & $\mathrm{X}$ \\
\hline Brown-crested Flycatcher & Myiarchus tyrannulus & $\mathrm{X}$ & $\mathrm{X}$ & $\mathrm{X}$ & $\mathrm{X}$ & $\mathrm{X}$ \\
\hline Cassin's Kingbird & Tyrannus vociferans & - & - & $\mathrm{X}$ & - & - \\
\hline
\end{tabular}


Table 6-1. List of other bird species observed during 2007 yellow-billed cuckoo surveys, in the lower Colorado River watershed along the White and Muddy Rivers, Nevada, lower Colorado, Bill Williams and Gila Rivers, Arizona and California.-Continued

\begin{tabular}{|c|c|c|c|c|c|c|}
\hline Common name & Scientific name & $\begin{array}{c}\text { Survey } \\
1\end{array}$ & $\begin{array}{c}\text { Survey } \\
2 \\
\end{array}$ & $\begin{array}{c}\text { Survey } \\
3\end{array}$ & $\begin{array}{c}\text { Survey } \\
4\end{array}$ & $\begin{array}{c}\text { Survey } \\
5\end{array}$ \\
\hline Western Kingbird & Tyrannus verticalis & $\mathrm{X}$ & $\mathrm{X}$ & $\mathrm{X}$ & $\mathrm{X}$ & $\mathrm{X}$ \\
\hline Loggerhead Shrike & Lanius ludovicianus & - & - & - & $\mathrm{X}$ & $\mathrm{X}$ \\
\hline Bell's Vireo & Vireo bellii & $\mathrm{X}$ & $\mathrm{X}$ & $\mathrm{X}$ & $\mathrm{X}$ & $\mathrm{X}$ \\
\hline Cassin's Vireo & Vireo cassinii & - & - & - & $\mathrm{X}$ & - \\
\hline Warbling Vireo & Vireo gilvus & - & - & - & $\mathrm{X}$ & $\mathrm{X}$ \\
\hline Common Raven & Corvus corax & $\mathrm{X}$ & $\mathrm{X}$ & - & - & $\mathrm{X}$ \\
\hline Tree Swallow & Tachycineta bicolor & - & $\mathrm{X}$ & $\mathrm{X}$ & $\mathrm{X}$ & $\mathrm{X}$ \\
\hline Violet-green Swallow & Tachycineta thalassina & $\mathrm{X}$ & $\mathrm{X}$ & - & $\mathrm{X}$ & - \\
\hline $\begin{array}{l}\text { Northern Rough-winged } \\
\text { Swallow }\end{array}$ & Stelgidopteryx serripennis & $\mathrm{X}$ & $\mathrm{X}$ & $\mathrm{X}$ & $\mathrm{X}$ & $\mathrm{X}$ \\
\hline Cliff Swallow & Petrochelidon pyrrhonota & $\mathrm{X}$ & $\mathrm{X}$ & $\mathrm{X}$ & $\mathrm{X}$ & $\mathrm{X}$ \\
\hline Barn Swallow & Hirundo rustica & - & - & - & $\mathrm{X}$ & $\mathrm{X}$ \\
\hline Verdin & Auriparus flaviceps & $\mathrm{X}$ & $\mathrm{X}$ & $\mathrm{X}$ & $\mathrm{X}$ & $\mathrm{X}$ \\
\hline Bushtit & Psaltriparus minimus & - & $\mathrm{X}$ & - & - & - \\
\hline White-breasted Nuthatch & Sitta carolinensis & - & - & - & - & $\mathrm{X}$ \\
\hline Cactus Wren & Campylorhynchus brunneicapillus & - & $\mathrm{X}$ & - & - & $\mathrm{X}$ \\
\hline Rock Wren & Salpinctes obsoletus & - & $\mathrm{X}$ & - & - & - \\
\hline Canyon Wren & Catherpes mexicanus & $\mathrm{X}$ & $\mathrm{X}$ & $\mathrm{X}$ & $\mathrm{X}$ & $\mathrm{X}$ \\
\hline Bewick's Wren & Thryomanes bewickii & $X$ & $\mathrm{X}$ & - & $\mathrm{X}$ & $\mathrm{X}$ \\
\hline House Wren & Troglodytes aedon & - & - & - & $\mathrm{X}$ & $\mathrm{X}$ \\
\hline Marsh Wren & Cistothorus palustris & - & $\mathrm{X}$ & $\mathrm{X}$ & $\mathrm{X}$ & $\mathrm{X}$ \\
\hline Blue-gray Gnatcatcher & Polioptila caerulea & - & - & - & $X$ & $\mathrm{X}$ \\
\hline Black-tailed Gnatcatcher & Polioptila nigriceps & $\mathrm{X}$ & $\mathrm{X}$ & $\mathrm{X}$ & $\mathrm{X}$ & $\mathrm{X}$ \\
\hline Northern Mockingbird & Mimus polyglottos & - & - & $\mathrm{X}$ & - & $\mathrm{X}$ \\
\hline Crissal Thrasher & Toxostoma crissale & $\mathrm{X}$ & $\mathrm{X}$ & $\mathrm{X}$ & $\mathrm{X}$ & $\mathrm{X}$ \\
\hline Phainopepla & Phainopepla nitens & $\mathrm{X}$ & - & $\mathrm{X}$ & $\mathrm{X}$ & $\mathrm{X}$ \\
\hline Orange-crowned Warbler & Vermivora celata & $\mathrm{X}$ & - & - & $\mathrm{X}$ & $\mathrm{X}$ \\
\hline Nashville Warbler & Vermivora ruficapilla & - & - & - & $\mathrm{X}$ & $\mathrm{X}$ \\
\hline Lucy's Warbler & Vermivora luciae & $\mathrm{X}$ & $\mathrm{X}$ & $\mathrm{X}$ & $\mathrm{X}$ & - \\
\hline Yellow Warbler & Dendroica petechia & $\mathrm{X}$ & $\mathrm{X}$ & $\mathrm{X}$ & $\mathrm{X}$ & $\mathrm{X}$ \\
\hline Magnolia Warbler & Dendroica magnolia & - & - & - & $\mathrm{X}$ & - \\
\hline Yellow-rumped Warbler & Dendroica coronata & - & - & - & - & $\mathrm{X}$ \\
\hline
\end{tabular}


Table 6-1. List of other bird species observed during 2007 yellow-billed cuckoo surveys, in the lower Colorado River watershed along the White and Muddy Rivers, Nevada, lower Colorado, Bill Williams and Gila Rivers, Arizona and California.-Continued

\begin{tabular}{|c|c|c|c|c|c|c|}
\hline Common name & Scientific name & $\begin{array}{c}\text { Survey } \\
1\end{array}$ & $\begin{array}{c}\text { Survey } \\
2 \\
\end{array}$ & $\begin{array}{c}\text { Survey } \\
\mathbf{3} \\
\end{array}$ & $\begin{array}{c}\text { Survey } \\
4\end{array}$ & $\begin{array}{c}\text { Survey } \\
5\end{array}$ \\
\hline Black-throated Gray Warbler & Dendroica nigrescens & - & - & - & $\mathrm{X}$ & $\mathrm{X}$ \\
\hline Townsend's Warbler & Dendroica townsendi & - & - & - & - & $\mathrm{X}$ \\
\hline Common Yellowthroat & Geothlypis trichas & $\mathrm{X}$ & $\mathrm{X}$ & $\mathrm{X}$ & $\mathrm{X}$ & $\mathrm{X}$ \\
\hline Wilson's Warbler & Wilsonia pusilla & - & - & $\mathrm{X}$ & $\mathrm{X}$ & - \\
\hline Yellow-breasted Chat & Icteria virens & $\mathrm{X}$ & $\mathrm{X}$ & $\mathrm{X}$ & $\mathrm{X}$ & $\mathrm{X}$ \\
\hline Summer Tanager & Piranga rubra & $\mathrm{X}$ & $\mathrm{X}$ & $\mathrm{X}$ & $\mathrm{X}$ & $\mathrm{X}$ \\
\hline Western Tanager & Piranga ludoviciana & $\mathrm{X}$ & $\mathrm{X}$ & $\mathrm{X}$ & $\mathrm{X}$ & $\mathrm{X}$ \\
\hline Canyon Towhee & Pipilo fuscus & - & $\mathrm{X}$ & - & $\mathrm{X}$ & - \\
\hline Abert's Towhee & Pipilo aberti & $\mathrm{X}$ & $\mathrm{X}$ & $\mathrm{X}$ & $\mathrm{X}$ & $\mathrm{X}$ \\
\hline Cassin's Sparrow & Aimophila cassinii & - & $\mathrm{X}$ & - & - & - \\
\hline Chipping Sparrow & Spizella passerina & - & $\mathrm{X}$ & - & $\mathrm{X}$ & $\mathrm{X}$ \\
\hline Black-throated Sparrow & Amphispiza bilineata & - & $\mathrm{X}$ & $\mathrm{X}$ & $\mathrm{X}$ & - \\
\hline Song Sparrow & Melospiza melodia & $\mathrm{X}$ & $\mathrm{X}$ & $\mathrm{X}$ & $\mathrm{X}$ & $\mathrm{X}$ \\
\hline Black-headed Grosbeak & Pheucticus melanocephalus & $\mathrm{X}$ & $\mathrm{X}$ & $\mathrm{X}$ & $\mathrm{X}$ & $\mathrm{X}$ \\
\hline Blue Grosbeak & Guiraca caerulia & $\mathrm{X}$ & $\mathrm{X}$ & $\mathrm{X}$ & $\mathrm{X}$ & $\mathrm{X}$ \\
\hline Lazuli Bunting & Passerina amoena & - & - & $\mathrm{X}$ & $\mathrm{X}$ & $\mathrm{X}$ \\
\hline Indigo Bunting & Passerina cyanea & - & $\mathrm{X}$ & - & - & - \\
\hline Red-winged Blackbird & Agelaius phoenieus & $\mathrm{X}$ & $\mathrm{X}$ & $\mathrm{X}$ & $\mathrm{X}$ & $\mathrm{X}$ \\
\hline Yellow-headed Blackbird & Xanthocephalus Xanthocephalus & $\mathrm{X}$ & $\mathrm{X}$ & - & $\mathrm{X}$ & $\mathrm{X}$ \\
\hline Great-tailed Grackle & Quiscalus mexicanus & $\mathrm{X}$ & $\mathrm{X}$ & $\mathrm{X}$ & $\mathrm{X}$ & $\mathrm{X}$ \\
\hline Brown-headed Cowbird & Molothrus ater & $\mathrm{X}$ & $\mathrm{X}$ & $\mathrm{X}$ & $\mathrm{X}$ & - \\
\hline Bullock's Oriole & Icterus bullockii & $\mathrm{X}$ & $\mathrm{X}$ & $\mathrm{X}$ & $\mathrm{X}$ & $\mathrm{X}$ \\
\hline House Finch & Carpodacus mexicanus & $\mathrm{X}$ & $\mathrm{X}$ & $\mathrm{X}$ & $\mathrm{X}$ & $\mathrm{X}$ \\
\hline Lesser Goldfinch & Carduelis psaltria & $\mathrm{X}$ & $\mathrm{X}$ & $\mathrm{X}$ & $\mathrm{X}$ & $\mathrm{X}$ \\
\hline \multicolumn{7}{|c|}{ Ahakhav Tribal Preserve (Colorado River) } \\
\hline Double-crested Cormorant & Phalacrocorax auritus & - & $\mathrm{X}$ & - & - & \\
\hline Black-crowned Night Heron & Nycticorax nycticorax & - & - & - & $\mathrm{X}$ & \\
\hline Cooper's Hawk & Accipiter cooperii & - & - & - & $\mathrm{X}$ & \\
\hline Peregrine Falcon & Falco peregrinus & - & - & - & $\mathrm{X}$ & \\
\hline Gambel's Quail & Callipepla gambellii & - & $\mathrm{X}$ & $\mathrm{X}$ & $\mathrm{X}$ & \\
\hline White-winged Dove & Zenaida asiatica & - & $\mathrm{X}$ & $\mathrm{X}$ & $\mathrm{X}$ & \\
\hline Mourning Dove & Zenaida Macraura & - & $\mathrm{X}$ & $\mathrm{X}$ & $X$ & \\
\hline
\end{tabular}


Table 6-1. List of other bird species observed during 2007 yellow-billed cuckoo surveys, in the lower Colorado River watershed along the White and Muddy Rivers, Nevada, lower Colorado, Bill Williams and Gila Rivers, Arizona and California.-Continued

\begin{tabular}{|c|c|c|c|c|c|c|}
\hline Common name & Scientific name & $\begin{array}{c}\text { Survey } \\
1\end{array}$ & $\begin{array}{c}\text { Survey } \\
2\end{array}$ & $\begin{array}{c}\text { Survey } \\
\mathbf{3}\end{array}$ & $\begin{array}{c}\text { Survey } \\
4\end{array}$ & $\begin{array}{c}\text { Survey } \\
5\end{array}$ \\
\hline Barn Owl & Tyto alba & - & $\mathrm{X}$ & - & - & \\
\hline Great Horned Owl & Bubo virginianus & - & $\mathrm{X}$ & $\mathrm{X}$ & - & \\
\hline Lesser Nighthawk & Chordeiles acutipennis & - & $\mathrm{X}$ & - & - & \\
\hline Black-chinned Hummingbird & Archilochus alexandri & - & $\mathrm{X}$ & - & - & \\
\hline Anna's Hummingbird & Calypte anna & - & $\mathrm{X}$ & - & $\mathrm{X}$ & \\
\hline Rufous Hummingbird & Selasphorus rufus & - & - & $\mathrm{X}$ & $\mathrm{X}$ & \\
\hline Ladder-backed Woodpecker & Picoides scalaris & - & - & $\mathrm{X}$ & $\mathrm{X}$ & \\
\hline Pacific-slope Flycatcher & Empidonax difficilis & - & - & - & $\mathrm{X}$ & \\
\hline Willow Flycatcher & Empidonax traillii & - & - & - & $\mathrm{X}$ & \\
\hline Black Phoebe & Sayornis nigricans & - & - & - & $\mathrm{X}$ & \\
\hline Vermillion Flycatcher & Pyrocephalus rubinus & - & $\mathrm{X}$ & - & - & \\
\hline Brown-crested Flycatcher & Myairchus tyrannulus & - & - & $\mathrm{X}$ & $\mathrm{X}$ & \\
\hline Ash-throated Flycatcher & Myiarchus cinerascens & - & $\mathrm{X}$ & - & $\mathrm{X}$ & \\
\hline Western Kingbird & Tyrranus verticalis & - & $\mathrm{X}$ & - & $\mathrm{X}$ & \\
\hline Common Raven & Corvus corax & - & - & - & $\mathrm{X}$ & \\
\hline Tree Swallow & Tachycineta bicolor & - & $\mathrm{X}$ & - & - & \\
\hline Cliff Swallow & Petrochelidon pyrrhonota & - & $\mathrm{X}$ & - & - & \\
\hline Verdin & Auriparus flaviceps & - & $\mathrm{X}$ & $\mathrm{X}$ & $\mathrm{X}$ & \\
\hline Bewick's Wren & Thryomanes bewickii & - & - & $\mathrm{X}$ & - & \\
\hline House Wren & Troglodytes aedon & - & - & - & $\mathrm{X}$ & \\
\hline Ruby-crowned Kinglet & Regulus calendula & - & - & - & $\mathrm{X}$ & \\
\hline Blue-gray Gnatcatcher & Polioptila caerulea & - & - & - & $\mathrm{X}$ & \\
\hline Northern Mockingbird & Mimus polyglottos & - & $\mathrm{X}$ & - & - & \\
\hline Phainopepla & Phainopepla nitens & - & - & - & $\mathrm{X}$ & \\
\hline Orange-crowned Warbler & Vermivora celata & - & - & - & $\mathrm{X}$ & \\
\hline Nashville Warbler & Vermivora ruficapilla & - & - & - & $\mathrm{X}$ & \\
\hline Lucy's Warbler & Vermivora luciae & - & - & - & $\mathrm{X}$ & \\
\hline Yellow Warbler & Dendroica petechia & $\mathrm{X}$ & - & - & $\mathrm{X}$ & \\
\hline Black-throated Gray Warbler & Dendroica nigrescens & - & - & - & $\mathrm{X}$ & \\
\hline Common Yellowthroat & Geothlypis trichas & - & - & - & $\mathrm{X}$ & \\
\hline Wilson's Warbler & Wilsonia pusilla & - & - & $\mathrm{X}$ & $\mathrm{X}$ & \\
\hline Yellow-breased Chat & Icteria virens & $\mathrm{X}$ & - & - & - & \\
\hline
\end{tabular}


Table 6-1. List of other bird species observed during 2007 yellow-billed cuckoo surveys, in the lower Colorado River watershed along the White and Muddy Rivers, Nevada, lower Colorado, Bill Williams and Gila Rivers, Arizona and California.-Continued

\begin{tabular}{|c|c|c|c|c|c|c|}
\hline Common name & Scientific name & $\begin{array}{c}\text { Survey } \\
1\end{array}$ & $\begin{array}{c}\text { Survey } \\
2\end{array}$ & $\begin{array}{c}\text { Survey } \\
3\end{array}$ & $\begin{array}{c}\text { Survey } \\
4\end{array}$ & $\begin{array}{c}\text { Survey } \\
5\end{array}$ \\
\hline Western Tanager & Piranga ludoviciana & - & - & - & $\mathrm{X}$ & \\
\hline Spotted Towhee & Pipilo maculates & - & - & - & $\mathrm{X}$ & \\
\hline Abert's Towhee & Pipilo aberti & - & $\mathrm{X}$ & $\mathrm{X}$ & $\mathrm{X}$ & \\
\hline Song Sparrow & Melospiza melodia & $\mathrm{X}$ & - & - & $\mathrm{X}$ & \\
\hline Black-headed Grosbeak & Pheuticus melanocephalus & - & $\mathrm{X}$ & & $\mathrm{X}$ & \\
\hline Blue Grosbeak & Guiraca caerulea & $\mathrm{X}$ & $\mathrm{X}$ & - & $\mathrm{X}$ & \\
\hline Lazuli Bunting & Passerina ciris & - & - & $\mathrm{X}$ & $\mathrm{X}$ & \\
\hline Red-winged Blackbird & Agelaius phoeniceus & - & $\mathrm{X}$ & $\mathrm{X}$ & - & \\
\hline Western Meadowlark & Sternella neglecta & - & - & $\mathrm{X}$ & $\mathrm{X}$ & \\
\hline Yellow-headed Blackbird & Xanthocephalus xanthocephalus & - & $\mathrm{X}$ & - & - & \\
\hline Great-tailed Grackle & Quiscalus mexicanus & - & $\mathrm{X}$ & $\mathrm{X}$ & $\mathrm{X}$ & \\
\hline Brown-headed Cowbird & Molothrus ater & - & $X$ & $\mathrm{X}$ & - & \\
\hline Bullock's Oriole & Icterus bullockii & - & $\mathrm{X}$ & - & $\mathrm{X}$ & \\
\hline House Finch & Carpodacus mexicanus & - & $\mathrm{X}$ & $\mathrm{X}$ & $\mathrm{X}$ & \\
\hline Lesser Goldfinch & Carduelis psaltria & - & $X$ & $X$ & $X$ & \\
\hline \multicolumn{7}{|c|}{ Cibola National Wildlife Refuge (Colorado River) } \\
\hline Snowy Egret & Egretta thula & - & - & - & $\mathrm{X}$ & \\
\hline White-faced Ibis & Plegadis chihi & - & - & - & $\mathrm{X}$ & \\
\hline Turkey Vulture & Cathartes aura & - & $\mathrm{X}$ & - & - & \\
\hline Northern Harrier & Circus cyaneus & - & - & - & $\mathrm{X}$ & \\
\hline American Kestrel & Falco sparverius & - & - & $X$ & $\mathrm{X}$ & \\
\hline Prairie Falcon & Falco mexicanus & - & - & - & $\mathrm{X}$ & \\
\hline Gambel's Quail & Callipepla gambellii & - & - & $\mathrm{X}$ & - & \\
\hline Killdeer & Charadrius vociferus & - & - & $\mathrm{X}$ & - & \\
\hline American Coot & Fulica americana & - & - & $\mathrm{X}$ & - & \\
\hline Eurasian Collared Dove & Streptopelia decaocto & - & - & $\mathrm{X}$ & - & \\
\hline White-winged Dove & Zenaida asiatica & $\mathrm{X}$ & $\mathrm{X}$ & $\mathrm{X}$ & $\mathrm{X}$ & \\
\hline Mourning Dove & Zenaida macraura & $\mathrm{X}$ & $\mathrm{X}$ & $\mathrm{X}$ & - & \\
\hline Common Ground-dove & Columbina passerine & - & - & - & $\mathrm{X}$ & \\
\hline Great Horned Owl & Bubo virginianus & $\mathrm{X}$ & - & $\mathrm{X}$ & - & \\
\hline Lesser Nighthawk & Chordeiles acutipennis & - & $\mathrm{X}$ & - & - & \\
\hline Black-chinned Hummingbird & Archilochus alexandri & - & - & $\mathrm{X}$ & - & \\
\hline
\end{tabular}


Table 6-1. List of other bird species observed during 2007 yellow-billed cuckoo surveys, in the lower Colorado River watershed along the White and Muddy Rivers, Nevada, lower Colorado, Bill Williams and Gila Rivers, Arizona and California.-Continued

\begin{tabular}{|c|c|c|c|c|c|c|}
\hline Common name & Scientific name & $\begin{array}{c}\text { Survey } \\
1\end{array}$ & $\begin{array}{c}\text { Survey } \\
2\end{array}$ & $\begin{array}{c}\text { Survey } \\
\mathbf{3}\end{array}$ & $\begin{array}{c}\text { Survey } \\
4\end{array}$ & $\begin{array}{c}\text { Survey } \\
5\end{array}$ \\
\hline Anna's Hummingbird & Calypte anna & - & - & - & $\mathrm{X}$ & \\
\hline Ladder-backed Woodpecker & Picoides scalaris & $\mathrm{X}$ & $\mathrm{X}$ & - & - & \\
\hline Willow Flycatcher & Empidonax traillii & - & - & - & $\mathrm{X}$ & \\
\hline Pacific-slope Flycatcher & Empidonax difficilis & - & - & - & $\mathrm{X}$ & \\
\hline Black Phoebe & Sayornis nigricans & - & - & - & $\mathrm{X}$ & \\
\hline Ash-throated Flycatcher & Myiarchus cinerascens & $\mathrm{X}$ & $\mathrm{X}$ & $\mathrm{X}$ & $\mathrm{X}$ & \\
\hline Western Kingbird & Tyrannus verticalis & $\mathrm{X}$ & $\mathrm{X}$ & $\mathrm{X}$ & $\mathrm{X}$ & \\
\hline Bell's Vireo & Vireo bellii & - & $\mathrm{X}$ & - & $\mathrm{X}$ & \\
\hline Common Raven & Corvus corax & - & - & $\mathrm{X}$ & - & \\
\hline Cliff Swallow & Petrochelidon pyrrhonota & $\mathrm{X}$ & - & - & - & \\
\hline Verdin & Auriparus flaviceps & - & $\mathrm{X}$ & - & - & \\
\hline Bewick's Wren & Thyromanes bewickii & - & - & - & $\mathrm{X}$ & \\
\hline Northern Mockingbird & Mimus polyglottos & - & $\mathrm{X}$ & $\mathrm{X}$ & $\mathrm{X}$ & \\
\hline Crissal Thrasher & Toxostoma crissale & - & - & $\mathrm{X}$ & - & \\
\hline Black-tailed Gnatcatcher & Polioptila melanura & - & - & $\mathrm{X}$ & $\mathrm{X}$ & \\
\hline Yellow Warbler & Dendroica petechia & - & $\mathrm{X}$ & - & $\mathrm{X}$ & \\
\hline American Redstart & Setophaga ruticilla & - & - & - & $\mathrm{X}$ & \\
\hline Common Yellowthroat & Geothlypis trichas & - & - & $\mathrm{X}$ & - & \\
\hline Wilson's Warbler & Wilsonia pusilla & - & - & - & $\mathrm{X}$ & \\
\hline Yellow-breasted Chat & Icteria virens & $\mathrm{X}$ & $\mathrm{X}$ & $\mathrm{X}$ & - & \\
\hline Western Tanager & Piranga ludoviciana & - & - & $\mathrm{X}$ & - & \\
\hline Abert's Towhee & pipilo aberti & $\mathrm{X}$ & $\mathrm{X}$ & $\mathrm{X}$ & $\mathrm{X}$ & \\
\hline Black-headed Grosbeak & Pheuticus melanocephalus & - & - & $\mathrm{X}$ & - & \\
\hline Blue Grosbeak & Guiraca caerulea & - & $\mathrm{X}$ & - & $\mathrm{X}$ & \\
\hline Yellow-headed Blackbird & Xanthocephalus xanthocephalus & $\mathrm{X}$ & $\mathrm{X}$ & - & - & \\
\hline Red-winged Blackbird & Agelaius phoeniceus & - & $\mathrm{X}$ & $\mathrm{X}$ & - & \\
\hline Great-tailed Grackle & Quiscalus mexicanus & $\mathrm{X}$ & $\mathrm{X}$ & $\mathrm{X}$ & - & \\
\hline Brown-headed Cowbird & Molothrus Ater & $\mathrm{X}$ & - & $\mathrm{X}$ & $\mathrm{X}$ & \\
\hline Bullock's Oriole & Icterus bullockii & - & - & $\mathrm{X}$ & - & \\
\hline House Finch & Carpdacus mexicanus & - & - & - & $\mathrm{X}$ & \\
\hline \multicolumn{7}{|c|}{ Picacho State Recreation Area (Colorado River) } \\
\hline Green Heron & Butorides virescens & $\mathrm{X}$ & - & - & - & \\
\hline
\end{tabular}


Table 6-1. List of other bird species observed during 2007 yellow-billed cuckoo surveys, in the lower Colorado River watershed along the White and Muddy Rivers, Nevada, lower Colorado, Bill Williams and Gila Rivers, Arizona and California.-Continued

\begin{tabular}{|c|c|c|c|c|c|c|}
\hline Common name & Scientific name & $\begin{array}{c}\text { Survey } \\
1 \\
\end{array}$ & $\begin{array}{c}\text { Survey } \\
2 \\
\end{array}$ & $\begin{array}{c}\text { Survey } \\
\mathbf{3} \\
\end{array}$ & $\begin{array}{c}\text { Survey } \\
4 \\
\end{array}$ & $\begin{array}{c}\text { Survey } \\
5 \\
\end{array}$ \\
\hline White-faced Ibis & Plegadis chihi & - & - & - & $\mathrm{X}$ & \\
\hline Turkey Vulture & Cathartes aura & $\mathrm{X}$ & $\mathrm{X}$ & $\mathrm{X}$ & $\mathrm{X}$ & \\
\hline Gambel's Quail & Callipepla gambellii & - & $\mathrm{X}$ & $\mathrm{X}$ & $\mathrm{X}$ & \\
\hline White-winged Dove & Zenaida asiatica & $\mathrm{X}$ & $\mathrm{X}$ & $\mathrm{X}$ & - & \\
\hline Great Horned Owl & Bubo virginianus & $\mathrm{X}$ & - & - & - & \\
\hline Gila Woodpecker & Melanerpes uropygialis & $\mathrm{X}$ & $\mathrm{X}$ & $\mathrm{X}$ & - & \\
\hline Ladder-backed Woodpecker & Picoides scalaris & $\mathrm{X}$ & $\mathrm{X}$ & - & - & \\
\hline Ash-throated Flycatcher & Myiarchus cinerascens & $\mathrm{X}$ & $\mathrm{X}$ & $\mathrm{X}$ & - & \\
\hline Western Kingbird & Tyrannus verticalis & $\mathrm{X}$ & $\mathrm{X}$ & - & - & \\
\hline Loggerhead Shrike & Lanius ludovicianus & - & $\mathrm{X}$ & $\mathrm{X}$ & $\mathrm{X}$ & \\
\hline Bell's Vireo & Vireo bellii & - & $\mathrm{X}$ & $\mathrm{X}$ & $\mathrm{X}$ & \\
\hline Verdin & Auriparus flaviceps & $\mathrm{X}$ & $\mathrm{X}$ & $\mathrm{X}$ & $\mathrm{X}$ & \\
\hline Black-tailed Gnatcatcher & Polioptila melanura & - & - & - & $X$ & \\
\hline Wilson's Warbler & Wilsonia pusilla & - & - & - & $\mathrm{X}$ & \\
\hline Common Yellowthroat & Geothlypis trichas & $\mathrm{X}$ & $\mathrm{X}$ & - & - & \\
\hline Yellow-breasted Chat & Icteria virens & $\mathrm{X}$ & $\mathrm{X}$ & - & - & \\
\hline Western Tanager & Piranga ludoviciana & - & $\mathrm{X}$ & $\mathrm{X}$ & - & \\
\hline Abert's Towhee & pipilo aberti & $\mathrm{X}$ & - & - & $\mathrm{X}$ & \\
\hline Black-headed Grosbeak & Pheuticus melanocephalus & - & - & $\mathrm{X}$ & - & \\
\hline Great-tailed Grackle & Quiscalus mexicanus & $\mathrm{X}$ & - & - & $\mathrm{X}$ & \\
\hline Brown-headed Cowbird & Molothrus Ater & - & $\mathrm{X}$ & - & - & \\
\hline Bullock's Oriole & Icterus bullockii & - & - & - & $\mathrm{X}$ & \\
\hline House Finch & Carpdacus mexicanus & $\mathrm{X}$ & - & $\mathrm{X}$ & - & \\
\hline \multicolumn{7}{|c|}{ Imperial National Wildlife Refuge (Colorado River) } \\
\hline Pied-billed Grebe & Podilymbus podiceps & $\mathrm{X}$ & - & - & - & \\
\hline Least Bittern & Ixobrychus exilis & $\mathrm{X}$ & - & - & - & \\
\hline White-faced Ibis & Plegadis chihi & $\mathrm{X}$ & - & - & - & \\
\hline American Coot & Fulica americana & $\mathrm{X}$ & - & - & - & \\
\hline White-winged Dove & Zenaida asiatica & $\mathrm{X}$ & - & - & - & \\
\hline Lesser Nighthawk & Chordeiles acutipennis & $\mathrm{X}$ & - & - & - & \\
\hline Ladder-backed Woodpecker & Picoides scalaris & $\mathrm{X}$ & - & - & - & \\
\hline Ash-throated Flycatcher & Myiarchus cinerascens & $\mathrm{X}$ & - & - & - & \\
\hline
\end{tabular}


Table 6-1. List of other bird species observed during 2007 yellow-billed cuckoo surveys, in the lower Colorado River watershed along the White and Muddy Rivers, Nevada, lower Colorado, Bill Williams and Gila Rivers, Arizona and California.-Continued

\begin{tabular}{|c|c|c|c|c|c|c|}
\hline Common name & Scientific name & $\begin{array}{c}\text { Survey } \\
1\end{array}$ & $\begin{array}{c}\text { Survey } \\
2 \\
\end{array}$ & $\begin{array}{c}\text { Survey } \\
\mathbf{3} \\
\end{array}$ & $\begin{array}{c}\text { Survey } \\
4\end{array}$ & $\begin{array}{c}\text { Survey } \\
5\end{array}$ \\
\hline Loggerhead Shrike & Lanius ludovicianus & $\mathrm{X}$ & - & - & - & \\
\hline Bell's Vireo & Vireo bellii & $\mathrm{X}$ & - & - & - & \\
\hline Verdin & Auriparus flaviceps & $\mathrm{X}$ & - & - & - & \\
\hline Summer Tanager & Piranga rubra & $\mathrm{X}$ & - & - & - & \\
\hline Blue Grosbeak & Guiraca caerulea & $\mathrm{X}$ & - & - & - & \\
\hline Red-winged Blackbird & Agelaius phoeniceus & $X$ & - & - & - & \\
\hline Great-tailed Grackle & Quiscalus mexicanus & $\mathrm{X}$ & - & - & - & \\
\hline Bullock's Oriole & Icterus bullockii & $\mathrm{X}$ & - & - & - & \\
\hline \multicolumn{7}{|c|}{ Mittry Lake Wildlife Magangement Area (Colorado River) } \\
\hline Great Egret & Ardea alba & $\mathrm{X}$ & - & $\mathrm{X}$ & - & \\
\hline White-faced Ibis & Plegadis chihi & $\mathrm{X}$ & - & - & $\mathrm{X}$ & \\
\hline Turkey Vulture & Cathartes aura & - & - & - & $\mathrm{X}$ & \\
\hline Cooper's Hawk & Accipeter cooperi & - & - & - & $\mathrm{X}$ & \\
\hline Zone-tailed Hawk & Buteo albonotatus & - & - & - & $\mathrm{X}$ & \\
\hline Ring-necked Pheasant & Phasianus colcichus & - & - & - & $\mathrm{X}$ & \\
\hline Gambel's Quail & Callipepla gambellii & $\mathrm{X}$ & $\mathrm{X}$ & - & - & \\
\hline American Coot & Fulica americana & $\mathrm{X}$ & $\mathrm{X}$ & $\mathrm{X}$ & $\mathrm{X}$ & \\
\hline Killdeer & Charadrius vociferus & - & - & - & $\mathrm{X}$ & \\
\hline White-winged Dove & Zenaida asiatica & $\mathrm{X}$ & $\mathrm{X}$ & $\mathrm{X}$ & $\mathrm{X}$ & \\
\hline Mourning Dove & Zenaida macroura & $\mathrm{X}$ & $\mathrm{X}$ & $\mathrm{X}$ & - & \\
\hline Common Ground-Dove & Columbina passerine & - & - & - & $\mathrm{X}$ & \\
\hline Great Horned Owl & Bubo virginianus & - & - & $\mathrm{X}$ & - & \\
\hline Lesser Nighthawk & Chordeiles acutipennis & $\mathrm{X}$ & $\mathrm{X}$ & - & - & \\
\hline Anna's Hummingbird & Calypte anna & - & $\mathrm{X}$ & - & - & \\
\hline Gila Woodpecker & Melanerpes uropygialis & $\mathrm{X}$ & - & - & - & \\
\hline Ladder-backed Woodpecker & Picoides scalaris & $\mathrm{X}$ & $\mathrm{X}$ & $\mathrm{X}$ & $\mathrm{X}$ & \\
\hline Ash-throated Flycatcher & Myiarchus cinerascens & $\mathrm{X}$ & - & - & - & \\
\hline Western Kingbird & Tyrannus verticalis & $\mathrm{X}$ & - & - & - & \\
\hline Bell's Vireo & Vireo bellii & $X$ & - & - & - & \\
\hline Cliff Swallow & Petrochelidon pyrrhonota & $\mathrm{X}$ & $\mathrm{X}$ & - & - & \\
\hline Verdin & Auriparus flaviceps & $\mathrm{X}$ & $\mathrm{X}$ & - & - & \\
\hline Common Yellowthroat & Geothlypis trichas & $X$ & - & - & - & \\
\hline
\end{tabular}


Table 6-1. List of other bird species observed during 2007 yellow-billed cuckoo surveys, in the lower Colorado River watershed along the White and Muddy Rivers, Nevada, lower Colorado, Bill Williams and Gila Rivers, Arizona and California.-Continued

\begin{tabular}{|c|c|c|c|c|c|c|}
\hline Common name & Scientific name & $\begin{array}{c}\text { Survey } \\
1\end{array}$ & $\begin{array}{c}\text { Survey } \\
2 \\
\end{array}$ & $\begin{array}{c}\text { Survey } \\
\mathbf{3} \\
\end{array}$ & $\begin{array}{c}\text { Survey } \\
4\end{array}$ & $\begin{array}{c}\text { Survey } \\
5\end{array}$ \\
\hline Western Tanager & Piranga ludoviciana & - & - & $\mathrm{X}$ & - & \\
\hline Abert's Towhee & Pipilo aberti & $\mathrm{X}$ & $\mathrm{X}$ & $\mathrm{X}$ & $\mathrm{X}$ & \\
\hline Song Sparrow & Melospiza melodia & $\mathrm{X}$ & $\mathrm{X}$ & $\mathrm{X}$ & - & \\
\hline Red-winged Blackbird & Agelaius phoeniceus & $\mathrm{X}$ & $\mathrm{X}$ & $\mathrm{X}$ & $\mathrm{X}$ & \\
\hline Black-headed Grosbeak & Pheucticus melanocephalus & - & $\mathrm{X}$ & - & - & \\
\hline Great-tailed Grackle & Quiscalus mexicanus & - & $\mathrm{X}$ & - & - & \\
\hline Brown-headed Cowbird & Molothrus Ater & $\mathrm{X}$ & $\mathrm{X}$ & - & - & \\
\hline House Finch & Carpdacus mexicanus & $\mathrm{X}$ & - & - & - & \\
\hline \multicolumn{7}{|c|}{ Gila/Colorado Rivers Confluence (Gila and Colorado Rivers) } \\
\hline Great Egret & Ardea alba & - & - & $\mathrm{X}$ & - & \\
\hline Snowy Egret & Egretta thula & - & $\mathrm{X}$ & - & - & \\
\hline Green Heron & Butorides virescens & $\mathrm{X}$ & - & - & - & \\
\hline White-faced Ibis & Plegadis chihi & $\mathrm{X}$ & - & - & - & \\
\hline Northern Harrier & Circus cyaneus & - & $\mathrm{X}$ & - & - & \\
\hline Red-tailed Hawk & Buteo jamaicensis & $\mathrm{X}$ & - & - & - & \\
\hline American Kestrel & Falco sparverius & $\mathrm{X}$ & $\mathrm{X}$ & $\mathrm{X}$ & - & \\
\hline Black-necked Stilt & Himantopus mexicanus & $\mathrm{X}$ & $\mathrm{X}$ & - & - & \\
\hline Gambel's Quail & Callipepla gambellii & $\mathrm{X}$ & $\mathrm{X}$ & $\mathrm{X}$ & - & \\
\hline Common Moorhen & Gallinula chloropus & - & $\mathrm{X}$ & - & - & \\
\hline American Coot & Fulica americana & - & $\mathrm{X}$ & $\mathrm{X}$ & - & \\
\hline Killdeer & Charadrius vociferus & - & $\mathrm{X}$ & - & - & \\
\hline Black Tern & Chlidonias niger & - & $\mathrm{X}$ & - & - & \\
\hline White-winged Dove & Zenaida asiatica & $\mathrm{X}$ & $\mathrm{X}$ & $\mathrm{X}$ & - & \\
\hline Mourning Dove & Zenaida macroura & $\mathrm{X}$ & $\mathrm{X}$ & $\mathrm{X}$ & - & \\
\hline Common Ground-Dove & Columbina passerine & $\mathrm{X}$ & - & - & - & \\
\hline Great Horned Owl & Bubo virginianus & - & $\mathrm{X}$ & - & - & \\
\hline Anna's Hummingbird & Calypte anna & - & - & $\mathrm{X}$ & - & \\
\hline Black-chinned Hummingbird & Archilochus alexandri & - & $\mathrm{X}$ & - & - & \\
\hline Gila Woodpecker & Melanerpes uropygialis & - & - & $\mathrm{X}$ & - & \\
\hline Ladder-backed Woodpecker & Picoides scalaris & $\mathrm{X}$ & - & $\mathrm{X}$ & - & \\
\hline Willow Flycatcher & Empidonax traillii & - & - & - & $\mathrm{X}$ & \\
\hline Ash-throated Flycatcher & Myiarchus cinerascens & - & $\mathrm{X}$ & - & - & \\
\hline
\end{tabular}


Table 6-1. List of other bird species observed during 2007 yellow-billed cuckoo surveys, in the lower Colorado River watershed along the White and Muddy Rivers, Nevada, lower Colorado, Bill Williams and Gila Rivers, Arizona and California.-Continued

\begin{tabular}{|c|c|c|c|c|c|c|}
\hline Common name & Scientific name & $\begin{array}{c}\text { Survey } \\
1\end{array}$ & $\begin{array}{c}\text { Survey } \\
2\end{array}$ & $\begin{array}{c}\text { Survey } \\
\mathbf{3}\end{array}$ & $\begin{array}{c}\text { Survey } \\
4\end{array}$ & $\begin{array}{c}\text { Survey } \\
5\end{array}$ \\
\hline Black Phoebe & Sayornis nigricans & - & - & $\mathrm{X}$ & - & \\
\hline Western Kingbird & Tyrannus verticalis & $\mathrm{X}$ & $\mathrm{X}$ & $\mathrm{X}$ & - & \\
\hline $\begin{array}{l}\text { Northern Rough-winged } \\
\text { Swallow }\end{array}$ & Stelgidopteryx serripennis & - & $\mathrm{X}$ & - & - & \\
\hline Verdin & Auriparus flaviceps & $\mathrm{X}$ & - & $\mathrm{X}$ & - & \\
\hline Cactus Wren & Campylorhynchus brunneicapillus & - & $\mathrm{X}$ & - & - & \\
\hline Marsh Wren & Cistothorus palustris & - & $\mathrm{X}$ & - & - & \\
\hline Black-tailed Gnatcatcher & Polioptila melanura & $\mathrm{X}$ & - & - & - & \\
\hline Northern Mockingbird & Mimus polyglottos & $\mathrm{X}$ & - & - & - & \\
\hline Yellow Warbler & Dendroica petechia & - & - & - & $\mathrm{X}$ & \\
\hline Common Yellowthroat & Geothlypis trichas & - & $\mathrm{X}$ & $\mathrm{X}$ & - & \\
\hline Abert's Towhee & pipilo aberti & $\mathrm{X}$ & $\mathrm{X}$ & $\mathrm{X}$ & - & \\
\hline Song Sparrow & Melospiza melodia & - & - & $\mathrm{X}$ & - & \\
\hline Red-winged Blackbird & Agelaius phoeniceus & $\mathrm{X}$ & $\mathrm{X}$ & - & - & \\
\hline Yellow-headed Blackbird & Xanthocephalus xanthocephalus & - & - & $\mathrm{X}$ & - & \\
\hline Blue Grosbeak & Guiraca caerulea & $\mathrm{X}$ & - & $\mathrm{X}$ & - & \\
\hline Great-tailed Grackle & Quiscalus mexicanus & $\mathrm{X}$ & $X$ & - & - & \\
\hline Brown-headed Cowbird & Molothrus Ater & $\mathrm{X}$ & - & - & - & \\
\hline House Finch & Carpdacus mexicanus & - & - & $X$ & - & \\
\hline Lesser Goldfinch & Carduelis psaltria & - & $\mathrm{X}$ & - & - & \\
\hline \multicolumn{7}{|c|}{ Yuma West Wetlands (Colorado River) } \\
\hline Great Egret & Ardea alba & - & $\mathrm{X}$ & - & $\mathrm{X}$ & \\
\hline Snowy Egret & Egretta thula & - & $\mathrm{X}$ & - & - & \\
\hline Green Heron & Butorides virescens & $\mathrm{X}$ & $\mathrm{X}$ & $\mathrm{X}$ & - & \\
\hline Black-crowned Night Heron & Nycticorax nycticorax & - & $\mathrm{X}$ & - & - & \\
\hline White-faced Ibis & Plegadis chihi & - & $\mathrm{X}$ & $\mathrm{X}$ & - & \\
\hline American Kestrel & Falco sparverius & - & - & $\mathrm{X}$ & - & \\
\hline Gambel's Quail & Callipepla gambellii & - & $\mathrm{X}$ & - & - & \\
\hline Common Moorhen & Gallinula chloropus & $\mathrm{X}$ & - & - & - & \\
\hline Rock Dove & Columba livia & $X$ & - & - & - & \\
\hline White-winged Dove & Zenaida asiatica & $X$ & $X$ & $X$ & $\mathrm{X}$ & \\
\hline Mourning Dove & Zenaida macraura & $\mathrm{X}$ & $\mathrm{X}$ & - & $\mathrm{X}$ & \\
\hline
\end{tabular}


Table 6-1. List of other bird species observed during 2007 yellow-billed cuckoo surveys, in the lower Colorado River watershed along the White and Muddy Rivers, Nevada, lower Colorado, Bill Williams and Gila Rivers, Arizona and California.-Continued

\begin{tabular}{|c|c|c|c|c|c|c|}
\hline Common name & Scientific name & $\begin{array}{c}\text { Survey } \\
1\end{array}$ & $\begin{array}{c}\text { Survey } \\
2 \\
\end{array}$ & $\begin{array}{c}\text { Survey } \\
\mathbf{3} \\
\end{array}$ & $\begin{array}{c}\text { Survey } \\
4\end{array}$ & $\begin{array}{c}\text { Survey } \\
5\end{array}$ \\
\hline Common Ground-Dove & Columbina passerine & $\mathrm{X}$ & $\mathrm{X}$ & $\mathrm{X}$ & $\mathrm{X}$ & \\
\hline Greater Roadrunner & Geococcyx californianus & - & $\mathrm{X}$ & - & - & \\
\hline Burrowing Owl & Athene cunicularia & $\mathrm{X}$ & - & - & - & \\
\hline Black-chinned Hummingbird & Archilochus alexandri & - & - & $\mathrm{X}$ & - & \\
\hline Anna's Hummingbird & Calypte anna & $\mathrm{X}$ & $\mathrm{X}$ & $\mathrm{X}$ & $\mathrm{X}$ & \\
\hline Gila Woodpecer & Melanerpes uropygialis & - & $\mathrm{X}$ & $\mathrm{X}$ & $\mathrm{X}$ & \\
\hline Ladder-backed Woodpecker & Picoides scalaris & - & $\mathrm{X}$ & - & - & \\
\hline Black Phoebe & Sayornis nigricans & - & - & $\mathrm{X}$ & - & \\
\hline Ash-throated Flycatcher & Myiarchus cinerascens & - & $\mathrm{X}$ & $\mathrm{X}$ & - & \\
\hline Western Kingbird & Tyrannus verticalis & $\mathrm{X}$ & $\mathrm{X}$ & $\mathrm{X}$ & - & \\
\hline Loggerhead Shrike & Lanius ludovicianus & - & $\mathrm{X}$ & - & - & \\
\hline Bell's Vireo & Vireo bellii & - & $\mathrm{X}$ & $\mathrm{X}$ & $\mathrm{X}$ & \\
\hline Cliff Swallow & Petrochelidon pyrrhonota & - & - & - & $\mathrm{X}$ & \\
\hline Verdin & Auriparus flaviceps & $\mathrm{X}$ & $\mathrm{X}$ & - & $\mathrm{X}$ & \\
\hline Cactus Wren & Campylorhynchus brunneicapillus & $\mathrm{X}$ & $\mathrm{X}$ & $\mathrm{X}$ & $\mathrm{X}$ & \\
\hline Northern Mockingbird & Mimus polyglottos & $\mathrm{X}$ & $\mathrm{X}$ & $\mathrm{X}$ & $\mathrm{X}$ & \\
\hline Nashville Warbler & Vermivora ruficapilla & - & - & - & $\mathrm{X}$ & \\
\hline Yellow Warbler & Dendroica petechia & - & - & - & $\mathrm{X}$ & \\
\hline Common Yellowthroat & Geothlypis trichas & $\mathrm{X}$ & $\mathrm{X}$ & - & $\mathrm{X}$ & \\
\hline Wilson's Warbler & Wilsonia pusilla & - & - & - & $\mathrm{X}$ & \\
\hline Abert's Towhee & pipilo aberti & $\mathrm{X}$ & $X$ & $X$ & $X$ & \\
\hline Red-winged Blackbird & Agelaius phoeniceus & - & $\mathrm{X}$ & - & $\mathrm{X}$ & \\
\hline Black-headed Grosbeak & Pheuticus melanocephalus & - & $\mathrm{X}$ & - & $\mathrm{X}$ & \\
\hline Blue Grosbeak & Guiraca caerulea & - & - & $\mathrm{X}$ & $\mathrm{X}$ & \\
\hline Great-tailed Grackle & Quiscalus mexicanus & $\mathrm{X}$ & - & $\mathrm{X}$ & $\mathrm{X}$ & \\
\hline House Finch & Carpdacus mexicanus & - & - & $\mathrm{X}$ & - & \\
\hline Lesser Goldfinch & Carduelis psaltria & - & $\mathrm{X}$ & - & - & \\
\hline \multicolumn{7}{|c|}{ Limitrophe Division (Colorado River) } \\
\hline Great Blue Heron & Ardea herodias & - & $\mathrm{X}$ & $\mathrm{X}$ & - & \\
\hline Great Egret & Ardea alba & $\mathrm{X}$ & $\mathrm{X}$ & $\mathrm{X}$ & - & \\
\hline Snowy Egret & Egretta thula & $\mathrm{X}$ & - & - & - & \\
\hline Green Heron & Butorides virescens & - & - & $\mathrm{X}$ & $\mathrm{X}$ & \\
\hline
\end{tabular}


Table 6-1. List of other bird species observed during 2007 yellow-billed cuckoo surveys, in the lower Colorado River watershed along the White and Muddy Rivers, Nevada, lower Colorado, Bill Williams and Gila Rivers, Arizona and California.-Continued

\begin{tabular}{|c|c|c|c|c|c|c|}
\hline Common name & Scientific name & $\begin{array}{c}\text { Survey } \\
1\end{array}$ & $\begin{array}{c}\text { Survey } \\
2\end{array}$ & $\begin{array}{c}\text { Survey } \\
\mathbf{3}\end{array}$ & $\begin{array}{c}\text { Survey } \\
4\end{array}$ & $\begin{array}{c}\text { Survey } \\
5\end{array}$ \\
\hline Black-crowned Night Heron & Nycticorax nycticorax & $\mathrm{X}$ & - & - & - & \\
\hline Cattle Egret & Bubulcus ibis & $\mathrm{X}$ & - & - & - & \\
\hline White-faced Ibis & Plegadis chihi & $\mathrm{X}$ & - & - & $\mathrm{X}$ & \\
\hline Turkey Vulture & Cathartes aura & $\mathrm{X}$ & $\mathrm{X}$ & $\mathrm{X}$ & - & \\
\hline Osprey & Pandion haliaetus & $\mathrm{X}$ & - & - & - & \\
\hline Northern Harrier & Circus cyaneus & - & - & - & $\mathrm{X}$ & \\
\hline American Kestrel & Falco sparverius & - & - & $\mathrm{X}$ & - & \\
\hline Ring-necked Pheasant & Phasianus colcichus & $\mathrm{X}$ & $\mathrm{X}$ & - & - & \\
\hline Gambel's Quail & Callipepla gambellii & $\mathrm{X}$ & $\mathrm{X}$ & $\mathrm{X}$ & $\mathrm{X}$ & \\
\hline Common Moorhen & Gallinula chloropus & - & $\mathrm{X}$ & - & $\mathrm{X}$ & \\
\hline American Coot & Fulica Americana & $\mathrm{X}$ & - & - & - & \\
\hline Killdeer & Charadrius vociferus & - & - & $\mathrm{X}$ & $\mathrm{X}$ & \\
\hline Western Sandpiper & Calidris mauri & - & - & - & $\mathrm{X}$ & \\
\hline Rock Dove & Columba livia & - & $\mathrm{X}$ & - & - & \\
\hline White-winged Dove & Zenaida asiatica & $\mathrm{X}$ & $\mathrm{X}$ & $\mathrm{X}$ & $\mathrm{X}$ & \\
\hline Mourning Dove & Zenaida macraura & $\mathrm{X}$ & $\mathrm{X}$ & $\mathrm{X}$ & $\mathrm{X}$ & \\
\hline Common Ground-Dove & Columbina passerine & - & $\mathrm{X}$ & - & $\mathrm{X}$ & \\
\hline Greater Roadrunner & Geococcyx californianus & $\mathrm{X}$ & - & - & $\mathrm{X}$ & \\
\hline Burrowing Owl & Athene cunicularia & $\mathrm{X}$ & $\mathrm{X}$ & - & - & \\
\hline Lesser Nighthawk & Chordeiles acutipennis & $\mathrm{X}$ & - & $\mathrm{X}$ & - & \\
\hline Black-chinned Hummingbird & Archilochus alexandri & $\mathrm{X}$ & - & - & - & \\
\hline Anna's Hummingbird & Calypte anna & $\mathrm{X}$ & $\mathrm{X}$ & $\mathrm{X}$ & $\mathrm{X}$ & \\
\hline Belted Kingfisher & Ceryle alcyon & - & - & - & $\mathrm{X}$ & \\
\hline Ladder-backed Woodpecker & Picoides scalaris & $\mathrm{X}$ & $\mathrm{X}$ & $\mathrm{X}$ & $\mathrm{X}$ & \\
\hline Willow Flycatcher & Empidonax traillii & - & - & - & $\mathrm{X}$ & \\
\hline Black Phoebe & Sayornis nigricans & $\mathrm{X}$ & - & $\mathrm{X}$ & $\mathrm{X}$ & \\
\hline Vermillion Flycatcher & Pyrocephalus rubinus & - & - & - & $\mathrm{X}$ & \\
\hline Ash-throated Flycatcher & Myiarchus cinerascens & $\mathrm{X}$ & - & - & - & \\
\hline Brown-crested Flycatcher & Myiarchus tyrannulus & - & - & - & $\mathrm{X}$ & \\
\hline Western Kingbird & Tyrannus verticalis & $\mathrm{X}$ & $\mathrm{X}$ & $\mathrm{X}$ & $\mathrm{X}$ & \\
\hline Warbling Vireo & Vireo gilvus & - & - & $\mathrm{X}$ & - & \\
\hline $\begin{array}{l}\text { Northern Rough-winged } \\
\text { Swallow }\end{array}$ & Stelgidopteryx serripennis & - & $\mathrm{X}$ & - & - & \\
\hline
\end{tabular}


Table 6-1. List of other bird species observed during 2007 yellow-billed cuckoo surveys, in the lower Colorado River watershed along the White and Muddy Rivers, Nevada, lower Colorado, Bill Williams and Gila Rivers, Arizona and California.-Continued

\begin{tabular}{|c|c|c|c|c|c|c|}
\hline Common name & Scientific name & $\begin{array}{c}\text { Survey } \\
1\end{array}$ & $\begin{array}{c}\text { Survey } \\
2\end{array}$ & $\begin{array}{c}\text { Survey } \\
\mathbf{3}\end{array}$ & $\begin{array}{c}\text { Survey } \\
4\end{array}$ & $\begin{array}{c}\text { Survey } \\
5\end{array}$ \\
\hline Cliff Swallow & Petrochelidon pyrrhonota & $\mathrm{X}$ & - & $\mathrm{X}$ & $\mathrm{X}$ & \\
\hline Verdin & Auriparus flaviceps & $\mathrm{X}$ & $\mathrm{X}$ & - & $\mathrm{X}$ & \\
\hline Cactus Wren & Campylorhynchus brunneicapillus & $\mathrm{X}$ & $\mathrm{X}$ & $\mathrm{X}$ & $\mathrm{X}$ & \\
\hline Bewick's Wren & Thryomanes bewickii & - & - & - & $\mathrm{X}$ & \\
\hline Black-tailed Gnatcatcher & Polioptila melanura & $\mathrm{X}$ & $\mathrm{X}$ & - & - & \\
\hline Hermit Thrush & Catharus guttatus & - & - & - & $\mathrm{X}$ & \\
\hline Northern Mockingbird & Mimus polyglottos & $\mathrm{X}$ & $\mathrm{X}$ & $\mathrm{X}$ & $\mathrm{X}$ & \\
\hline Crissal Thrasher & Toxostoma crissale & - & - & - & $\mathrm{X}$ & \\
\hline European Starling & Sturnus vulgaris & $\mathrm{X}$ & $\mathrm{X}$ & - & - & \\
\hline Nashville Warbler & Vermivora ruficapilla & - & - & - & $\mathrm{X}$ & \\
\hline Lucy's Warbler & Vermivora luciae & - & $\mathrm{X}$ & - & - & \\
\hline Yellow Warbler & Dendroica petechia & - & - & $\mathrm{X}$ & $\mathrm{X}$ & \\
\hline Common Yellowthroat & Geothlypis trichas & $\mathrm{X}$ & $\mathrm{X}$ & $\mathrm{X}$ & - & \\
\hline Wilson's Warbler & Wilsonia pusilla & - & - & - & $\mathrm{X}$ & \\
\hline Yellow-breasted Chat & Icteria virens & $\mathrm{X}$ & - & - & - & \\
\hline Western Tanager & Piranga ludoviciana & $\mathrm{X}$ & - & - & $\mathrm{X}$ & \\
\hline Song Sparrow & Melospiza melodia & $\mathrm{X}$ & - & - & - & \\
\hline Abert's Towhee & pipilo aberti & $\mathrm{X}$ & $\mathrm{X}$ & $\mathrm{X}$ & $\mathrm{X}$ & \\
\hline Red-winged Blackbird & Agelaius phoeniceus & $\mathrm{X}$ & $\mathrm{X}$ & $\mathrm{X}$ & $\mathrm{X}$ & \\
\hline Yellow-headed Blackbird & Xanthocephalus xanthocephalus & $\mathrm{X}$ & - & - & - & \\
\hline Black-headed Grosbeak & Pheuticus melanocephalus & - & - & $\mathrm{X}$ & - & \\
\hline Blue Grosbeak & Guiraca caerulea & $\mathrm{X}$ & $\mathrm{X}$ & $\mathrm{X}$ & $\mathrm{X}$ & \\
\hline Great-tailed Grackle & Quiscalus mexicanus & $\mathrm{X}$ & $\mathrm{X}$ & $\mathrm{X}$ & $\mathrm{X}$ & \\
\hline Brown-headed Cowbird & Molothrus Ater & $\mathrm{X}$ & $\mathrm{X}$ & $\mathrm{X}$ & - & \\
\hline House Finch & Carpdacus mexicanus & $\mathrm{X}$ & $\mathrm{X}$ & $\mathrm{X}$ & $\mathrm{X}$ & \\
\hline Lesser Goldfinch & Carduelis psaltria & - & $\mathrm{X}$ & - & - & \\
\hline
\end{tabular}

Gila River/Quigley Pond Wildlife Management Area (Gila River)

\begin{tabular}{llllll}
\hline Great Blue Heron & Ardea herodias & $\mathrm{X}$ & - & $\mathrm{X}$ & - \\
Great Egret & Ardea alba & - & $\mathrm{X}$ & - & - \\
Cattle Egret & Bubulcus ibis & - & $\mathrm{X}$ & - & - \\
Green Heron & Butorides virescens & - & - & $\mathrm{X}$ & $\mathrm{X}$ \\
Turkey Vulture & Cathartes aura & - & $\mathrm{X}$ & - & $\mathrm{X}$
\end{tabular}


Table 6-1. List of other bird species observed during 2007 yellow-billed cuckoo surveys, in the lower Colorado River watershed along the White and Muddy Rivers, Nevada, lower Colorado, Bill Williams and Gila Rivers, Arizona and California.-Continued

\begin{tabular}{|c|c|c|c|c|c|c|}
\hline Common name & Scientific name & $\begin{array}{c}\text { Survey } \\
1\end{array}$ & $\begin{array}{c}\text { Survey } \\
2\end{array}$ & $\begin{array}{c}\text { Survey } \\
\mathbf{3}\end{array}$ & $\begin{array}{c}\text { Survey } \\
4\end{array}$ & $\begin{array}{c}\text { Survey } \\
5\end{array}$ \\
\hline Zone-tailed Hawk & Buteo albonotatus & $\mathrm{X}$ & - & - & - & \\
\hline Red-tailed Hawk & Buteo jamaicensis & - & $\mathrm{X}$ & - & - & \\
\hline Gambel's Quail & Callipepla gambellii & $\mathrm{X}$ & $\mathrm{X}$ & - & $\mathrm{X}$ & \\
\hline White-winged Dove & Zenaida asiatica & $\mathrm{X}$ & $\mathrm{X}$ & $\mathrm{X}$ & - & \\
\hline Mourning Dove & Zenaida macroura & $\mathrm{X}$ & $\mathrm{X}$ & $\mathrm{X}$ & $\mathrm{X}$ & \\
\hline Common Ground-Dove & Columbina passerine & - & $\mathrm{X}$ & $\mathrm{X}$ & $\mathrm{X}$ & \\
\hline Greater Roadrunner & Geococcyx californianus & $\mathrm{X}$ & $\mathrm{X}$ & $\mathrm{X}$ & - & \\
\hline Lesser Nighthawk & Chordeiles acutipennis & - & $\mathrm{X}$ & - & - & \\
\hline Black-chinned Hummingbird & Archilochus alexandri & $\mathrm{X}$ & - & $\mathrm{X}$ & - & \\
\hline Ladder-backed Woodpecker & Picoides scalaris & - & $\mathrm{X}$ & $\mathrm{X}$ & - & \\
\hline Willow Flycatcher & Empidonax traillii & $\mathrm{X}$ & - & - & - & \\
\hline Black Phoebe & Sayornis nigricans & - & $\mathrm{X}$ & $\mathrm{X}$ & $\mathrm{X}$ & \\
\hline Vermillion Flycatcher & Pyrocephalus rubinus & $\mathrm{X}$ & - & - & - & \\
\hline Western Kingbird & Tyrannus verticalis & $\mathrm{X}$ & $\mathrm{X}$ & - & $\mathrm{X}$ & \\
\hline Bell's Vireo & Vireo bellii & - & - & $\mathrm{X}$ & - & \\
\hline Warbling Vireo & Vireo gilvus & - & - & - & $\mathrm{X}$ & \\
\hline $\begin{array}{l}\text { Northern Rough-winged } \\
\text { Swallow }\end{array}$ & Stelgidopteryx serripennis & - & - & $\mathrm{X}$ & $\mathrm{X}$ & \\
\hline Verdin & Auriparus flaviceps & - & - & $\mathrm{X}$ & $\mathrm{X}$ & \\
\hline House Wren & Troglodytes aedon & - & - & $\mathrm{X}$ & - & \\
\hline Black-tailed Gnatcatcher & Polioptila melanura & - & $\mathrm{X}$ & - & - & \\
\hline Yellow Warbler & Dendroica petechia & $\mathrm{X}$ & $\mathrm{X}$ & $\mathrm{X}$ & $\mathrm{X}$ & \\
\hline Wilson's Warbler & Wilsonia pusilla & - & - & - & $\mathrm{X}$ & \\
\hline Yellow-breasted Chat & Icteria virens & $\mathrm{X}$ & - & $\mathrm{X}$ & - & \\
\hline Western Tanager & Piranga ludoviciana & - & - & $\mathrm{X}$ & $\mathrm{X}$ & \\
\hline Abert's Towhee & pipilo aberti & $\mathrm{X}$ & $\mathrm{X}$ & - & $\mathrm{X}$ & \\
\hline Lark Sparrow & Chondestes grammacus & - & $\mathrm{X}$ & - & - & \\
\hline Song Sparrow & Melospiza melodia & - & $\mathrm{X}$ & - & - & \\
\hline Black-headed Grosbeak & Peucticus melanocephalus & - & - & $\mathrm{X}$ & $\mathrm{X}$ & \\
\hline Blue Grosbeak & Guiraca caerulea & $\mathrm{X}$ & $\mathrm{X}$ & $\mathrm{X}$ & - & \\
\hline Lazuli Bunting & Passerina amoena & - & - & $\mathrm{X}$ & $\mathrm{X}$ & \\
\hline Red-winged Blackbird & Agelaius phoeniceus & $\mathrm{X}$ & $\mathrm{X}$ & $\mathrm{X}$ & $\mathrm{X}$ & \\
\hline Western Meadowlark & Sternella neglecta & - & - & - & $\mathrm{X}$ & \\
\hline
\end{tabular}


Table 6-1. List of other bird species observed during 2007 yellow-billed cuckoo surveys, in the lower Colorado River watershed along the White and Muddy Rivers, Nevada, lower Colorado, Bill Williams and Gila Rivers, Arizona and California.-Continued

\begin{tabular}{lllllll}
\hline \multicolumn{1}{c}{ Common name } & \multicolumn{1}{c}{ Scientific name } & Survey & Survey & Survey & Survey & Survey \\
$\mathbf{5}$ & \multicolumn{1}{c}{$\mathbf{1}$} & $\mathbf{2}$ & $\mathbf{3}$ & $\mathbf{4}$ \\
\hline Great-tailed Grackle & Quiscalus mexicanus & $\mathrm{X}$ & $\mathrm{X}$ & - & $\mathrm{X}$ & \\
Brown-headed Cowbird & Molothrus Ater & $\mathrm{X}$ & $\mathrm{X}$ & $\mathrm{X}$ & $\mathrm{X}$ & \\
Bullock's Oriole & Icterus bullockii & - & $\mathrm{X}$ & $\mathrm{X}$ & - & \\
House Finch & Carpdacus mexicanus & $\mathrm{X}$ & $\mathrm{X}$ & - & - & \\
Lesser Goldfinch & Carduelis psaltria & - & - & $\mathrm{X}$ & $\mathrm{X}$ & \\
Lawrence's Goldfinch & Carduelis lawrencei & - & $\mathrm{X}$ & - & - & \\
\hline
\end{tabular}


This page intentionally left blank 


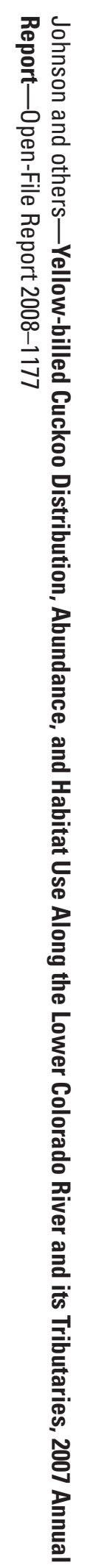

